\title{
Waste Isolation Pilot Plant Annual Site Environmental Report for 2010
}

\author{
U.S. Department of Energy
}

September 2011

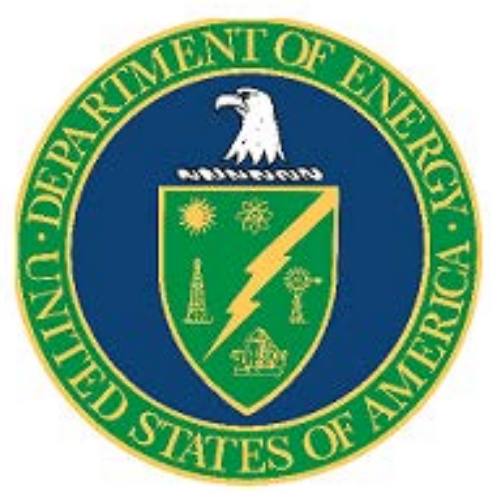


This page intentionally left blank 


\section{Waste Isolation Pilot Plant Annual Site Environmental Report for 2010 DOE/WIPP-11-2225}

\section{Annual Site Environmental Report}

To our readers:

This Waste Isolation Pilot Plant (WIPP) Annual Site Environmental Report for 2010 presents summary environmental data to (1) characterize site environmental management performance, (2) summarize environmental occurrences and responses reported during the calendar year, (3) confirm compliance with environmental standards and requirements, and (4) highlight the WIPP Environmental Management System (EMS), significant environmental programs, and accomplishments including progress toward the DOE Environmental Sustainability Goals.

It is important that the information we provide is easily understood, of interest, and communicates WIPP's efforts to protect human health and minimize our impact on the environment. We would like to know from you whether we are successful in achieving these goals. Your comments are appreciated and will help us to improve our communications.

1. Is the writing

2. Is the technical content

3. Is the text easy to understand If you selected "no," is it:

\begin{abstract}
Too concise
\end{abstract}
Too concise

$\square$ Yes

Too technical
Too wordy

Too wordy

$\square$ No

Too detailed $\square$ Uneven $\square$ Just right

Uneven $\square$ Just right

4. Is the report comprehensive? $\square$ Yes $\square$ No (Please identify issues you believe are missing in the comments section.)

Yes No

5. Do the illustrations help you understand the text better?

Are the illustrations understandable?

Are there enough?

Too few?

Too many?

6. Are the data tables of interest?

Would you prefer short summaries of data trends instead?

7. Is the background information sufficient?

Is there too much background information?

Are the methodologies described reasonably understandable?

8. Are the appendices useful?

Other Comments: 
Please return this survey to Office of Regulatory Compliance, MS GSA-224, U.S. Department of Energy, Carlsbad Field Office, P.O. Box 3090, Carlsbad, NM 88221-3090.

Optional Information:

Your Name

Occupation

Address 
This document has been submitted as required to:

U.S. Department of Energy

Office of Scientific and Technical Information

PO Box 62

Oak Ridge, TN 37831

(865) 576-8401

Additional information about this document may be obtained by calling 1800-336-9477

Unlimited, publicly available full-text scientific and technical reports are produced since 1991 are available online at Information Bridge (www.osti.gov/bridge).

U.S Department of Energy and its contractors may obtain full-text reports produced prior to 1991 in paper form for a processing fee from:

U.S. Department of Energy

Office of Scientific and Technical Information

P.O. Box 62

Oak Ridge, TN 37831-0062

Telephone: (865) 576-8401

Facsimile: (865) 576-5728

E-mail: reports@osti.gov

Available for sale to the public from:

U.S. Department of Commerce

National Technical Information Service

5301 Shawnee Rd

Alexandra, VA 22312

Phone: (800) 553-6847 or (703) 605-6000

Fax: (703) 605-6900

Email: info@ntis.gov 
This page intentionally left blank 


\section{TABLE OF CONTENTS}

LIST OF TABLES

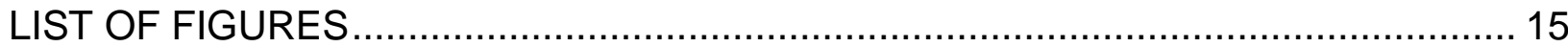

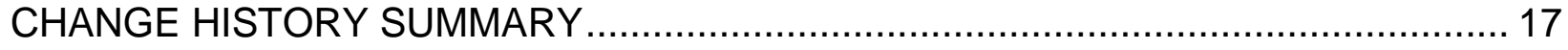

ACRONYMS, ABBREVIATIONS, AND UNITS OF MEASURE ............................... 19

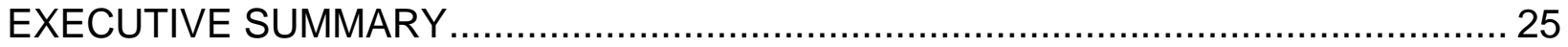

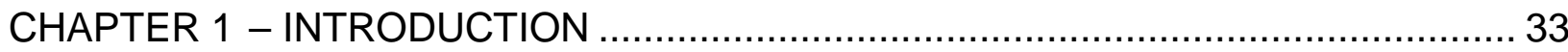

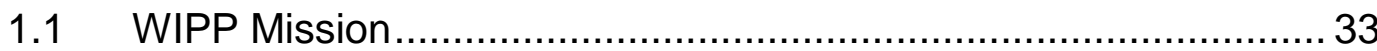

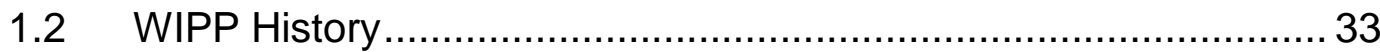

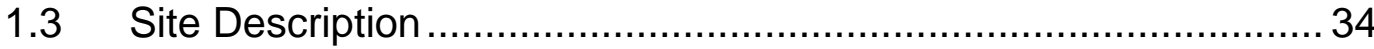

1.3.1 WIPP Property Areas ................................................ 36

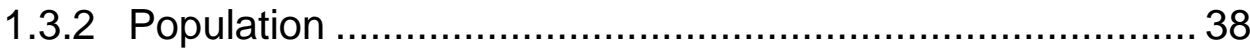

1.4 WIPP Environmental Stewardship ........................................... 38

1.4.1 Environmental Monitoring Plan..................................... 38

1.4.2 WIPP Facility Environmental Monitoring Program and Surveillance Activities..................................................... 39

$1.5 \quad$ Environmental Performance ............................................... 40

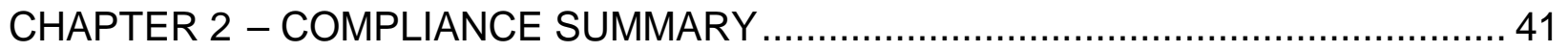

2.1 Comprehensive Environmental Response, Compensation and Liability Act (CERCLA) ........................................................... 41

2.1.1 Superfund Amendments and Reauthorization Act of 1986 (SARA) ............................................................ 41

2.1.2 Accidental Releases of Reportable Quantities of Hazardous Substances .................................................... 42

2.2 Resource Conservation And Recovery Act ................................ 42

2.2.1 Hazardous Waste Facility Permit ................................... 43

2.2.2 Modification Requests .................................................. 43

2.2.3 Permit Renewals .................................................... 43

2.2.4 Underground Storage Tanks ....................................... 43

2.2.5 Hazardous Waste Generator Compliance ........................ 44

2.2.6 Program Deliverables and Schedule ............................... 44

$2.3 \quad$ National Environmental Policy Act .............................................. 45

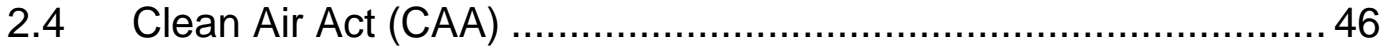

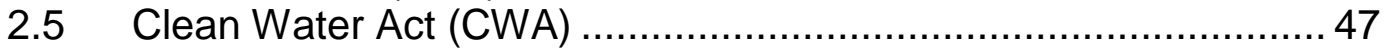

2.6 New Mexico Water Quality Act................................................ 47

2.7 Safe Drinking Water Act (SDWA) ................................................ 48

$2.8 \quad$ National Historic Preservation Act........................................... 49

2.9 Toxic Substances Control Act ................................................ 49

2.10 Federal Insecticide, Fungicide, and Rodenticide Act.................... 49

2.11 Endangered Species Act....................................................... 49

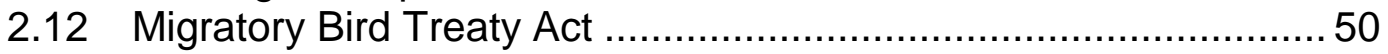

2.13 Federal Land Policy and Management Act ................................5 50 


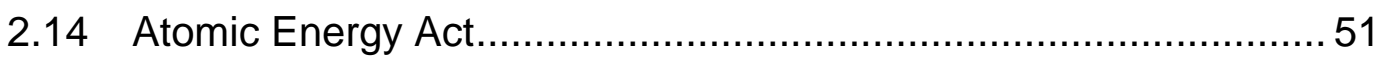

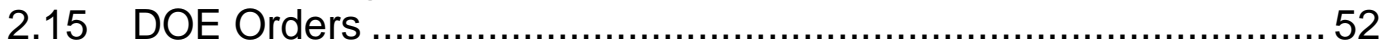

2.15.1 DOE Order 151.1C, Comprehensive Emergency Management System .................................................. 52

2.15.2 DOE Order 231.1A, Environment, Safety and Health

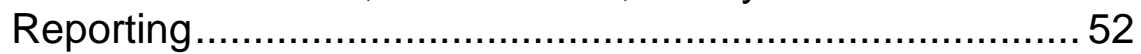

2.15.3 DOE Order 414.1C, Quality Assurance .............................53

2.15.4 DOE Order 435.1, Radioactive Waste Management.......... 53

2.15.5 DOE Order 450.1A, Environmental Protection Program .... 53

2.15.6 DOE Order 451.1B, Chg. 2, National Environmental Policy Act Compliance Program ..................................... 54

2.15.7 DOE Order 5400.5, Chg. 2, Radiation Protection of the Public and the Environment............................................. 54

2.16 Executive Orders.................................................................. 54

2.16.1 Executive Order 13423, Strengthening Federal Environmental, Energy, and Transportation Management . 55

2.16.2 Executive Order 13514, Federal Leadership in Environmental, Energy, and Economic Performance ......... 55

CHAPTER 3 - ENVIRONMENTAL MANAGEMENT SYSTEM ................................5 57

3.1 EMS 2010 Highlights........................................................... 59

3.2 Significant Environmental Programs ....................................... 59

3.3 Environmental Performance Measurement............................... 61

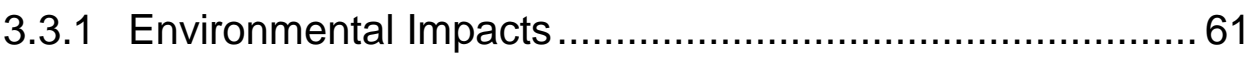

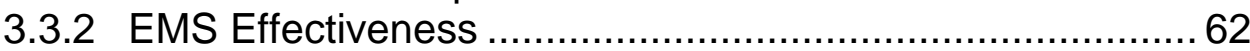

3.3.3 Sustainability Progress (Continuous Improvement)............62 62

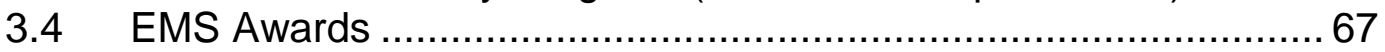

CHAPTER 4 - ENVIRONMENTAL RADIOLOGICAL PROGRAM INFORMATION ......69

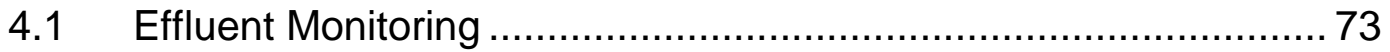

4.1.1 Sample Collection ................................................ 73

4.1.2 Sample Preparation.................................................. 73

4.1.3 Determination of Individual Radionuclides........................ 74

4.1.4 Results and Discussion ............................................... 74

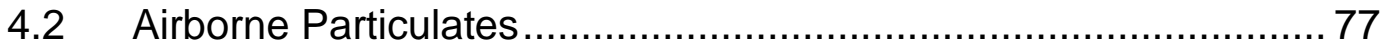

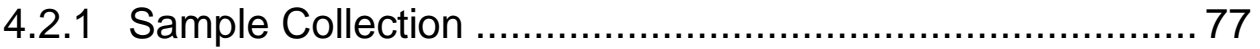

4.2.2 Sample Preparation....................................................... 78

4.2.3 Determination of Individual Radionuclides........................ 79

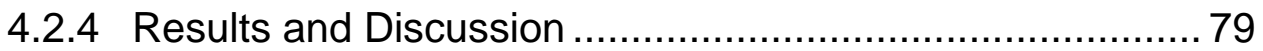

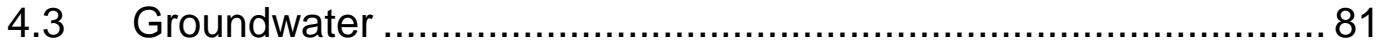

4.3.1 Sample Collection ........................................................ 81

4.3.2 Sample Preparation................................................... 82

4.3.3 Determination of Individual Radionuclides......................... 82

4.3.4 Results and Discussion ............................................... 82

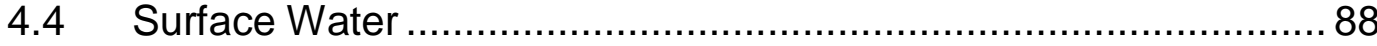

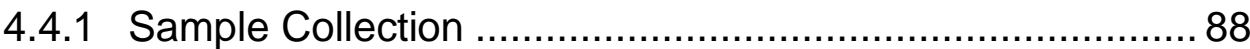

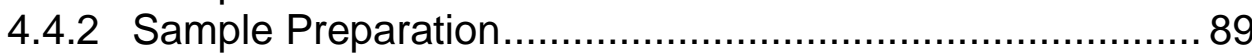

4.4.3 Determination of Individual Radionuclides........................ 90

4.4.4 Results and Discussion ................................................. 90 


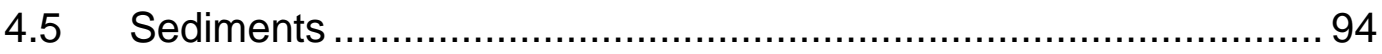

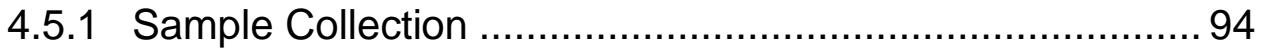

4.5.2 Sample Preparation........................................................ 95

4.5.3 Determination of Individual Radionuclides......................... 95

4.5.4 Results and Discussion .................................................. 95

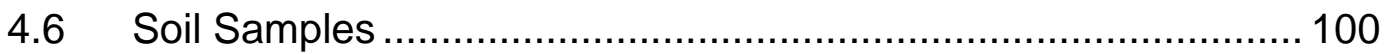

4.6.1 Sample Collection ................................................ 100

4.6.2 Sample Preparation.................................................... 101

4.6.3 Determination of Individual Radionuclides...................... 102

4.6.4 Results and Discussion .............................................. 102

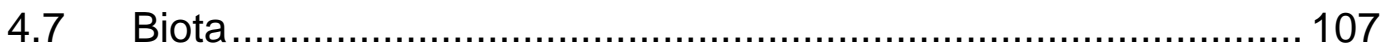

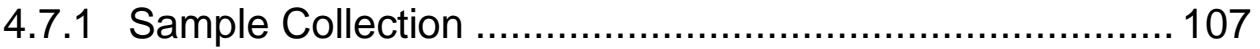

4.7.2 Sample Preparation................................................... 107

4.7.3 Determination of Individual Radionuclides....................... 108

4.7.4 Results and Discussion ............................................. 108

4.8 Potential Dose From WIPP Operations ................................... 112

4.8.1 Dose Limits............................................................. 112

4.8.2 Background Radiation ............................................. 112

4.8.3 Dose From Air Emissions .......................................... 113

4.8.4 Total Potential Dose From WIPP Operations …............... 113

4.8.5 Dose to Nonhuman Biota ........................................... 116

4.8.6 Release of Property Containing Residual Radioactive Material....................................................................... 118

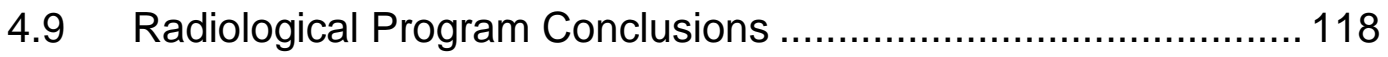

4.9.1 Effluent Monitoring …............................................ 118

4.9.2 Environmental Monitoring ......................................... 121

\section{CHAPTER 5 - ENVIRONMENTAL NONRADIOLOGICAL PROGRAM}

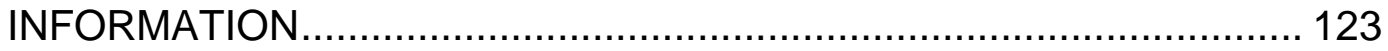

5.1 Principal Functions of Nonradiological Sampling ...................... 123

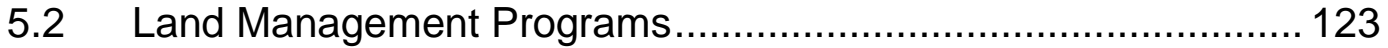

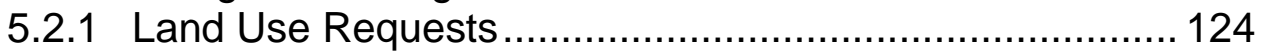

5.2.2 Wildlife Population Monitoring ....................................... 124

5.2.3 Reclamation of Disturbed Lands .................................. 124

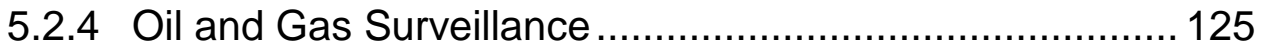

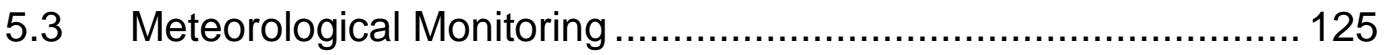

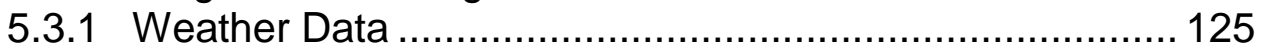

5.3.2 Wind Direction and Wind Speed................................... 127

$5.4 \quad$ Volatile Organic Compound Monitoring..................................... 129

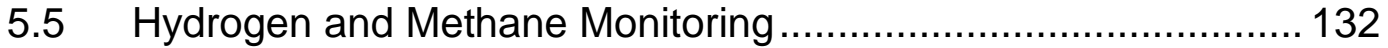

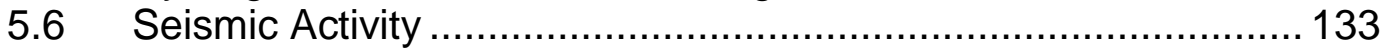

$5.7 \quad$ Liquid Effluent Monitoring ................................................... 134

CHAPTER 6 - SITE HYDROLOGY, GROUNDWATER MONITORING, AND

PUBLIC DRINKING WATER PROTECTION ................................... 137

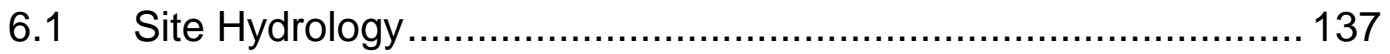

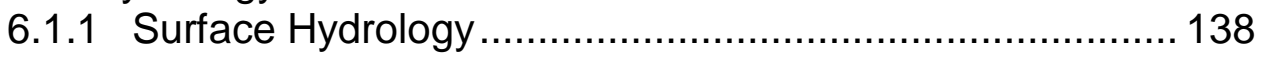

6.1.2 Subsurface Hydrology …........................................... 138

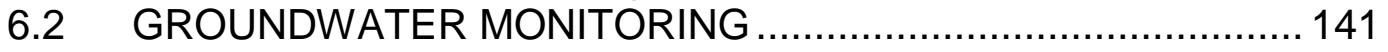




\begin{tabular}{|c|c|c|}
\hline & 6.2 .1 & Program Objectives .......... \\
\hline & 6.2 .2 & Summary of 2010 Activities ... \\
\hline & 6.2 .3 & Groundwater Quality Sampling.... \\
\hline & 6.2 .4 & Evaluation of Groundwater Quality.. \\
\hline & 6.2 .5 & Groundwater Level Surveillance....... \\
\hline & 6.2 .6 & Pressure Density Surveys ............... \\
\hline 6.3 & Drillin & g Activities \\
\hline 6.4 & Hydra & ulic Testing and Other Water Quality Sampling ................. 162 \\
\hline 6.5 & Well $\Lambda$ & Vaintenance \\
\hline 6.6 & Shallc & Ww Subsurface Water Monitoring Program................... \\
\hline & 6.6 .1 & Shallow Subsurface Water Quality Sampling ............ \\
\hline & 6.6 .2 & Shallow Subsurface Water Level Surveillance .... \\
\hline 6.7 & Public & 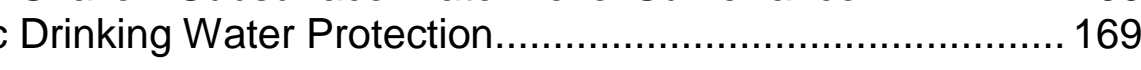 \\
\hline HAPTER 7 - Q & ALITY & ASSURANCE . \\
\hline 7.1 & WIPP & Laboratories.. \\
\hline & 7.1 .1 & Completeness . \\
\hline & 7.1 .2 & Precision. \\
\hline & 7.1.3 & 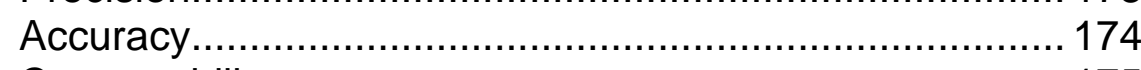 \\
\hline & 7.1.4 & Comparability \\
\hline & 7.1 .5 & Representativeness \\
\hline 7.2 & Carlsk & oad Environmental Monitoring and Research Center ......... 179 \\
\hline & 7.2 .1 & Completeness \\
\hline & 7.2 .2 & Precision...1. 180 \\
\hline & 7.2 .3 & Accuracy. \\
\hline & 7.2 .4 & Comparability ................ \\
\hline & 7.2 .5 & 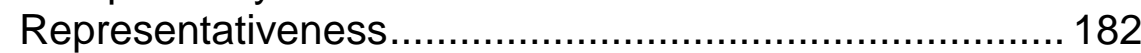 \\
\hline 7.3 & Hall E & nvironmental Analysis Laboratory \\
\hline & 7.3 .1 & 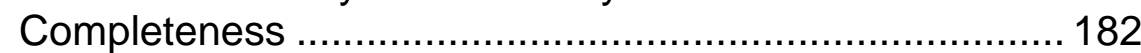 \\
\hline & 7.3.2 & Precision. \\
\hline & 7.3 .3 & Accuracy \\
\hline & 7.3.4 & Comparability \\
\hline & 7.3 .5 & Representativeness \\
\hline
\end{tabular}


Appendix A - References.

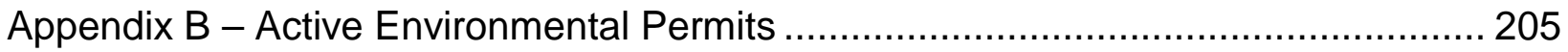

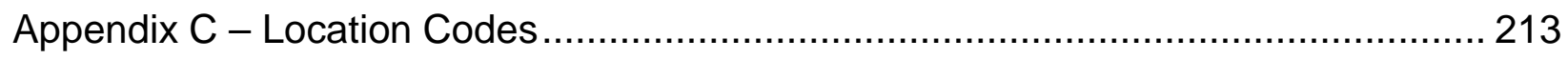

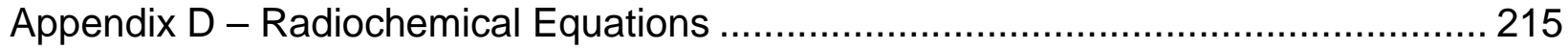

Appendix E - Time Trend Plots for Detectable Constituents in Groundwater ............. 217

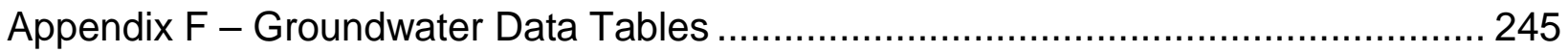

Appendix G - Air Sampling Data: Concentrations of Radionuclides in Air Filter Composites............................................................................... 283

Appendix H - Comparison of Detected Radionuclides to the Radiological Baseline... 295 
This page intentionally left blank 


\section{LIST OF TABLES}

Table 1.1 - Environmental Monitoring Sampling ${ }^{a}$..... 39

Table 2.1 - Status of Emergency Planning and Community Right-to-Know Act

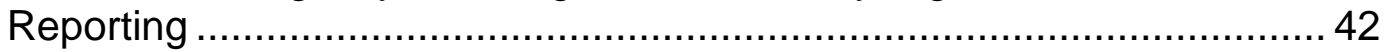

Table 2.2 - Permit Modification Notifications and Requests Submitted in 2010......... 43

Table 2.3 - Implementation of the WIPP Environmental Compliance

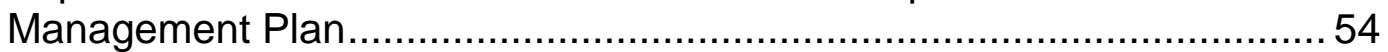

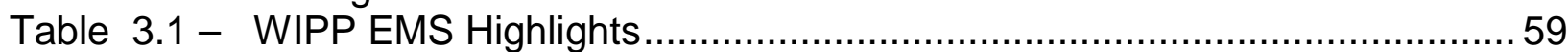

Table 4.1 - Radioactive Nuclides Monitored at the WIPP Site................................ 70

Table 4.2 - Activity (Bq) of Quarterly Composite Air Samples from the WIPP Effluent Monitoring Stations A, B and C for 2010............................... 75

Table 4.3 - 2010 Mean, Minimum, and Maximum Radionuclide Concentrations (Bq/sample) in Air Filter Composite Samples from Stations Surrounding the WIPP Site 80

Table 4.4 - 2010 Radionuclide Concentrations (Bq/L) of Groundwater from Wells at the WIPP Site.

Table 4.5 - 2010 Results of Duplicate Groundwater Sample Analyses for Sampling Round 30; Units are in $\mathrm{Bq} / \mathrm{L}$

Table 4.6 - Results of Duplicate Groundwater Sample Analyses for Sampling Round 31; Units are in Bq/L

Table 4.7 - 2010 Uranium Concentrations $(\mathrm{Bq} / \mathrm{L})$ in Surface Waters Taken near the WIPP Site

Table 4.8 - 2010 Americium and Plutonium Concentrations (Bq/L) in Surface

Waters Taken near the WIPP Site

Table 4.9 - 2010 Gamma Radionuclides and ${ }^{90} \mathrm{Sr}$ Concentrations $(\mathrm{Bq} / \mathrm{L})$ in Surface Waters Taken near the WIPP Site

Table 4.10 - Results of 2010 Duplicate Surface Water Sampling and Analysis; Units are in $\mathrm{Bq} / \mathrm{g}$....

Table 4.11 - 2010 Uranium Concentrations (Bq/g) in Sediment Samples

Taken near the WIPP Site

Table 4.12 - 2010 Americium and Plutonium Concentrations (Bq/g) in Sediment Samples Taken near the WIPP Site ................................................ 98

Table 4.13 - 2010 Gamma Radionuclides and ${ }^{90} \mathrm{Sr}$ Concentrations (Bq/g) in Sediment Samples Taken near the WIPP Site

Table 4.14 - Results of 2010 Duplicate Sediment Sampling and Analysis, Units are in $\mathrm{Bq} / \mathrm{g}$.

Table 4.15 - 2010 Uranium Concentrations (Bq/g) in Soil Samples Taken near the WIPP Site

Table 4.16 - 2010 Americium and Plutonium Concentrations (Bq/g) in Soil Samples Taken near the WIPP Site

Table 4.17 - 2010 Radionuclide Concentrations (Bq/g) in Soil Samples Taken near the WIPP Site ....................................................................... 105

Table 4.18 - Results of 2010 Duplicate Soil Sampling and Analysis; Units are in $\mathrm{Bq} / \mathrm{g}$......

Table 4.19 - Radionuclide Concentrations (Bq/g Wet Mass) in 2010 Vegetation Samples Taken near the WIPP Site 109

Table 4.20 - Results of Duplicate Analysis of Vegetation Samples Taken in 2010; Units are in $\mathrm{Bq} / \mathrm{g}$ 


\section{Waste Isolation Pilot Plant Annual Site Environmental Report for 2010 DOE/WIPP-11-2225}

Table 4.21 - Radionuclide Concentrations (Bq/g Wet Mass) in 2010 Quail, Rabbit, Deer, Javelina and Fish Samples Taken near the WIPP Site.... 110

Table 4.22 - Results of 2010 Animal Biota Laboratory Duplicate Analysis Precision; Units are in $\mathrm{Bq} / \mathrm{g}$.

Table 4.23 - WIPP Radiological Dose and Release Summary .......................... 115

Table 4.24 - General Screening Results for Potential Radiation Dose to Nonhuman Biota From Radionuclide Concentrations in Surface Water $(\mathrm{Bq} / \mathrm{L})$, Sediment $(\mathrm{Bq} / \mathrm{g})$, and Soil $(\mathrm{Bq} / \mathrm{g})$ near the WIPP Site in 2010 .

Table 4.25 - Comparison of Dose to the Whole Body to EPA Limit of 25 mrem/year per 40 CFR 191.03(b)

Table 4.26 - Comparison of Dose to the Critical Organ to EPA Limit of 75 mrem/year per 40 CFR §191.03(b)

Table 4.27 - Comparison of EDEs to EPA Limit of 10 mrem/year per 40 CFR $\$ 61.92$

Table 5.1 - Concentrations of Concern for Volatile Organic Compounds, from Part 4 of the Permit (No. NM4890139088-TSDF) ............................ 129

Table 5.2 - Repository Air Volatile Organic Compound Method Reporting Limits and Maximum Concentrations Detected

Table 5.3 - Disposal Room Volatile Organic Compound Method Reporting Limits and Maximum Concentrations Detected

Table 5.4 - Ongoing Disposal Room Volatile Organic Compound Method Reporting Limits and Maximum Concentrations Detected.... 132

Table 5.5 - Hydrogen and Methane Method Reporting Limits Action Levels and Maximum Concentrations Detected

Table 5.6 - Sewage Lagoon and H-19 Analytical Results for January through

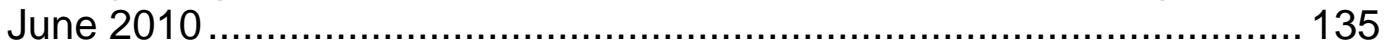

Table 5.7 - Sewage Lagoon, H-19, and Infiltration Control Pond Analytical

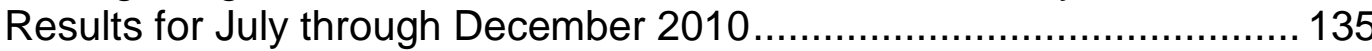

Table 6.1 - Summary of 2010 DOE WIPP Region Groundwater Monitoring Program ............................................................................ 142

Table 6.2 - Analytical Parameters for which Groundwater Was Analyzed.............. 145

Table 6.3 - Water Level Elevations for the February 2010 Potentiometric Surface Calibration, Culebra Hydraulic Unit.................................. 152

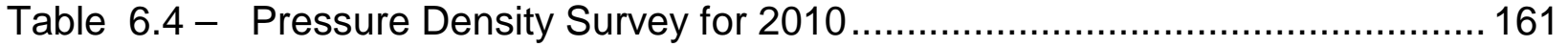

Table 6.5 - 2010 Well and Water Quality Sampling Testing Activities .................. 163

Table 6.6 - 2010 Survey Data................................................................ 163

Table 6.7 - 2010 Shallow Subsurface Water Quality Sampling Results ................ 166

Table 7.1 - Mixed Analyte Performance Evaluation Program Review for WIPP Laboratories, 2010, First Set (Series 21) ..................................... 176

Table 7.2 - Mixed Analyte Performance Evaluation Program Review for WIPP Laboratories, 2010 Second Set (Series 22) ............................... 177

Table 7.3 - Mixed Analyte Performance Evaluation Program Review for WIPP Laboratories, 2010, Third Set (Series 23) ..................................... 178

Table 7.4 - Individual Cases Where the Precision Objective Was Not Met in 2010 for

Table 7.5 - Individual Cases where the Accuracy Quality Assurance Objective Analyses was not Met in 2010 for Groundwater QA Sample... 


\section{Waste Isolation Pilot Plant Annual Site Environmental Report for 2010 DOE/WIPP-11-2225}

\section{LIST OF FIGURES}

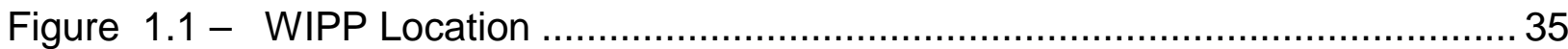

Figure 1.2 - WIPP Property Areas ..................................................... 37

Figure 3.1 - South Access Road Reconstruction Pollution .............................. 58

Figure 3.2 - WIPP Project Greenhouse Gas Baseline Inventory ........................ 62

Figure 3.3 - GHG Reduction Efforts...................................................... 63

Figure 3.4 - WIPP Energy Efficiency History ................................................ 63

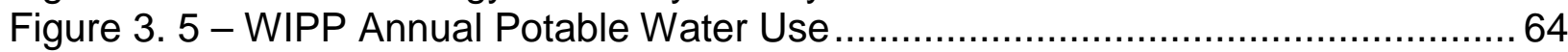

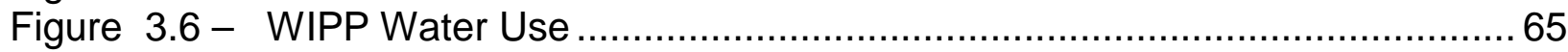

Figure 3.7 - WIPP Recycling Program .................................................. 66

Figure 3.8 - Life Cycle Management of Electronics at WIPP ............................ 67

Figure 4.1 - Air Sampling Locations On and Near the WIPP Site ........................ 78

Figure 4.2 - Routine Surface Water Sampling Locations................................... 89

Figure 4.3 - Sediment Sampling Sites ................................................. 95

Figure 4.4 - Routine Soil and Vegetation Sampling Areas............................... 101

Figure 4.5 - Dose to the Whole Body for the Hypothetical Maximally Exposed Individual at the WIPP Fence Line ....................................... 118

Figure 4.6 - Dose to the Critical Organ for Hypothetical Maximally Exposed Individual at the WIPP Fence Line.......................................................... 119

Figure 4.7 - WIPP Effective Dose Equivalent to the Off-Site Maximally Exposed Individual ............................................................................ 120

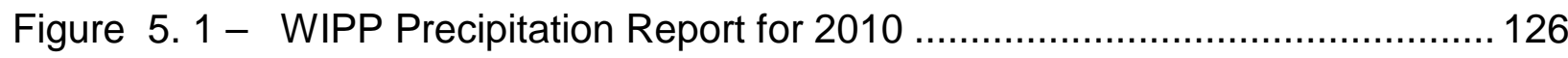

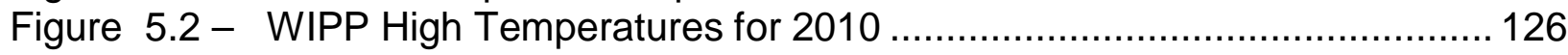

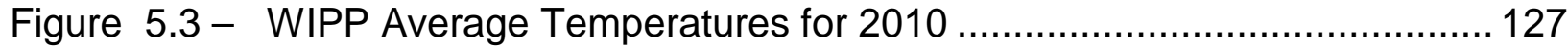

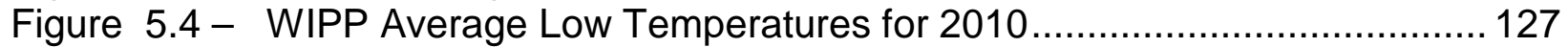

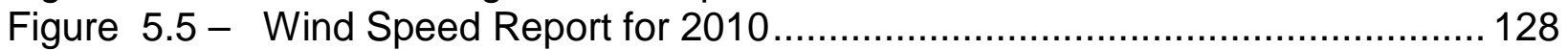

Figure 5.6 - Typical Disposal Room Volatile Organic Compound Sampling

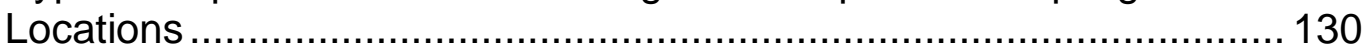

Figure 5.7 - Seismograph Station Locations in the Vicinity of the WIPP Site ......... 134

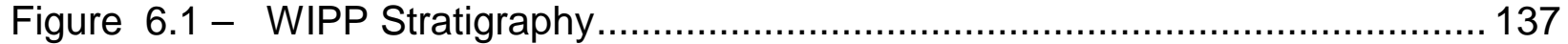

Figure 6.2 - Groundwater Level Surveillance Wells (Insert Represents the Groundwater Surveillance Wells in the WIPP Land

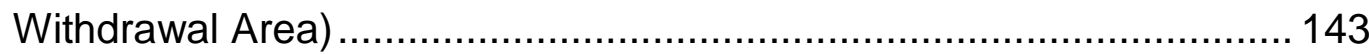

Figure 6.3 - Water Quality Sampling Program Wells .................................. 144

Figure $6.4-$ Hydrograph of WQSP-1 f..................................................... 149

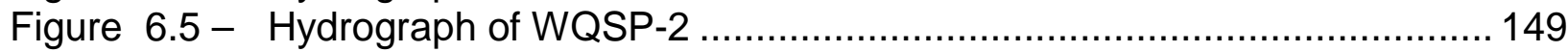

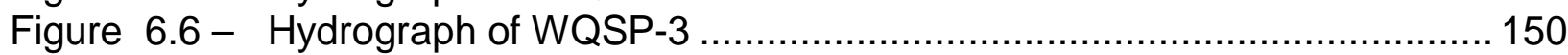

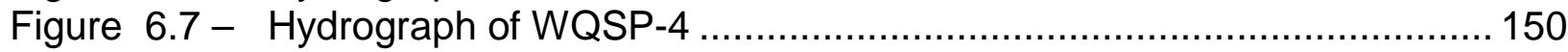

Figure 6.8 - Hydrograph of WQSP-5 ..................................................... 151

Figure 6.9 - Hydrograph of WQSP-6 .................................................... 151

Figure 6.10 - Hydrograph of WQSP-6A ............................................... 152

Figure 6.11 - Model Generated February 2010 Freshwater Head Contours in the Model Domain .......................................................... 155

Figure 6.12 - Model-Generated February 2010 Freshwater Head Contours (5-Foot Contour Interval) in the WIPP Vicinity with Blue Water Particle Track from Waste Handling Shaft to WIPP Land Withdrawal Boundary (Contour interval in $\mathrm{ft} A M S L)$ 
Figure 6.13 - Measured Versus Modeled Scatter Plot for PEST-Calibrated MODFLOW 2000.

Figure 6.14 - Frequency of Modeled Freshwater Head Residuals ......................... 159

Figure 6.15 - Modeled Residual Freshwater Head at Each Well ............................ 160

Figure 6.16 - Location of Shallow Subsurface Water Wells (Piezometers PZ 1 through 15, C 2811, C 2505, C 2506, C 2507

Figure 6.17 - Shallow Subsurface Water Potentiometric Surface ........................... 168 
Waste Isolation Pilot Plant Annual Site Environmental Report for 2010 DOE/WIPP-11-2225

\section{CHANGE HISTORY SUMMARY}

\begin{tabular}{|c|c|c|}
\hline $\begin{array}{c}\text { REVISION } \\
\text { NUMBER }\end{array}$ & $\begin{array}{c}\text { DATE } \\
\text { ISSUED }\end{array}$ & DESCRIPTION OF CHANGES \\
\hline 0 & $09 / 12 / 11$ & This is a new report. \\
\hline
\end{tabular}


This page intentionally left blank 


\section{ACRONYMS, ABBREVIATIONS, AND UNITS OF MEASURE}

$\begin{array}{ll}\text { ALARA } & \text { as low as reasonably achievable } \\ \text { Am } & \text { americium } \\ \text { ANOVA } & \text { analysis of variance } \\ \text { ANSI } & \text { American National Standards Institute } \\ \text { ASER } & \text { annual site environmental report } \\ \text { ASME } & \text { American Society of Mechanical Engineers } \\ & \\ \text { BCG } & \text { biota concentration guide } \\ \text { BLM } & \text { U.S. Department of the Interior, Bureau of Land Management } \\ \text { Bq } & \text { becquerel(s) } \\ \text { Bq/L } & \text { becquerels per liter } \\ \text { Bq/m } & \text { becquerels per cubic meter } \\ & \\ \text { CAO } & \text { Carlsbad Area Office (now Carlsbad Field Office) } \\ \text { CBFO } & \text { Carlsbad Field Office } \\ \text { CEMRC } & \text { Carlsbad Environmental Monitoring and Research Center } \\ \text { CFR } & \text { Code of Federal Regulations } \\ \text { CH } & \text { contact-handled } \\ \text { Ci } & \text { curie } \\ \text { Cm } & \text { centimeter } \\ \text { CO } & \text { cobalt } \\ \text { CS } & \text { cesium } \\ \text { CY } & \text { calendar year } \\ & \text { day } \\ \text { d } & \text { Duplicate Error Ratio } \\ \text { DER } & \text { detection monitoring program } \\ \text { DMP } & \text { U.S. Department of Energy } \\ \text { DOE } & \text { DOE Laboratory Accreditation Program } \\ \text { DOELAP } & \text { discharge permit } \\ \text { DP } & \text { effective dose equivalent } \\ \text { EDE } & \text { Environmental Management System } \\ \text { EMS } & \text { Executive Order } \\ \text { EO } & \text { U.S. Environmental Protection Agency } \\ \text { EPA } & \text { Emergency Planning and Community Right-to-Know Act } \\ \text { EPCRA } & \text { foot/feet } \\ \text { ft } & \text { cubic feet } \\ \text { ft } & \text { fiscal year } \\ \text { FY } & \text { greenhouse gas } \\ \text { GHG } & \text { Gross Square Feet } \\ \text { Gsf } & \\ \text { GWQB } & \text { Ground Water Quality Bureau } \\ \text { HEAL } & \text { Hall Environmental Analysis Laboratory } \\ \text { HEPA } & \text { highey particulate air (filter) } \\ & \end{array}$




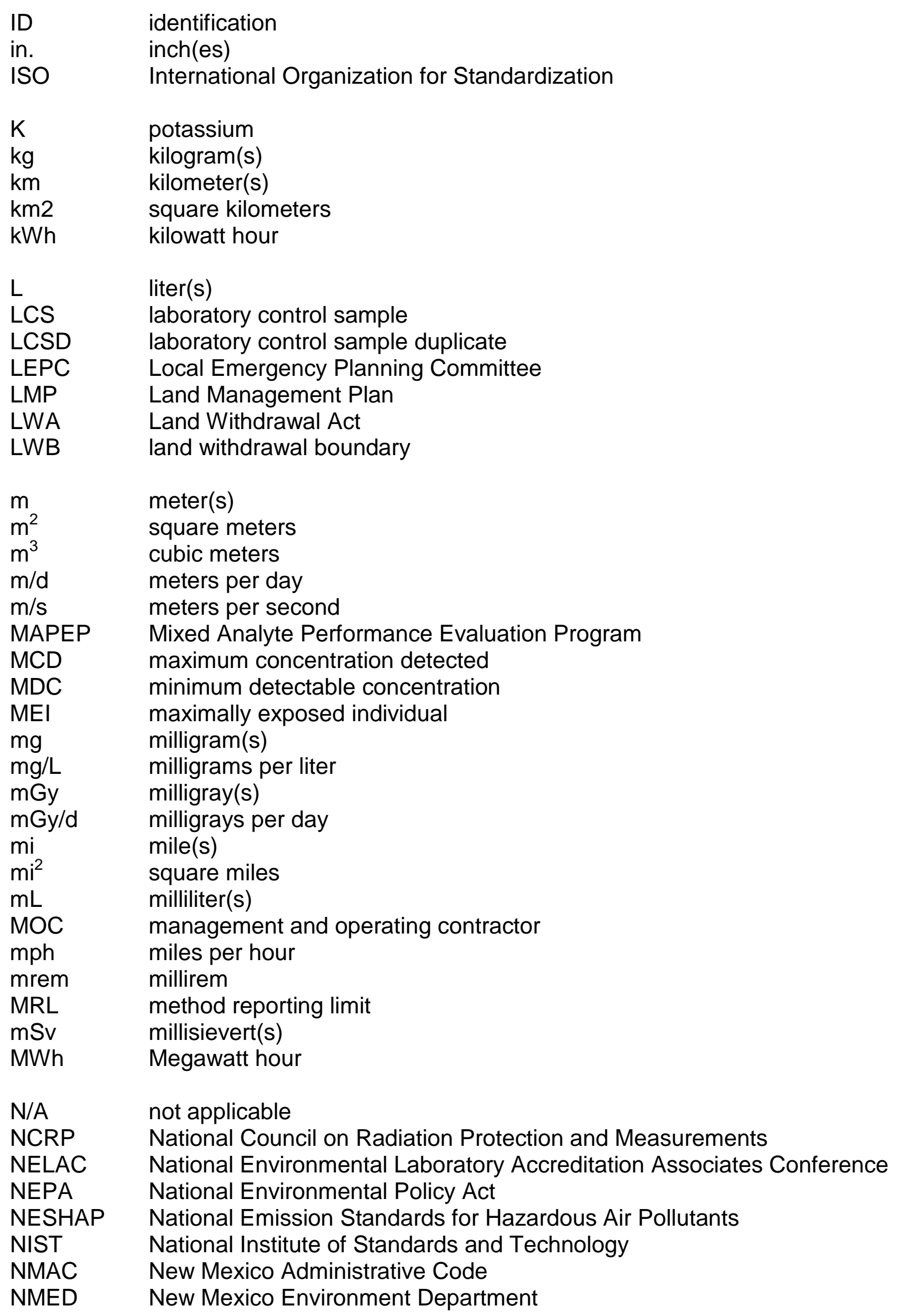




\begin{tabular}{|c|c|}
\hline NMIMT & New Mexico Institute of Mining and Technology \\
\hline NMSA & New Mexico Statutes Annotated \\
\hline NOV & notice of violation \\
\hline NPDES & National Pollutant Discharge Elimination System \\
\hline NQA & Nuclear Quality Assurance \\
\hline NRIP & $\begin{array}{l}\text { National Institute of Standards and Technology Radiochemistry } \\
\text { Intercomparison Program }\end{array}$ \\
\hline $\mathrm{Oz}$ & ounce(s) \\
\hline PCB & polychlorinated biphenyl \\
\hline PE & performance evaluation \\
\hline pH & measure of the acidity or basicity of a solution \\
\hline PIP & production-injection packer \\
\hline ppmv & parts per million by volume \\
\hline ppbv & parts per billion by volume \\
\hline $\mathrm{Pu}$ & plutonium \\
\hline QA & quality assurance \\
\hline QC & quality control \\
\hline $\mathrm{rad}$ & radiation absorbed dose \\
\hline RBL & room-based limits \\
\hline RCRA & Resource Conservation and Recovery Act \\
\hline rem & Roentgen equivalent man \\
\hline RER & relative error ratio \\
\hline $\mathrm{RH}$ & remote-handled \\
\hline RPD & relative percent difference \\
\hline SEIS & Supplemental Environmental Impact Statement \\
\hline SERC & State Emergency Response Commission \\
\hline SNL & Sandia National Laboratories \\
\hline SOP & standard operating procedure \\
\hline sow & statement of work \\
\hline SPDV & site and preliminary design validation \\
\hline $\mathrm{Sr}$ & strontium \\
\hline SR/DL & Santa Rosa/Dewey Lake \\
\hline SSW & shallow subsurface water \\
\hline SVOC & semivolatile organic compound \\
\hline TDS & total dissolved solids \\
\hline TOC & total organic carbon \\
\hline TOX & total organic halogen \\
\hline TPU & total propagated uncertainty \\
\hline TRU & transuranic (waste) \\
\hline TSCA & Toxic Substances Control Act \\
\hline TSDF & treatment, storage, and disposal facility \\
\hline TSS & total suspended solids \\
\hline
\end{tabular}


Waste Isolation Pilot Plant Annual Site Environmental Report for 2010 DOE/WIPP-11-2225

\begin{tabular}{|c|c|}
\hline $\mathrm{U}$ & uranium \\
\hline U.S. & United States \\
\hline U.S.C. & United States Code \\
\hline UNSCEAR & United Nations Scientific Committee on the Effects of Atomic Radiation \\
\hline USFWS & U.S. Fish and Wildlife Service \\
\hline UST & underground storage tank \\
\hline UTLV & Upper Tolerance Limit Value \\
\hline VOC & volatile organic compound \\
\hline WIPP & Waste Isolation Pilot Plant \\
\hline WQSP & Water Quality Sampling Program \\
\hline WTS & Washington TRU Solutions LLC \\
\hline
\end{tabular}


Waste Isolation Pilot Plant Annual Site Environmental Report for 2010

$\begin{array}{ll}{ }^{\circ} \mathrm{C} & \text { degrees Celsius } \\ { }^{\circ} \mathrm{F} & \text { degrees Fahrenheit } \\ > & \text { greater than } \\ < & \text { less than } \\ \leq & \text { less than or equal to } \\ \mu \mathrm{Ci} & \text { microCurie } \\ \mu \mathrm{g} & \text { microgram } \\ \mu \mathrm{mhos} & \text { micromhos } \\ \% & \text { percent } \\ \pm & \text { plus or minus } \\ {[\mathrm{RN}]} & \text { radionuclide concentration } \\ \sigma & \text { sigma }\end{array}$

Symbols 
This page intentionally left blank 


\section{EXECUTIVE SUMMARY}

\section{PURPOSE}

The purpose of the Waste Isolation Pilot Plant (WIPP) Annual Site Environmental Report for 2010 (ASER) is to provide information required by U.S. Department of Energy (DOE) Order 231.1A, Environment, Safety, and Health Reporting. Specifically, the ASER presents summary environmental data to:

- $\quad$ Characterize site environmental management performance.

- $\quad$ Summarize environmental occurrences and responses reported during the calendar year.

- $\quad$ Confirm compliance with environmental standards and requirements.

- $\quad$ Highlight significant environmental accomplishments, including progress toward the DOE Environmental Sustainability Goals made through implementation of the WIPP Environmental Management System (EMS).

The DOE Carlsbad Field Office (CBFO) and the management and operating contractor (MOC), Washington TRU Solutions LLC (WTS), maintain and preserve the environmental resources at the WIPP. DOE Order 231.1A; DOE Order 450.1A, Environmental Protection Program; and DOE Order 5400.5, Radiation Protection of the Public and the Environment, require that the affected environment at and near DOE facilities be monitored to ensure the safety and health of the public and workers, and preservation of the environment.

This report was prepared in accordance with DOE Order 231.1A, which requires that DOE facilities submit an ASER to the DOE Headquarters Chief Health, Safety, and Security Officer. The WIPP Hazardous Waste Facility Permit Number NM4890139088TSDF (Permit) further requires that the ASER be provided to the New Mexico Environment Department (NMED).

\section{WIPP MISSION}

The WIPP mission is to safely dispose of transuranic (TRU) radioactive waste generated by the production of nuclear weapons and other activities related to the national defense of the United States. In 2010, 7,918 cubic meters $\left(\mathrm{m}^{3}\right)$ of TRU waste were disposed of at the WIPP facility, including $7,839 \mathrm{~m}^{3}$ of contact-handled $(\mathrm{CH})$ TRU waste and $79 \mathrm{~m}^{3}$ of remote-handled $(\mathrm{RH})$ TRU waste. From the first receipt of waste in March 1999 through the end of $2010,72,422 \mathrm{~m}^{3}$ of TRU waste had been disposed of at the WIPP facility.

\section{WIPP Environmental Management System}

The WIPP Environmental Management System (EMS) is the mechanism through which the WIPP project protects human health and the environment; maintains compliance with applicable environmental laws and regulations; and implements sustainable 
practices for enhancing environmental, energy, and transportation management. The EMS is described in the Waste Isolation Pilot Plant Environmental Management System Description (DOE/WIPP-05-3318). Measuring and monitoring to assure that the project meets these objectives are key elements in the EMS.

\section{Monitoring for Environmental Impacts}

The DOE collects data needed to detect and quantify potential impacts that WIPP facility operations may have on the surrounding environment. The Waste Isolation Pilot Plant Environmental Monitoring Plan (DOE/WIPP-99-2194) (WIPP Environmental Monitoring Plan) outlines major environmental monitoring and surveillance activities at the WIPP facility and the WIPP facility quality assurance/quality control (QA/QC) program as it relates to environmental monitoring.

WIPP facility employees conduct both effluent monitoring (i.e., point source monitoring at release points such as the exhaust shaft) to detect radionuclides and quantify dose rates, and traditional pathway and receptor monitoring in the broader environment. The WIPP facility environmental monitoring program is designed to monitor pathways that radionuclides and other contaminants could take to reach the environment surrounding the WIPP facility. Pathways monitored include air, groundwater, surface water, soils, sediments, vegetation, and game animals. The goal of this monitoring is to determine if the local ecosystem has been, or is being, adversely impacted by WIPP facility operations and, if so, to evaluate the geographic extent and the effects on the environment.

The Waste Isolation Pilot Plant Land Management Plan (DOE/WIPP-93-004) (LMP) was created in compliance with the WIPP Land Withdrawal Act of 1992 (LWA) (Public Law 102-579, as amended by Public Law 104-201, National Defense Authorization Act for Fiscal Year 1997). This plan identifies resource values, promotes multiple-use management, and identifies long-term goals for the management of WIPP project lands. The LMP includes a land reclamation program that addresses both the short-term and long-term effects of WIPP facility operations and includes monitoring for environmental impacts. WIPP personnel also conduct surveillance in the region surrounding the site to protect the WIPP facility from trespass.

WIPP facility monitoring and surveillance programs to determine if the local ecosystem has been impacted are listed below:

Environmental Radiological Programs

- $\quad$ Airborne particulates

- Biota

- $\quad$ Effluent

- Groundwater

- Sediments

- Soil

- $\quad$ Surface water 
Environmental Nonradiological Programs

- Hydrogen and methane monitoring

- $\quad$ Land management

- $\quad$ Liquid effluent

- Meteorology

- $\quad$ Seismic activity

- $\quad$ Volatile organic compound (VOC) monitoring

Groundwater Protection Programs

- $\quad$ Groundwater levels

- Groundwater quality

- $\quad$ Pressure density surveys

- $\quad$ Shallow subsurface water (SSW) levels

- $\quad$ SSW quality

In 2010, results of these programs, including observations and analytical data, demonstrated that (1) compliance with applicable environmental requirements was maintained; and (2) the operations at the WIPP facility have not had a negative impact on human health or the environment.

\section{Environmental Compliance}

The WIPP facility is required to comply with applicable federal and state laws and DOE orders. In order to accomplish and document compliance with certain requirements, the following submittals, which are required on a routine basis, were among those completed in 2010:

New Mexico Submittals

- $\quad$ Hazardous Waste Facility Permit

- 2009 Annual Site Environmental Report

- Semiannual VOC, Hydrogen, and Methane Data Summary Report

- Mine Ventilation Rate Monitoring Report

- Waste Minimization Statement

- Semiannual WIPP Groundwater Detection Monitoring Reports

- Geotechnical Data Report

- Monthly Water Level Reports

- $\quad$ Discharge Permit (DP-831)

- Semiannual Discharge Monitoring Reports

- $\quad$ Superfund Amendments and Reauthorization Act of 1986 
- Emergency and Hazardous Chemical Inventory Report

- Toxic Chemical Release Inventory Report

Environmental Protection Agency Submittals

- $\quad$ Delaware Basin Monitoring Annual Report

- $\quad 2010$ Annual Polychlorinated Biphenyls Report

- $\quad$ WIPP Subsidence Monument Leveling Survey

- 2009/2010 Annual Change Report

- $\quad$ Toxic Chemical Release Inventory Report

- 2009 Biennial Environmental Compliance Report

Other correspondence, regulatory submittals, monitoring reports, and the results of the U.S. Environmental Protection Agency (EPA) Annual Inspection, as well as other inspections, are described in Chapters 2 and 3 of this report.

The DOE maintains an in-depth, integrated evaluation program that consists of audits, assessments, surveillances, and inspections. In fiscal year (FY) 2010, 220 evaluations were conducted that monitored for compliance with environmental requirements. This program, coupled with the WIPP project corrective action programs, assures that potential compliance issues are identified and corrective/preventive actions are tracked formally through completion.

Overall, the data provided in the required submissions and the evaluation program results confirmed that WIPP maintained compliance with environmental requirements during 2010. There was one compliance exception, a field notice of violation (NOV) that was issued for failure to use proper forms for the underground storage tanks. Corrected documentation was submitted with no follow-up inspection required and no fines issued.

\section{Sustainable Practices}

WIPP's EMS objectives and targets support achievement of DOE's sustainability goals. Highlights of WIPP's progress for 2010 in sustainability include the following:

- $\quad$ Groundwork was laid for transition to renewable diesel with a test of the renewable fuel to be conducted in 2011.

- $\quad$ Site energy use was maintained at approximately 3.0 megawatt hours (MWh) per $\mathrm{m}^{3}$ of TRU waste disposed at the WIPP facility. 1,500,000 kilowatt hours (kWh) of wind sourced energy was used by WIPP, representing 7.5 percent of total energy used.

- $\quad$ A 13 percent reduction in energy intensity for WIPP site operations compared to the FY 2003 baseline has been achieved. 
- $\quad$ CBFO and MOC personnel actively pursued renewable energy generation on WIPP lands. This included pursuit of a Power Purchase Agreement for construction and operation of a $2 \mathrm{MW}$ solar array and other renewable projects through the DOE "Energy Parks" Initiative.

- $\quad$ WIPP has been nominated for DOE E-Star awards for FY 2010 accomplishments in water reuse during the South Access Road project and for the sale of mined salt for reuse as a livestock feed supplement.

- $\quad$ WIPP continued to employ sustainable life cycle management of electronics.

\section{EMS Implementation}

Semiannual surveillance audits were conducted by the International Organization for Standardization (ISO) 14001 registrar during 2010 to confirm the EMS continued to be effectively implemented. No issues were identified from these audits and the EMS continued to be certified as conforming to the ISO 14001:2004, Environmental Management Systems - Specification with Guidance for Use.

Significant accomplishments of the EMS for 2010 were as follows:

- $\quad$ WIPP had no reportable, unauthorized contaminant releases to the environment in 2010.

- $\quad$ The 2010 environmental monitoring data continued to demonstrate that there has been no adverse impact to human health or the environment from WIPP facility operations.

- $\quad$ Permit was renewed by NMED on November 30, 2010 and was implemented by December 30, 2010.

- $\quad$ Received second Compliance Recertification from EPA on November 18, 2010.

- $\quad$ WIPP earned a "green score" from the DOE for full implementation of the EMS.

\section{SUMMARY OF RELEASES AND RADIOLOGICAL DOSES TO THE PUBLIC}

\section{Doses to the Public and the Environment}

The radiation dose to members of the public from WIPP facility operations has been calculated from WIPP facility effluent monitoring results and demonstrates compliance with federal regulations. 


\section{Dose Limits}

The regulatory limit for the WIPP facility is established in Title 10 Code of Federal Regulations (CFR) Part 191, Subpart A, "Environmental Standards for Management and Storage." The referenced standard requires that the combined annual dose equivalent to any member of the public in the general environment resulting from discharges of radioactive material and direct radiation from such management and storage shall not exceed 25 millirem (mrem) ("rem" is roentgen equivalent man) to the whole body and 75 mrem to any critical organ. In addition, in a 1995 memorandum of understanding between the EPA and the DOE, the DOE agreed that the WIPP facility would comply with 40 CFR Part 61, Subpart H, "National Emission Standards for Emissions of Radionuclides Other Than Radon from Department of Energy Facilities," hereafter referred to as the NESHAP (National Emissions Standards for Hazardous Air Pollutants). The NESHAP standard for radionuclides requires that the emissions of radionuclides to the ambient air from DOE facilities shall not exceed those amounts that would cause any member of the public to receive in any year an effective dose equivalent (EDE) of 10 mrem per year.

\section{Background Radiation}

There are several sources of naturally occurring radiation: cosmic and cosmogenic radiation (from outer space and the earth's atmosphere), terrestrial radiation (from the earth's crust), and internal radiation (naturally occurring radioactive material in our bodies). In addition to natural radioactivity, small amounts of radioactivity from aboveground nuclear weapons tests and from the 1986 Chernobyl nuclear accident are present in the environment. A potential source of radiation in the environment near and at the WIPP site is the result of Project Gnome. Under Project Gnome, a nuclear device was detonated in bedded salt on December 10, 1961, approximately 9 kilometers (km) (5.4 miles [mi]) from the WIPP site. The Project Gnome shot vented into the atmosphere; therefore, environmental samples taken at the WIPP site may contain residual contamination from this occurrence. Together, natural radiation and residual fallout are called "background" radiation. Exposure to radioactivity from weapons testing fallout is quite small compared to natural radioactivity. Site-specific background gamma measurements on the surface, conducted by Sandia National Laboratories (SNL), showed an average dose rate of 7.65 micro rem per hour (Minnema and Brewer, 1983), which would equate to the background gamma radiation dose of 0.67 millisieverts (mSv) (67.0 mrem) per year. A comprehensive radiological baseline study before WIPP facility disposal operations began was also documented in Statistical Summary of the Radiological Baseline for the Waste Isolation Pilot Plant (DOEMIPP-92-037), which provides the basis for environmental background comparison after WIPP facility disposal operations commenced.

\section{Dose from Air Emissions}

WIPP personnel have identified air emissions as the major pathway of concern for radionuclide transport during the receipt and emplacement of waste at the WIPP facility. To determine the radiation dose received by members of the public from WIPP facility operations, WIPP personnel used the emission monitoring and test procedure for DOE facilities (40 CFR §61.93, "Emission Monitoring and Test Procedure"), which requires 
the use of the EPA-approved CAP88-PC (computer code for calculating both dose and risk from radionuclide emissions) to calculate the EDE to members of the public.

CAP88-PC dose calculations are based on the assumption that exposed people remain at home during the entire year and all vegetables, milk, and meat consumed are homeproduced. Thus, this dose calculation is a maximum dose that encompasses dose from inhalation, plume immersion, deposition, and ingestion of air-emitted radionuclides.

\section{Total Dose from WIPP Facility Operations}

The dose to an individual from the ingestion of WIPP facility-managed radionuclides transported in water is nonexistent because drinking water for communities near the WIPP site comes from groundwater sources that are too far away to be affected by WIPP facility operations.

Game animals sampled during 2010 were deer, quail, fish, javelina, and rabbit. The radionuclides detected were not different from baseline levels. By extrapolation, no dose from WIPP facility-related radionuclides has been received by any individual from this pathway (e.g., the ingestion of meat from game animals) during 2010.

Based on the results of the WIPP effluent monitoring program, concentrations of radionuclides in air emissions did not exceed regulatory dose limits set by 40 CFR Part 191, Subpart A, "Environmental Standards for Management and Storage," or by 40 CFR Part 61, Subpart H, "National Emission Standards for Hazardous Air Pollutants." The results indicate that the hypothetical maximally exposed individual (MEl) who resides year-round at the fence line, $350 \mathrm{~m}(1148 \mathrm{ft})$ from the exhaust shaft, receives a dose that is less than 1.31E-05 mSv (1.31E-03 mrem) per year for the whole body and less than 1.73E-05 mSv (1.73E-03 mrem) per year to the critical organ. These values are in compliance with the Subpart A requirements specified in 40 CFR §191.03(b). For NESHAP (40 CFR §61.92) standards, the EDE potentially received by the MEI residing $7.5 \mathrm{~km}(4.66 \mathrm{mi})$ west-northwest of WIPP was calculated to be less than $1.91 \mathrm{E}-07 \mathrm{mSv}$ (1.91E-05 mrem) per year for the whole body. This value is in compliance with the 40 CFR §61.92 requirements.

Chapter 4 of this report presents figures and tables that provide the EDE values from calendar years (CYs) 1999 through 2010. These EDE values are below the EPA limit specified in 40 CFR Part 191, Subpart A, and 40 CFR Part 61, Subpart H.

\section{Dose to Nonhuman Biota}

Dose limits that cause no deleterious effects on populations of aquatic and terrestrial organisms have been suggested by the National Council on Radiation Protection and Measurements (NCRPM) and the International Atomic Energy Agency. These absorbed dose limits are listed below:

- $\quad$ Aquatic Animals 10 milligray/day (mGy/d) (1 radiation absorbed dose per day $[\mathrm{rad} / \mathrm{d}])$

- Terrestrial Plants $10 \mathrm{mGy} / \mathrm{d}(1 \mathrm{rad} / \mathrm{d})$ 
- $\quad$ Terrestrial Animals1 mGy/d (0.1 rad/d)

The DOE requires discussion of radiation doses to nonhuman biota in the ASER using the DOE Technical Standard, DOE-STD-1153-2002, A Graded Approach for Evaluating Radiation Doses to Aquatic and Terrestrial Biota. This standard requires an initial screening phase using conservative assumptions. This guidance was used to screen radionuclide concentrations observed around the WIPP site during 2010 . The screening results indicate that radiation in the environment surrounding the WIPP site does not have a deleterious effect on populations of plants and animals.

\section{Release of Property Containing Residual Radioactive Material}

There was no release of radiologically contaminated materials or property in 2010 . 


\section{CHAPTER 1 - INTRODUCTION}

The purpose of this report is to provide information needed by the DOE to assess WIPP facility environmental performance and to make WIPP Project environmental information available to members of the public. This report has been prepared in accordance with DOE Order 231.1A, Environment, Safety, and Health Reporting. This report documents the WIPP facility environmental monitoring and results for CY 2010.

The WIPP facility is authorized by the DOE National Security and Military Applications of Nuclear Energy Authorization Act of 1980 (Public Law 96-164). After more than 20 years of scientific study and public input, the WIPP facility received its first shipment of waste on March 26, 1999.

Located in southeastern New Mexico, the WIPP facility is the nation's first underground repository permitted to safely and permanently dispose of TRU radioactive and mixed waste generated through defense activities and programs. TRU waste is defined in the WIPP LWA (Public Law 102-579) as radioactive waste containing more than 100 nanocuries $(3,700$ becquerels [Bq]) of alpha-emitting TRU isotopes per gram of waste, with half-lives greater than 20 years except for high-level waste; waste that has been determined not to require the degree of isolation required by the disposal regulations; and waste the U.S. Nuclear Regulatory Commission has approved for disposal. Most TRU waste is contaminated industrial trash, such as rags and tools, sludges from solidified liquids, glass, metal, and other materials. The waste must meet the criteria in Transuranic Waste Acceptance Criteria for the Waste Isolation Pilot Plant (DOE/WIPP-02-3122).

TRU waste is disposed of $655 \mathrm{~m}(2,150 \mathrm{ft})$ below the surface in excavated disposal rooms in the Salado Formation (Salado), which is a thick sequence of Permian Age evaporite salt beds. At the conclusion of the WIPP disposal phase, seals will be placed in the shafts. One of the main attributes of salt, as a rock formation in which to isolate radioactive waste, is the ability of the salt to creep, that is, to deform continuously over time. Excavations into which the waste-filled drums are placed will close eventually and the surrounding salt will flow around the drums and seal them within the Salado. A detailed description of the WIPP geology and hydrology may be found in Chapter 2 of Title 40 CFR Part 191 Subparts B and C Compliance Recertification Application 2004 (DOE/WIPP-04-3231).

\section{$1.1 \quad$ WIPP Mission}

The WIPP mission is to provide for the safe, environmentally sound disposal of defense TRU radioactive waste left from research, development, and production of nuclear weapons.

\section{$1.2 \quad$ WIPP History}

Government officials and scientists initiated the WIPP site selection process in the 1950s. At that time, the National Academy of Sciences initiated an evaluation of stable geological formations to contain radioactive wastes for thousands of years. In 1955, 
after extensive study, salt deposits were recommended as a promising medium for the disposal of radioactive waste.

Salt deposits were selected as the host for the disposal of nuclear waste for several reasons. Most deposits of salt are found in stable geological areas with very little earthquake activity, assuring the stability of a waste repository. Salt deposits also demonstrate the absence of water that could move waste to the surface. Water, if it had been or were present, would have dissolved the salt beds. In addition, salt is relatively easy to mine. Finally, rock salt heals its own fractures because it is relatively plastic. This means salt formations will slowly and progressively move in to fill mined areas and will safely seal radioactive waste from the biosphere.

Government scientists searched for an appropriate site for the disposal of radioactive waste throughout the 1960s, and finally tested the area of southeastern New Mexico in the early 1970s. Salt formations at the WIPP site were deposited in thick beds during the evaporation of the Permian Sea. These geologic formations consist mainly of sodium chloride, the same substance as table salt. However, the salt is not granular, but in the form of solid rock. The main salt formation is approximately $610 \mathrm{~m}(2,000 \mathrm{ft})$ thick, begins $259 \mathrm{~m}(850 \mathrm{ft})$ below the earth's surface, and constitutes a stable geologic environment.

In 1979, Congress authorized the construction of the WIPP facility, and the DOE constructed the facility during the 1980s. In late 1993, the DOE created the Carlsbad Area Office (CAO), subsequently redesignated as the CBFO, to lead the TRU waste disposal effort. The CBFO coordinates the TRU program at waste-generating sites and national laboratories.

In 1999, the WIPP facility received its first waste shipment. On March 25, the first waste bound for the WIPP facility departed Los Alamos National Laboratory in New Mexico; it arrived at the WIPP facility the following morning, and the first wastes were placed underground later that day. On April 27, the first out-of-state shipment arrived at the WIPP site from the Idaho National Engineering and Environmental Laboratory. Later in the year, on October 27, the Secretary of the NMED issued the WIPP Permit (NM4890139088-TSDF), which allowed CH TRU mixed waste to be managed, stored, and disposed at the WIPP facility. Mixed waste is waste that contains both hazardous and radioactive waste. $\mathrm{CH}$ TRU mixed waste is TRU mixed waste with a maximum surface dose rate of 200 mrem per hour. The surface dose rate is the measurable amount of radioactivity from neutrons and gamma rays at the external surface of the container.

On October 16, 2006, the Secretary of the NMED approved a revision to the Permit allowing the WIPP facility to receive RH TRU mixed waste. RH TRU waste allowable at the WIPP facility has a surface dose rate greater than or equal to 200 mrem per hour and up to 1,000 rem per hour.

\section{$1.3 \quad$ Site Description}

Located in Eddy County in the Chihuahuan Desert of southeastern New Mexico (Figure 1.1), the WIPP site encompasses $41.4 \mathrm{~km}^{2}$, or $16 \mathrm{mi}^{2}$. This part of New Mexico is 
relatively flat and is sparsely inhabited, with little surface water. The site is $42 \mathrm{~km}$ (26 mi) east of Carlsbad, New Mexico, in a region known as Los Medaños (the Dunes).

Figure 1.1 - WIPP Location

The WIPP LWA was signed into law on October 30, 1992, transferring the administration of federal land from the U.S. Department of the Interior to the DOE. With the exception of facilities within the boundaries of the posted $1.2 \mathrm{~km}^{2}\left(0.463 \mathrm{mi}^{2}\right)$ Exclusive Use Area, the surface land uses remain largely unchanged from pre-1992 uses, and are managed in accordance with accepted practices for multiple land use.

However, mining and drilling for purposes other than those which support the WIPP Project are prohibited within the WIPP site, with the exception of two mineral leases.

The majority of the lands in the immediate vicinity of the WIPP site are managed by the U.S. Department of the Interior Bureau of Land Management (BLM). Land uses in the surrounding area include livestock grazing; potash mining; oil and gas exploration and production; and recreational activities such as hunting, camping, hiking, and bird watching. The region is home to diverse populations of animals and plants. 


\subsubsection{WIPP Property Areas}

Four property areas are defined within the WIPP site boundary (Figure 1.2).

\section{Property Protection Area}

The interior core of the facility encompasses $0.14 \mathrm{~km}^{2}\left(0.05 \mathrm{mi}^{2}\right)$ (35 acres) surrounded by a chain link fence. Security is provided for this area 24 hours a day.

\section{Exclusive Use Area}

The Exclusive Use Area is comprised of $1.1 \mathrm{~km}^{2}\left(0.43 \mathrm{mi}^{2}\right)$ (277 acres). It is surrounded by a barbed wire fence and is restricted exclusively for the use of the DOE and its contractors and subcontractors in support of the project. This area is marked by DOE warning (e.g., "no trespassing") signs and is patrolled by WIPP facility security personnel to prevent unauthorized activities or uses.

\section{Off Limits Area}

The Off-Limits Area is an area where unauthorized entry and introduction of weapons and/or dangerous materials are prohibited. The Off-Limits Area includes $5.9 \mathrm{~km}^{2}(2.3$ $\left.\mathrm{mi}^{2}\right)(1,454$ acres). Pertinent prohibitions are posted along the perimeter. Grazing and public thoroughfare will continue in this area unless these activities present a threat to the security, safety, or environmental quality of the WIPP site. This area is patrolled by WIPP facility security personnel to prevent unauthorized activities or use.

\section{WIPP Land Withdrawal Area}

The WIPP site boundary delineates the perimeter of the $41.4 \mathrm{~km}^{2}\left(16 \mathrm{mi}^{2}\right)(10,240$ acres) WIPP LWA. This tract includes the Property Protection Area, the Exclusive Use Area, and the Off-Limits Area, as well as outlying areas. 


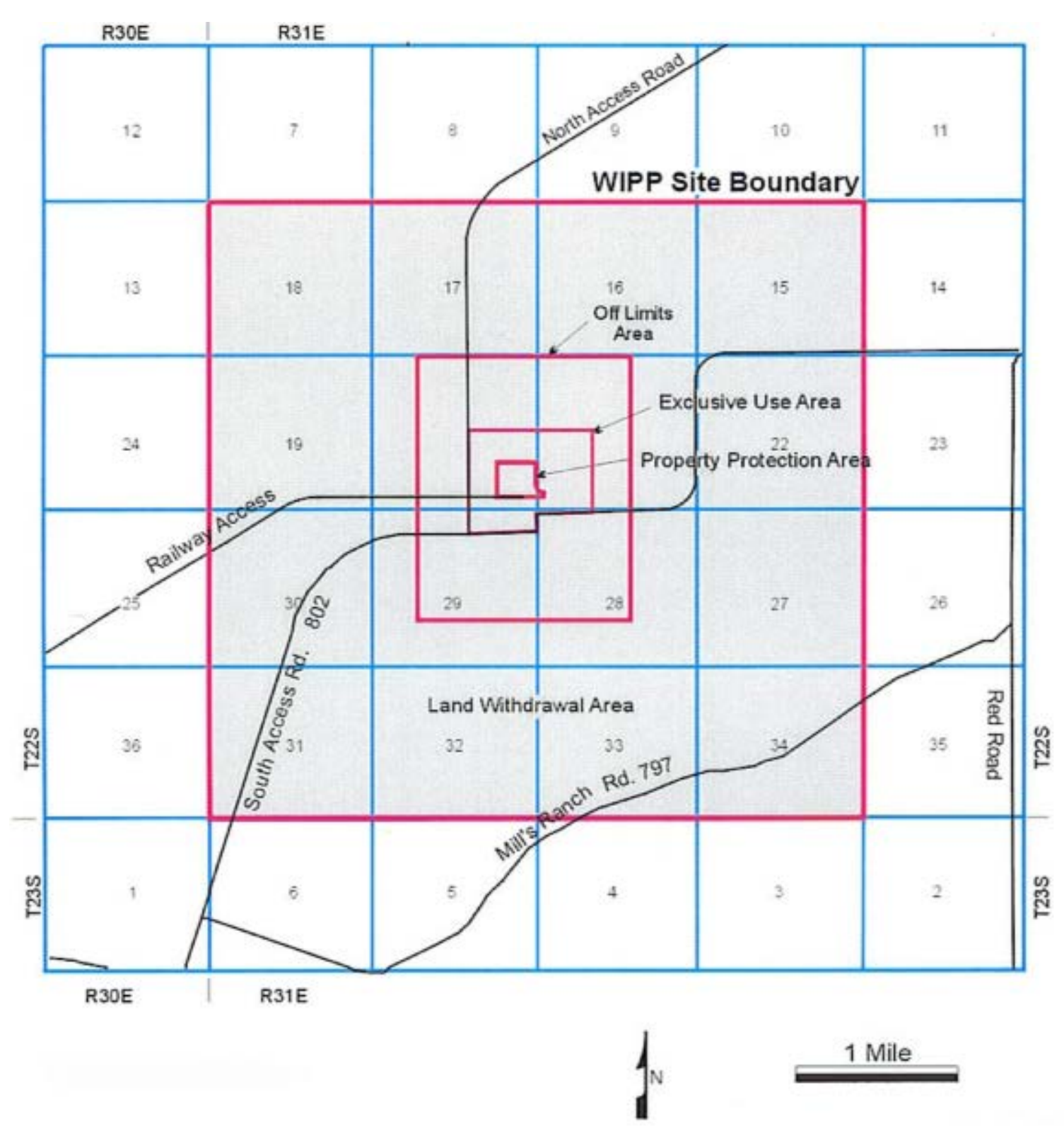

Figure 1.2 - WIPP Property Areas

\section{Special Management Areas}

Certain properties used in the execution of the WIPP Project (e.g., reclamation sites, well pads, roads) are, or may be, identified as Special Management Areas in accordance with the WIPP LMP (DOEMIPP-93-004), which is described further in chapter 5. A Special Management Area designation is made due to values, resources, and/or circumstances that meet criteria for protection and management under special management designations. Unique resources of value that are in danger of being lost or damaged, areas where ongoing construction is occurring, fragile plant and/or animal communities, sites of archaeological significance, locations containing safety hazards, or sectors that may receive an unanticipated elevated security status would be suitable for designation as a Special Management Area. In 2010, there were no areas designated as Special Management Areas. 


\subsubsection{Population}

There are 11 permanent residents living within $16 \mathrm{~km}(10 \mathrm{mi})$ of the WIPP site (DOE/WIPP-93-004). The population within $16 \mathrm{~km}$ (10 mi) of WIPP is associated with ranching, oil and gas exploration/production, and potash mining.

The majority of the local population within $80.5 \mathrm{~km}$ (50 mi) of WIPP is concentrated in and around the communities of Carlsbad, Hobbs, Eunice, Loving, Jal, Lovington, and Artesia, New Mexico. According to 2010 census data, the estimated population within this radius is 88,952 . The nearest community is the village of Loving (estimated population 1,413), $29 \mathrm{~km}(18 \mathrm{mi})$ west-southwest of the WIPP site. The nearest major populated area is Carlsbad, $42 \mathrm{~km}(26 \mathrm{mi})$ west of the WIPP site. The 2010 census reported the population of Carlsbad as 26,138.

\subsection{WIPP Environmental Stewardship}

The DOE policy is to conduct its operations in compliance with applicable environmental laws and regulations, and to safeguard the integrity of the southeastern New Mexico environment. The DOE conducts effluent monitoring, environmental surveillance, land management, and assessments to verify that these objectives are met. Environmental monitoring includes collecting and analyzing environmental samples from various media and evaluating whether WIPP facility operations have caused any adverse environmental impacts.

\subsubsection{Environmental Monitoring Plan}

The Waste Isolation Pilot Plant Environmental Monitoring Plan (DOEMIPP-99-2194) outlines the program for monitoring the environment at and around the WIPP site, including the major environmental monitoring and surveillance activities at the WIPP facility. The plan also discusses the WIPP Project Quality Assurance/Quality Control (QA/QC) program as it relates to environmental monitoring. The purpose of the plan is to specify how the effects of WIPP facility operations on the local ecosystem are to be determined. Effluent and environmental monitoring data are necessary to demonstrate compliance with applicable environmental protection regulations. The frequency of 2010 sampling is provided in Table 1.1. 
Waste Isolation Pilot Plant Annual Site Environmental Report for 2010 DOE/WIPP-11-2225

Table 1.1 - Environmental Monitoring Sampling ${ }^{a}$

\begin{tabular}{|c|c|c|c|}
\hline Program & Type of Sample & $\begin{array}{l}\text { Number of } \\
\text { Sampling } \\
\text { Locations }\end{array}$ & Sampling Frequency \\
\hline \multirow[t]{11}{*}{ Radiological } & Airborne effluent & 3 & Periodic/confirmatory \\
\hline & Airborne particulate & 7 & Weekly \\
\hline & Sewage treatment system (DP-831) & 3 & Semiannual \\
\hline & $\mathrm{H}-19(\mathrm{DP}-831)^{\mathrm{b}}$ & 1 & Semiannual \\
\hline & Liquid effluent & 1 (WHB sump) & If needed \\
\hline & \multicolumn{3}{|c|}{ Biotic } \\
\hline & $\begin{array}{ll}\text { - } & \text { Quail } \\
\text { - } & \text { Rabbits } \\
\text { - } & \text { Beef/Deer } \\
\text { - Javelina } \\
\text { - Fish } \\
\end{array}$ & $\begin{array}{l}\text { WIPP vicinity } \\
\text { WIPP vicinity } \\
\text { WIPP vicinity } \\
\text { WIPP vicinity } \\
3 \\
6\end{array}$ & $\begin{array}{l}\text { Annual } \\
\text { As available } \\
\text { As available } \\
\text { As available } \\
\text { Annual } \\
\text { Annual }\end{array}$ \\
\hline & Soil & 6 & Annual \\
\hline & Surface water & Maximum of 14 & Annual \\
\hline & Sediment & $\begin{array}{l}\text { Maximum of } 12 ; 13 \text { if } \\
\text { sediment is present } \\
\text { at sewage lagoon } \\
\text { outfall }\end{array}$ & Annual \\
\hline & Groundwater & 7 & Semiannual \\
\hline \multirow[t]{6}{*}{ Nonradiological } & Meteorology & 1 & Continuous \\
\hline & \multicolumn{3}{|c|}{ Volatile organic compounds (VOCs) } \\
\hline & $\begin{array}{l}\text { VOCs - Repository } \\
\text { VOCs - Disposal Room }\end{array}$ & $\begin{array}{c}2 \\
\text { \# of active panel } \\
\text { disposal rooms }\end{array}$ & $\begin{array}{l}\text { Semiweekly } \\
\text { Biweekly }\end{array}$ \\
\hline & Hydrogen and methane & 18 per closed panel & Monthly \\
\hline & Groundwater & 7 & Semiannual \\
\hline & Shallow subsurface water (SSW) & 11 & Semiannual \\
\hline & \multicolumn{2}{|l|}{ Surface water (DP-831) } & $\begin{array}{l}\text { After a major storm event or } \\
\text { annually, whichever is more } \\
\text { frequent }\end{array}$ \\
\hline \multicolumn{4}{|c|}{$\begin{array}{l}\text { (a) The number of certain types of samples taken can be driven by site conditions. For example, during dry } \\
\text { periods there may be no surface water or sediment to sample at certain locations. Likewise, the number of } \\
\text { samples for biota will also vary. For example, the number of rabbits available as samples of opportunity will } \\
\text { vary as will fishing conditions that are affected by weather and algae levels in the water. } \\
\text { (b) Includes a nonradiological program component. }\end{array}$} \\
\hline
\end{tabular}

The plan describes the monitoring of naturally occurring and specific anthropogenic (human-made) radionuclides. The geographic scope of radiological sampling is based on projections of potential release pathways from the waste disposed at the WIPP facility. The plan also describes monitoring of VOCs, groundwater chemistry, and other nonradiological environmental parameters, and collection of meteorological data.

\subsubsection{WIPP Facility Environmental Monitoring Program and Surveillance Activities}

Employees of the WIPP facility monitor air, surface water, groundwater, sediments, soils, and biota (e.g., vegetation, select mammals, quail, and fish). Environmental monitoring activities are performed in accordance with procedures that govern how samples are to be taken, preserved, and transferred. Procedures also direct the verification and validation of environmental sampling data. 
The atmospheric pathway, which can lead to the inhalation of radionuclides, has been determined to be the most likely exposure pathway to the public from the WIPP facility. Therefore, airborne particulate sampling for alpha-emitting radionuclides is emphasized. Air sampling results are used to trend environmental radiological levels and determine if there has been a deviation from established baseline concentrations. The geographic scope of radiological sampling is based on projections of potential release pathways and nearby populations for the types of radionuclides in TRU wastes that are managed at the WIPP facility, and includes Carlsbad and nearby ranches.

Nonradiological environmental monitoring activities at the WIPP site consist of sampling and analyses designed to detect and quantify impacts of construction and operational activities, and verify compliance with applicable requirements.

\subsection{Environmental Performance}

DOE Order 450.1A, Environmental Protection Program, describes the DOE commitment to environmental protection and pledges to implement sound stewardship practices that are protective of the air, water, land, and other natural and cultural resources. The provisions of DOE Order $450.1 \mathrm{~A}$ are implemented by the WIPP Project environmental policy and EMS.

In 2010, WIPP maintained compliance with applicable environmental laws, regulations, and permit conditions, except as noted. Furthermore, analyses of the WIPP environmental monitoring data have demonstrated that WIPP operations have not had an adverse impact on the environment. Implementation of the WIPP Environmental Monitoring Plan fulfills the environmental monitoring requirements of DOE Order 450.1A. Detailed information on WIPP programs are contained in the remaining chapters. 


\section{CHAPTER 2 - COMPLIANCE SUMMARY}

The WIPP facility is required to comply with the applicable regulations promulgated pursuant to federal and state statutes, DOE orders, and Executive Orders (EOs). Compliance with regulatory requirements is incorporated into facility plans and implementing procedures. Methods for maintaining compliance with environmental requirements include the use of engineered controls and written procedures, routine training of facility personnel, ongoing self-assessments, and personnel accountability. The following sections list the environmental statutes/regulations applicable to WIPP, and describe significant accomplishments and ongoing compliance activities. A detailed breakdown of WIPP facility compliance with environmental laws is available in the Waste Isolation Pilot Plant Biennial Environmental Compliance Report (DOEMIPP-10-2171).

A summary of WIPP facility compliance with major environmental regulations is presented below. A list of active WIPP environmental permits appears in Appendix B.

\subsection{Comprehensive Environmental Response, Compensation and Liability Act (CERCLA)}

The Comprehensive Environmental Response, Compensation, and Liability Act (42 U.S.C. [United States Code] §§9601, et seq.), or Superfund, establishes a comprehensive federal strategy for responding to, and establishing liability for, releases of hazardous substances from a facility to the environment. Any spills of hazardous substances that exceed a reportable quantity must be reported to the National Response Center under the provisions of the Comprehensive Environmental Response, Compensation, and Liability Act and 40 CFR Part 302, "Designation, Reportable Quantities, and Notification." Hazardous substance cleanup procedures are specified in 40 CFR Part 300, "National Oil and Hazardous Substances Pollution Contingency Plan."

\subsubsection{Superfund Amendments and Reauthorization Act of 1986 (SARA)}

The WIPP facility is required by the Superfund Amendments and Reauthorization Act of 1986 Title III (42 U.S.C. §11001) (also known as the Emergency Planning and community Right-to-Know Act [EPCRA]), which is implemented by 40 CFR Parts 355, 370,372 , and 373 to submit (1) a list of hazardous chemicals present at the facility in excess of 10,000 pounds for which Material Safety Data Sheets are required, (2) an Emergency and Hazardous Chemical Inventory Form (Tier II Form) that identifies the inventory of hazardous chemicals present during the preceding year, and (3) notification to the State Emergency Response Commission (SERC) and the Local Emergency Planning Committee (LEPC) of any accidental releases of hazardous chemicals in excess of reportable quantities. The list of hazardous chemicals and the Tier II Form are also submitted to the regional fire departments.

The list of chemicals provides external emergency responders with information they may need when responding to a hazardous chemical emergency at WIPP. The list of chemicals is a one-time notification unless new chemicals in excess of 10,000 pounds, or new information on existing chemicals, are received. 


\section{Waste Isolation Pilot Plant Annual Site Environmental Report for 2010 DOE/WIPP-11-2225}

The LEPC and the SERC are notified whenever a new chemical is received on site in excess of 10,000 pounds at any one time. The chemical is reported to the LEPC and the SERC within 30 days of receipt of the chemical.

The Tier II Form, due on March 1 of each year, provides information to the public about hazardous chemicals above threshold planning quantities that a facility has on site at any time during the year. The Tier II Form is submitted annually to the LEPC and the SERC, and to each fire department with which the CBFO maintains a memorandum of understanding.

Title 40 CFR Part 372, "Toxic Chemical Release Reporting: Community Right to Know," identifies requirements for facilities to submit a toxic chemical release report to the EPA and the resident state if toxic chemicals are used at the facility in excess of established threshold amounts. The Toxic Chemical Release Report was submitted to the EPA and to the SERC prior to the July 1, 2010, reporting deadline. Table 2.1 presents the 2010 EPCRA reporting status. A response of "yes" indicates that the report was required and submitted.

Table 2.1 - Status of Emergency Planning and Community Right-to-Know Act Reporting

\begin{tabular}{|c|l|c|}
\hline $\begin{array}{c}\text { EPCRA Regulations - } \\
\text { 40 CFR Parts }\end{array}$ & \multicolumn{1}{|c|}{ Description of Reporting } & \multicolumn{1}{c|}{ Status } \\
\hline 355 & Planning Notification & Further Notification Not Required \\
\hline 302 & $\begin{array}{l}\text { Extremely Hazardous Substance Release } \\
\text { Notification }\end{array}$ & Not Required \\
\hline 355 & $\begin{array}{l}\text { Material Safety Data Sheet/Chemical Inventory } \\
\text { (Tier II Form) }\end{array}$ & Yes \\
\hline 372 & Toxics Release Inventory Reporting & Yes \\
\hline
\end{tabular}

\subsubsection{Accidental Releases of Reportable Quantities of Hazardous Substances}

There were no releases of hazardous substances exceeding the reportable quantity limits during 2010.

\subsection{Resource Conservation And Recovery Act}

The Resource Conservation and Recovery Act (RCRA) (42 U.S.C. §§6901, et seq.) was enacted in 1976. Implementing regulations were promulgated in May 1980. This body of regulations ensures that hazardous waste is managed and disposed of in a way that protects human health and the environment. The Hazardous and Solid Waste Amendments of 1984 (Public Law 98-616, Stat. 3221) prohibit land disposal of hazardous waste unless treatment standards are met or specific exemptions apply. The amendments also emphasize waste minimization. Section 9(a) of the WIPP LWA exempts transuranic mixed waste designated by the Secretary of Energy for disposal at the WIPP facility from treatment standards. Such waste is not subject to the land disposal prohibitions of the Solid Waste Disposal Act (42 U.S.C. §§6901-6992, et seq.). The NMED is authorized by the EPA to implement the hazardous waste program in New Mexico pursuant to the New Mexico Hazardous Waste Act (New Mexico Statutes Annotated [NMSA] $\S \S 74-4-1$, et seq., 1978). The technical standards for hazardous waste treatment, storage, and disposal facilities in New Mexico are outlined in 
20.4.1.500 New Mexico Administrative Code (NMAC), which adopts, by reference, 40 CFR Part 264, "Standards for Owners and Operators of Hazardous Waste Treatment, Storage, and Disposal Facilities." The hazardous waste management permitting program is administered through 20.4.1.900 NMAC, "Adoption of 40 CFR Part 270" [EPA Administered Permit Programs: The Hazardous Waste Permit Program].

\subsubsection{Hazardous Waste Facility Permit}

The NMED renewed the WIPP Permit on November, 30 2010, and it became effective December 30, 2010. The Permit authorizes DOE and WTS (known as the Permittees) to receive, store, and dispose of $\mathrm{CH}$ and $\mathrm{RH}$ TRU mixed waste at the WIPP facility. Two storage units (the parking area container storage unit and the Waste Handling Building container storage unit) are permitted for storage of TRU mixed waste. Eight underground hazardous waste disposal units are currently permitted for the disposal of $\mathrm{CH}$ and RH TRU mixed waste.

As a condition of a partial settlement agreement regarding a July 2009 Compliance Order, a Class 2 permit modification clarifying language regarding the liquid prohibition, visual examination, and nonconformance reporting was delivered to NMED on January 7, 2010. The Final Stipulated Settlement became effective May 30, 2010.

\subsubsection{Modification Requests}

In 2010, the Permittees submitted two Permit modification notification/requests to the NMED. Table 2.2 provides details on the modification requests submitted to the NMED in 2010.

Table 2.2 - Permit Modification Notifications and Requests Submitted in 2010

\begin{tabular}{|c|l|c|}
\hline Class & \multicolumn{1}{|c|}{ Description } & Date Submitted \\
\hline 2 & $\begin{array}{l}\text { Revise Volatile Organic Compound Concentrations of Concern and } \\
\text { Update these Values Using Current EPA Integrated Risk Information } \\
\text { System Data. }\end{array}$ & April 12, 2010 \\
\hline 1 & Editorial Corrections to the New Permit Issued November 30, 2010. & December 30, 2010 \\
\hline
\end{tabular}

\subsubsection{Permit Renewals}

Subsequent to two days of public hearing and public/non-technical comments in Santa Fe, New Mexico, and one day of public/ non-technical comments in Carlsbad, New Mexico, the NMED renewed the WIPP Permit for another ten- year term on November 30, 2010. It became effective 30 days later on December 30, 2010.

\subsubsection{Underground Storage Tanks}

Title 40 CFR Part 280, "Technical Standards and Corrective Action Requirements for Owners and Operators of Underground Storage Tanks (UST)," addresses USTs containing petroleum products or hazardous chemicals. Requirements for UST management pertain to the design, construction, installation, and operation of USTs, as well as notification and corrective action requirements in the event of a release and 
actions required for out-of-service USTs. The NMED has been authorized by the EPA to regulate USTs, and implements the EPA program through 20.5 NMAC, "Petroleum Storage Tanks."

The NMED conducted an inspection of the USTs on March 16, 2010. An administrative NOV was issued because the monthly inspections were documented on the old form instead of the newly approved Monthly Inspection Form. Inspections for March and April were documented on the new forms and submitted to NMED. On April 14, 2010, the Inspector documented that the NOV had been satisfied.

\subsubsection{Hazardous Waste Generator Compliance}

Nonradioactive hazardous waste is currently generated through routine facility operations, and is managed in satellite accumulation areas, a "less-than-90-day" accumulation area on the surface, and a "less-than-90-day" accumulation area underground.

Hazardous waste generated at the WIPP facility is accumulated, characterized, packaged, labeled, and manifested to off-site treatment, storage, and disposal facilities in accordance with the requirements codified in 20.4.1.300 NMAC, which adopts, by reference, 40 CFR Part 262, "Standards Applicable to Generators of Hazardous Waste."

\subsubsection{Program Deliverables and Schedule}

WIPP is in compliance with the Permit conditions related to reporting as noted below. (Note that the Permit Section numbers are those from the version of the Permit in effect at the time. The renewed Permit that became effective on December 30, 2010 revised many of the Permit Section numbers.)

- $\quad$ Permit Module IV, Section F, Maintenance and Monitoring Requirements, required annual reports evaluating the geomechanical monitoring program and the mine ventilation rate monitoring. The WIPP facility continued to comply with these requirements by preparation and submission of annual reports in October 2010, representing results for July 1, 2009, through June 30, 2010.

- $\quad$ Semiannual reports are required describing the implementation and results (data and analysis) of the confirmatory VOC monitoring. The WIPP facility continued to comply with these requirements by preparation and submission of semiannual reports in April 2010, representing results for July 1, 2009, through December 31, 2009, and another semiannual report in October 2010 representing results for January 1, 2010, through June 30,2010 . Reporting of hydrogen and methane program data was included with the semiannual reports in 2010.

- $\quad$ Permit Module V, Section V.J.2.a, requires reports of the analytical results for semiannual detection monitoring program (DMP) well samples and duplicates, as well as results of the statistical analysis of the 
samples showing whether or not statistically significant evidence of contamination is demonstrated. These reports for Sampling Rounds 30 and 31 were submitted to the NMED in 2010. Sampling results are also summarized in Appendices $E$ and $F$ of this ASER.

- $\quad$ Permit Module V, Section V.J.2.b. requires monthly submittal of groundwater surface elevation results. This includes groundwater surface elevations calculated from field measurements and fresh-water head elevations calculated as specified in Permit Attachment L, Section L-4c(1). Twelve monthly reports were submitted to the NMED in 2010 as required.

- $\quad$ Permit Module V, Section V.J.2.c. requires that radionuclide sampling results and groundwater flow rate and direction be included in the ASER by October 1 of each year. These 2010 data are presented in Chapter 4, Environmental Radiological Program Information, and Chapter 6, Site Hydrology, Groundwater Monitoring, and Public Drinking Water Protection, respectively.

\subsection{National Environmental Policy Act}

The National Environmental Policy Act (NEPA) (42 U.S.C. §§4321, et seq.) requires the federal government to use all practicable means to consider potential environmental impacts of proposed projects as part of the decision-making process. The NEPA also dictates that the public shall be allowed to review and comment on proposed projects that have the potential to significantly affect the environment.

NEPA requirements are detailed in the Council on Environmental Quality regulations in 40 CFR Parts 1500-1508, "Council on Environmental Quality." The DOE codified its requirements for implementing the council's regulations in 10 CFR Part 1021, "National Environmental Policy Act Implementing Procedures." Title 10 CFR §1021.331 requires that, following completion of each environmental impact statement and its associated record of decision, the DOE prepare a mitigation action plan that addresses mitigation commitments expressed in the record of decision. The CBFO tracks the performance of mitigation commitments in the WIPP annual mitigation report. This report was issued June 28, 2010.

Day-to-day operational compliance with the NEPA at the WIPP facility is achieved through implementation of a NEPA compliance plan and procedure. Forty-three projects were reviewed and approved by the CBFO NEPA Compliance Officer through the NEPA screening and approval process in 2010. These projects were primarily upgrades to the facilities and equipment at the WIPP site. These approvals were in addition to routine activities which have been determined to be bounded by existing NEPA documentation and which do not require additional evaluation by the CBFO NEPA Compliance Officer. The CBFO NEPA Compliance Officer also routinely participates in the development of NEPA documents for other DOE offices and other federal agencies for proposed actions that may have environmental impacts on WIPP. 


\section{Waste Isolation Pilot Plant Annual Site Environmental Report for 2010 DOE/WIPP-11-2225}

During 2010, DOE CBFO adopted an Environmental Assessment prepared by the BLM for the reconstruction of the WIPP South Access Road. Based on this assessment, CBFO prepared a Mitigation Action Plan and issued a Finding of No Significant Impact for the proposed project. Upon completion of the project, a Mitigation Report was issued. Also during 2010 one categorical exclusion determination was issued for performance of a three-dimensional seismic survey on a portion of the WIPP LWA. In September of 2010, CBFO issued a Supplement Analysis that examined the impacts associated with packaging and handling remote-handled TRU wastes in shielded containers. This analysis addressed a proposed action to package at the generator sites, and to emplace at WIPP, a portion of the remote-handled TRU waste inventory using a new container design called the lead shielded container.

\subsection{Clean Air Act (CAA)}

The Clean Air Act (42 U.S.C. $\S \S 7401$, et seq.) provides for the preservation, protection, and enhancement of air quality. Both the state of New Mexico and the EPA have authority for regulating compliance with portions of the Clean Air Act. Radiological effluent monitoring in compliance with EPA standards is discussed in Chapter 4.

The Clean Air Act established National Ambient Air Quality Standards for six "criteria" pollutants: sulfur oxides, particulate matter, carbon monoxide, ozone, nitrogen dioxide, and lead. The initial 1993 WIPP air emissions inventory was developed as a baseline document to calculate maximum potential hourly and annual emissions of both hazardous and criteria pollutants. Based on the current air emissions inventory, WIPP facility operations do not exceed the 10-ton-per-year emission limit for any individual hazardous air pollutant, the 25-ton-per-year limit for any combination of hazardous air pollutant emissions, or the 10-ton-per-year emission limit for criteria pollutants except for total suspended particulate matter and particulate matter less than 10 microns in diameter. Particulate matter is produced from fugitive sources related to the management of salt tailings extracted from the underground. Consultation with the NMED Air Quality Bureau resulted in a March 2006 determination that a permit is not required for fugitive emissions of particulate matter that result from salt management at the WIPP facility. Proposed facility modifications are reviewed to determine if they will create new air emission sources and require permit applications.

Based on the initial 1993 air emissions inventory, the WIPP site is not required to obtain Clean Air Act permits. In 1993, the DOE did obtain a New Mexico Air Quality Control (NMSA 1978 §74-2) Regulation 702 Operating Permit (recodified in 2001 as 20.2.72 NMAC, "Construction Permits") for two backup diesel generators at the WIPP facility. There have been no activities or modifications to the operating conditions of the diesel generators that would require reporting under the conditions of the permit in 2010 .

VOC emissions from containers of TRU and TRU mixed waste that are vented to prevent the buildup of gases generated by radiolysis do not approach permitting thresholds or the 10 pounds per hour or 10 tons per year requiring a Notice of Intent to be submitted to NMED under 20.2.72 NMAC. These emissions have exceeded estimated emissions in the SEIS-I (Final Supplement Environmental Impact Statement for the Waste Isolation Pilot Plant, DOE/EIS-0026-FS) and SEIS-II; however, they remain considerably less than 5 tons per year for all VOCs monitored under the Permit. 


\section{$2.5 \quad$ Clean Water Act (CWA)}

The Clean Water Act (33 U.S.C. §§1251, et seq.) establishes provisions for the issuance of permits for discharges into waters of the United States. The regulation defining the scope of the permitting process is contained in 40 CFR §122.1(b), "Scope of the NPDES [National Pollutant Discharge Elimination System] Permit Requirement," which states that "The NPDES program requires permits for the discharge of 'pollutants' from any 'point source' into 'waters of the United States. "

The WIPP facility does not have any discharges of wastewater or storm water runoff into waters of the United States and is not subject to regulation under the NPDES program. Wastewaters generated at the WIPP facility are either disposed of offsite or managed in on-site, lined evaporation ponds. Storm water runoff is also collected in lined detention basins. The management of wastewater and storm water runoff is regulated under the New Mexico Water Quality Act (NMSA 1978, §§74-6-1, et seq.); those permits are discussed further in Section 2.6.

\subsection{New Mexico Water Quality Act}

The New Mexico Water Quality Act created the New Mexico Water Quality Control Commission and tasked the commission with the development of regulations to protect New Mexico ground and surface water. New Mexico water quality regulations for ground and surface water protection are contained in 20.6.2 NMAC, "Ground and Surface Water Protection." The WIPP facility does not have any discharges to surface water, but does have a discharge permit designed to prevent impacts to groundwater.

The DOE was issued a discharge permit (DP-831) from the NMED Ground Water Quality Bureau (GWQB) for the operation of the WIPP sewage treatment facility in January 1992. The discharge permit was renewed and modified to include the $\mathrm{H}-19$ Evaporation Pond in July 1997. The H-19 Evaporation Pond is used for the treatment of wastewater generated during groundwater monitoring activities, water removed from sumps in the underground, and condensation from duct work in the mine ventilation system. The discharge permit was modified in December 2003 to incorporate the infiltration controls for salt contact storm water runoff and in December 2006 to provide a more detailed closure plan. The discharge permit was renewed on September 9, 2008.

A discharge permit modification to incorporate the construction of the Salt Storage Extension Basin II to provide additional capacity for the storage and evaporation of salt contact runoff from the Salt Storage Extension was submitted to the GWQB in November of 2009. The GWQB issued a modified permit incorporating the Salt Storage Extension Basin II into the discharge permit in April, 2010.

A plan for the control of storm water runoff and minimization of erosion required by Condition III.6 of the discharge permit was submitted to and approved by the GWQB in May 2009. The plan involves grading the surface contours of the covered Salt Storage Area to direct runoff to runoff chutes that will be lined with high-density polyethylene. The conceptual design was submitted to and approved by the GWQB in October 2009. The work began and was completed in 2010. The GWQB conducted an inspection on 
November 17, 2010, and the inspector indicated he was impressed with improved drainage conditions.

Evaporation Pond $\mathrm{C}$ at the sewage treatment facility was relined during the ASER reporting period in September 2010. This action completed a five-year commitment the DOE made to the GWQB in 2005 to reline each of the seven ponds in the treatment facility.

In accordance with the discharge permit requirements, monthly inspections are conducted on each of the infiltration control ponds and each salt storage area to ensure that the infiltration controls are maintained in good condition. When deficiencies are observed (e.g., liner tears or significant erosion), the appropriate repairs are conducted. The sewage lagoons and H-19 Evaporation Pond are inspected weekly for signs of erosion or damage to the liners even though the permit only requires monthly inspections. Freeboard is monitored daily at the sewage lagoons, the $\mathrm{H}-19$ Evaporation Pond, and all infiltration control ponds.

The discharge permit requires the sewage lagoons and H-19 Evaporation Pond to be sampled semiannually and analyzed for nitrate, total Kjeldahl nitrogen, total dissolved solids (TDS), sulfate, and chloride. The infiltration control ponds must be sampled annually for TDS, sulfates, and chlorides. The results of this monitoring are reported in Section 5.7, Liquid Effluent Monitoring. Additionally, the permit requires annual groundwater level monitoring and semiannual groundwater monitoring for sulfate, chloride, and TDS. There are no regulatory limits associated with the analytes. Subsurface shallow water monitoring results are discussed in Chapter 6.

\subsection{Safe Drinking Water Act (SDWA)}

The Safe Drinking Water Act (42 U.S.C. §§300f, et seq.) provides the regulatory strategy for protecting public water supply systems and underground sources of drinking water. New Mexico's drinking water regulations are contained in 20.7.10 NMAC, "Drinking Water," which adopts, by reference, 40 CFR Part 141, "National Primary Drinking Water Regulations," and 40 CFR Part 143, "National Secondary Drinking Water Regulations." Water is supplied to the WIPP facility by the city of Carlsbad; however, the WIPP facility is classified as a nontransient, noncommunity water system subject to the New Mexico drinking water regulations.

The WIPP facility qualifies for a reduced monitoring schedule under 40 CFR $\S 141.86(d)(4)$, and is required to sample for lead and copper every three years. Lead and copper in drinking water were last sampled in August 2008. All samples were below action levels as specified by New Mexico monitoring requirements for lead and copper in tap water. The next lead and copper samples will be collected between June and September 2011.

Bacterial samples are collected and residual chlorine levels tested monthly. Chlorine levels are reported to the NMED monthly. All bacteriological analytical results have been below the Safe Drinking Water Act regulatory limits. Disinfectant byproducts testing per 40 CFR $\$ 141.132$ is conducted annually by the state of New Mexico. All results have been below regulatory limits. 


\subsection{National Historic Preservation Act}

The National Historic Preservation Act (16 U.S.C. $\S \S 470$, et seq.) was enacted to protect the nation's cultural resources and establish the National Register of Historic Places. No archaeological investigations were required to support the WIPP facility in 2010.

\subsection{Toxic Substances Control Act}

The Toxic Substances Control Act (TSCA) (15 U.S.C. §§2601, et seq.) was enacted to provide information about all chemicals and to control the production of new chemicals that might present an unreasonable risk of injury to health or the environment. The TSCA authorizes the EPA to require testing of old and new chemical substances. The TSCA also provides the EPA authority to regulate the manufacturing, processing, import, use, and disposal of chemicals.

Polychlorinated biphenyls (PCBs) are one of the compounds regulated by the TSCA. The PCB storage and disposal regulations are listed in the applicable subparts of 40 CFR Part 761, "Polychlorinated Biphenyls (PCBs) Manufacturing, Processing, Distribution in Commerce, and Use Prohibitions." On May 15, 2003, EPA Region VI approved the disposal of waste containing PCBs at the WIPP facility. The WIPP facility began receiving PCB-contaminated waste on February 5, 2005. The EPA renewed the disposal authority April 30, 2010.

The required PCB annual report, containing information on PCB waste received and disposed of at the WIPP facility in 2009, was submitted to EPA Region VI on June 30, 2010.

\subsection{Federal Insecticide, Fungicide, and Rodenticide Act}

The Federal Insecticide, Fungicide, and Rodenticide Act (7 U.S.C. §§136, et seq.) authorizes the EPA to regulate the registration, certification, use, storage, disposal, transportation, and recall of pesticides (40 CFR Parts 150-189).

All applications of restricted-use pesticides at the WIPP facility are conducted by commercial pesticide contractors who are required to meet federal and state standards. General-use pesticides are stored according to label instructions. Used, empty cans are discarded by WIPP facility personnel into satellite accumulation area containers and are properly managed and disposed.

\subsection{Endangered Species Act}

The Endangered Species Act of 1973 (16 U.S.C. §§1531, et seq.) was enacted in 1973 to prevent the extinction of certain species of animals and plants. This act provides strong measures to help alleviate the loss of species and their habitats, and places restrictions on activities that may affect endangered and threatened animals and plants to help ensure their continued survival. With limited exceptions, this act prohibits activities that could impact protected species, unless a permit is granted from the U.S. Fish and Wildlife Service (USFWS). A biological assessment and "formal consultation," 
followed by the issuance of a "biological opinion" by the USFWS, may be required for any species that is determined to be in potential jeopardy.

There are no known species of plants or animals at the WIPP site that are protected by the Endangered Species Act. The Lesser Prairie Chicken, which is a candidate for listing under the act, does have favorable habitat within the WIPP LWA and surrounding areas impacted by WIPP operational activities (e.g., drilling boreholes). Therefore, the DOE, in consultation with the BLM, has instituted measures to protect the Lesser Prairie Chicken and its habitat. During the Lesser Prairie Chicken's breeding season, there are BLM-established time periods in effect for the WIPP facility during which off-site well drilling and well plugging activities may not be performed. In December 2010, the USFWS proposed a rule to list the dunes sagebrush lizard (Sceloporus arenicolus) as endangered under the Endangered Species Act. The proposed rule will be available for comment through February 2011. No instances associated with WIPP activities that had any adverse implications associated with the act were recorded in 2010.

\section{$2.12 \quad$ Migratory Bird Treaty Act}

The Migratory Bird Treaty Act (16 U.S.C. §\$703, et seq.) is intended to protect birds that have common migratory flyways between the United States, Canada, Mexico, Japan, and Russia. The act makes it unlawful "at any time, by any means or in any manner, to pursue, hunt, take, capture, kill, or attempt to take, capture, or kill... any migratory bird, any part, nest, or eggs of any such bird" unless specifically authorized by the Secretary of the Interior by direction or through regulations permitting and governing these actions (50 CFR Part 20, "Migratory Bird Hunting").

In 2010, no activities involving migratory birds took place at the WIPP facility.

\subsection{Federal Land Policy and Management Act}

The objective of the Federal Land Policy and Management Act (43 U.S.C. §§1701, et seq.) is to ensure that

...public lands be managed in a manner that will protect the quality of scientific, scenic, historical, ecological, environmental, air and atmospheric, water resource, and archeological values; that, where appropriate, will preserve and protect certain public lands in their natural condition; that will provide food and habitat for fish and wildlife and domestic animals; and that will provide for outdoor recreation and human occupancy and use.

Title II under the act, Land Use Planning; Land Acquisition and Disposition, directs the Secretary of the Interior to prepare and maintain an inventory of all public lands and to develop and maintain, with public involvement, land use plans regardless of whether subject public lands have been classified as withdrawn, set aside, or otherwise designated. The DOE developed, and operates in accordance with, the WIPP LMP, which is described in further detail in Section 5.2.

Under Title V, Rights-of-Way, the Secretary of the Interior is authorized to grant, issue, or renew rights-of-way over, upon, under, or through public lands. To date, several right- 
of-way reservations and land-use permits have been granted to the DOE. Examples of right-of-way permits include those obtained for a water pipeline, an access road, a caliche borrow pit, and a sampling station. Each "facility" (road, pipeline, railroad, etc.) is maintained and operated in accordance with the stipulations provided in the respective right-of-way reservation. Areas that are the subject of a right-of-way reservation are reclaimed and revegetated consistent with the terms of the right-of-way. A list of active environmental permits for the WIPP facility, including rights-of-way, is in Appendix B of this report.

\subsection{Atomic Energy Act}

The Atomic Energy Act of 1954, as amended (42 U.S.C. §§2011, et seq.), initiated a national program with responsibility for the development and production of nuclear weapons and a civilian program for the development and the regulation of civilian uses of nuclear materials and facilities in the United States. The act split these functions between the DOE, which is responsible for the development and production of nuclear weapons, promotion of nuclear power, and other energy-related work, and the U.S. Nuclear Regulatory Commission, which regulates the use of nuclear energy for domestic civilian purposes.

The statutory authority for the EPA to establish and implement the regulatory standards applicable to the operation, closure, and long-term performance of the WIPP facility can be found in the Atomic Energy Act of 1954, Reorganization Plan Number 3 of 1970, and in the Nuclear Waste Policy Act of 1982 (42 U.S.C. \$10101, et seq.). The regulations affecting the radioactive waste disposal operations that will occur at the WIPP are found in 40 CFR Part 191, Subpart A. The EPA final rule, 40 CFR Part 191, was first published on September 19, 1985. This standard was vacated and remanded to the EPA by a Federal Court of Appeals in 1987. The LWA, Public Law 102-579, as amended, reinstated the 1985 disposal standard except for the aspects of the standard that were specifically questioned by the court (i.e., 40 CFR §191.15, "Individual Protection Requirements," and 40 CFR §191.16, Alternate Provisions for Disposal). On December 20, 1993, the EPA promulgated (effective January 19, 1994) final disposal standards, which consist of three subparts: Subpart A, Environmental Standards for Management and Storage; Subpart B, Environmental Standards for Disposal; and Subpart C, Environmental Standards for Ground-Water Protection.

The results of monitoring and dose calculations have confirmed that there have been no releases of radionuclides that may adversely impact the public. WIPP personnel have conducted periodic confirmatory monitoring since receipt of waste began in March 1999. Results of the monitoring program demonstrate compliance with the dose limits discussed above and are addressed in further detail in Chapter 4.

WIPP is subject to EPA inspections in accordance with 40 CFR 191, Subpart A and 40 CFR §194.21, "Inspections." During the week of June 28, 2010, the EPA conducted an inspection to assess the implementation of monitoring programs developed by the DOE to monitor emissions and geomechanical, hydrological, waste activity, drilling-related, and subsidence parameters. No findings or concerns resulted from this inspection. Additional information concerning this inspection can be found in EPA Docket A-98-49, Item II-B3-112. 
The LWA establishes the regulatory authority of the EPA by specifying that the underground emplacement of TRU waste for disposal at WIPP could not commence until the DOE submitted a Compliance Certification Application (CCA) demonstrating compliance with the EPA radioactive waste disposal standards found in Subparts B and C of 40 CFR Part 191. The LWA further requires the EPA to conduct periodic recertification of continued compliance beginning five years after the initial receipt of TRU waste for disposal and at five-year intervals thereafter until the end of the decommissioning phase. The second Compliance Recertification Application for the WIPP facility was submitted to the EPA on March 24, 2009 (DOE/WIPP-09-3424). On November 18, 2010, EPA certified that the WIPP continues to comply with the waste disposal regulations at 40 CFR 191, Subparts B and C and WIPP compliance criteria at 40 CFR Part 194.

\subsection{DOE Orders}

DOE orders are used to direct and guide project participants in the performance of their work and establish the standards of operations at WIPP. The DOE orders documented in this report require that emission, effluent, and environmental monitoring programs be conducted to ensure that the WIPP mission can be accomplished while protecting the public, the worker, and the environment. The list of DOE orders identified for the WIPP facility is reviewed and updated annually.

\subsubsection{DOE Order 151.1C, Comprehensive Emergency Management System}

This order establishes requirements for emergency planning hazards assessment, categorization, classification, preparedness, response, notification, coordination control, public protection, and readiness assurance activities. The applicable requirements of this order are implemented through the WIPP emergency management program, the emergency response program, the training program, the emergency readiness program, the records management program, and the RCRA Contingency Plan.

\subsubsection{DOE Order 231.1A, Environment, Safety and Health Reporting}

This order specifies collection and reporting of information on environment, safety, and health that are required by law or regulation, or that are essential for evaluating DOE operations and identifying opportunities for improvement needed for planning purposes within the DOE. The order specifies the reports that must be filed, the persons or organizations responsible for filing the reports, the recipients of the reports, the format in which the reports must be prepared, and the schedule for filing the reports. This order is implemented in part at the WIPP facility through NEPA reporting, ASERs, environmental protection program reports, occupational injury and illness reports, the radiation safety manual, the dosimetry program, the fire protection program, and WIPP facility procedures. 


\subsubsection{DOE Order 414.1C, Quality Assurance}

This order provides the criteria for establishing, implementing, and maintaining programs, plans, and actions to ensure quality achievement in DOE programs. This order is implemented at WIPP through the CBFO Quality Assurance Program Document (DOE/CBFO-94-1012), which establishes QA program requirements for all quality-affecting programs, projects, and activities sponsored by the CBFO. Chapter 7, Quality Assurance, of this ASER provides additional details on the WIPP QA programs.

\subsubsection{DOE Order 435.1, Radioactive Waste Management}

The objective of this order is to ensure that all DOE radioactive waste, including TRU waste that is disposed of at the WIPP site, is managed in a manner that is protective of workers and the public. In the event that a conflict exists between any requirements of this order and the WIPP LWA regarding their application to the WIPP facility, the requirements of the LWA prevail. The DOE implements the requirements of this order through the Waste Acceptance Criteria, and procedures governing the management and disposal of TRU radioactive waste generated off site.

\subsubsection{DOE Order 450.1A, Environmental Protection Program}

This order, issued on June 4, 2008, requires that each DOE site develop and implement an EMS that is integrated into the site integrated safety management system. The system must also reflect the elements and framework of the ISO 14001:2004 standard for EMS; contribute to DOE sustainable environmental, energy, and transportation stewardship goals; assure compliance with environmental legal requirements through an environmental compliance management plan; and promote long-term stewardship of a site's natural and cultural resources. The order further requires that to be considered fully implemented, the EMS must undergo a formal audit by an independent, qualified party and that a declaration of conformance be issued based on the results of the audit. Audits and declarations of conformance must be repeated every three years.

The CBFO issued the required Declaration of Conformance on June 18, 2009, based on the successful completion of the ISO 14001 EMS certification audit. During 2010, the EMS retained certification to the ISO 14001:2004(E) standard based on successfully completing semiannual surveillance audits.

The WIPP EMS provides a structured and sustainable method for maintaining compliance with environmental requirements and appropriately managing environmental aspects of WIPP operations and activities (including energy and transportation) at the WIPP site and supporting buildings in Carlsbad, New Mexico. DOE sustainable environmental stewardship goals are incorporated into the environmental goals as relevant to the WIPP project. Goal selection is informed by the WIPP Site Sustainability Plan that was issued 12/15/2010. Progress in these areas is summarized in Chapter 3.

The EMS includes a system of programs and procedures associated with the EMS cycle of Plan, Do, Check, Act. Table 2.3 highlights how the order's requirement for an environmental compliance management plan is implemented at WIPP through the EMS. 
Waste Isolation Pilot Plant Annual Site Environmental Report for 2010 DOE/WIPP-11-2225

Table 2.3 - Implementation of the WIPP Environmental Compliance Management Plan

\begin{tabular}{|l|l|}
\hline \multicolumn{1}{|c|}{ Phase } & \multicolumn{1}{c|}{ WIPP EMS } \\
\hline Environmental Policy & $\begin{array}{l}\text { Provides a clear commitment to maintain compliance by CBFO and WTS senior } \\
\text { managers. }\end{array}$ \\
\hline Environmental Policy & $\begin{array}{l}\text { Provides a clear commitment to maintain compliance by CBFO and WTS senior } \\
\text { managers. }\end{array}$ \\
\hline Planning & $\begin{array}{l}\text { Monthly regulatory reviews assure that new or changed requirements are identified. } \\
\text { Compliance activities (targets) are included in annual budgets. } \\
\text { Programs and procedures are implemented to ensure compliance. }\end{array}$ \\
\hline Operating & $\begin{array}{l}\text { Training clearly communicates employee responsibility for compliance. } \\
\text { Specific compliance responsibilities are included in compliance programs/procedures. } \\
\text { Operational controls are integrated into procedures. }\end{array}$ \\
\hline Checking & $\begin{array}{l}\text { Environmental compliance audits are routinely conducted. } \\
\text { WIPP issues management program ensures that causal analysis and corrective and } \\
\text { preventive actions are implemented. }\end{array}$ \\
\hline Management Review & $\begin{array}{l}\text { Annual EMS management review includes review of compliance audit results and } \\
\text { compliance status. } \\
\text { Ongoing review and adjustment occur as significant issues arise. }\end{array}$ \\
\hline
\end{tabular}

\subsubsection{DOE Order 451.1B, Chg. 2, National Environmental Policy Act Compliance Program}

This order establishes DOE requirements and responsibilities for implementing the NEPA, the Council on Environmental Quality Regulations Implementing the Procedural Provisions of NEPA (40 CFR Parts 1500-1508), and the DOE NEPA implementing procedures (10 CFR Part 1021). This order is implemented by the DOE for the WIPP facility through compliance plans and a screening procedure. These tools are used to evaluate environmental impacts associated with proposed activities and to determine if additional analyses are required.

\subsubsection{DOE Order 5400.5, Chg. 2, Radiation Protection of the Public and the Environment}

This order, along with portions of DOE Order 231.1A, establishes standards and requirements for operations of the DOE and its contractors with respect to protecting members of the public and the environment against undue risk from radiation. Activities and analyses describing compliance with the applicable requirements of the order are contained in the Waste Isolation Pilot Plant Documented Safety Analysis (DOE/WIPP-08-3372). Monitoring activities to document compliance with the order are described in the WIPP ALARA (as low as reasonably achievable) program manual, the records management program, and the radiation safety manual.

\section{$2.16 \quad$ Executive Orders}

EOs generally are used to direct federal agencies and officials in their execution of congressionally established laws or policies. Compliance with the EOs in this section is accomplished through the WIPP programs, plans, and procedures that comply with the EOs implementing DOE order. Compliance is confirmed through the WIPP assessment process. 


\subsubsection{Executive Order 13423, Strengthening Federal Environmental, Energy, and Transportation Management}

In January 2007, EO 13423 was issued, replacing five prior EOs that established requirements for greening the government (EOs 13101,13123, 13134, 13148, and 13149) relative to waste prevention, recycling, federal acquisition, energy management, use of biobased products and energy, fleet and transportation efficiency and EMSs. Requirements from the EO are mapped out in the WIPP EMS and are implemented into operations through energy management, fleet and vehicle management, affirmative procurement, and pollution prevention programs. Annual EMS goals have been established in one or more of these areas and are discussed in Chapter 3.

\subsubsection{Executive Order 13514, Federal Leadership in Environmental, Energy, and Economic Performance}

This EO was issued in October, 2009, to establish an integrated strategy toward sustainability in the federal government and to make reduction of greenhouse gas (GHG) emissions a priority for federal agencies. Goals for improvements in GHG emissions, energy efficiency, water use efficiency and management, pollution prevention and waste elimination, regional and local integrated planning, sustainable federal buildings, sustainable acquisition, electronics stewardship and environmental management were established for federal agencies. The WIPP project complies with the EO through its EMS. Accomplishments toward goals established in the EO are discussed in Chapter 3. 
This page intentionally left blank 


\section{CHAPTER 3 - ENVIRONMENTAL MANAGEMENT SYSTEM}

The CBFO and the MOC consider protection of workers, the public, and the environment to be the highest priority of all activities at WIPP. This commitment is made public in the WIPP Environmental Policy and is carried out through the WIPP EMS. Effectiveness of the EMS is demonstrated by the negligible effect of WIPP site operations on the environment, reduced environmental risk from safe disposal of generator sites' TRU and TRU mixed waste at WIPP, WIPP's excellent compliance history, and the project's progress in sustainability.

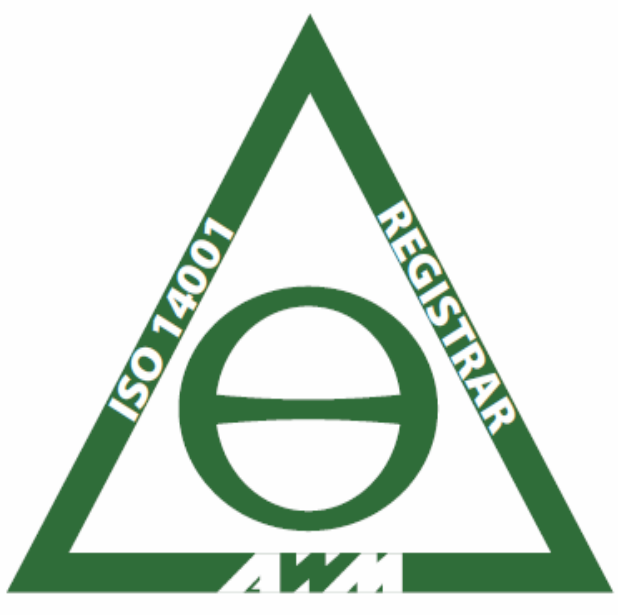

The EMS continued to result in strong environmental performance in 2010. The WIPP maintained certification of the EMS to the ISO standard 14001:2004, Environmental Management Systems - Specification with Guidance for Use, and earned a "green score" from the DOE for full implementation of the EMS. Maintaining the ISO certification is based on semiannual surveillance audits by the ISOaccredited registrar, Advanced Waste Management Systems. The DOE green score confirms the system meets the EMS requirements issued by the President's Council on Environmental Quality.

Extensive environmental monitoring conducted during 2010 demonstrates there are no significant environmental impacts (radiological or nonradiological) from operation of the WIPP facility. This is accomplished by WIPP personnel carrying out their daily responsibilities in accordance with the strong conduct of operations program, which is part of the operational control element of the EMS. It is also accomplished by the EMS ensuring that potential environmental impacts are identified, and appropriate controls and actions are taken to address them. As a prime example, the EMS took continued actions to address the increasing levels of carbon tetrachloride emissions in the underground. These actions, including passive barriers and an active capture system, slowed the rate of increase in the carbon tetrachloride levels, assured underground workers are not exposed to hazardous levels of carbon tetrachloride, and assured continued compliance with the Permit.

Compliance with applicable environmental requirements is a core commitment achieved through implementation of the EMS and its supporting programs, procedures, and work practices. As noted in Chapter 2, compliance performance has been excellent. Compliance highlights are listed below:

- $\quad$ EPA recertified the WIPP project for the second time on November 18, 2010, confirming that WIPP protects human health and the environment and complies with the strict EPA requirements for the disposal of transuranic radioactive wastes. 
- $\quad$ The WIPP Permit was renewed by the NMED on November 30, 2010, and was implemented by December 30, 2010.

- $\quad$ WIPP continued to have no reportable, unauthorized contaminant releases.

- $\quad$ There were no external agency compliance issues other than the administrative NOV for the use of an out-of-date form for monthly inspection of the UST system. The issue was confirmed as corrected by the inspector within 30 days from issuance of the NOV.

Sustainable performance improvements were made based on completion of Pollution Prevention Opportunity Assessments (PPOAs). The improvements resulted in significant reuse and recycling of materials. Figure 3.1 illustrates achievements during the reconstruction of the South Access Road to the WIPP site.

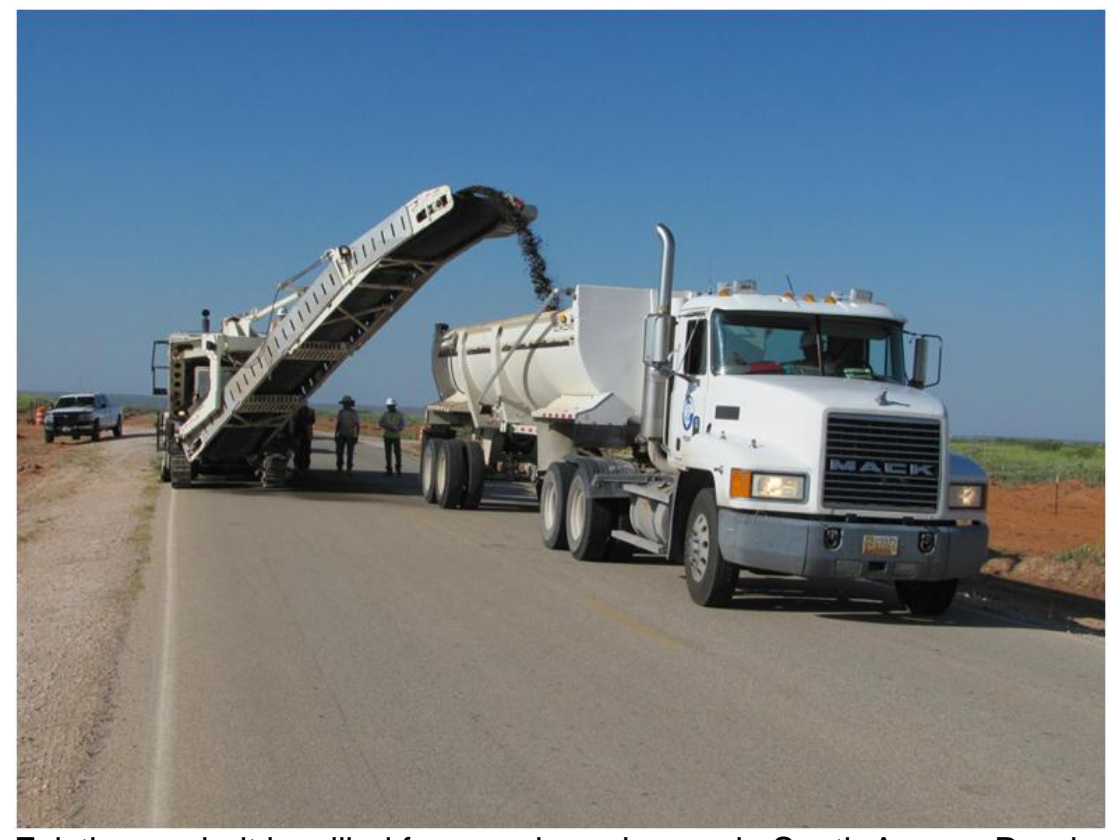

Existing asphalt is milled for recycle and reuse in South Access Road Reconstruction

Figure 3.1 - South Access Road Reconstruction Pollution Prevention Opportunity Assessments
Recycle / Reuse Accomplishments

- 340,000 gallons of clean storm water used rather than fresh water

- 4,818 yards of caliche spoils from prior projects reused

- 7,800 tons of recycled asphalt product used for construction

Other PPOAs resulting in sustainability improvements included the reprocessing of non-contaminated slip sheets eliminating the disposal of 29 tons of material, and the sale of over 1100 tons of mined salt material for reprocessing by a regional manufacturer of livestock feed supplements. 


\section{1 $\quad$ EMS 2010 Highlights}

Highlights related to the WIPP EMS are included in Table 3.1.

Table 3.1 - WIPP EMS Highlights

\begin{tabular}{|c|c|}
\hline Element & $\begin{array}{l}\text { Highlights } \\
\end{array}$ \\
\hline Environmental Aspects & $\begin{array}{l}\text { WIPP processes continued to identify and consider significant environmental aspects } \\
\text { and impacts. }\end{array}$ \\
\hline $\begin{array}{l}\text { Legal and Other } \\
\text { Requirements }\end{array}$ & There were no significant new or changed legal requirements during 2010. \\
\hline $\begin{array}{l}\text { Objectives, Targets, and } \\
\text { Program(s) }\end{array}$ & $\begin{array}{l}\text { Achieved the following environmental targets } \\
\text { - Zero reportable, unauthorized contaminant releases. } \\
\text { - } \quad \text { Developed greenhouse gas baseline Inventory. } \\
\text { - } \quad \text { Low power mode was enabled on } 80 \% \text { of WIPP personal computers. } \\
\text { - } \quad \text { Potential use of biobased and/or recycled lubricants in WIPP industrial equipment } \\
\text { was evaluated. } \\
\text { - } \text { Received second Compliance Recertification from EPA. } \\
\text { - } \text { by Decem was renewed by NMED on November, } 2010 \text { with implementation completed } \\
\text { - } \quad \text { Completed the WIPP Site Sustainability Plan. } \\
\text { - } \text { grovided ongoing technical support for pursuit of an industrial photovoltaic energy } \\
\text { - Two hybrid vehicles added to WIPP fleet. }\end{array}$ \\
\hline Communication & $\begin{array}{l}\text { Began developing WIPP Community Relations Plan. } \\
\text { Implemented On Line Information Repository. }\end{array}$ \\
\hline $\begin{array}{l}\text { Competence, Awareness } \\
\text { and Training }\end{array}$ & $\begin{array}{l}\text { Completed employee EMS awareness campaign, including completion of EMS online } \\
\text { training by each employee. }\end{array}$ \\
\hline Operational Control & $\begin{array}{l}\text { Environmental controls are integrated into procedures and implemented in accordance } \\
\text { with the WIPP Conduct of Operations program. }\end{array}$ \\
\hline $\begin{array}{l}\text { Emergency } \\
\text { Preparedness and } \\
\text { Response }\end{array}$ & $\begin{array}{l}\text { An off-site evacuation assembly area was designated for use during in the event of } \\
\text { emergencies requiring evacuation. } \\
\text { Road barricades have been installed on the North and South access roads to restrict } \\
\text { travel into secured areas during emergency events. } \\
\text { Emergency Management performed a total of } 41 \text { exercises/drills/events in FY } 2010 \text {. }\end{array}$ \\
\hline $\begin{array}{l}\text { Monitoring and } \\
\text { Measurement }\end{array}$ & $\begin{array}{l}\text { No significant environmental impact from operations was confirmed by results of the } \\
\text { environmental monitoring program. } \\
\text { EMS earned a green score from DOE in } 2010 \text { reflecting its maturity. }\end{array}$ \\
\hline Evaluation of Compliance & $\begin{array}{l}\text { No regulatory noncompliance issues were identified from over } 220 \text { completed } \\
\text { evaluations (audits/assessments) of WIPP facility operations. } \\
\text { Weekly inspections for environmental compliance continue to be performed. }\end{array}$ \\
\hline $\begin{array}{l}\text { Nonconformity, } \\
\text { Corrective Action, and } \\
\text { Preventive Action }\end{array}$ & $\begin{array}{l}\text { Seventy percent of issues needing action were self discovered. } \\
\text { Issues identified continue to be corrected / prevented through various management } \\
\text { programs. }\end{array}$ \\
\hline Internal Audit & Internal audit of the WIPP EMS was completed with the five minor findings corrected. \\
\hline Management Review & $\begin{array}{l}\text { CBFO and WTS senior managers established aggressive FY } 2011 \text { environmental } \\
\text { targets as part of the annual management review of the EMS. }\end{array}$ \\
\hline
\end{tabular}

\subsection{Significant Environmental Programs}

Fundamental to the EMS are the implementing programs through which environmental protection is integrated with operations. Programs, with supporting procedures, translate the environmental policy's higher order commitments into practical actions for individual employees to take to protect the environment as they work. Significant WIPP environmental programs are described below: 


\section{Affirmative Procurement}

This program provides a systematic and cost-effective structure for promoting and procuring environmentally preferable (sustainable) products. These include bio-based, recycled content, energy efficient and water efficient products, and products with fewer hazards or toxicity.

\section{Delaware Basin Drilling Surveillance}

This program includes conducting active surveillance of drilling activities within the Delaware Basin with specific emphasis on the nine-township area that includes the WIPP site. The surveillance of drilling activities builds on the data used to develop modeling assumptions for performance assessment for the EPA's Compliance Certification.

\section{Environmental Monitoring}

The environmental monitoring program includes radiological and nonradiological monitoring, land management monitoring, and oil and gas surveillance. Radiological constituents are monitored in airborne effluent and particulates, sewage treatment and water disposal evaporation ponds, biotics, soils, surface water, sediment and groundwater. Nonradiological monitoring includes meteorology, VOCs, groundwater surveillance, hydrogen, methane and SSW monitoring.

\section{Environmental Compliance Audit}

Audits and reviews of compliance are conducted via the MOC's environmental department's environmental compliance assessments and the CBFO and MOC QA assessment programs.

\section{Groundwater Protection}

Groundwater, which may potentially be affected by DOE operations, is monitored to detect and document the effects of operations on groundwater quality and quantity, and to show compliance with applicable federal and state laws and regulations.

\section{Land Management}

The land management program provides for management and oversight of WIPP lands under the jurisdiction of the DOE and lands used for WIPP activities outside of the WIPP boundary. It provides protocols that are used for managing and oversight of wildlife practices, cultural resources, grazing, recreation, energy and mineral resources, lands/realty, reclamation, security, industrial safety, emergency management, maintenance and work control on these lands.

\section{Meteorological Monitoring}

The meteorological monitoring program provides on-site meteorological data. Data collected are used for modeling of potential accidental radionuclide releases, effluent 
monitoring, assessing waste shipment transportation safety, evaluating conditions to promote employee safety for travel to and from the WIPP site, and for monitoring realtime meteorological conditions for responding to events involving spills or releases of hazardous materials.

\section{NEPA Compliance}

This program ensures requirements of the NEPA are met prior to making decisions to implement work at or on behalf of the WIPP facility. It also assures permit requirements are met and sufficient compliance direction is available to personnel conducting work.

\section{Pollution Prevention}

Promotes integration of energy and water efficiency, environmentally preferred purchasing, waste minimization, and recycling and reuse into the WIPP project.

\section{Waste Stream Profile}

This is a critical program for ensuring compliance requirements are met for wastes being disposed at the WIPP facility. Profiles for each waste stream are reviewed to verify that the generator's characterization information is complete and accurate, and that waste streams comply with the Permit, Waste Acceptance Criteria, and Waste Analysis Plan.

\section{Waste Confirmation}

Under this program, waste containers are confirmed to have no ignitable, corrosive, or reactive waste using radiography and/or visual examination of a statistically representative subpopulation of the waste. The DOE demonstrates compliance with the Permit through this program.

\section{Waste Management}

This program ensures that site-generated hazardous, universal, special, low-level and mixed low-level radioactive wastes are properly handled, accumulated, and transported to approved disposal facilities in accordance with legal and internal requirements.

\subsection{Environmental Performance Measurement}

Extensive monitoring and measurement is conducted by the WIPP to assure that the WIPP mission is carried out in accordance with its environmental policy. This includes monitoring (1) impacts to environment, (2) EMS effectiveness, and (3) sustainability progress. Each of these is discussed in the following subsections.

\subsubsection{Environmental Impacts}

There was no significant environmental impact from WIPP operations in 2010 as determined from environmental monitoring program implementation results. Detailed analysis and summaries of the results of this program are included in Chapters $4-6$. 


\subsubsection{EMS Effectiveness}

System indicators demonstrate the EMS continues to be suitable and effective for carrying out the WIPP mission and meeting environmental policy commitments. The indicators include those that confirm that environmental protection is integrated into WIPP processes (e.g., significant aspects / impacts are current; environmental compliance is included audits) and those indicating performance results (e.g., energy use, fresh water use, reportable contaminant releases, external agency compliance issues, progress toward targets).

\subsubsection{Sustainability Progress (Continuous Improvement)}

Progress in this area is measured in relationship to the DOE Sustainability Goals established under Executive Order 13514. Progress related to each of the DOE goals for FY 2010 is summarized as follows.

\section{Reduce Greenhouse Gas Emissions}

The WIPP comprehensive GHG baseline inventory was completed in FY 2010 and is summarized in Figure 3.2.
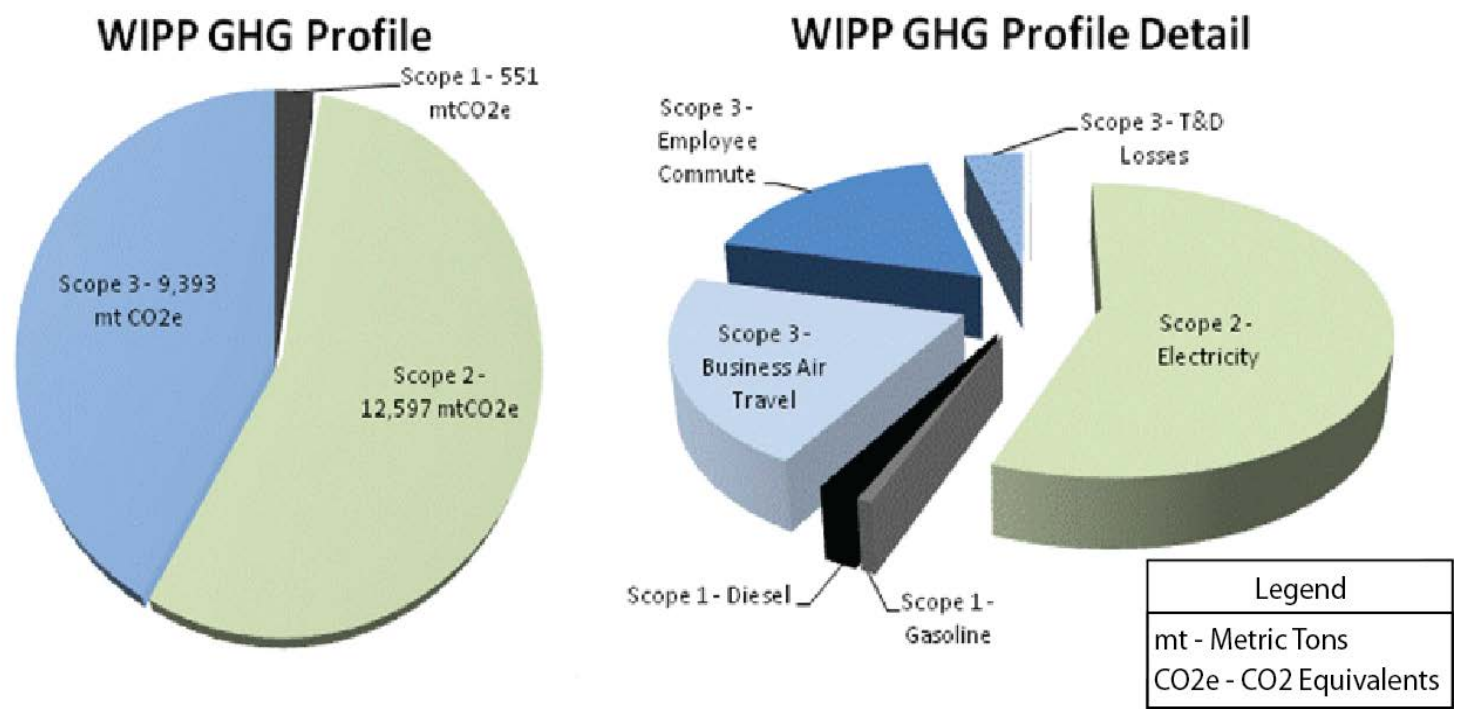

Figure 3.2 - WIPP Project Greenhouse Gas Baseline Inventory

As a result of determining the baseline, the WIPP facility priority is to reduce emissions associated with electricity use (Scope 2 emissions) through increasing use and/or generation of renewable energy. During 2010, CBFO and MOC personnel actively pursued renewable energy generation on WIPP lands. This included pursuit of a Power Purchase Agreement for construction and operation of a 2 megawatt (MW) solar array and other renewable projects through the DOE "Energy Parks" Initiative. Other FY 2010 progress supporting GHG reductions are highlighted in Figure 3.3. Energy efficiency for operation of the WIPP is illustrated in Figure 3.4. 


\begin{tabular}{|c|c|}
\hline $\begin{array}{c}\text { Energy } \\
\text { Efficiency }\end{array}$ & $\begin{array}{l}\text { - For the third year, site energy use was maintained at approximately } 3.0 \\
\text { MWh per cubic meter of TRU waste emplaced at the site. } \\
\text { - WIPP has achieved a } 13 \% \text { reduction in energy intensity for WIPP site } \\
\text { operations compared to the FY } 2003 \text { baseline. }\end{array}$ \\
\hline Cool Roofs & $\begin{array}{l}\text { - Installed Cool Roof on one building and repaired second Cool Roof } \\
\text { using ARRA funding. }\end{array}$ \\
\hline $\begin{array}{l}\text { Renewable } \\
\text { Energy }\end{array}$ & $\begin{array}{l}\text { - } 1,500,000 \mathrm{kwh} \text { of wind sourced energy was used by the WIPP facility } \\
\text { representing } 7.5 \% \text { of total energy used. } \\
\text { - Installed two additional small solar security lighting systems. }\end{array}$ \\
\hline $\begin{array}{l}\text { Alternative } \\
\text { Fuels }\end{array}$ & $\begin{array}{l}\text { - } 72 \text { percent of WIPP fleet are alternative fuel vehicles } \\
\text { - Two hybrid vehicles are added to fleet } \\
\text { - Pursuit of alternative fuel sources continued with anticipated test of } \\
\text { renewable diesel in } 2011 \text {. }\end{array}$ \\
\hline
\end{tabular}

Figure 3.3 - GHG Reduction Efforts

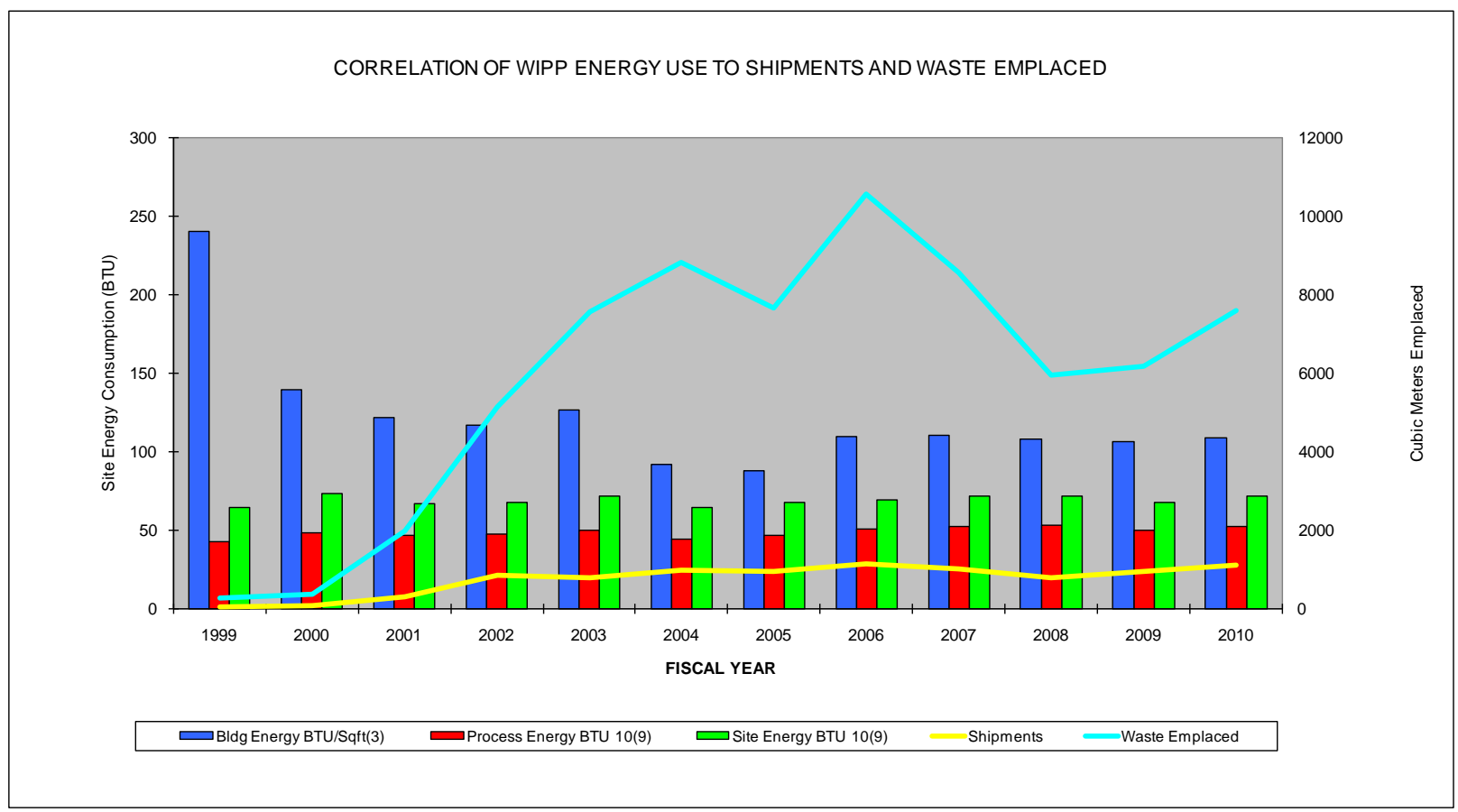

Figure 3.4 - WIPP Energy Efficiency History

As noted in Figure 3.3 and dramatically depicted in the WIPP Energy Efficiency History graph (Figure 3.4) the WIPP continues to maintain site energy use at a constant level while maintaining or increasing the cubic meters of waste emplaced.

\section{Regional and Local Planning}

The CBFO, with MOC support, pursued development of a site energy park through the Energy Parks Initiative in conjunction with regional and local entities. The intent is to stimulate renewable energy production that can be used at the WIPP site and other 
entities. WIPP continues to be involved in the local research of algae-based bio-fuel generation.

\section{High-Performance Sustainable Building Principles}

Three buildings at the WIPP site have potential for meeting the DOE goal of 15 percent of existing buildings larger than 5,000 gross square feet (gsf) conforming to the five guiding High-Performance Sustainable Building Principles by 2015. In 2010, WIPP initiated a lighting retrofit on the first of these three buildings. WIPP also has a small modular building (less than 5,000 gsf) that was installed in 2009 using HighPerformance Sustainable Building Principles.

\section{Water Use Efficiency and Management}

The WIPP has reduced fresh water usage as demonstrated by Figure 3.3.4, which depicts total water used by the WIPP site from fiscal years 2003 through 2010.

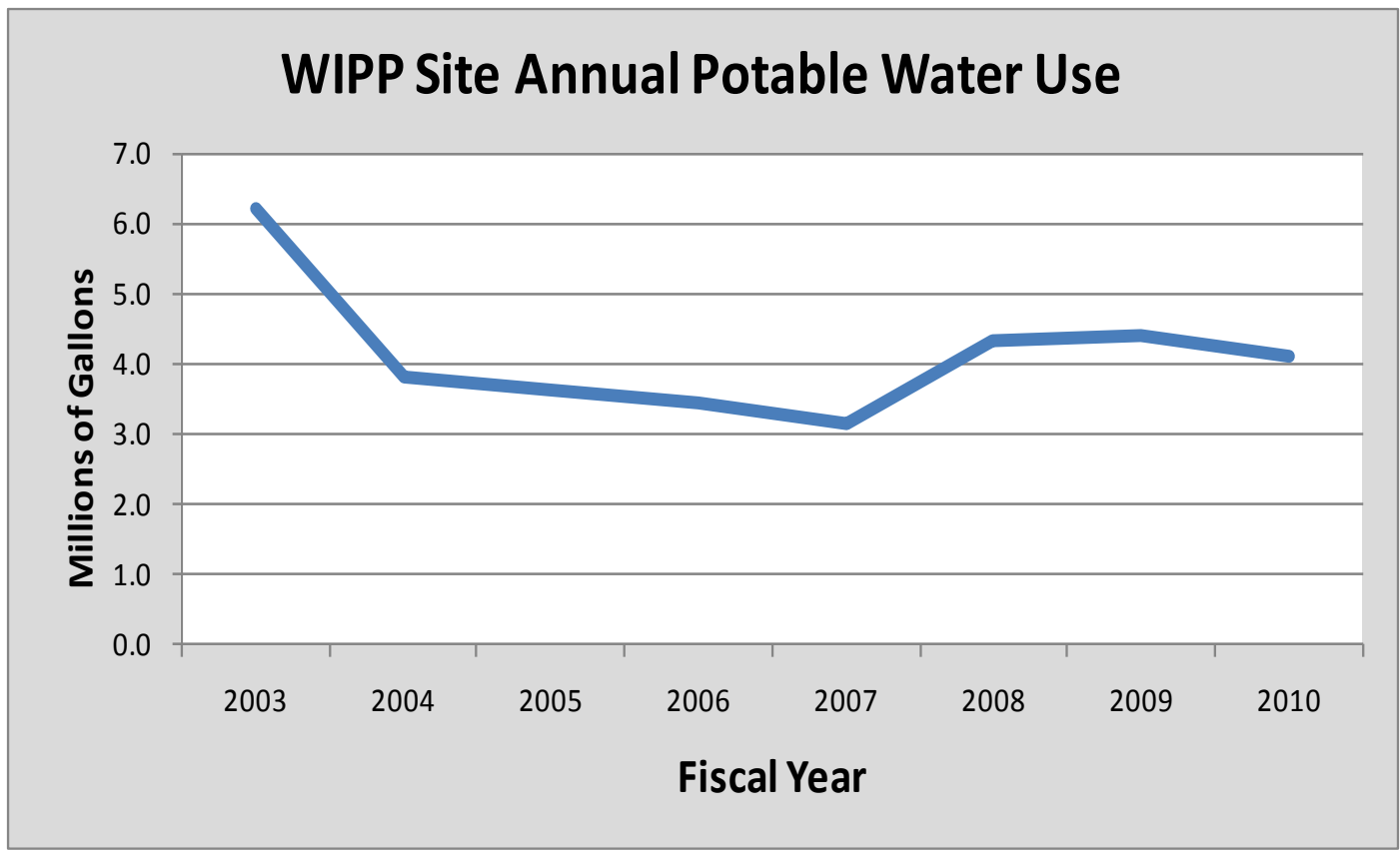

Figure 3. 5 - WIPP Annual Potable Water Use

Water is used primarily for personal use at the WIPP site with the exception that water must be used for the fire protection system. During 2010, WIPP's water efficiency efforts were focused on water distribution system maintenance to identify and repair any leaks while complying with the site mission. In addition, WIPP continues to focus on maintaining plumbing fixtures (toilets, urinals, sinks, showers) and providing information and education to encourage personal conservation. Although still above the 2007 rate, normalized (gallons / per employee / per day) water usage at WIPP has decreased since 2008. This is illustrated in Figure 3.6. 


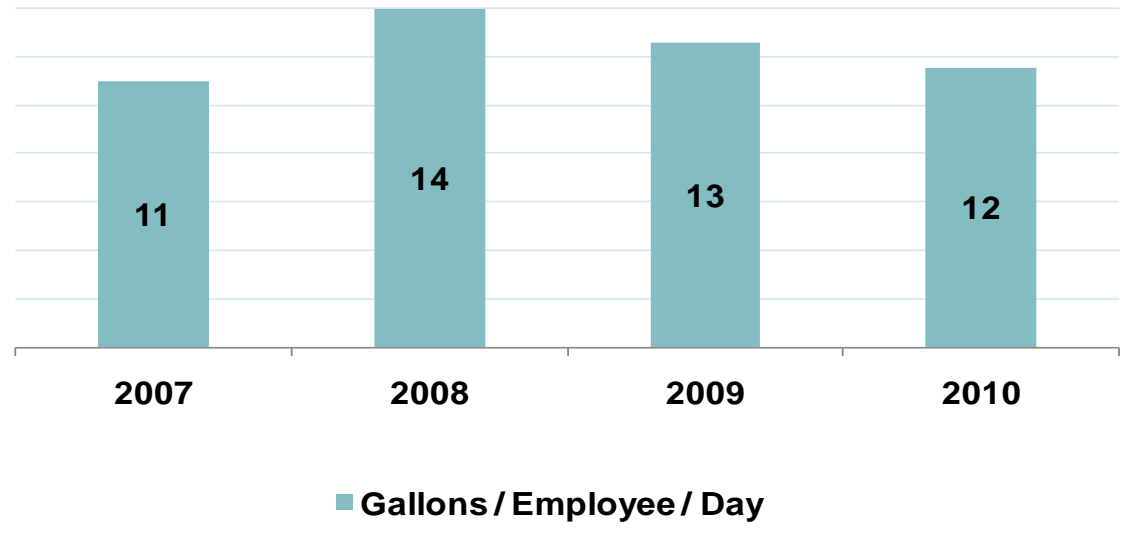

Figure 3.6 - WIPP Water Use

\section{Pollution Prevention}

WIPP's accomplishments in this area in 2010 included the following:

- $\quad$ Completion of five Pollution Prevention Opportunity Assessments and implementation of actions to improve waste minimization or reuse / recycle performance.

- Waste minimization and recycling requirements were incorporated into the contract for reconstructing the South Access Road to the WIPP site. As noted at the beginning of this chapter (Figure 3.1), this project resulted in significant recycling and reuse of materials.

- $\quad$ Established a new source for recycling metals when the existing recycler would no longer provide service to the WIPP site.

- $\quad$ Maintained a healthy recycling program. Figure 3.7 illustrates the materials recycled at WIPP and that the project continues to recycle over 50 percent of the total materials generated that would otherwise require disposal. 


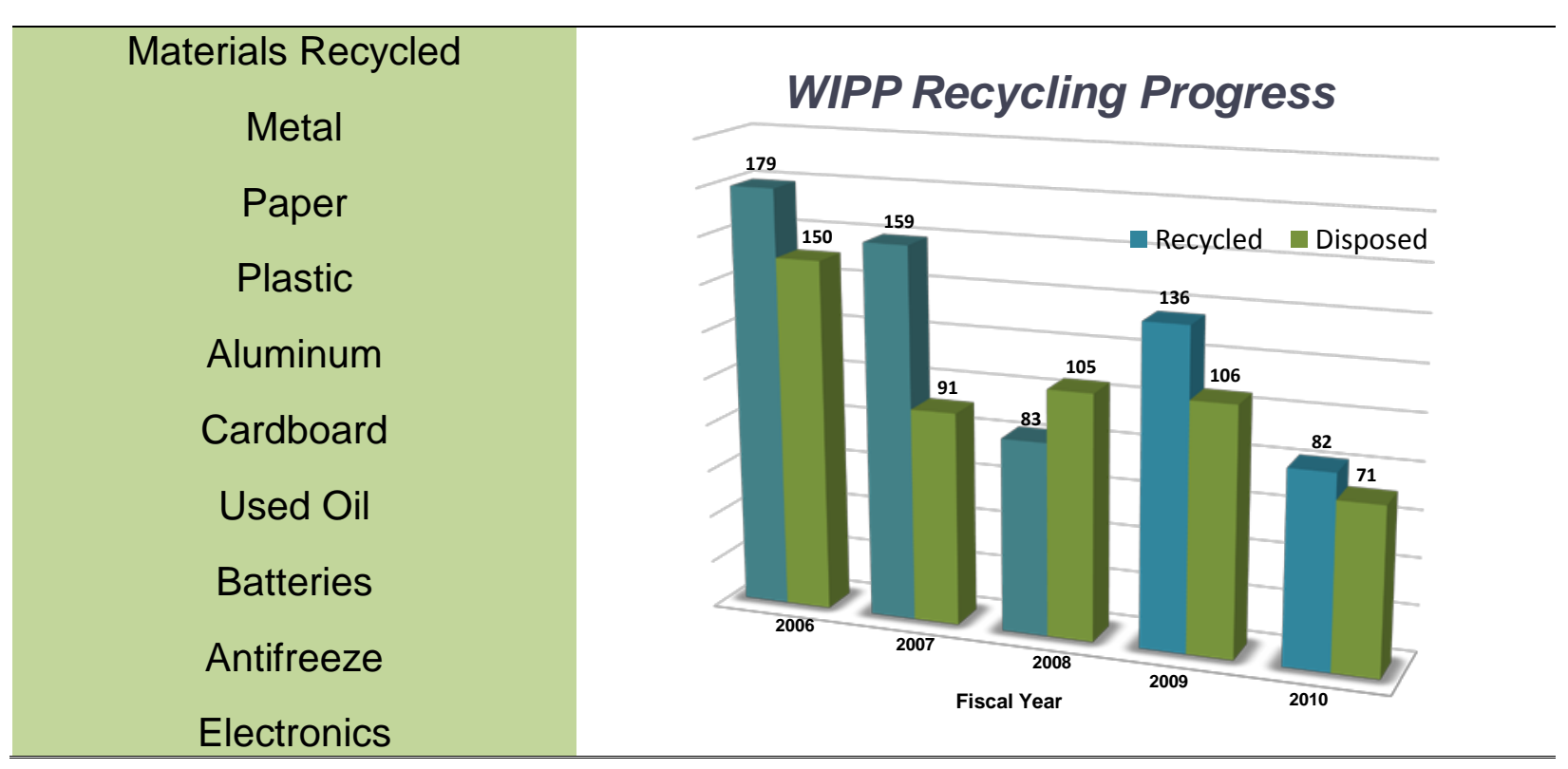

Figure 3.7 - WIPP Recycling Program

\section{Sustainable Acquisition}

WIPP continued to purchase 30 percent recycled content paper and use environmentally friendly products for janitorial services when they meet cost, performance, and availability requirements. Improvements in the methods for measuring the quantities of sustainable products purchased made in 2010 identified the opportunity to increase the quantity of sustainable office products purchased. As a result, FY 2011 EMS targets include several goals for increasing the purchase of these products.

\section{Electronics Stewardship and Data Centers}

WIPP continued to use sustainable life cycle management of electronics as demonstrated in Figure 3.8. and achieved its target to verify that power management capability is set for energy efficiency on a minimum of $80 \%$ of personal computers. 


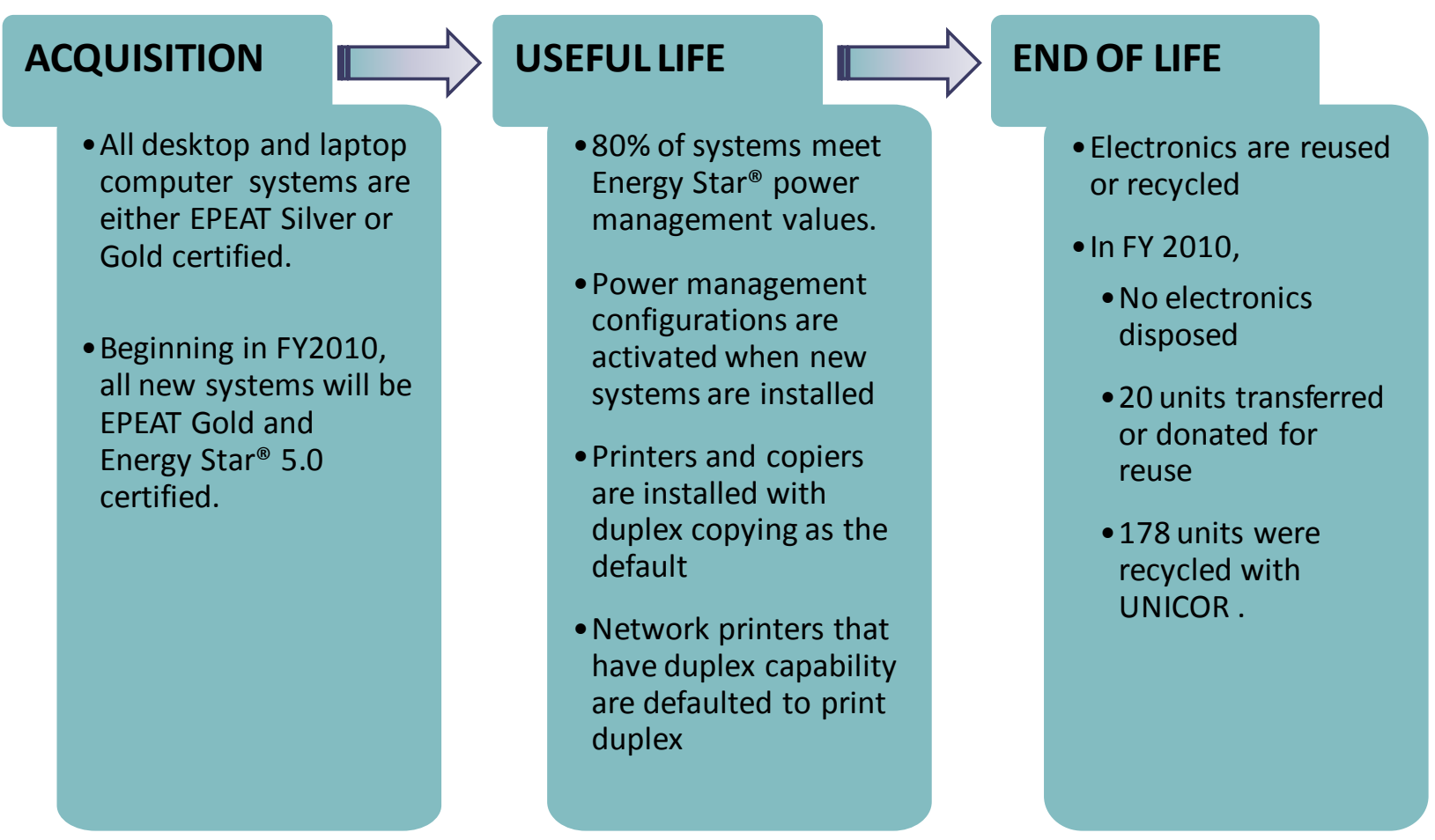

Figure 3.8 - Life Cycle Management of Electronics at WIPP

\subsection{EMS Awards}

WIPP has been nominated for DOE E-Star awards for FY 2010 accomplishments in water reuse during the South Access Road project and for the sale of mined salt for reuse as livestock feed supplement. These projects demonstrate successful integration of sustainability into planning and execution of products. 
This page intentionally left blank. 


\section{CHAPTER 4 - ENVIRONMENTAL RADIOLOGICAL PROGRAM INFORMATION}

DOE Order 450.1 states that the DOE must "conduct environmental monitoring, as appropriate, to support the site's integrated safety management system; to detect, characterize, and respond to releases from DOE activities; assess impacts; estimate dispersal patterns in the environment; characterize the pathways of exposures and doses to members of the public; characterize the exposures and doses to individuals and to the population; and evaluate the potential impacts to biota in the vicinity of the DOE activity."

Radionuclides present in the environment, whether naturally occurring or anthropogenic (human-made), may contribute to radiation doses to humans. Therefore, environmental monitoring around nuclear facilities is imperative to characterize radiological baseline conditions, identify any releases, and determine the effects of releases should they occur.

Personnel at the WIPP facility sample air, groundwater, surface water, soils, sediments, and biota to monitor the radiological environment around the WIPP facility. This monitoring is carried out in accordance with the WIPP Environmental Monitoring Plan. The radiological effluent monitoring portion of this plan meets the requirements contained in DOE/EH-0173T, Environmental Regulatory Guide for Radiological Effluent Monitoring and Environmental Surveillance.

The WIPP facility is regulated under 40 CFR $\$ 191.03$, Subpart A, which applies to management and storage of radioactive waste at disposal facilities operated by the DOE. The standards in 40 CFR \$191.03(b) state that management and storage of TRU waste at the DOE facilities shall be conducted in such a manner as to provide reasonable assurance that the annual radiation to any member of the public in the general environment resulting from discharges of radioactive material and direct radiation from such management and storage shall not exceed specified limits. Based on analysis of WIPP facility operations, the DOE has identified air emissions as the only plausible pathway for radionuclide transport during receipt and emplacement of waste at the WIPP facility.

The regulatory limits for the WIPP effluent monitoring program can be found in $40 \mathrm{CFR}$ Part 191, Subpart A. Radionuclides being released from WIPP operations, including the underground TRU waste disposal areas and the Waste Handling Building, are monitored through the WIPP effluent monitoring program. The referenced standard specifies that the combined annual dose equivalent to any member of the public in the general environment resulting from discharges of radioactive material and direct radiation from such management and storage shall not exceed 25 mrem to the whole body and 75 mrem to any critical organ. In addition, in a 1995 memorandum of understanding between the EPA and the DOE, the DOE agreed that the WIPP facility would comply with 40 CFR Part 61, "National Emissions Standards for Hazardous Air Pollutants" (NESHAP), Subpart H, "National Emissions Standards for Hazardous Air Pollutants Other than Radon from Department of Energy Facilities." The NESHAP standard (40 CFR §61.92) states that the emissions of radionuclides to the ambient air from DOE facilities shall not exceed those amounts that would cause any member of the public to receive in any year an EDE of 10 mrem per year. 


\section{Waste Isolation Pilot Plant Annual Site Environmental Report for 2010 DOE/WIPP-11-2225}

A report titled Statistical Summary of the Radiological Baseline Program for the Waste Isolation Pilot Plant (DOE/WIPP-92-037) summarizes the radiological baseline data obtained at and near the WIPP site during the period from 1985 through 1989, prior to the time that the WIPP facility became operational. Radioisotope concentrations in environmental media sampled under the current ongoing monitoring program are compared with this baseline to gain information regarding annual fluctuations. Appendix $\mathrm{H}$ presents data that compare the highest concentrations of radionuclides detected from the WIPP environmental monitoring program to the baseline data.

The sampling media for the environmental monitoring program include airborne particulates, soil, surface water, groundwater, sediments, and biota (vegetation and animals). These samples are analyzed for ten radionuclides, including natural uranium $\left({ }^{233 / 234} \mathrm{U},{ }^{235} \mathrm{U}\right.$, and $\left.{ }^{238} \mathrm{U}\right)$; potassium-40 $\left({ }^{40} \mathrm{~K}\right)$; transuranic actinides expected to be present in the waste (plutonium $\left[{ }^{238} \mathrm{Pu}\right],{ }^{239 / 240} \mathrm{Pu}$, and americium $\left[{ }^{241} \mathrm{Am}\right]$ ); and major fission products (cesium $\left[{ }^{137} \mathrm{Cs}\right]$, cobalt $\left[{ }^{60} \mathrm{Co}\right]$, and strontium $\left[{ }^{90} \mathrm{Sr}\right]$ ). Environmental levels of these radionuclides could provide corroborating information on which to base conclusions regarding releases from WIPP facility operations.

Table 4.1 summarizes the list of target radionuclides along with their type of radiation, method of detection, and reason for monitoring at the WIPP site. The WIPP effluent monitoring program also monitors for these same radionuclides with the exception of ${ }^{235} \mathrm{U},{ }^{40} \mathrm{~K}$, and ${ }^{60} \mathrm{Co}$.

Table 4.1 - Radioactive Nuclides Monitored at the WIPP Site

\begin{tabular}{|c|c|c|c|}
\hline Radionuclide & Radiation & Detection Method & Reason for Monitoring \\
\hline${ }^{233 / 234} \mathrm{U}$ & Alpha & Alpha spectroscopy & Naturally occurring \\
\hline${ }^{235} \mathrm{U}$ & Alpha & Alpha spectroscopy & Naturally occurring \\
\hline${ }^{238} \mathrm{U}$ & Alpha & Alpha spectroscopy & Ubiquitous in nature \\
\hline${ }^{40} \mathrm{~K}$ & Gamma & Gamma spectroscopy & Component of waste \\
\hline${ }^{238} \mathrm{Pu}$ & Alpha & Alpha spectroscopy & Component of waste \\
\hline${ }^{239 / 240} \mathrm{Pu}$ & Alpha & Alpha spectroscopy & Component of waste \\
\hline${ }^{241} \mathrm{Am}$ & Alpha & Alpha spectroscopy & Fission product/potential component of waste \\
\hline${ }^{137} \mathrm{Cs}$ & Gamma & Gamma spectroscopy & Fission product/potential component of waste \\
\hline${ }^{60} \mathrm{Co}$ & Gamma & Gamma spectrometry & Fission product/potential component of waste \\
\hline${ }^{90} \mathrm{Sr}$ & Beta & Gas Proportional Counting & Laboratories. \\
\hline \multicolumn{2}{|c|}{ Note: The radionuclides ${ }^{243} \mathrm{Am},{ }^{242} \mathrm{Pu}$, and ${ }^{232} \mathrm{U}$ are used as tracers in the WIPP Laboraty } \\
\hline
\end{tabular}

Radionuclides are considered "detected" in a sample if the measured concentration or activity is greater than the total propagated uncertainty (TPU) at the 2 sigma $(\sigma)$ TPU level, and greater than the minimum detectable concentration (MDC). This methodology was patterned after that described in Hanford Decision Level for Alpha Spectrometry Bioassay Analyses Based on the Sample-Specific Total Propagated Uncertainty (MacLellan, 1999). The MDC is determined by the analytical laboratories based on the natural background radiation, the analytical technique, and inherent characteristics of the analytical equipment. The MDC represents the minimum concentration of a radionuclide detectable in a given sample using the given equipment and techniques with a specific statistical confidence (usually 95 percent). The TPU is an estimate of the uncertainty in the measurement due to all sources, including counting error, 
measurement error, chemical recovery error, detector efficiency, randomness of radioactive decay, and any other sources of uncertainty.

Measurements of radioactivity are actually probabilities due to the random nature of the disintegration process. A sample is decaying as it is being measured, so no finite value can be assigned. Instead, the ranges of possible activities are reported by incorporating the TPUs of the method. For radionuclides determined by gamma spectroscopy $\left({ }^{137} \mathrm{Cs}\right.$, ${ }^{60} \mathrm{Co}$, and ${ }^{40} \mathrm{~K}$ ), an additional factor considered in the determination of detectability is the identification (ID) confidence with which the peak or peaks associated with the particular radionuclide can be identified by the gamma spectroscopy software. In accordance with the statement of work (SOW) for the laboratory analyses, gamma spectroscopy samples with ID confidence less than 90 percent $(<0.90)$ are not considered "detects," regardless of their magnitudes compared to the TPU and MDC. Sample results are also normalized with the instrument background and/or the method blank. If either of those measurements have greater activity ranges than the actual sample, it is possible to get negative values on one end of the reported range of activities. Additional information on the equations used is provided in Appendix $\mathrm{D}$.

WIPP Laboratories performed the analyses for the 10 target radionuclides in all radiological samples. Highly sensitive radiochemical analysis and detection techniques were used that resulted in very low detection limits. This allowed detection of radionuclides at concentration levels far below those of environmental and human health concern. The MDCs attained by WIPP Laboratories were below the recommended MDCs specified in American National Standards Institute (ANSI) N13.30, Performance Criteria for Radiobioassay.

Comparisons of radionuclide concentrations were made between years and locations using the statistical procedure, ANOVA (analysis of variance) for those data sets containing sufficient "detects" to make such comparisons statistically meaningful. When this or other statistical tests were used, the $p$ value was reported. The $p$ value is the significance level for ANOVA calculations. A p value $>0.05$ indicates no significant difference in the values from a data set, and a $p$ value $<0.05$ indicates a significant difference in the values from a data set.

The $\mathrm{p}$ value is the probability under the null hypothesis of observing a value as unlikely or more unlikely than the value of the test statistic. In many cases, scientists have accepted a value of $p<0.05$ as indicative of a difference between samples.

Interpretation of $p$ values requires some judgment on the part of the reader, and individual readers may choose to defend a higher or lower value for $p$ as the cutoff value. However, for this report, a $\mathrm{p}$ value of 0.05 was used.

The air monitoring for radionuclides is divided between two programs: the WIPP effluent monitoring program and the environmental monitoring program. Descriptions of these two programs are provided in the sections below. 


\section{Effluent Monitoring Program}

The primary sampling location for the WIPP effluent monitoring program is at station A. Stations B, C and D are backup and support locations to station A. Each station employs one or more fixed air samplers, collecting particulate from the effluent air stream using a Versapor ${ }^{\circledR}$ filter. Fixed air samplers at Station A sample the unfiltered underground exhaust air. At Station B, samples are collected from the underground exhaust air after HEPA (high- efficiency particulate air) filtration and, sometimes, nonfiltered air during ventilation fan maintenance. At Station $\mathrm{C}$, samples are collected from the exhaust air from the Waste Handling Building after HEPA filtration. Station D is located at the base of the exhaust shaft and is considered a "supplementary station" to Station $A$. Station $D$ radiochemistry results are used for verification and/or comparison of Station A, as applicable. The Station D sampling system was designed and installed per the ANSI N13.1-1999 Standard. Station D was also supported by the Texas A\&M University research design and documentation. For each sampling event, chain-ofcustody forms are initiated to track and maintain an accurate written record of filter sample handling and treatment from the time of sample collection through laboratory procedures to disposal. During 2010, filter samples from all three effluent air monitoring stations were analyzed for ${ }^{238} \mathrm{Pu},{ }^{239 / 240} \mathrm{Pu},{ }^{241} \mathrm{Am},{ }^{90} \mathrm{Sr},{ }^{137} \mathrm{Cs},{ }^{233 / 234} \mathrm{U}$, and ${ }^{238} \mathrm{U}$.

In June 2011, the Annual Periodic Confirmatory Measurement Compliance Report for Calendar Year 2010, was submitted to the EPA as required by 40 CFR Part 61, Subpart $\mathrm{H}$ (NESHAP). The report provided descriptions of the ongoing $\mathrm{CH}$ and $\mathrm{RH} T \mathrm{TU}$ and TRU mixed waste receipt and emplacement. For CY 2010, the CAP88-PC dose assessment computer model was used to calculate the EDE value of 1.91E-05 $\mathrm{mrem} / \mathrm{year}$ to the MEI.

\section{Environmental Monitoring Program}

The purpose of the radiological environmental monitoring program is to measure radionuclides in the ambient environmental media. These data allow for a comparison of sample data to results from previous years and to baseline data, to determine what impact, if any, WIPP is having on the surrounding environment. Radiological monitoring at the WIPP site includes sampling and analysis of air, groundwater, surface water, sediment, soil, and biota for all ten of the target radionuclides listed in Table 4.1. For each sampling event, chain-of-custody forms were initiated to track and maintain an accurate written record of sample handling and treatment from the time of sample collection through delivery to the laboratory. Internal chain-of-custody forms are used by the laboratory to track and maintain custody while samples are being analyzed.

The radionuclides analyzed were ${ }^{238} \mathrm{Pu},{ }^{239 / 240} \mathrm{Pu},{ }^{241} \mathrm{Am},{ }^{233 / 234} \mathrm{U},{ }^{235} \mathrm{U},{ }^{238} \mathrm{U},{ }^{137} \mathrm{Cs},{ }^{60} \mathrm{Co}$, ${ }^{40} \mathrm{~K}$, and ${ }^{90} \mathrm{Sr}$. Isotopes of plutonium and americium were analyzed because they are the most significant alpha-emitting radionuclides among the constituents of TRU wastes received at the WIPP site. Uranium isotopes were analyzed because they are prominent alpha-emitting radionuclides in the natural environment.

Strontium-90, ${ }^{60} \mathrm{Co}$, and ${ }^{137} \mathrm{Cs}$ were analyzed to demonstrate the ability to quantify these beta and gamma-emitting contaminants should they appear in the TRU waste stream. 
Potassium-40, a natural gamma-emitting radionuclide that is ubiquitous in the earth's crust, was also monitored.

\subsection{Effluent Monitoring}

\subsubsection{Sample Collection}

Stations $A, B$, and $C$ use skid-mounted fixed air samplers at each effluent air monitoring station. The volume of air sampled at each location varied depending on the sampling location and configuration. Each system is designed to provide a representative sample

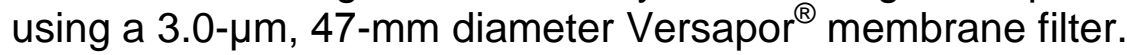

Daily (24-hour) filter samples were collected from Station A from the unfiltered underground exhaust stream. Each day at Station A, approximately $78 \mathrm{~m}^{3}$ (2,735 cubic feet $\left[\mathrm{ft}^{3}\right]$ ) of air was filtered through the Versapor ${ }^{\circledR}$ filter.

Weekly (24 hours/seven days per week) filter samples were collected at Stations B and C. Station B samples the underground exhaust air after HEPA filtration and, sometimes, nonfiltered air during maintenance. Each week at Station B, approximately $583 \mathrm{~m}^{3}$ $\left(20,588 \mathrm{ft}^{3}\right)$ of air were filtered through the Versapor ${ }^{\circledR}$ filter. Weekly filter samples were also collected at Station $\mathrm{C}$, which sampled the air from the Waste Handling Building after HEPA filtration. Each week at Station C, approximately $171 \mathrm{~m}^{3}\left(6,038 \mathrm{ft}^{3}\right)$ of air were filtered through the Versapor ${ }^{\circledR}$ filter. Based on the specified sampling periods, these air volumes were within \pm 10 percent of the volume derived using the flow rate set point of $0.057 \mathrm{~m}^{3} / \mathrm{min}\left(2 \mathrm{ft}^{3} / \mathrm{min}\right)$ for Stations $A$ and $B$. The air volume for Station $\mathrm{C}$ was within \pm 10 percent of the volume derived using the flow rate required for isokinetic sampling conditions and the specified sampling period. The sample flow rate for Station $\mathrm{C}$ varied according to the exhaust air flow in the Waste Handling Building in order to maintain isokinetic sampling conditions.

The filter samples for Stations B and $C$ were composited each quarter. Because of the large number of samples from Station A, these samples were composited monthly. All filter samples were analyzed radiochemically for ${ }^{241} \mathrm{Am},{ }^{238} \mathrm{Pu},{ }^{239 / 240} \mathrm{Pu},{ }^{90} \mathrm{Sr},{ }^{233 / 234} \mathrm{U}$, ${ }^{238} \mathrm{U}$, and ${ }^{137} \mathrm{Cs}$.

\subsubsection{Sample Preparation}

The monthly and quarterly filter samples were composited. The composites were transferred to a Pyrex ${ }^{\circledR}$ beaker, spiked with appropriate tracers $\left({ }^{232} \mathrm{U},{ }^{243} \mathrm{Am}\right.$, and $\left.{ }^{242} \mathrm{Pu}\right)$, and heated in a muffle furnace at $250^{\circ} \mathrm{C}\left(482^{\circ} \mathrm{F}\right)$ for two hours, followed by two hours of heating at $375^{\circ} \mathrm{C}\left(707^{\circ} \mathrm{F}\right)$ and six hours of heating at $525^{\circ} \mathrm{C}\left(977^{\circ} \mathrm{F}\right)$.

The filters were ashed and cooled, and then transferred into Teflon ${ }^{\circledR}$ beakers by rinsing with concentrated nitric acid and heated with concentrated hydrofluoric acid until completely dissolved. Hydrofluoric acid was removed by evaporating to dryness.

Approximately 25 milliliters ( $\mathrm{mL}$ ) (0.845 fluid ounce [oz]) of concentrated nitric acid and 1 gram ( $0.0353 \mathrm{oz}$ ) of boric acid were added (to remove residual hydrofluoric acid), and the samples were heated and evaporated to dryness. The sample residues were 
dissolved in 8 molar nitric acid for gamma spectroscopy and measurement of ${ }^{90} \mathrm{Sr}$ and the alpha emitting radionuclides.

\subsubsection{Determination of Individual Radionuclides}

Gamma-emitting radionuclides were measured in the air filters by gamma spectroscopy. Strontium-90 and alpha-emitting radionuclides were measured by sequential separation and counting. Strontium-90 was counted on a gas proportional counter. The actinides were co-precipitated, separated on an anion exchange column, and analyzed by alpha spectroscopy.

\subsubsection{Results and Discussion}

For 2010, out of 20 total composite samples, there were 140 analyses, as shown in Table 4.2. These analytes comprised of the following radionuclides: ${ }^{241} \mathrm{Am},{ }^{238} \mathrm{Pu}$, ${ }^{239 / 240} \mathrm{Pu},{ }^{90} \mathrm{Sr},{ }^{233 / 234} \mathrm{U},{ }^{238} \mathrm{U}$ and ${ }^{137} \mathrm{Cs}$.

Radionuclides are considered detected in a sample if the measured activity is greater than the 2бTPU and MDC. The detected radionuclides that met this definition were selected as the nuclide data for the CAP88-PC dataset report, as shown in Table 4.2. Another criteria was to have the $2 \sigma T P U$ added to the activity value. The final result was compared to the MDC. The highest result of the two was also selected for the nuclide data in the CAP88-PC dataset report. 
Waste Isolation Pilot Plant Annual Site Environmental Report for 2010 DOE/WIPP-11-2225

Table 4.2 - Activity (Bq) of Quarterly Composite Air Samples from the WIPP Effluent Monitoring Stations A, B and C for 2010

\begin{tabular}{|c|c|c|c|c|c|c|c|c|c|}
\hline \multirow[t]{2}{*}{ Nuclide } & Activity & $2 \sigma T P U^{a}$ & $\mathrm{MDC}^{\mathrm{b}}$ & Activity & $2 \sigma T P U$ & MDC & Activity & $2 \sigma T P U$ & MDC \\
\hline & \multicolumn{3}{|c|}{ Station A } & \multicolumn{3}{|c|}{ Station B } & \multicolumn{3}{|c|}{ Station C } \\
\hline \multicolumn{10}{|c|}{$1^{\text {st }}$ Quarter } \\
\hline${ }^{241} \mathrm{Am}$ & & & & $9.29 \mathrm{E}-06$ & 3.77E-04 & $5.40 \mathrm{E}-04$ & 4.44E-04 & $6.88 \mathrm{E}-04$ & $5.85 \mathrm{E}-04$ \\
\hline${ }^{238} \mathrm{Pu}$ & & & & $-1.25 \mathrm{E}-04$ & $2.53 \mathrm{E}-04$ & $4.66 \mathrm{E}-04$ & $0.00 \mathrm{E}+00$ & $6.59 \mathrm{E}-04$ & $7.51 \mathrm{E}-04$ \\
\hline${ }^{239 / 240} \mathrm{Pu}$ & & & & $8.45 \mathrm{E}-05$ & 3.05E-04 & $4.48 \mathrm{E}-04$ & 1.35E-04 & 5.59E-04 & $7.29 \mathrm{E}-04$ \\
\hline${ }^{90} \mathrm{Sr}$ & \multicolumn{3}{|l|}{ See below ${ }^{c}$} & $-2.45 \mathrm{E}-02$ & $3.89 \mathrm{E}-02$ & $-8.66 \mathrm{E}-03$ & $4.18 \mathrm{E}-02$ & 3.33E-03 & $7.40 \mathrm{E}-03$ \\
\hline $233 / 234 U$ & & & & $5.59 \mathrm{E}-04$ & $5.14 \mathrm{E}-04$ & 9.07E-04 & 2.33E-04 & 3.89E-04 & $9.10 \mathrm{E}-04$ \\
\hline${ }^{238} U$ & & & & $6.44 \mathrm{E}-04$ & $5.55 \mathrm{E}-04$ & $7.36 \mathrm{E}-04$ & $6.51 \mathrm{E}-04$ & 5.62E-04 & $7.36 \mathrm{E}-04$ \\
\hline${ }^{137} \mathrm{Cs}$ & & & & $-4.70 \mathrm{E}-01$ & 8.03E-01 & 8.47E-01 & 1.09E-01 & $1.05 \mathrm{E}+00$ & $1.24 \mathrm{E}+00$ \\
\hline \multicolumn{10}{|c|}{$2^{\text {nd }}$ Quarter } \\
\hline${ }^{241} \mathrm{Am}$ & & & & $0.00 E+00$ & 7.47E-04 & $8.73 \mathrm{E}-04$ & $2.52 \mathrm{E}-04$ & $8.21 \mathrm{E}-04$ & $8.03 E-04$ \\
\hline${ }^{238} \mathrm{Pu}$ & & & & 3.96E-04 & 7.77E-04 & $5.40 \mathrm{E}-04$ & $-4.48 \mathrm{E}-05$ & $5.66 \mathrm{E}-04$ & $5.29 E-04$ \\
\hline${ }^{239 / 240} \mathrm{Pu}$ & & & & $1.25 \mathrm{E}-04$ & $4.51 \mathrm{E}-04$ & $5.88 \mathrm{E}-04$ & $-1.09 \mathrm{E}-04$ & 2.84E-04 & $5.74 \mathrm{E}-04$ \\
\hline${ }^{90} \mathrm{Sr}$ & \multicolumn{3}{|l|}{ See below } & $-2.43 \mathrm{E}-02$ & $2.38 \mathrm{E}-02$ & $-3.00 \mathrm{E}-02$ & 3.36E-02 & $2.50 \mathrm{E}-03$ & $-3.29 E-02$ \\
\hline $233 / 234 U$ & & & & $1.29 \mathrm{E}-03$ & $8.14 \mathrm{E}-04$ & $9.51 \mathrm{E}-04$ & $4.26 \mathrm{E}-04$ & 5.33E-04 & $9.84 \mathrm{E}-04$ \\
\hline${ }^{238} \mathrm{U}$ & & & & $1.29 \mathrm{E}-03$ & $8.10 \mathrm{E}-04$ & $8.03 E-04$ & $4.55 \mathrm{E}-04$ & $5.18 \mathrm{E}-04$ & $8.36 \mathrm{E}-04$ \\
\hline${ }^{137} \mathrm{Cs}$ & & & & $6.33 \mathrm{E}-01$ & 7.55E-01 & $8.51 \mathrm{E}-01$ & $-1.70 \mathrm{E}-01$ & $1.38 \mathrm{E}+00$ & $1.58 \mathrm{E}+00$ \\
\hline \multicolumn{10}{|c|}{$3^{\text {rd }}$ Quarter } \\
\hline${ }^{241} \mathrm{Am}$ & & & & 2.69E-04 & $6.77 \mathrm{E}-04$ & $9.18 \mathrm{E}-04$ & 6.62E-04 & $1.00 \mathrm{E}-03$ & $9.51 \mathrm{E}-04$ \\
\hline${ }^{238} \mathrm{Pu}$ & & & & $1.59 \mathrm{E}-04$ & $8.10 \mathrm{E}-04$ & $1.11 \mathrm{E}-03$ & $-6.88 \mathrm{E}-05$ & 5.22E-04 & $9.66 \mathrm{E}-04$ \\
\hline${ }^{239 / 240} \mathrm{Pu}$ & & & & 3.25E-04 & $7.14 \mathrm{E}-04$ & $9.69 \mathrm{E}-04$ & $4.00 \mathrm{E}-05$ & 4.48E-04 & $8.18 \mathrm{E}-04$ \\
\hline${ }^{90} \mathrm{Sr}$ & \multicolumn{3}{|l|}{ See below } & $2.11 \mathrm{E}-03$ & $3.05 E-02$ & $9.99 \mathrm{E}-04$ & $2.53 \mathrm{E}-02$ & $2.05 \mathrm{E}-02$ & $-1.26 \mathrm{E}-03$ \\
\hline $233 / 234 U$ & & & & $2.65 \mathrm{E}-03$ & $1.65 \mathrm{E}-03$ & $1.18 \mathrm{E}-03$ & 1.44E-03 & 1.14E-03 & $1.12 \mathrm{E}-03$ \\
\hline${ }^{238} \mathrm{U}$ & & & & $8.55 \mathrm{E}-04$ & $9.55 \mathrm{E}-04$ & $1.27 \mathrm{E}-03$ & $8.36 \mathrm{E}-04$ & 8.17E-04 & $1.21 \mathrm{E}-03$ \\
\hline${ }^{137} \mathrm{Cs}$ & & & & 1.69E-01 & 7.33E-01 & $8.21 \mathrm{E}-01$ & $-6.44 \mathrm{E}-01$ & $1.69 \mathrm{E}+00$ & $1.86 \mathrm{E}+00$ \\
\hline \multicolumn{10}{|c|}{$4^{\text {th }}$ Quarter } \\
\hline${ }^{241} \mathrm{Am}$ & & & & $2.04 \mathrm{E}-04$ & 9.36E-04 & 1.16E-03 & 4.00E-04 & 7.36E-04 & $9.58 \mathrm{E}-04$ \\
\hline${ }^{238} \mathrm{Pu}$ & & & & $-6.25 \mathrm{E}-05$ & $7.66 \mathrm{E}-04$ & $9.44 \mathrm{E}-04$ & $-1.35 \mathrm{E}-04$ & $5.37 \mathrm{E}-04$ & $8.73 E-04$ \\
\hline${ }^{239 / 240} \mathrm{Pu}$ & & & & $-2.49 \mathrm{E}-05$ & 5.37E-04 & 8.40E-04 & $-3.24 \mathrm{E}-05$ & 1.42E-04 & $7.70 \mathrm{E}-04$ \\
\hline${ }^{90} \mathrm{Sr}$ & \multicolumn{3}{|l|}{ See below } & $6.29 \mathrm{E}-03$ & 3.77E-02 & $-2.07 \mathrm{E}-02$ & $2.58 \mathrm{E}-02$ & $2.28-02$ & $-3.18 \mathrm{E}-03$ \\
\hline $233 / 234 U$ & & & & $8.14 \mathrm{E}-04$ & $8.36 \mathrm{E}-04$ & $1.15 \mathrm{E}-03$ & $2.62 \mathrm{E}-04$ & $5.00 \mathrm{E}-04$ & $1.12 \mathrm{E}-03$ \\
\hline${ }^{238} \mathrm{U}$ & & & & 4.74E-04 & $6.44 \mathrm{E}-04$ & $9.51 \mathrm{E}-04$ & $5.88 \mathrm{E}-04$ & $6.85 \mathrm{E}-04$ & $9.14 \mathrm{E}-04$ \\
\hline${ }^{137} \mathrm{Cs}$ & & & & $-5.70 \mathrm{E}-01$ & $1.20 \mathrm{E}+00$ & $1.27 \mathrm{E}+00$ & $1.44 \mathrm{E}+00$ & $1.16 \mathrm{E}+00$ & $1.36 \mathrm{E}+00$ \\
\hline
\end{tabular}




\section{Waste Isolation Pilot Plant Annual Site Environmental Report for 2010 DOE/WIPP-11-2225}

Table 4.2 - Activity (Bq) of Quarterly Composite Air Samples from the WIPP Effluent Monitoring Stations A, B and C for 2010

\begin{tabular}{|c|c|c|c|c|c|c|c|c|c|}
\hline Nuclide & Activity & $2 \sigma T P U^{a}$ & $M^{\prime b} C^{b}$ & Activity & $2 \sigma \mathrm{TPU}$ & MDC & Activity & 2бTPU & MDC \\
\hline & \multicolumn{9}{|c|}{ Station A $1^{\text {st }}$ Quarter Monthly } \\
\hline & \multicolumn{3}{|c|}{ January } & \multicolumn{3}{|c|}{ February } & \multicolumn{3}{|c|}{ March } \\
\hline${ }^{241} \mathrm{Am}$ & $1.95 \mathrm{E}-04$ & 3.77E-04 & 4.88E-04 & 9.07E-05 & 4.59E-04 & 5.00E-04 & -4.03E-04 & 6.33E-04 & 8.84E-04 \\
\hline${ }^{238} \mathrm{Pu}$ & 3.63E-04 & $1.26 \mathrm{E}-03$ & 6.36E-04 & 2.02E-04 & $7.88 \mathrm{E}-04$ & 4.55E-04 & $-3.27 \mathrm{E}-04$ & 5.18E-04 & 6.81E-04 \\
\hline${ }^{239 / 240} \mathrm{Pu}$ & $-2.95 \mathrm{E}-05$ & 6.36E-04 & 6.36E-04 & $-1.14 \mathrm{E}-04$ & 2.60E-04 & 4.55E-04 & -1.99E-04 & 4.03E-04 & $6.22 \mathrm{E}-04$ \\
\hline${ }^{90} \mathrm{Sr}$ & $-1.41 \mathrm{E}-02$ & 3.65E-02 & 2.28E-03 & 4.03E-03 & 3.56E-02 & 2.08E-03 & $-6.11 E-03$ & 2.09E-02 & 2.26E-03 \\
\hline $233 / 234 U$ & $1.08 \mathrm{E}-03$ & 8.07E-04 & 1.09E-03 & $1.48 \mathrm{E}-03$ & 9.88E-04 & 1.12E-03 & 9.51E-04 & 8.88E-04 & 1.07E-03 \\
\hline${ }^{238} \mathrm{U}$ & 4.48E-04 & $5.44 \mathrm{E}-04$ & 8.10E-04 & $1.34 \mathrm{E}-03$ & $9.36 \mathrm{E}-04$ & $8.44 \mathrm{E}-04$ & $9.58 \mathrm{E}-04$ & 8.81E-04 & 8.77E-04 \\
\hline \multirow[t]{3}{*}{${ }^{137} \mathrm{Cs}$} & -4.96E-01 & $8.21 \mathrm{E}-01$ & 8.66E-01 & $1.55 \mathrm{E}-01$ & $7.88 \mathrm{E}-01$ & $8.81 E+01$ & $-1.42 \mathrm{E}-01$ & $9.62 \mathrm{E}-01$ & $1.12 \mathrm{E}+00$ \\
\hline & \multicolumn{9}{|c|}{ Station A $2^{\text {nd }}$ Quarter Monthly } \\
\hline & \multicolumn{3}{|c|}{ April } & \multicolumn{3}{|c|}{ May } & \multicolumn{3}{|c|}{ June } \\
\hline${ }^{241} \mathrm{Am}$ & $-1.80 \mathrm{E}-04$ & 8.29E-04 & 8.36E-04 & $2.29 \mathrm{E}-04$ & 8.10E-04 & 7.84E-04 & 4.07E-04 & 8.66E-04 & 7.33E-04 \\
\hline${ }^{238} \mathrm{Pu}$ & 2.91E-04 & 7.10E-04 & $5.14 \mathrm{E}-04$ & $-1.88 \mathrm{E}-04$ & 3.36E-04 & 4.29E-04 & 2.92E-04 & 4.59E-04 & 4.37E-04 \\
\hline${ }^{239 / 240} \mathrm{Pu}$ & 9.29E-05 & 4.14E-04 & 5.48E-04 & $-6.77 \mathrm{E}-05$ & 2.01E-04 & 4.74E-04 & 1.85E-04 & $5.25 \mathrm{E}-04$ & 4.81E-04 \\
\hline${ }^{90} \mathrm{Sr}$ & $-2.26 \mathrm{E}-02$ & 3.81E-02 & 2.89E-03 & $-2.88 \mathrm{E}-02$ & 3.25E-02 & 2.47E-03 & $-1.34 \mathrm{E}-02$ & 3.22E-02 & 2.35E-03 \\
\hline $233 / 234 \mathrm{U}$ & 1.41E-03 & $1.21 \mathrm{E}-03$ & 1.11E-03 & 8.92E-04 & 8.10E-04 & 1.04E-03 & $9.73 E-04$ & 7.62E-04 & 9.95E-04 \\
\hline${ }^{238} \mathrm{U}$ & 4.96E-04 & 7.29E-04 & 9.69E-04 & 1.79E-03 & 1.09E-03 & 8.88E-04 & $7.29 \mathrm{E}-04$ & $6.55 \mathrm{E}-04$ & 8.47E-04 \\
\hline \multirow[t]{3}{*}{${ }^{137} \mathrm{Cs}$} & 8.10E-02 & 9.69E-01 & $1.15 \mathrm{E}+00$ & 7.22E-01 & $9.47 \mathrm{E}-01$ & $1.15 \mathrm{E}+00$ & $1.14 \mathrm{E}+00$ & $9.14 \mathrm{E}-01$ & $1.14 \mathrm{E}+00$ \\
\hline & \multicolumn{9}{|c|}{ Station A $3^{\text {rd }}$ Quarter Monthly } \\
\hline & \multicolumn{3}{|c|}{ July } & \multicolumn{3}{|c|}{ July Backup } & \multicolumn{3}{|c|}{ August } \\
\hline${ }^{241} \mathrm{Am}$ & 8.21E-04 & 9.18E-04 & 6.03E-04 & $\mathrm{N} / \mathrm{R}$ & N/R & N/R & $-1.39 \mathrm{E}-05$ & 5.85E-04 & 6.96E-04 \\
\hline${ }^{238} \mathrm{Pu}$ & -1.05E-05 & 4.40E-04 & 4.40E-04 & $-3.51 E-05$ & 6.07E-04 & $1.06 \mathrm{E}-03$ & 2.93E-04 & 7.36E-04 & 5.14E-04 \\
\hline${ }^{239 / 240} \mathrm{Pu}$ & 1.88E-03 & 1.15E-03 & $5.00 \mathrm{E}-04$ & $-1.26 \mathrm{E}-04$ & 3.19E-04 & $9.21 \mathrm{E}-04$ & $1.20 \mathrm{E}-04$ & 4.03E-04 & 5.03E-04 \\
\hline${ }^{90} \mathrm{Sr}$ & $-6.92 \mathrm{E}-03$ & 2.90E-02 & 2.50E-03 & $\mathrm{N} / \mathrm{R}$ & N/R & $\mathrm{N} / \mathrm{R}$ & $-1.01 \mathrm{E}-02$ & 3.07E-02 & 2.63E-03 \\
\hline${ }^{233 / 234} \mathrm{U}$ & $5.25 E-04$ & $7.59 \mathrm{E}-04$ & $1.27 \mathrm{E}-03$ & $\mathrm{~N} / \mathrm{R}$ & $\mathrm{N} / \mathrm{R}$ & $\mathrm{N} / \mathrm{R}$ & 9.92E-04 & 1.04E-03 & $1.24 \mathrm{E}-03$ \\
\hline${ }^{238} \mathrm{U}$ & 3.34E-04 & $6.22 \mathrm{E}-04$ & 1.15E-03 & $\mathrm{N} / \mathrm{R}$ & $\mathrm{N} / \mathrm{R}$ & $\mathrm{N} / \mathrm{R}$ & 1.07E-03 & 1.01E-03 & 1.13E-03 \\
\hline \multirow[t]{3}{*}{${ }^{137} \mathrm{Cs}$} & $-3.53 \mathrm{E}-01$ & $1.47 \mathrm{E}+00$ & $1.67 \mathrm{E}+00$ & $\mathrm{~N} / \mathrm{R}$ & N/R & $\mathrm{N} / \mathrm{R}$ & 7.84E-01 & $1.76 \mathrm{E}+00$ & $2.02 \mathrm{E}+00$ \\
\hline & \multicolumn{3}{|c|}{ Station A $3^{\text {rd }}$ Quarter Con't. } & \multicolumn{6}{|c|}{$4^{\text {th }}$ Quarter Monthly } \\
\hline & \multicolumn{3}{|c|}{ September } & \multicolumn{3}{|c|}{ October } & \multicolumn{3}{|c|}{ November } \\
\hline${ }^{241} \mathrm{Am}$ & $-1.34 \mathrm{E}-05$ & $5.62 \mathrm{E}-04$ & $1.01 \mathrm{E}-03$ & $-3.46 \mathrm{E}-04$ & $5.88 \mathrm{E}-04$ & 1.17E-03 & $7.70 \mathrm{E}-04$ & 1.04E-03 & $1.04 \mathrm{E}-03$ \\
\hline${ }^{238} \mathrm{Pu}$ & 2.53E-05 & $5.44 \mathrm{E}-04$ & $1.01 \mathrm{E}-03$ & $-2.38 \mathrm{E}-04$ & $5.48 \mathrm{E}-04$ & $8.25 \mathrm{E}-04$ & $-1.00 \mathrm{E}-04$ & 8.33E-04 & $9.84 \mathrm{E}-04$ \\
\hline${ }^{239 / 240} \mathrm{Pu}$ & $-1.71 \mathrm{E}-04$ & 3.54E-04 & 8.70E-04 & $9.25 E-05$ & 3.33E-04 & 7.88E-04 & 9.99E-05 & 4.81E-04 & $9.21 \mathrm{E}-04$ \\
\hline${ }^{90} \mathrm{Sr}$ & $-1.49 \mathrm{E}-02$ & 2.98E-02 & 2.12E-02 & -8.07E-03 & $3.68 \mathrm{E}-02$ & $2.02 \mathrm{E}-02$ & $-1.84 \mathrm{E}-02$ & 3.06E-02 & 2.00E-02 \\
\hline${ }^{233 / 234} \mathrm{U}$ & 1.86E-03 & 1.53E-03 & 1.31E-03 & 1.05E-03 & 9.88E-04 & 1.23E-03 & 8.33E-04 & 8.62E-04 & 1.11E-03 \\
\hline${ }^{238} \mathrm{U}$ & 7.40E-05 & 6.29E-04 & $1.40 \mathrm{E}-03$ & 8.84E-04 & $8.88 \mathrm{E}-04$ & $1.08 \mathrm{E}-03$ & $1.54 \mathrm{E}-03$ & 1.09E-03 & 9.92E-04 \\
\hline${ }^{137} \mathrm{Cs}$ & $-2.70 \mathrm{E}-01$ & $9.88 \mathrm{E}-01$ & $1.14 \mathrm{E}+00$ & 6.92E-01 & 8.95E-01 & $1.11 \mathrm{E}+00$ & $-1.06 \mathrm{E}-01$ & 9.21E-01 & $1.07 \mathrm{E}+00$ \\
\hline
\end{tabular}


Table 4.2 - Activity (Bq) of Quarterly Composite Air Samples from the WIPP Effluent Monitoring Stations A, B and C for 2010

\begin{tabular}{|c|c|c|c|c|}
\hline Nuclide & Activity & $2 \sigma T P U^{a}$ & $M^{\prime b}$ & \\
\hline & \multicolumn{3}{|c|}{ Stations A 4 ${ }^{\text {th }}$ Quarter Con't. } & \\
\hline & \multicolumn{3}{|c|}{ December } & \\
\hline${ }^{241} \mathrm{Am}$ & $-2.08 E-05$ & 4.48E-04 & 8.62E-04 & \\
\hline${ }^{238} \mathrm{Pu}$ & $-1.52 E-05$ & 4.11E-04 & 8.25E-04 & \\
\hline${ }^{239 / 240} \mathrm{Pu}$ & 3.65E-04 & $5.29 \mathrm{E}-04$ & 7.22E-04 & \\
\hline${ }^{90} \mathrm{Sr}$ & $-1.99 \mathrm{E}-02$ & 2.51E-02 & $2.28 \mathrm{E}-02$ & \\
\hline $233 / 234 U$ & 4.18E-03 & $1.63 \mathrm{E}-03$ & 1.02E-03 & \\
\hline${ }^{238} \mathrm{U}$ & 2.09E-03 & $1.12 \mathrm{E}-03$ & 7.99E-04 & \\
\hline${ }^{137} \mathrm{Cs}$ & 5.70E-01 & $1.11 \mathrm{E}+00$ & $1.26 \mathrm{E}+00$ & \\
\hline \multicolumn{5}{|c|}{$\begin{array}{l}\text { (a) Total propagated uncertainty. } \\
\text { (b) Minimum detectable concentration. } \\
\text { (c) Station A - composited monthly due to the large number of samples. } \\
\text { (d) N/R - Not Requested. }\end{array}$} \\
\hline
\end{tabular}

Sampling was performed in the underground and at the WHB using fixed air samplers. The July 2010 backup composite samples were reanalyzed to confirm results obtained in the initial July 2010 analysis for two radionuclides, ${ }^{238} \mathrm{Pu}$ and ${ }^{239 / 240} \mathrm{Pu}$. The reanalysis showed no detection.

Evaluation of the filter sample results indicated that there were no detectable releases from the WIPP facility that exceeded $25 \mathrm{mrem}$ to the whole body and 75 mrem to any critical organ in accordance with the provisions of 40 CFR \$191.03(b). In addition, there were no detectable releases that exceeded the 10 mrem per year limit, as specified in 40 CFR §61.92, and the 0.1 mrem per year limit for periodic confirmatory sampling required by 40 CFR $\S 61.93(b)(4)(I)$, from the WIPP facility.

\subsection{Airborne Particulates}

\subsubsection{Sample Collection}

Weekly airborne particulate samples were collected from seven locations on or near the WIPP site (Figure 4.1) using low-volume air samplers. Locations were selected based on the prevailing wind direction. Location codes are shown in Appendix C. Each week at each sampling location, approximately $600 \mathrm{~m}^{3}\left(21,187 \mathrm{ft}^{3}\right)$ of air were sampled through a 4.7-centimeter $(\mathrm{cm})(1.85$-inch [in.]) diameter glass microfiber filter using a continuous low-volume air sampler. 


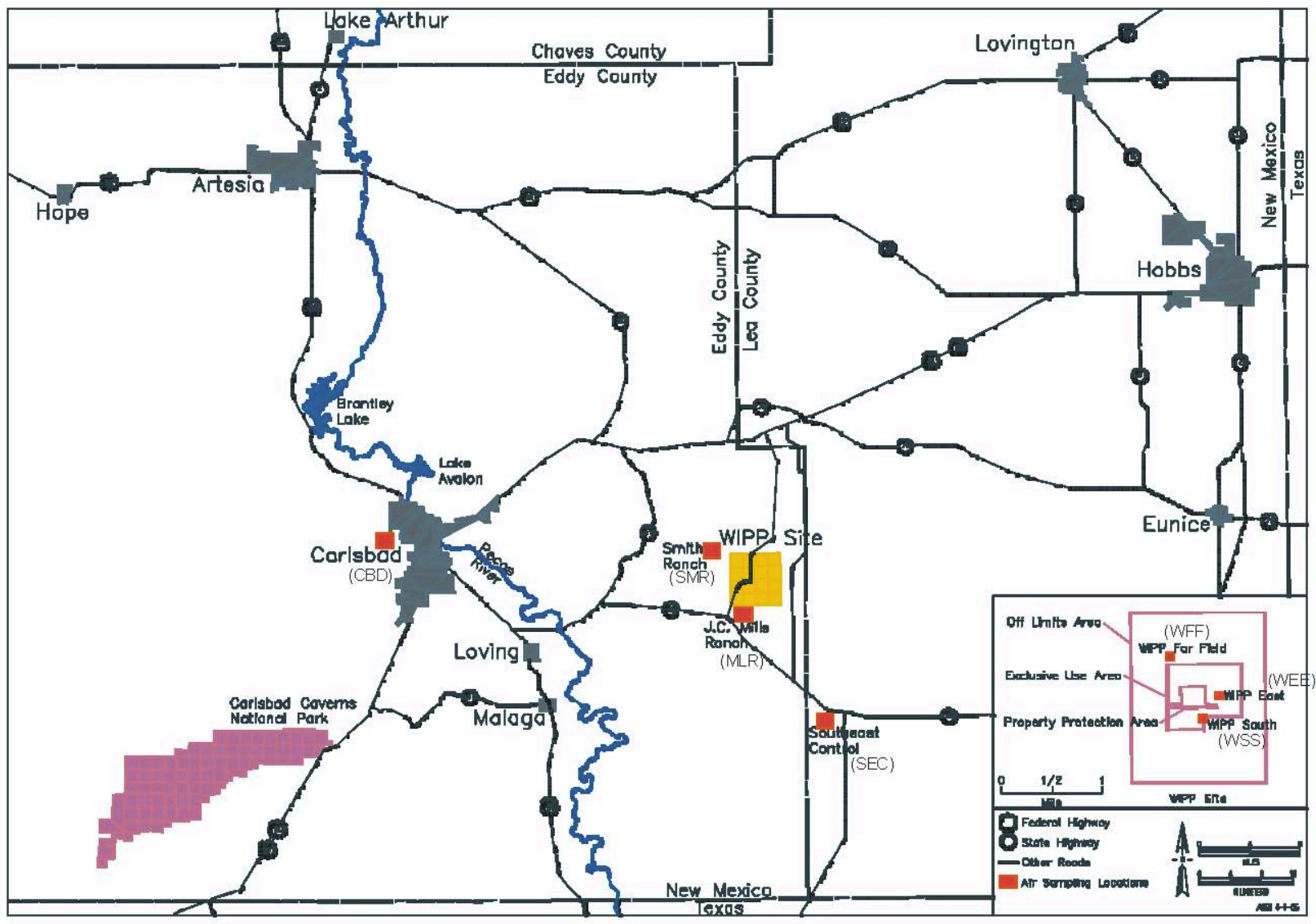

Figure 4.1 - Air Sampling Locations On and Near the WIPP Site

\subsubsection{Sample Preparation}

Weekly air particulate samples were composited for each quarter. The composite samples were transferred into a Pyrex ${ }^{\circledR}$ beaker, spiked with appropriate tracers $\left({ }^{232} \mathrm{U}\right.$, ${ }^{243} \mathrm{Am}$ and ${ }^{242} \mathrm{Pu}$ ), and heated in a muffle furnace at $250^{\circ} \mathrm{C}$ for two hours, followed by heating for two hours at $375^{\circ} \mathrm{C}$, and heating for six hours at $525^{\circ} \mathrm{C}$.

The filters were ashed and cooled, and then transferred into Teflon ${ }^{\circledR}$ beakers by rinsing with concentrated nitric acid, and the mixture was heated with concentrated hydrofluoric acid until completely dissolved. Hydrofluoric acid was removed by evaporating to dryness.

Approximately $25 \mathrm{~mL}$ of concentrated nitric acid and one gram of boric acid were added, and the samples were heated and finally evaporated to dryness. The residues were dissolved in $8 \mathrm{M}$ nitric acid for subsequent separation and analysis. 


\subsubsection{Determination of Individual Radionuclides}

The acid digestates of the sediment samples were split into two fractions. One fraction was analyzed by gamma spectroscopy for ${ }^{40} \mathrm{~K},{ }^{60} \mathrm{Co}$, and ${ }^{137} \mathrm{Cs}$. The other fraction was analyzed for the uranium/transuranic radioisotopes and ${ }^{90} \mathrm{Sr}$ by employing a series of chemical, physical, and ion exchange procedures to separate the radionuclides followed by mounting the sample residues on a planchet for counting. Uranium/ transuranics were counted by alpha spectroscopy and ${ }^{90} \mathrm{Sr}$ was counted for beta emissions using gas proportional counting.

\subsubsection{Results and Discussion}

The combined mean, minimum, and maximum concentrations (becquerels per composite air filter sample [Bq/sample]) of target radionuclides for all air sampling locations are reported in Table 4.3. Detailed sample analysis data for each station are reported in Appendix G (Table G.1). Whenever the word "sample" is used for air filter samples, it should be taken to mean "composite sample" and does not include blanks. The average concentrations are reported for those locations where duplicate samples were collected using low-volume air samples. A Qualifier column has been added to all the data tables, which designates whether the activity of the radionuclide is greater than the 2 sigma TPU and MDC and thus whether the radionuclide was detected in the sample. In Table $\mathrm{G} .2$, the $\mathrm{Bq} /$ sample has been converted to $\mathrm{Bq} / \mathrm{m}^{3}$ by dividing the sample activity by the total quarterly air volumes.

The only radionuclide detections in any of the air filter composite (AFC) samples were detection of ${ }^{233 / 234} U$ in samples from WFF, WEE, WSS, MLR, SEC, SMR, and CBD during the second quarter sampling; ${ }^{233 / 234} U$ in MLR, CBD, and SMR during the fourth quarter sampling; and ${ }^{238} \mathrm{U}$ in WFF, WEE, WSS, MLR, SEC, SMR, and CBD during the second quarter sampling (same samples as ${ }^{233 / 234} \mathrm{U}$ ). However, the WAB blank filters also contained detections of ${ }^{233 / 234} \mathrm{U}$ and ${ }^{238} \mathrm{U}$ in the second and fourth quarter blank filter samples with activities that ranged from about half to almost equal (0.56 to 0.94$)$ of the activity in the samples for ${ }^{233 / 234} \mathrm{U}$ and about half to almost equal $(0.55$ to 0.96$)$ of the activity in the samples for ${ }^{238} \mathrm{U}$. This means the activity in the samples was less than two times higher than the activity in the associated filter blanks. As such, only a few of the air filter composites contained negligible concentrations of naturally occurring uranium isotopes. The uranium isotopes were not detected in the 2009 samples and thus ANOVA comparisons between years and between locations were not performed.

In contrast to 2009 , no ${ }^{239 / 240} \mathrm{Pu}$ and ${ }^{241} \mathrm{Am}$ were detected in any of the 2010 samples.

Since the ${ }^{239 / 240} \mathrm{Pu}$ and ${ }^{241} \mathrm{Am}$ were not detected in the 2010 air filter composite samples, no ANOVA comparisons between years or between locations could be performed.

There were no measurable concentrations of ${ }^{40} \mathrm{~K},{ }^{37} \mathrm{Cs},{ }^{60} \mathrm{Co}$, or ${ }^{90} \mathrm{Sr}$ in any of the 2010 air filter composite samples. Thus, no ANOVA comparisons could be performed between years or between locations for these gamma radionuclides. 


\section{Waste Isolation Pilot Plant Annual Site Environmental Report for 2010 DOE/WIPP-11-2225}

Table 4.3 - 2010 Mean, Minimum, and Maximum Radionuclide Concentrations (Bq/sample) in Air Filter Composite Samples from Stations Surrounding the WIPP Site

See Appendix G for Supporting Data

\begin{tabular}{|c|c|c|c|c|}
\hline Radionuclide & & {$[\mathrm{RN}]^{\mathrm{a}}$} & $2 \sigma \mathrm{TPU}^{\mathrm{b}}$ & $\mathrm{MDC}^{\mathrm{C}}$ \\
\hline \multirow[t]{3}{*}{${ }^{233 / 234} U$} & Mean $^{d}$ & $5.98 \mathrm{E}-03$ & $2.21 \mathrm{E}-03$ & $2.67 \mathrm{E}-02$ \\
\hline & Minimum $^{\mathrm{e}}$ & $7.06 \mathrm{E}-04$ & $1.99 \mathrm{E}-03$ & 1.19E-03 \\
\hline & Maximum $^{\mathrm{e}}$ & $1.33 \mathrm{E}-02$ & $2.65 \mathrm{E}-03$ & $6.79 \mathrm{E}-03$ \\
\hline \multirow[t]{3}{*}{${ }^{235} \mathrm{U}$} & Mean $^{d}$ & $4.88 \mathrm{E}-04$ & 5.99E-04 & $3.48 \mathrm{E}-03$ \\
\hline & Minimum $^{\mathrm{e}}$ & $-1.55 E-04$ & $3.21 \mathrm{E}-04$ & $4.27 \mathrm{E}-04$ \\
\hline & Maximum $^{\mathrm{e}, \mathrm{f}}$ & $2.22 \mathrm{E}-03$ & $1.27 \mathrm{E}-03$ & 1.97E-03 \\
\hline \multirow[t]{3}{*}{${ }^{238} \mathrm{U}$} & Mean $^{\mathrm{d}}$ & $5.79 \mathrm{E}-03$ & $2.07 \mathrm{E}-03$ & $2.27 \mathrm{E}-02$ \\
\hline & Minimum & $8.78 \mathrm{E}-04$ & $1.84 \mathrm{E}-03$ & $7.81 \mathrm{E}-04$ \\
\hline & Maximum $^{\mathrm{e}}$ & $1.58 \mathrm{E}-02$ & $2.99 \mathrm{E}-03$ & $5.74 \mathrm{E}-03$ \\
\hline \multirow[t]{3}{*}{${ }^{241} \mathrm{Am}$} & Mean $^{d}$ & 9.37E-05 & $5.64 \mathrm{E}-04$ & $3.10 \mathrm{E}-03$ \\
\hline & Minimum $^{\mathrm{e}}$ & $-4.00 E-04$ & $4.98 \mathrm{E}-04$ & $6.97 \mathrm{E}-04$ \\
\hline & Maximum $^{\mathrm{e}, \mathrm{f}}$ & $2.90 \mathrm{E}-03$ & $1.86 \mathrm{E}-03$ & 9.37E-04 \\
\hline \multirow[t]{3}{*}{${ }^{238} \mathrm{Pu}$} & Mean $^{\mathrm{d}}$ & $-6.41 \mathrm{E}-06$ & $4.62 \mathrm{E}-04$ & $6.45 \mathrm{E}-04$ \\
\hline & Minimum $^{\mathrm{e}, \mathrm{f}}$ & $-2.31 \mathrm{E}-04$ & $3.30 \mathrm{E}-04$ & $4.11 \mathrm{E}-04$ \\
\hline & Maximum $^{\mathrm{e}}$ & $5.78 \mathrm{E}-04$ & $7.55 \mathrm{E}-04$ & 4.90E-04 \\
\hline \multirow[t]{3}{*}{${ }^{239 / 240} \mathrm{Pu}$} & Mean $^{d}$ & $-2.23 E-04$ & $4.40 \mathrm{E}-04$ & $1.85 \mathrm{E}-03$ \\
\hline & Minimum & $-1.30 \mathrm{E}-03$ & 2.07E-04 & $5.50 \mathrm{E}-04$ \\
\hline & Maximum $^{\mathrm{e}}$ & 1.99E-03 & $1.40 \mathrm{E}-03$ & $6.50 \mathrm{E}-04$ \\
\hline \multirow[t]{3}{*}{${ }^{40} \mathrm{~K}$} & Mean $^{d}$ & $4.66 \mathrm{E}+00$ & $9.76 \mathrm{E}+00$ & $9.88 \mathrm{E}+00$ \\
\hline & Minimum $^{\mathrm{e}}$ & $-8.14 \mathrm{E}+00$ & $1.34 \mathrm{E}+01$ & $1.40 \mathrm{E}+01$ \\
\hline & Maximum $^{\mathrm{e}, \mathrm{f}}$ & $1.48 \mathrm{E}+01$ & $1.24 \mathrm{E}+01$ & $1.51 \mathrm{E}+01$ \\
\hline \multirow[t]{3}{*}{${ }^{60} \mathrm{Co}$} & Mean $^{\mathrm{d}}$ & $1.58 \mathrm{E}+01$ & $1.05 E+00$ & $1.03 E+00$ \\
\hline & Minimum $^{\mathrm{e}}$ & $-1.46 \mathrm{E}+00$ & $1.54 \mathrm{E}+00$ & $1.52 \mathrm{E}+00$ \\
\hline & Maximum $^{\mathrm{e}, \mathrm{f}}$ & $1.05 \mathrm{E}+00$ & $9.58 \mathrm{E}+01$ & $1.24 \mathrm{E}+00$ \\
\hline \multirow[t]{3}{*}{${ }^{137} \mathrm{Cs}$} & Mean $^{\text {d }}$ & $-3.79 \mathrm{E}-01$ & $1.25 \mathrm{E}+00$ & $1.16 \mathrm{E}+00$ \\
\hline & Minimum $^{\mathrm{e}}$ & $-2.00 \mathrm{E}+00$ & $1.72 \mathrm{E}+00$ & $1.74 \mathrm{E}+00$ \\
\hline & Maximum $^{\mathrm{e}, \mathrm{f}}$ & $1.04 \mathrm{E}+00$ & $1.33 \mathrm{E}+00$ & $1.49 \mathrm{E}+00$ \\
\hline \multirow[t]{3}{*}{${ }^{90} \mathrm{Sr}$} & Mean $^{d}$ & $-1.64 \mathrm{E}-02$ & 3.07E-02 & 1.57E-02 \\
\hline & Minimum $^{\mathrm{e}}$ & $-3.90 \mathrm{E}-02$ & 4.37E-02 & $2.96 \mathrm{E}-03$ \\
\hline & Maximum $^{\mathrm{e}, \mathrm{f}}$ & $1.80 \mathrm{E}-03$ & $2.05 \mathrm{E}-02$ & $2.12 \mathrm{E}-03$ \\
\hline \multicolumn{5}{|c|}{$\begin{array}{l}\text { (a) Radionuclide Concentration. Values are for eight locations and four quarterly composites (Appendix G). } \\
\text { (b) Total Propagated Uncertainty at the } 2 \text { sigma level. } \\
\text { (c) Minimum Detectable Concentration. } \\
\text { (d) Arithmetic average for concentration } 2 \sigma \text { TPU, and MDC. } \\
\text { (e) Minimum and maximum reported concentrations for each radionuclide are based on [RN], while the associated } \\
2 \sigma \text { TPU and MDC values are inherited with the specific [RN]. } \\
\text { (f) Undetected because activity was less than } 2 \text { TPU and/or MDC. }\end{array}$} \\
\hline
\end{tabular}

During 2010, duplicate samples were taken from four rotating air sampling locations including location WSS during the first quarter; location MLR during the second quarter; location SEC during the third quarter; and location CBD during the fourth quarter. The MLR duplicates from the second quarter contained detectable concentrations of both ${ }^{233 / 234} \mathrm{U}$ and ${ }^{238} \mathrm{U}$. The relative error ratios (RERs) were 0.395 for ${ }^{233 / 234} \mathrm{U}$ and 0.130 for 
${ }^{238} \mathrm{U}$. The CBD duplicate samples from the fourth quarter contained a detectable concentration of ${ }^{233 / 234} \mathrm{U}$ in one of the duplicates, but the MDC was higher than the activity in the other duplicate. However, precision as RER can still be calculated and reported for non-detects, and the duplicate samples yielded a RER of 0.91.

Note that this ASER reports the precision of duplicate field samples as RER for the radionuclides that were detected during analysis of the primary and duplicate samples. RER is equivalent to Duplicate Error Ratio (DER) for duplicate samples. The RER calculations are performed for all the matrices where duplicate samples are collected in the field such as the duplicate particulate filters discussed in this section, duplicate groundwater samples, and other duplicate matrices discussed later in this chapter. There is no firm established quality assurance objective for the precision of field duplicates since the composition of the field samples could be slightly different. One source (Rocky Flats Annual Report of Site Surveillance and Maintenance ActivitiesCY2008, Doc. No. S05247, U.S. Department of Energy, April, 2009) suggested that 85 percent of field duplicates should yield RERs (DERs) $<1.96$. Field duplicate RERs $<1$ indicate very good precision for the combined sampling and laboratory analysis procedures. Poorer precision suggests that there could be actual differences in the composition of the samples collected in the field.

The laboratory generates lab duplicate samples from a single field sample. In the case of laboratory duplicates, the quality assurance objective for laboratory precision is a RER (DER) of $<1$ for the WIPP environmental analysis program. The laboratory generates precision data for all the radionuclides in a sample whether the radionuclide was detected or not based on the activities and $2 \sigma$ TPUs measured in the samples. The laboratory duplicate RERs are not provided in the ASER, but $>99$ percent of all the laboratory RERs generated for this study were $<1$. Only one set of aqueous lab control spike/lab control spike duplicate yielded a RER $>1$ (1.17) for ${ }^{239 / 240} \mathrm{Pu}$ during analysis of a biota sample batch. The laboratory's SOW indicates that "the Laboratory shall assess the need for corrective actions" if the laboratory duplicate precision yields RERs $>1$, but this was not necessary for this biota sample with a RER of 1.17, which was a QC sample and not a field sample.

The RER precision data for all the duplicate environmental sample matrices analyzed was calculated and reported except for animal biota samples where duplicate animal samples are not able to be collected. The laboratory precision data are reported for the analysis of duplicate portions of the animal samples in Section 4.7.4 of this report.

\subsection{Groundwater}

\subsubsection{Sample Collection}

Groundwater samples were collected twice in 2010 (Rounds 30 and 31) from seven different groundwater quality sampling program (WQSP) wells on the WIPP site, as shown in Figure 6.1. During each of the resulting 14 sampling episodes, a primary sample and a duplicate sample were simultaneously collected from each well. Six of these wells are completed in the Culebra (wells WQSP-1 through WQSP-6) and the seventh well (WQSP-6A) is completed in the Dewey Lake Redbeds Formation (Dewey Lake). Approximately three bore volumes of water were pumped out of each well before 
collecting approximately 38 liters (L) (10 gallons) of water samples. The water samples were collected from depths ranging from 180 to $270 \mathrm{~m}$ (591-886 ft) from the six wells (WQSP-1 to WQSP-6), and from a depth of $69 \mathrm{~m}(226 \mathrm{ft}$ ) from WQSP-6A. Approximately $8 \mathrm{~L}$ ( 2 gallons) of water per well were sent to the laboratory for the measurement of the target radionuclides. The remaining sample portions were used to analyze for nonradiological parameters (volatile and semivolatile organics, metals, and general chemistry indicator parameters) or were placed in storage. The radiological samples were filtered during collection and acidified to $\mathrm{pH} \leq 2$ with concentrated nitric acid.

\subsubsection{Sample Preparation}

The acidified groundwater sample containers were shaken to distribute any suspended material evenly, and sample aliquots were measured into glass beakers. The first $0.5-\mathrm{L}$ portion was used directly for gamma spectroscopy analysis and the second $0.5-\mathrm{L}$ portion was used for uranium and transuranic target isotopes and ${ }^{90} \mathrm{Sr}$. Tracers $\left({ }^{232} \mathrm{U}\right.$, ${ }^{243} \mathrm{Am}$, and ${ }^{242} \mathrm{Pu}$ ) and carriers (strontium nitrate and barium nitrate) were added to the second portion and the samples were then digested using concentrated nitric acid and hydrofluoric acid. The samples were then heated to dryness and wet-ashed using concentrated nitric acid and hydrogen peroxide. Finally, the samples were heated to dryness again, and the isotopic separation process was initiated.

\subsubsection{Determination of Individual Radionuclides}

The first portion of water sample was used directly for the measurement of the gammaemitting radionuclides ${ }^{40} \mathrm{~K},{ }^{60} \mathrm{Co}$, and ${ }^{137} \mathrm{Cs}$, by gamma spectroscopy. The second $0.5-\mathrm{L}$ portion of the water was used for the sequential separation of the uranium isotopes, the transuranics and ${ }^{90} \mathrm{Sr}$. The digested samples from Section 4.3.2 above were prepared for counting by co-precipitating the target isotopes and corresponding tracers with an iron carrier, performing ion exchange and chromatographic separations of the individual radionuclides, and micro-precipitating the separated radionuclides onto planchets for counting the uranium/transuranics by alpha spectroscopy and ${ }^{90} \mathrm{Sr}$ by gas proportional counting.

\subsubsection{Results and Discussion}

Isotopes of naturally occurring uranium $\left({ }^{233 / 234} U,{ }^{235} U\right.$, and $\left.{ }^{238} U\right)$ were detected in all the groundwater well samples in 2010 as shown by the data in Table 4.4. The concentrations reported in Table 4.4 are from the primary samples collected from each WQSP well. A duplicate sample from each well was analyzed during each sampling episode. The data from the duplicate samples was used for the precision determinations as reported later in this section. The radionuclides were considered detected if the activity is greater than the $2 \sigma T P U$ and MDC.

The 2010 groundwater concentrations in the WQSP wells were compared with the concentrations from the same locations in 2009 using ANOVA. ANOVA calculations were performed using the mean uranium concentrations from the spring and fall sampling (Rounds 30 and 31). The uranium isotopes were also detected in all the groundwater samples in 2009. 
The concentrations of the uranium isotopes measured in 2010 did not vary significantly from the concentrations measured in the same wells in 2009, as demonstrated by the combined ANOVA of the wells with ANOVA, ${ }^{233 / 234} \mathrm{U} p=0.131 ;{ }^{235} \mathrm{U} p=0.900$; and ${ }^{238} \mathrm{U}$ $p=0.112$, with all the $p$ values above the significance level of 0.05 .

The concentrations of the uranium isotopes measured in 2010 were also compared to the 2009 concentrations by location. The variation by location between the wells sampled in 2009 and 2010 was similar to the variation between years for ${ }^{233 / 234} \mathrm{U}$ and ${ }^{238} U$ as shown by the combined ANOVA results of ${ }^{233 / 234} U p=0.185$ and ${ }^{238} U p=0.162$. The variation for ${ }^{235} U$ was greater with ${ }^{235} U p=0.0342$. The differences in the concentrations of the uranium isotopes at the various wells (locations) are likely due to the differences in the abundance of these naturally occurring isotopes in the earth's crust and the associated leaching of the radioisotopes into the groundwater.

Concentrations of uranium isotopes were also compared with baseline concentrations measured between 1985 and 1989 (baseline values: ${ }^{233 / 234} \mathrm{U}=1.30 \mathrm{~Bq} / \mathrm{L},{ }^{235} \mathrm{U}=3.10 \mathrm{E}-$ $02 \mathrm{~Bq} / \mathrm{L}$, and ${ }^{238} \mathrm{U}=3.20 \mathrm{E}-01 \mathrm{~Bq} / \mathrm{L}$ ). For 2010 , the highest average Round 30 concentrations of ${ }^{233 / 234} \mathrm{U}$ were an average concentration of $9.66 \mathrm{E}-01 \mathrm{~Bq} / \mathrm{L}$ at WQSP-1 and $1.18 \mathrm{~Bq} / \mathrm{L}$ at WQSP-2. The Round 31 average concentrations were $1.35 \mathrm{~Bq} / \mathrm{L}$ at WQSP-1 and 1.17 Bq/L at WQSP-2. The $1.35 \mathrm{~Bq} / \mathrm{L}$ measured in both the primary and duplicate sample at WQSP-1 was slightly higher than the baseline concentration of 1.30 $\mathrm{Bq} / \mathrm{L}$. The ${ }^{235} \mathrm{U}$ and ${ }^{238} \mathrm{U}$ concentrations were also highest at WQSP-1 and WQSP-2 during Rounds 30 and 31but were well within the 99 percent confidence interval ranges of baseline concentrations (DOEMIPP-92-037).

The transuranic alpha spectroscopy radionuclides, ${ }^{238} \mathrm{Pu},{ }^{239 / 240} \mathrm{Pu}$, and ${ }^{241} \mathrm{Am}$ were also analyzed for in the groundwater samples (Table 4.4). These isotopes, which are related to WIPP waste disposal operations, were not detected in any of the groundwater samples, so no ANOVA comparisons between years and among locations could be performed. 


\section{Waste Isolation Pilot Plant Annual Site Environmental Report for 2010 DOE/WIPP-11-2225}

Table 4.4 - 2010 Radionuclide Concentrations (Bq/L) of Groundwater from Wells at the WIPP Site

See Chapter 6 for Sampling Locations

\begin{tabular}{|c|c|c|c|c|c|c|c|c|c|c|c|c|c|}
\hline Location & Round & {$[R N]^{a}$} & $2 \sigma \mathrm{TPU}^{\mathrm{b}}$ & $M C^{c}$ & $Q^{d}$ & [RN] & $2 \sigma$ TPU & MDC & $\mathbf{Q}$ & [RN] & $2 \sigma$ TPU & MDC & Q \\
\hline & & \multicolumn{3}{|c|}{${ }^{233 / 234} U$} & & \multicolumn{3}{|c|}{${ }^{235} U$} & & \multicolumn{3}{|c|}{${ }^{238} U$} & \\
\hline WQSP-1 & 30 & 9.93E-01 & 2.12E-01 & 9.83E-04 & + & 2.28E-02 & $6.31 \mathrm{E}-03$ & 5.57E-04 & + & 1.71E-01 & 3.75E-02 & 8.24E-04 & + \\
\hline \multirow[t]{2}{*}{ WQSP-2 } & 30 & $1.23 \mathrm{E}+00$ & 2.05E-01 & 9.50E-04 & + & 2.32E-02 & 5.38E-03 & 4.96E-04 & + & 1.94E-01 & 3.34E-02 & 7.59E-04 & + \\
\hline & 31 & $1.16 \mathrm{E}+00$ & 1.99E-01 & 9.30E-04 & + & 1.11E-02 & 3.07E-03 & 6.68E-04 & + & 1.81E-01 & 3.21E-02 & 1.03E-03 & + \\
\hline WQSP-3 & 31 & 2.46E-01 & 4.14E-02 & 1.10E-03 & + & 1.68E-03 & 9.59E-04 & 5.79E-04 & + & 3.43E-02 & 6.89E-03 & 1.11E-03 & + \\
\hline \multirow[t]{2}{*}{ WQSP-4 } & 30 & 6.44E-01 & 3.16E-02 & 1.07E-03 & + & 3.75E-03 & 1.56E-03 & 5.28E-04 & + & 1.10E-01 & 8.60E-03 & 8.05E-04 & + \\
\hline & 31 & 3.70E-01 & 7.96E-02 & 1.08E-03 & + & 5.49E-03 & 2.28E-03 & 5.46E-04 & + & 5.93E-02 & 1.38E-02 & 9.79E-04 & + \\
\hline WQSP-5 & 30 & 2.93E-01 & 6.82E-02 & 1.32E-03 & + & 1.07E-02 & 3.89E-03 & 6.76E-04 & + & 4.66E-02 & 1.20E-02 & 1.01E-03 & + \\
\hline \multirow[t]{3}{*}{ WQSP-6A } & 30 & 2.31E-01 & 3.97E-02 & $1.22 \mathrm{E}-03$ & + & 8.58E-03 & 2.72E-03 & 5.10E-04 & + & 1.64E-01 & 2.89E-02 & 9.32E-04 & + \\
\hline & 31 & 1.39E-01 & 2.60E-02 & 9.89E-04 & + & 4.71E-03 & 1.83E-03 & 4.66E-04 & + & 7.20E-02 & 1.40E-02 & 9.03E-04 & + \\
\hline & & \multicolumn{3}{|c|}{${ }^{241} \mathrm{Am}$} & & \multicolumn{3}{|c|}{${ }^{238} \mathrm{Pu}$} & & \multicolumn{3}{|c|}{${ }^{239 / 240} \mathrm{Pu}$} & \\
\hline \multirow[t]{2}{*}{ WQSP-1 } & 30 & $-5.29 \mathrm{E}-06$ & 4.48E-04 & 5.90E-04 & $U$ & 5.13E-04 & 7.15E-04 & 4.94E-04 & $U$ & $-6.71 E-05$ & 1.92E-04 & 4.23E-04 & U \\
\hline & 31 & 3.06E-04 & 4.96E-04 & 7.74E-04 & $U$ & $-1.58 \mathrm{E}-04$ & 2.75E-04 & 7.23E-04 & U & -7.06E-05 & 1.84E-04 & 7.31E-04 & $U$ \\
\hline \multirow[t]{2}{*}{ WQSP-2 } & 30 & $-2.52 \mathrm{E}-05$ & 4.35E-04 & 5.69E-04 & $U$ & $-2.93 E-04$ & 5.56E-04 & 8.29E-04 & $U$ & 4.58E-05 & 7.28E-04 & 8.24E-04 & U \\
\hline & 31 & 3.27E-04 & 1.11E-03 & 1.36E-03 & U & $-1.99 \mathrm{E}-05$ & $3.44 \mathrm{E}-04$ & 8.10E-04 & $U$ & 1.35E-04 & 3.96E-04 & $6.86 \mathrm{E}-04$ & $U$ \\
\hline WQSP-3 & 30 & 8.99E-04 & 1.09E-03 & 7.99E-04 & $U$ & 3.02E-04 & 7.95E-04 & $6.12 \mathrm{E}-04$ & $U$ & -8.99E-05 & 2.58E-04 & 5.93E-04 & U \\
\hline WQSP-6 & 31 & 3.73E-04 & $6.64 \mathrm{E}-04$ & $5.26 \mathrm{E}-04$ & $U$ & $-3.75 \mathrm{E}-04$ & 4.38E-04 & 3.73E-04 & $\mathrm{U}$ & 8.34E-05 & 2.84E-04 & 3.67E-04 & U \\
\hline \multirow[t]{3}{*}{ WQSP-6A } & 30 & 4.75E-04 & $6.10 \mathrm{E}-04$ & 4.86E-04 & $U$ & -7.89E-06 & 6.68E-04 & 6.57E-04 & $U$ & $-1.35 E-04$ & 3.53E-04 & 7.19E-04 & $U$ \\
\hline & 31 & 4.02E-04 & 7.55E-04 & 6.31E-04 & $U$ & $-3.87 E-04$ & $4.52 \mathrm{E}-04$ & 3.84E-04 & $U$ & 2.15E-04 & 3.91E-04 & 3.69E-04 & U \\
\hline & & \multicolumn{3}{|c|}{${ }^{40} \mathrm{~K}$} & & & ${ }^{60} \mathrm{Co}$ & & & & ${ }^{137} \mathrm{Cs}$ & & \\
\hline WQSP-1 & 30 & $1.89 \mathrm{E}+01$ & $5.62 \mathrm{E}+00$ & $5.08 \mathrm{E}+00$ & + & $-4.86 \mathrm{E}-01$ & 7.31E-01 & 6.65E-01 & $U$ & $-3.42 \mathrm{E}-02$ & 4.86E-01 & 5.82E-01 & U \\
\hline & 31 & $1.59 \mathrm{E}+01$ & $5.15 E+00$ & $4.98 \mathrm{E}+00$ & + & $-1.18 E+00$ & 7.88E-01 & 5.81E-01 & $U$ & 4.00E-01 & 4.29E-01 & 5.88E-01 & U \\
\hline WQSP-2 & 30 & $1.59 \mathrm{E}+01$ & $4.42 \mathrm{E}+00$ & $4.34 \mathrm{E}+00$ & + & -1.96E-02 & 3.83E-01 & 4.40E-01 & U & -1.08E-01 & 3.74E-01 & 4.03E-01 & U \\
\hline & 31 & $1.61 \mathrm{E}+01$ & $6.59 \mathrm{E}+00$ & $7.79 \mathrm{E}+00$ & + & $-1.30 \mathrm{E}-01$ & 9.17E-01 & $1.01 \mathrm{E}+00$ & $U$ & 3.46E-01 & 9.16E-01 & $1.09 \mathrm{E}+00$ & $U$ \\
\hline WQSP-3 & 30 & $5.56 \mathrm{E}+01$ & $1.08 \mathrm{E}+01$ & $5.99 \mathrm{E}+00$ & + & $-2.31 \mathrm{E}-01$ & $6.24 \mathrm{E}-01$ & 6.65E-01 & U & 8.55E-02 & 4.74E-01 & 5.85E-01 & U \\
\hline & 31 & $4.79 \mathrm{E}+01$ & $1.00 \mathrm{E}+01$ & $6.82 \mathrm{E}+00$ & + & 1.32E-01 & 5.83E-01 & 7.25E-01 & $U$ & 1.81E-01 & 4.86E-01 & 6.15E-01 & U \\
\hline WQSP-4 & 30 & $2.71 \mathrm{E}+01$ & $8.27 \mathrm{E}+00$ & $9.57 \mathrm{E}+00$ & + & 9.94E-01 & $9.62 \mathrm{E}-01$ & $1.23 \mathrm{E}+00$ & $U$ & $-1.39 E+00$ & $1.19 \mathrm{E}+00$ & $1.21 \mathrm{E}+00$ & U \\
\hline & 31 & $2.55 \mathrm{E}+01$ & $7.01 \mathrm{E}+00$ & $6.56 \mathrm{E}+00$ & + & $-1.28 \mathrm{E}-01$ & 5.95E-01 & 6.65E-01 & $U$ & 3.77E-01 & 4.70E-01 & $6.28 \mathrm{E}-01$ & U \\
\hline WQSP-5 & 30 & $1.20 \mathrm{E}+01$ & $5.69 \mathrm{E}+00$ & $7.00 \mathrm{E}+00$ & + & $-3.45 E-01$ & 8.76E-01 & 9.46E-01 & U & $-8.48 \mathrm{E}-02$ & 7.86E-01 & 8.84E-01 & U \\
\hline & 31 & $1.13 \mathrm{E}+01$ & $4.41 \mathrm{E}+00$ & $4.81 \mathrm{E}+00$ & + & $-5.55 E-02$ & 6.01E-01 & $6.72 \mathrm{E}-01$ & U & $-3.21 E-01$ & 5.31E-01 & 5.76E-01 & U \\
\hline WQSP-6 & 30 & $5.02 E+00$ & $5.87 \mathrm{E}+00$ & $8.09 \mathrm{E}+00$ & $U$ & $1.80 \mathrm{E}-01$ & 5.22E-01 & 6.72E-01 & U & 2.86E-01 & 3.81E-01 & 5.22E-01 & $U$ \\
\hline
\end{tabular}




\section{Waste Isolation Pilot Plant Annual Site Environmental Report for 2010 DOE/WIPP-11-2225}

Table 4.4 - 2010 Radionuclide Concentrations (Bq/L) of Groundwater from Wells at the WIPP Site

See Chapter 6 for Sampling Locations

\begin{tabular}{|c|c|c|c|c|c|c|c|c|c|c|c|c|c|}
\hline Location & Round & {$[\mathrm{RN}]^{\mathrm{a}}$} & $2 \sigma \mathrm{TPU}^{\mathrm{b}}$ & MDC $^{c}$ & $Q^{d}$ & [RN] & $2 \sigma \mathrm{TPU}$ & MDC & $\mathbf{Q}$ & [RN] & $2 \sigma$ TPU & MDC & $\mathbf{Q}$ \\
\hline & 31 & $1.56 \mathrm{E}+01$ & $9.41 \mathrm{E}+00$ & $1.25 \mathrm{E}+01$ & + & 2.69E-01 & 9.34E-01 & $1.12 \mathrm{E}+00$ & U & 7.40E-01 & $1.01 \mathrm{E}+00$ & $1.22 \mathrm{E}+00$ & U \\
\hline \multirow[t]{2}{*}{ WQSP-6A } & 30 & 9.31E-01 & $5.93 E+00$ & $7.27 \mathrm{E}+00$ & U & $-1.34 \mathrm{E}-01$ & 5.26E-01 & 5.84E-01 & $\mathrm{U}$ & 8.70E-02 & 4.11E-01 & 5.19E-01 & U \\
\hline & & \multicolumn{3}{|c|}{${ }^{90} \mathrm{Sr}$} & & & & & & & & & \\
\hline WQSP-1 & 30 & $-1.48 \mathrm{E}-02$ & 3.26E-02 & 3.03E-03 & $\mathrm{U}$ & & & & & & & & \\
\hline \multirow[t]{2}{*}{ WQSP-2 } & 30 & $-1.13 E-02$ & 2.36E-02 & $2.40 \mathrm{E}-03$ & $U$ & & & & & & & & \\
\hline & 31 & $-1.05 E-02$ & 4.03E-02 & 2.17E-02 & U & & & & & & & & \\
\hline \multirow[t]{2}{*}{ WQSP-3 } & 30 & $-2.89 \mathrm{E}-02$ & $2.95 \mathrm{E}-02$ & 2.71E-03 & $U$ & & & & & & & & \\
\hline & 31 & $-2.76 \mathrm{E}-02$ & 4.63E-02 & $2.28 \mathrm{E}-02$ & $U$ & & & & & & & & \\
\hline WQSP-5 & 31 & -8.36E-03 & 2.80E-02 & 2.17E-03 & U & & & & & & & & \\
\hline \multirow[t]{2}{*}{ WQSP-6 } & 30 & $-1.96 \mathrm{E}-03$ & 3.27E-02 & 2.39E-03 & $U$ & & & & & & & & \\
\hline & 31 & $8.21 E-04$ & 3.15E-02 & $2.66 \mathrm{E}-03$ & $U$ & & & & & & & & \\
\hline \multirow[t]{2}{*}{ WQSP-6A } & 30 & 1.34E-02 & 3.19E-02 & 2.42E-03 & U & & & & & & & & \\
\hline & 31 & $-2.96 \mathrm{E}-03$ & 3.39E-02 & 2.88E-03 & U & & & & & & & & \\
\hline \multicolumn{14}{|c|}{$\begin{array}{l}\text { (a) Radionuclide activity of the primary sample. Only radionuclides with activities greater than } 2 \sigma T P U \text { and MDC are considered } \\
\text { detections. }\end{array}$} \\
\hline \multicolumn{14}{|c|}{ (b) Two $\sigma$ the Total Propagated Uncertainty. } \\
\hline \multicolumn{14}{|c|}{ (c) Minimum Detectable Concentration. } \\
\hline
\end{tabular}

The beta emitter, ${ }^{90} \mathrm{Sr}$, was not detected in any of the groundwater samples, thus no ANOVA comparisons between years or among locations could be performed.

The gamma isotope ${ }^{40} \mathrm{~K}$ was detected in most of the Round 30 and Round 31 primary groundwater samples. It was detected in the WQSP-1, WQSP-2, WQSP-3, WQSP-4, and WQSP-5 samples from both rounds and in the Round 31 autumn sample from WQSP-6. It was not detected in the WQSP-6A samples from either round.

During 2009, ${ }^{40} \mathrm{~K}$ showed the same pattern with detection in the WQSP-1 through WQSP-5 samples, the autumn sampling from WQSP-6, and neither sample from WQSP-6A.

The 2010 concentrations of ${ }^{40} \mathrm{~K}$ did not vary significantly from the 2009 concentrations based on a $\mathrm{p}$ value of 0.804 . However, the ${ }^{40} \mathrm{~K}$ concentrations did vary significantly from well to well, yielding a $p$ value of 0.000119 . Some differences in ${ }^{40} \mathrm{~K}$ concentrations at the various wells (locations) would be expected due to differences in the abundance of this naturally occurring isotope at various locations in the earth's crust and the associated variable leaching into groundwater.

The measured concentrations of ${ }^{40} \mathrm{~K}$ in 2010 were within the 99 percent confidence interval range of the baseline concentrations (baseline concentration: 6.30E+01 Bq/L). 
The nearest concentration measured in 2010 was $5.56 \mathrm{E}+01 \mathrm{~Bq} / \mathrm{L}$ in the sample from the spring sampling (Round 30) from WQSP-3.

The gamma isotopes, ${ }^{137} \mathrm{Cs}$ and ${ }^{60} \mathrm{Co}$, were not detected in any of the 2010 groundwater samples and no ANOVA comparisons were performed.

This ASER reports the precision of the duplicate field sample precision as RERs only for the radionuclides that were detected during analysis of the primary and duplicate samples collected at each WQSP well. The detected radionuclides in the 2010 groundwater samples included the uranium isotopes and ${ }^{40} \mathrm{~K}$. The analysis data and resulting RERs are shown in Table 4.5 for 2010 Sampling Round 30 and in Table 4.6 for 2010 Sampling Round 31.

The Round 30 RERs in Table 4.5 show that there were no RERs greater than 1.96 and three RERs with values between 1.0 and 1.96. The Round 31 RERs in Table 4.6 show that there were no values greater than 1.96 and also none greater than 1.0. The only imprecision in the analysis results was that ${ }^{40} \mathrm{~K}$ was detected in the WQSP-6 duplicate sample but not in the WQSP-6 primary sample for both Round 30 and Round 31.

The laboratory analyzed the primary groundwater sample from each well in duplicate from each sampling round. All RERs calculated from analysis of laboratory duplicates were $<1.0$, which indicated good laboratory precision for measurement of the target radionuclides.

In theory, the primary and duplicate groundwater samples should have identical concentrations since the sample containers are filled simultaneously. The RER results show slightly higher RERs for a few of the uranium isotope and ${ }^{40} \mathrm{~K}$ analysis results in the field duplicates compared to the laboratory duplicates as indicated by a few RERs $>1$. The alpha spectroscopy sample preparation requires many different laboratory procedures, and all the steps combined can contribute to some lack of precision. The laboratory re-analyzed some batches of samples because of spectral interferences, and some samples contained relatively weak alpha spectra as evidenced by low tracer recoveries, although the laboratory's QA/QC criteria for tracer recovery were met.

The greater imprecision of a few field duplicates compared to lab duplicates suggests that some imprecision could be associated with the samples and may reflect slight differences in the composition of samples. 
Waste Isolation Pilot Plant Annual Site Environmental Report for 2010 DOE/WIPP-11-2225

Table 4.5 - 2010 Results of Duplicate Groundwater Sample Analyses for Sampling Round 30; Units are in Bq/L

See Chapter 6 for Sampling Locations

\begin{tabular}{|c|c|c|c|c|c|c|}
\hline \multirow[t]{2}{*}{ Location } & & \multicolumn{2}{|c|}{ Sample } & \multicolumn{3}{|c|}{ Duplicate } \\
\hline & & {$[\mathrm{RN}]^{\mathrm{a}}$} & $2 \sigma \mathrm{TPU}^{\mathrm{b}}$ & [RN] & $2 \sigma$ TPU & RER $^{c}$ \\
\hline \multirow[t]{4}{*}{ WQSP-1 } & ${ }^{233 / 234} U$ & 9.93E-01 & 2.12E-01 & $9.40 \mathrm{E}-01$ & 1.95E-01 & 0.184 \\
\hline & ${ }^{235} \mathrm{U}$ & 2.28E-02 & 6.31E-03 & 2.12E-02 & 5.93E-03 & 0.185 \\
\hline & ${ }^{238} \mathrm{U}$ & 1.71E-01 & 3.75E-02 & $1.56 \mathrm{E}-01$ & 3.36E-02 & 0.298 \\
\hline & ${ }^{40} \mathrm{~K}$ & 1.89E+01 & $5.62 \mathrm{E}+00$ & $1.51 \mathrm{E}+01$ & $5.24 \mathrm{E}+00$ & 0.495 \\
\hline \multirow[t]{4}{*}{ WQSP-2 } & ${ }^{233 / 234} U$ & $1.23 E+00$ & 2.05E-01 & $1.13 \mathrm{E}+00$ & 1.51E-01 & 0.393 \\
\hline & ${ }^{235} \mathrm{U}$ & 2.32E-02 & 5.38E-03 & $1.92 \mathrm{E}-02$ & 4.04E-03 & 0.595 \\
\hline & ${ }^{238} \mathrm{U}$ & 1.94E-01 & 3.34E-02 & $1.85 \mathrm{E}-01$ & 2.58E-02 & 0.213 \\
\hline & ${ }^{40} \mathrm{~K}$ & $1.59 \mathrm{E}+01$ & $4.42 \mathrm{E}+00$ & $1.28 \mathrm{E}+01$ & $4.85 E+00$ & 0.472 \\
\hline \multirow[t]{4}{*}{ WQSP-3 } & ${ }^{233 / 234} \cup$ & 1.17E-01 & 2.51E-02 & 1.26E-01 & 1.84E-02 & 0.289 \\
\hline & ${ }^{235} \mathrm{U}$ & 1.79E-03 & $1.22 \mathrm{E}-03$ & 7.50E-04 & 6.56E-04 & 0.751 \\
\hline & ${ }^{238} \mathrm{U}$ & 1.88E-02 & 5.04E-03 & 2.02E-02 & 3.96E-03 & 0.218 \\
\hline & ${ }^{40} \mathrm{~K}$ & $5.56 \mathrm{E}+01$ & $1.08 \mathrm{E}+01$ & $5.24 \mathrm{E}+01$ & $1.16 \mathrm{E}+01$ & 0.202 \\
\hline \multirow[t]{4}{*}{ WQSP-4 } & ${ }^{233 / 234} U$ & 6.44E-01 & 3.16E-02 & 5.87E-01 & 3.36E-02 & 1.236 \\
\hline & ${ }^{235} \mathrm{U}$ & 3.75E-03 & 1.56E-03 & 6.97E-03 & 2.02E-03 & 1.262 \\
\hline & ${ }^{238} \mathrm{U}$ & $1.10 \mathrm{E}-01$ & 8.60E-03 & 9.45E-02 & 8.04E-03 & 1.317 \\
\hline & ${ }^{40} \mathrm{~K}$ & $2.71 \mathrm{E}+01$ & $8.27 \mathrm{E}+00$ & $2.29 \mathrm{E}+01$ & $6.92 \mathrm{E}+00$ & 0.389 \\
\hline \multirow[t]{4}{*}{ WQSP-5 } & ${ }^{233 / 234} U$ & 2.93E-01 & 6.82E-02 & 3.02E-01 & 6.63E-02 & 0.095 \\
\hline & ${ }^{235} \mathrm{U}$ & 1.07E-02 & 3.89E-03 & 1.13E-02 & 3.91E-03 & 0.109 \\
\hline & ${ }^{238} U$ & 4.66E-02 & $1.20 \mathrm{E}-02$ & 5.65E-02 & $1.36 \mathrm{E}-02$ & 0.546 \\
\hline & ${ }^{40} \mathrm{~K}$ & $1.20 \mathrm{E}+01$ & $5.69 \mathrm{E}+00$ & $7.56 \mathrm{E}+00$ & $3.43 \mathrm{E}+00$ & 0.668 \\
\hline \multirow[t]{3}{*}{ WQSP-6 } & ${ }^{233 / 234} U$ & 5.99E-01 & $1.48 \mathrm{E}-01$ & 6.55E-01 & $1.75 \mathrm{E}-01$ & 0.244 \\
\hline & ${ }^{235} \mathrm{U}$ & 4.20E-03 & 2.27E-03 & 4.38E-03 & 2.46E-03 & 0.054 \\
\hline & ${ }^{238} U$ & 7.39E-02 & 1.96E-02 & 8.77E-02 & 2.47E-02 & 0.438 \\
\hline \multirow[t]{3}{*}{ WQSP-6A } & ${ }^{233 / 234} U$ & 2.31E-01 & 3.97E-02 & 2.11E-01 & 2.95E-02 & 0.404 \\
\hline & ${ }^{235} \mathrm{U}$ & 8.58E-03 & 1.49E-03 & 5.76E-03 & 1.67E-03 & 0.063 \\
\hline & ${ }^{238} U$ & 1.64E-01 & 2.89E-02 & 1.31E-01 & 1.93E-02 & 0.950 \\
\hline \multicolumn{7}{|c|}{$\begin{array}{l}\text { (b) Total Propagated Uncertainty. } \\
\text { (c) Relative Error Ratio. }\end{array}$} \\
\hline
\end{tabular}




\section{Waste Isolation Pilot Plant Annual Site Environmental Report for 2010}

DOE/WIPP-11-2225

Table 4.6 - Results of Duplicate Groundwater Sample Analyses for Sampling Round 31; Units are in $\mathrm{Bq} / \mathrm{L}$

See Chapter 6 for Sampling Locations

\begin{tabular}{|c|c|c|c|c|c|c|}
\hline \multirow[t]{2}{*}{ Location } & & \multicolumn{2}{|c|}{ Sample } & \multicolumn{3}{|c|}{ Duplicate } \\
\hline & & {$[\mathrm{RN}]^{\mathrm{a}}$} & $2 \sigma \mathrm{TPU}^{\mathrm{b}}$ & [RN] & $2 \sigma$ TPU & RER $^{c}$ \\
\hline \multirow[t]{4}{*}{ WQSP-1 } & ${ }^{233 / 234} U$ & $1.35 E+00$ & 1.99E-01 & $1.35 \mathrm{E}+00$ & 2.17E-01 & 0.000 \\
\hline & ${ }^{235} \mathrm{U}$ & 1.05E-02 & $2.85 \mathrm{E}-03$ & 1.03E-02 & $2.94 \mathrm{E}-03$ & 0.049 \\
\hline & ${ }^{238} \mathrm{U}$ & 2.15E-01 & 3.29E-02 & 2.17E-01 & 3.60E-02 & 0.041 \\
\hline & ${ }^{40} \mathrm{~K}$ & $1.59 \mathrm{E}+01$ & $5.15 E+00$ & $1.94 \mathrm{E}+01$ & $6.59 \mathrm{E}+00$ & 0.418 \\
\hline \multirow[t]{4}{*}{ WQSP-2 } & ${ }^{233 / 234} U$ & $1.16 \mathrm{E}+00$ & 1.99E-01 & $1.18 \mathrm{E}+00$ & $1.82 \mathrm{E}-01$ & 0.074 \\
\hline & ${ }^{235} \mathrm{U}$ & 1.11E-02 & 3.07E-03 & $9.17 \mathrm{E}-03$ & $2.66 \mathrm{E}-03$ & 0.475 \\
\hline & ${ }^{238} \mathrm{U}$ & 1.81E-01 & 3.21E-02 & 1.79E-01 & $2.89 \mathrm{E}-02$ & 0.046 \\
\hline & ${ }^{40} \mathrm{~K}$ & $1.61 \mathrm{E}+01$ & $6.59 \mathrm{E}+00$ & $1.59 \mathrm{E}+01$ & $6.04 \mathrm{E}+00$ & 0.022 \\
\hline \multirow[t]{4}{*}{ WQSP-3 } & ${ }^{233 / 234} U$ & 2.46E-01 & 4.14E-02 & 2.49E-01 & 4.59E-02 & 0.049 \\
\hline & ${ }^{235} \mathrm{U}$ & 1.68E-03 & 9.59E-04 & 1.15E-03 & 8.24E-04 & 0.419 \\
\hline & ${ }^{238} \mathrm{U}$ & 3.43E-02 & 6.89E-03 & 4.01E-02 & 8.48E-03 & 0.531 \\
\hline & ${ }^{40} \mathrm{~K}$ & $4.79 \mathrm{E}+01$ & $1.00 E+00$ & $5.14 \mathrm{E}+01$ & $8.63 E+00$ & 0.403 \\
\hline \multirow[t]{4}{*}{ WQSP-4 } & ${ }^{233 / 234} U$ & 3.70E-01 & 7.96E-02 & 3.65E-01 & 7.11E-02 & 0.047 \\
\hline & ${ }^{235} \mathrm{U}$ & 5.49E-03 & 2.28E-03 & 7.01E-03 & 2.59E-03 & 0.441 \\
\hline & ${ }^{238} \mathrm{U}$ & 5.93E-02 & 1.38E-02 & 6.81E-02 & 1.44E-02 & 0.441 \\
\hline & ${ }^{40} \mathrm{~K}$ & $2.55 \mathrm{E}+01$ & $7.01 E+00$ & $2.35 \mathrm{E}+01$ & $8.62 \mathrm{E}+00$ & 0.180 \\
\hline \multirow[t]{4}{*}{ WQSP-5 } & ${ }^{233 / 234} U$ & 3.46E-01 & 5.55E-02 & 3.72E-01 & $6.47 \mathrm{E}-02$ & 0.305 \\
\hline & ${ }^{235} \mathrm{U}$ & $4.00 \mathrm{E}-03$ & 1.67E-03 & $6.38 \mathrm{E}-03$ & 2.27E-03 & 0.845 \\
\hline & ${ }^{238} \mathrm{U}$ & $5.01 \mathrm{E}-02$ & $9.21 \mathrm{E}-03$ & 5.36E-02 & 1.05E-02 & 0.251 \\
\hline & ${ }^{40} \mathrm{~K}$ & $1.13 \mathrm{E}+01$ & $4.41 \mathrm{E}+00$ & $1.06 \mathrm{E}+01$ & $6.29 \mathrm{E}+00$ & 0.091 \\
\hline \multirow[t]{3}{*}{ WQSP-6 } & ${ }^{233 / 234} U$ & $3.28 \mathrm{E}-01$ & $6.00 \mathrm{E}-02$ & 3.05E-01 & 4.97E-02 & 0.295 \\
\hline & ${ }^{235} \mathrm{U}$ & 4.18E-03 & $1.84 \mathrm{E}-03$ & 4.74E-03 & 1.81E-03 & 0.217 \\
\hline & ${ }^{238} \mathrm{U}$ & 4.23E-02 & 8.91E-03 & 3.73E-02 & 7.20E-03 & 0.436 \\
\hline \multirow[t]{3}{*}{ WQSP-6A } & ${ }^{233 / 234} U$ & 1.39E-01 & $2.60 \mathrm{E}-02$ & $1.50 \mathrm{E}-01$ & 2.66E-02 & 0.296 \\
\hline & ${ }^{235} \mathrm{U}$ & 4.71E-03 & 1.83E-03 & $3.50 \mathrm{E}-03$ & 1.59E-03 & 0.063 \\
\hline & ${ }^{238} U$ & 7.20E-02 & $1.40 \mathrm{E}-02$ & 8.00E-02 & 1.48E-02 & 0.393 \\
\hline
\end{tabular}

(a) Radionuclide Concentration.

(b) Total Propagated Uncertainty.

(c) Relative Error Ratio.

\subsection{Surface Water}

\subsubsection{Sample Collection}

Surface water samples were collected from various locations around the WIPP site as shown in Figure 4.2 (see Appendix $C$ for location codes). If a particular surface water collection location was dry, only a sediment sample from the site was collected. Sediment sample analysis results are discussed in Section 4.5. 


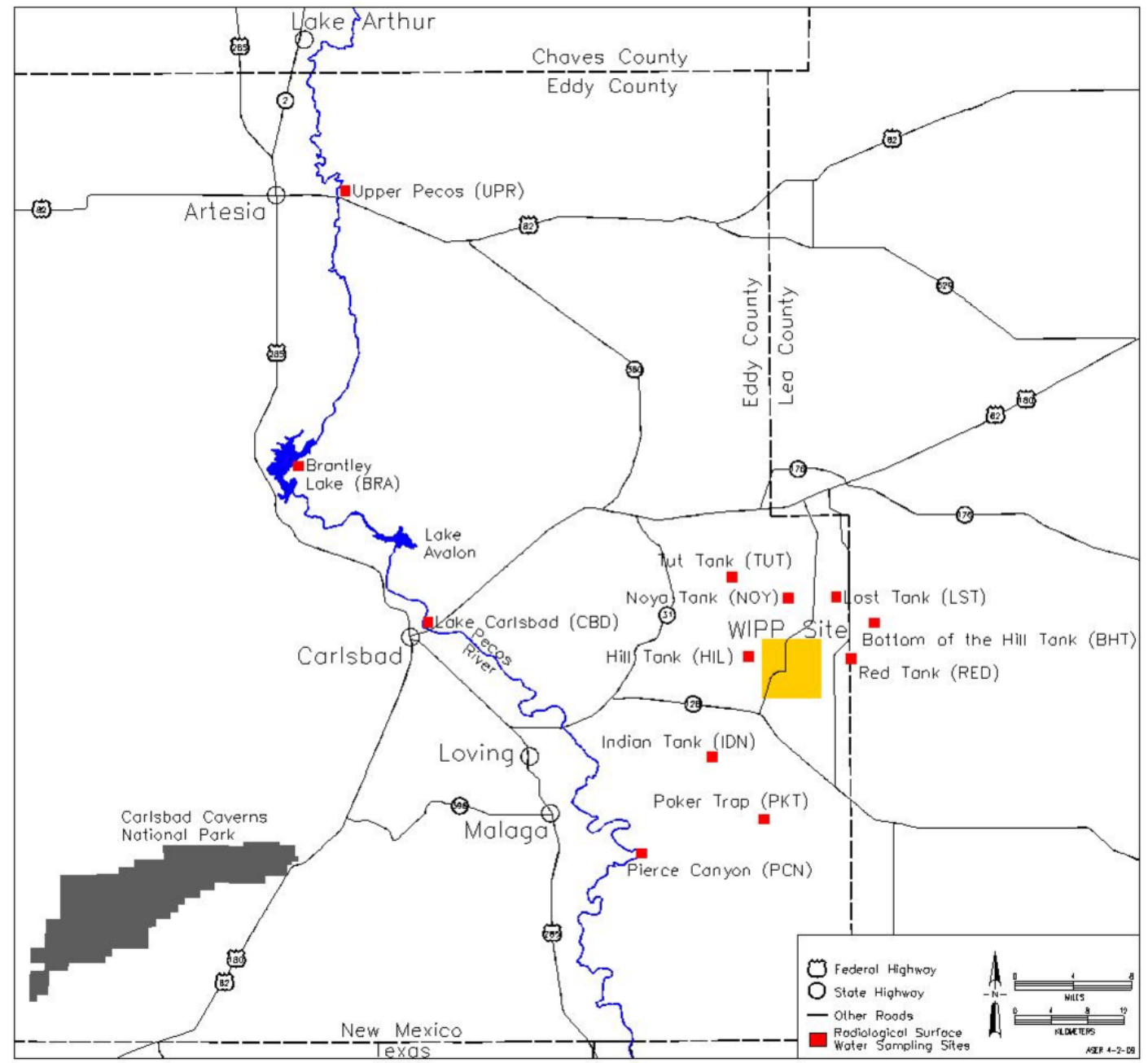

Figure 4.2 - Routine Surface Water Sampling Locations

Water from each sampling location was used to rinse 3.78-L (1-gallon) polyethylene containers at least three times prior to taking the sample. Approximately one gallon of water was collected from each location. The samples were acidified to $\mathrm{pH} \leq 2$ immediately after collection with concentrated nitric acid. Later, the samples were transferred to WIPP Laboratories for analysis. Chain of custody was maintained throughout the process.

\subsubsection{Sample Preparation}

Surface water sample containers were shaken to distribute suspended material evenly, and sample aliquots were measured into glass beakers. One $0.5-\mathrm{L}$ portion was used for gamma spectroscopy and another 0.5 -L portion was used for sequential analysis of the uranium/transuranic isotopes and ${ }^{90} \mathrm{Sr}$. Tracers $\left({ }^{232} \mathrm{U},{ }^{243} \mathrm{Am}\right.$, and $\left.{ }^{242} \mathrm{Pu}\right)$ and carriers (strontium nitrate and barium nitrate) were added to the second sample portion, and the samples were then digested using concentrated nitric acid and hydrofluoric acid. The samples were heated to dryness and wet-ashed using concentrated nitric acid and hydrogen peroxide. Finally, the samples were heated to dryness again, and the isotopic separation steps were initiated. 


\subsubsection{Determination of Individual Radionuclides}

A 0.5-L portion of the acidified water sample was used directly for the measurement of the gamma-emitting radionuclides ${ }^{40} \mathrm{~K},{ }^{60} \mathrm{Co}$, and ${ }^{137} \mathrm{Cs}$, by gamma spectroscopy. The other $0.5-\mathrm{L}$ portion of the water was prepared by co-precipitating the target isotopes and corresponding tracers with an iron carrier, performing ion exchange and chromatographic separations of the individual radionuclides, and micro-precipitating the separated radionuclides onto planchets for counting. The uranium isotopes and transuranics were counted using alpha spectroscopy, and ${ }^{90} \mathrm{Sr}$ was beta counted using a gas proportional detector.

\subsubsection{Results and Discussion}

Uranium isotopes were detected in most of the surface water samples, which included 14 separate samples, 2 sets of duplicate samples, and a distilled water field blank (COW). The field blank sample (sample location COW) was submitted to the laboratory as a "blind" QC sample, and sample COY was submitted as a blind duplicate of Sample PKT. The uranium isotope analyses resulted in detection of ${ }^{233 / 234} \mathrm{U}$ in all the surface water samples including the COW field blank; detection of ${ }^{235} \mathrm{U}$ in RED, IDN, PCN, SWL, CBD, BRA, UPR, and the UPR dup; and detection of ${ }^{238} U$ in all the samples except the COW field blank (Table 4.7).

The concentrations of the uranium isotopes were compared between 2009 and 2010 and also between sampling locations using ANOVA for those locations where the uranium isotopes were detected both years. The average concentrations were used for detections at IDN and BRA in 2009 and PKT and UPR in 2010. The ${ }^{233 / 234} \mathrm{U}$ was detected in 12 common locations in 2009 and $2010 ;{ }^{235} U$ was detected in three common locations in 2009 and 2010; and ${ }^{238} \mathrm{U}$ was detected in 11 common locations.

There was no significant variation in the concentrations of the uranium isotopes in the surface water between 2009 and 2010 (ANOVA, ${ }^{233 / 234} U p=0.399$; ANOVA ${ }^{235} U$ $p=0.278 ;$ and $\left.A N O V A{ }^{238} \cup p=0.315\right)$.

There was much greater variability in the concentrations of ${ }^{233 / 234} \mathrm{U}$ and ${ }^{238} \mathrm{U}$ between sampling locations with ANOVA ${ }^{233 / 234} \mathrm{U} p=2.18 \mathrm{E}-05$ and the ANOVA $238 \mathrm{U} p=1.01 \mathrm{E}-$ 03 . The ${ }^{235} U$ with lower activities and detection at only three common locations between 2009 and 2010 yielded ANOVA ${ }^{235} \mathrm{U} p=0.249$ suggesting less variability when the isotope is detected. The significant variability in the concentrations between sampling locations likely reflects differences in soil chemistry as well as differences in rainfall amounts and evaporation rates. 
Waste Isolation Pilot Plant Annual Site Environmental Report for 2010 DOE/WIPP-11-2225

Table 4.7 - 2010 Uranium Concentrations (Bq/L) in Surface Waters Taken near the WIPP Site

\begin{tabular}{|c|c|c|c|c|c|c|c|c|c|c|c|}
\hline Location & & & & & {$[\mathrm{RN}$} & & MDC & 0 & & & MDC \\
\hline & \multicolumn{3}{|c|}{${ }^{233 / 234} U$} & & \multicolumn{3}{|c|}{${ }^{235} \mathrm{U}$} & & \multicolumn{3}{|c|}{${ }^{238} U$} \\
\hline RED & 1.76E-02 & 3.78E-03 & 8.43E-04 & + & $1.01 \mathrm{E}-03$ & 7.91E-04 & $4.29 \mathrm{E}-04$ & + & 1.08E-02 & 2.67E-03 & 7.09E-04 \\
\hline NOY & 2.54E-03 & 1.13E-03 & 8.34E-04 & + & 7.89E-05 & 3.05E-04 & 4.18E-04 & $U$ & 1.79E-03 & 9.47E-04 & 7.00E-04 \\
\hline HIL & 4.40E-03 & 1.68E-03 & 8.92E-04 & + & 9.19E-05 & 3.81E-04 & 4.53E-04 & $U$ & 2.94E-03 & 1.34E-03 & 7.38E-04 \\
\hline TUT & 6.93E-03 & 2.17E-03 & 8.69E-04 & + & 2.63E-04 & 4.50E-04 & 4.25E-04 & $U$ & 5.71E-03 & 1.91E-03 & 7.15E-04 \\
\hline FWT & 2.97E-02 & 6.34E-03 & 8.69E-04 & + & 6.98E-04 & 7.01E-04 & 4.30E-04 & $U$ & 1.07E-02 & 2.92E-03 & 6.87E-04 \\
\hline cow & 1.12E-03 & 8.67E-04 & 9.36E-04 & + & 1.40E-04 & 3.97E-04 & 5.13E-04 & $U$ & 5.34E-04 & $6.11 E-04$ & 7.54E-04 \\
\hline PKT & 1.05E-02 & 2.54E-03 & 8.37E-04 & + & 9.31E-05 & 2.98E-04 & 4.22E-04 & $U$ & 7.59E-03 & 2.05E-03 & 7.03E-04 \\
\hline $\begin{array}{l}\text { COY (PKT } \\
\text { Dup) }\end{array}$ & 1.03E-02 & 2.69E-03 & 8.30E-04 & + & 2.08E-04 & 3.96E-04 & 4.13E-04 & $U$ & 7.09E-03 & 2.08E-03 & 6.97E-04 \\
\hline IDN & 3.51E-02 & 7.95E-03 & 9.35E-04 & + & $1.54 \mathrm{E}-03$ & 1.14E-03 & 5.07E-04 & + & 2.78E-02 & 6.55E-03 & 7.81E-04 \\
\hline $\mathrm{PCN}$ & 1.32E-01 & 2.39E-02 & 8.82E-04 & + & 3.89E-03 & 1.69E-03 & 4.41E-04 & + & 6.65E-02 & $1.27 \mathrm{E}-02$ & 7.28E-04 \\
\hline SWL & 1.31E-01 & 2.97E-02 & 1.01E-03 & + & 4.26E-03 & 2.09E-03 & 5.95E-04 & + & 4.56E-02 & 1.12E-02 & 8.52E-04 \\
\hline CBD & 6.66E-02 & 1.26E-02 & 8.80E-04 & + & 2.77E-03 & 1.39E-03 & 4.38E-04 & + & 3.17E-02 & 6.64E-03 & 7.26E-04 \\
\hline BRA & 9.44E-02 & 1.68E-02 & 9.06E-04 & + & 3.14E-03 & 1.54E-03 & $4.75 \mathrm{E}-04$ & + & 4.63E-02 & 8.97E-03 & 7.24E-04 \\
\hline UPR & 1.22E-01 & 2.38E-02 & $9.48 \mathrm{E}-04$ & + & 4.45E-03 & 1.99E-03 & 5.28E-04 & + & 6.27E-02 & 1.30E-02 & 7.66E-04 \\
\hline UPR Dup & 1.22E-01 & $2.18 \mathrm{E}-02$ & 8.88E-04 & + & 3.74E-03 & 1.68E-03 & 4.53E-04 & + & 5.67E-02 & 1.08E-02 & 7.06E-04 \\
\hline LST & 4.47E-03 & 1.61E-03 & 8.77E-04 & + & -2.01E-05 & 1.08E-04 & 4.70E-04 & U & 5.17E-03 & 1.75E-03 & 7.43E-04 \\
\hline BHT & 9.04E-03 & 2.74E-03 & 9.03E-04 & + & 2.72E-04 & 4.90E-04 & 5.03E-04 & $U$ & 7.18E-03 & 2.34E-03 & 7.69E-04 \\
\hline $\begin{array}{l}\text { (a) Radionu } \\
\text { (b) Total Pr } \\
\text { (c) Minimun } \\
\text { (d) Oualifie }\end{array}$ & $\begin{array}{l}\text { de Concen } \\
\text { agated Unc }\end{array}$ & $\begin{array}{l}\text { ation. } \\
\text { rtainty. }\end{array}$ & & & & & & & & & \\
\hline
\end{tabular}

The 2010 uranium isotope surface water concentrations were also compared with the baseline concentrations measured between 1985 and 1989 (DOE/WIPP-92-037).

The highest concentrations detected for ${ }^{233 / 234} U,{ }^{235} U$, and ${ }^{238} U$ in the Pecos River and associated bodies of water, which include locations BRA, CBD, PCN, were within the 99 percent confidence interval ranges of the measured baseline concentrations (baseline levels: ${ }^{233 / 234} \mathrm{U}=3.30 \mathrm{E}-01 \mathrm{~Bq} / \mathrm{L},{ }^{235} \mathrm{U}=1.40 \mathrm{E}-02 \mathrm{~Bq} / \mathrm{L}$, and $\left.{ }^{238} \mathrm{U}=1.10 \mathrm{E}-01 \mathrm{~Bq} / \mathrm{L}\right)$.

Likewise, the highest concentrations of all three uranium isotopes in the surface water samples taken from tanks and tank-like structures (BHT, HIL, PKT, RED, FWT, IDN, LST, NOY, and TUT) were within the 99 percent confidence interval ranges of baseline concentrations (baseline levels: ${ }^{233 / 234} \mathrm{U}=1.00 \mathrm{E}-01 \mathrm{~Bq} / \mathrm{L},{ }^{235} \mathrm{U}=5.20 \mathrm{E}-03 \mathrm{~Bq} / \mathrm{L}$, and $\left.{ }^{238} \mathrm{U}=3.20 \mathrm{E}-02 \mathrm{~Bq} / \mathrm{L}\right)$.

The 2010 uranium isotope surface water concentrations were also compared with the baseline concentrations measured between 1985 and 1989 (DOE/WIPP-92-037). The highest concentrations detected for ${ }^{233 / 234} \mathrm{U},{ }^{235} \mathrm{U}$, and ${ }^{238} \mathrm{U}$ in the Upper Pecos River and associated bodies of water (BRA, CBD, PCN) were within the 99 percent confidence interval ranges of the measured baseline concentrations (baseline levels: $233 / 234 \mathrm{U}=3.30 \mathrm{E}-01 \mathrm{~Bq} / \mathrm{L}, 235 \mathrm{U}=1.40 \mathrm{E}-02 \mathrm{~Bq} / \mathrm{L}$, and $238 \mathrm{U}=1.10 \mathrm{E}-01 \mathrm{~Bq} / \mathrm{L})$. 


\section{Waste Isolation Pilot Plant Annual Site Environmental Report for 2010 DOE/WIPP-11-2225}

The surface water samples were also analyzed for ${ }^{238} \mathrm{Pu},{ }^{239 / 240} \mathrm{Pu}$, and ${ }^{241} \mathrm{Am}$ (Table 4.8). None of these radionuclides were detected in the surface water samples in 2010. Thus, no ANOVA comparisons between years and among locations could be performed.

Table 4.8 - 2010 Americium and Plutonium Concentrations $(\mathrm{Bq} / \mathrm{L})$ in Surface Waters Taken near the WIPP Site

See Appendix C for Sampling Location Codes

\begin{tabular}{|c|c|c|c|c|c|c|c|c|c|c|c|c|}
\hline Location & {$[R N]^{a}$} & $2 \sigma \mathrm{TPU}^{\mathrm{b}}$ & MDC $^{c}$ & $Q^{d}$ & [RN] & $2 \sigma$ TPU & MDC & Q & [RN] & $2 \sigma$ TPU & MDC & Q \\
\hline & \multicolumn{3}{|c|}{${ }^{241} \mathrm{Am}$} & & \multicolumn{3}{|c|}{${ }^{238} \mathrm{Pu}$} & & \multicolumn{3}{|c|}{${ }^{239 / 240} \mathrm{Pu}$} & \\
\hline RED & 3.27E-04 & 4.78E-04 & 4.66E-04 & U & 6.33E-04 & 8.72E-04 & 5.14E-04 & $U$ & 7.60E-05 & 4.31E-04 & 5.18E-04 & $U$ \\
\hline NOY & -1.62E-05 & $3.48 \mathrm{E}-04$ & 5.00E-04 & U & 2.71E-04 & 9.57E-04 & 7.97E-04 & $U$ & $-2.43 \mathrm{E}-04$ & 5.11E-04 & 8.01E-04 & $U$ \\
\hline HIL & 1.67E-04 & 6.67E-04 & 7.39E-04 & $U$ & 4.31E-05 & 3.28E-04 & 3.75E-04 & $\mathrm{U}$ & $-1.29 \mathrm{E}-07$ & 8.02E-06 & 4.31E-04 & $U$ \\
\hline TUT & 8.14E-04 & 8.17E-04 & 6.68E-04 & $U$ & $-2.29 E-04$ & 3.48E-04 & 3.97E-04 & $U$ & $-1.38 E-04$ & 2.70E-04 & 4.53E-04 & $U$ \\
\hline FWT & 1.34E-04 & 7.60E-04 & 7.96E-04 & $U$ & 2.13E-04 & 4.75E-04 & 3.44E-04 & $U$ & $-1.02 E-04$ & 2.16E-04 & 3.82E-04 & $U$ \\
\hline cow & $-6.28 E-05$ & $6.22 \mathrm{E}-04$ & 7.90E-04 & $U$ & $-1.23 E-04$ & 4.88E-04 & 4.25E-04 & U & $-1.82 \mathrm{E}-04$ & 3.22E-04 & 4.62E-04 & $U$ \\
\hline PKT & -3.16E-05 & 3.97E-04 & 5.38E-04 & $U$ & -8.27E-05 & 5.13E-04 & 4.86E-04 & $U$ & -1.11E-05 & 4.66E-04 & 4.90E-04 & $U$ \\
\hline $\begin{array}{l}\text { COY (PKT } \\
\text { Dup) }\end{array}$ & 3.04E-04 & 5.29E-04 & 5.46E-04 & $U$ & -1.19E-04 & 7.83E-04 & 7.27E-04 & U & $-9.32 \mathrm{E}-05$ & 7.66E-04 & 7.31E-04 & $U$ \\
\hline IDN & 3.11E-04 & 5.98E-04 & 6.33E-04 & $U$ & 1.08E-04 & 8.24E-04 & 9.06E-04 & $U$ & $-3.25 E-04$ & 6.38E-04 & 9.62E-04 & U \\
\hline $\mathrm{PCN}$ & $-5.40 E-05$ & 4.44E-04 & 6.17E-04 & U & -3.96E-05 & 1.34E-04 & $3.46 \mathrm{E}-04$ & $U$ & $-7.92 \mathrm{E}-05$ & 1.90E-04 & 4.02E-04 & U \\
\hline SWL & $-5.05 E-05$ & 1.72E-04 & $6.29 E-04$ & U & $0.00 \mathrm{E}+00$ & 5.32E-04 & 5.44E-04 & $U$ & 4.47E-04 & 7.21E-04 & 6.00E-04 & $U$ \\
\hline CBD & 7.16E-04 & 7.71E-04 & 6.17E-04 & $U$ & $-2.50 \mathrm{E}-04$ & 4.91E-04 & 7.02E-04 & $U$ & $-3.33 E-04$ & 5.66E-04 & 7.58E-04 & U \\
\hline BRA & $-2.09 E-04$ & 4.04E-04 & 7.72E-04 & U & 1.34E-05 & 6.38E-04 & 3.87E-04 & U & $1.92 \mathrm{E}-04$ & 5.61E-04 & 4.25E-04 & U \\
\hline UPR & 7.51E-05 & 6.98E-04 & 7.32E-04 & $U$ & 2.53E-04 & 5.53E-04 & 3.99E-04 & $U$ & 8.75E-05 & 3.17E-04 & 4.36E-04 & U \\
\hline UPR Dup & $2.60 \mathrm{E}-04$ & $6.21 E-04$ & 6.37E-04 & $U$ & $-6.49 E-05$ & 4.02E-04 & $3.76 \mathrm{E}-04$ & $U$ & $6.49 \mathrm{E}-05$ & 3.12E-04 & 4.13E-04 & $U$ \\
\hline LST & 2.30E-04 & 5.63E-04 & 5.44E-04 & U & $-3.65 E-04$ & 5.48E-04 & $6.19 \mathrm{E}-04$ & $U$ & $-2.07 E-04$ & 4.13E-04 & $6.24 \mathrm{E}-04$ & U \\
\hline BHT & 1.21E-04 & 4.66E-04 & 5.36E-04 & U & 1.09E-04 & 4.77E-04 & 4.07E-04 & $\mathrm{U}$ & $2.90 \mathrm{E}-04$ & $5.25 \mathrm{E}-04$ & 4.11E-04 & $U$ \\
\hline
\end{tabular}

(a) Radionuclide Concentration.

(b) Total Propagated Uncertainty.

(c) Minimum Detectable Concentration.

(d) Qualifier. Indicated whether radionuclide was detected. Plus (+) equals detected. U equals undetected.

As shown in Table $4.9,{ }^{40} \mathrm{~K}$ was detected in only one of the surface water samples, SWL. SWL was also the only location where ${ }^{40} \mathrm{~K}$ was detected in 2009 . Thus there were not enough data to perform ANOVA comparisons. 


\section{Waste Isolation Pilot Plant Annual Site Environmental Report for 2010 DOE/WIPP-11-2225}

Table 4.9 - 2010 Gamma Radionuclides and ${ }^{90}$ Sr Concentrations (Bq/L) in Surface Waters Taken near the
WIPP Site

See Appendix C for Sampling Location Codes

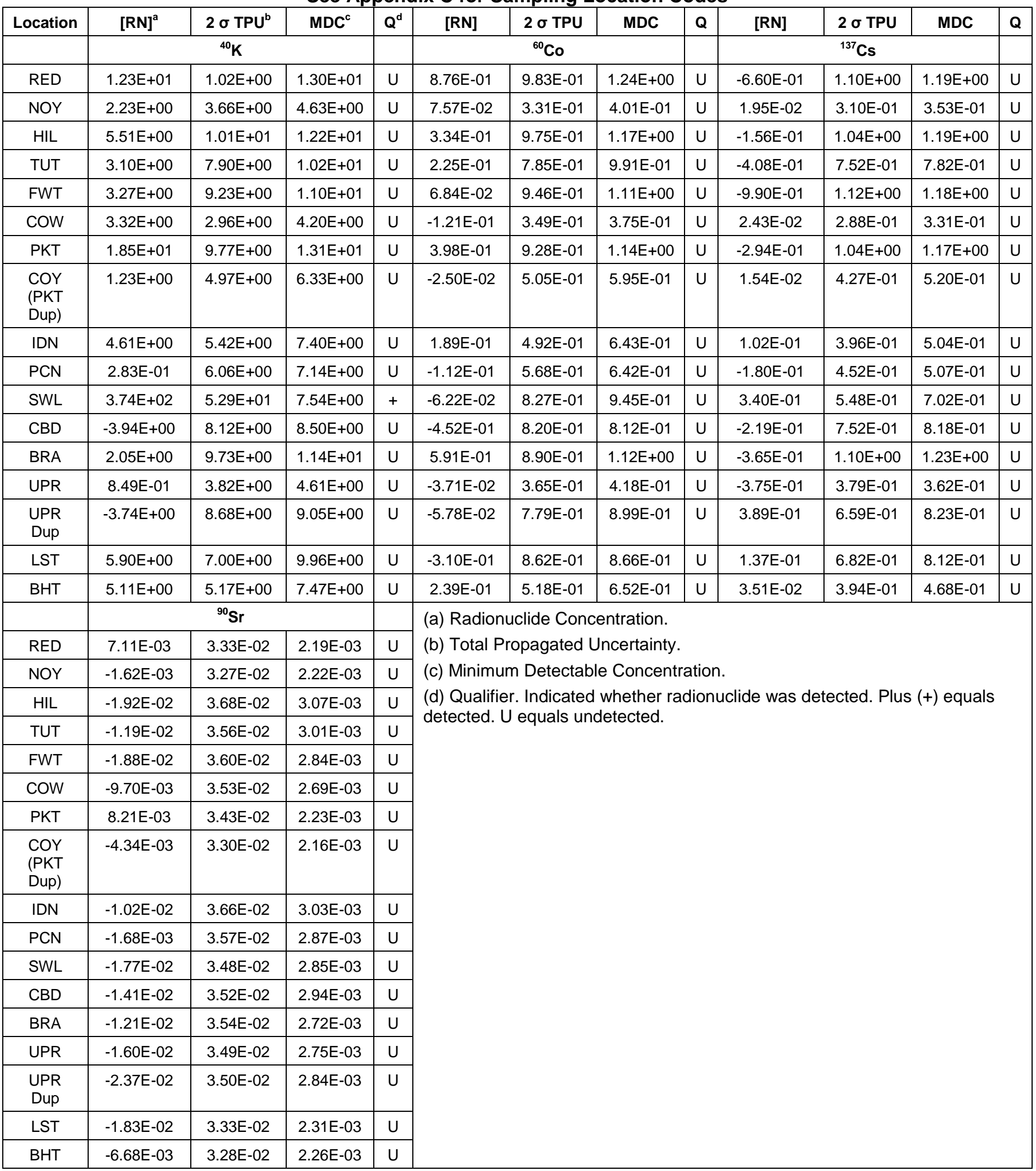


Comparison of the detected ${ }^{40} \mathrm{~K}(3.47 \mathrm{E}+02 \mathrm{~Bq} / \mathrm{L})$ in the SWL sample with the baseline data (baseline value: $7.60 \mathrm{E}+01 \mathrm{~Bq} / \mathrm{L}$ ) shows that, like in 2009 , the concentration was higher than the 99 percent confidence interval range of the baseline concentration (DOE/WIPP-92-037). Since ${ }^{40} \mathrm{~K}$ was not detected in any other surface water sample, sewage is the likely source of the ${ }^{40} \mathrm{~K}$. Sewage contains significant potassium from human excretions and $40 \mathrm{~K}$ makes up 0.012 percent of all naturally occurring potassium.

Cesium-137, ${ }^{60} \mathrm{Co}$, and ${ }^{90} \mathrm{Sr}$, were not detected in any of the surface water samples (Table 4.9). Since these isotopes were not detected, no ANOVA comparisons between years or among locations were performed.

The reproducibility of the sampling and analysis procedures was assessed by collecting and analyzing duplicate samples from two locations (PKT, UPR). The PKT duplicate was blind to the laboratory and labeled "COY." The RERs were calculated for the isotopes with measurable concentrations of the target radionuclides in both the primary and duplicate samples. The RERs for the analysis results are presented in Table 4.10.

The RERs for ${ }^{233 / 234} U$ and ${ }^{238} U$ were $<1$ in the PKT duplicates. The RERs for ${ }^{233 / 234} U$, ${ }^{235} \mathrm{U}$, and ${ }^{238} \mathrm{U}$ were all $<1$ for the UPR duplicates. The analysis data demonstrate good reproducibility for the combined sampling and analysis procedures.

Table 4.10 - Results of 2010 Duplicate Surface Water Sampling and Analysis; Units are in $\mathrm{Bq} / \mathrm{g}$

See Chapter 6 for Sampling Locations

\begin{tabular}{|c|c|c|c|c|c|c|c|c|}
\hline \multirow[t]{2}{*}{ Location } & & \multicolumn{3}{|c|}{ Sample } & \multicolumn{4}{|c|}{ Duplicate } \\
\hline & & {$[R N]^{a}$} & $2 \sigma \mathrm{TPU}^{\mathrm{b}}$ & MDC $^{c}$ & {$[\mathrm{RN}]$} & $2 \sigma \mathrm{TPU}$ & MDC & RER $^{d}$ \\
\hline PKT & ${ }^{233 / 234} U$ & 1.05E-02 & $2.54 \mathrm{E}-03$ & 8.37E-04 & 1.03E-02 & $2.69 \mathrm{E}-03$ & 8.30E-04 & 0.321 \\
\hline $\begin{array}{l}\text { Dup labeled } \\
\text { "COY" }\end{array}$ & ${ }^{238} \mathrm{U}$ & 7.59E-03 & $2.05 \mathrm{E}-03$ & 7.03E-04 & $7.09 \mathrm{E}-03$ & 2.08E-03 & $6.97 \mathrm{E}-04$ & 0.169 \\
\hline UPR & ${ }^{233 / 234} U$ & 1.22E-01 & $2.38 \mathrm{E}-02$ & $9.48 \mathrm{E}-04$ & $1.22 \mathrm{E}-01$ & 2.18E-02 & 8.88E-04 & 0.013 \\
\hline \multirow[t]{2}{*}{ UPR Dup } & ${ }^{235} U$ & 4.45E-03 & $1.99 \mathrm{E}-03$ & $5.28 \mathrm{E}-04$ & $3.74 \mathrm{E}-03$ & $1.68 \mathrm{E}-03$ & 4.53E-04 & 0.174 \\
\hline & ${ }^{238} U$ & $6.27 \mathrm{E}-02$ & 1.30E-02 & 7.66E-04 & 5.67E-02 & $1.08 \mathrm{E}-02$ & 7.06E-04 & 0.357 \\
\hline \multicolumn{9}{|c|}{$\begin{array}{l}\text { (a) Radionuclide Concentration. } \\
\text { (b) Total Propagated Uncertainty. } \\
\text { (c) Minimum Detectable Concentration. } \\
\text { (d) Relative Error Ratio. }\end{array}$} \\
\hline
\end{tabular}

\subsection{Sediments}

\subsubsection{Sample Collection}

Sediment samples were collected from 12 locations around the WIPP site, with duplicate samples collected from two sites (14 samples total). The sites included all the same sites as for surface water except for FWT, SWL, and the COW blank (see Figure 4.3; see Appendix C for location codes). The samples were collected in 1-L plastic containers from the top $15 \mathrm{~cm}$ ( 6 in.) of the sediments of the water bodies and transferred to WIPP Laboratories for determination of individual radionuclides. 


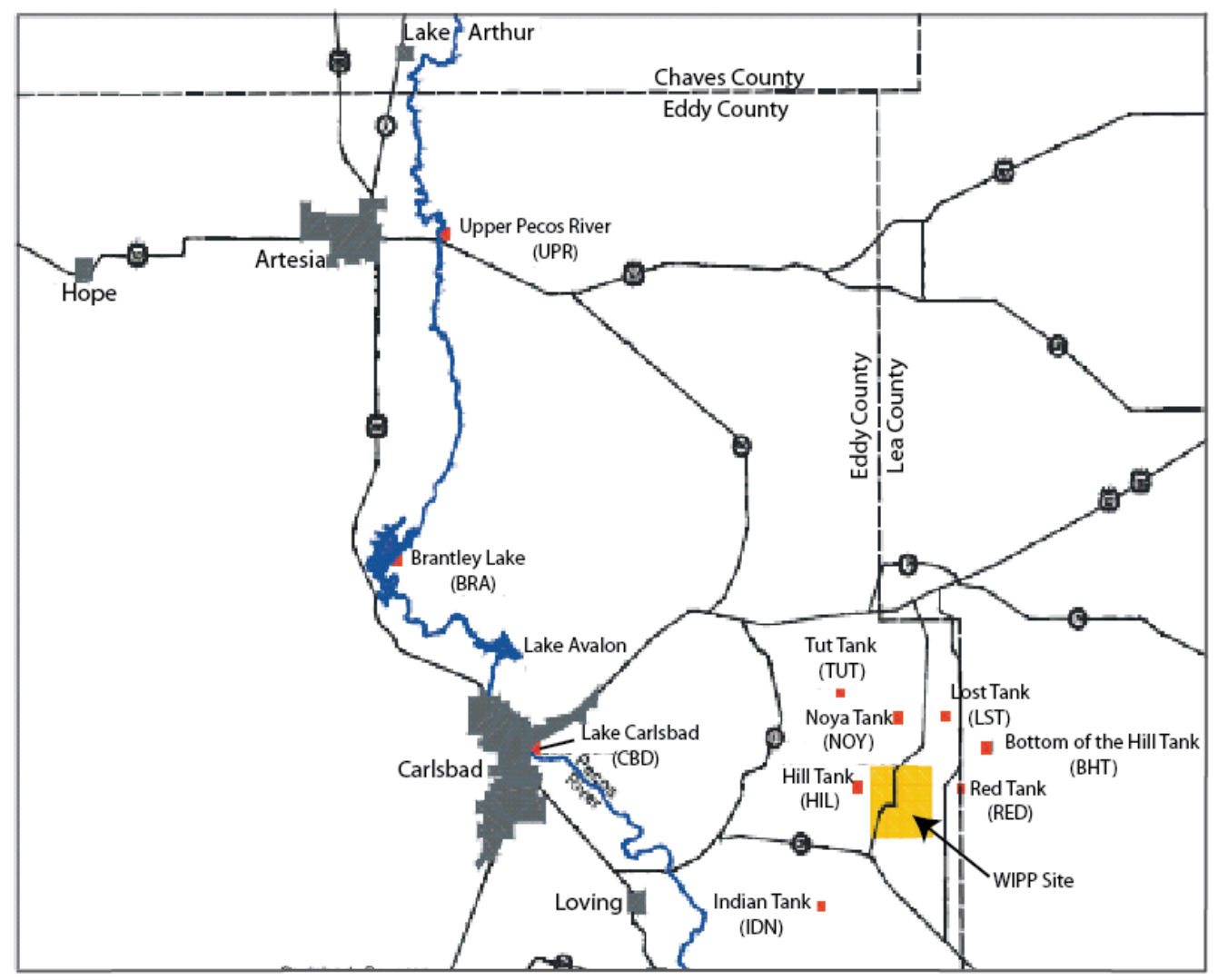

Figure 4.3 - Sediment Sampling Sites

\subsubsection{Sample Preparation}

Sediment samples were dried at $110^{\circ} \mathrm{C}\left(230^{\circ} \mathrm{F}\right)$ for several hours and homogenized by grinding into smaller particle sizes. A 2-gram aliquot of each of the dried and homogenized sediment samples was dissolved by heating with a mixture of nitric, hydrochloric, and hydrofluoric acids. The sample residues were heated with nitric and boric acids to remove hydrofluoric acid. Finally, the residues were dissolved in hydrochloric acid in preparation for separation of the radionuclides.

\subsubsection{Determination of Individual Radionuclides}

The hydrochloric acid digestates of the sediment samples were split into two fractions. One acid fraction was analyzed by gamma spectroscopy for ${ }^{40} \mathrm{~K},{ }^{60} \mathrm{Co}$, and ${ }^{137} \mathrm{Cs}$. The other fraction was analyzed sequentially for the uranium/transuranic radioisotopes and ${ }^{90} \mathrm{Sr}$ by employing a series of chemical, physical, and ion exchange separations followed by mounting the sample residues on a planchet for counting. The uranium/transuranic isotopes were measured by alpha spectroscopy and the ${ }^{90} \mathrm{Sr}$ by gas proportional counting.

\subsubsection{Results and Discussion}

Uranium-233/234 and ${ }^{238} \mathrm{U}$ were detected in all the sediment samples. Uranium-235 was detected in 9 of the 14 samples. It was not detected in TUT, CBD, BRA, and the UPR duplicates as shown in Table 4.11. 
Table 4.11 - 2010 Uranium Concentrations (Bq/g) in Sediment Samples Taken near the WIPP Site

\begin{tabular}{|c|c|c|c|c|c|c|c|c|c|c|c|c|}
\hline \multirow[t]{2}{*}{ Location } & {$[\mathrm{RN}]^{\mathrm{a}}$} & $2 \sigma \mathrm{TPU}^{\mathrm{b}}$ & $\mathrm{MDC}^{\mathrm{C}}$ & \multirow[t]{2}{*}{$Q^{d}$} & [RN] & $2 \times$ TPU & MDC & \multirow[t]{2}{*}{ Q } & [RN] & $2 \sigma$ TPU & MDC & \multirow[t]{2}{*}{ Q } \\
\hline & \multicolumn{3}{|c|}{${ }^{233 / 234} U$} & & \multicolumn{3}{|c|}{${ }^{235} U$} & & \multicolumn{3}{|c|}{${ }^{238} U$} & \\
\hline NOY & 2.20E-02 & 4.12E-03 & 6.28E-04 & + & $1.25 \mathrm{E}-03$ & 5.01E-04 & 1.19E-04 & + & 2.24E-02 & 4.19E-03 & 4.67E-04 & + \\
\hline HIL & 2.00E-02 & 3.12E-03 & 6.02E-04 & + & 6.83E-04 & 3.02E-04 & 8.66E-05 & + & 1.92E-02 & 3.01E-03 & 4.41E-04 & + \\
\hline PKT & 2.61E-02 & 5.19E-03 & 6.31E-04 & + & $1.20 \mathrm{E}-03$ & $5.05 \mathrm{E}-04$ & 1.23E-04 & + & 3.04E-02 & 5.97E-03 & 4.70E-04 & + \\
\hline PKT Dup & 2.82E-02 & 5.41E-03 & 6.26E-04 & + & 1.38E-03 & 5.32E-04 & 1.16E-04 & + & 2.84E-02 & 5.44E-03 & 4.65E-04 & + \\
\hline IDN & 6.95E-03 & 1.43E-03 & 5.74E-04 & + & 3.41E-04 & $2.80 \mathrm{E}-04$ & 1.23E-04 & + & 7.38E-03 & 1.50E-03 & 4.92E-04 & + \\
\hline $\mathrm{PCN}$ & 2.08E-02 & 3.70E-03 & 5.75E-04 & + & 5.83E-04 & $3.26 \mathrm{E}-04$ & $1.25 \mathrm{E}-04$ & + & $1.20 \mathrm{E}-02$ & 2.27E-03 & 4.94E-04 & + \\
\hline UPR Dup & 5.00E-03 & 1.00E-03 & 6.16E-04 & + & 1.58E-04 & $1.59 E-04$ & 1.13E-04 & $U$ & 4.70E-03 & 9.59E-04 & 4.60E-04 & + \\
\hline LST & 2.17E-02 & 4.03E-03 & $6.24 \mathrm{E}-04$ & + & 7.54E-04 & 3.68E-04 & 1.14E-04 & + & 2.23E-02 & 4.12E-03 & 4.63E-04 & + \\
\hline $\mathrm{BHT}$ & 2.30E-02 & 3.77E-03 & 6.19E-04 & + & 7.81E-04 & 3.62E-04 & 1.07E-04 & + & 2.19E-02 & 3.60E-03 & 4.58E-04 & + \\
\hline $\begin{array}{l}\text { (a) Radio } \\
\text { (b) Total } \\
\text { (c) Minim } \\
\text { (d) Qualif }\end{array}$ & $\begin{array}{l}\text { huclide Cor } \\
\text { Propagated } \\
\text { um Detecta }\end{array}$ & $\begin{array}{l}\text { centration. } \\
\text { Uncertaint } \\
\text { ble Concer }\end{array}$ & ration. & & & & & & & & & \\
\hline
\end{tabular}

The concentrations of the uranium isotopes were compared between 2009 and 2010 and also between sampling locations using ANOVA. Average concentrations were used for BRA and IDN in 2009 and for PKT and UPR in 2010. There were 12 common locations for ${ }^{233 / 234} U$ and ${ }^{238} U$ with detections in both 2009 and 2010 , and seven common locations where ${ }^{235} \mathrm{U}$ was detected in 2009 and 2010 including RED, HIL, PKT, IDN, PCN, LST, and BHT.

The ANOVA calculations showed that the concentrations of ${ }^{233 / 234} \mathrm{U},{ }^{235} \mathrm{U}$, and ${ }^{238} \mathrm{U}$ did not vary significantly between 2009 and 2010 (ANOVA, ${ }^{233 / 234} \mathrm{U} p=0.113$; ANOVA, ${ }^{235} \mathrm{U}$ $p=0.465$; and ANOVA, ${ }^{238} \mathrm{U}=0.139$ ) based on 12 common locations for ${ }^{233 / 234} \mathrm{U}$ and ${ }^{238} \mathrm{U}$ and 7 common locations for ${ }^{235} \mathrm{U}$.

In contrast to last year, the ANOVA calculations also showed that the concentrations of the uranium isotopes did not vary significantly by location (ANOVA, ${ }^{233 / 234} \mathrm{U} p=0.254$; ANOVA, ${ }^{235} \cup p=0.383$; and ANOVA, ${ }^{238} \cup p=0.369$ ).

The uranium isotope composition of the sediments may not have been impacted as much as in recent years due to less rainfall to wash away and deposit sediments.

Concentrations of all three uranium isotopes fell within the 99 percent confidence interval ranges of the baseline data $\left({ }^{233 / 234} \mathrm{U}: 1.10 \mathrm{E}-01 \mathrm{~Bq} / \mathrm{g} ;{ }^{235} \mathrm{U}: 3.20 \mathrm{E}-03 \mathrm{~Bq} / \mathrm{g} ;{ }^{238} \mathrm{U}\right.$ : 5.00E-02 Bq/g). 
Sediment samples were also analyzed for ${ }^{241} \mathrm{Am},{ }^{238} \mathrm{Pu}$, and ${ }^{239 / 240} \mathrm{Pu}$ by alpha spectroscopy, with the results reported in Table 4.12. Am-241 was not detected in any of the samples; ${ }^{238} \mathrm{Pu}$ was detected in one sample, $\mathrm{HIL}$, and ${ }^{239 / 240} \mathrm{Pu}$ was detected in three samples, HIL, the PKT dups, and BHT compared to four detects for ${ }^{239 / 240} \mathrm{Pu}$ in 2009 including HIL, PKT, LST, and BHT. ANOVA calculations for the three common detections at HIL, PKT, and BHT using the average PKT concentration for the duplicate samples in 2010 showed that the concentrations did not vary significantly between the two years, ANOVA, ${ }^{239 / 240} \mathrm{Pu} p=0.503$. In addition the concentrations did not vary significantly by location, ANOVA, ${ }^{239 / 240} \mathrm{Pu} p=0.120$. The concentration of ${ }^{238} \mathrm{Pu}$ fell within the 99 percent confidence interval range of $2.90 \mathrm{E}-03 \mathrm{~Bq} / \mathrm{g}$ for sediments.

The concentrations of ${ }^{239 / 240} \mathrm{Pu}$ in the three sediments also fell within the 99 percent confidence interval range of $1.90 \mathrm{E}-03 \mathrm{~Bq} / \mathrm{g}$. All detected concentrations of ${ }^{40} \mathrm{~K}$ observed in the sediment samples associated with the tanks and tank-like structures (these include BHT, HIL, RED, IDN, LST, NOY, and TUT) were within the 99 percent confidence interval range of baseline concentrations (baseline concentration: $1.20 \mathrm{E}+00$ $\mathrm{Bq} / \mathrm{g})$.

The ANOVA calculations showed that the concentrations did not vary significantly from year to year (ANOVA, ${ }^{40} \mathrm{~K}, \mathrm{p}=0.315$ ). However, the ${ }^{40} \mathrm{~K}$ concentrations varied significantly by location (ANOVA, ${ }^{40} \mathrm{~K}, \mathrm{p}=0.0316$ ). The reason for the significant variation by location is likely due to the variable ${ }^{40} \mathrm{~K}$ concentrations in the source soils deposited as sediment.

The sediment locations associated with the Pecos River and associated bodies of water (these include PCN, CBD, BRA, and UPR) have a baseline concentration of 4.00E-01 $\mathrm{Bq} / \mathrm{g}$. The $2010^{40} \mathrm{~K}$ concentrations at both BRA and BHT exceeded the baseline concentration for sediments with concentrations of 5.06E-01 Bq/g and $6.98 \mathrm{E}-01 \mathrm{~Bq} / \mathrm{g}$, respectively. Potassium is ubiquitous throughout the earth's crust with variable concentrations in the rocks, soil, and water, and therefore would be expected to be present at variable concentrations in the sediment samples. 


\section{Waste Isolation Pilot Plant Annual Site Environmental Report for 2010 DOE/WIPP-11-2225}

Table 4.12 - 2010 Americium and Plutonium Concentrations (Bq/g) in Sediment Samples Taken near the WIPP Site

See Appendix C for Sampling Location Codes

\begin{tabular}{|c|c|c|c|c|c|c|c|c|c|c|c|c|}
\hline Location & {$[R N]^{a}$} & $2 \sigma \mathrm{TPU}^{\mathrm{b}}$ & $M^{\prime} C^{c}$ & \multirow[t]{2}{*}{$Q^{d}$} & [RN] & $2 \times$ TPU & MDC & \multirow[t]{2}{*}{$\mathbf{Q}$} & [RN] & $2 \sigma$ TPU & MDC & \multirow[t]{2}{*}{ Q } \\
\hline & \multicolumn{3}{|c|}{${ }^{241} \mathrm{Am}$} & & \multicolumn{3}{|c|}{${ }^{238} \mathrm{Pu}$} & & \multicolumn{3}{|c|}{${ }^{239 / 240} \mathrm{Pu}$} & \\
\hline RED & 1.43E-04 & 2.12E-04 & 3.43E-04 & $U$ & 1.26E-04 & 1.29E-04 & 8.19E-05 & $U$ & $1.28 \mathrm{E}-04$ & $1.28 \mathrm{E}-04$ & $1.44 \mathrm{E}-04$ & U \\
\hline NOY & 7.78E-05 & 1.86E-04 & 3.37E-04 & $U$ & -1.06E-05 & 8.69E-05 & 1.11E-04 & $U$ & 1.34E-05 & 6.98E-05 & 1.35E-04 & U \\
\hline HIL & 1.92E-04 & 2.25E-04 & 3.27E-04 & $U$ & 1.71E-04 & 1.69E-04 & 8.88E-05 & + & 5.29E-04 & 2.46E-04 & 1.50E-04 & + \\
\hline TUT & $0.00 \mathrm{E}+00$ & 1.34E-04 & 3.36E-04 & $U$ & $-9.58 E-06$ & 3.25E-05 & 9.69E-05 & $U$ & 3.83E-05 & 9.20E-05 & 1.58E-04 & $U$ \\
\hline PKT & $2.76 \mathrm{E}-04$ & 2.94E-04 & 3.51E-04 & $U$ & 1.07E-04 & 1.34E-04 & 8.92E-05 & $U$ & 7.12E-04 & 2.88E-04 & 1.51E-04 & + \\
\hline PKT Dup & 3.29E-04 & 2.94E-04 & 3.46E-04 & $U$ & 1.30E-04 & $1.58 \mathrm{E}-04$ & 9.38E-05 & $U$ & 5.40E-04 & 2.67E-04 & $1.55 \mathrm{E}-04$ & + \\
\hline IDN & 2.30E-04 & 2.79E-04 & 3.61E-04 & $U$ & 3.09E-05 & 6.05E-05 & 1.03E-04 & $U$ & 3.09E-05 & 1.05E-04 & 1.64E-04 & U \\
\hline $\mathrm{PCN}$ & 1.24E-06 & 1.03E-04 & 3.06E-04 & U & 1.86E-05 & 6.32E-05 & 9.47E-05 & $U$ & 8.37E-05 & $1.22 \mathrm{E}-04$ & 1.56E-04 & $U$ \\
\hline CBD & 7.98E-05 & 1.60E-04 & 3.14E-04 & U & 1.91E-05 & 6.49E-05 & 9.67E-05 & $U$ & 2.87E-05 & 5.62E-05 & 1.58E-04 & U \\
\hline BRA & 9.75E-05 & 1.87E-04 & 3.34E-04 & $U$ & $-9.69 E-06$ & 3.29E-05 & $9.78 \mathrm{E}-05$ & $U$ & $-9.68 E-06$ & 8.70E-05 & $1.59 \mathrm{E}-04$ & U \\
\hline UPR & 6.00E-05 & 2.04E-04 & 3.67E-04 & $U$ & $-1.03 E-05$ & 3.51E-05 & 1.03E-04 & $U$ & 3.10E-05 & 1.05E-04 & 1.65E-04 & U \\
\hline UPR Dup & $-8.60 E-06$ & 1.85E-04 & 3.79E-04 & $U$ & 2.14E-05 & 7.25E-05 & 1.06E-04 & $U$ & 7.47E-05 & 1.20E-04 & 1.67E-04 & U \\
\hline LST & 2.60E-04 & 2.75E-04 & 3.42E-04 & U & 2.73E-05 & 1.87E-04 & 1.72E-04 & $U$ & $2.52 \mathrm{E}-04$ & 2.67E-04 & $1.95 \mathrm{E}-04$ & $U$ \\
\hline BHT & 2.94E-04 & 2.66E-04 & 3.33E-04 & U & 1.38E-04 & 1.54E-04 & 8.59E-05 & $U$ & 2.76E-04 & 1.76E-04 & 1.47E-04 & + \\
\hline $\begin{array}{l}\text { (a) Radio } \\
\text { (b) Total } \\
\text { (c) Minim }\end{array}$ & $\begin{array}{l}\text { nuclide Co } \\
\text { Propagatec } \\
\text { um Detectá }\end{array}$ & $\begin{array}{l}\text { centration. } \\
\text { Uncertaint } \\
\text { ole Concen }\end{array}$ & ration. & & 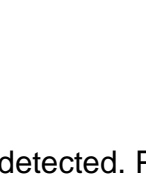 & 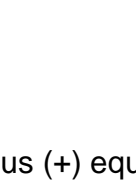 & & & 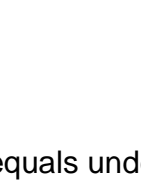 & 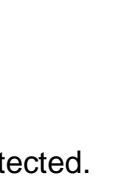 & & \\
\hline
\end{tabular}

Cesium-137 was detected in 8 of the 12 locations including the duplicate samples from PKT as shown by the data in Table 4.13. The radionuclide was not detected at the four locations PCN, CBD, BRA, or the UPR duplicate samples.

In comparing the 2009 data with the 2010 data, ${ }^{137} \mathrm{Cs}$ was detected in six common locations including RED, HIL, PKT, IDN, LST, and BHT, all which are tanks and tanklike structures.

There was no significant difference in the concentrations between 2009 and 2010 (ANOVA, $p=0.659$ ). There was more variability in the concentrations by location with the ANOVA, ${ }^{137} \mathrm{Cs} p=0.048$, just below the 0.05 significance factor.

All the measured ${ }^{137} \mathrm{Cs}$ concentrations in the sediments associated with tanks and tanklike structures (the tank and tank-like structures include BHT, HIL, TUT, PKT, RED, FWT, IDN, LST, and NOY) were within the 99 percent confidence interval range of the baseline concentration ( $3.50 \mathrm{E}-02 \mathrm{~Bq} / \mathrm{g})$. Cesium-137 is a fission product and is quite ubiquitous in sediment and soil because of global fallout from atmospheric nuclear weapons testing (Beck and Bennett, 2002; and UNSCEAR [United Nations Scientific Committee on the Effects of Atomic Radiation], 2000). 


\section{Waste Isolation Pilot Plant Annual Site Environmental Report for 2010 DOE/WIPP-11-2225}

Table 4.13 - 2010 Gamma Radionuclides and ${ }^{90}$ Sr Concentrations (Bq/g) in Sediment Samples Taken near the WIPP Site

See Appendix C for Sampling Location Codes

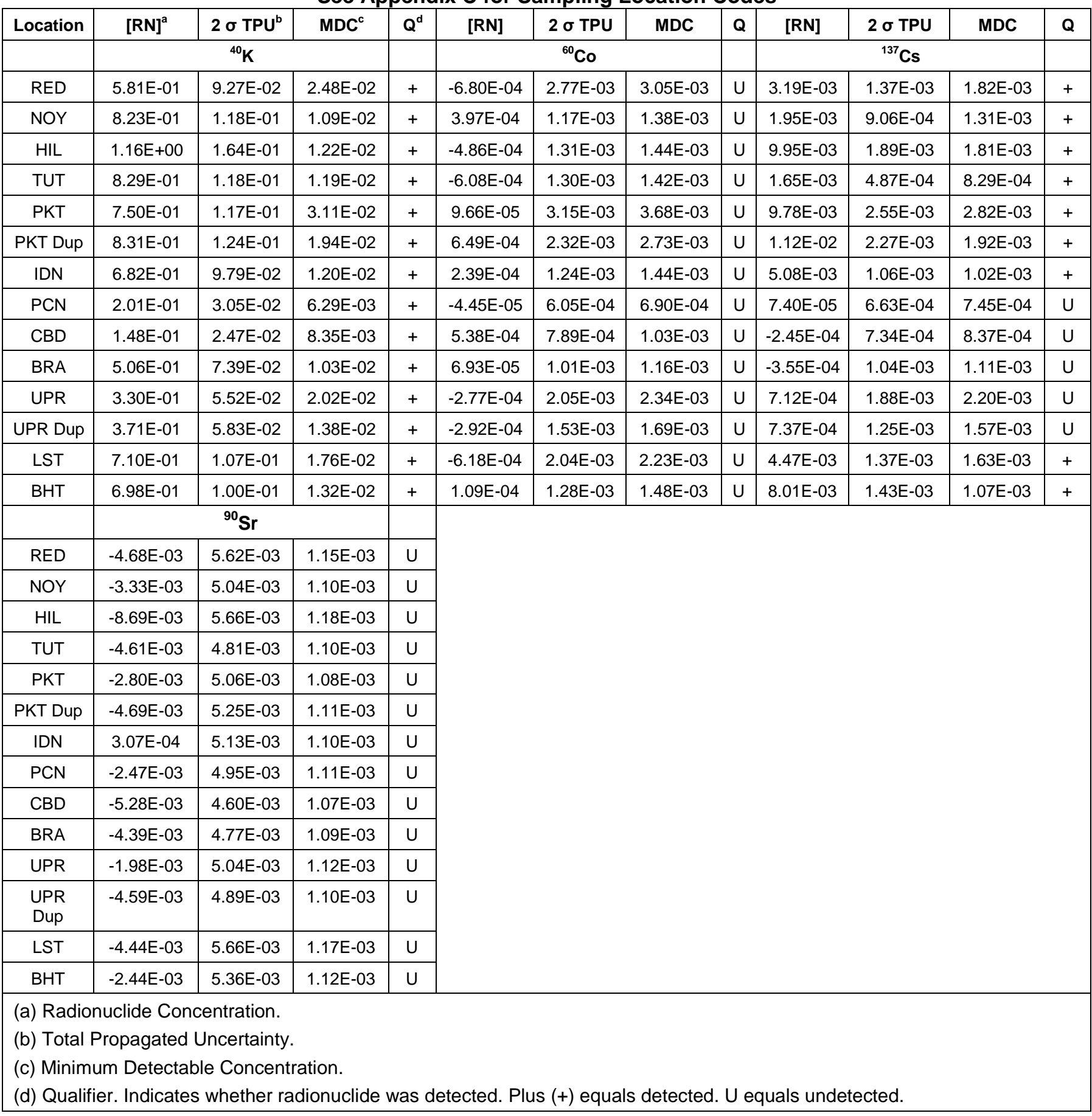

Strontium-90 and ${ }^{60} \mathrm{Co}$ were not detected in any of the sediment samples as shown in Table 4.13. Thus, no ANOVA among sampling locations or between years could be calculated.

Duplicate analyses were performed for all the target radionuclides in sediment samples from sampling locations PKT and UPR. Precision calculations were able to be performed for the uranium isotopes, ${ }^{40} \mathrm{~K}$, and ${ }^{137} \mathrm{Cs}$, as shown in Table 4.14. Relative 


\section{Waste Isolation Pilot Plant Annual Site Environmental Report for 2010 DOE/WIPP-11-2225}

error ratios are reported for the isotopes with measurable concentrations in both the primary and the duplicate samples.

The precision quality objective was met for the sediment samples. The RERs were $<1.0$ for all the uranium isotopes detected in the primary and duplicate samples in the PKT samples, indicating good precision for the combined sampling and alpha spectroscopy analysis procedures. The RERs were also $<1$ for ${ }^{239 / 240} \mathrm{Pu},{ }^{40} \mathrm{~K}$, and ${ }^{137} \mathrm{Cs}$ detected in PKT primary and duplicate samples.

The only radioisotopes detected in the duplicate Upper Pecos River (UPR) samples were ${ }^{233 / 234} U,{ }^{238} U$, and ${ }^{40} \mathrm{~K}$. The RER was $<1$ for ${ }^{233 / 234} \mathrm{U}$ and ${ }^{40} \mathrm{~K}$, and $>1$ but $<1.96$ for ${ }^{238} \mathrm{U}$ with a RER of 1.287 .

Table 4.14 - Results of 2010 Duplicate Sediment Sampling and Analysis, Units are in Bq/g.

See Chapter 6 for Sampling Locations

\begin{tabular}{|c|c|c|c|c|c|c|c|c|}
\hline \multirow[t]{2}{*}{ Location } & & \multirow[b]{2}{*}[\mathrm{RN}]{$^{\mathrm{a}}$} & \multirow{2}{*}{$\frac{\text { Sample }}{2 \sigma \mathrm{TPU}^{\mathrm{b}}}$} & \multirow[b]{2}{*}{$M C^{c}$} & \multicolumn{4}{|c|}{ Duplicate } \\
\hline & & & & & [RN] & $2 \sigma$ TPU & MDC & RER $^{d}$ \\
\hline \multirow[t]{6}{*}{ PKT } & ${ }^{233 / 234} U$ & 2.61E-02 & 5.19E-03 & 6.31E-04 & 2.82E-02 & 5.41E-03 & 6.26E-04 & 0.276 \\
\hline & ${ }^{235} U$ & $1.20 \mathrm{E}-03$ & 5.05E-04 & $1.23 \mathrm{E}-04$ & $1.38 \mathrm{E}-03$ & 5.32E-04 & 1.16E-04 & 0.244 \\
\hline & ${ }^{238} \mathrm{U}$ & 3.04E-02 & 5.97E-03 & 4.70E-04 & 2.84E-02 & 5.44E-03 & 4.65E-04 & 0.245 \\
\hline & ${ }^{239 / 240} \mathrm{Pu}$ & 7.12E-04 & 2.88E-04 & 1.51E-04 & $5.40 \mathrm{E}-04$ & 2.67E-04 & 1.55E-04 & 0.475 \\
\hline & ${ }^{40} \mathrm{~K}$ & 7.50E-01 & 1.17E-01 & 3.11E-02 & 8.31E-01 & 1.24E-01 & 1.94E-02 & 0.437 \\
\hline & ${ }^{137} \mathrm{Cs}$ & $9.78 \mathrm{E}-03$ & $2.55 \mathrm{E}-03$ & 2.82E-03 & 1.12E-02 & 2.27E-03 & 1.92E-03 & 0.416 \\
\hline \multirow[t]{3}{*}{ UPR } & ${ }^{233 / 234} U$ & 4.10E-03 & 9.82E-04 & 5.73E-04 & 5.00E-03 & 1.00E-03 & $6.16 \mathrm{E}-04$ & 0.638 \\
\hline & ${ }^{238} \mathrm{U}$ & 3.10E-03 & 7.95E-04 & 4.92E-04 & 4.70E-03 & 9.59E-04 & 4.60E-04 & 1.287 \\
\hline & ${ }^{40} \mathrm{~K}$ & 3.30E-01 & 5.52E-02 & 2.02E-02 & 3.71E-01 & 5.83E-02 & 1.38E-02 & 0.511 \\
\hline
\end{tabular}

(a) Radionuclide Concentration.

(b) Total Propagated Uncertainty.

(c) Minimum Detectable Concentration.

(d) Relative Error Ratio.

\subsection{Soil Samples}

\subsubsection{Sample Collection}

Soil samples were collected from six of the locations where the low-volume air samplers are stationed around the WIPP site: MLR, SEC, SMR, WEE, WFF, and WSS (Figure 4.4). Samples were collected from each location in three incremental profiles: surface soil (0-2 cm [0-0.8 in.]), intermediate soil (2-5 cm [0.8-2 in.]), and deep soil (5-10 cm [2-4 in.]). Measurements of radionuclides in depth profiles may provide information about their vertical movements in the soil systems. 


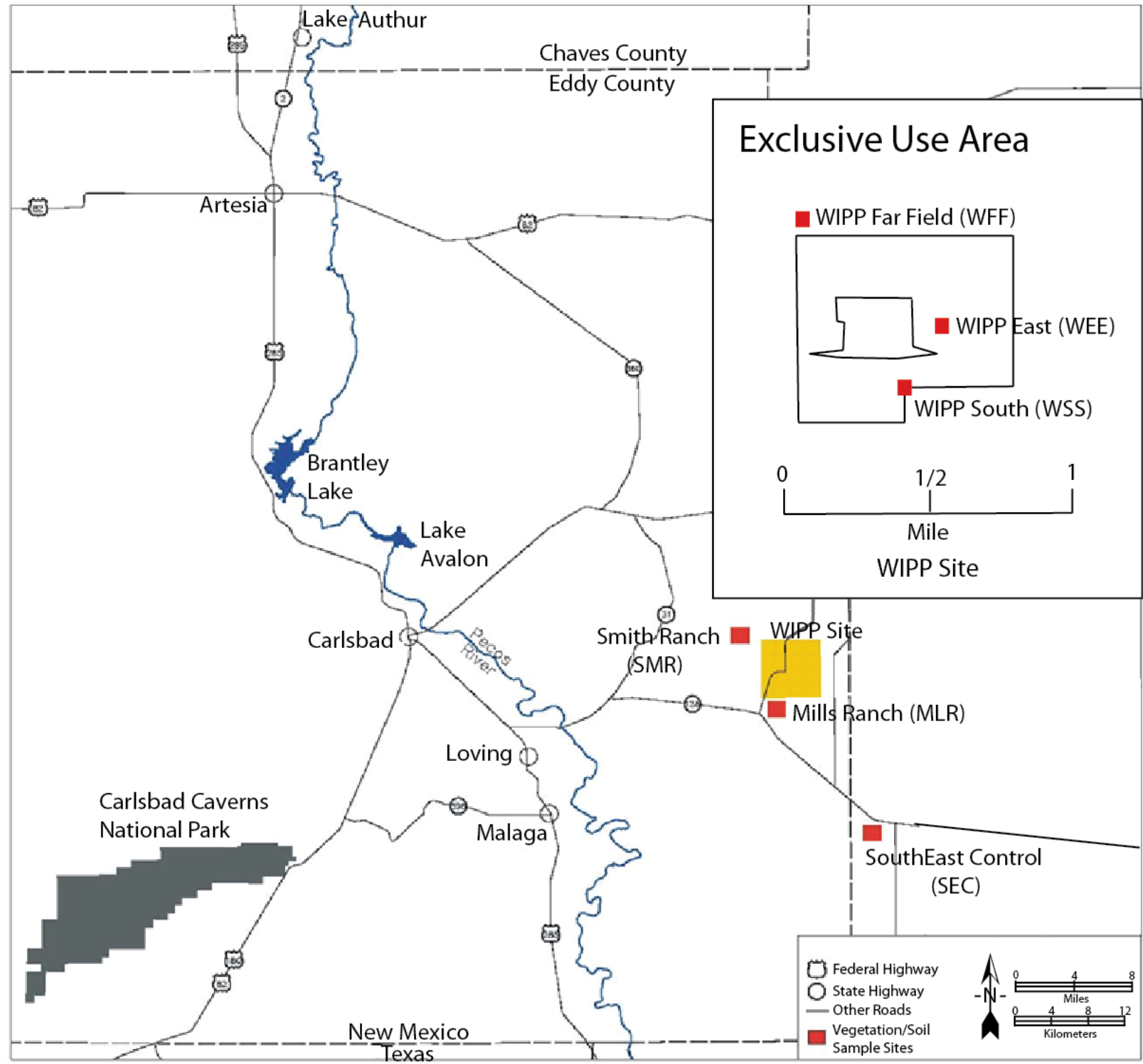

Figure 4.4 - Routine Soil and Vegetation Sampling Areas

\subsubsection{Sample Preparation}

Soil samples were dried at $110^{\circ} \mathrm{C}\left(230^{\circ} \mathrm{F}\right)$ for several hours and homogenized by grinding to small particle sizes. A 2-g aliquot of each of the dried and homogenized soil samples was dissolved by heating with a mixture of nitric, hydrochloric, and hydrofluoric acids. The sample residues were heated with nitric and boric acids to remove hydrofluoric acid. Finally, the residues were dissolved in nitric acid for the measurement of the individual radionuclide concentrations. 


\subsubsection{Determination of Individual Radionuclides}

The nitric acid digestates of the soil samples were split into two fractions. One acid fraction was analyzed by gamma spectroscopy for ${ }^{40} \mathrm{~K},{ }^{60} \mathrm{Co}$, and ${ }^{137} \mathrm{Cs}$. The other fraction was analyzed sequentially for the uranium/transuranic radioisotopes and ${ }^{90} \mathrm{Sr}$ by employing a series of chemical, physical, and ion exchange separations followed by mounting the sample residues on a planchet for counting. The uranium/transuranic isotopes were measured by alpha spectroscopy and the ${ }^{90} \mathrm{Sr}$ by gas proportional counting.

\subsubsection{Results and Discussion}

The ${ }^{233 / 234} \mathrm{U}$ and ${ }^{238} \mathrm{U}$ isotopes were detected in all soil samples, and ${ }^{235} \mathrm{U}$ was detected in over half of the samples as shown in Table 4.15. Uranium-235 was not detected in any of the SEC samples, which were collected and analyzed in duplicate. Uranium-235 was detected in the shallow sample at SMR but not in the intermediate and deep samples.

In comparing the 2009 and 2010 uranium data, the average of the primary and duplicate samples was used for those sample locations where duplicate samples were taken and the uranium isotopes were detected. The general trend for these samples was that there was no significant difference in concentrations between years for ${ }^{233 / 234} \mathrm{U}$ and ${ }^{238} \mathrm{U}$ (ANOVA, ${ }^{233 / 234} \cup p=0.412$ and ANOVA ${ }^{238} \cup p=0.218$ ), while the concentrations between locations also were not significantly different (ANOVA ${ }^{233 / 234} \cup p=0.843$ and $A N O V A{ }^{238} U$ $\mathrm{p}=0.543)$.

The ${ }^{235} \mathrm{U}$ had very few common locations where ${ }^{235} \mathrm{U}$ was detected in both 2009 and 2010. When the activities were considered at all locations regardless of whether the ${ }^{235} \mathrm{U}$ met the detection criterion, there was not a significant difference between years (ANOVA, ${ }^{235} \cup p=0.917$ ) or between locations (ANOVA, ${ }^{235} \cup p=0.167$ ). When only the five common locations are considered, which included WEE 0-2 cm, WEE 2-5 cm, and the three MLR depths, there still was not a significant difference in concentrations between years (ANOVA, ${ }^{235} \mathrm{U} p=0.454$ ), but there was a more significant difference between locations (ANOVA, ${ }^{235} \mathrm{U} p=0.0369$ ).

The highest concentrations of ${ }^{233 / 234} U$ measured in $2010(1.55 \mathrm{E}-02 \mathrm{~Bq} / \mathrm{g}$ at the $2-5 \mathrm{~cm}$ depth of MLR) fell within the 99 percent confidence interval range of baseline concentrations (baseline $=2.20 \mathrm{E}-02 \mathrm{~Bq} / \mathrm{g}$ ). The highest concentration of ${ }^{235} \mathrm{U}$ at $6.25 \mathrm{E}$ $04 \mathrm{~Bq} / \mathrm{g}(5-10 \mathrm{~cm}$ at MLR) fell within the 99 percent confidence interval of $1.70 \mathrm{E}-03$ $\mathrm{Bq} / \mathrm{g}$. The highest concentration of ${ }^{238} \mathrm{U}$ at $7.66 \mathrm{E}-03 \mathrm{~Bq} / \mathrm{g}(0-2 \mathrm{~cm}$ at WSS) was lower than the ${ }^{238} \mathrm{U}$ baseline concentration of 1.30E-02 Bq/g (DOE/WIPP-92-037). 


\section{Waste Isolation Pilot Plant Annual Site Environmental Report for 2010 DOE/WIPP-11-2225}

The 2010 detected concentrations were also lower than the range of natural concentrations of uranium found in soils throughout the world. The average concentration of ${ }^{238} \mathrm{U}$ in the earth's soil (upper crust) is 3.60E-02 Bq/g (NCRP Report No. 94, 1987). The agreement of the measured uranium concentrations with natural uranium in soils throughout the world, and the fact that none of the transuranics that would be expected to be released along with uranium were detected in concentrations in excess of baseline quantities, suggests that these soil concentrations follow a pattern of variability consistent with the existence of natural uranium.

Table 4.15 - 2010 Uranium Concentrations (Bq/g) in Soil Samples Taken near the WIPP Site

See Appendix C for Sampling Location Codes

\begin{tabular}{|c|c|c|c|c|c|c|c|c|c|c|c|c|c|}
\hline \multirow{2}{*}{ Location } & \multirow{2}{*}{\begin{tabular}{|c} 
Depth \\
(cm)
\end{tabular}} & {$[\mathrm{RN}]^{\mathrm{a}}$} & $2 \sigma \mathrm{TPU}^{\mathrm{b}}$ & $M^{\prime} C^{c}$ & $Q^{d}$ & [RN] & $2 \sigma \mathrm{TPU}$ & MDC & \multirow[t]{2}{*}{$\mathbf{Q}$} & [RN] & $2 \sigma \mathrm{TPU}$ & MDC & \multirow[t]{2}{*}{ Q } \\
\hline & & \multicolumn{3}{|c|}{${ }^{233 / 234} U$} & & \multicolumn{3}{|c|}{${ }^{235} U$} & & \multicolumn{3}{|c|}{${ }^{238} U$} & \\
\hline WFF & $0-2$ & 6.48E-03 & 1.17E-03 & 9.13E-04 & + & 3.31E-04 & 2.14E-04 & 1.38E-04 & + & 7.02E-03 & 1.24E-03 & 5.24E-04 & + \\
\hline WFF & $2-5$ & 6.74E-03 & 1.37E-03 & 9.27E-04 & + & 3.26E-04 & 2.34E-04 & 1.55E-04 & + & 6.03E-03 & 1.26E-03 & 5.38E-04 & + \\
\hline WFF & $5-10$ & 5.94E-03 & 1.18E-03 & $9.18 \mathrm{E}-04$ & + & 2.92E-04 & 2.06E-04 & $1.44 \mathrm{E}-04$ & + & 5.43E-03 & 1.10E-03 & 5.29E-04 & + \\
\hline WEE & $0-2$ & 5.86E-03 & 1.17E-03 & $9.19 \mathrm{E}-04$ & + & 2.93E-04 & 2.11E-04 & $1.45 \mathrm{E}-04$ & + & 5.87E-03 & 1.17E-03 & $5.30 \mathrm{E}-04$ & + \\
\hline WEE & $2-5$ & 7.81E-03 & 1.76E-03 & 9.37E-04 & + & 3.27E-04 & 2.48E-04 & 1.68E-04 & + & 7.21E-03 & 1.65E-03 & 5.48E-04 & + \\
\hline WEE & $5-10$ & 8.10E-03 & $1.58 \mathrm{E}-03$ & $9.28 \mathrm{E}-04$ & + & 2.63E-04 & 2.03E-04 & $1.55 \mathrm{E}-04$ & + & 7.56E-03 & 1.49E-03 & 5.39E-04 & + \\
\hline WSS & $0-2$ & $8.24 \mathrm{E}-03$ & 1.73E-03 & $9.38 \mathrm{E}-04$ & + & $2.43 E-04$ & $2.15 \mathrm{E}-04$ & $1.63 \mathrm{E}-04$ & + & 7.66E-03 & 1.63E-03 & 5.39E-04 & + \\
\hline WSS & $2-5$ & 6.77E-03 & $6.79 \mathrm{E}-04$ & 8.83E-04 & + & $2.48 \mathrm{E}-04$ & $1.98 \mathrm{E}-04$ & $1.39 \mathrm{E}-04$ & + & $6.25 \mathrm{E}-03$ & $1.22 \mathrm{E}-03$ & $5.20 \mathrm{E}-04$ & + \\
\hline WSS & $5-10$ & 7.55E-03 & 1.36E-03 & 9.13E-04 & + & 2.38E-04 & 1.82E-04 & 1.33E-04 & + & 6.02E-03 & 1.13E-03 & 5.15E-04 & + \\
\hline MLR & $0-2$ & 1.35E-02 & $2.25 \mathrm{E}-03$ & 9.15E-04 & + & 6.00E-04 & 2.91E-04 & 1.35E-04 & + & 1.34E-02 & 2.23E-03 & 5.16E-04 & + \\
\hline MLR & $2-5$ & 1.55E-02 & 2.85E-03 & 9.30E-04 & + & 7.35E-04 & 3.58E-04 & 1.54E-04 & + & 1.40E-02 & 2.60E-03 & 5.32E-04 & + \\
\hline MLR & $5-10$ & 1.43E-02 & $2.71 \mathrm{E}-03$ & $9.27 \mathrm{E}-04$ & + & $6.25 E-04$ & $3.27 \mathrm{E}-04$ & $1.50 \mathrm{E}-04$ & + & 1.59E-02 & $2.98 \mathrm{E}-03$ & $5.28 \mathrm{E}-04$ & + \\
\hline SEC & $0-2$ & 1.17E-03 & $3.75 \mathrm{E}-04$ & $9.12 \mathrm{E}-04$ & + & 7.95E-05 & 1.13E-04 & $1.36 \mathrm{E}-04$ & $U$ & 1.16E-03 & 3.74E-04 & 4.94E-04 & + \\
\hline SEC & $2-5$ & 1.18E-03 & 4.03E-04 & $9.21 \mathrm{E}-04$ & + & 2.69E-05 & 7.65E-05 & 1.47E-04 & $U$ & 1.12E-03 & 3.90E-04 & 5.04E-04 & + \\
\hline SEC & $5-10$ & 1.55E-03 & 5.23E-04 & 9.36E-04 & + & 6.88E-05 & 1.27E-04 & 1.66E-04 & U & 9.98E-04 & 4.04E-04 & 5.19E-04 & + \\
\hline SEC Dup & $0-2$ & 1.07E-03 & 4.08E-04 & 9.31E-04 & + & 2.65E-05 & 8.99E-05 & 1.60E-04 & $U$ & $9.76 \mathrm{E}-04$ & 3.85E-04 & 5.14E-04 & + \\
\hline SEC Dup & $2-5$ & 1.09E-03 & 3.86E-04 & $9.20 \mathrm{E}-04$ & + & 1.15E-05 & 8.73E-05 & $1.46 \mathrm{E}-04$ & U & 1.00E-03 & $3.68 \mathrm{E}-04$ & 5.02E-04 & + \\
\hline SEC Dup & $5-10$ & $1.28 \mathrm{E}-03$ & 4.09E-04 & 9.17E-04 & + & 1.88E-05 & 7.77E-05 & 1.42E-04 & $U$ & 9.52E-04 & 3.44E-04 & 4.99E-04 & + \\
\hline SMR & $0-2$ & 3.03E-03 & 7.09E-04 & $9.16 \mathrm{E}-04$ & + & $2.18 \mathrm{E}-04$ & $1.78 \mathrm{E}-04$ & $1.41 \mathrm{E}-04$ & + & 3.37E-03 & 7.62E-04 & $4.99 \mathrm{E}-04$ & + \\
\hline SMR & $2-5$ & 2.46E-03 & $6.58 \mathrm{E}-04$ & 9.27E-04 & + & 6.41E-05 & 1.12E-04 & 1.54E-04 & $U$ & 2.61E-03 & 6.82E-04 & 5.09E-04 & + \\
\hline SMR & $5-10$ & 2.23E-03 & $5.72 \mathrm{E}-04$ & $9.14 \mathrm{E}-04$ & + & 7.96E-05 & 1.17E-04 & $1.38 \mathrm{E}-04$ & $\mathrm{U}$ & 1.56E-03 & 4.54E-04 & 4.96E-04 & + \\
\hline $\begin{array}{l}\text { (a) Radic } \\
\text { (b) Total } \\
\text { (c) Minin }\end{array}$ & $\begin{array}{l}\text { ionuclid } \\
\text { I Propa } \\
\text { num De }\end{array}$ & $\begin{array}{l}\text { Concent } \\
\text { gated Unc } \\
\text { tectable }\end{array}$ & $\begin{array}{l}\text { tion. } \\
\text { tainty. } \\
\text { ncentratio }\end{array}$ & . & & & & & & & & & \\
\hline
\end{tabular}

Plutonium-238, ${ }^{239 / 240} \mathrm{Pu}$, and ${ }^{241} \mathrm{Am}$ were analyzed for in all the soil samples (Table 4.16). Americium-241 and ${ }^{238} \mathrm{Pu}$ were not detected in any of the soil samples.

Plutonium-239/240 was detected in just one soil sample compared to seven soil samples in 2009. The isotope was detected in the 0-2 cm range of MLR. With only one common detection between 2009 and 2010, there were not enough data to perform any ANOVA calculations. 


\section{Waste Isolation Pilot Plant Annual Site Environmental Report for 2010 DOE/WIPP-11-2225}

The detected concentrations of ${ }^{239 / 240} \mathrm{Pu}$ fell within the 99 percent confidence interval range of the baseline concentration of 1.90E-03 Bq/g (DOE/WIPP-92-037).

Table 4.16 - 2010 Americium and Plutonium Concentrations (Bq/g) in Soil Samples Taken near the WIPP Site

See Appendix C for Sampling Location Codes

\begin{tabular}{|c|c|c|c|c|c|c|c|c|c|c|c|c|c|}
\hline \multirow{2}{*}{ Location } & \multirow{2}{*}{$\begin{array}{l}\text { Depth } \\
\text { (cm) }\end{array}$} & {$[\mathrm{RN}]^{\mathrm{a}}$} & $2 \sigma \mathrm{TPU}^{\mathrm{b}}$ & $M C^{c}$ & \multirow[t]{2}{*}{$Q^{d}$} & [RN] & $2 \sigma$ TPU & MDC & \multirow[t]{2}{*}{$\mathbf{Q}$} & [RN] & $2 \sigma$ TPU & MDC & \multirow[t]{2}{*}{ Q } \\
\hline & & \multicolumn{3}{|c|}{${ }^{241} \mathrm{Am}$} & & \multicolumn{3}{|c|}{${ }^{238} \mathrm{Pu}$} & & \multicolumn{3}{|c|}{${ }^{239 / 240} \mathrm{Pu}$} & \\
\hline WFF & $0-2$ & $-2.51 E-05$ & 7.09E-05 & 2.97E-04 & $U$ & 3.36E-05 & 1.48E-04 & 1.93E-04 & $U$ & 1.53E-04 & 2.30E-04 & 2.12E-04 & $U$ \\
\hline WFF & $2-5$ & 1.43E-05 & $1.24 \mathrm{E}-04$ & 2.87E-04 & $U$ & $-4.11 E-05$ & 1.06E-04 & 2.17E-04 & $U$ & $3.28 \mathrm{E}-05$ & 1.73E-04 & 2.35E- & $U$ \\
\hline WFF & $5-10$ & 3.01E-05 & 1.21E-04 & 2.97E-04 & U & 6.08E-05 & $1.55 \mathrm{E}-04$ & 2.22E-04 & $U$ & $6.88 \mathrm{E}-05$ & 1.47E-04 & 2.40E-04 & U \\
\hline WEE & $0-2$ & $0.00 \mathrm{E}+00$ & 1.69E-04 & 3.21E-04 & $U$ & $-6.09 E-05$ & 1.19E-04 & 1.89E-04 & $U$ & 7.10E-05 & 2.01E-04 & 2.08E-04 & U \\
\hline WEE & $2-5$ & 2.73E-05 & $1.38 \mathrm{E}-04$ & 2.61E-04 & $U$ & $-1.06 E-04$ & 1.77E-04 & 2.32E-04 & U & $-8.82 E-06$ & 2.19E-04 & 2.51E-04 & $U$ \\
\hline WEE & $5-10$ & $-3.06 \mathrm{E}-05$ & 7.55E-05 & 2.87E-04 & $U$ & $-4.39 E-05$ & 1.10E-04 & 2.17E-04 & $U$ & 1.10E-05 & 1.90E-04 & 2.36E-04 & $U$ \\
\hline WSS & $0-2$ & 2.51E-05 & $1.98 \mathrm{E}-04$ & 3.12E-04 & $U$ & $-5.49 E-05$ & 1.04E-04 & 1.73E-04 & $U$ & $-4.45 E-05$ & 9.38E-05 & 1.77E-04 & $U$ \\
\hline WSS & $2-5$ & $-8.52 E-05$ & $1.46 \mathrm{E}-04$ & 3.43E-04 & $U$ & 8.07E-05 & 2.97E-04 & 2.67E-04 & $U$ & 2.04E-04 & 3.23E-04 & 2.72E-04 & U \\
\hline WSS & $5-10$ & $1.74 \mathrm{E}-04$ & 2.26E-04 & 2.91E-04 & $U$ & $0.00 \mathrm{E}+00$ & 2.09E-04 & 2.38E-04 & $U$ & -8.06E-05 & 1.53E-04 & 2.43E-04 & U \\
\hline MLR & $0-2$ & $-6.33 E-05$ & $1.22 \mathrm{E}-04$ & 3.32E-04 & $U$ & 1.13E-05 & 6.86E-05 & 1.46E-04 & U & 5.31E-04 & 2.48E-04 & 1.46E-04 & + \\
\hline MLR & $2-5$ & $-6.53 E-05$ & $1.02 \mathrm{E}-04$ & 2.79E-04 & $U$ & 2.18E-04 & 2.65E-04 & 1.82E-04 & $U$ & $2.20 \mathrm{E}-05$ & 1.36E-04 & 1.87E-04 & U \\
\hline MLR & $5-10$ & $-1.02 \mathrm{E}-05$ & 1.76E-04 & 3.31E-04 & $U$ & 8.65E-05 & 1.56E-04 & 1.43E-04 & U & 2.30E-05 & 9.50E-05 & 1.48E-04 & U \\
\hline SEC & $0-2$ & 6.86E-05 & $1.49 \mathrm{E}-04$ & 2.38E-04 & $U$ & $-2.81 E-05$ & $6.74 \mathrm{E}-05$ & 1.57E-04 & $U$ & 1.77E-04 & 1.98E-04 & 1.42E-04 & U \\
\hline SEC & $2-5$ & 7.95E-05 & 1.74E-04 & 2.27E-04 & U & 3.22E-05 & 1.18E-04 & 1.36E-04 & U & 7.35E-05 & 1.33E-04 & 1.22E-04 & U \\
\hline SEC & $5-10$ & $-1.47 \mathrm{E}-05$ & $1.45 \mathrm{E}-04$ & 2.42E-04 & $U$ & $1.29 \mathrm{E}-04$ & 2.09E-04 & 1.69E-04 & $U$ & $-2.32 E-05$ & 6.44E-05 & 1.54E-04 & $U$ \\
\hline SEC Dup & $0-2$ & 7.27E-05 & 1.97E-04 & 2.38E-04 & $U$ & $-4.38 E-05$ & 7.34E-05 & 1.29E-04 & U & $6.40 \mathrm{E}-05$ & 1.25E-04 & 1.15E-04 & U \\
\hline SEC Dup & $2-5$ & 1.20E-04 & 1.97E-04 & 2.28E-04 & U & $-9.32 E-06$ & 1.03E-04 & 1.37E-04 & $U$ & $-8.13 E-06$ & 1.02E-04 & 1.23E-04 & U \\
\hline SEC Dup & $5-10$ & 1.31E-04 & $2.10 \mathrm{E}-04$ & 2.36E-04 & $U$ & 2.56E-05 & 1.18E-04 & 1.33E-04 & $U$ & 8.23E-05 & 1.23E-04 & 1.19E-04 & U \\
\hline SMR & $0-2$ & 1.32E-04 & $1.98 \mathrm{E}-04$ & 2.31E-04 & $U$ & $-1.09 E-06$ & 9.24E-05 & 1.32E-04 & $U$ & $2.21 \mathrm{E}-06$ & 9.00E-05 & 1.18E-04 & U \\
\hline SMR & $2-5$ & 1.46E-04 & 2.17E-04 & 2.26E-04 & $U$ & $-5.85 E-05$ & 9.27E-05 & 1.46E-04 & U & 3.81E-05 & 1.30E-04 & 1.32E-04 & U \\
\hline SMR & $5-10$ & 1.00E-04 & 2.09E-04 & 2.52E-04 & $\mathrm{U}$ & $-9.93 E-07$ & 8.41E-05 & $1.24 \mathrm{E}-04$ & $U$ & 3.71E-05 & 9.81E-05 & 1.10E-04 & $U$ \\
\hline $\begin{array}{l}\text { (a) Radio } \\
\text { (b) Total } \\
\text { (c) Minim }\end{array}$ & $\begin{array}{l}\text { nuclide } \\
\text { Propag } \\
\text { um Det }\end{array}$ & $\begin{array}{l}\text { e Concentr } \\
\text { gated Unce } \\
\text { atectable C }\end{array}$ & $\begin{array}{l}\text { ration. } \\
\text { ertainty. } \\
\text { oncentrati }\end{array}$ & ion. & & & & & & & & & \\
\hline
\end{tabular}

The sample data in Table 4.17 show that ${ }^{40} \mathrm{~K}$ and ${ }^{137} \mathrm{Cs}$ were detected in all of the soil samples in 2010 , while ${ }^{60} \mathrm{Co}$ and ${ }^{90} \mathrm{Sr}$ were not detected in any of the soil samples. In 2009 the ${ }^{40} \mathrm{~K}$ was detected in all the samples except for the 5-10 cm depth of WFF and the 0-2 cm depth of WSS. There were 16 common locations between 2009 and 2010 for ANOVA comparisons. The average concentrations were used for the duplicate samples. There was no significant variation in the ${ }^{40} \mathrm{~K}$ concentrations between 2009 and 2010 (ANOVA, $p=0.339$ ). There also was no significant variation in the concentrations between locations, including the various soil depths (ANOVA, $p=0.427$ ). These $p$ values were very similar to the comparison of the 2008 and $2009{ }^{40} \mathrm{~K}$ concentrations. Potassium-40 is a naturally occurring gamma-emitting radionuclide that is ubiquitous in soils and would be expected to be present at consistent concentrations. 


\section{Waste Isolation Pilot Plant Annual Site Environmental Report for 2010 DOE/WIPP-11-2225}

The highest ${ }^{40} \mathrm{~K}$ concentration of $6.78 \mathrm{E}-01 \mathrm{~Bq} / \mathrm{g}$ occurred at the $0-2 \mathrm{~cm}$ depth at location SMR (same as in 2009). A total of six ${ }^{40} \mathrm{~K}$ concentrations were higher than the 99 percent confidence interval range of baseline levels in 2010 (3.40E-01 Bq/g) (DOEMIPP-92-037).

Statistical analyses of ${ }^{137} \mathrm{Cs}$ were performed for 16 common locations using the mean concentration for the 2010 SEC duplicate samples and the duplicate sample for the 2009 MLR sample at 5-10 cm ( ${ }^{137} \mathrm{Cs}$ was not detected in the primary MLR sample). Two other samples in which ${ }^{137} \mathrm{Cs}$ was not detected in 2009 were the WSS 0-2 cm and WSS 5-10 cm samples. The ANOVA calculations showed that there was no statistical difference between the concentrations in 2009 and 2010 (ANOVA, $p=0.237$ ). In addition there was no significant difference in the concentrations between the sampling locations (ANOVA, ${ }^{137} \mathrm{Cs} p=0.534$ ).

Table 4.17 - 2010 Radionuclide Concentrations (Bq/g) in Soil Samples Taken near the WIPP Site

See Appendix C for Sampling Location Codes

\begin{tabular}{|c|c|c|c|c|c|c|c|c|c|c|c|c|c|}
\hline \multirow{2}{*}{ Location } & \multirow{2}{*}{$\begin{array}{l}\text { Depth } \\
\text { (cm) }\end{array}$} & {$[\mathrm{RN}]^{\mathrm{a}}$} & $2 \sigma \mathrm{TPU}^{\mathrm{b}}$ & $M C^{c}$ & \multirow[t]{2}{*}{$Q^{d}$} & [RN] & $2 \sigma$ TPU & MDC & \multirow[t]{2}{*}{ Q } & [RN] & $2 \sigma$ TPU & MDC & \multirow[t]{2}{*}{ Q } \\
\hline & & \multicolumn{3}{|c|}{${ }^{40} \mathrm{~K}$} & & \multicolumn{3}{|c|}{${ }^{60} \mathrm{Co}$} & & \multicolumn{3}{|c|}{${ }^{137} \mathrm{Cs}$} & \\
\hline WFF & $0-2$ & 1.86E-01 & 3.03E-02 & 8.74E-03 & + & 1.72E-04 & 8.60E-04 & 1.04E-03 & $U$ & 1.71E-03 & 6.37E-04 & 8.18E-04 & + \\
\hline WFF & $2-5$ & 1.86E-01 & $2.76 \mathrm{E}-02$ & 5.97E-03 & + & $1.72 \mathrm{E}-04$ & 5.32E-04 & 6.31E-04 & $U$ & 1.44E-03 & 4.06E-04 & 4.88E-04 & + \\
\hline WFF & $5-10$ & 1.82E-01 & $2.76 \mathrm{E}-02$ & 6.09E-03 & + & 3.61E-04 & 4.76E-04 & $6.12 \mathrm{E}-04$ & $U$ & 1.84E-03 & 4.80E-04 & $5.25 \mathrm{E}-04$ & + \\
\hline WEE & $0-2$ & 2.03E-01 & 3.45E-02 & 1.11E-02 & + & $-1.86 \mathrm{E}-04$ & 1.32E-03 & 1.50E-03 & $U$ & 1.31E-03 & 7.21E-04 & 1.03E-03 & + \\
\hline WEE & $2-5$ & 2.00E-01 & 3.20E-02 & 7.37E-03 & + & $-2.34 \mathrm{E}-04$ & 9.83E-04 & 1.08E-03 & $U$ & 1.84E-03 & 6.35E-04 & 7.84E-04 & + \\
\hline WEE & $5-10$ & 2.13E-01 & 3.13E-02 & $5.79 \mathrm{E}-03$ & + & $-2.44 \mathrm{E}-04$ & 5.73E-04 & $6.27 \mathrm{E}-04$ & $U$ & 1.76E-03 & $4.71 \mathrm{E}-04$ & 5.57E-04 & + \\
\hline WSS & $0-2$ & 2.14E-01 & $3.21 \mathrm{E}-02$ & $6.75 \mathrm{E}-03$ & + & 7.40E-07 & 6.51E-04 & 7.48E-04 & U & 1.99E-03 & 5.31E-04 & $6.00 \mathrm{E}-04$ & + \\
\hline WSS & $2-5$ & 1.97E-01 & $3.20 \mathrm{E}-02$ & 1.03E-02 & + & $3.24 \mathrm{E}-04$ & 9.26E-04 & 1.13E-03 & $U$ & 2.91E-03 & 7.12E-04 & 6.64E-04 & + \\
\hline WSS & $5-10$ & 2.08E-01 & 3.34E-02 & 6.27E-03 & + & 5.52E-05 & 6.09E-04 & $6.99 \mathrm{E}-04$ & $U$ & 1.92E-03 & 5.92E-04 & 7.09E-04 & + \\
\hline MLR & $0-2$ & 3.84E-01 & 6.12E-02 & 1.76E-02 & + & 1.12E-03 & 1.72E-03 & 2.18E-03 & $U$ & 7.98E-03 & 1.66E-03 & 1.36E-03 & + \\
\hline MLR & $2-5$ & 3.95E-01 & 6.41E-02 & $1.20 \mathrm{E}-02$ & + & 1.46E-04 & 1.16E-03 & 1.36E-03 & $U$ & 2.60E-03 & 9.05E-04 & 1.11E-03 & + \\
\hline MLR & $5-10$ & 3.85E-01 & 5.94E-02 & 7.89E-03 & + & 4.08E-04 & 7.52E-04 & 8.92E-04 & $U$ & 6.79E-04 & 2.55E-04 & 4.69E-04 & + \\
\hline SEC & $0-2$ & 2.06E-01 & 3.31E-02 & 6.74E-03 & + & $-4.01 E-04$ & 6.65E-04 & 6.81E-04 & $U$ & 3.42E-03 & 7.75E-04 & 7.31E-04 & + \\
\hline SEC & $2-5$ & 1.81E-01 & 3.37E-02 & 1.17E-02 & + & $-7.30 \mathrm{E}-04$ & 1.53E-03 & 1.61E-03 & $U$ & 1.96E-03 & 1.04E-03 & 1.47E-03 & + \\
\hline SEC & $5-10$ & 2.21E-01 & 3.56E-02 & 1.09E-02 & + & $-3.28 \mathrm{E}-04$ & 9.97E-04 & 1.07E-03 & $U$ & 1.23E-03 & 6.38E-04 & $9.11 \mathrm{E}-04$ & + \\
\hline SEC Dup & $0-2$ & 1.83E-01 & $3.24 \mathrm{E}-02$ & 1.31E-02 & + & $-5.34 E-04$ & 1.62E-03 & 1.78E-03 & $U$ & 4.24E-03 & 1.16E-03 & $1.25 \mathrm{E}-03$ & + \\
\hline SEC Dup & $2-5$ & 2.11E-01 & 3.39E-02 & 9.91E-03 & + & $-2.91 E-04$ & 1.08E-03 & 1.19E-03 & $U$ & 2.78E-03 & 7.74E-04 & 8.52E-04 & + \\
\hline SEC Dup & $5-10$ & 2.27E-01 & 3.34E-02 & $6.39 \mathrm{E}-03$ & + & 1.24E-04 & 6.20E-04 & 7.26E-04 & $U$ & 1.46E-03 & 5.36E-04 & 7.39E-04 & + \\
\hline SMR & $0-2$ & $6.78 \mathrm{E}-01$ & $9.75 \mathrm{E}-02$ & 9.42E-03 & + & $-5.66 \mathrm{E}-04$ & 1.07E-03 & 1.13E-03 & U & 1.33E-03 & 5.96E-04 & 8.40E-04 & + \\
\hline SMR & $2-5$ & 5.02E-01 & 7.57E-02 & 1.34E-02 & + & $-5.89 E-04$ & 1.51E-03 & 1.60E-03 & $U$ & 1.80E-03 & 8.89E-04 & 1.27E-03 & + \\
\hline SMR & $5-10$ & 3.99E-01 & 6.35E-02 & $1.58 \mathrm{E}-02$ & + & 2.47E-04 & 1.74E-03 & 2.08E-03 & $U$ & 2.15E-03 & 1.13E-03 & 1.62E-03 & + \\
\hline
\end{tabular}


Waste Isolation Pilot Plant Annual Site Environmental Report for 2010 DOE/WIPP-11-2225

Table 4.17 - 2010 Radionuclide Concentrations (Bq/g) in Soil Samples Taken near the WIPP Site

See Appendix C for Sampling Location Codes

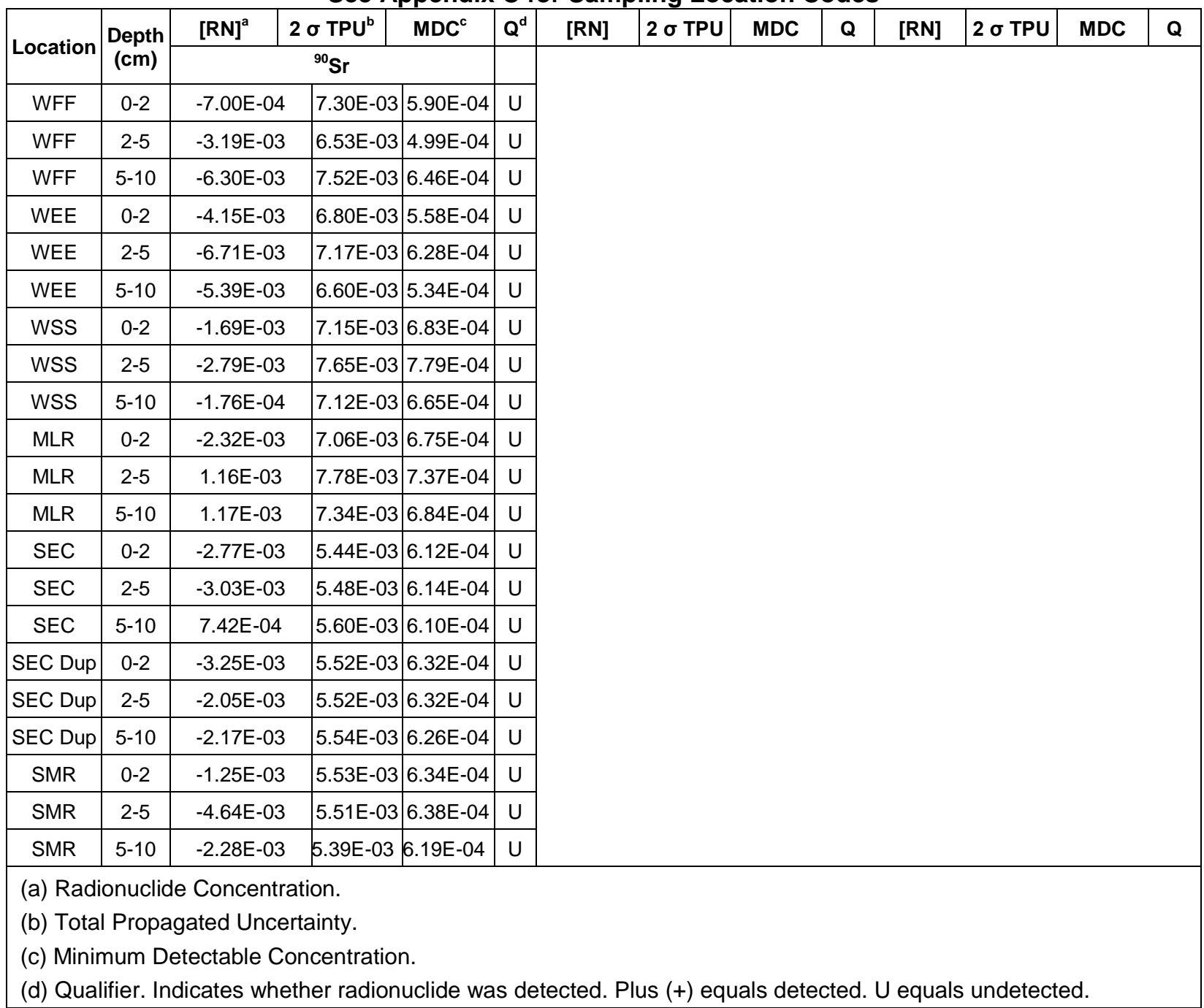

Cesium-137 concentrations for 2010 were within the 99 percent confidence interval range of the baseline concentration (4.00E-02 Bq/g). Cesium-137 is a fission product and is ubiquitous in soils because of global fallout from atmospheric nuclear weapons testing (Beck and Bennett, 2002 and UNSCEAR, 2000).

Since ${ }^{90} \mathrm{Sr}$ and ${ }^{60} \mathrm{Co}$ were not detected at any sampling locations (Table 4.17), there was insufficient data to permit any kind of variance analysis between years or among sampling locations.

Precision data were calculated for the duplicate soil samples collected from all three depths at location SEC. The analysis results are shown in Table 4.18. The RERs were calculated for ${ }^{233 / 234} \mathrm{U},{ }^{235} \mathrm{U}$, and ${ }^{238} \mathrm{U}$ and for ${ }^{40} \mathrm{~K}$ and ${ }^{137} \mathrm{Cs}$.

All of the calculated RERs were significantly less than 1.0 demonstrating good reproducibility for the combined sampling and radiochemical analysis procedures. 
Waste Isolation Pilot Plant Annual Site Environmental Report for 2010 DOE/WIPP-11-2225

Table 4.18 - Results of 2010 Duplicate Soil Sampling and Analysis; Units are in Bq/g

See Chapter 6 for Sampling Locations

\begin{tabular}{|c|c|c|c|c|c|c|c|c|c|}
\hline \multirow[t]{2}{*}{ Location } & \multirow{2}{*}{$\begin{array}{c}\text { Depth } \\
\text { (cm) }\end{array}$} & & \multicolumn{3}{|c|}{ Sample } & \multicolumn{4}{|c|}{ Duplicate } \\
\hline & & & {$[\mathrm{RN}]^{\mathrm{a}}$} & $2 \sigma \mathrm{TPU}^{\mathrm{b}}$ & $M C^{C}$ & [RN] & $2 \sigma$ TPU & MDC & RER $^{d}$ \\
\hline SEC & $0-2$ & ${ }^{233 / 234} U$ & 1.17E-03 & 3.75E-04 & $9.12 \mathrm{E}-04$ & 1.07E-03 & 4.08E-04 & 9.31E-04 & 0.180 \\
\hline SEC & $2-5$ & ${ }^{233 / 234} U$ & 1.18E-03 & 4.03E-04 & $9.21 \mathrm{E}-04$ & 1.09E-03 & 3.86E-04 & 9.20E-04 & 0.162 \\
\hline SEC & $5-10$ & ${ }^{233 / 234} U$ & $1.55 \mathrm{E}-03$ & 5.23E-04 & 9.36E-04 & 1.28E-03 & 4.09E-04 & 9.17E-04 & 0.419 \\
\hline SEC & $0-2$ & ${ }^{238} \mathrm{U}$ & 1.16E-03 & 3.74E-04 & 4.94E-04 & 9.76E-04 & 3.85E-04 & 5.14E-04 & 0.600 \\
\hline SEC & $2-5$ & ${ }^{238} \mathrm{U}$ & 1.12E-03 & 3.90E-04 & 5.04E-04 & 1.00E-03 & 3.68E-04 & 5.02E-04 & 0.225 \\
\hline SEC & $5-10$ & ${ }^{238} \mathrm{U}$ & 9.98E-04 & 4.04E-04 & 5.19E-04 & 9.52E-04 & 3.44E-04 & 4.99E-04 & 0.087 \\
\hline SEC & $0-2$ & ${ }^{40} \mathrm{~K}$ & 2.06E-01 & 3.31E-02 & $6.74 \mathrm{E}-03$ & 1.83E-01 & $3.24 \mathrm{E}-02$ & 1.31E-02 & 0.497 \\
\hline SEC & $2-5$ & ${ }^{40} \mathrm{~K}$ & 1.81E-01 & 3.37E-02 & 1.17E-02 & 2.11E-01 & 3.39E-02 & 9.91E-03 & 0.140 \\
\hline SEC & $5-10$ & ${ }^{40} \mathrm{~K}$ & 2.21E-01 & 3.56E-02 & $1.09 \mathrm{E}-02$ & 2.27E-01 & 3.34E-02 & 6.39E-03 & 0.123 \\
\hline SEC & $0-2$ & ${ }^{137} \mathrm{Cs}$ & 3.42E-03 & 7.75E-04 & 7.31E-04 & 4.24E-03 & 1.16E-03 & $1.25 \mathrm{E}-03$ & 0.588 \\
\hline SEC & $2-5$ & ${ }^{137} \mathrm{Cs}$ & 1.96E-03 & 1.04E-03 & 1.47E-03 & 2.78E-03 & 7.74E-04 & 8.52E-04 & 0.633 \\
\hline SEC & $5-10$ & ${ }^{137} \mathrm{Cs}$ & $1.23 E-03$ & 6.38E-04 & $9.11 E-04$ & 1.46E-03 & 5.36E-04 & 7.39E-04 & 0.276 \\
\hline
\end{tabular}

(a) Radionuclide Concentration.

(b) Total Propagated Uncertainty.

(c) Minimum Detectable Concentration.

(d) Relative Error Ratio.

\subsection{Biota}

\subsubsection{Sample Collection}

Rangeland vegetation samples were collected from the same six locations from which the soil samples were collected (Figure 4.4). Fauna (animal) samples were also collected when available. All biota samples were analyzed for the target radionuclides.

\subsubsection{Sample Preparation}

\subsubsection{Vegetation}

The vegetation samples were chopped into 2.5- to 5-cm (1- to 2-in.) pieces, mixed together well, and air dried at room temperature. Weighed aliquots were spiked with tracers and carriers and heated in a muffle furnace to burn off organic matter.

The samples were digested with concentrated nitric acid, hydrochloric acid, hydrofluoric acid, and hydrogen peroxide. The samples were dried and heated in a muffle furnace. The remaining residue was repetitively wet-ashed with concentrated acids until only a white or pale yellow residue remained. The residue was dissolved in nitric acid for separation of the individual radionuclides. 


\subsubsection{Fauna}

The tissue samples were spiked with tracers and carriers and dried in a muffle furnace. The samples were then digested with concentrated acids and hydrogen peroxide in the same manner as the vegetation samples and dissolved in nitric acid for the separation of the individual radionuclides.

\subsubsection{Determination of Individual Radionuclides}

The nitric acid digestates of the biota samples were split into two fractions. One acid fraction was analyzed by gamma spectroscopy for ${ }^{40} \mathrm{~K},{ }^{60} \mathrm{Co}$, and ${ }^{137} \mathrm{Cs}$. The other fraction was analyzed sequentially for the uranium/transuranic radionuclides and ${ }^{90} \mathrm{Sr}$ by employing a series of chemical, physical, and ion exchange separations followed by mounting the sample residues on a planchet for counting. The uranium/transuranics were counted by alpha spectroscopy and the ${ }^{90} \mathrm{Sr}$ by gas proportional counting.

\subsubsection{Results and Discussion}

\subsubsection{Vegetation}

Table 4.19 shows that the only detection of uranium isotopes was for ${ }^{233 / 234} \mathrm{U}$ and ${ }^{238} \mathrm{U}$ in the vegetation sample from location SMR. There were no detections of uranium isotopes in vegetation samples in 2009 , and no ANOVA comparisons could be performed. The ${ }^{233 / 234} \mathrm{U}$ concentration was higher than the 99 percent confidence range of the baseline concentration of $6.00 \mathrm{E}-05 \mathrm{~Bq} / \mathrm{g}$, and the ${ }^{238} \mathrm{U}$ was also a little higher than the 99 percent confidence range of the baseline concentration of $6.90 \mathrm{E}-04 \mathrm{~Bq} / \mathrm{g}$.

Potassium-40 was detected in every vegetation sample analyzed in 2010 (Table 4.19) as it was in 2009. The average concentrations of ${ }^{40} \mathrm{~K}$ were used for WEE in 2009 and WSS in 2010. The ANOVA calculations showed that there was no statistical difference in ${ }^{40} \mathrm{~K}$ vegetation concentrations between 2009 and 2010 (ANOVA, ${ }^{40} \mathrm{~K} p=0.375$ ).

There was more of a variation in the concentrations between locations, but the $p$ value was still greater than the 0.05 significance factor with ANOVA, ${ }^{40} \mathrm{~K}, \mathrm{p}=0.186$. The natural variability of this naturally occurring radionuclide in the soil would be expected to yield some variation in the vegetation concentrations between locations. The concentrations of ${ }^{40} \mathrm{~K}$ all fell within the 99 percent ID confidence range of the average baseline concentration of $3.2 \mathrm{~Bq} / \mathrm{g}$.

A duplicate analysis of the vegetation sample from sampling location WSS was performed for all the radionuclides of interest (Table 4.20). An RER was calculated for ${ }^{40} \mathrm{~K}$. The RER was less than 1 , indicating good precision for the duplicate analysis. 


\section{Waste Isolation Pilot Plant Annual Site Environmental Report for 2010}

DOE/WIPP-11-2225

\section{Table 4.19 - Radionuclide Concentrations (Bq/g Wet Mass) in 2010 Vegetation Samples Taken} near the WIPP Site

See Appendix C for Sampling Location Codes

\begin{tabular}{|c|c|c|c|c|c|c|c|c|c|c|c|c|}
\hline \multirow[t]{2}{*}{ Location } & {$[R N]^{a}$} & $2 \sigma \mathrm{TPU}^{\mathrm{b}}$ & $M C^{c}$ & $Q^{d}$ & [RN] & $2 \sigma$ TPU & MDC & Q & [RN] & $2 \sigma$ TPU & MDC & $\mathbf{Q}$ \\
\hline & \multicolumn{3}{|c|}{${ }^{233 / 234} U$} & & \multicolumn{3}{|c|}{${ }^{235} U$} & & \multicolumn{3}{|c|}{${ }^{238} \mathrm{U}$} & \\
\hline WFF & 2.30E-04 & $1.31 \mathrm{E}-04$ & 7.05E-04 & $U$ & -8.77E-06 & $2.52 \mathrm{E}-05$ & 1.17E-04 & $U$ & 1.18E-04 & 8.86E-05 & $6.00 \mathrm{E}-04$ & U \\
\hline WEE & 2.12E-04 & 1.33E-04 & 7.08E-04 & U & 3.04E-05 & 6.31E-05 & 1.21E-04 & $U$ & 2.04E-04 & $1.26 \mathrm{E}-04$ & 6.04E-04 & U \\
\hline WSS & 2.07E-04 & $1.21 \mathrm{E}-04$ & 7.05E-04 & $U$ & $9.46 \mathrm{E}-06$ & 4.54E-05 & 1.18E-04 & $U$ & 1.75E-04 & $1.11 \mathrm{E}-04$ & $6.01 \mathrm{E}-04$ & U \\
\hline WSS Dup & 1.53E-04 & 1.04E-04 & 7.04E-04 & U & $9.78 \mathrm{E}-06$ & 4.36E-05 & 1.16E-04 & $U$ & $6.32 \mathrm{E}-05$ & 7.06E-05 & 5.99E-04 & $U$ \\
\hline MLR & $1.57 \mathrm{E}-04$ & 1.07E-04 & 7.05E-04 & U & $-6.25 E-06$ & 2.13E-05 & 1.17E-04 & U & 1.58E-04 & 1.06E-04 & $6.00 \mathrm{E}-04$ & U \\
\hline SEC & 1.07E-04 & 7.46E-05 & $6.37 \mathrm{E}-04$ & U & 8.38E-06 & $3.24 \mathrm{E}-05$ & 9.95E-05 & $U$ & 9.73E-05 & $6.99 \mathrm{E}-05$ & $4.95 \mathrm{E}-04$ & U \\
\hline \multirow[t]{2}{*}{ SMR } & 7.59E-04 & 2.35E-04 & $6.42 \mathrm{E}-04$ & + & 1.14E-05 & 3.64E-05 & 1.06E-04 & U & 7.84E-04 & 2.39E-04 & 5.00E-04 & + \\
\hline & \multicolumn{3}{|c|}{${ }^{241} \mathrm{Am}$} & & \multicolumn{3}{|c|}{${ }^{238} \mathrm{Pu}$} & & \multicolumn{3}{|c|}{${ }^{239 / 240} \mathrm{Pu}$} & \\
\hline WFF & 6.43E-05 & 6.94E-05 & $1.74 \mathrm{E}-04$ & $U$ & 9.66E-05 & 1.00E-04 & 5.71E-05 & $U$ & 3.16E-05 & 5.83E-05 & 1.04E-04 & U \\
\hline WEE & $1.01 \mathrm{E}-05$ & 4.84E-05 & 1.82E-04 & $U$ & 1.33E-05 & 5.57E-05 & 4.80E-05 & $U$ & 1.49E-05 & $5.48 \mathrm{E}-05$ & $9.54 \mathrm{E}-05$ & U \\
\hline WSS & $-8.73 E-06$ & $2.42 \mathrm{E}-05$ & $1.75 \mathrm{E}-04$ & U & $1.14 \mathrm{E}-05$ & $5.23 E-05$ & 4.50E-05 & $U$ & $6.42 \mathrm{E}-06$ & 3.64E-05 & $9.23 \mathrm{E}-05$ & U \\
\hline WSS Dup & $-9.96 E-06$ & 2.76E-05 & 1.81E-04 & U & $-1.02 \mathrm{E}-06$ & 4.29E-05 & 4.60E-05 & $U$ & $1.72 \mathrm{E}-05$ & $5.05 E-05$ & 9.33E-05 & U \\
\hline MLR & 4.47E-05 & 6.56E-05 & $1.76 \mathrm{E}-04$ & U & 1.22E-05 & $3.12 \mathrm{E}-05$ & 4.46E-05 & $U$ & $-1.22 \mathrm{E}-05$ & $2.63 \mathrm{E}-05$ & $9.19 \mathrm{E}-05$ & U \\
\hline SEC & -8.10E-06 & 3.73E-05 & 1.64E-04 & $U$ & $-2.11 E-06$ & 4.54E-05 & 5.24E-05 & $U$ & 3.33E-05 & 6.13E-05 & 1.19E-04 & U \\
\hline \multirow[t]{2}{*}{ SMR } & $1.45 \mathrm{E}-05$ & 4.92E-05 & $1.72 \mathrm{E}-04$ & $U$ & 1.83E-06 & 5.98E-05 & 6.92E-05 & $U$ & $9.18 \mathrm{E}-06$ & 5.43E-05 & $1.36 \mathrm{E}-04$ & $U$ \\
\hline & \multicolumn{3}{|c|}{${ }^{40} \mathrm{~K}$} & & \multicolumn{3}{|c|}{${ }^{60} \mathrm{Co}$} & & \multicolumn{3}{|c|}{${ }^{137} \mathrm{Cs}$} & \\
\hline WFF & 9.42E-01 & 1.51E-01 & 4.72E-02 & + & $5.55 \mathrm{E}-03$ & 4.05E-03 & 6.08E-03 & $U$ & $-1.30 E-03$ & $5.16 \mathrm{E}-03$ & 5.55E-03 & U \\
\hline WEE & 7.27E-01 & 1.21E-01 & 6.26E-02 & + & $-6.85 E-05$ & $6.62 \mathrm{E}-03$ & 7.69E-03 & $U$ & $-4.35 E-03$ & $6.44 \mathrm{E}-03$ & $6.95 \mathrm{E}-03$ & U \\
\hline WSS & 5.15E-01 & $1.21 \mathrm{E}-01$ & 7.95E-02 & + & $-3.80 \mathrm{E}-03$ & $1.04 \mathrm{E}-02$ & 1.10E-02 & $U$ & 5.27E-05 & $7.26 \mathrm{E}-03$ & 8.85E-03 & U \\
\hline WSS Dup & 6.37E-01 & $1.38 \mathrm{E}-01$ & 7.97E-02 & + & $-5.39 \mathrm{E}-03$ & 1.10E-02 & 1.09E-02 & $U$ & $-4.10 \mathrm{E}-04$ & 8.02E-03 & $9.54 \mathrm{E}-03$ & U \\
\hline MLR & $1.03 E+00$ & 1.68E-01 & 6.30E-02 & + & $-2.29 \mathrm{E}-03$ & $6.73 \mathrm{E}-03$ & 7.30E-03 & $U$ & $-3.04 E-03$ & $6.40 \mathrm{E}-03$ & $6.72 \mathrm{E}-03$ & U \\
\hline SEC & 2.47E-01 & 7.89E-02 & $9.45 \mathrm{E}-02$ & + & 7.92E-03 & 8.42E-03 & 1.08E-02 & $U$ & 5.26E-03 & 8.52E-03 & $1.03 E-02$ & $U$ \\
\hline \multirow[t]{2}{*}{ SMR } & $1.24 \mathrm{E}+00$ & $2.22 \mathrm{E}-01$ & 1.05E-01 & + & 1.64E-03 & 8.38E-03 & 1.05E-02 & $U$ & $-2.78 \mathrm{E}-03$ & 8.15E-03 & $9.28 \mathrm{E}-03$ & $U$ \\
\hline & \multicolumn{3}{|c|}{${ }^{90} \mathrm{Sr}$} & & & & & & & & & \\
\hline WFF & $-1.99 E-03$ & $2.88 \mathrm{E}-03$ & $6.09 \mathrm{E}-04$ & $U$ & & & & & & & & \\
\hline WEE & $-2.92 \mathrm{E}-03$ & $2.73 \mathrm{E}-03$ & $5.88 \mathrm{E}-04$ & $U$ & & & & & & & & \\
\hline WSS & $-2.29 E-03$ & $2.88 \mathrm{E}-03$ & $6.11 \mathrm{E}-04$ & $U$ & & & & & & & & \\
\hline $\begin{array}{l}\text { WSS } \\
\text { Dup }\end{array}$ & $-1.13 E-03$ & $3.20 \mathrm{E}-03$ & $6.38 \mathrm{E}-04$ & $U$ & & & & & & & & \\
\hline MLR & $-2.25 \mathrm{E}-04$ & $3.16 \mathrm{E}-03$ & $6.35 \mathrm{E}-04$ & $U$ & & & & & & & & \\
\hline SEC & 1.85E-03 & 3.95E-03 & 4.29E-04 & U & & & & & & & & \\
\hline SMR & 1.32E-03 & $3.97 \mathrm{E}-03$ & 4.39E-04 & $U$ & & & & & & & & \\
\hline $\begin{array}{l}\text { (a) Radio } \\
\text { (b) Total } \\
\text { (c) Minim }\end{array}$ & $\begin{array}{l}\text { uclide Con } \\
\text { ropagated } \\
\text { m Detecta }\end{array}$ & $\begin{array}{l}\text { entration. } \\
\text { Jncertainty } \\
\text { le Concent }\end{array}$ & tration. & & & 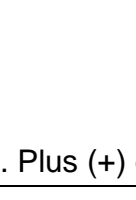 & 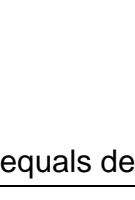 & & 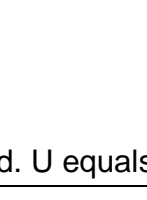 & & & \\
\hline
\end{tabular}




\section{Waste Isolation Pilot Plant Annual Site Environmental Report for 2010 DOE/WIPP-11-2225}

Table 4.20 - Results of Duplicate Analysis of Vegetation Samples Taken in 2010; Units are in $\mathrm{Bq} / \mathrm{g}$

See Chapter 6 for Sampling Locations

\begin{tabular}{|c|c|c|c|c|c|c|c|c|}
\hline \multirow{2}{*}{ Location } & \multirow{3}{*}{} & \multicolumn{3}{|c|}{ Sample } & \multicolumn{5}{c|}{ Duplicate } \\
\cline { 3 - 9 } & & {$[\mathrm{RN}]^{\mathbf{a}}$} & $\mathbf{2} \boldsymbol{\sigma} \mathbf{T P U}^{\mathbf{b}}$ & $\mathbf{M D C}^{\mathbf{c}}$ & {$[\mathrm{RN}]$} & $\mathbf{2} \boldsymbol{\sigma}$ TPU & MDC & RER $^{\mathbf{d}}$ \\
\hline WSS & ${ }^{40} \mathrm{~K}$ & $5.15 \mathrm{E}-01$ & $1.21 \mathrm{E}-01$ & $7.95 \mathrm{E}-02$ & $6.37 \mathrm{E}-01$ & $1.38 \mathrm{E}-01$ & $7.97 \mathrm{E}-02$ & 0.665 \\
\hline
\end{tabular}

(a) Radionuclide Concentration.

(b) Total Propagated Uncertainty.

(c) Minimum Detectable Concentration.

(d) Relative Error Ratio.

\subsubsection{Fauna}

Table 4.21 shows that the only radionuclide to be detected in any of the animal samples was ${ }^{40} \mathrm{~K}$, and that it was detected in all the samples. Uranium-233/234, ${ }^{235} \mathrm{U},{ }^{238} \mathrm{U}$, ${ }^{241} \mathrm{Am},{ }^{238} \mathrm{Pu},{ }^{239 / 240} \mathrm{Pu},{ }^{137} \mathrm{Cs},{ }^{60} \mathrm{Co}$, and ${ }^{90} \mathrm{Sr}$, were not detected in any of the animal samples. No statistical comparisons between locations or years could be performed for any of these undetected radionuclides.

Table 4.21 - Radionuclide Concentrations (Bq/g Wet Mass) in 2010 Quail, Rabbit, Deer, Javelina and Fish Samples Taken near the WIPP Site

See Appendix $\mathrm{C}$ for Sampling Location Codes

\begin{tabular}{|c|c|c|c|c|c|c|c|c|c|c|c|c|}
\hline \multirow[t]{2}{*}{$\begin{array}{c}\text { Biota } \\
\text { (Location) }\end{array}$} & {$[\mathrm{RN}]^{\mathrm{a}}$} & $\begin{array}{c}2 \sigma \\
\text { TPU }^{b}\end{array}$ & $M^{\prime} C^{c}$ & $Q^{d}$ & [RN] & $\begin{array}{l}2 \sigma \\
\text { TPU }\end{array}$ & MDC & Q & [RN] & $\begin{array}{l}2 \sigma \\
\text { TPU }\end{array}$ & MDC & Q \\
\hline & \multicolumn{3}{|c|}{${ }^{233 / 234} U$} & & \multicolumn{3}{|c|}{${ }^{235} \mathrm{U}$} & & \multicolumn{3}{|c|}{${ }^{238} U$} & \\
\hline Quail (WEE) & 3.40E-05 & $1.00 \mathrm{E}-05$ & 8.22E-04 & $U$ & 2.93E-06 & 2.55E-06 & 7.72E-05 & U & 3.27E-05 & 9.71E-06 & 5.55E-04 & U \\
\hline Rabbit (SOO) & 2.18E-05 & $6.40 \mathrm{E}-06$ & 5.47E-04 & $U$ & 6.33E-07 & $1.35 \mathrm{E}-06$ & 3.43E-05 & $U$ & 2.11E-05 & $6.25 \mathrm{E}-06$ & 4.51E-04 & $U$ \\
\hline Deer (SOO) & 2.23E-06 & 2.03E-06 & $5.46 \mathrm{E}-04$ & $U$ & $-2.69 \mathrm{E}-07$ & 6.81E-07 & 2.49E-05 & $\mathrm{U}$ & 5.54E-07 & 1.12E-06 & 3.90E-04 & U \\
\hline Fish (PCN) & 2.29E-04 & 3.53E-05 & 5.75E-04 & $U$ & 4.01E-06 & $2.45 E-06$ & 5.30E-05 & $U$ & 1.15E-04 & 1.93E-05 & 4.09E-04 & $\mathrm{U}$ \\
\hline Fish (BRA) & 2.11E-04 & 4.62E-05 & 5.66E-04 & U & 3.76E-06 & 3.11E-06 & 5.36E-05 & $U$ & 1.11E-04 & 2.62E-05 & 4.23E-04 & $U$ \\
\hline Javelina (SOO) & 1.01E-05 & 4.76E-06 & 6.04E-04 & $U$ & 2.41E-07 & $1.25 \mathrm{E}-06$ & 5.35E-05 & $U$ & 5.57E-06 & 3.37E-06 & 5.42E-04 & U \\
\hline \multirow[t]{2}{*}{ Fish (CBD) } & $1.11 \mathrm{E}-04$ & 2.51E-05 & 6.27E-04 & U & 3.30E-06 & 2.37E-06 & 6.27E-05 & $\mathrm{U}$ & 4.97E-05 & 1.26E-05 & 5.37E-04 & $U$ \\
\hline & \multicolumn{3}{|c|}{${ }^{241} \mathrm{Am}$} & & \multicolumn{3}{|c|}{${ }^{238} \mathrm{Pu}$} & & \multicolumn{3}{|c|}{${ }^{239 / 240} \mathrm{Pu}$} & \\
\hline Quail (WEE) & 1.84E-06 & 2.73E-06 & 1.91E-04 & $U$ & 1.06E-06 & $1.55 \mathrm{E}-06$ & 2.47E-05 & U & $1.48 \mathrm{E}-06$ & $1.68 \mathrm{E}-06$ & 8.63E-05 & $U$ \\
\hline Rabbit (SOO) & $0.00 E+00$ & $1.50 \mathrm{E}-06$ & 1.67E-04 & $U$ & $1.56 \mathrm{E}-06$ & $1.94 \mathrm{E}-06$ & 8.65E-05 & $U$ & 5.46E-07 & 1.27E-06 & 4.38E-05 & $U$ \\
\hline Deer (SOO) & $-5.44 \mathrm{E}-07$ & 8.43E-07 & 2.14E-04 & U & $-5.47 \mathrm{E}-07$ & 9.17E-07 & 2.48E-05 & $\mathrm{U}$ & $-2.00 \mathrm{E}-07$ & 5.54E-07 & 7.69E-05 & U \\
\hline Fish (PCN) & $-4.63 E-07$ & 2.13E-06 & $1.49 \mathrm{E}-04$ & $U$ & $1.15 \mathrm{E}-06$ & 2.22E-06 & 6.79E-05 & $U$ & 1.13E-06 & $2.22 \mathrm{E}-06$ & 4.89E-05 & $U$ \\
\hline Fish (BRA) & 5.63E-07 & 1.99E-06 & $1.34 \mathrm{E}-04$ & $U$ & 2.62E-06 & 3.11E-06 & 5.87E-05 & $U$ & $0.00 \mathrm{E}+00$ & $1.80 \mathrm{E}-06$ & 3.49E-05 & U \\
\hline Javelina (SOO) & $-5.73 E-07$ & 1.03E-06 & 1.34E-04 & $U$ & $-1.19 \mathrm{E}-07$ & 1.73E-06 & 6.35E-06 & $U$ & $-7.15 E-07$ & 1.28E-06 & 5.37E-05 & U \\
\hline Fish (CBD) & 2.37E-06 & 3.61E-06 & $1.54 \mathrm{E}-04$ & $U$ & $6.42 \mathrm{E}-07$ & $1.54 \mathrm{E}-06$ & 5.76E-06 & U & $-1.26 \mathrm{E}-07$ & 4.27E-07 & 4.37E-05 & $\mathrm{U}$ \\
\hline
\end{tabular}
(a) Radionuclide Concentration.
(b) Total Propagated Uncertainty.
(c) Minimum Detectable Concentration.
(d) Qualifier. Indicates whether radionuclide was detected. Plus (+) equals detected. U equals undetected. 


\section{Waste Isolation Pilot Plant Annual Site Environmental Report for 2010 DOE/WIPP-11-2225}

The fauna samples with the ${ }^{40} \mathrm{~K}$ detections included a quail, three fish, a rabbit, and a javelina sample. However, there were too few samples to allow statistical comparison between years. The detected ${ }^{40} \mathrm{~K}$ concentrations were within the baseline analysis results, including $0.39 \mathrm{~Bq} / \mathrm{g}$ for rabbit (dry); $0.41 \mathrm{~Bq} / \mathrm{g}$ for quail (dry); $0.61 \mathrm{~Bq} / \mathrm{g}$ for fish (dry (DOE/WIPP-92-037). Baseline concentrations were not available for the other animals.

These results can only be used as a gross indication of uptake by the animals, since the sample sizes are too small to provide a thorough analysis. Within this limitation, the data suggest that there has not been any animal uptake of the radionuclides at the WIPP facility.

Precision data for animal samples were limited to laboratory duplicates from the same sample since duplicate animal samples were not collected. The precision is measurable in samples whether or not the radionuclides were detected. Some representative laboratory duplicate analysis results for animals are shown in Table. 4.22. The laboratory duplicate RERs were all $<1$ for the selected radionuclides shown in the table as well as for the other radionuclides and the other animal biota samples, demonstrating good precision for the complex analysis procedures.

Table 4.22 - Results of 2010 Animal Biota Laboratory Duplicate Analysis Precision; Units are in $\mathrm{Bq} / \mathrm{g}$

\begin{tabular}{|c|c|c|c|c|c|c|c|}
\hline \multicolumn{8}{|c|}{ See Chapter 6 for Sampling Locations } \\
\hline \multirow[b]{2}{*}{ Animal } & \multirow[b]{2}{*}{ Location } & \multirow[b]{2}{*}{ Isotope } & \multicolumn{2}{|c|}{ Sample } & \multicolumn{3}{|c|}{ Duplicate } \\
\hline & & & {$[\mathrm{RN}]^{\mathrm{a}}$} & $2 \sigma T^{T} U^{b}$ & {$[\mathrm{RN}]$} & $2 \sigma$ TPU & RER $^{c}$ \\
\hline Quail & WEE & $233 / 234 U$ & $3.40 \mathrm{E}-05$ & $1.00 \mathrm{E}-05$ & $3.20 \mathrm{E}-05$ & $9.53 E-06$ & 0.14 \\
\hline Quail & WEE & ${ }^{235} \mathrm{U}$ & 2.93E-06 & $2.55 \mathrm{E}-06$ & $3.57 \mathrm{E}-07$ & 1.14E-06 & 0.92 \\
\hline Quail & WEE & ${ }^{238} \mathrm{U}$ & 3.27E-05 & $9.71 \mathrm{E}-06$ & 2.94E-05 & 8.97E-06 & 0.25 \\
\hline Quail & WEE & ${ }^{40} \mathrm{~K}$ & 3.95E-02 & 1.40E-02 & 4.86E-02 & 1.45E-02 & 0.45 \\
\hline Rabbit & SOO & ${ }^{233 / 234} U$ & $2.18 \mathrm{E}-05$ & $6.40 \mathrm{E}-06$ & $1.38 \mathrm{E}-05$ & 4.99E-06 & 0.98 \\
\hline Rabbit & soo & ${ }^{235} U$ & $6.33 \mathrm{E}-07$ & 1.35E-06 & $2.58 \mathrm{E}-07$ & 1.07E-06 & 0.22 \\
\hline Rabbit & SOO & ${ }^{238} \mathrm{U}$ & 2.11E-05 & $6.25 \mathrm{E}-06$ & 1.67E-05 & $5.58 \mathrm{E}-06$ & 0.53 \\
\hline Rabbit & SOO & ${ }^{40} \mathrm{~K}$ & 9.45E-02 & 2.42E-02 & 7.92E-02 & 2.83E-02 & 0.41 \\
\hline Deer & SOO & $233 / 234 U$ & 2.23E-06 & 2.03E-06 & 2.13E-06 & $2.40 \mathrm{E}-06$ & 0.03 \\
\hline Deer & SOO & ${ }^{235} U$ & $-2.69 \mathrm{E}-07$ & $6.81 \mathrm{E}-07$ & $-2.39 \mathrm{E}-07$ & 7.13E-07 & 0.03 \\
\hline Deer & SOO & ${ }^{238} \mathrm{U}$ & 5.54E-07 & $1.12 \mathrm{E}-06$ & 8.16E-07 & $1.79 \mathrm{E}-06$ & 0.12 \\
\hline Deer & soo & ${ }^{40} \mathrm{~K}$ & $1.01 \mathrm{E}-01$ & $2.43 E-02$ & $9.01 \mathrm{E}-02$ & $2.93 \mathrm{E}-02$ & 0.29 \\
\hline Fish & PCN & $233 / 234 U$ & $2.29 \mathrm{E}-04$ & 3.53E-05 & 2.94E-04 & 4.91E-05 & 0.98 \\
\hline Fish & $\mathrm{PCN}$ & ${ }^{235} \mathrm{U}$ & 4.01E-06 & $2.45 \mathrm{E}-06$ & 4.74E-06 & 2.95E-06 & 0.19 \\
\hline Fish & $\mathrm{PCN}$ & ${ }^{238} \mathrm{U}$ & 1.15E-04 & 1.93E-05 & 1.43E-04 & $2.58 \mathrm{E}-05$ & 0.86 \\
\hline Fish & $\mathrm{PCN}$ & ${ }^{40} \mathrm{~K}$ & $9.54 \mathrm{E}-02$ & $2.70 \mathrm{E}-02$ & 7.18E-02 & $2.17 \mathrm{E}-02$ & 0.68 \\
\hline \multicolumn{8}{|c|}{$\begin{array}{l}\text { (a) Radionuclide Concentration. } \\
\text { (b) Total Propagated Uncertainty. } \\
\text { (c) Relative Error Ratio. }\end{array}$} \\
\hline
\end{tabular}




\subsection{Potential Dose From WIPP Operations}

\subsubsection{Dose Limits}

Compliance with the regulatory standards is determined by comparing annual radiation doses to the regulatory standards. The regulatory standards can be found in $40 \mathrm{CFR}$ Part 191, Subpart A. The referenced standard specifies that the combined annual dose equivalent to any member of the public in the general environment resulting from discharges of radioactive material and direct radiation from such management and storage shall not exceed $25 \mathrm{mrem}$ to the whole body and $75 \mathrm{mrem}$ to any critical organ. In addition, in a 1995 memorandum of understanding between the EPA and the DOE, the DOE agreed that the WIPP facility would comply with the applicable National Emissions Standards for Hazardous Air Pollutants (NESHAP) for radionuclides. The NESHAP standard states that the emissions of radionuclides to the ambient air from DOE facilities shall not exceed those amounts that would cause any member of the public to receive in any year an EDE of 10 mrem per year. The EDE is the weighted sum of the doses to the individual organs of the body. The dose to each organ is weighted according to the risk that dose represents. These organ doses are then added together, and that total is the EDE. In this manner, the risk from different sources of radiation can be controlled by a single standard.

Compliance with applicable regulatory requirements is determined by monitoring, extracting, and calculating the EDE. Calculating the EDE to members of the public requires the use of CAP88-PC or other EPA-approved computer models and procedures. The WIPP effluent monitoring program generally uses CAP88-PC, which is a set of computer programs, datasets and associated utility programs for estimating dose and risk from radionuclide air emissions. CAP88-PC uses a Gaussian Plume dispersion model, which calculates deposition rates, concentrations in food, and intake rates for people. CAP88-PC estimates dose and risk to individuals and populations from multiple pathways. Dose and risk is calculated for ingestion, inhalation, ground-level air immersion, and ground-surface irradiation exposure pathways.

The Safe Drinking Water Act (40 CFR §141.66, "Maximum Contaminant Levels for Radionuclides") states that average annual concentrations for beta- and gammaemitting human-made radionuclides in drinking water shall not result in an annual dose equivalent $>0.04 \mathrm{mSv}$ (4 mrem). It is important to note that all of these dose equivalent limits are set for radionuclides released to the environment from DOE operations. They do not include, but are limits in addition to, doses from natural background radiation or from medical procedures.

\subsubsection{Background Radiation}

There are several sources of natural radiation: cosmic and cosmogenic radiation (from outer space and the earth's atmosphere), terrestrial radiation (from the earth's crust), and internal radiation (naturally occurring radiation in our bodies, such as ${ }^{40} \mathrm{~K}$ ). The most common sources of terrestrial radiation are uranium, thorium, and their decay products. Potassium- 40 is another source of terrestrial radiation. While not a major radiation source, ${ }^{40} \mathrm{~K}$ in the southeastern New Mexico environment may be due to the deposition of tailings from local potash mining. Radon gas, a decay product of uranium, is a widely 
known naturally occurring terrestrial radionuclide. In addition to natural radioactivity, small amounts of radioactivity from aboveground nuclear weapons tests that occurred from 1945 through 1980, and the 1986 Chernobyl nuclear accident are also present in the environment. Together, these sources of radiation are called "background" radiation.

Naturally occurring radiation in the environment can deliver both internal and external doses. Internal dose is received as a result of the intake of radionuclides. The routes of intake of radionuclides for members of the public are ingestion and inhalation. Ingestion includes eating and drinking food or drink containing radionuclides. Inhalation includes the intake of radionuclides through breathing radioactive particulates. External dose can occur from immersion in contaminated air or deposition of contaminants on surfaces. The average annual dose received by a member of the public from naturally occurring radionuclides is approximately $3 \mathrm{mSv}$ (300 mrem).

\subsubsection{Dose From Air Emissions}

The 40 CFR Part 191, Subpart A, standard limits radiation doses to members of the public in the general environment. The DOE has identified air emissions as the major pathway of concern for the WIPP facility.

Compliance with Subpart A (40 CFR §191.03[b]) and the NESHAP standard (40 CFR $\S 61.92)$ is determined by comparing annual radiation doses to the MEI to the regulatory standards. As recommended by the EPA, the DOE uses computer modeling to calculate radiation doses for compliance with the Subpart A and NESHAP standards. Compliance procedures for DOE facilities (40 CFR \$61.93[a]) require the use of CAP88-PC or AIRDOS-PC computer models, or equivalent, to calculate dose to members of the public. Source term input for CAP88-PC was determined by radiochemical analyses of filter air samples taken from Stations A, B, and C. Air filter samples were analyzed for ${ }^{241} \mathrm{Am},{ }^{239 / 240} \mathrm{Pu},{ }^{238} \mathrm{Pu},{ }^{90} \mathrm{Sr},{ }^{233 / 234} \mathrm{U},{ }^{238} \mathrm{U}$, and ${ }^{137} \mathrm{Cs}$ because these radionuclides constitute over 98 percent of the dose potential from $\mathrm{CH}$ and $\mathrm{RH}$ waste. A combination of measured concentration or activity results, the $2 \sigma T P U$ and MDC, were used as input nuclide data in the CAP88-PC computer model to calculate the EDEs to members of the public (see Section 4.1.4 for more information on the results and discussion of the effluent monitoring data).

CAP88-PC dose calculations are based on the assumption that exposed persons remain at home during the entire year and all vegetables, milk, and meat consumed are home produced. Thus, this dose calculation is a maximum potential dose which encompasses dose from inhalation, submersion, deposition, and ingestion of radionuclides emitted via the air pathway from the WIPP facility.

\subsubsection{Total Potential Dose From WIPP Operations}

The radiation dose equivalent received by members of the public as a result of the management and storage of TRU radioactive wastes at any disposal facility operated by the DOE is regulated under 40 CFR Part 191, Subpart A. Specific standards state that the combined annual dose equivalent to any member of the public in the general environment resulting from the discharges of radioactive material and direct radiation from management and storage shall not exceed $0.25 \mathrm{mSv}$ ( $25 \mathrm{mrem}$ ) to the whole body and $0.75 \mathrm{mSv}$ (75 mrem) to any other critical organ. Section 4.8.4.3 discusses the 
potential dose equivalent received from radionuclides released to the air from WIPP. The following sections discuss the potential dose equivalent through other pathways and the total potential dose equivalent a member of the public may have received from the WIPP facility during 2010.

\subsubsection{Potential Dose From Water Ingestion Pathway}

The potential dose to individuals from the ingestion of WIPP facility-related radionuclides transported in water is determined to be zero for several reasons. Drinking water for communities near the WIPP facility comes from groundwater sources that are not expected to be affected by WIPP facility contaminants based on current radionuclide transport scenarios summarized in the Waste Isolation Pilot Plant Documented Safety Analysis (DOE/WIPP-08-3372). The only credible pathway for contaminants from the WIPP facility to accessible groundwater is through the Culebra as stated in Title 40 CFR Part 191 Compliance Certification Application for the Waste Isolation Pilot Plant 2004 (DOE/CAO-96-2184). Water from the Culebra is naturally not potable due to high levels of TDS. Water from the Dewey Lake is suitable for livestock consumption, having TDS values below 10,000 milligrams per liter (mg/L). Groundwater samples collected around the WIPP facility during 2010 did not contain radionuclide concentrations discernable from those in samples collected prior to the WIPP facility receiving waste.

\subsubsection{Potential Dose from Wild Game Ingestion}

Game animals sampled during 2010 were deer, rabbit, fish, javelina and quail. The only radionuclides detected were not different from baseline levels measured prior to commencement of waste shipments to the WIPP facility. Therefore, no dose from WIPP facility-related radionuclides could have been received by any individual from this pathway during 2010.

\subsubsection{Total Potential Dose from All Pathways}

The only credible pathway from the WIPP facility to humans is through air emissions and, therefore, this is the only pathway for which a dose is calculated. The total radiological dose and atmospheric release at WIPP in 2010 is summarized in Table 4.23 for the regulations in both 40 CFR $\$ 61.92$ and 40 CFR §191.03(b).

In compliance with 40 CFR Part 191, Subpart A, the receptor selected is assumed to reside year-round at the fence line in the northwest sector. For 2010, the dose to this receptor was estimated to be $<1.31 \mathrm{E}-05 \mathrm{mSv}(1.31 \mathrm{E}-03 \mathrm{mrem})$ per year for the whole body and $<1.73 \mathrm{E}-05 \mathrm{mSv}(1.73 \mathrm{E}-03 \mathrm{mrem})$ per year to the critical organ. These values are in compliance with the requirements specified in 40 CFR §191.03(b).

For the NESHAP standard (40 CFR \$61.92), the EDE potentially received by the MEl in 2010 assumed to be residing $7.5 \mathrm{~km}(4.66 \mathrm{mi})$ west-northwest of WIPP is calculated to be $<1.91 \mathrm{E}-07 \mathrm{mSv}(1.91 \mathrm{E}-05 \mathrm{mrem})$ per year for the whole body. This value is in compliance with 40 CFR $\S 61.92$ requirements. 


\section{Waste Isolation Pilot Plant Annual Site Environmental Report for 2010 DOE/WIPP-11-2225}

As required by DOE Order 5400.5, Chapter II, Section 6.b, the collective dose to the public within $80 \mathrm{~km}$ (50 mi) of the WIPP facility has been evaluated, and is 6.08E-07 Sv (6.08E-05 rem) in 2010.

Table 4.23 - WIPP Radiological Dose and Release Summary

\begin{tabular}{|c|c|c|c|c|c|c|c|c|}
\hline \multicolumn{9}{|c|}{ WIPP Radiological Atmospheric Releases ${ }^{\mathrm{a}}$ During 2010} \\
\hline \multicolumn{2}{|c|}{${ }^{238} \mathrm{Pu}$} & \multicolumn{2}{|c|}{\begin{tabular}{l|l}
${ }^{239 / 240} \mathrm{Pu}$ & \\
\end{tabular}} & \multicolumn{2}{|c|}{${ }^{241} \mathrm{Am}$} & \multicolumn{3}{|c|}{${ }^{90} \mathrm{Sr}$} \\
\hline \multicolumn{2}{|c|}{ 8.1E-08 Ci } & \multicolumn{2}{|c|}{ 7.1E-08 Ci } & \multicolumn{2}{|c|}{ 8.9E-08 Ci } & \multicolumn{3}{|c|}{ 1.8E-06 Ci } \\
\hline \multicolumn{2}{|c|}{$2,997 \mathrm{~Bq}$} & \multicolumn{2}{|c|}{$2,627 \mathrm{~Bq}$} & \multicolumn{2}{|c|}{$3,293 \mathrm{~Bq}$} & \multicolumn{3}{|c|}{$66,600 \mathrm{~Bq}$} \\
\hline \multicolumn{2}{|c|}{${ }^{233 / 234} U$} & \multicolumn{2}{|c|}{${ }^{238} \mathrm{U}$} & \multicolumn{2}{|c|}{${ }^{137} \mathrm{Cs}$} & & & \\
\hline \multicolumn{2}{|c|}{ 1.7E-07 Ci } & \multicolumn{2}{|c|}{ 1.3E-07 Ci } & \multicolumn{2}{|c|}{ 1.3E-04 Ci } & & & \\
\hline \multicolumn{2}{|c|}{$6,290 \mathrm{~Bq}$} & \multicolumn{2}{|c|}{$4,810 \mathrm{~Bq}$} & \multicolumn{2}{|c|}{$4.81 \mathrm{E}+06 \mathrm{~Bq}$} & & & \\
\hline \multicolumn{9}{|c|}{ WIPP Radiological Dose Reporting Table in 2010} \\
\hline \multirow[t]{2}{*}{ Pathway } & \multicolumn{2}{|c|}{$\begin{array}{c}\text { EDE to the MEI at } 7,500 \\
\text { Meters WNW }\end{array}$} & \multirow{2}{*}{$\begin{array}{l}\text { Percent of } \\
\text { EPA 10- } \\
\text { mrem/ Year } \\
\text { Limit to } \\
\text { Member of the } \\
\text { Public }\end{array}$} & \multicolumn{2}{|c|}{$\begin{array}{l}\text { Estimated Population } \\
\text { Dose Within } 50 \text { Miles }\end{array}$} & \multirow{2}{*}{\multicolumn{2}{|c|}{$\begin{array}{l}\text { Estimated } \\
\text { Population } \\
\text { Dose Within } \\
50 \text { Miles }^{b}\end{array}$}} & $\begin{array}{l}\text { Estimated } \\
\text { Natural } \\
\text { Radiation } \\
\text { Population } \\
\text { Dose }^{\mathrm{C}}\end{array}$ \\
\hline & (mrem/year) & (mSv/year) & & $\begin{array}{l}\text { (person- } \\
\text { rem/year) }\end{array}$ & $\begin{array}{l}\text { (person- } \\
\text { Sv/year) }\end{array}$ & & & $\begin{array}{l}\text { (person- } \\
\text { rem) }\end{array}$ \\
\hline Air & 1.91E-05 & $1.91 \mathrm{E}-07$ & 1.91E-04 & $6.08 \mathrm{E}-05$ & $6.08 \mathrm{E}-07$ & 101 & 017 & 30,305 \\
\hline Water & $N / A^{d}$ & N/A & N/A & N/A & N/A & & & N/A \\
\hline $\begin{array}{c}\text { Other } \\
\text { Pathways }\end{array}$ & N/A & N/A & $\mathrm{N} / \mathrm{A}$ & $\mathrm{N} / \mathrm{A}$ & $\mathrm{N} / \mathrm{A}$ & & & $\mathrm{N} / \mathrm{A}$ \\
\hline \multicolumn{9}{|c|}{ WIPP Radiological Dose Reporting Table in 2010} \\
\hline \multirow[t]{2}{*}{ Pathway } & \multicolumn{2}{|c|}{$\begin{array}{l}\text { Dose equivalent to the whole } \\
\text { body of the receptor who } \\
\text { resides year-round at WIPP } \\
\text { fence line } 350 \text { meters NW }\end{array}$} & \multirow{2}{*}{$\begin{array}{l}\text { Percent of } \\
\text { EPA } \\
\text { 25-mrem/Year } \\
\text { Whole Body } \\
\quad \text { Limit }\end{array}$} & \multicolumn{3}{|c|}{$\begin{array}{l}\text { Dose equivalent to the critical } \\
\text { organ of the receptor who } \\
\text { resides year-round at WIPP } \\
\text { fence line } 350 \text { meters NW }\end{array}$} & \multirow{2}{*}{\multicolumn{2}{|c|}{$\begin{array}{c}\text { Percent of EPA } \\
\text { 75-mrem/Year } \\
\text { Critical Organ Limit }\end{array}$}} \\
\hline & (mrem/year) & (mSv/year) & & (mrem/year) & (mSv/ye & & & \\
\hline Air & 1.31E-03 & 1.31E-05 & $5.24 \mathrm{E}-03$ & 1.73E-03 & 1.73E-C & & & $.31 E-03$ \\
\hline Water & N/A & $\mathrm{N} / \mathrm{A}$ & $\mathrm{N} / \mathrm{A}$ & $\mathrm{N} / \mathrm{A}$ & $\mathrm{N} / \mathrm{A}$ & & & $\mathrm{N} / \mathrm{A}$ \\
\hline $\begin{array}{c}\text { Other } \\
\text { Pathways }\end{array}$ & N/A & $\mathrm{N} / \mathrm{A}$ & N/A & N/A & $N / A$ & & & N/A \\
\hline \multicolumn{9}{|c|}{$\begin{array}{l}\text { (a) Total releases from combination of Stations A, B, and C. Values are calculated from detected activities plus } \\
2 \sigma T P U \text { or the MDC, whichever are greater and multiplied by the ratio of flow to stack flow volumes. } \\
\text { (b) Source: } 2003 \text { Census Data. } \\
\text { (c) Estimated natural radiation populations dose = (estimated population within } 50 \mathrm{mi}) \times(300 \mathrm{mrem} / \text { year). } \\
\text { (d) Not applicable at WIPP. }\end{array}$} \\
\hline
\end{tabular}




\section{Waste Isolation Pilot Plant Annual Site Environmental Report for 2010 DOE/WIPP-11-2225}

\subsubsection{Dose to Nonhuman Biota}

Dose limits for populations of aquatic and terrestrial organisms are discussed in NCRP Report No. 109, Effects of Ionizing Radiation on Aquatic Organisms (NCRP, 1991), and the International Atomic Energy Agency Technical Report Series No. 332, Effects of Ionizing Radiation on Plants and Animals at Levels Implied by Current Radiation Protection Standards. Those dose limits are:

- $\quad$ Aquatic animals - $10 \mathrm{mGy} / \mathrm{d}(1 \mathrm{rad} / \mathrm{d})$

- Terrestrial plants - $10 \mathrm{mGy} / \mathrm{d}(1 \mathrm{rad} / \mathrm{d})$

- $\quad$ Terrestrial animals - $1 \mathrm{mGy} / \mathrm{d}(0.1 \mathrm{rad} / \mathrm{d})$

The DOE has considered establishing these dose standards for aquatic and terrestrial biota in proposed rule 10 CFR Part 834, "Radiation Protection of the Public and the Environment," but has delayed finalizing this rule until guidance for demonstrating compliance was developed. A Graded Approach for Evaluating Radiation Doses to Aquatic and Terrestrial Biota (DOE-STD-1153-2002) was developed to meet this need.

The DOE requires reporting of radiation doses to nonhuman biota in the ASER using DOE-STD-1153-2002, which requires an initial general screening using conservative assumptions. In the initial screen, biota concentration guides (BCGs) are derived using conservative assumptions for a variety of generic organisms. Maximum concentrations of radionuclides detected in soil, sediment, and water during environmental monitoring are divided by the BCGs and the results are summed for each organism. If the sum of these fractions is $<1.0$, the site is deemed to have passed the screen and no further action is required. This screening evaluation is intended to provide a very conservative evaluation of the site in relation to the recommended limits. This guidance was used to screen radionuclide concentrations observed around WIPP during 2010 using the maximum radionuclide concentrations listed in Table 4.24, and the sum of fractions was $<1.0$ for all media. The element ${ }^{40} \mathrm{~K}$ is not included in Table 4.24 since it is a natural component of the earth's crust and is not part of TRU-waste-related radionuclides.

Table 4.24 - General Screening Results for Potential Radiation Dose to Nonhuman Biota From Radionuclide Concentrations in Surface Water (Bq/L), Sediment (Bq/g), and Soil (Bq/g) near the WIPP Site in 2010

\begin{tabular}{|c|c|c|c|c|}
\hline Medium & Radionuclide & $\begin{array}{l}\text { Maximum Detected } \\
\text { Concentration }\end{array}$ & $\mathrm{BCG}^{\mathrm{a}}$ & Concentration/BCG \\
\hline \multicolumn{5}{|c|}{ Aquatic System Evaluation } \\
\hline \multirow{6}{*}{ Sediment $(\mathrm{Bq} / \mathrm{g})$} & ${ }^{90} \mathrm{Sr}$ & ND & $2.00 \mathrm{E}+01$ & NA \\
\hline & ${ }^{137} \mathrm{Cs}$ & 1.12E-02 & $1.00 \mathrm{E}+02$ & 1.12E-04 \\
\hline & ${ }^{238} \mathrm{U}$ & 3.04E-02 & $9.00 \mathrm{E}+01$ & 3.38E-04 \\
\hline & ${ }^{238} \mathrm{Pu}$ & ND & $2.00 \mathrm{E}+02$ & NA \\
\hline & ${ }^{239 / 240} \mathrm{Pu}$ & 7.12E-04 & $2.00 \mathrm{E}+02$ & 3.56E-06 \\
\hline & ${ }^{241} \mathrm{Am}$ & ND & $2.00 \mathrm{E}+02$ & NA \\
\hline
\end{tabular}




\section{Waste Isolation Pilot Plant Annual Site Environmental Report for 2010 DOE/WIPP-11-2225}

Table 4.24 - General Screening Results for Potential Radiation Dose to Nonhuman Biota From Radionuclide Concentrations in Surface Water (Bq/L), Sediment (Bq/g), and Soil (Bq/g) near the WIPP Site in 2010

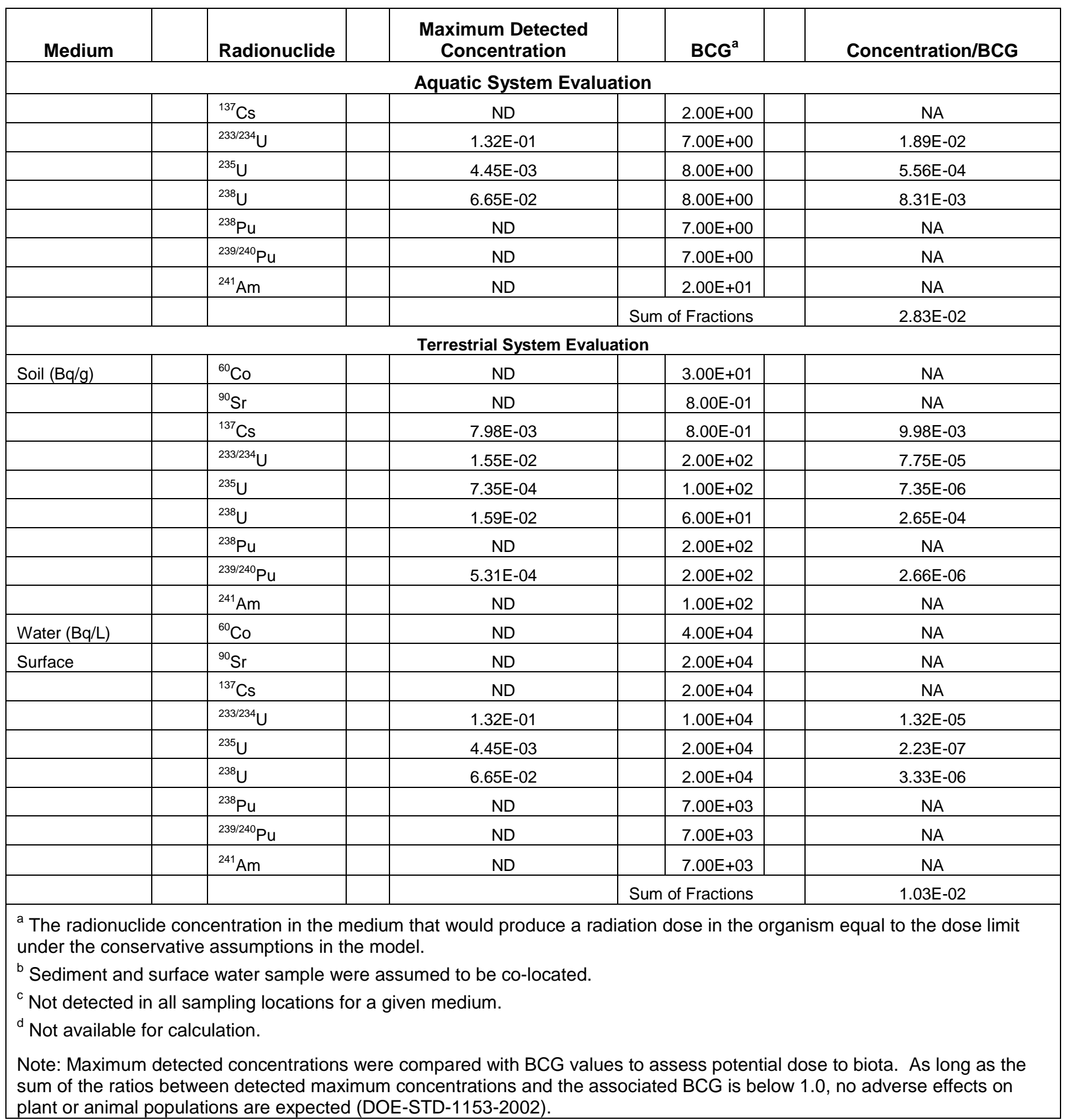




\subsubsection{Release of Property Containing Residual Radioactive Material}

There was no release of radiologically contaminated materials or property from the WIPP facility in 2010. The criteria used for release of potentially radioactive materials are specified in DOE Order 5400.5, Radiation Protection of the Public and the Environment, Figure IV-1, Allowable Total Residual Surface Contamination. The values in Order 5400.5 for transuranics are $<20$ percent of the values in ANSI/HPS [Health Physics Society] N13.12-1999, Surface and Volume Radioactivity Standards for Clearance.

\subsection{Radiological Program Conclusions}

\subsubsection{Effluent Monitoring}

For 2010, the EDE to the receptor (hypothetical MEI) who resides year-round at the fence line is <1.31E-05 mSv (1.31E-03 mrem) per year for the whole body, and is $<1.73 \mathrm{E}-05 \mathrm{mSv}$ (1.73E-03 mrem) per year for the critical organ. For the WIPP effluent monitoring program, Figure 4.5 and Table 4.25 show the dose to the whole body for the hypothetical MEI for CY 1999 to CY 2010. In addition, Figure 4.6 and Table 4.26 show the dose to the critical organ for the hypothetical MEI for CY 1999 to CY 2010. These dose equivalent values are below the $25 \mathrm{mrem}$ to the whole body and $75 \mathrm{mrem}$ to any critical organ, in accordance with the provisions of 40 CFR \$191.03(b).

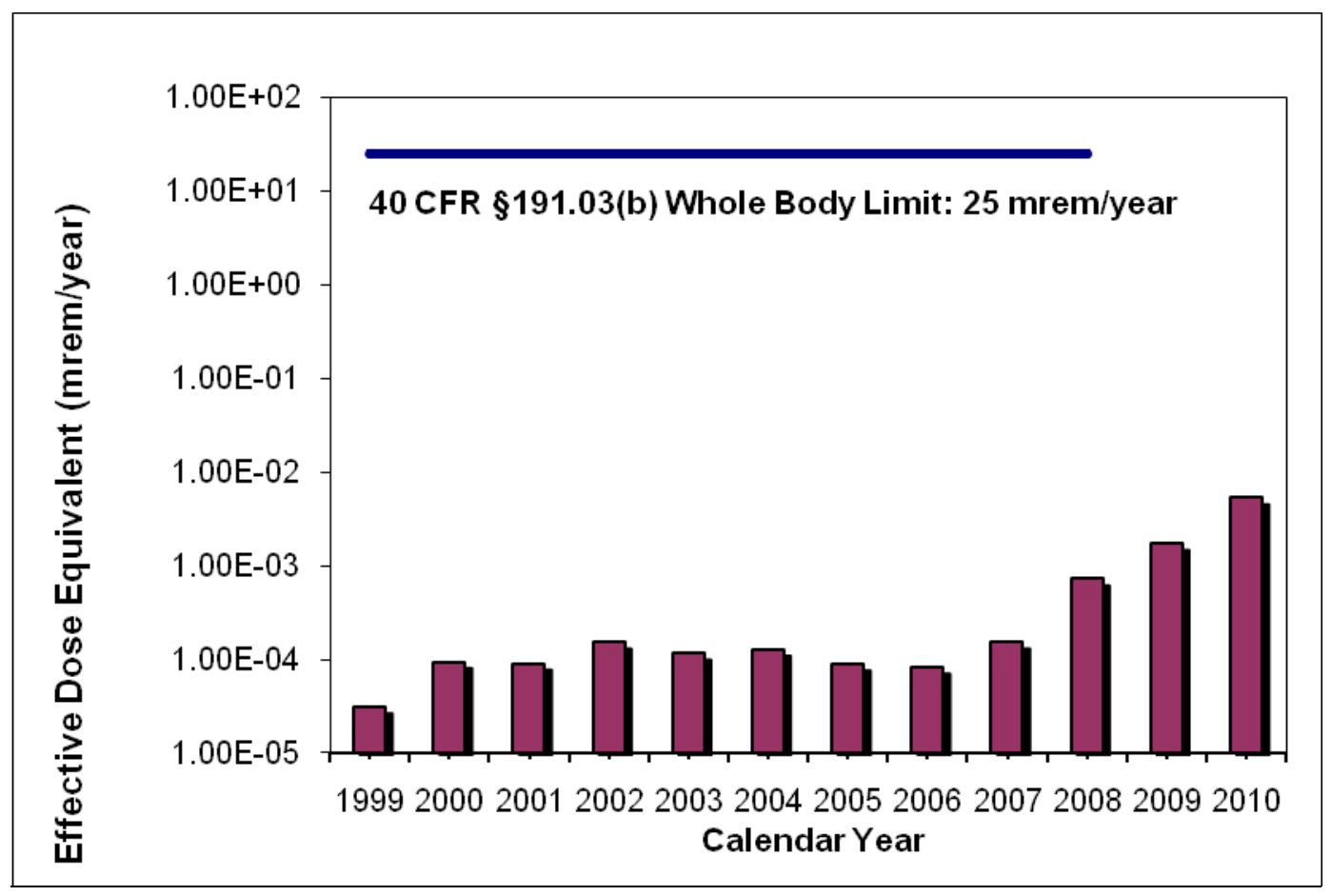

Figure 4.5 - Dose to the Whole Body for the Hypothetical Maximally Exposed Individual at the WIPP Fence Line 
Waste Isolation Pilot Plant Annual Site Environmental Report for 2010 DOE/WIPP-11-2225

Table 4.25 - Comparison of Dose to the Whole Body to EPA Limit of 25 mrem/year per 40 CFR 191.03(b)

\begin{tabular}{|c|c|c|}
\hline Year & Annual Dose (mrem/yr) & Percent of EPA Limit \\
\hline 1999 & $3.10 \mathrm{E}-05$ & 0.00012 \\
\hline 2000 & $9.35 \mathrm{E}-05$ & 0.00037 \\
\hline 2001 & $8.99 \mathrm{E}-05$ & 0.00036 \\
\hline 2002 & $1.51 \mathrm{E}-04$ & 0.00060 \\
\hline 2003 & $1.15 \mathrm{E}-04$ & 0.00046 \\
\hline 2004 & $1.27 \mathrm{E}-04$ & 0.00051 \\
\hline 2005 & $8.86 \mathrm{E}-05$ & 0.00035 \\
\hline 2006 & $8.16 \mathrm{E}-05$ & 0.00033 \\
\hline 2007 & $1.52 \mathrm{E}-04$ & 0.00061 \\
\hline 2008 & $7.14 \mathrm{E}-04$ & 0.00290 \\
\hline 2009 & $1.71 \mathrm{E}-03$ & 0.00684 \\
\hline 2010 & $5.24 \mathrm{E}-03$ & 0.02096 \\
\hline 40 CFR §191.03(b) Whole Body Limit & 25 & \\
\hline
\end{tabular}

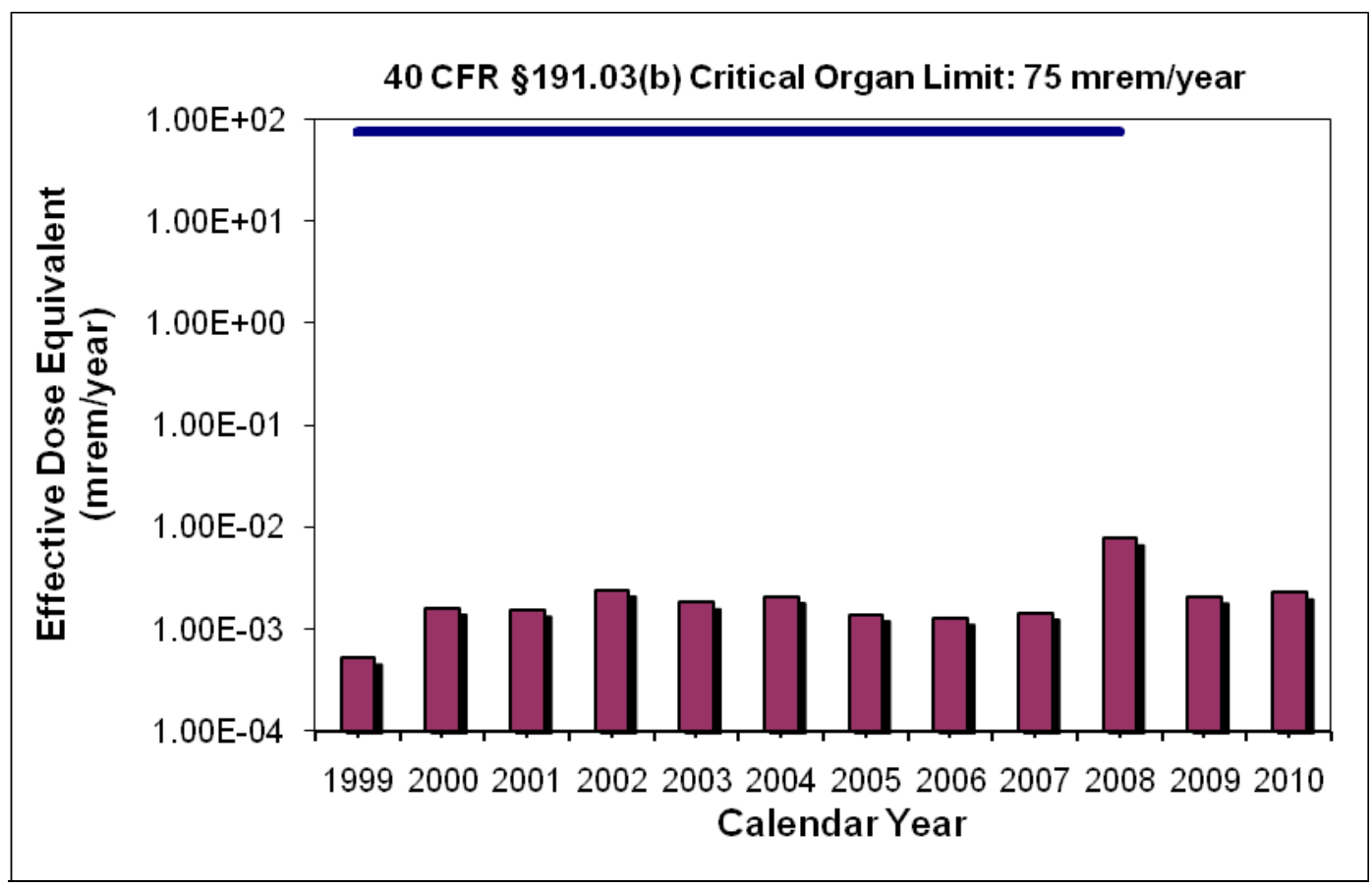

Figure 4.6 - Dose to the Critical Organ for Hypothetical Maximally Exposed Individual at the WIPP Fence Line 
Waste Isolation Pilot Plant Annual Site Environmental Report for 2010 DOE/WIPP-11-2225

Table 4.26 - Comparison of Dose to the Critical Organ to EPA Limit of 75 mrem/year per 40 CFR §191.03(b)

\begin{tabular}{|c|c|c|}
\hline Year & Annual Dose (mrem/yr) & Percent of EPA Limit \\
\hline 1999 & $5.30 \mathrm{E}-04$ & 0.00071 \\
\hline 2000 & $1.63 \mathrm{E}-03$ & 0.0022 \\
\hline 2001 & $1.56 \mathrm{E}-03$ & 0.0021 \\
\hline 2002 & $2.46 \mathrm{E}-03$ & 0.0033 \\
\hline 2003 & $1.85 \mathrm{E}-03$ & 0.0025 \\
\hline 2004 & $2.11 \mathrm{E}-03$ & 0.0028 \\
\hline 2005 & $1.41 \mathrm{E}-03$ & 0.0019 \\
\hline 2006 & $1.30 \mathrm{E}-03$ & 0.0017 \\
\hline 2007 & $1.46 \mathrm{E}-03$ & 0.0019 \\
\hline 2008 & $7.81 \mathrm{E}-03$ & 0.0014 \\
\hline 2009 & $2.10 \mathrm{E}-03$ & 0.0028 \\
\hline 2010 & $2.31 \mathrm{E}-03$ & 0.0031 \\
\hline 40 CFR §191.03(b) Critical Organ Limit & 75 & \\
\hline
\end{tabular}

In addition, for 2010, the EDE to the MEl from normal operations conducted at the WIPP facility is <1.91E-03 mSv (1.91E-05 mrem). For the WIPP effluent monitoring program, Figure 4.7 and Table 4.27 show the EDE to the MEI for CY 1999 to CY 2010. These EDE values are more than six orders of magnitude below the EPA NESHAP standard of 10 mrem per year, as specified in 40 CFR $§ 61.92$.

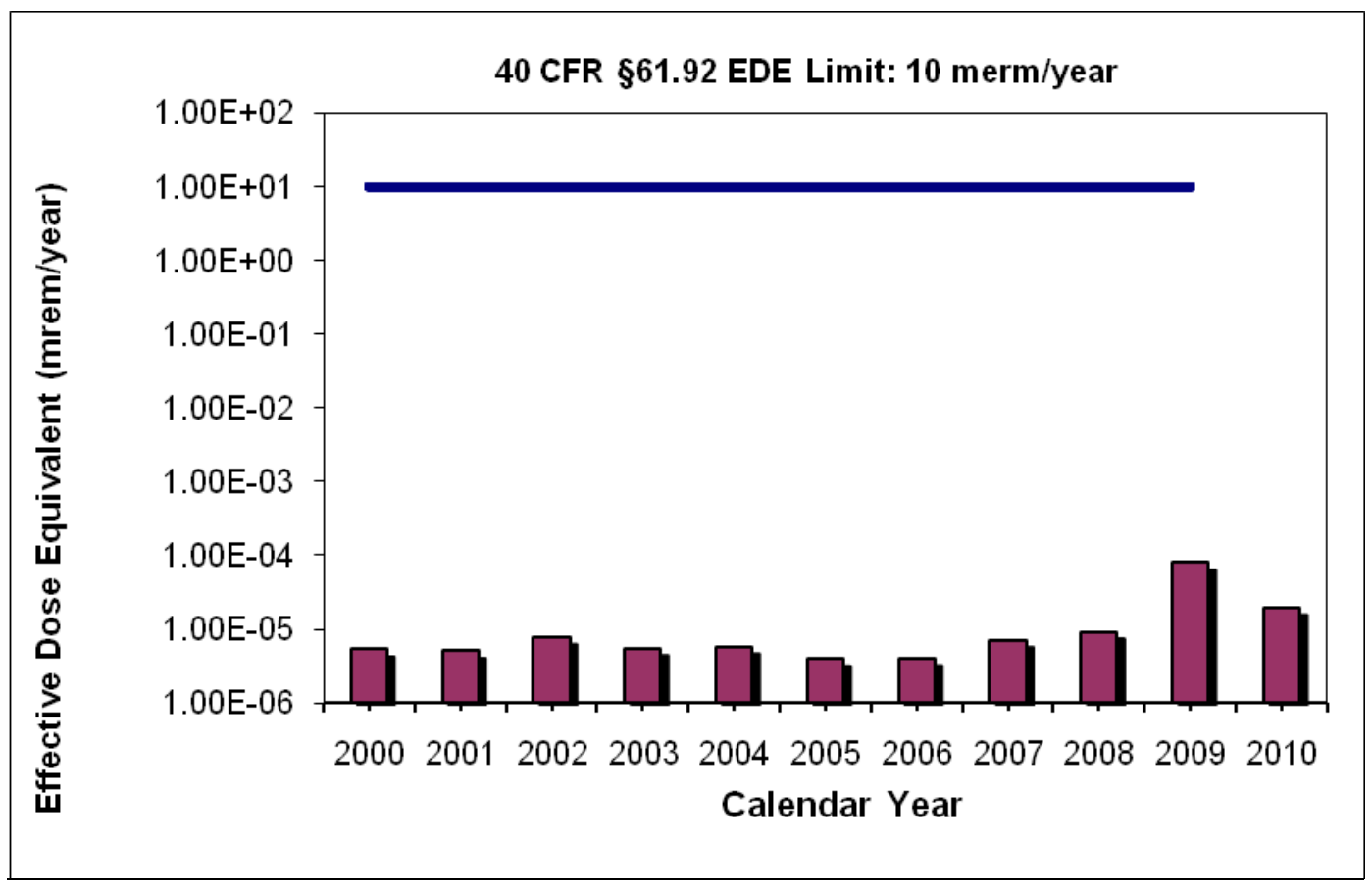

Figure 4.7 - WIPP Effective Dose Equivalent to the Off-Site Maximally Exposed Individual 
Waste Isolation Pilot Plant Annual Site Environmental Report for 2010 DOE/WIPP-11-2225

Table 4.27 - Comparison of EDEs to EPA Limit of 10 mrem/year per 40 CFR $\$ 61.92$

\begin{tabular}{|c|c|c|}
\hline Year & Annual Dose (mrem/yr) & Percent of EPA Limit \\
\hline 1999 & $2.23 \mathrm{E}-06$ & 0.000022 \\
\hline 2000 & $5.18 \mathrm{E}-06$ & 0.000051 \\
\hline 2001 & $4.96 \mathrm{E}-06$ & 0.000050 \\
\hline 2002 & $7.61 \mathrm{E}-06$ & 0.000076 \\
\hline 2003 & $5.43 \mathrm{E}-06$ & 0.000054 \\
\hline 2004 & $5.69 \mathrm{E}-06$ & 0.000057 \\
\hline 2005 & $3.85 \mathrm{E}-06$ & 0.000039 \\
\hline 2006 & $3.93 \mathrm{E}-06$ & 0.000039 \\
\hline 2007 & $7.01 \mathrm{E}-06$ & 0.000070 \\
\hline 2008 & $9.05 \mathrm{E}-06$ & 0.000091 \\
\hline 2009 & $7.80 \mathrm{E}-05$ & 0.000780 \\
\hline 2010 & $1.91 \mathrm{E}-05$ & 0.000191 \\
\hline
\end{tabular}

\subsubsection{Environmental Monitoring}

Radionuclide concentrations observed in environmental monitoring were extremely small and comparable to radiological baseline levels. Appendix $\mathrm{H}$ contains graphs comparing detected radionuclide concentrations to their respective baseline values. In cases where the radionuclide concentrations slightly exceeded baseline levels (uranium isotopes and ${ }^{40} \mathrm{~K}$ in some samples), these differences are most likely due to natural spatial variability, and they are so far below the regulatory limit as to be nonimpactive. 
This page intentionally left blank. 
CHAPTER 5 - ENVIRONMENTAL NONRADIOLOGICAL PROGRAM INFORMATION

Nonradiological programs at the WIPP facility include land management, meteorological monitoring, $\mathrm{VOC}$ monitoring, hydrogen and methane monitoring, seismic monitoring, certain aspects of liquid effluent, surface and groundwater monitoring. The monitoring is performed to comply with the provisions of the WIPP authorization documents. Radiological and nonradiological groundwater monitoring is discussed in Chapters 4 and 6 , respectively.

\subsection{Principal Functions of Nonradiological Sampling}

The principal functions of the nonradiological environmental surveillance program are to

- $\quad$ Assess the impacts of WIPP facility operations on the surrounding ecosystem.

- Monitor ecological conditions in the Los Medaños region.

- $\quad$ Provide environmental data which are important to the mission of the WIPP project, but which have not or will not be acquired by other programs.

- $\quad$ Comply with applicable commitments (e.g., BLM/DOE Memorandum of Understanding and interagency agreements).

\subsection{Land Management Programs}

On October 30, 1992, the WIPP LWA was signed by the President. This law transfers the responsibility for the management of the 16 sections of land that compromises the WIPP site to the Secretary of Energy.

The DOE developed an LMP as required to identify resource values, promote multipleuse management, and identify long-term goals for the management of WIPP lands. The LMP was developed in consultation with the BLM and the state of New Mexico.

The LMP sets forth cooperative arrangements and protocols for addressing WIPPrelated land management actions. Commitments contained in current permits, agreements, or concurrent Memoranda of Understanding with other agencies will be respected when addressing and evaluating land use management activities and future amendments that affect the management of WIPP lands.

In November 2010 the DOE, with concurrence from the U.S. Department of Interior and New Mexico State agencies, issued an update to the LMP as provided in Chapter 1 of the LMP. The update includes reference to the January 2010 formal transfer of the WIPP South Access Road right-of-way, formerly Eddy County Road 802, to the DOE for a 40-year term. 


\subsubsection{Land Use Requests}

Parties who wish to conduct activities that may impact lands under the jurisdiction of the DOE, but outside the Property Protection Area, are required by the LMP to prepare a land use request. A land use request consists of a narrative description of the project, a completed environmental review, and a map depicting the location of the proposed activity. This documentation is used to determine if applicable regulatory requirements have been met prior to the approval of a proposed project. A land use request is submitted to the Land Use Coordinator by organizations wishing to complete construction, right-of-way, pipeline easement, or similar action within the WIPP LWA or on lands used in the operation of the WIPP facility, under the jurisdiction of the DOE. In 2010, eight land use requests were submitted to, and approved by, the Land Use Coordinator.

\subsubsection{Wildlife Population Monitoring}

In 1995, the USFWS provided an updated list of threatened and endangered species for Eddy and Lea Counties, New Mexico. Included were 18 species that may be present on DOE lands. A comprehensive evaluation in support of the SEIS-II (Waste Isolation Pilot Plant Disposal Phase Final Supplemental Environmental Impact Statement, DOE/EIS-0026-S-2) was conducted in 1996 to determine the presence or absence of threatened or endangered species in the vicinity of the WIPP site and the effect of WIPP facility operations on these species. Results indicated that activities associated with the operation of the WIPP facility have no impact on any threatened or endangered species.

Employees of the WIPP facility continue to consider resident species when planning activities that may impact their habitat, in accordance with the DOE/BLM memorandum of understanding, the Joint Powers Agreement with the state of New Mexico, and 50 CFR Part 17, "Endangered and Threatened Plants and Wildlife." An example of this is protection is the Lesser Prairie Chicken (a candidate for listing under the Endangered Species Act) and its habitat in accordance with BLM guidance.

\subsubsection{Reclamation of Disturbed Lands}

Reclamation serves to mitigate the effects of WIPP-related activities on affected plant and animal communities. The objective of the reclamation program is to restore lands used in the operation of the WIPP facility that are no longer needed for those activities. Reclamation is intended to reduce soil erosion, increase the rate of plant colonization and succession, and provide habitat for wildlife in disturbed areas.

The DOE follows a reclamation program and a long-range reclamation plan in accordance with the LMP and specified permit conditions. As locations are identified for reclamation, WIPP personnel reclaim these areas by using the best acceptable reclamation practices. Seed mixes used reflect those species indigenous to the area, with priority given to those plant species which are conducive to soil stabilization, wildlife, and livestock needs. 


\subsubsection{Oil and Gas Surveillance}

Oil and gas activities within $1.6 \mathrm{~km}(1 \mathrm{mi})$ of the WIPP site boundary are routinely monitored in accordance with the LMP to identify new activities associated with oil and gas exploration and production, including the following:

- $\quad$ Survey staking

- $\quad$ Geophysical exploration

- $\quad$ Drilling

- $\quad$ Pipeline construction

- Work-overs

- $\quad$ Changes in well status

- $\quad$ Anomalous occurrences (e.g., leaks, spills, accidents)

During 2010, WIPP surveillance teams conducted weekly surveillances and field inspections.

Proposed new well locations staked within one mile of the WIPP site are field-verified. This ensures that the proposed location is of sufficient distance from the WIPP boundary to protect the WIPP site from potential trespass. Eight new wells were drilled and completed in 2010. If a well is within $330 \mathrm{ft}$ of the WIPP site boundary, the driller is required to submit daily deviation surveys to the WIPP Land Use Coordinator to assess the horizontal drift of the well bore during drilling. Deviation calculations showed that there were no trespass conditions.

\subsection{Meteorological Monitoring}

The WIPP facility meteorological station is located $600 \mathrm{~m}(1,970 \mathrm{ft})$ northeast of the Waste Handling Building. The main function of the station is to provide data for atmospheric dispersion modeling. The station measures and records wind speed, wind direction, and temperature at elevations of 2, 10, and $50 \mathrm{~m}(6.5,33$, and $165 \mathrm{ft})$.

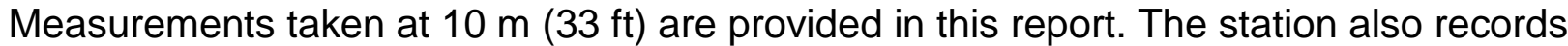
ground-level measurements of barometric pressure, relative humidity, precipitation, and solar radiation.

\subsubsection{Weather Data}

The precipitation at the WIPP site for 2010 was $329.95 \mathrm{~mm}$ (12.9 in.). Figure 5.1 displays the monthly precipitation at the WIPP site. 


\section{Precipitation}

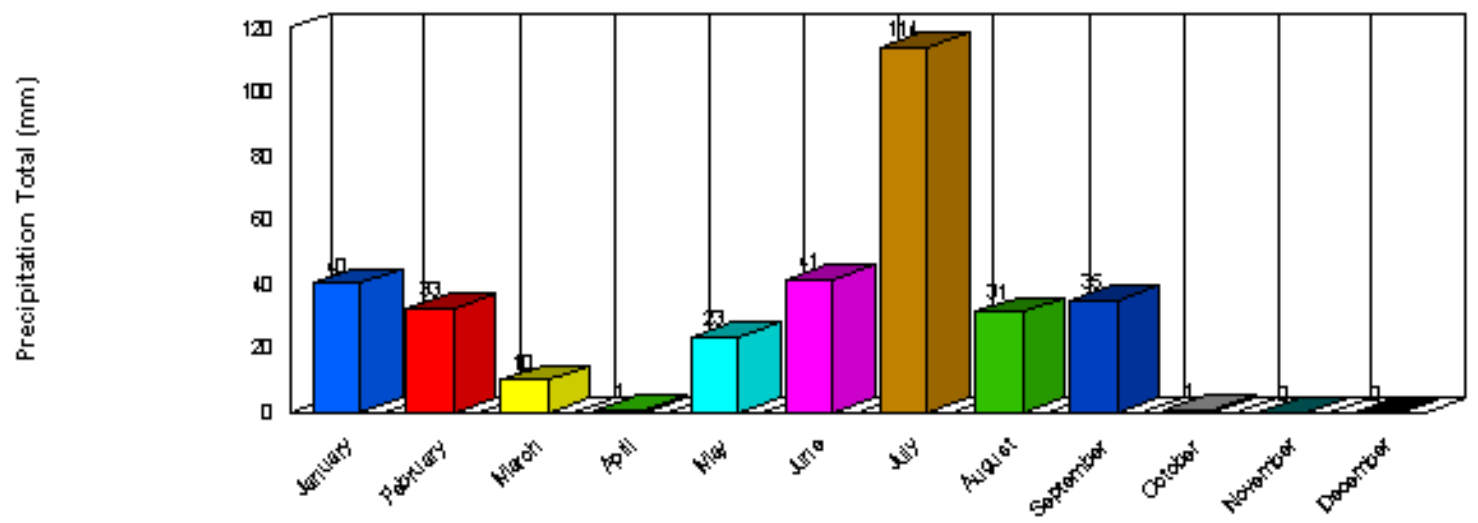

Figure 5. 1 - WIPP Precipitation Report for 2010

The maximum recorded temperature at the WIPP site in 2010 was $41.25^{\circ} \mathrm{C}\left(106.25^{\circ} \mathrm{F}\right)$ in June (Figure 5.2). Monthly temperatures are illustrated in Figure 5.2, Figure 5.3, and Figure 5.4. The mean temperature at the WIPP site in 2010 was $17.33^{\circ} \mathrm{C}\left(63.19^{\circ} \mathrm{F}\right)$. The average monthly temperatures for the WIPP area ranged from $27.8^{\circ} \mathrm{C}\left(82.04^{\circ} \mathrm{F}\right)$ during June to $5.58^{\circ} \mathrm{C}\left(42.04^{\circ} \mathrm{F}\right)$ in January (Figure 5.3). The lowest recorded temperature was $-7.97^{\circ} \mathrm{C}\left(17.65^{\circ} \mathrm{F}\right)$ in January (Figure 5.4$)$.

Highs

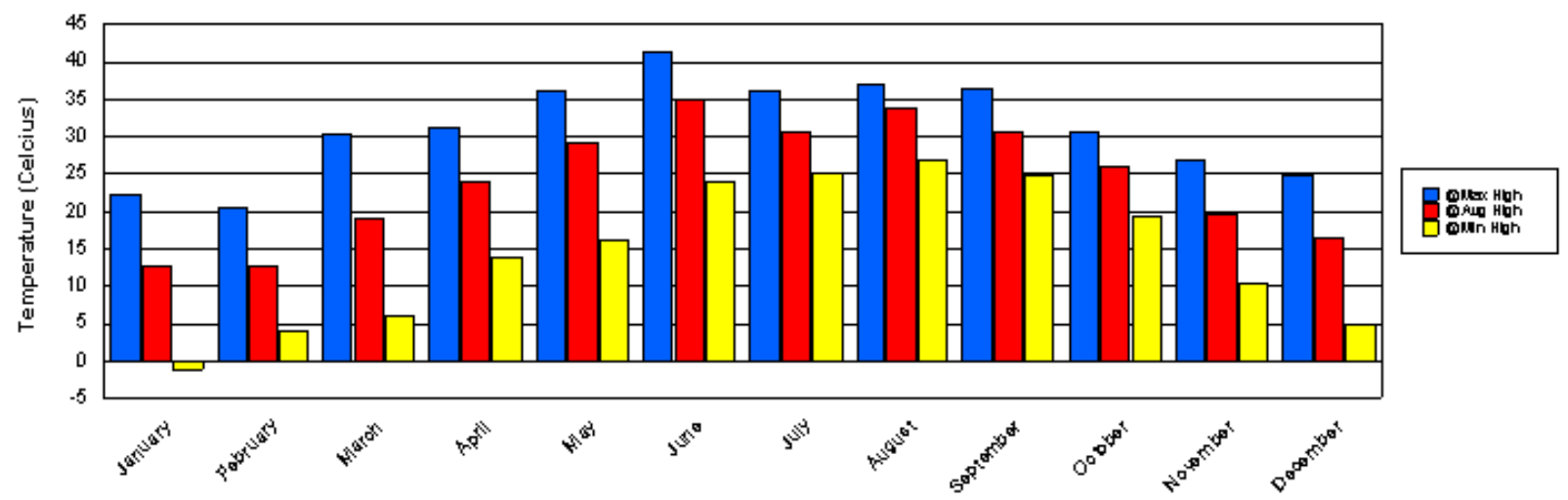

Figure 5.2 - WIPP High Temperatures for 2010 
Averages

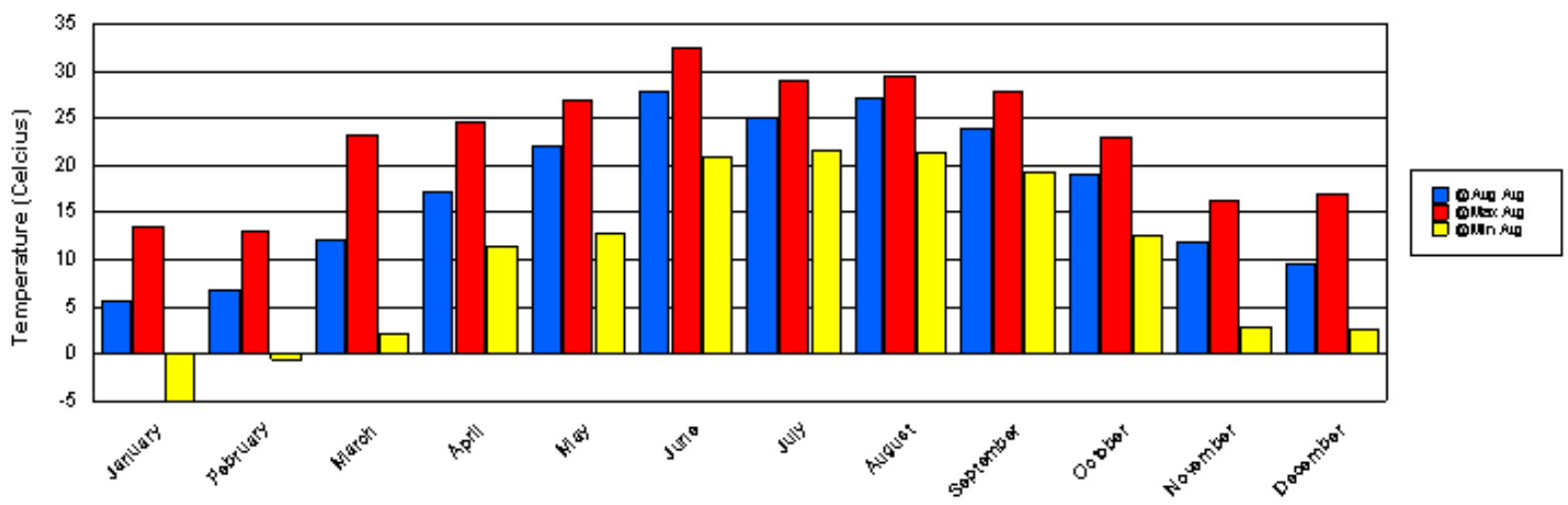

Figure 5.3 - WIPP Average Temperatures for 2010

\section{Lows}

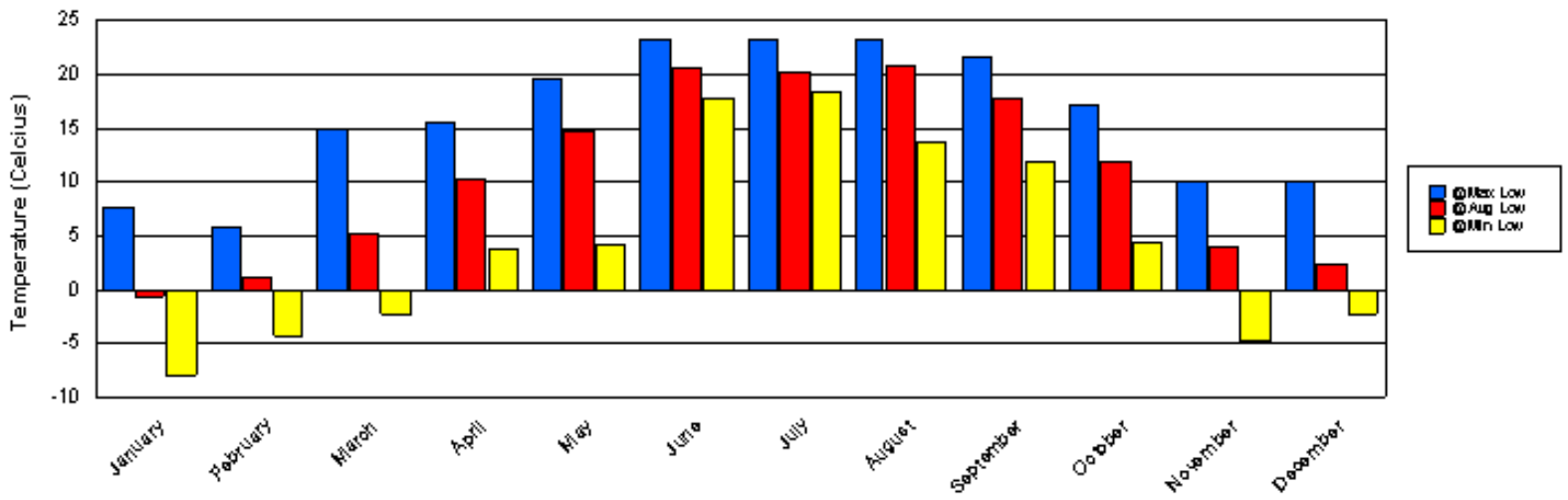

Figure 5.4 - WIPP Average Low Temperatures for 2010

\subsubsection{Wind Direction and Wind Speed}

Winds in the WIPP area are predominantly from the southeast. In 2010, wind speed measured at the 10-m (33-ft) level was calm (less than 0.5 meters per second [m/s]) (1.1 miles per hour [mph]) approximately 55 percent of the time. Winds of 3.71 to 6.30 $\mathrm{m} / \mathrm{s}$ (8.30 to $14.09 \mathrm{mph}$ ) were the most prevalent over 2010, occurring approximately 38.8 percent of the time. There were no tornadoes at the WIPP site in 2010; the strongest wind recorded at WIPP was $16.95 \mathrm{~m} / \mathrm{s}$ (37.92 mph). Figure 5.5 displays the annual wind data at WIPP for 2010. 


\section{Percent Occurrence By Direction}

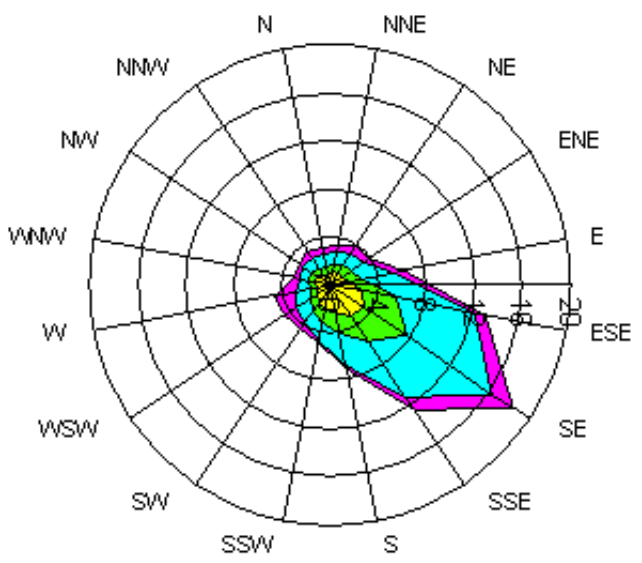

Figure 5.5 - Wind Speed Report for 2010

\begin{tabular}{|c|c|c|c|c|c|c|c|}
\hline & & anuary 1,2 & $\begin{array}{l}\text { nd Speed R } \\
\text { to Decemb }\end{array}$ & $\begin{array}{l}\text { ort (meters) } \\
31,2010-\mathrm{E}\end{array}$ & $\begin{array}{l}\text { econd) } \\
\text { evation } 10.0\end{array}$ & neters & \\
\hline $\begin{array}{c}\text { Wind } \\
\text { Direction }\end{array}$ & $0.0-0.50$ & $0.51-1.40$ & $1.41-2.80$ & $2.81-3.70$ & $3.71-6.30$ & $>6.30$ & $\begin{array}{l}\text { Total Percent } \\
\text { Occurrence by } \\
\text { Direction }\end{array}$ \\
\hline$E$ & 0.04 & 0.37 & 1.14 & 1.08 & 2.74 & 0.98 & 6.34 \\
\hline ENE & 0.03 & 0.37 & 0.84 & 0.81 & 1.30 & 0.56 & 3.91 \\
\hline NE & 0.03 & 0.30 & 0.88 & 0.80 & 1.19 & 0.70 & 3.88 \\
\hline NNE & 0.04 & 0.26 & 0.89 & 0.59 & 1.05 & 0.58 & 3.40 \\
\hline $\mathrm{N}$ & 0.03 & 0.20 & 0.63 & 0.64 & 1.18 & 0.45 & 3.14 \\
\hline NNW & 0.04 & 0.20 & 0.73 & 0.58 & 1.10 & 0.68 & 3.32 \\
\hline NW & 0.03 & 0.28 & 0.97 & 0.56 & 0.88 & 0.31 & 3.03 \\
\hline WNW & 0.03 & 0.28 & 0.99 & 0.43 & 0.74 & 0.63 & 3.11 \\
\hline W & 0.06 & 0.29 & 0.78 & 0.52 & 1.24 & 1.80 & 4.69 \\
\hline WSW & 0.02 & 0.32 & 0.97 & 0.68 & 1.44 & 1.15 & 4.58 \\
\hline SW & 0.04 & 0.40 & 1.30 & 0.94 & 1.09 & 0.61 & 4.37 \\
\hline SSW & 0.03 & 0.43 & 1.71 & 1.07 & 1.48 & 0.27 & 4.99 \\
\hline S & 0.03 & 0.44 & 1.93 & 1.70 & 2.69 & 0.28 & 7.07 \\
\hline SSE & 0.05 & 0.43 & 2.60 & 2.69 & 5.43 & 1.35 & 12.56 \\
\hline SE & 0.03 & 0.48 & 2.97 & 4.12 & 8.64 & 2.14 & 18.38 \\
\hline \multirow[t]{2}{*}{ ESE } & 0.03 & 0.52 & 2.22 & 2.81 & 6.62 & 1.03 & 13.24 \\
\hline & $0.55 \%$ & $5.54 \%$ & $21.56 \%$ & $20.02 \%$ & $38.80 \%$ & $13.53 \%$ & $100.00 \%$ \\
\hline
\end{tabular}




\subsection{Volatile Organic Compound Monitoring}

VOC monitoring was implemented on April 21, 1997, in accordance with WP 12-VC.01, Confirmatory Volatile Organic Compound Monitoring Program. This program is a requirement of the Permit. Volatile organic compound monitoring is performed to verify that VOCs emitted by the waste are within the concentration limits specified by the Permit.

Nine target compounds, which contribute approximately 99 percent of the calculated human health risks from RCRA constituents, were chosen for monitoring. These target compounds are shown in Table 5.1.

Table 5.1 - Concentrations of Concern for Volatile Organic Compounds, from Part 4 of the Permit (No. NM4890139088-TSDF)

\begin{tabular}{|l|c|c|}
\hline \multicolumn{1}{|c|}{ Compound } & Concentration of Concern ppbv & Room Based Limits ppmv $^{\mathbf{b}}$ \\
\hline 1,1,1-Trichloroethane & 590 & 33,700 \\
\hline 1,1,2,2-Tetrachloroethane & 50 & 2,960 \\
\hline 1,1-Dichloroethylene & 100 & 5,490 \\
\hline 1,2-Dichloroethane & 45 & 2,400 \\
\hline Carbon tetrachloride & $165,630,412.5,960$ & 9,625 \\
\hline Chlorobenzene & 220 & 13,000 \\
\hline Chloroform & 180 & 9,930 \\
\hline Methylene chloride & 1,930 & 100,000 \\
\hline Toluene & 190 & 11,000 \\
\hline
\end{tabular}

(a) Parts per billion by volume

(b) Parts per million by volume

On November 16, 2006, additional Permit conditions were implemented, requiring the addition of disposal room VOC monitoring to the program. This new requirement included the addition of sampling locations within active hazardous waste facility units. Within each active unit, two sampling locations are required for each filled room, one at the exhaust side of the room and one at the inlet side of the room. In addition, each room actively receiving waste is required to be sampled at the exhaust side of the room. The sampling frequency for disposal room sampling is once every two weeks. Typical disposal room VOC sampling locations are shown in Figure 5.6. Sampling in panel 5 included two locations in rooms 7, 6, 5, 4, and 3, while rooms 2 and 1 had one location at the exhaust side. 


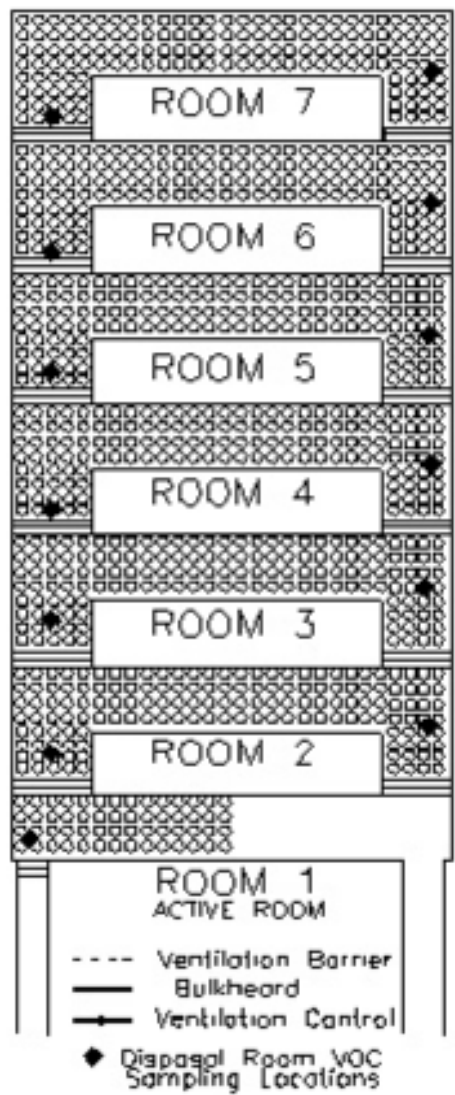

Figure 5.6 - Typical Disposal Room Volatile Organic Compound Sampling Locations

On March 25, 2008, new permit conditions were added, requiring ongoing disposal room VOC monitoring in "filled" panels (panels in which waste emplacement is complete). Ongoing disposal room VOC monitoring included the continued monitoring of VOCs in room 1 of the filled panel. The sampling frequency for ongoing disposal room monitoring is once per month. For 2010, ongoing disposal room monitoring was conducted in panels 3 and 4 .

Repository VOC sampling for target compounds is performed semiweekly at two ambient air monitoring stations. The stations are identified as VOC-A, located downstream from hazardous waste disposal unit panel 1 in Drift E300, and VOC-B, located upstream from the active panel. As waste is placed in new panels, VOC-B will be relocated to ensure that it samples underground air before it passes the waste panels. The location of VOC-A is not anticipated to change.

Target compounds found in VOC-B are not attributable to open or closed panels. The VOC concentrations measured at this location are VOCs entering the mine through the air intake shaft and VOCs contributed by facility operations upstream of the waste panels. Differences measured between the two stations represent any VOC contributions from the waste panels. Any positive concentration differences in the annual averages between the two stations must be less than the concentrations of concern listed in the Permit (Table 5.1). 


\section{Waste Isolation Pilot Plant Annual Site Environmental Report for 2010 DOE/WIPP-11-2225}

VOC sampling reported in this section was performed using guidance included in Compendium Method TO-15, Determination of Volatile Organic Compounds (VOCs) in Air Collected in Specially-Prepared Canisters and Analysis By Gas Chromatography/ Mass Spectrometry (GC/MS) (EPA, 1999), as a basis. The samples were analyzed using gas chromatography/mass spectrometry under an established QA/QC program. Laboratory analytical procedures were developed based on the concepts contained in both TO-15 and the draft EPA Contract Laboratory Program Volatile Organics Analysis of Ambient Air in Canisters (EPA, 1994).

For repository VOC sampling, the routine method reporting limits (MRLs) and maximum concentrations detected (MCDs) are shown in Table 5.2. It should be noted that the MRLs are between 20 times and 386 times lower than the respective concentrations of concern for the nine target compounds.

The results of 2010 repository VOC monitoring, compared to 2009 (found in the Semiannual VOC, Hydrogen, and Methane Data Summary Report [DOE/WIPP-093443]), indicated an increase in the maximum and mean concentration of each detected target compound in air downstream of panel 1. Although the sample results for 2010 showed an overall increase in the concentration of detections and 16 individual sample sets (VOC-A and VOC-B) exceeded the concentration of concern for carbon tetrachloride (14 at 165 ppbv $\mathrm{CoC}$ and 2 at 412.5 ppbv CoC), the running annual average for repository VOC sample results remained below the concentrations of concern listed in Table 5.1.

Table 5.2 - Repository Air Volatile Organic Compound Method Reporting Limits and Maximum Concentrations Detected

\begin{tabular}{|c|c|c|c|}
\hline Compound & $\begin{array}{l}\text { MRL } \\
\text { (ppbv) }\end{array}$ & $\begin{array}{c}\text { Annual Average } \\
\text { (ppbv) }\end{array}$ & $\begin{array}{c}\text { MCD } \\
(\text { ppbv)* }\end{array}$ \\
\hline 1,1,1-Trichloroethane & 5 & 18.74 & 95.31 \\
\hline 1,1,2,2-Tetrachloroethane & 2 & $<\mathrm{MRL}$ & $<M R L$ \\
\hline 1,1-Dichloroethylene & 5 & $<M R L$ & $<M R L$ \\
\hline 1,2-Dichloroethane & 2 & $<M R L$ & $<M R L$ \\
\hline Carbon Tetrachloride & 2 & 155.5 & 633.1 \\
\hline Chlorobenzene & 2 & $<M R L$ & $<M R L$ \\
\hline Chloroform & 2 & 16.19 & 53.9 \\
\hline Methylene chloride & 5 & $<M R L$ & 22.1 \\
\hline Toluene & 5 & $<M R L$ & $<M R L$ \\
\hline
\end{tabular}

* ppbv = parts per billion by volume

For disposal room VOC monitoring, 234 samples were collected during 2010. The routine MRLs and MCDs are shown in Table 5.3. Five of the nine target compounds were detected above the MRL. The sample results indicated an increase in maximum concentrations detected in disposal rooms for chloroform at 604 ppmv (less than 6.1 percent of room-based limits [RBL]), and methylene chloride at $46.6 \mathrm{ppmv}$ (less than 0.01 percent of RBL) 1,1,1-trichloroethane at 201 ppmv (0.5 percent of RBL), and 
Waste Isolation Pilot Plant Annual Site Environmental Report for 2010 DOE/WIPP-11-2225

carbon tetrachloride at 4,823 ppmv (50.1 percent of RBL). There was also one detection of 1,1, 2,2-Tetrachloroethane at $8.6 \mathrm{ppmv}(0.3$ percent of the RBL).

Table 5.3 - Disposal Room Volatile Organic Compound Method Reporting Limits and Maximum Concentrations Detected

\begin{tabular}{|l|c|c|}
\hline \multicolumn{1}{|c|}{ Compound } & MRL (ppmv) $^{*}$ & MCD (ppmv) $^{*}$ \\
\hline 1,1,1-Trichloroethane & 0.5 & 201 \\
\hline 1,1,2,2-Tetrachloroethane & 0.5 & 8.6 \\
\hline 1,1-Dichloroethylene & 0.5 & $<\mathrm{MRL}$ \\
\hline 1,2-Dichloroethane & 0.5 & $<\mathrm{MRL}$ \\
\hline Carbon Tetrachloride & 0.5 & 4,823 \\
\hline Chlorobenzene & 0.5 & $<\mathrm{MRL}$ \\
\hline Chloroform & 0.5 & 604 \\
\hline Methylene chloride & 0.5 & 46.6 \\
\hline Toluene & 0.5 & $<\mathrm{MRL}$ \\
\hline
\end{tabular}

* ppmv = parts per million by volume

Ongoing disposal room VOC monitoring was conducted in panels 3 and 4 during 2010. A total of 12 samples and 12 field duplicates were collected in panels 3 and 4 . Ongoing disposal room VOC monitoring results are listed in Table 5.4.

Table 5.4 - Ongoing Disposal Room Volatile Organic Compound Method Reporting Limits and Maximum Concentrations Detected

\begin{tabular}{|l|c|c|}
\hline \multicolumn{1}{|c|}{ Compound } & MRL (ppmv) $^{*}$ & MCD (ppmv) $^{*}$ \\
\hline 1,1,1-Trichloroethane & 0.5 & 119 \\
\hline 1,1,2,2-Tetrachloroethane & 0.5 & $<\mathrm{MRL}$ \\
\hline 1,1-Dichloroethylene & 0.5 & $<\mathrm{MRL}$ \\
\hline 1,2-Dichloroethane & 0.5 & $<\mathrm{MRL}$ \\
\hline Carbon Tetrachloride & 0.5 & 600 \\
\hline Chlorobenzene & 0.5 & $<\mathrm{MRL}$ \\
\hline Chloroform & 0.5 & 54 \\
\hline Methylene chloride & 0.5 & 27.8 \\
\hline Toluene & 0.5 & $<\mathrm{MRL}$ \\
\hline
\end{tabular}

* ppmv $=$ parts per million by volume

\subsection{Hydrogen and Methane Monitoring}

Hydrogen and methane monitoring in "filled" panels 3 through 7 was included as a new permit condition on March 25, 2008. Hydrogen and methane are required to be monitored at two locations in each room and at four additional bulkhead locations in the panel area upon the completion of waste emplacement in each panel. Monitoring is required for each location on a monthly basis. In April 2008, this permit condition was implemented. For 2010, hydrogen and methane monitoring was conducted in panels 3 and 4. 
Hydrogen and methane samples are analyzed using gas chromatography with thermal conductivity detection under an established QA/QC program. Specialized laboratory analytical procedures were developed based on standard laboratory techniques and approved through established QA processes.

A total of 398 samples were collected between January 1, 2010, and December 31, 2010. The maximum detected value for hydrogen, $1,012 \mathrm{ppmv}$, was considerably lower than the action levels (less than 26 percent of Action Level 1 and less than 13 percent of Action Level 2 shown in Table 5.5). None of the samples contained methane.

Table 5.5 - Hydrogen and Methane Method Reporting Limits Action Levels and Maximum Concentrations Detected

\begin{tabular}{|l|c|c|c|c|}
\hline \multicolumn{1}{|c|}{ Compound } & MRL (ppmv) $^{*}$ & Action Level 1 & Action Level 2 & MCD (ppmv) \\
\hline Hydrogen & 0.5 & 4,000 & 8,000 & 1,012 \\
\hline Methane & 0.5 & 5,000 & 10,000 & N/A \\
\hline
\end{tabular}

* ppmv = parts per million by volume

\subsection{Seismic Activity}

Currently, seismicity within $300 \mathrm{~km}(186 \mathrm{mi})$ of the WIPP site is being monitored by the New Mexico Institute of Mining and Technology (NMIMT) using data from a nine-station network approximately centered on the site (Figure 5.7). Station signals are transmitted to the NMIMT Seismological Observatory in Socorro. When appropriate, readings from the WIPP network stations are combined with readings from an additional NMIMT network in the central Rio Grande Rift. Occasionally, data are also exchanged with the University of Texas at El Paso and Texas Tech University in Lubbock, both of which operate stations in West Texas.

The mean operational efficiency of the WIPP seismic monitoring stations during 2010 was approximately 92.6 percent. From January 1 through December 31, 2010, locations for 169 seismic events were recorded within $300 \mathrm{~km}$ (186 mi) of the WIPP site. These data included origin times, epicenter coordinates, and magnitudes. The strongest recorded event (magnitude 3.7) occurred on March, 28, 2010, and was located approximately $89 \mathrm{~km}(55 \mathrm{mi})$ southwest of the site. The closest event to the site was located approximately $36 \mathrm{~km}$ (22 mi) southwest and had a magnitude of 1.0. These events had no effect on WIPP structures. 


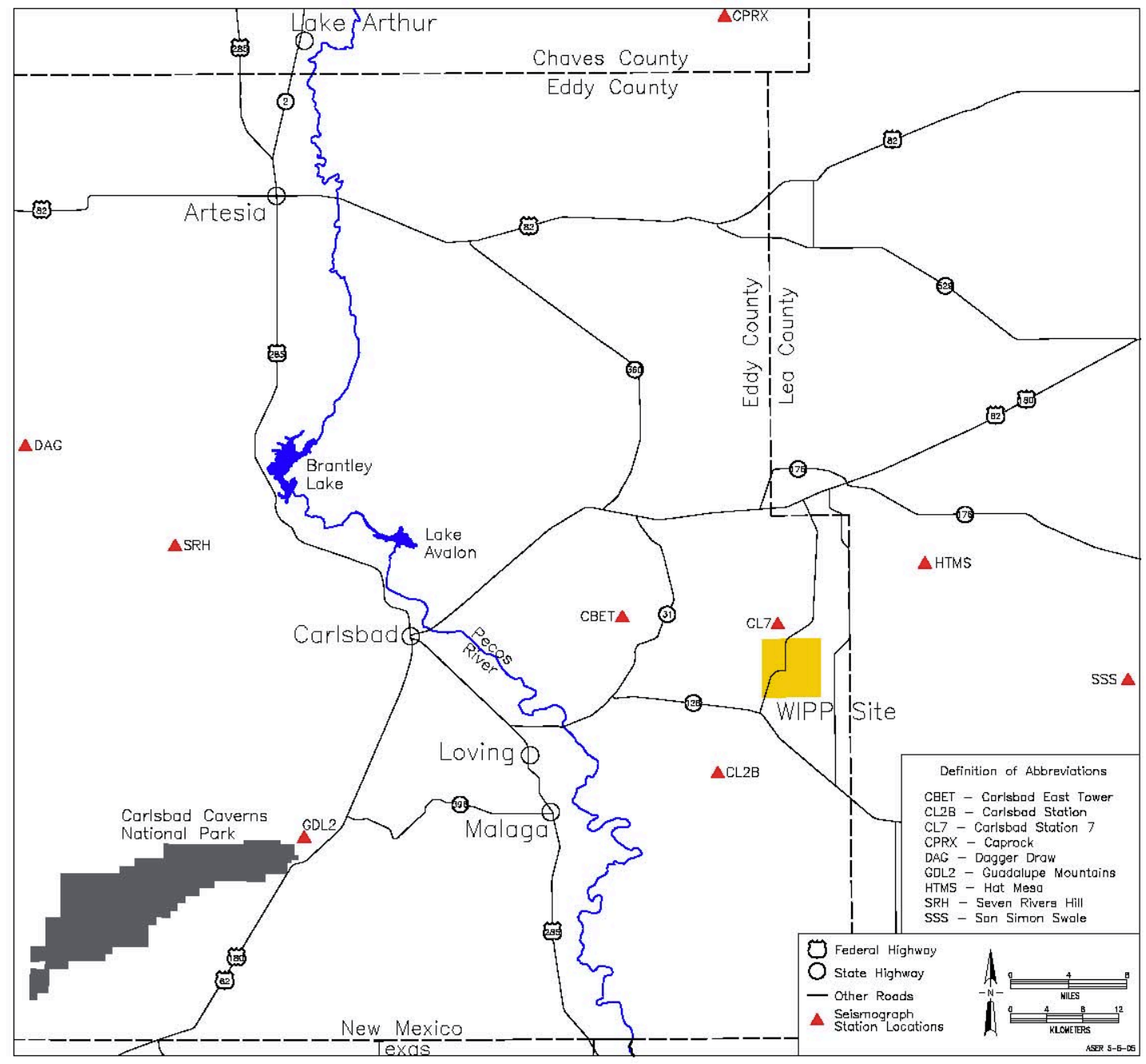

Figure 5.7 - Seismograph Station Locations in the Vicinity of the WIPP Site

\subsection{Liquid Effluent Monitoring}

The NMED Ground and Surface Water Protection regulations set forth in 20.6.2 NMAC regulate discharges that could impact surface water or groundwater. DOE compliance with the Ground and Surface Water Protection Regulations is discussed in Chapter 2. The discharge permit was renewed on September 9, 2008. A modification to the discharge permit was submitted on November 15, 2009, to incorporate a new pond (the Salt Storage Extension Basin II) into the permit that was built to provide additional holding and evaporation capacity for runoff from the active Salt Storage Area. Analytical data from the discharge monitoring reports are summarized in Table 5.6 and Table 5.7, respectively. 
Waste Isolation Pilot Plant Annual Site Environmental Report for 2010 DOE/WIPP-11-2225

Table 5.6 - Sewage Lagoon and H-19 Analytical Results for January through June 2010

\begin{tabular}{|l|c|c|c|c|}
\hline \multicolumn{1}{|c|}{ Analyte } & Influent Pond 2A & Evaporation Pond B & Evaporation Pond C & H-19 Evaporation Pond \\
\hline Nitrate $(\mathrm{mg} / \mathrm{L})$ & 0.61 & $\mathrm{~N} / \mathrm{A}^{\mathrm{a}}$ & $\mathrm{N} / \mathrm{A}$ & N/A \\
\hline $\operatorname{TKN}^{\mathrm{b}}(\mathrm{mg} / \mathrm{L})$ & 79 & $\mathrm{~N} / \mathrm{A}$ & $\mathrm{N} / \mathrm{A}$ & N/A \\
\hline $\operatorname{TDS}^{\mathrm{c}}(\mathrm{mg} / \mathrm{L})$ & 490 & 89 & 307,000 & 178,000 \\
\hline Sulfate $(\mathrm{mg} / \mathrm{l})$ & 58 & 4.8 & 22,000 & 390 \\
\hline Chloride $(\mathrm{mg} / \mathrm{l})$ & 77 & 19 & 160,000 & 130,000 \\
\hline
\end{tabular}

(a) N/A - The analytical parameter not required.

(b) Total Kjeldahl Nitrogen (as N).

(c) Total dissolved solids.

Table 5.7 - Sewage Lagoon, H-19, and Infiltration Control Pond Analytical Results for July through December 2010

\begin{tabular}{|c|c|c|c|c|c|}
\hline Location & $\begin{array}{l}\text { Nitrate } \\
(\mathrm{mg} / \mathrm{l})\end{array}$ & $\operatorname{TKN}^{\mathrm{a}}(\mathrm{mg} / \mathrm{l})$ & $\operatorname{TDS}^{\mathrm{b}}(\mathrm{mg} / \mathrm{l})$ & Sulfate (mg/l) & Chloride (mg/l) \\
\hline Influent Pond 2A & $N D^{c}$ & 86 & 575 & 60 & 70 \\
\hline Evaporation Pond B & $N A^{d}$ & NA & 388,000 & 63,000 & 140,000 \\
\hline Evaporation Pond C & NA & NA & NS & NS & NS \\
\hline $\begin{array}{l}\text { H-19 Evaporation } \\
\text { Pond }\end{array}$ & $N / A^{d}$ & N/A & 351,000 & 1,300 & 250,000 \\
\hline $\begin{array}{l}\text { Salt Pile Evaporation } \\
\text { Pond }\end{array}$ & N/A & N/A & 85,300 & 270 & 57,000 \\
\hline $\begin{array}{l}\text { Salt Storage } \\
\text { Extension } \\
\text { Evaporation Basin }\end{array}$ & $N / A$ & $\mathrm{~N} / \mathrm{A}$ & 338,000 & 17,000 & 220,000 \\
\hline Pond 1 & $N / A$ & $N / A$ & 397 & 44 & 140 \\
\hline Pond 2 & N/A & N/A & 1,000 & 7.1 & 580 \\
\hline Pond $\mathrm{A}$ & $N / A$ & $N / A$ & 394 & 11 & 200 \\
\hline
\end{tabular}
(a) Total Kjeldahl Nitrogen (as $\mathrm{N}$ ).
(b) Total dissolved solids.
(c) ND - not detected, analyte below detection limit.
(d) N/A - The analytical parameter not required. 
This page intentionally left blank 


\section{CHAPTER 6 - SITE HYDROLOGY, GROUNDWATER MONITORING, AND PUBLIC DRINKING WATER PROTECTION}

Current groundwater monitoring activities for the WIPP facility are outlined in the WIPP Groundwater Monitoring Program Plan (WP 02-1). In addition, the WIPP facility has detailed procedures for performing specific activities, such as pumping system installations, field parameter analyses and documentation, and QA records management. Groundwater monitoring activities are also included in the Waste Isolation Pilot Plant Environmental Monitoring Plan (DOE/WIPP-99-2194).

\subsection{Site Hydrology}

The hydrology at and surrounding the WIPP site has been studied extensively over the last 30 years. A summary of the hydrology in this area is contained in the following sections. Figure 6.1 presents the stratigraphy.

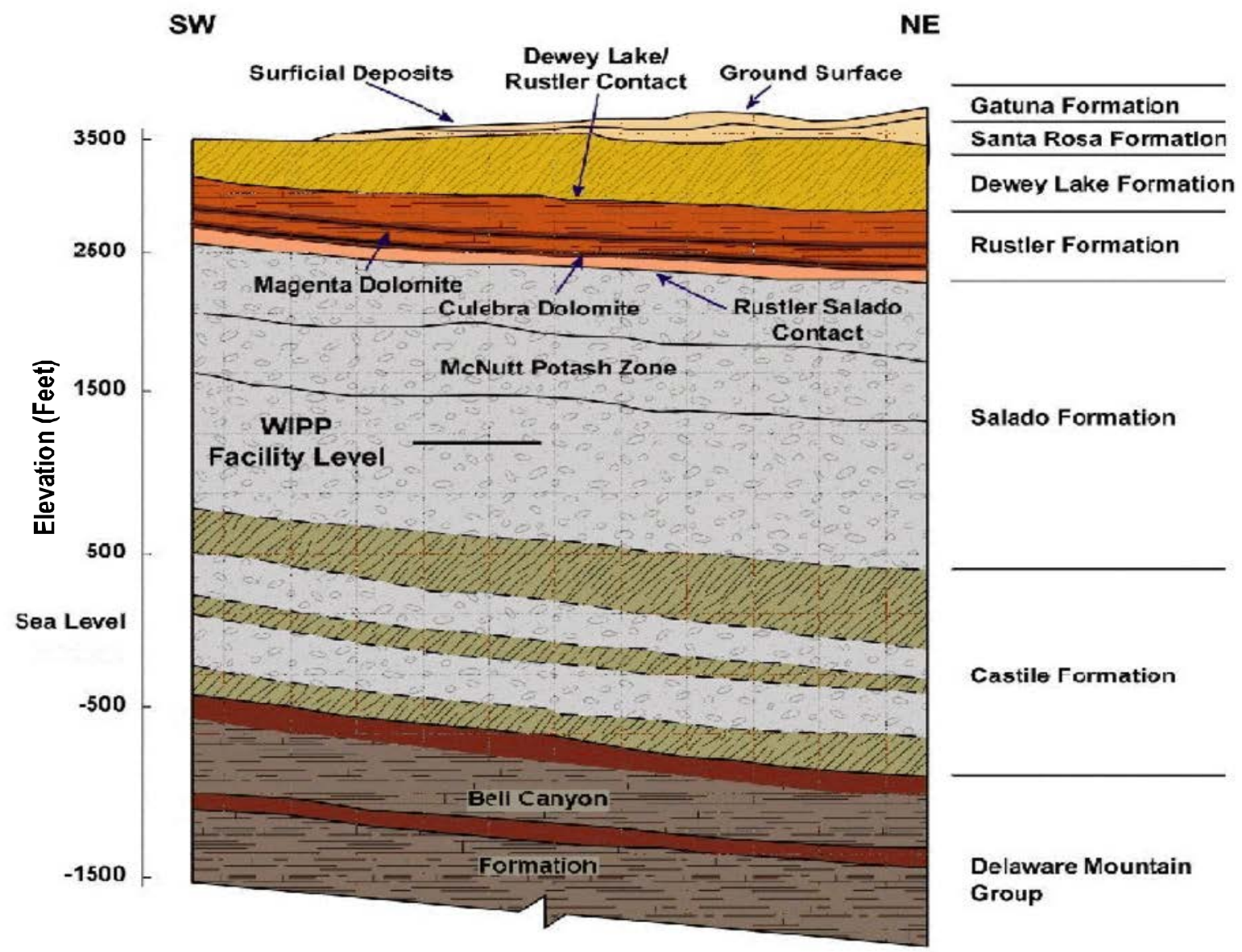

Figure 6.1 - WIPP Stratigraphy 


\subsubsection{Surface Hydrology}

Surface water is absent at the WIPP site. The nearest significant surface water body, Laguna Grande de la Sal, is $13 \mathrm{~km}$ (8 mi) west-southwest of the center of the WIPP site in Nash Draw, where shallow brine ponds occur. Small, manmade livestock watering holes ("tanks") occur several kilometers from the WIPP site, but are not hydrologically connected to the formations overlying the WIPP repository.

\subsubsection{Subsurface Hydrology}

Several water-bearing zones have been identified and extensively studied at and near the WIPP site. Limited amounts of potable water are found in the middle Dewey Lake and the overlying Triassic Dockum group in the southern part of the WIPP LWA. Two water-bearing units, the Culebra and Magenta Dolomite Member (Magenta), occur in the Rustler Formation (Rustler) and produce brackish to saline water at and in the vicinity of the site. Another very low transmissivity, saline water-bearing zone is the Rustler-Salado contact.

\subsubsection{Hydrology of the Castile Formation}

The Castile Formation (Castile) is composed of a sequence of three thick anhydrite beds separated by two thick halite beds. This formation acts as an aquitard, separating the Salado from the underlying water-bearing sandstones of the Bell Canyon Formation. In the halite zones, the occurrence of circulating groundwater is restricted because halite at these depths does not readily maintain secondary porosity, open fractures, or solution channels.

No regional groundwater flow system appears to be present in the Castile in the vicinity of the WIPP site. The only significant water present in the formation occurs in isolated brine reservoirs in fractured anhydrite. Wells have encountered pressurized brine reservoirs in the upper anhydrite unit of the Castile in the vicinity of the WIPP site. Two such encounters have been made by boreholes drilled for the WIPP facility: (1) ERDA 6, located northeast of the current WIPP site, encountered a pressurized brine reservoir in 1975; and (2) borehole WIPP-12, located one mile north of the center of the WIPP site, encountered a brine reservoir in 1981. Both encounters were hydrologically and chemically tested in 1981 and determined to be not connected with each other (Popielak et al., 1983).

\subsubsection{Hydrology of the Salado Formation}

The massive halite beds within the Salado host the WIPP facility horizon. The Salado represents a regional aquiclude due to the hydraulic properties of the bedded halite that forms most of the formation. In the halites, the presence of circulating groundwater is restricted because halites do not readily maintain primary porosity, solution channels, or open fractures.

The results of permeability testing, both within the facility and from the surface, are generally consistent with a hydraulic conductivity of the undisturbed salt mass of less than $6.5 \mathrm{E}-09 \mathrm{~m}$ per day $(\mathrm{m} / \mathrm{d})(2.1 \mathrm{E}-08 \mathrm{ft} / \mathrm{d})$, with the more pure (less argillaceous) 
halites having even lower permeability. Anhydrite interbeds typically have hydraulic conductivities ranging from $6.5 \mathrm{E}-09 \mathrm{~m} / \mathrm{d}$ to $6.5 \mathrm{E}-07 \mathrm{~m} / \mathrm{d}(2.1 \mathrm{E}-08$ to $2.1 \mathrm{E}-06 \mathrm{ft} / \mathrm{d})$ (Beauheim and Roberts, 2002). The only significant variation to these extremely low permeabilities occurs in the immediate vicinity of the underground workings (Stormont et al., 1991). This increase is believed to be a result of near-field fracturing due to the excavation.

Small quantities of brine have been observed to collect in boreholes drilled into Marker Bed 139 a few feet below the floor of the WIPP underground repository rooms and have also been observed to seep out of the excavated walls. The long-term performance assessment for the WIPP disposal system assumes that small quantities of brine will be present in the WIPP repository.

\subsubsection{Hydrology of the Rustler-Salado Contact}

In Nash Draw and areas immediately west of the site, the Rustler-Salado contact exists as a dissolution residue capable of transmitting water. Eastward from Nash Draw toward the WIPP site, the amount of dissolution decreases and the transmissivity of this interval decreases (Mercer, 1983). Small quantities of brine were found in the test holes in this zone at the WIPP site (Mercer and Orr, 1977).

\subsubsection{Hydrology of the Culebra Member}

The Culebra is the most transmissive hydrologic unit in the WIPP site area and is considered the most significant potential hydrologic pathway for a radiologic release to the accessible environment.

Tests show that the Culebra is a fractured, heterogeneous system with varying local anisotropic characteristics (Mercer and Orr, 1977; Mercer, 1983; Beauheim, 1986, 1987; Beauheim and Ruskauff, 1998). Calculated transmissivities for the Culebra within the WIPP site boundary have a wide range, with values between 1.2E-08 square meters per day (m2/d) to approximately $112 \mathrm{~m}^{2} / \mathrm{d}\left(1.29 \mathrm{E}-07 \mathrm{ft}^{2} / \mathrm{d}\right.$ to $\left.1.20 \mathrm{E} 03 \mathrm{ft}^{2} / \mathrm{d}\right)$; the majority of the values are less than 9.3E-02 $\mathrm{m}^{2} / \mathrm{d}\left(1 \mathrm{ft}^{2} / \mathrm{d}\right.$ ) (DOE/WIPP-09-3424; Compliance Recertification Application Appendix HYDRO, 2009). Transmissivities generally decrease from west to east across the site area, with a relatively high transmissivity zone trending southeast from the center of the WIPP site to the site boundary. The regional flow direction of groundwater in the Culebra is generally south.

\subsubsection{Hydrology of the Magenta Member}

The Magenta is situated above the Culebra and, though not the water-bearing zone of interest for monitoring of a facility release, is of interest in understanding water-level changes that occur in the Culebra. The Magenta has been tested in 18 cased and open holes at and around the WIPP site. Magenta transmissivities within the WIPP site range from 2.0E-04 to 3.5E-02 $\mathrm{m}^{2} / \mathrm{d}$ (2.1E-03 to 3.8E-01 $\mathrm{ft}^{2} / \mathrm{d}$ ) (Beauheim et al., 1991; Beauheim and Ruskauff, 1998; SNL, 2003; Bowman and Roberts, 2009). 


\subsubsection{Hydrology of the Dewey Lake Redbeds Formation}

The Dewey Lake at the WIPP site is approximately $152 \mathrm{~m}$ (500 ft) thick and consists of alternating thin beds of siltstone and fine-grained sandstone. The upper Dewey Lake consists of a thick, generally unsaturated section. The middle Dewey Lake is the interval immediately above a cementation change, from carbonate (above) to sulfate (below), where saturated conditions and a natural water table have been identified in limited areas. An anthropogenic saturated zone has been observed in the overlying Santa Rosa Formation (Santa Rosa) and in the upper part of the Dewey Lake since 1995. This is described in Section 6.6. The lower Dewey Lake is below the sulfate cementation change, with much lower permeabilities.

WIPP monitoring well WQSP-6A (see Figure 6.2) intersects natural water in the Dewey Lake. At this location, the saturated horizon is within the middle portion of the formation. The saturated zone at well WQSP-6A is both vertically and laterally distinct from the water at C-2811 (see Section 6.6 for a full discussion of SSW). Well C-2811 is located approximately one mile $(1.61 \mathrm{~km})$ to the northeast of WQSP-6A on the C-2737 well pad (see Figure 6.2). Approximately one mile south of the WIPP site, domestic and stock supply wells produce water from the middle Dewey Lake.

\subsubsection{Hydrology of the Santa Rosa and Gatuña Formations}

Within the WIPP site boundary, the Santa Rosa is relatively thin to absent. At the Air Intake Shaft, $0.6 \mathrm{~m}(2 \mathrm{ft})$ of rock is classified as the Santa Rosa. The Santa Rosa is a maximum of $78 \mathrm{~m}(255 \mathrm{ft})$ thick in exploratory potash holes drilled for WIPP, east of the site boundary. The Santa Rosa is thicker to the east. The geologic data from design studies have been incorporated with data from drilling to investigate SSW in the Santa Rosa to provide structure and thickness maps of the Santa Rosa in the vicinity of the WIPP surface structures area. These results are consistent with the broader regional distribution of the Santa Rosa (Compliance Recertification Application, DOEMIPP-043231).

Water in the Santa Rosa has been found in the center part of the WIPP site since 1995 and because no water was found in this zone during the mapping of the shafts in 1980s, this water is deemed to be anthropogenic (Daniel B. Stephens \& Associates, Inc., 2003). To assess the quantity and quality of this water, piezometers PZ-1 to PZ-12 were installed in the area between the WIPP shafts. Also, wells C-2505, C-2506, and C-2507 were drilled and tested in 1996 and 1997 (Exhaust Shaft Hydraulic Assessment Data Report, DOE/WIPP-97-2219). These wells are shown in Figure 6.15 of this report. During October 2007, three additional piezometers were installed around the site and preliminary design validation (SPDV) tailings pile to evaluate the nature and extent of SSW around this area.

The Gatuña Formation (Gatuña) unconformably overlies the Santa Rosa at the WIPP site. This formation ranges in thickness from approximately 6 to $9 \mathrm{~m} \mathrm{(19} \mathrm{to} 31 \mathrm{ft}$ ) at the WIPP site and consists of silt, sand, and clay, with deposits formed in localized depressions during the Pleistocene period. 
The Gatuña is water-bearing in some areas, with saturation occurring in discontinuous perched zones. However, because of its erratic distribution, the Gatuña has no known continuous saturation zone. Drilling at the WIPP site, including 30 exploration borings drilled between 1978 and 1979, did not identify any saturated zones in the Gatuña (Daniel B. Stephens \& Associates, Inc., 2003).

\subsection{GROUNDWATER MONITORING}

\subsubsection{Program Objectives}

The objectives of the groundwater monitoring program are to

- Monitor the physical and chemical characteristics of groundwater;

- $\quad$ Maintain surveillance of groundwater levels surrounding the WIPP facility throughout the operational lifetime of the facility; and

- $\quad$ Document and identify effects, if any, of WIPP operations on groundwater parameters throughout the operational lifetime (including closure) and postclosure of the facility.

Data obtained by the WIPP groundwater monitoring program support two major programs: (1) the RCRA DMP supporting the Permit in compliance with 20.4.1.500 NMAC (incorporating 40 CFR Part 264, Subparts F, "Releases From Solid Waste Management Units"; and X, "Miscellaneous Units"), and (2) performance assessment supporting the Compliance Certification Application for the Waste Isolation Pilot Plant (DOE/CAO-96-2184) and five-year recertification applications.

Baseline water chemistry data were collected from 1995 through 1997 and reported in the Waste Isolation Pilot Plant RCRA Background Groundwater Quality Baseline Report (DOEMIPP-98-2285). The baseline data were expanded in 2000 to include ten rounds of sampling instead of five. The data were published in Addendum 1, Waste Isolation Pilot Plant RCRA Background Groundwater Quality Baseline Update Report (IT Corporation, 2000). These baseline data are compared to water quality data collected semiannually.

\subsubsection{Summary of 2010 Activities}

Routine groundwater monitoring activities include groundwater quality sampling, groundwater level monitoring, and the pressure density survey, as described in this section. These annual programs are required by the Permit. Supporting activities during 2010 included hydraulic testing and non-Permit groundwater quality sampling (Section 6.4), and well maintenance (Section 6.5). Table 6.1 presents a summary of WIPP groundwater monitoring activities at the end of 2010. Wells are classified as environmental surveillance wells. The WIPP facility does not have wells required for remediation, waste management, or other requirements. Appendix F, Table F.8, lists active groundwater monitoring wells used by the DOE for the WIPP facility at the end of 2010. 
Radiological data for 2010 from the groundwater monitoring program are summarized in Chapter 4 . The remainder of the results from the groundwater monitoring program are contained in this chapter.

Table 6.1 - Summary of 2010 DOE WIPP Region Groundwater Monitoring Program

\begin{tabular}{|l|c|}
\hline & Environmental Surveillance \\
\hline Number of Active Wells & 84 \\
\hline Number of Samples Taken & $28^{\mathrm{a}}$ \\
\hline Number of Water Level Measurements & 780 \\
\hline Number of Analyses Performed & 1,708 \\
\hline$\%$ of Analyses that are Non-Detects & $79 \%^{\mathrm{b}}$ \\
\hline
\end{tabular}

(a) Primary and duplicate samples taken from seven wells, twice per year. Sixty-one constituents analyzed per sample.

(b) All VOCs, SVOCs (semivolatile organic compounds), and the majority of the target trace metals were nondetect. Most detections were for the routine major water chemistry parameters.

Regular monthly groundwater level data were gathered from 57 wells across the WIPP region (Figure 6.2), two of which were equipped with production-injection packers (PIPs) to allow groundwater level surveillance of more than one hydrologic zone in the same well. The 6 redundant wells on the $\mathrm{H}-19$ pad, the 19 shallow water wells, and $\mathrm{H}-3 \mathrm{D}$, which was dry (for "SR/DL" [Santa Rosa/Dewey Lake contact] listed in Appendix F, Table F.8), were measured quarterly. Table F.9 shows the water level data. Water levels were not taken where access was poor, or in certain wells when testing equipment was present. 


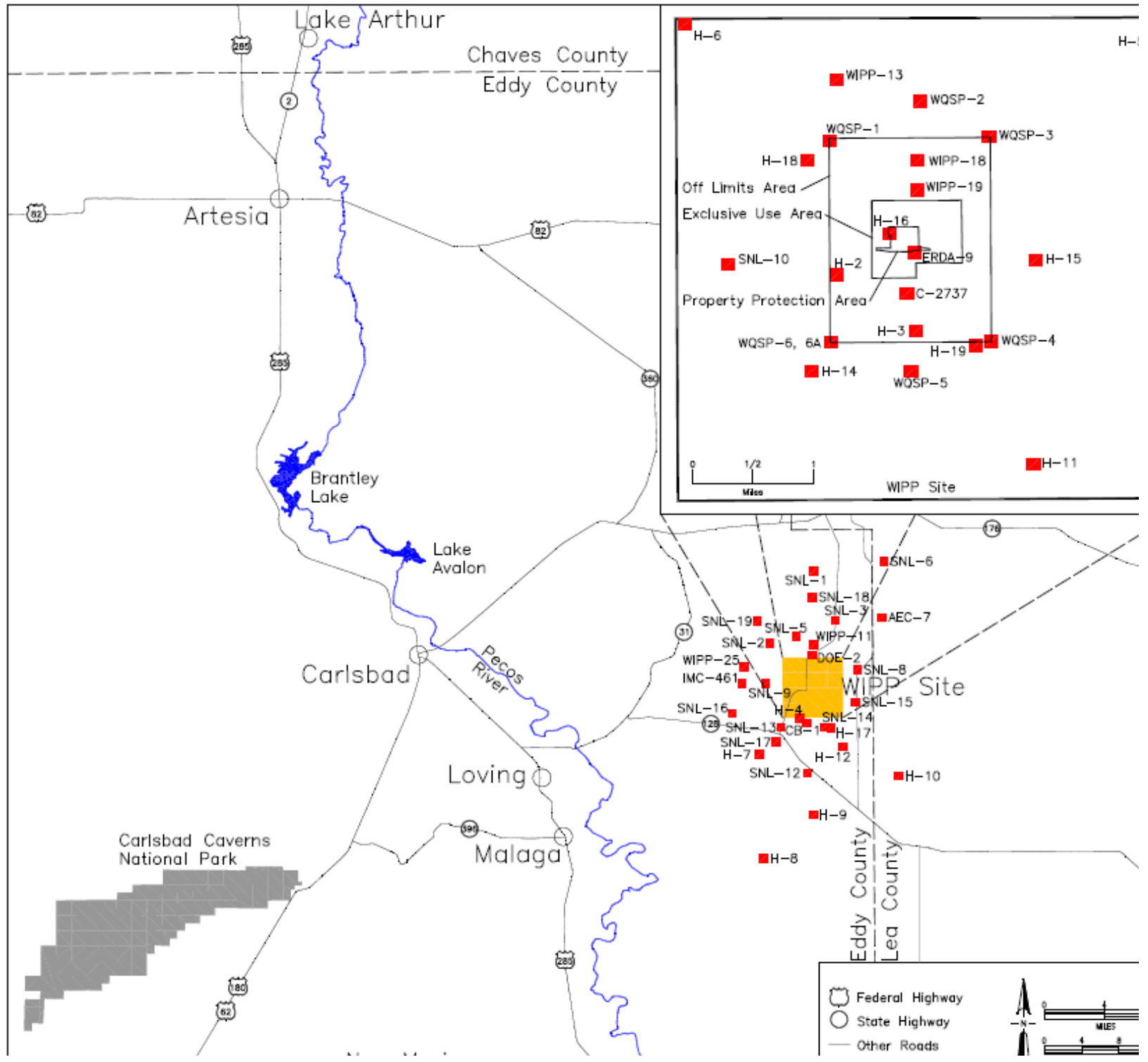

Figure 6.2 - Groundwater Level Surveillance Wells (Insert Represents the Groundwater Surveillance Wells in the WIPP Land Withdrawal Area)

\subsubsection{Groundwater Quality Sampling}

The Permit requires groundwater quality sampling twice a year, from March through May (Round 30 for 2010), and again from September through November (Round 31 for 2010). Sampling for groundwater quality was performed at seven well sites (Figure 6.3). Field analyses for oxygen-reduction potential, $\mathrm{pH}$, specific gravity, specific conductance, temperature, acidity or alkalinity, chloride, divalent cations, and total iron were performed periodically during the sampling. 


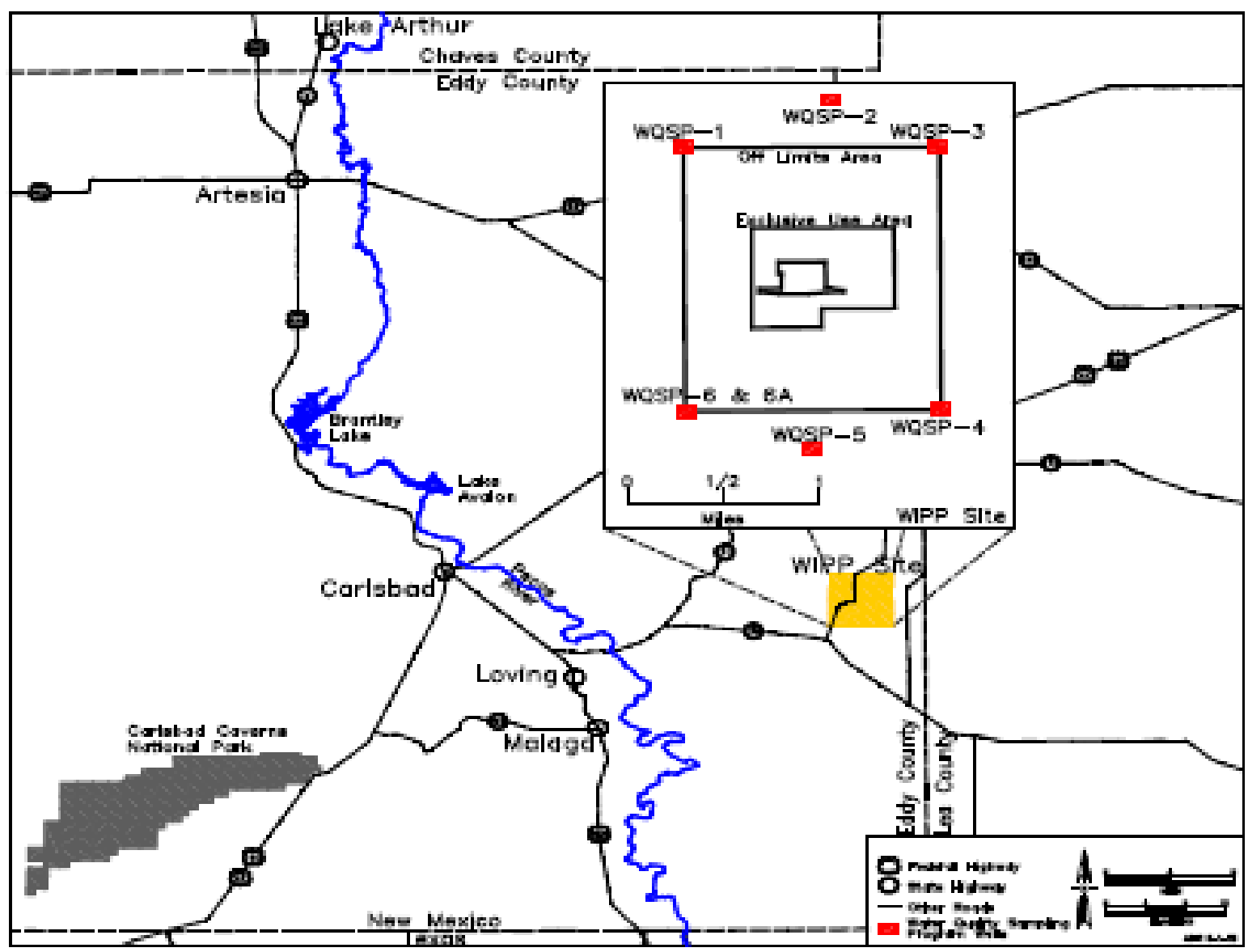

Figure 6.3 - Water Quality Sampling Program Wells

Primary and duplicate samples for groundwater quality were taken from each of the seven wells: six wells completed in the Culebra (WQSP-1 through WQSP-6) and one well completed in the Dewey Lake (WQSP-6A), for a total of 14 samples analyzed per sampling round.

Wells WQSP-1, WQSP-2, and WQSP-3 are located upgradient of the WIPP shaft area. The locations of the three upgradient wells were selected to be representative of the groundwater moving downgradient onto the WIPP site. Wells WQSP-4, WQSP-5, and WQSP-6 are located downgradient of the WIPP shaft area. WQSP-4 was also specifically located to monitor a zone of higher transmissivity. WQSP-6A was installed in the Dewey Lake at the WQSP-6 well pad to assess shallower groundwater conditions at this location.

The difference between the depth of the WIPP repository and the depth of the WQSP

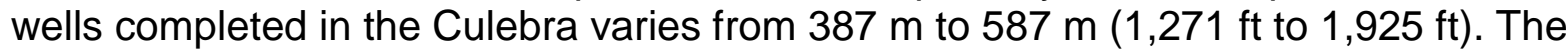
DOE does not anticipate finding WIPP-related contamination in the groundwater because a release from the repository to the Culebra is highly unlikely. In order for contaminated liquid to move from the repository to the Culebra, three conditions would have to be met. First, sufficient brine would have to accumulate in the waste disposal areas to leach contaminants from the disposed waste. Second, sufficient pressure would have to build up in the disposal area to overcome the hydrostatic head between 


\section{Waste Isolation Pilot Plant Annual Site Environmental Report for 2010 DOE/WIPP-11-2225}

the repository and the Culebra. Third, a pathway would have to exist and remain open for contaminated brine to flow from the repository to the Culebra. Since the times required for the brine accumulation and repository pressurization are on the order of thousands of years, and current plans call for the sealing of the shafts and boreholes that could potentially become such a pathway upon closure of the facility, WIPP-related contamination of the groundwater is highly unlikely.

Table 6.2 lists the analytical parameters included in the 2010 groundwater sampling program.

Table 6.2 - Analytical Parameters for which Groundwater Was Analyzed

\begin{tabular}{|c|c|c|c|c|c|}
\hline CAS No. ${ }^{a}$ & Parameter & $\begin{array}{c}\text { EPA } \\
\text { Method } \\
\text { Number }\end{array}$ & CAS No. & Parameter & $\begin{array}{l}\text { Method } \\
\text { Number }\end{array}$ \\
\hline $71-55-6$ & 1,1,1-Trichloroethane & $8260 B$ & $7782-50-5$ & Chloride & EPA 300.0 \\
\hline $79-34-5$ & 1,1,2,2-Tetrachloroethane & $8260 B$ & & Specific Gravity & SM2710F \\
\hline $79-00-5$ & 1,1,2-Trichloroethane & $8260 B$ & $7727-37-9$ & Nitrate (as N) & EPA 300.0 \\
\hline $75-34-3$ & 1,1-Dichloroethane & $8260 B$ & & $\mathrm{pH}$ & $\mathrm{SM} 4500-\mathrm{H}^{+} \mathrm{B}$ \\
\hline $75-35-4$ & 1,1-Dichloroethylene & $8260 B$ & & Specific conductance & EPA 120.1 \\
\hline $107-06-2$ & 1,2-Dichloroethane & $8260 B$ & & Sulfate & EPA 300.0 \\
\hline $56-23-5$ & Carbon tetrachloride & $8260 B$ & & Total dissolved solids & SM2540C \\
\hline $108-90-7$ & Chlorobenzene & $8260 B$ & & Total organic carbon & SM5310B \\
\hline $67-66-3$ & Chloroform & $8260 B$ & & Total organic halogen & EPA 9020B \\
\hline $540-59-0$ & cis-1,2-Dichloroethylene & $8260 B$ & & Total suspended solids & SM2540D \\
\hline $540-59-0$ & trans-1, 2-Dichloroethylene & $8260 \mathrm{~B}$ & $7440-36-0$ & Alkalinity & SM2320B \\
\hline $78-93-3$ & $\begin{array}{l}\text { Methyl ethyl ketone (2- } \\
\text { butanone) }\end{array}$ & $8260 \mathrm{~B}$ & $7440-38-2$ & Antimony & 6020 \\
\hline $75-09-2$ & Methylene chloride & $8260 B$ & $7440-39-3$ & Arsenic & 6020 \\
\hline $127-18-4$ & Tetrachloroethylene & $8260 \mathrm{~B}$ & $7440-41-7$ & Barium & $6010 \mathrm{~B}$ \\
\hline $108-88-3$ & Toluene & $8260 B$ & $7440-43-9$ & Beryllium & $6010 \mathrm{~B}$ \\
\hline $79-01-6$ & Trichloroethylene & $8260 B$ & $7440-70-2$ & Cadmium & $6010 \mathrm{~B}$ \\
\hline $75-69-4$ & Trichlorofluoromethane & $8260 B$ & $7440-47-3$ & Calcium & $6010 \mathrm{~B}$ \\
\hline $75-01-4$ & Vinyl chloride & $8260 B$ & $7439-89-6$ & Chromium & $6010 \mathrm{~B}$ \\
\hline $1330-20-7$ & Xylene & $8260 B$ & $7439-92-1$ & Iron & $6010 \mathrm{~B}$ \\
\hline $95-50-1$ & 1,2-Dichlorobenzene & $8270 \mathrm{C}$ & $7439-95-4$ & Lead & $6010 \mathrm{~B}$ \\
\hline $106-46-7$ & 1,4-Dichlorobenzene & $8270 \mathrm{C}$ & $7439-97-6$ & Magnesium & $6010 \mathrm{~B}$ \\
\hline $51-28-5$ & 2,4-Dinitrophenol & $8270 \mathrm{C}$ & $7439-97-6$ & Mercury & $7470 A$ \\
\hline $121-14-2$ & 2,4-Dinitrotoluene & $8270 \mathrm{C}$ & $7440-02-0$ & Nickel & $6010 \mathrm{~B}$ \\
\hline $95-48-7$ & 2-Methylphenol & $8270 \mathrm{C}$ & $7782-49-2$ & Potassium & $6010 \mathrm{~B}$ \\
\hline $\begin{array}{l}108-39-4 / \\
106-44-5\end{array}$ & $\begin{array}{l}\text { 3-Methylphenol/ } \\
\text { 4-Methylphenol }\end{array}$ & $8270 \mathrm{C}$ & $7440-22-4$ & Selenium & 6020 \\
\hline $118-74-1$ & Hexachlorobenzene & $8270 \mathrm{C}$ & $7440-23-5$ & Silver & $6010 \mathrm{~B}$ \\
\hline $67-72-1$ & Hexachloroethane & $8270 \mathrm{C}$ & $7440-28-0$ & Sodium & $6010 \mathrm{~B}$ \\
\hline $98-95-3$ & Nitrobenzene & $8270 \mathrm{C}$ & $7440-62-2$ & Thallium & 6020 \\
\hline $87-86-5$ & Pentachlorophenol & $8270 \mathrm{C}$ & $7440-66-6$ & Vanadium & $6010 B$ \\
\hline
\end{tabular}


Waste Isolation Pilot Plant Annual Site Environmental Report for 2010 DOE/WIPP-11-2225

Table 6.2 - Analytical Parameters for which Groundwater Was Analyzed

\begin{tabular}{|l|l|l|l|l|l|}
\hline CAS No. $^{\mathrm{a}}$ & \multicolumn{1}{|c|}{ Parameter } & $\begin{array}{c}\text { EPA } \\
\text { Method } \\
\text { Number }\end{array}$ & CAS No. & Parameter & $\begin{array}{c}\text { Method } \\
\text { Number }\end{array}$ \\
\hline $110-86-1$ & Pyridine & $8270 \mathrm{C}$ & & & \\
\hline $78-83-1$ & Isobutanol (isobutyl alcohol) & $8260 \mathrm{~B}$ & & & \\
\hline
\end{tabular}

(a) Chemical Abstract Service Registry Number

(b) Methods are EPA methods except those designated SM which are from Standard Methods.

\subsubsection{Evaluation of Groundwater Quality}

The quality of the Culebra water sampled at the WIPP site is naturally poor and not suitable for human consumption or for agricultural purposes, because the TDS concentrations are generally above $10,000 \mathrm{mg} / \mathrm{L}$. In 2010 , average TDS concentrations in the Culebra (as measured in WQSP wells) varied from a low of $14,950 \mathrm{mg} / \mathrm{L}$ (WQSP6 ) to a high of $223,500 \mathrm{mg} / \mathrm{L}$ (WQSP-3). The groundwater of the Culebra is considered to be Class III water (non-potable) by EPA guidelines.

Water quality measurements performed in the Dewey Lake indicate that the water is considerably better quality than that from the Culebra. In 2010, the TDS concentrations in water from the well WQSP-6A, obtained from the Dewey Lake, averaged 3,530 mg/L. This water is suitable for livestock consumption, and is classified as Class II water by EPA guidelines. Saturation of the Dewey Lake in the area of the WIPP facility is discontinuous. In addition to this naturally occurring groundwater, anthropogenic SSW has been encountered in the upper Dewey Lake at the Santa Rosa contact (see Section 6.6).

Because of the highly variable TDS concentrations within the Culebra, baseline groundwater quality was defined for each individual well. The 2010 analytical results showing the concentrations of detectable constituents are displayed as Time Trend Plots compared to the baseline concentrations (Appendix E, Figures E.1 through E.49). The analysis results for each parameter or constituent for the two sampling sessions in 2010 (Rounds 30 and 31) are summarized in Appendix F, Tables F.1 through F.7.

The tables display either the 95th upper tolerance limit value (UTLV) or the 95th percentile value (as calculated for the background sampling rounds) for each parameter depending on the type of distribution exhibited by the particular parameter or constituent. Both values represent the concentrations beneath which 95 percent of the concentrations in a population are expected to occur. The UTLVs were calculated for data that exhibited a normal or a lognormal distribution. The 95th percentile was applied to data that were considered nonparametric (i.e., having neither a normal nor a lognormal distribution with 16-95 percent non-detects). Due to the large number of nondetectable concentrations of organic compounds, the limits for organic compounds were considered nonparametric and based on the contract-required method reporting limit for the contract laboratory. These values were recomputed after the baseline sampling was completed in 2000, and were applied to sampling Rounds 30 and 31 to evaluate potential contamination of the local groundwater. None of the constituents of interest (organics and trace metals) exceeded the baseline concentrations. 


\subsubsection{Groundwater Level Surveillance}

Wells were used to perform surveillance of the groundwater surface elevation of five water-bearing zones in the vicinity of the WIPP facility:

$\begin{array}{ll}\text { - } & \text { SSW (SR/DL contact) } \\ \text { - } & \text { Dewey Lake } \\ \text { - } & \text { Magenta } \\ \text { - } & \text { Culebra } \\ \text { - } & \text { Bell Canyon }\end{array}$

The two zones of most interest are the Culebra and Magenta (see Figure 6.1). Throughout 2010, water levels in up to 49 Culebra wells were measured (including the Culebra zone of dual completion wells) and 13 wells in the Magenta (including the Magenta zone of dual completion wells). One Dewey Lake well and two Bell Canyon wells were monitored. Nineteen wells in the shallow zone of the SR/DL contact were monitored. Groundwater level measurements were taken monthly in at least one accessible well bore at each well site for each available formation (Figure 6.2). Water levels in redundant well bores (well bores located on well pads with multiple wells completed in the same formation) at each well site were measured on a quarterly basis (Appendix F, Table F.9). Water levels at SSW wells and piezometers were measured on a quarterly basis.

A breakdown of the groundwater zone(s) intercepted by each well measured at least once in 2010 is given in Appendix F, Table F.8. Note that two existing wells (Culebra/Magenta, C-2737 and Culebra/Magenta, H-9c [converted to a Magenta only well in October 2010]) are completed at multiple depths. By using PIPs, these wells monitor more than one formation.

Water elevation trend analysis was performed for 40 of 49 wells completed or isolated in the Culebra. The subset of wells analyzed were those which had a sufficient period of record to analyze through CY 2010, did not display anomalous levels or trends, and were representative of more than one well at a given well pad (Appendix F, Table F.8). Excluded from trend analysis were SNL-6 and SNL-15 because they both were in longterm water level recovery. SNL-13 was also excluded due to a sudden rise and then stabilization following the drilling of a new oil or gas well nearby.

The dominant trend through 2010 was a spatially uniform, rising freshwater equivalent level in the Culebra monitoring wells north of the WIPP site. By "dominant," it is meant that (1) water levels rose in 25 of 40 wells from January through December (or shorter periods in wells that still had a discernable trend), (2) the average water level increase was 1.13 feet $(0.34 \mathrm{~m})$, and (3) the general water level rise is best indicated by twenty measured water levels increasing in the zero (neutral) to 2.0 foot range, and five being more than 2.0 feet.

Water levels in most (14 of 22) Culebra wells to the south of the WIPP site showed a decreasing trend compared to the northern wells in 2010. This difference could be attributed to heavy rains. The National Weather Service estimated 6-8 inches of rain spread across the area in July of 2010. The rain appeared heaviest across northern 


\section{Waste Isolation Pilot Plant Annual Site Environmental Report for 2010 DOE/WIPP-11-2225}

Nash Draw where the Culebra wells there show a greater response to rainfall events (Hillesheim et al., 2006). The rise then spread eastward in the form of a pressure wave toward the WIPP site during the next few months, causing water levels to rise in wells to the north and west. By the time the wave reached the WIPP site and southern monitoring wells, it had dissipated to the point that no effect was recorded.

Water levels in the Culebra, and to a lesser extent in the Magenta, have generally been rising since the completion of site characterization activities in 1989. The rise was not recognized as having a regional extent for many years because well drilling and testing, shaft sinking, and other human activities disturbed water levels. Since these activities were completed, a rise in water levels over the monitored area has become evident. However, 2009 and 2008 trends indicated a decrease in water levels regionally.

The historical water-level rise is not monotonic, but shows variations related to factors both known and hypothesized. Water levels in the Culebra in Nash Draw, west of the WIPP site, respond to major rainfall events within a few days (Hillesheim et al., 2006). It is hypothesized that the change in head in Nash Draw then propagates under Livingston Ridge to the WIPP site in the succeeding weeks or months. It is also hypothesized that the Culebra may be receiving leakage through poorly plugged and abandoned drillholes, or through fractures in Nash Draw, from higher hydrologic units and/or potash tailings piles north of the WIPP site. For example, the observed long-term rise in water levels might be caused by the leakage into the Culebra of approximately 74 acre-ft/yr of brine discharged onto the Intrepid East tailings pile north of the WIPP site, and/or by the leakage of a similar volume through 26 potash exploration holes north, west, and south of the WIPP site that may not have been properly plugged through the Culebra (Lowry and Beauheim, 2004; 2005). Likewise, a number of plugged and abandoned oil or gas wells have been identified, mostly to the east and south of the WIPP site, that may not be plugged through the Culebra with cement and could, hypothetically, be sources of leakage that affects the head in the Culebra (Powers, 2004).

Because of the wide area distribution of the rise, it does not result in significant changes in the hydraulic gradient in the Culebra, which controls the rate and direction of groundwater flow. The DOE uses updated heads in calculating potential radionuclide releases through the Culebra in the 10,000-year performance assessments that are part of each Compliance Recertification Application that is submitted to the EPA every five years.

Figures 6.4 through 6.10 provide hydrographs of wells WQSP-1 to WQSP-6A for CY 2010. The six Culebra wells (Figures 6.4 through 6.9; WQSP-6A is Dewey Lake) are typical of the hydrographs of the 40 wells analyzed for Culebra water level trends. Temporary declines from spring and fall water quality sampling are evident in some wells, such as WQSP-3 and WQSP-5. The Permit requires that the NMED be notified if a cumulative groundwater surface elevation change of more than 2 feet is detected in wells WQSP-1 to WQSP-6A over the course of one year that is not attributable to site tests or natural stabilization of the site hydrologic system. There was no abnormal or unexplained rise in the DMP wells outside the regional trend. Wells WQSP-1 and -2 had cumulative increases in water level in excess of 1 foot during the course of the year 
Waste Isolation Pilot Plant Annual Site Environmental Report for 2010 DOE/WIPP-11-2225

from January to December. These wells are typical of the wells in the northern section of the monitoring network.

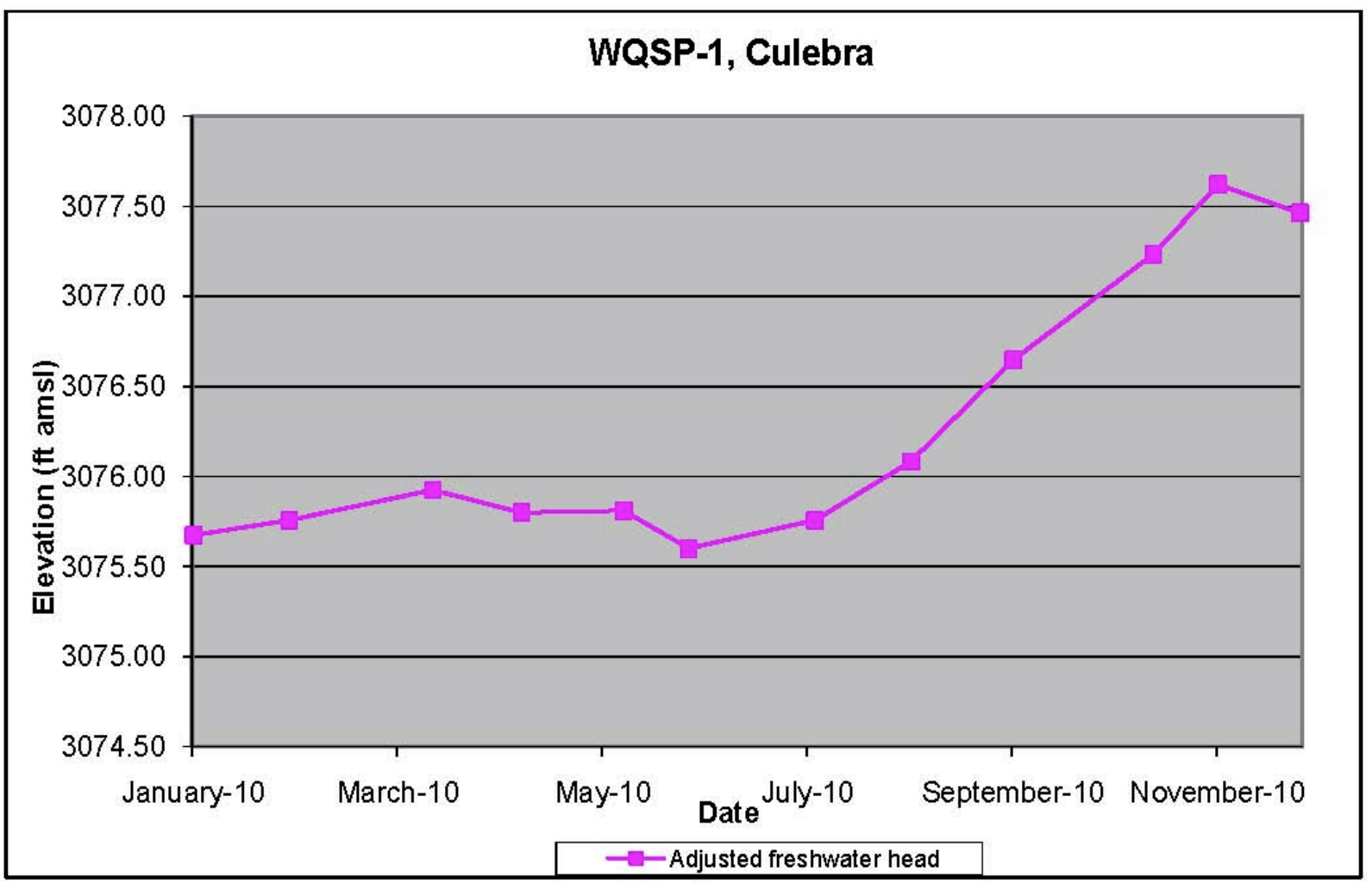

Figure $6.4-$ Hydrograph of WQSP-1

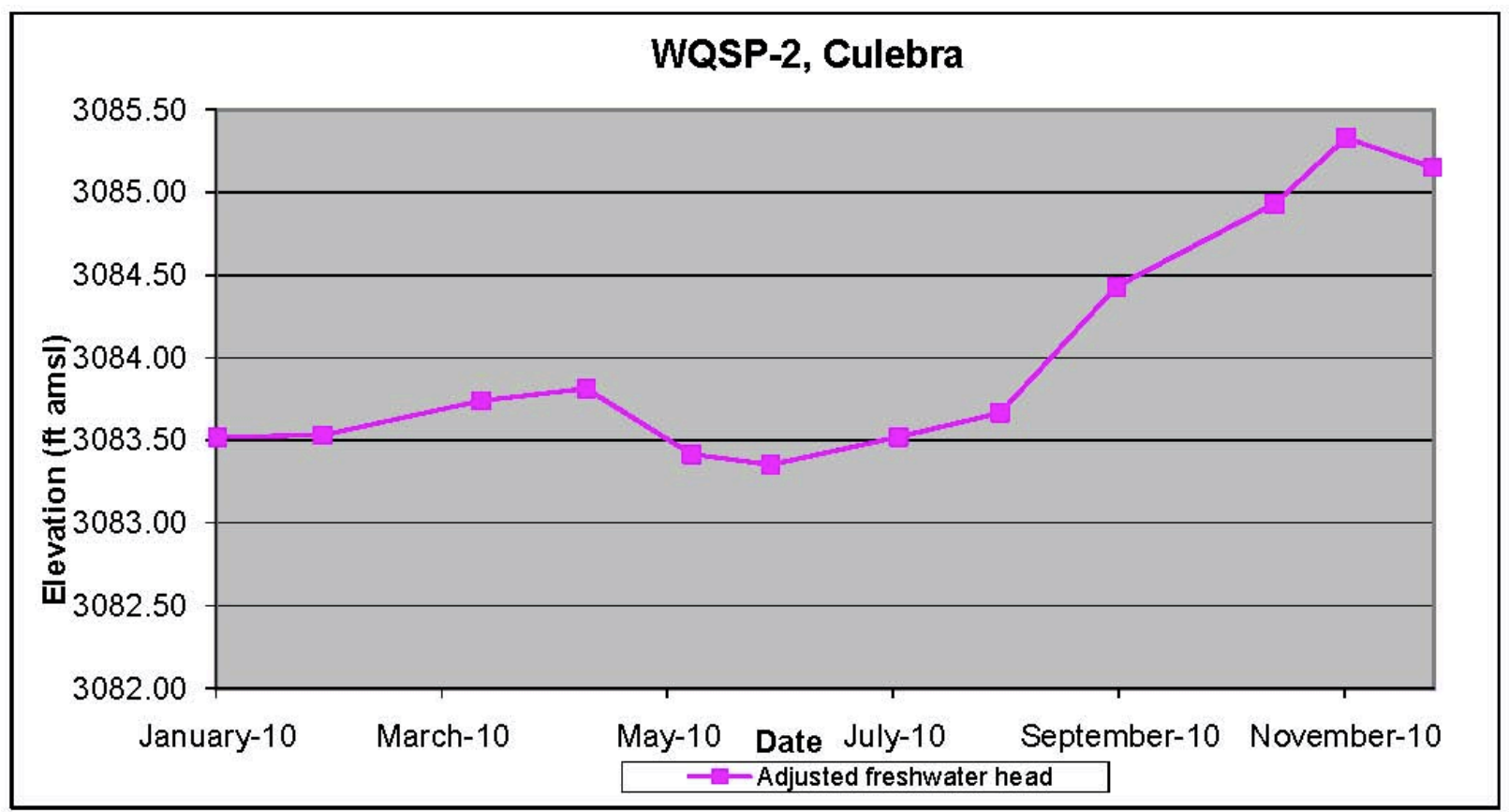

Figure 6.5 - Hydrograph of WQSP-2 
Waste Isolation Pilot Plant Annual Site Environmental Report for 2010 DOE/WIPP-11-2225

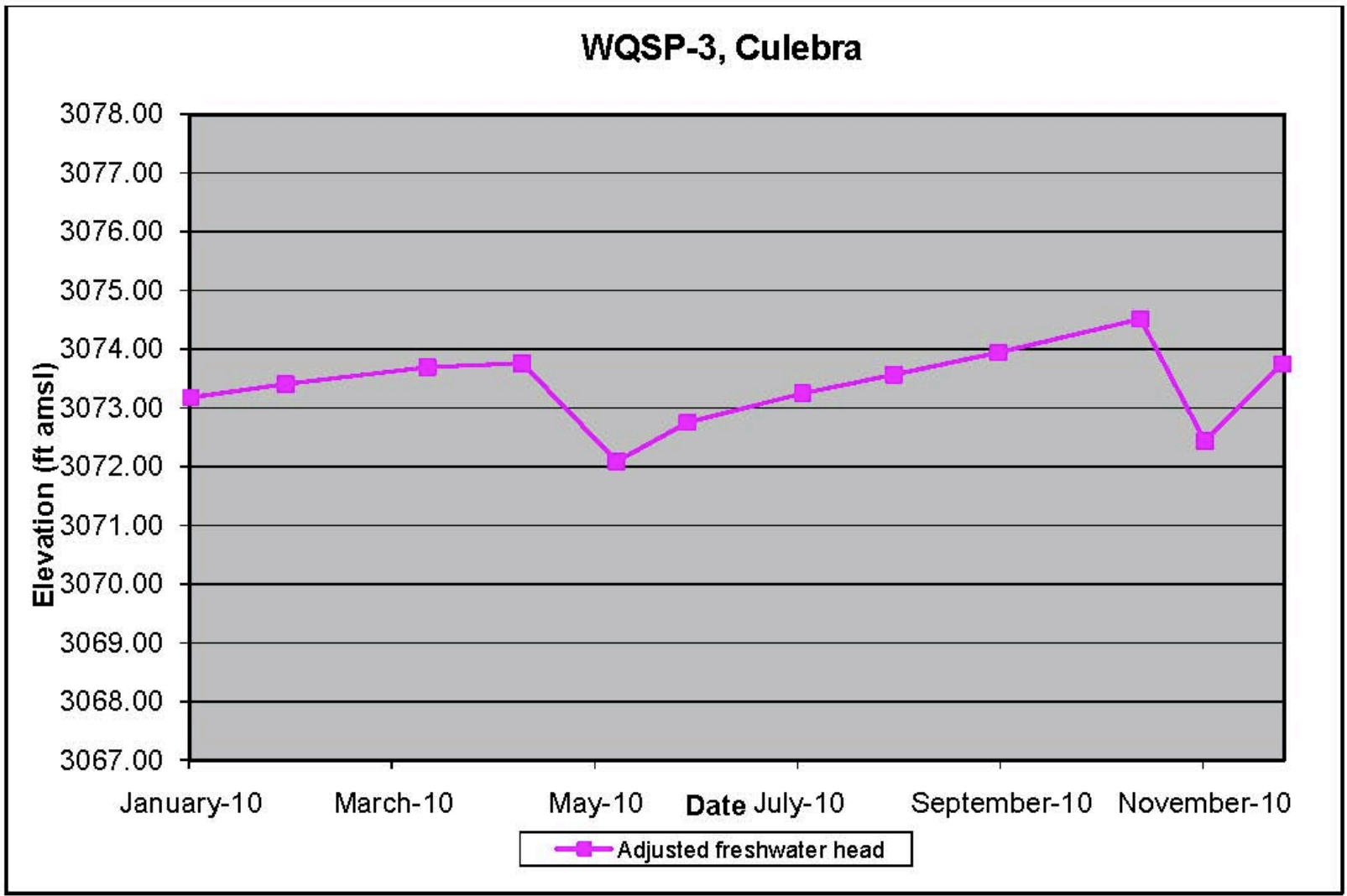

Figure 6.6 - Hydrograph of WQSP-3

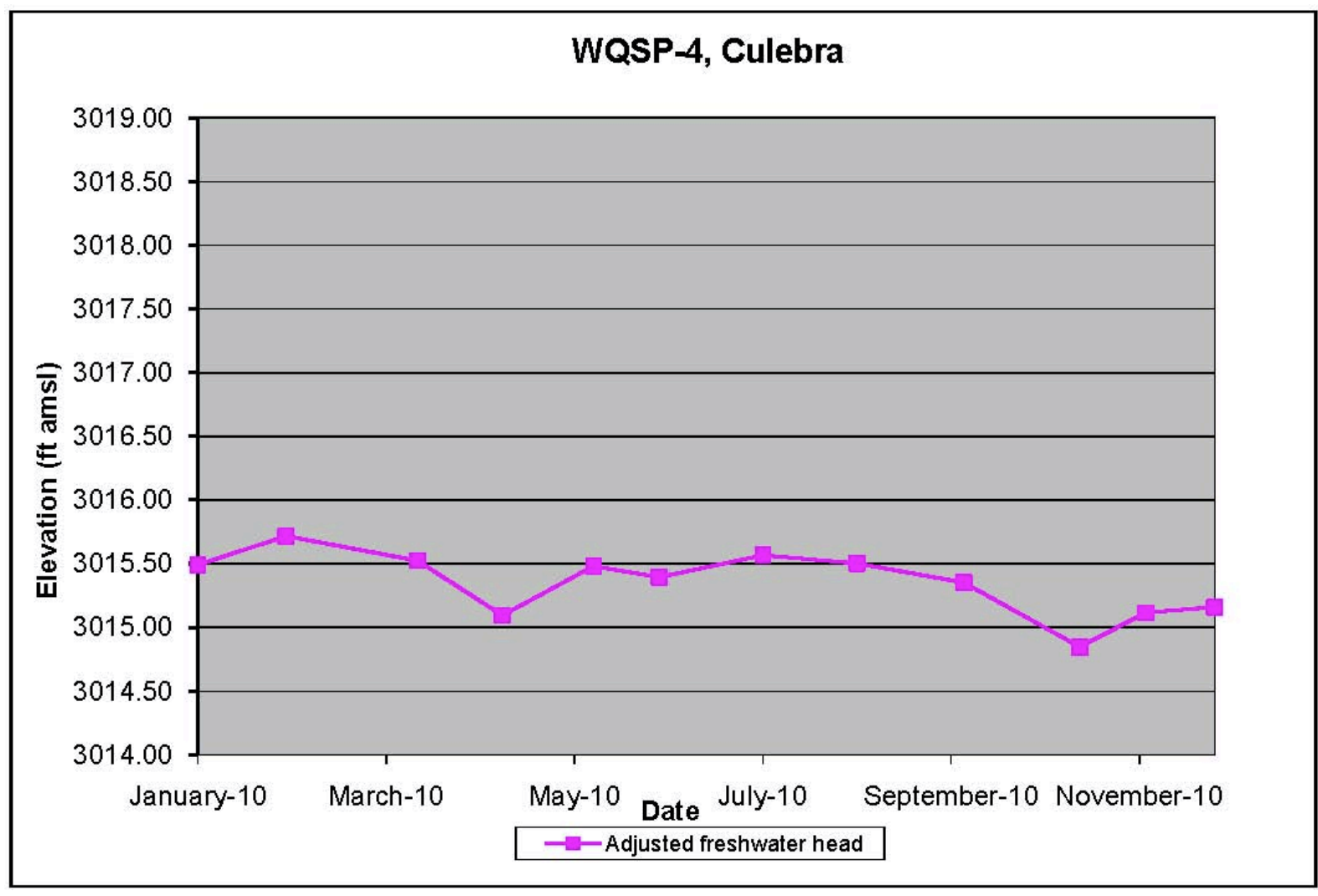

Figure 6.7 - Hydrograph of WQSP-4 
Waste Isolation Pilot Plant Annual Site Environmental Report for 2010 DOE/WIPP-11-2225

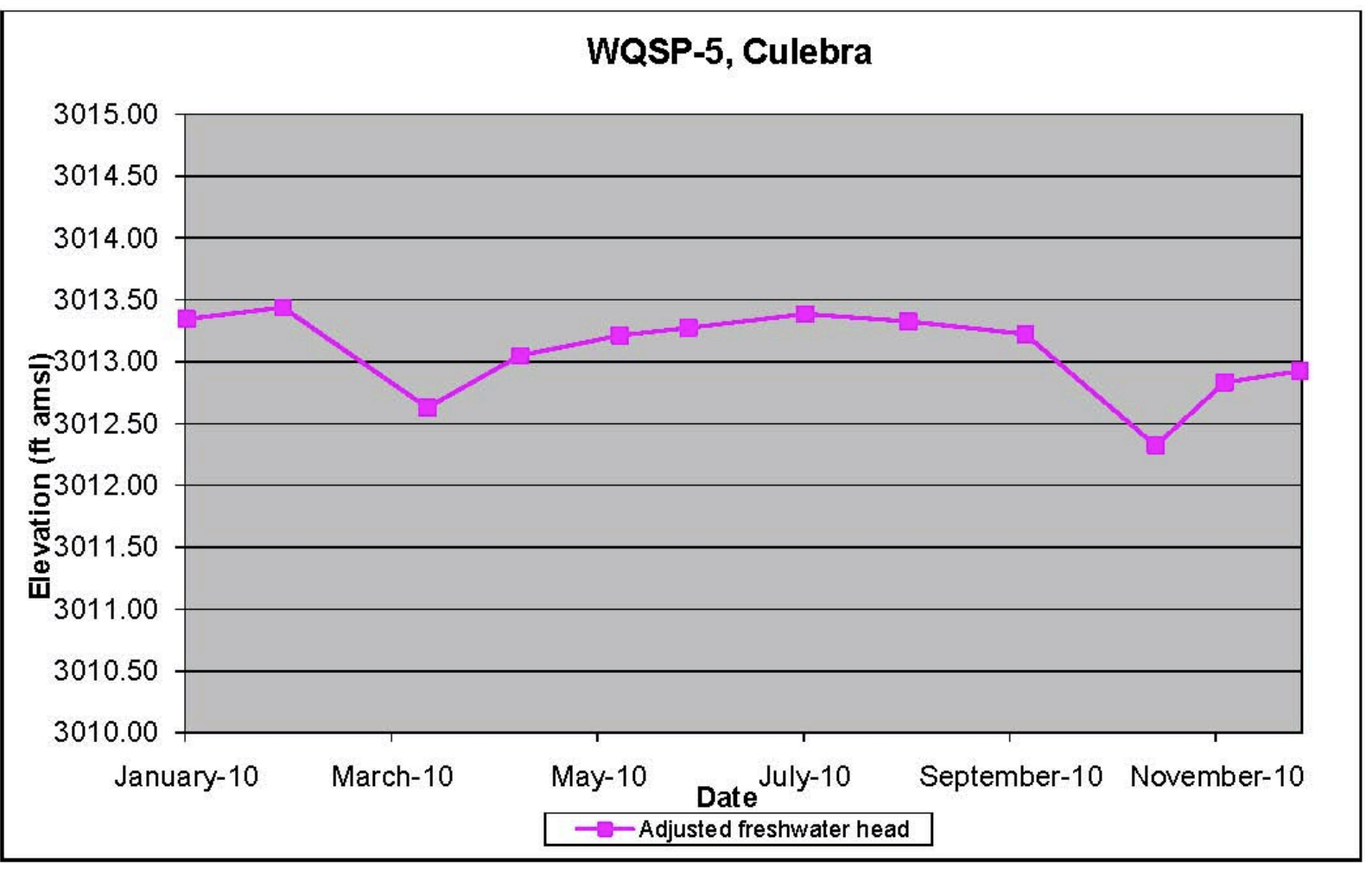

Figure 6.8 - Hydrograph of WQSP-5

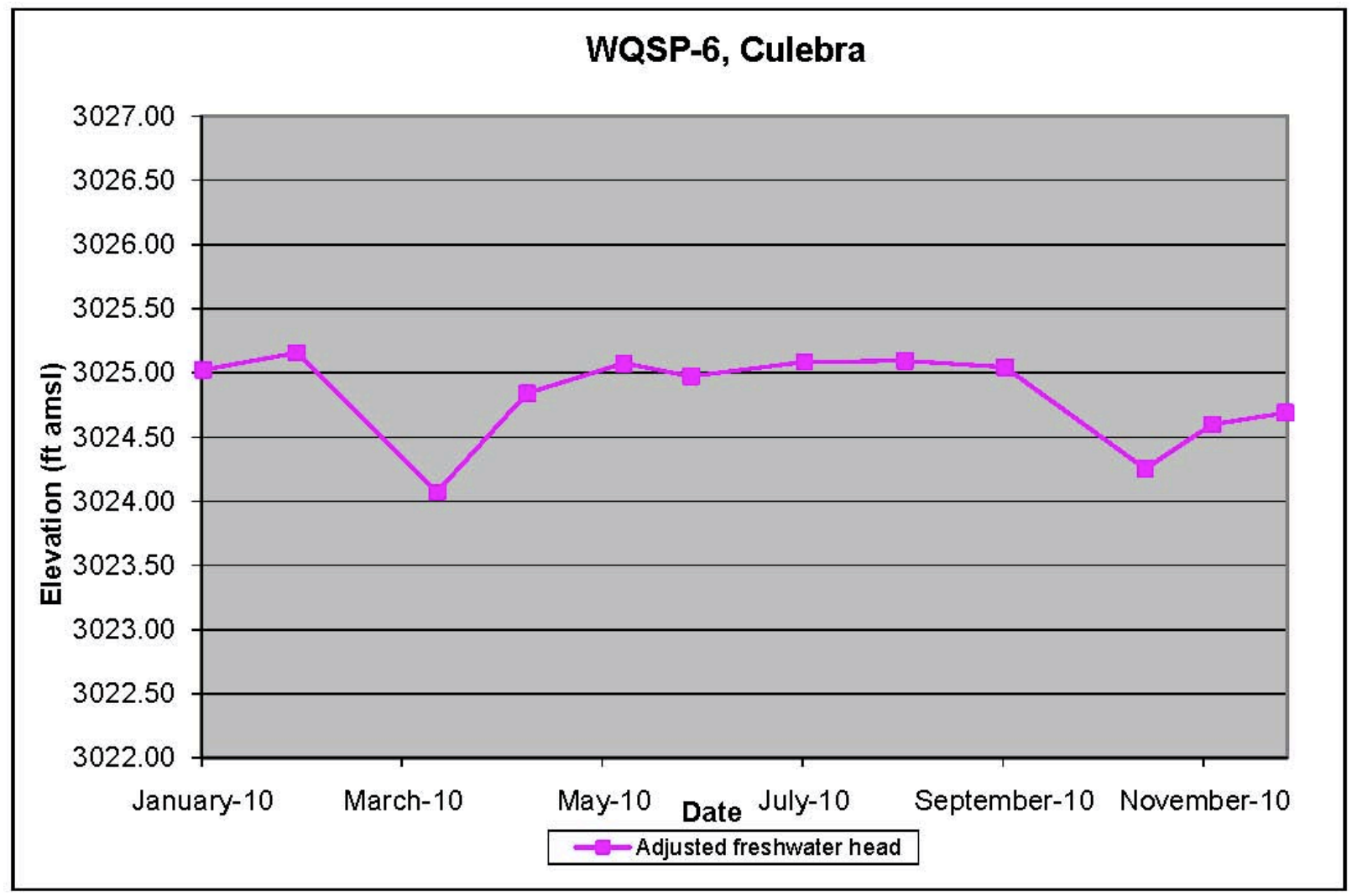

Figure 6.9 - Hydrograph of WQSP-6 


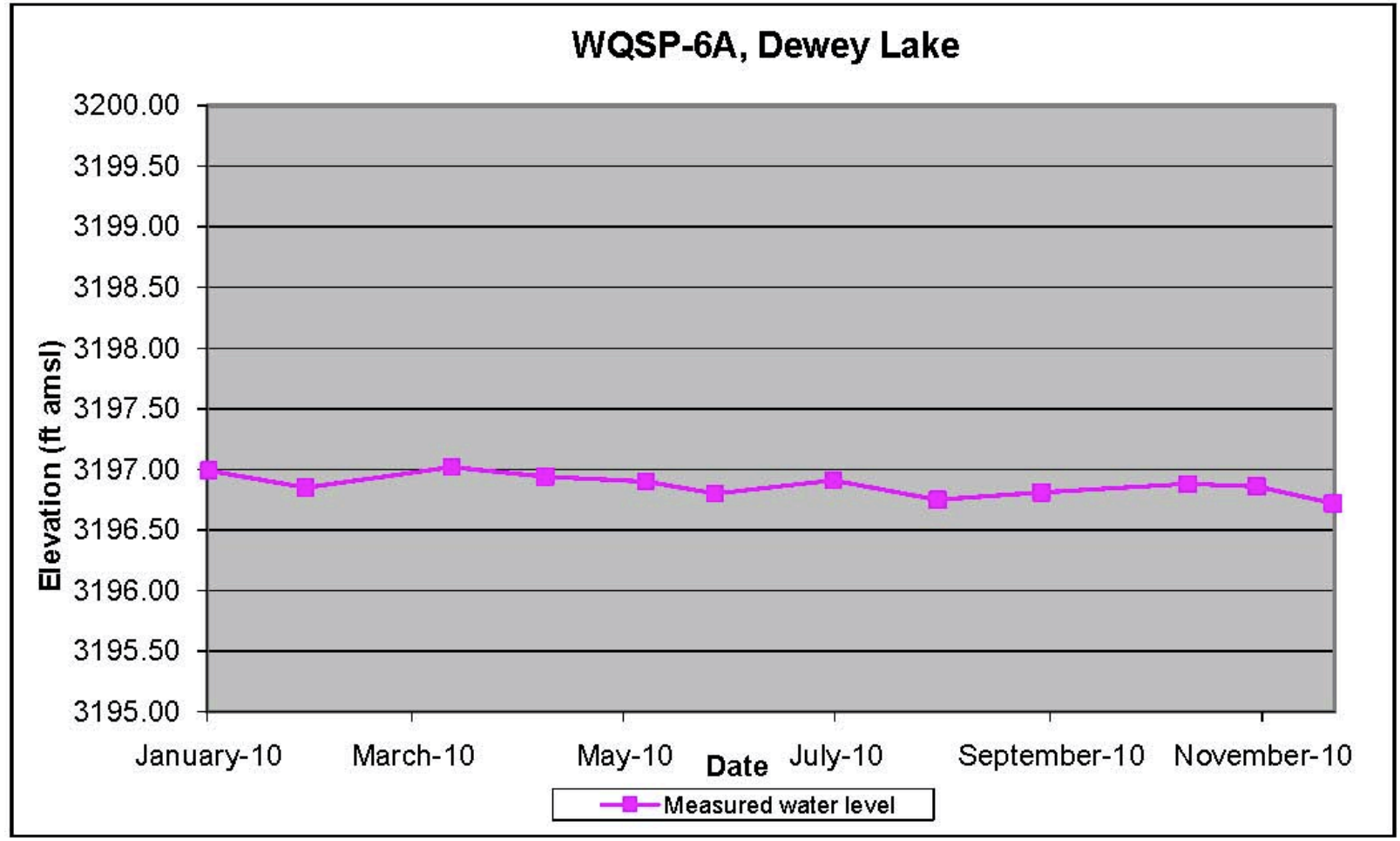

Figure 6.10 - Hydrograph of WQSP-6A

Groundwater level data were transmitted on a monthly basis to the NMED and the CBFO. A copy of the data was placed in the operating record for inspection.

For the Culebra wells in the vicinity of the WIPP site, equivalent freshwater heads for February 2010 were used to calibrate a groundwater flow model, which was used by SNL to compute a potentiometric surface using SNL procedure SP 9-9. This month was judged to have a large number of Culebra water levels available, few wells affected by pumping events, and all wells in quasi-steady state with few individual wells contrary to the general water level trend. Table 6.3 shows the water level data set. Wells SNL-6 and SNL-15 were not included in the mapping because the elevations do not represent static conditions. These wells are located in the low transmissivity zone of the Culebra and after drilling and testing, are still in recovery to reach equilibrium. Adjusted freshwater heads are typically accurate to \pm 1.5 feet given the density measurement error. Density measurement error is less than 0.019 specific gravity units (WP 02-1).

Table 6.3 - Water Level Elevations for the February 2010 Potentiometric Surface Calibration, Culebra Hydraulic Unit

\begin{tabular}{|c|c|c|c|c|}
\hline Well I.D. & $\begin{array}{c}\text { Date of } \\
\text { Measurement }\end{array}$ & $\begin{array}{c}\text { Adjusted } \\
\text { Freshwater Head } \\
\text { (feet, } \mathbf{m s l} \text { ) }\end{array}$ & $\begin{array}{c}\text { Density Used } \\
\text { (grams/cc) }\end{array}$ & Notes \\
\hline AEC-7 & $02 / 09 / 10$ & 3065.10 & 1.080 & \\
\hline C-2737 (PIP) & $02 / 10 / 10$ & 3022.51 & 1.027 & \\
\hline ERDA-9 & $02 / 10 / 10$ & 3033.60 & 1.070 & \\
\hline H-02b2 & $02 / 10 / 10$ & 3045.97 & 1.011 & \\
\hline H-03b2 & $02 / 10 / 10$ & 3014.90 & 1.042 & \\
\hline
\end{tabular}


Waste Isolation Pilot Plant Annual Site Environmental Report for 2010 DOE/WIPP-11-2225

Table 6.3 - Water Level Elevations for the February 2010 Potentiometric Surface Calibration, Culebra Hydraulic Unit

\begin{tabular}{|c|c|c|c|c|}
\hline Well I.D. & $\begin{array}{c}\text { Date of } \\
\text { Measurement }\end{array}$ & $\begin{array}{c}\text { Adjusted } \\
\text { Freshwater Head } \\
\text { (feet, msl) }\end{array}$ & $\begin{array}{l}\text { Density Used } \\
\text { (grams/cc) }\end{array}$ & Notes \\
\hline $\mathrm{H}-04 \mathrm{bR}$ & 02/08/10 & 3008.06 & 1.018 & \\
\hline $\mathrm{H}-05 \mathrm{~b}$ & 02/09/10 & 3082.24 & 1.096 & \\
\hline $\mathrm{H}-06 \mathrm{bR}$ & 02/08/10 & 3071.78 & 1.037 & \\
\hline H-07b1 & 02/08/10 & 2998.55 & 1.006 & \\
\hline $\mathrm{H}-09 \mathrm{c}(\mathrm{PIP})$ & 02/08/10 & 2998.59 & 1.006 & \\
\hline $\mathrm{H}-10 \mathrm{c}$ & 02/09/10 & 3028.11 & 1.091 & \\
\hline $\mathrm{H}-11 \mathrm{~b} 4$ & 02/09/10 & 3006.87 & 1.060 & \\
\hline $\mathrm{H}-12$ & 02/09/10 & 3008.00 & 1.097 & \\
\hline $\mathrm{H}-15 \mathrm{R}$ & 02/10/10 & 3018.86 & 1.120 & \\
\hline $\mathrm{H}-16$ & $02 / 10 / 10$ & 3047.09 & 1.039 & \\
\hline $\mathrm{H}-17$ & 02/08/10 & 3008.66 & 1.135 & \\
\hline $\mathrm{H}-19 \mathrm{b0}$ & 02/10/10 & 3015.14 & 1.067 & \\
\hline $\mathrm{I}-461$ & 02/08/10 & 3045.85 & 1.007 & \\
\hline SNL-01 & 02/09/10 & 3083.66 & 1.030 & \\
\hline SNL-02 & 02/08/10 & 3072.56 & 1.008 & \\
\hline SNL-03 & 02/09/10 & 3082.66 & 1.032 & \\
\hline SNL-05 & 02/08/10 & 3075.58 & 1.009 & \\
\hline SNL-06 & 02/09/10 & 3019.66 & 1.232 & Exclude from mapping \\
\hline SNL-08 & 02/09/10 & 3052.63 & 1.093 & \\
\hline SNL-09 & 02/08/10 & 3055.05 & 1.018 & \\
\hline SNL-10 & 02/09/10 & 3054.46 & 1.009 & \\
\hline SNL-12 & 02/08/10 & 3003.62 & 1.004 & \\
\hline SNL-13 & 02/09/10 & 3011.86 & 1.025 & \\
\hline SNL-14 & 02/08/10 & 3005.84 & 1.046 & \\
\hline SNL-15 & 02/09/10 & 2955.79 & 1.225 & Exclude from mapping \\
\hline SNL-16 & $02 / 08 / 10$ & 3010.49 & 1.015 & \\
\hline SNL-17 & 02/09/10 & 3006.36 & 1.005 & \\
\hline SNL-18 & 02/09/10 & 3075.17 & 1.005 & \\
\hline SNL-19 & 02/08/10 & 3072.98 & 1.007 & \\
\hline WIPP-11 & $02 / 10 / 10$ & 3082.54 & 1.037 & \\
\hline WIPP-13 & 02/10/10 & 3077.56 & 1.045 & \\
\hline WIPP-19 & $02 / 10 / 10$ & 3064.23 & 1.051 & \\
\hline WQSP-1 & 02/10/10 & 3075.76 & 1.046 & \\
\hline WQSP-2 & 02/10/10 & 3083.53 & 1.045 & \\
\hline WQSP-3 & 02/10/10 & 3073.40 & 1.144 & \\
\hline WQSP-4 & 02/10/10 & 3015.72 & 1.074 & \\
\hline WQSP-5 & $02 / 10 / 10$ & 3013.44 & 1.025 & \\
\hline WQSP-6 & $02 / 10 / 10$ & 3025.16 & 1.014 & \\
\hline
\end{tabular}


Modeled freshwater head contours for February 2010 for the model domain are shown in Figure 6.11. These contours were generated using the results of the Culebra MODFLOW 2K (Harbaugh et al., 2000) run utilizing ensemble average distributed aquifer parameters from the SNL Culebra flow model, which was calibrated as part of the performance assessment baseline calculation for the 2009 Compliance Recertification Application (DOE, 2009). Because that model was calibrated to both a snapshot of assumed steady-state water levels (May 2007), and to transient multi-well responses observed during large-scale pumping tests throughout the domain, the boundary conditions were adjusted to improve the match between the model and the observed February 2010 Culebra freshwater heads presented in this report. The portion of the flow domain of interest to the site is extracted on Figure 6.12. The freshwater head values for February 2010 were computed using 2009 densities.

The base transmissivity fields-and the 100 calibrated model realizations derived from them for the performance assessment baseline calculation-embody the hydrologic and geologic understanding of the Culebra behavior in the vicinity of the WIPP site (Kuhlman, 2010). Using the ensemble average of these 100 realizations, therefore, captures the mean flow behavior of the system, and allows straightforward contouring of results from a single-flow model. 


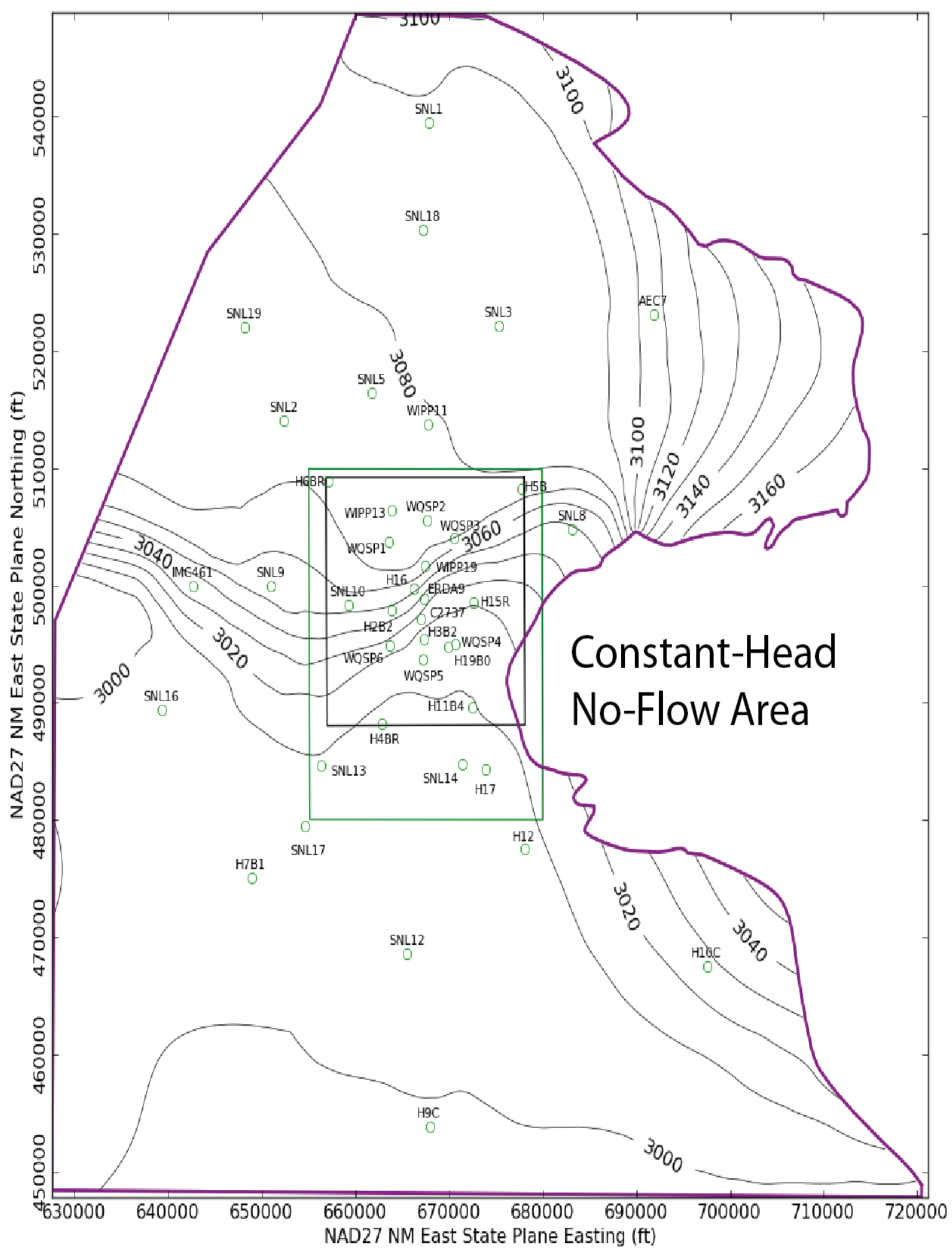

Figure 6.11 - Model Generated February 2010 Freshwater Head Contours in the Model Domain (Contour interval in ft AMSL) 


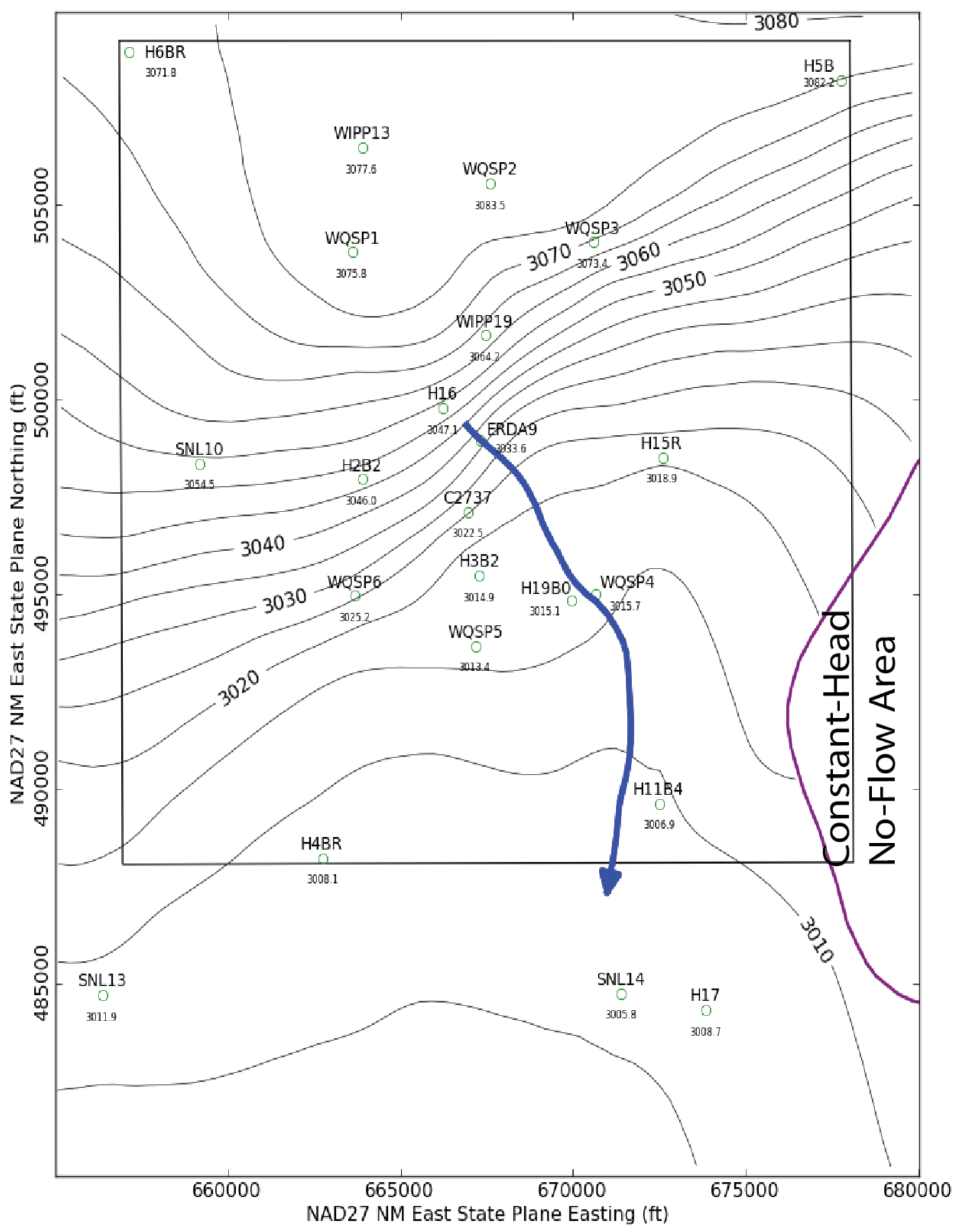

Figure 6.12 - Model-Generated February 2010 Freshwater Head Contours (5-Foot Contour Interval) in the WIPP Vicinity with Blue Water Particle Track from Waste Handling Shaft to WIPP Land Withdrawal Boundary (Contour interval in $\mathrm{ft}$ AMSL)

The Culebra flow model is a single-layer groundwater flow model. The boundary conditions of the flow model are of two types. First are the geologic or hydrologic-type boundary conditions, which include the specified head along the eastern boundary, and 
the no-flow boundary along the northwestern boundary of the domain. The second type of boundary condition is specified head. The northern and southern boundaries are of this type, along with the southern portion of the west boundary. The no-flow constant head boundary defined in Figure 6.12 is due to the low transmissivity for this area defined by such wells as SNL-15 and SNL-8 (Figure 6.2).

The second type of boundary conditions were determined using the parameter estimation code PEST (Doherty, 2002) as part of this modeling effort. PEST is used to systematically adjust and optimize the boundary conditions to maximize the fit between modeled and observed heads at wells.

The illustrated particle in Figure 6.12 (heavy blue line) shows the DTRKMF-predicted path a water particle would take through the Culebra from the coordinates corresponding to the WIPP waste handling shaft to the land withdrawal boundary (LWB) (a computed path length of $4.075 \mathrm{~km}$ ). Assuming a thickness of $4 \mathrm{~m}$ for the transmissive portion of the Culebra and a constant porosity of 16 percent, the travel time to the WIPP LWB is 6,283 years (output from DTRKMF is adjusted from a 7.75-m Culebra thickness), for an average velocity of $0.65 \mathrm{~m} / \mathrm{yr}$. Since the flow model has the ensemble hydraulic conductivity and anisotropy fields as inputs, the freshwater head contours and particle tracks take into account the variability of known aquifer conditions across the site.

The scatter plot in Figure 6.13 shows measured and modeled freshwater heads at the observation locations used in the PEST calibration. The observations are divided into three groups, based on proximity to the WIPP site. Wells within the LWB are represented by red crosses, wells outside but within $3 \mathrm{~km}$ of the LWB are represented with green " $x " s$, and other wells within the MODFLOW model domain but distant from the WIPP site are given by a blue asterisk. These groupings were utilized in the PEST calibration; higher weights (2.5) were given to wells inside the LWB, and lower weights (0.4) were given to wells distant to the WIPP site, while wells in the middle received an intermediate weight (1.0). Additional observations representing the average heads north of the LWB and south of the LWB were used to help prevent over-smoothing of the estimated results across the LWB. This allowed PEST to improve the fit of the model to observed heads inside the area contoured in Figure 6.12, at the expense of fitting wells closer to the boundary conditions (i.e., wells shown in Figure 6.11). 


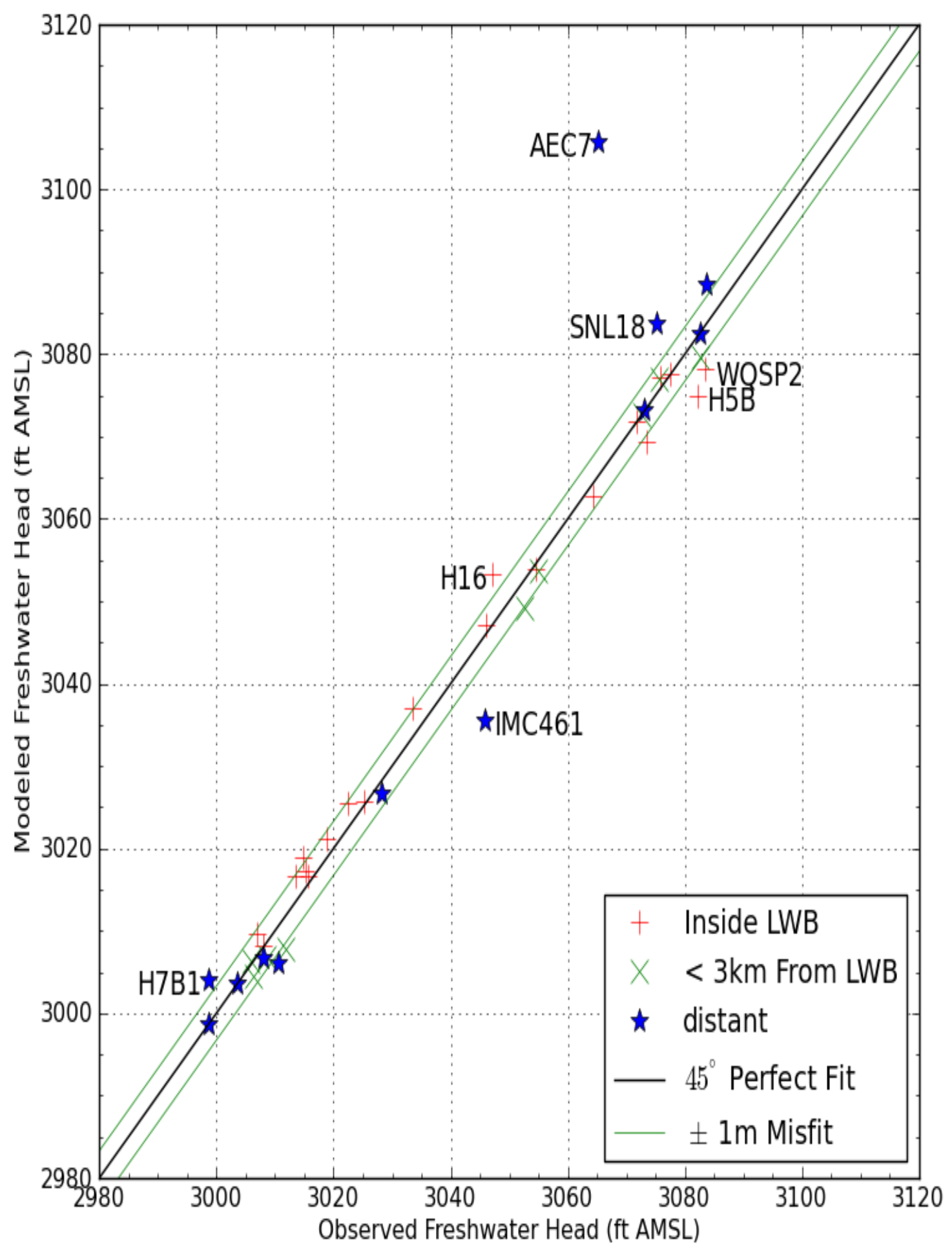

Figure 6.13 - Measured Versus Modeled Scatter Plot for PEST-Calibrated MODFLOW 2000 Generated Heads and February 2010 Observed Freshwater Heads

The central diagonal line in Figure 6.13 represents a perfect model fit (1:1 or 45-degree slope); the two lines on either side of this represent a 1-m misfit above or below the perfect fit. Wells more than $1.5 \mathrm{~m}$ from the 1:1 line are labeled. AEC-7 has a large misfit $(12.4 \mathrm{~m})$ for two reasons. The first reason is this well has historically had an 
anomalously low freshwater head elevation; the freshwater head elevation is lower than all wells surrounding it. The second reason is this well was undergoing well reconfiguration activities during May 2007 and was not measured. Therefore, AEC-7 was not included as a calibration target in the SNL Performance Assessment MODFLOW model calibration. The ensemble-average transmissivity, anisotropy, and recharge fields used here were not calibrated to accommodate this observation. This well is situated in a low-transmissivity region, and near the constant-head boundary associated with the halite margin, therefore PEST will not be able to improve this fit solely through adjustment of the second type boundary conditions along the edges of the domain (Figure 6.11).

Figure 6.14 and Figure 6.15 show the distribution of errors resulting from the PESTadjusted fit to observed data. The distribution in Figure 6.14 is roughly symmetric at about 0 , indicating there is not a strong bias. Aside from AEC-7, and to a lesser degree some other distant wells whose modeled values do not greatly impact the contours shown in Figure 6.12, the model fit to the February 2010 observations is very good. The ensemble-average model captures the average Culebra behavior, while the PEST calibration improved the model fit to the specific February 2010 observations.

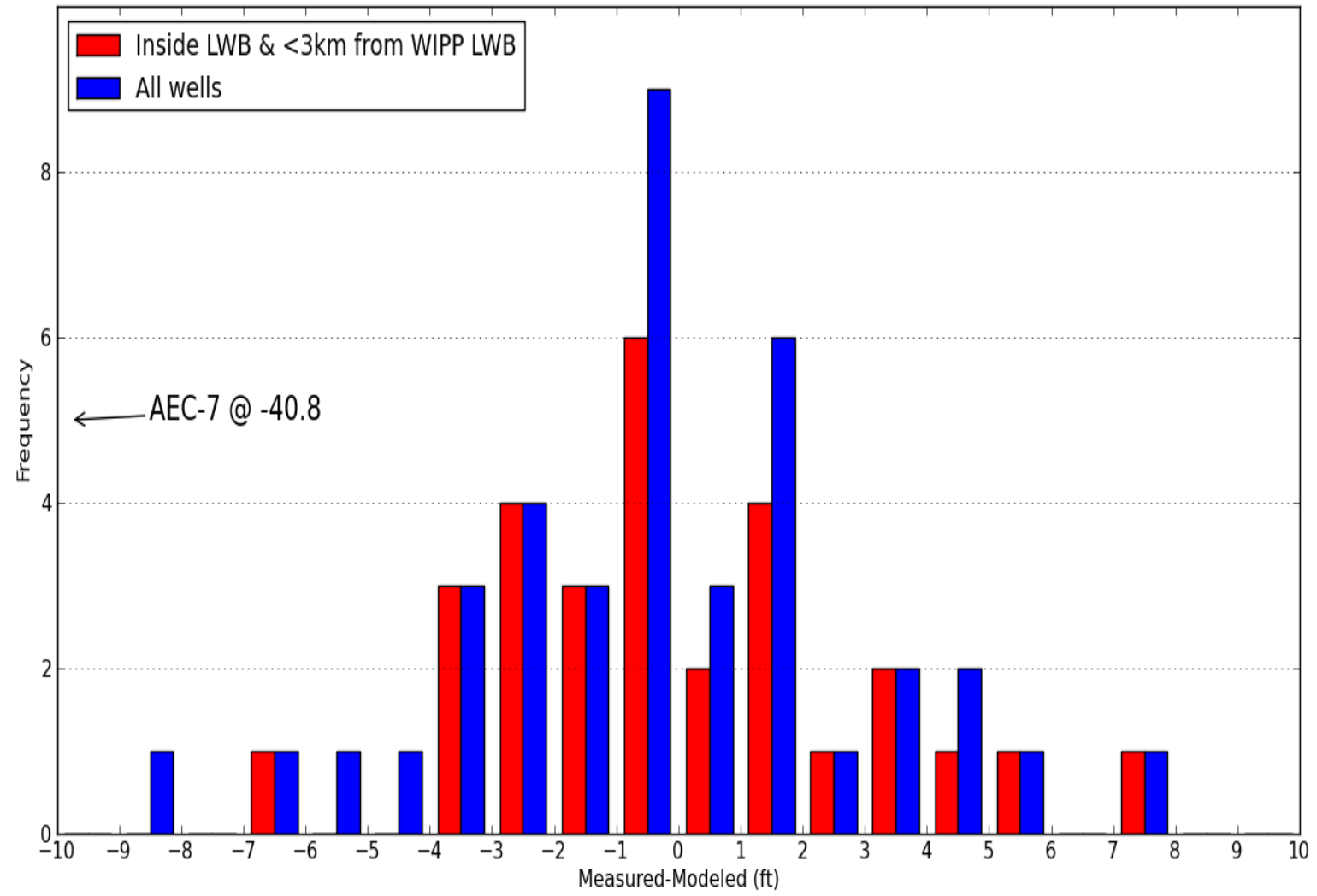

Figure 6.14 - Frequency of Modeled Freshwater Head Residuals 


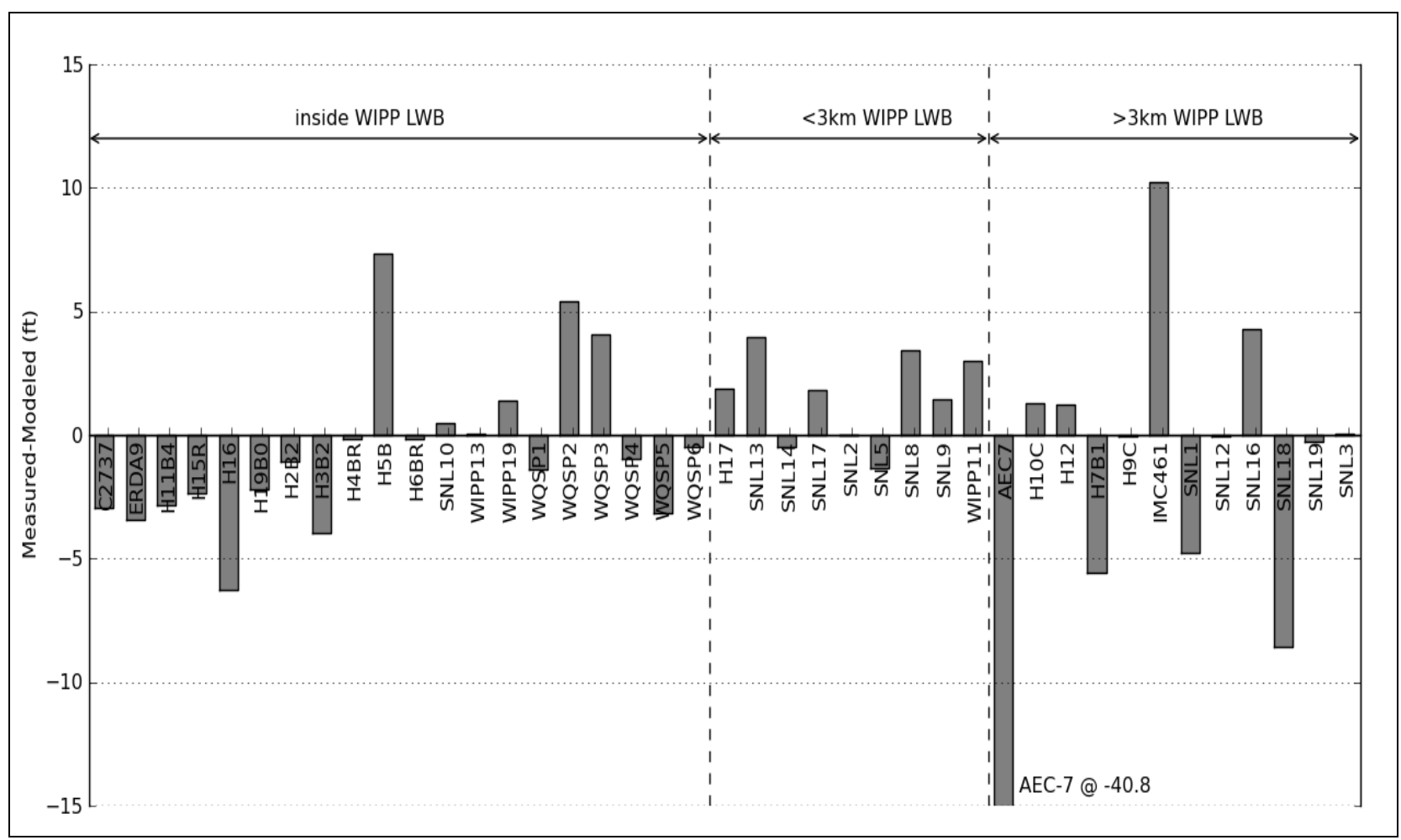

Figure 6.15 - Modeled Residual Freshwater Head at Each Well

\subsubsection{Pressure Density Surveys}

At the WIPP site, variable TDS concentrations result in variability in groundwater density (WP 02-1). WIPP measures the density of well-bore fluids in water level monitoring wells to adjust water levels to their equivalent freshwater head values. This allows more accurate determination of relative heads between wells. Pressure density surveys have been performed by two different methods during past years. In 2006 (and prior years), pressure density was obtained by a mobile trailer-mounted system that obtained data at each well. In 2007, SNL installed a dedicated pressure transducer in each well.

In 2010, densities were derived from 37 wells, as shown in Table 6.4, from Mini-Trolls installed by SNL, 6 from hydrometers as part of the WQSP sampling program, and 6 from the redundant $\mathrm{H}-19$ wells. This approach employed several calibrated pressuremeasuring transducers dedicated to given wells at varying times during the year. For the WQSP wells, field hydrometer measurements are always used. For comparison, 2008 and 2009 density data are shown. All year-to-year density differences are within the error as described in WP 02-1. 


\section{Waste Isolation Pilot Plant Annual Site Environmental Report for 2010 DOE/WIPP-11-2225}

Table 6.4 - Pressure Density Survey for 2010

\begin{tabular}{|c|c|c|c|c|c|c|}
\hline Well I.D. & $\begin{array}{c}2008 \\
\text { Pressure } \\
\text { Density } \\
\text { Survey } \\
\text { Result }\end{array}$ & $\begin{array}{c}2009 \\
\text { Pressure } \\
\text { Density } \\
\text { Survey } \\
\text { Result }\end{array}$ & $\begin{array}{c}2009 \\
\text { Conversion } \\
\text { to Specific } \\
\text { Gravity at } \\
70^{\circ} \mathrm{F}\end{array}$ & $\begin{array}{c}2010 \\
\text { Pressure } \\
\text { Density } \\
\text { Survey } \\
\text { Result }\end{array}$ & $\begin{array}{c}2010 \\
\text { Conversion } \\
\text { to Specific } \\
\text { Gravity at } \\
70^{\circ} \mathrm{F}\end{array}$ & $\begin{array}{c}\text { Notes for 2008-2010 Pressure } \\
\text { Density Survey }\end{array}$ \\
\hline & $\begin{array}{c}\text { Density } \\
\text { (grams/cc) }\end{array}$ & $\begin{array}{c}\text { Density } \\
\text { (grams/cc) }\end{array}$ & $\begin{array}{c}\text { Density } \\
\text { (grams/cc) }\end{array}$ & $\begin{array}{c}\text { Density } \\
\text { (grams/cc) }\end{array}$ & $\begin{array}{c}\text { Density } \\
\text { (grams/cc) }\end{array}$ & \\
\hline AEC-7 & 1.078 & 1.078 & 1.080 & 1.076 & 1.078 & \\
\hline C-2737 & 1.029 & 1.025 & 1.027 & 1.025 & 1.027 & \\
\hline ERDA-9 & 1.067 & 1.068 & 1.070 & 1.070 & 1.072 & \\
\hline $\mathrm{H}-02 \mathrm{~b} 2$ & $1.000 *$ & 1.009 & 1.011 & 1.011 & 1.013 & * Rounded up in 2008 \\
\hline $\mathrm{H}-03 \mathrm{~b} 2$ & 1.038 & 1.040 & 1.042 & 1.041 & 1.043 & \\
\hline $\mathrm{H}-04 \mathrm{~b}$ & 1.013 & NA & NA & NA & NA & Plugged in July 2009 \\
\hline $\mathrm{H}-04 \mathrm{bR}$ & NA & 1.016 & 1.018 & 1.016 & 1.018 & $\begin{array}{l}\text { Replacement for well H-04b } \\
\text { drilled in July } 2009\end{array}$ \\
\hline $\mathrm{H}-05 \mathrm{~b}$ & 1.093 & 1.094 & 1.096 & 1.091 & 1.093 & \\
\hline $\mathrm{H}-06 \mathrm{bR}$ & 1.033 & 1.035 & 1.037 & 1.035 & 1.037 & $\begin{array}{l}\text { Replacement well for } \mathrm{H}-6 \mathrm{~b} \\
\text { drilled in } 2008\end{array}$ \\
\hline $\mathrm{H}-07 \mathrm{~b} 1$ & $1.000^{*}$ & 1.004 & 1.006 & 1.004 & 1.006 & ${ }^{*}$ Rounded up in 2008 \\
\hline $\mathrm{H}-09 \mathrm{c}$ & 1.003 & 1.004 & 1.006 & 1.004 & 1.006 & $\begin{array}{l}\text { Plugged back to Magenta only } \\
\text { in October } 2010\end{array}$ \\
\hline $\mathrm{H}-9 \mathrm{bR}$ & NA & NA & NA & NA & NA & $\begin{array}{l}\text { Replacement well for } \mathrm{H}-09 \mathrm{c}- \\
\text { Culebra, drilled in 2010, no } \\
\text { measurements made for } \\
\text { calculation }\end{array}$ \\
\hline $\mathrm{H}-10 \mathrm{c}$ & 1.001 & 1.005 & 1.007 & NA & NA & $\begin{array}{l}\text { Use up to July } 2009 \text {, Bailed in } \\
\text { July } 2009 \text { to restore fluid } \\
\text { density }\end{array}$ \\
\hline $\mathrm{H}-10 \mathrm{c}$ & NA & 1.089 & 1.091 & 1.089 & 1.091 & Use for July 2009 forward \\
\hline $\mathrm{H}-11 \mathrm{~b} 4$ & 1.062 & 1.058 & 1.060 & 1.049 & 1.051 & \\
\hline $\mathrm{H}-12$ & 1.096 & 1.095 & 1.097 & 1.105 & 1.107 & \\
\hline $\mathrm{H}-15 \mathrm{R}$ & 1.130 & 1.118 & 1.120 & 1.117 & 1.119 & $\begin{array}{l}\mathrm{H}-15 \text { Culebra replacement well } \\
\text { drilled in } 2008\end{array}$ \\
\hline $\mathrm{H}-16$ & 1.039 & 1.037 & 1.039 & 1.035 & 1.037 & $\begin{array}{l}\text { New in 2008; formerly multi- } \\
\text { packer transducer well }\end{array}$ \\
\hline $\mathrm{H}-17$ & 1.120 & 1.133 & 1.135 & 1.134 & 1.136 & \\
\hline $\mathrm{H}-19 \mathrm{b0}$ & 1.075 & 1.065 & 1.067 & 1.066 & 1.068 & \\
\hline I-461 & 1.019 & 1.005 & 1.007 & 1.003 & 1.005 & \\
\hline SNL-01 & 1.032 & 1.028 & 1.030 & 1.026 & 1.028 & \\
\hline SNL-02 & 1.015 & 1.006 & 1.008 & 1.007 & 1.009 & \\
\hline SNL-03 & 1.029 & 1.030 & 1.032 & 1.026 & 1.028 & \\
\hline SNL-05 & 1.012 & 1.007 & 1.009 & 1.006 & 1.008 & \\
\hline SNL-06 & 1.253 & 1.230 & 1.232 & 1.231 & 1.233 & \\
\hline SNL-08 & 1.104 & 1.091 & 1.093 & 1.092 & 1.094 & \\
\hline SNL-09 & 1.026 & 1.016 & 1.018 & 1.016 & 1.018 & \\
\hline SNL-10 & 1.013 & 1.007 & 1.009 & 1.007 & 1.009 & \\
\hline
\end{tabular}


Waste Isolation Pilot Plant Annual Site Environmental Report for 2010 DOE/WIPP-11-2225

Table 6.4 - Pressure Density Survey for 2010

\begin{tabular}{|c|c|c|c|c|c|c|}
\hline Well I.D. & $\begin{array}{c}2008 \\
\text { Pressure } \\
\text { Density } \\
\text { Survey } \\
\text { Result }\end{array}$ & $\begin{array}{c}2009 \\
\text { Pressure } \\
\text { Density } \\
\text { Survey } \\
\text { Result }\end{array}$ & $\begin{array}{c}2009 \\
\text { Conversion } \\
\text { to Specific } \\
\text { Gravity at } \\
70^{\circ} \mathrm{F}\end{array}$ & $\begin{array}{l}2010 \\
\text { Pressure } \\
\text { Density } \\
\text { Survey } \\
\text { Result }\end{array}$ & $\begin{array}{c}2010 \\
\text { Conversion } \\
\text { to Specific } \\
\text { Gravity at } \\
70^{\circ} \mathrm{F}\end{array}$ & $\begin{array}{c}\text { Notes for } 2008-2010 \text { Pressure } \\
\text { Density Survey }\end{array}$ \\
\hline & $\begin{array}{l}\text { Density } \\
\text { (grams/cc) }\end{array}$ & $\begin{array}{c}\text { Density } \\
\text { (grams/cc) }\end{array}$ & $\begin{array}{c}\text { Density } \\
\text { (grams/cc) }\end{array}$ & $\begin{array}{l}\text { Density } \\
\text { (grams/cc) }\end{array}$ & $\begin{array}{l}\text { Density } \\
\text { (grams/cc) }\end{array}$ & \\
\hline SNL-12 & 1.011 & 1.002 & 1.004 & 1.003 & 1.005 & \\
\hline SNL-13 & 1.028 & 1.023 & 1.025 & 1.021 & 1.023 & \\
\hline SNL-14 & 1.048 & 1.044 & 1.046 & 1.044 & 1.046 & \\
\hline SNL-15 & 1.232 & 1.223 & 1.225 & 1.226 & 1.228 & \\
\hline SNL-16 & 1.023 & 1.013 & 1.015 & 1.007 & 1.009 & \\
\hline SNL-17 & 1.007 & 1.003 & 1.005 & 1.002 & 1.004 & \\
\hline SNL-18 & 1.011 & 1.003 & 1.005 & 1.004 & 1.006 & \\
\hline SNL-19 & 1.008 & 1.005 & 1.007 & 1.004 & 1.006 & \\
\hline WIPP-11 & 1.035 & 1.035 & 1.037 & 1.035 & 1.037 & \\
\hline WIPP-13 & 1.055 & 1.043 & 1.045 & 1.042 & 1.044 & \\
\hline WIPP-19 & 1.046 & 1.049 & 1.051 & 1.049 & 1.051 & \\
\hline WIPP-25 & 1.010 & $1.000 *$ & $1.000 *$ & NA & NA & $\begin{array}{l}\text { *March-May, not reliable, } \\
\text { Plugged in } 2009\end{array}$ \\
\hline WQSP-1 & 1.048 & 1.046 & 1.048 & 1.047 & 1.049 & $\begin{array}{l}\text { Average Rounds } 30 \text { and } 31 \text {, } \\
\text { field hydrometer }\end{array}$ \\
\hline WQSP-2 & 1.048 & 1.045 & 1.047 & 1.045 & 1.047 & $\begin{array}{l}\text { Average Rounds } 30 \text { and } 31 \text {, } \\
\text { field hydrometer }\end{array}$ \\
\hline WQSP-3 & 1.144 & 1.144 & 1.146 & 1.144 & 1.146 & $\begin{array}{l}\text { Average Rounds } 30 \text { and } 31 \text {, } \\
\text { field hydrometer }\end{array}$ \\
\hline WQSP-4 & 1.074 & 1.074 & 1.076 & 1.076 & 1.078 & $\begin{array}{l}\text { Average Rounds } 30 \text { and } 31 \text {, } \\
\text { field hydrometer }\end{array}$ \\
\hline WQSP-5 & 1.025 & 1.025 & 1.027 & 1.026 & 1.028 & $\begin{array}{l}\text { Average Rounds } 30 \text { and } 31 \text {, } \\
\text { field hydrometer }\end{array}$ \\
\hline WQSP-6 & 1.015 & 1.014 & 1.016 & 1.014 & 1.016 & $\begin{array}{l}\text { Average Rounds } 30 \text { and } 31 \text {, } \\
\text { field hydrometer }\end{array}$ \\
\hline
\end{tabular}

\subsection{Drilling Activities}

Well $\mathrm{H}-9 \mathrm{bR}$ was drilled as a replacement for Culebra well $\mathrm{H}-9 \mathrm{~b}$, which was plugged and abandoned in September 2010. The new well was drilled to a total depth of 686 feet below ground surface, with the screened interval at 640.5 to 667 feet below ground surface.

\subsection{Hydraulic Testing and Other Water Quality Sampling}

In addition to the chemical testing in the seven WQSP wells required by the Permit, the WIPP personnel also conducted basic water chemistry tests in some other wells as shown in Table 6.5 below. 
Waste Isolation Pilot Plant Annual Site Environmental Report for 2010 DOE/WIPP-11-2225

Table 6.5 - 2010 Well and Water Quality Sampling Testing Activities

\begin{tabular}{|l|l|l|}
\hline \multicolumn{1}{|c|}{ Well Location } & \multicolumn{1}{c|}{ Dates } & \multicolumn{1}{c|}{ Activity* } \\
\hline H-2b2, Magenta & April and June 2010 & Purged for water quality testing in early 2011 \\
\hline H-8a, Magenta & April 2010 & Purging and Water Chemistry \\
\hline WIPP -18, Magenta & March 2010 & Purging and Water Chemistry \\
\hline H-4c, Magenta & August 2010 & Purging and Water Chemistry \\
\hline H-6c, Magenta & April 2010 & Purging and Water Chemistry \\
\hline
\end{tabular}

*Water chemistry obtained by SNL. General chemical parameters (Anions/Cations).

\subsection{Well Maintenance}

Well maintenance for 2010 included plugging and abandonment of $\mathrm{H}-9 \mathrm{~b}$, developing $\mathrm{H}$ $10 \mathrm{a}$, reconfiguring $\mathrm{H}-9 \mathrm{c}$, and surveying $\mathrm{H}-9 \mathrm{bR}$.

In 2002, the open-hole portion of well $\mathrm{H}-9 \mathrm{~b}$ was inadvertently plugged during the pressure grouting of well $\mathrm{H}-9 \mathrm{a}$. In 2010 the well was officially plugged to the surface and a monument was erected per BLM requirements. $\mathrm{H}-9 \mathrm{bR}$ was drilled as a replacement. $\mathrm{H}-9 \mathrm{c}$ was reconfigured to a Magenta only monitoring well by removing the PIP and cementing from the bottom of the well to below the Magenta perforations (DOEMIPP-11-3326).

Well H-10a was bailed in March to restore the fluid density due to freshwater remaining in borehole from past geophysical studies. H-9bR was surveyed for its top of casing elevation and location in November. Table 6.6 shows the survey results.

Table 6.6 - 2010 Survey Data

\begin{tabular}{|c|c|c|c|c|}
\hline Well & Northing NAD27(ft) & Easting NAD27(ft) & $\begin{array}{c}\text { Top of Casing } \\
\text { (TOC)(ft) }\end{array}$ & $\begin{array}{c}\text { Ground } \\
\text { Elevation(ft) }\end{array}$ \\
\hline H-9bR & $454,083.79$ & $667,850.39$ & $3,408.34$ & $3,405.43$ \\
\hline
\end{tabular}

Note: Coordinates are New Mexico State Plane (feet)

\subsection{Shallow Subsurface Water Monitoring Program}

SSW occurs beneath the WIPP site at a depth of less than 100 feet below ground level at the contact between the Santa Rosa and the Dewey Lake (Figure 6.16). Water yields are generally less than one gallon per minute in monitoring wells and piezometers and the water contains varying concentrations of TDS (1,530 mg/L to 246,000 mg/L) and chloride (360 mg/L to 190,000 mg/L). To the south, yields are greater and TDS and chloride concentrations lower. The origin of the high TDS and chlorides in this water is believed to be primarily from anthropogenic sources, with some contribution from natural sources. The SSW occurs not only under the WIPP site surface facilities but also to the south as indicated by shallow water in drill hole C-2811, about one-half mile south of the WIPP property protection fence.

Additionally, drilling in 2007 around the SPDV salt pile tailings revealed shallow water in three piezometers (PZ-13, PZ-14, and PZ-15, shown in Figure 6.16). Natural shallow 
groundwater occurs in the middle part of the Dewey Lake at the southern portion of the WIPP site (WQSP-6A) (see Figure 6.2) and to the south of the WIPP site (J. C. Mills Ranch). To date, there is no indication that the anthropogenic SSW has affected the naturally occurring groundwater in the Dewey Lake.

In order to investigate the SSW, 15 piezometers (PZ-1 to PZ-15) and four wells (C-2505, C-2506, C-2507, and C-2811) have been drilled as part of a monitoring program to measure spatial and temporal changes in SSW levels and water quality. Monitoring activities during 2010 included SSW level surveillance at these 19 locations (Figure 6.16). 
Waste Isolation Pilot Plant Annual Site Environmental Report for 2010 DOE/WIPP-11-2225

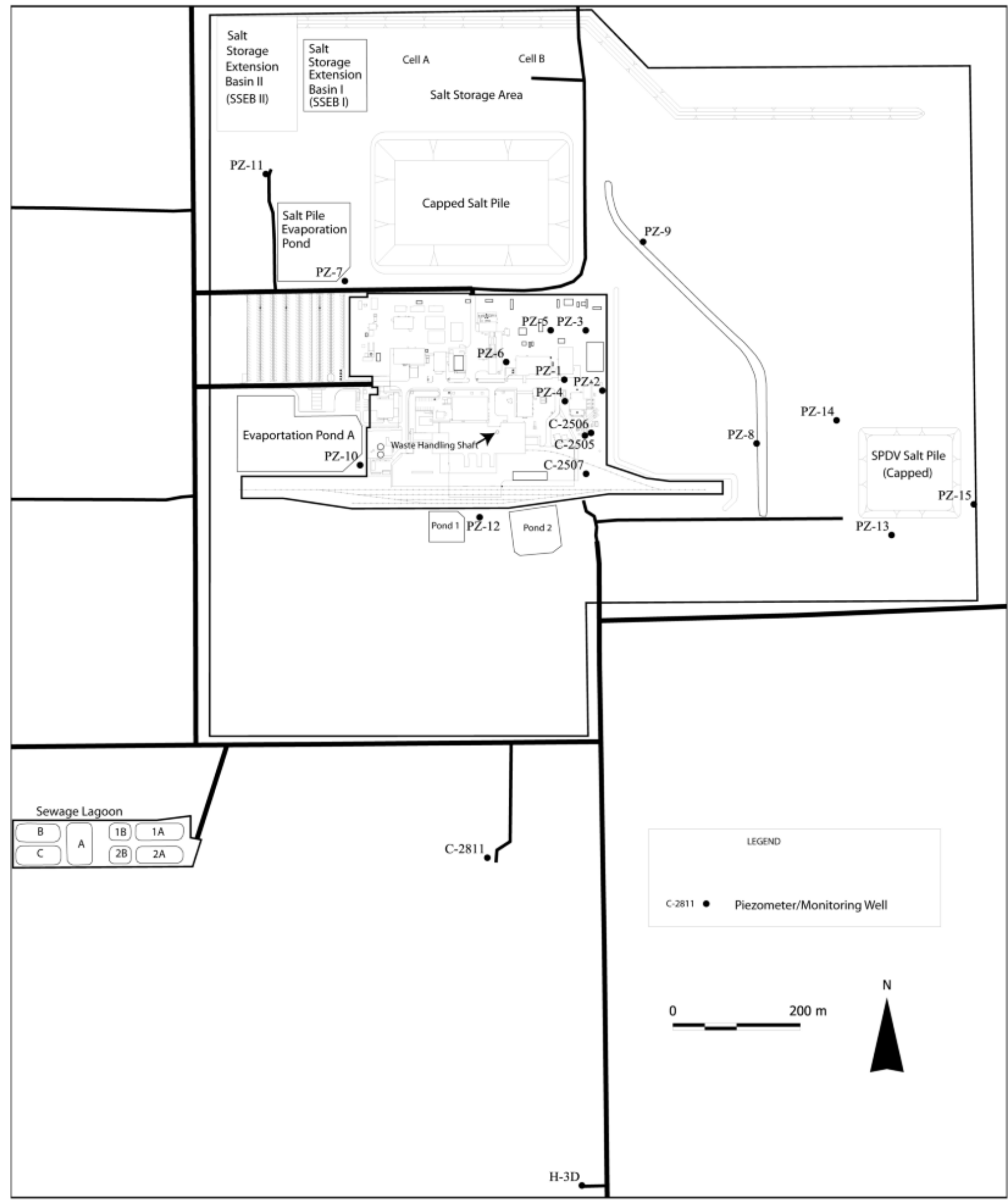

Figure 6.16 - Location of Shallow Subsurface Water Wells (Piezometers PZ 1 through 15, C 2811, C 2505, C 2506, C 2507 


\subsubsection{Shallow Subsurface Water Quality Sampling}

The discharge permit (DP-831), as modified, requires 11 SSW wells to be sampled on a semiannual basis. Wells PZ-1, PZ-5, PZ-6, PZ-7, PZ-9, PZ-10, PZ-11, PZ-12, PZ-13, C2811 , and $\mathrm{C}-2507$ are sampled for this program. These wells were sampled in May and October 2010 and the parameters presented in Table 6.7 were analyzed.

Table 6.7 - 2010 Shallow Subsurface Water Quality Sampling Results

\begin{tabular}{|c|c|c|c|c|}
\hline & \multicolumn{4}{|c|}{ General Chemistry Parameters } \\
\hline Monitoring Site & Sample Date & Sulfate (mg/L) & Chloride (mg/L) & TDS (mg/L) \\
\hline PZ-1 & $5 / 25 / 2010$ & 2,200 & 53,000 & 92,800 \\
\hline PZ-1 & $10 / 26 / 2010$ & 1,800 & 62,000 & 96,100 \\
\hline PZ-5 & $5 / 25 / 2010$ & 1,400 & 13,000 & 21,900 \\
\hline PZ-5 & $10 / 26 / 2010$ & 1,400 & 13,000 & 20,800 \\
\hline PZ-6 & $5 / 25 / 2010$ & 2,300 & 47,000 & 82,100 \\
\hline PZ-6 & $10 / 26 / 2010$ & 1,900 & 47,000 & 72,300 \\
\hline PZ-7 & $5 / 24 / 2010$ & 3,000 & 68,000 & 103,000 \\
\hline PZ-7 & $10 / 25 / 2010$ & 3,000 & 75,000 & 103,000 \\
\hline PZ-9 & $5 / 25 / 2010$ & 4,400 & 94,000 & 144,000 \\
\hline PZ-9 & $10 / 26 / 2010$ & 4,300 & 95,000 & 149,000 \\
\hline PZ-10 & $5 / 24 / 2010$ & 500 & 370 & 1,680 \\
\hline PZ-10 & $10 / 25 / 2010$ & 410 & 360 & 1,530 \\
\hline PZ-11 & $5 / 24 / 2010$ & 2,500 & 69,000 & 107,000 \\
\hline PZ-11 & $10 / 25 / 2010$ & 2,300 & 77,000 & 100,000 \\
\hline PZ-12 & $5 / 24 / 2010$ & 990 & 5,500 & 10,100 \\
\hline PZ-12 & $10 / 25 / 2010$ & 990 & 5,800 & 10,300 \\
\hline PZ-13 & $5 / 24 / 2010$ & 3,000 & 170,000 & 240,000 \\
\hline PZ-13 & $10 / 26 / 2010$ & 2,900 & 190,000 & 246,000 \\
\hline C-2811 & $5 / 24 / 2010$ & 340 & 920 & 2,090 \\
\hline C-2811 & $10 / 25 / 2010$ & 370 & 1,100 & 2,470 \\
\hline C-2507 & $5 / 25 / 2010$ & 910 & 3,500 & 6,640 \\
\hline C-2507 & $10 / 26 / 2010$ & 980 & 3,500 & 7,120 \\
\hline & & & & \\
\hline
\end{tabular}

\subsubsection{Shallow Subsurface Water Level Surveillance}

Nineteen wells were used to perform surveillance of the SSW-bearing horizon in the Santa Rosa and the upper portion of the Dewey Lake. Water levels were measured quarterly at all the piezometers and wells shown in Figure 6.16.

The potentiometric surface for the SSW using December 2010 data is presented in Figure 6.17. The contours were generated using SURFER version 9 surface mapping software by Golden Software. Sixteen data points were used in the contour development, whereas the contours around the SPDV salt pile were estimated by hand. 
Groundwater elevation measurements in the SSW indicate that flow is to the east and south away from a potentiometric high located near PZ-7 adjacent to the Salt Pile Evaporation Pond (Figure 6.17). At this time, it appears that the water identified in PZ-13 and PZ-14 is separate and distinct from the SSW in the other wells at the WIPP facilities area (DOE/WIPP-08-3375, Basic Data Report for Piezometers PZ-13, PZ-14, $P Z-15$ and SSW). PZ-13 and PZ-14 were completed the contact of the Santa Rosa and Dewey Lake. PZ-15 was completed much shallower in the Gatuña, where it appears rainwater has accumulated from a localized recharge source. Geochemically, the piezometer wells around the SPDV salt pile are distinct from the SSW wells located in the WIPP facilities area. Because of the recharge influence from a localized depression near PZ-15, this is geochemically distinct from the areas around the SPDV salt pile and the WIPP facilities.

In 2004 , storm water evaporation ponds were lined with high-density polyethylene in accordance with the discharge permit requirements. Since the installation of the liners, there has been a decrease in SSW elevations, which indicates that the liners have minimized the potential for groundwater to be impacted. 
Waste Isolation Pilot Plant Annual Site Environmental Report for 2010 DOE/WIPP-11-2225

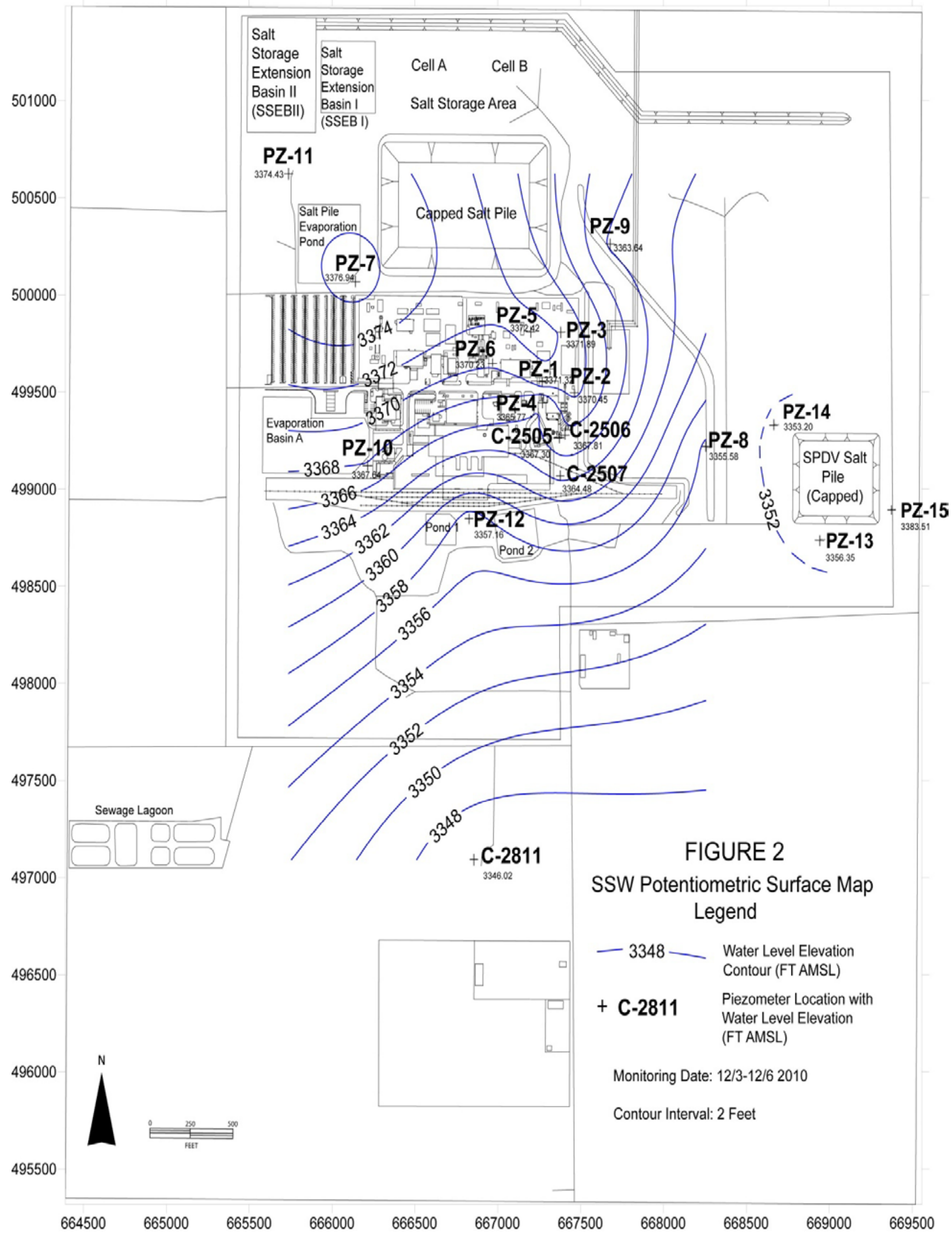

Figure 6.17 - Shallow Subsurface Water Potentiometric Surface 


\subsection{Public Drinking Water Protection}

The water wells nearest the WIPP site that use the natural shallow groundwater for domestic use are the Barn Well and Ranch Well located on the J. C. Mills Ranch. These wells are located approximately 3 miles south-southwest of the WIPP surface facilities, and about 1.75 miles south of WQSP-6A (see Figure 6.2 for location of WQSP-6A). TDS concentrations in the Barn Well have ranged from 630 to $720 \mathrm{mg} / \mathrm{L}$, and TDS concentrations in the Ranch Well have ranged from 2,800 to $3,300 \mathrm{mg} / \mathrm{L}$ (CCA, DOE/CAO-96-2184).

A water budget analysis in 2003 indicated that seepage from five primary sources (salt pile and four surface water detention basins) provided sufficient recharge to account for the observed SSW saturated lens and that the lens is expected to spread.

The potential extent for long-term SSW migration was examined by expanding the saturated flow model domain to include the 16-square-mile WIPP LWA. The long-term migration model simulations indicated that the engineered seepage controls that are now in place will substantially reduce the extent of migration. 
This page intentionally left blank 


\section{CHAPTER 7 - QUALITY ASSURANCE}

The fundamental objective of the environmental QA program is to obtain accurate and precise analytical data that are technically and legally defensible. This is accomplished through a series of management activities that plan, implement, review, assess, and correct as necessary. Samples are collected and analyzed using standardized and proven methods. The sample results and associated QC data are reviewed, verified, validated, and incorporated into succinct and informative reports, which describe how well the lab met its QA objectives.

In 2010, WIPP Laboratories performed the radiological analyses of environmental samples from the WIPP site. Carlsbad Environmental Monitoring and Research Center (CEMRC) in Carlsbad, New Mexico, and Hall Environmental Analysis Laboratory (HEAL) in Albuquerque, New Mexico, performed the nonradiological analyses. In addition, HEAL subcontracted some groundwater analyses to Columbia Analytical Systems and Anatek Laboratories. Both of these subcontracted laboratories have documented QA programs, including an established QA plan along with laboratoryspecific standard operating procedures (SOPs) based on published standard methods to perform the work.

The WIPP Laboratories and HEAL demonstrate the quality of their analytical data through participation in reputable, interlaboratory comparison programs such as the National Institute of Standards and Technology Radiochemistry Intercomparison Program (NRIP), Mixed Analyte Performance Evaluation Program (MAPEP), and National Environmental Laboratory Accreditation Conference (NELAC) Proficiency Testing (PT) studies. Laboratories used by the WIPP program are also required to meet the applicable requirements of the CBFO Quality Assurance Program Document (DOE/CBFO-94-1012), as flowed down through the Washington TRU Solutions LLC Quality Assurance Program Description (WP 13-1). CEMRC was not required to participate in intercomparison programs during 2010.

The WIPP sampling program and the subcontracted analytical laboratories operate in accordance with QA plans and QA project plans that incorporate QA requirements from the WTS Quality Assurance Program Description. These plans contain such elements as the following:

- Management and organization

- $\quad$ Quality system and description

- $\quad$ Personnel qualification and training

- $\quad$ Procurement of products and services

- $\quad$ Documents and records

- $\quad$ Computer hardware and software

- $\quad$ Planning

- $\quad$ Management of work process (SOPs)

- $\quad$ Assessment and response

- $\quad$ Quality improvement 
To ensure that the quality of the systems, processes, and deliverables are maintained or improved, three layers of assessments and audits are performed:

- $\quad$ DOE/CBFO performs assessments and audits of the WTS QA program.

- $\quad$ WTS performs internal assessments and audits of their own QA program.

- $\quad$ WTS performs assessments and audits of subcontractor QA programs as applied to WTS contract work.

The QA objectives for the sampling and analysis program are completeness, precision, accuracy, comparability, and representativeness.

Sections 7.1, 7.2, and 7.3 discuss the QC results for the WIPP Laboratories, CEMRC, and HEAL, in terms of how well they met the QA objectives.

\subsection{WIPP Laboratories}

Samples for analysis of radionuclides were collected using approved WIPP procedures. The procedures are based on generally accepted methodologies for environmental sampling, ensuring that the samples were representative of the media sampled. The samples were analyzed for natural radioactivity, fallout radioactivity from nuclear weapons tests, and anthropogenic radionuclides contained in the transuranic waste buried at the WIPP site. The reported concentrations at various locations in 2010 were representative of the baseline concentrations for radionuclides of interest at the WIPP facility.

\subsubsection{Completeness}

The SOW for analyses performed by WIPP Laboratories states that "analytical completeness, as measured by the amount of valid data collected versus the amount of data expected or needed, shall be greater than 90 percent for WTS sampling programs." For radiological sampling and analysis programs, this contract requirement translates into the following quantitative definition.

Completeness is expressed as the number of samples analyzed with valid results as a percent of the total number of samples submitted for analysis, or

$$
\% C=\frac{V}{n} \times 100
$$

Where:

$\% \mathrm{C}=$ Percent Completeness

$V=$ Number of Samples with Valid Results

$\mathrm{n}=$ Number of Samples Submitted for Analysis 
Samples and measurements for all environmental media (air particulate composites, groundwater, surface water, soil, sediment, plant, and animal) were 100 percent complete for 2010.

\subsubsection{Precision}

The SOW states that analytical precision (as evaluated through replicate measurements) will meet or surpass control criteria or guidelines established in the industry-standard methods used for sample analysis. To ensure overall quality of analysis of environmental samples, precision was evaluated for both sample collection and sample analysis procedures combined as well as the sample analysis procedures alone. At least one pair of field duplicates was collected and analyzed for each matrix type. (Field duplicates would not necessarily apply to all sample types such as small animals.) The precision of field duplicates and laboratory duplicates can be calculated for non-detected as well as detected radionuclide analytes, but only the precision of detected radionuclides is presented in this report.

The measure of precision for radionuclide sample analyses is the RER, which is expressed as follows:

$$
\mathrm{RER}=\frac{(\text { MeanActivity }) \text { ori }-(\text { MeanActivity }) d u p}{\sqrt{(2 \sigma T P U)^{2} \text { ori }+(2 \sigma T P U)^{2} \text { dup }}}
$$

Where:

$$
\begin{array}{ll}
(\text { Mean Activity) ori } & =\text { Mean Activity of the Original or Primary Sample } \\
(\text { Mean Activity })_{\text {dup }} & =\text { Mean Activity of the Duplicate Sample } \\
2 \sigma T P U & =\text { Total Propagated errors at the } 2 \text { sigma level }
\end{array}
$$

The laboratory performed duplicate analyses on separate portions of the same homogenized sample on at least one sample from each batch for each type of sample matrix in order to generate analysis precision data. The duplicate analyses of separate aliquots of the same sample evaluate the precision of subsampling in the laboratory, the heterogeneity of the media being sampled, and the precision of the analytical method. These laboratory precision data, as RERs, are reviewed and evaluated during verification and validation of the data, but are not included in this report. The verification and validation review showed that all the RERs were $<1$ for the sample batches analyzed in 2010, demonstrating good precision for the analysis procedures.

The RERs for field duplicate samples were also calculated as an indicator of the overall precision, reflecting the combination of both sample collection and laboratory analysis. Duplicate samples were collected at the same time, same place, and under similar conditions as the primary samples. In the case of animals, there were no duplicate field samples, but the laboratory generated duplicate laboratory samples for analysis for precision determination from the single field samples. These data are reported in Chapter 4 for each type of sample matrix analyzed. 


\section{Waste Isolation Pilot Plant Annual Site Environmental Report for 2010 DOE/WIPP-11-2225}

The quality assurance objective for precision on the WIPP Program is that the RER be < 1. This objective was met for most duplicate QA and field samples analyzed by WIPP Laboratories. The only exception was that ${ }^{239 / 240} \mathrm{Pu}$ in the aqueous laboratory control spike and laboratory control spike duplicate (LCS/LCSD) was 1.17 in Sample Delivery Group(SDG) 2010-37; however, the duplicate analysis of the quail sample met the RER $<1$ quality assurance objective for each radionuclide. These RERs demonstrated good reproducibility for all the radiological chemical analysis steps. All of the duplicate analyses of field samples, including groundwater, biota, surface water and sediment, and soil yielded RERs $<1$. Air filter composite samples are not analyzed in duplicate, but for the four quarterly sample sets where a portable low-volume air sampler was moved to a different location each quarter and collected a duplicate low-volume air particulate sample, the RERs of the duplicate field samples were all $\leq 1$.

\subsubsection{Accuracy}

The accuracy of the analyses was checked by analyzing initial and continuing calibration standards, method blanks, and laboratory control samples (blank spikes) as specified in the standard methods and in the corresponding lab SOPS. The daily calibration standards were used to confirm that the response in the daily standard closely matched the corresponding response during the initial calibration. The method blanks were used to confirm that the accuracy of the radiological sample analyses was not adversely affected by the presence of any of the target analytes as background contaminants that may have been introduced during sample preparation and analysis. The LCS was analyzed to check that the analytical method was in control by measuring the percent recoveries of the target analytes spiked into clean water. The LCS samples from applicable methods were analyzed in duplicate to check the precision of the measurement portion of the analytical method.

The accuracy of the radiochemical analyses was assured by analyzing calibration standards, method blanks, and LCS samples (blank spikes) as specified in the laboratory's SOPS. The radiochemistry SOW does not require the analysis of matrix spike samples. The SOW requires the measured accuracy to meet or surpass control criteria or guidelines established in the industry-standard methods used for sample analysis. Instrument accuracy was assured by using NIST-traceable radiochemistry standards for instrument calibration.

NIST-traceable standards were also spiked into clean water or a clean solid matrix to prepare LCS samples. Analysis of LCSs containing the isotopes of interest was performed on a minimum 10 percent basis (one per batch of ten or fewer samples). The QA objective for the analysis results was that the measured concentration be within \pm 20 percent of the known expected concentration. If this criterion was not met, the entire batch of samples was re-analyzed. LCS results for each isotope were tracked on a running basis using control charts. The verification and validation review of the data showed that all radiological LCS results fell within the established recovery ranges, indicating good accuracy.

Accuracy was also ensured through participation of WIPP Laboratories in the DOE MAPEP, the DOE Laboratory Accreditation Program (DOELAP), and the NRIP interlaboratory comparison program (through NIST), as discussed in more detail in 
Section 7.1.4. Under these programs, WIPP Laboratories analyzed blind check samples, and the analysis results were compared with the official results measured by the DOELAP, MAPEP, and NRIP agency laboratories. Performance was established by percent bias, calculated as shown below.

$$
\% \text { Bias }=\frac{\left(A_{m}-A_{k}\right)}{A_{k}} \times 100
$$

Where:

$$
\begin{array}{ll}
\%_{\text {Bias }} & =\text { Percent Bias } \\
A_{m} & =\text { Measured Sample Activity } \\
A_{k} & =\text { Known Sample Activity }
\end{array}
$$

The DOELAP and NRIP programs primarily include the analyses of bioassay samples (urine and feces). Bioassay samples are not analyzed as part of the WIPP environmental program, and NRIP and DOELAP program performance evaluation (PE) bioassay analysis results are not specifically discussed in this report. The NRIP bioassay samples are part of an emergency preparedness exercise where the accuracy has a relatively wide acceptance range, but a fast turnaround time for reporting the results is very important. The analysis results for the WIPP target radionuclides in the samples $\left({ }^{241} \mathrm{Am},{ }^{238} \mathrm{Pu},{ }^{240} \mathrm{Pu},{ }^{90} \mathrm{Sr}\right.$, and $\left.{ }^{137} \mathrm{Cs}\right)$ all met the accuracy criteria in a feces and urine sample.

WIPP Laboratories analyzed eight MAPEP environmental samples consisting of two each of soil, water, air filter, and vegetation samples. In addition, the laboratory analyzed one environmental soil sample from NRIP (NIST). The analysis results are presented in Section 7.1.4.

Based on the number of Acceptable (A) ratings earned by WIPP Laboratories for the analysis of PE samples, the laboratory provided accurate and reliable radionuclide analysis data for the WIPP environmental samples.

\subsubsection{Comparability}

The mission of WIPP Laboratories is to produce high-quality and defensible analytical data in support of the WIPP operations. The SOW requires WIPP Laboratories to ensure consistency through the use of standard analytical methods coupled with specific procedures that govern the handling of samples and the reporting of analytical results. A key element in the WIPP Laboratories QA program is analysis of PE samples as part of interlaboratory comparison programs administered by reputable agencies. During 2010, WIPP Laboratories participated in four rounds of the NRIP Emergency Preparedness Program and three rounds of the DOE MAPEP.

The DOELAP, MAPEP, and the NIST NRIP programs involve preparing QC samples containing various alpha-, beta-, and gamma-emitting radionuclides in synthetic urine, synthetic feces, air filter, water, soil, and vegetation media, and distributing the samples to the participating laboratories. The programs are interlaboratory comparisons in that 


\section{Waste Isolation Pilot Plant Annual Site Environmental Report for 2010 DOE/WIPP-11-2225}

results from the participants are compared with the analysis data experimentally measured by the administering agencies. The programs assess each laboratory's analysis results as acceptable (passing) or not acceptable (failing), based on the accuracy of the analyses. A warning (W) may be issued for a result near the borderline of acceptability.

Table 7.1 presents the analysis results for the first set of MAPEP soil, water, air filter, and vegetation PE samples (Series 21) analyzed in 2010. Table 7.2 presents the results for the second set of MAPEP soil, water, air filter, and vegetation PE samples (Series 22) analyzed in 2010. Table 7.3 presents the results for the third set of MAPEP soil, water, air filter, and vegetation PE samples (Series 23) analyzed in 2010. The results for the first set show that the MAPEP bias results met the acceptance criteria (-25 percent/ +50 percent) for all the radionuclides and media of interest at the WIPP site except that a not-acceptable $(\mathrm{N})$ result was determined for ${ }^{241} \mathrm{Am}$ in the air filter sample set due to a false positive report. The ${ }^{241} \mathrm{Am}$ had not been spiked into the samples but was reported with a low concentration by the laboratory.

WIPP Laboratories achieved acceptable results for all the samples in the Series 2 samples except for the reported ${ }^{137} \mathrm{Cs}$ concentration on the air filter. The lab reported a concentration of $2.64 \mathrm{~Bq} /$ filter which was 72.5 percent higher than the MAPEP concentration of $1.53 \mathrm{~Bq} /$ filter.

WIPP Laboratories achieved all acceptable analysis results for the third round of MAPEP samples including ${ }^{241} \mathrm{Am}$ and ${ }^{137} \mathrm{Cs}$ in the air filter sample.

Table 7.1 - Mixed Analyte Performance Evaluation Program Review for WIPP Laboratories, 2010, First Set (Series 21)

\begin{tabular}{|c|c|c|c|c|c|c|c|c|}
\hline \multirow[b]{2}{*}[\mathrm{RN}]{$^{\mathrm{a}}$} & \multicolumn{4}{|c|}{$\begin{array}{l}\text { MATRIX: Air Filter (Bq/Filter) } \\
\text { MAPEP-09- RdF21 }\end{array}$} & \multicolumn{4}{|c|}{$\begin{array}{l}\text { MATRIX: Water }(\mathrm{Bq} / \mathrm{L}) \\
\text { MAPEP- 09- MaW21 }\end{array}$} \\
\hline & Reported Value & $\begin{array}{l}\text { MAPEP }^{b} \\
\text { Value }\end{array}$ & $\mathbf{E}^{\mathbf{c}}$ & $\%$ Bias & & $\begin{array}{l}\text { MAPEP } \\
\text { Value }\end{array}$ & $\mathbf{E}$ & $\begin{array}{c}\% \\
\text { Bias }\end{array}$ \\
\hline${ }^{241} \mathrm{Am}$ & 0.0432 & ND & $\mathrm{N}$ & $\begin{array}{l}\text { False } \\
\text { Positive }\end{array}$ & 1.06 & 1.04 & $A$ & 1.9 \\
\hline${ }^{60} \mathrm{Co}$ & 0.977 & 1.03 & $A$ & -5.1 & 15.0 & 15.4 & $A$ & -2.6 \\
\hline${ }^{137} \mathrm{Cs}$ & 1.36 & 1.4 & $A$ & -2.9 & 40.3 & 41.2 & $A$ & -2.2 \\
\hline${ }^{238} \mathrm{Pu}$ & 0.108 & 0.091 & $A$ & 18.7 & 0.0223 & 0.018 & $A$ & d \\
\hline${ }^{239 / 240} \mathrm{Pu}$ & 0.154 & 0.138 & A & 11.6 & 1.76 & 1.64 & A & 7.3 \\
\hline${ }^{90} \mathrm{Sr}$ & 0.845 & 0.835 & $A$ & 1.2 & 12.7 & 12.99 & $A$ & -2.2 \\
\hline${ }^{233 / 234} U$ & 0.338 & 0.3 & A & 12.7 & 3.09 & 2.96 & $A$ & 4.4 \\
\hline \multirow[t]{2}{*}{${ }^{238} \mathrm{U}$} & 0.338 & 0.312 & $A$ & 8.3 & 3.19 & 3.03 & $A$ & 5.3 \\
\hline & \multicolumn{4}{|c|}{$\begin{array}{l}\text { MATRIX: Soil (Bq/kg) } \\
\text { MAPEP-09-MaS21 }\end{array}$} & \multicolumn{4}{|c|}{$\begin{array}{c}\text { MATRIX: Vegetation (Bq/Sample) } \\
\text { MAPEP-0 9-RdV21 }\end{array}$} \\
\hline [RN] & Reported Value & $\begin{array}{l}\text { MAPEP } \\
\text { Value }\end{array}$ & $\mathbf{E}$ & $\%$ Bias & $\begin{array}{c}\text { Reported } \\
\text { Value }\end{array}$ & $\begin{array}{c}\text { MAPEP } \\
\text { Value }\end{array}$ & $\mathbf{E}$ & $\begin{array}{c}\% \\
\text { Bias }\end{array}$ \\
\hline${ }^{241} \mathrm{Am}$ & 80.6 & 89.8 & A & -10.2 & 0.163 & 0.171 & $A$ & -4.7 \\
\hline
\end{tabular}


Waste Isolation Pilot Plant Annual Site Environmental Report for 2010 DOE/WIPP-11-2225

\begin{tabular}{|c|c|c|c|c|c|c|c|c|}
\hline${ }^{60} \mathrm{Co}$ & 298 & 327 & $\mathrm{~A}$ & -8.9 & 2.62 & 2.57 & $\mathrm{~A}$ & 1.9 \\
\hline${ }^{137} \mathrm{Cs}$ & 585 & 669 & $\mathrm{~A}$ & -12.6 & 2.36 & 2.43 & $\mathrm{~A}$ & -2.9 \\
\hline${ }^{238} \mathrm{Pu}$ & 68.9 & 63.2 & $\mathrm{~A}$ & 9.0 & 0.00347 & 0.0016 & $\mathrm{~A}$ & $\mathrm{~d}$ \\
\hline${ }^{239 / 240} \mathrm{Pu}$ & 120 & 116 & $\mathrm{~A}$ & 3.2 & 0.180 & 0.168 & $\mathrm{~A}$ & 7.1 \\
\hline${ }^{90} \mathrm{Sr}$ & 421 & 455 & $\mathrm{~A}$ & -7.5 & 1.15 & 1.260 & $\mathrm{~A}$ & -8.7 \\
\hline${ }^{233 / 234} \mathrm{U}$ & 191 & 209 & $\mathrm{~A}$ & -8.6 & 0.487 & 0.460 & $\mathrm{~A}$ & 5.9 \\
\hline${ }^{238} \mathrm{U}$ & 196 & 217 & $\mathrm{~A}$ & -9.7 & 0.484 & 0.477 & $\mathrm{~A}$ & 1.5 \\
\hline
\end{tabular}

(a) Radionuclide.

(b) Mixed Analyte Performance Evaluation Program.

(c) Evaluation Rating ( $A=$ acceptable, $W=$ Acceptable with warning, $N=$ Not acceptable).

(d) Not applicable for statistically zero result per MAPEP.

Table 7.2 - Mixed Analyte Performance Evaluation Program Review for WIPP Laboratories, 2010 Second Set (Series 22)

\begin{tabular}{|c|c|c|c|c|c|c|c|c|}
\hline \multirow[b]{2}{*}[\mathrm{RN}]{$^{\mathrm{a}}$} & \multicolumn{4}{|c|}{$\begin{array}{l}\text { MATRIX: Air Filter (Bq/Filter) } \\
\text { MAPEP-09-RdF22 }\end{array}$} & \multicolumn{4}{|c|}{$\begin{array}{l}\text { MATRIX: Water (Bq/ L) } \\
\text { MAPEP-09-MaW22 }\end{array}$} \\
\hline & $\begin{array}{c}\text { Reported } \\
\text { Value }\end{array}$ & $\begin{array}{l}\text { MAPEP }^{\mathbf{b}} \\
\text { Value }\end{array}$ & Ec & $\begin{array}{c}\% \\
\text { Bias }\end{array}$ & $\begin{array}{c}\text { Reported } \\
\text { Value }\end{array}$ & $\begin{array}{l}\text { MAPEP } \\
\text { Value }\end{array}$ & $E$ & $\%$ Bias \\
\hline${ }^{241} \mathrm{Am}$ & 0.135 & 0.146 & A & -7.5 & 1.2 & 1.3 & A & -7.7 \\
\hline${ }^{60} \mathrm{Co}$ & 2.64 & 2.473 & A & 6.8 & 0.159 & d & A & d \\
\hline${ }^{137} \mathrm{Cs}$ & 2.64 & 1.53 & $\mathrm{~N}$ & 72.5 & 60.1 & 60.6 & A & -0.8 \\
\hline${ }^{238} \mathrm{Pu}$ & 0.000154 & 0.001 & A & $d$ & 2.04 & 1.93 & A & 5.7 \\
\hline${ }^{239 / 240} \mathrm{Pu}$ & 0.00941 & 0.0832 & A & 13.1 & 0.00243 & 0.009 & A & d \\
\hline${ }^{90} \mathrm{Sr}$ & -0.0221 & d & A & d & -0.263 & $d$ & A & $d$ \\
\hline${ }^{233 / 234} U$ & 0.0727 & 0.068 & $A$ & 6.9 & 1.2 & 1.22 & A & -1.6 \\
\hline \multirow[t]{2}{*}{${ }^{238} \mathrm{U}$} & 0.0725 & 0.071 & $A$ & 2.1 & 1.24 & 1.25 & A & -0.8 \\
\hline & \multicolumn{4}{|c|}{$\begin{array}{l}\text { MATRIX: Soil (Bq/kg) } \\
\text { MAPEP-09-MaS22 }\end{array}$} & \multicolumn{4}{|c|}{$\begin{array}{c}\text { MATRIX: Vegetation (Bq/Sample) } \\
\text { MAPEP-09-RdV22 }\end{array}$} \\
\hline [RN] & $\begin{array}{l}\text { Reported } \\
\text { Value }\end{array}$ & $\begin{array}{l}\text { MAPEP } \\
\text { Value }\end{array}$ & E & $\begin{array}{c}\% \\
\text { Bias }\end{array}$ & $\begin{array}{l}\text { Reported } \\
\text { Value }\end{array}$ & $\begin{array}{l}\text { MAPEP } \\
\text { Value }\end{array}$ & E & $\%$ Bias \\
\hline${ }^{241} \mathrm{Am}$ & 0.717 & d & A & d & 0.235 & 0.225 & A & 4.4 \\
\hline${ }^{60} \mathrm{Co}$ & 646 & 622 & A & 3.9 & 3.38 & 3.27 & A & 3.4 \\
\hline${ }^{137} \mathrm{Cs}$ & 781 & 779 & A & 0.3 & 3.38 & 3.06 & A & 10.5 \\
\hline${ }^{238} \mathrm{Pu}$ & 28.1 & 24.1 & A & 9 & 0.182 & 0.16 & A & 13.8 \\
\hline${ }^{239 / 240} \mathrm{Pu}$ & 0.554 & d & A & d & 0.00161 & 0.0008 & A & d \\
\hline${ }^{90} \mathrm{Sr}$ & 253 & 288 & A & -12.2 & -0.0189 & d & A & d \\
\hline${ }^{233 / 234} U$ & 63.8 & 60 & A & 6.3 & 0.258 & 0.216 & A & 19.4 \\
\hline${ }^{238} \mathrm{U}$ & 65.5 & 64 & A & 2.3 & 0.248 & 0.223 & A & 11.2 \\
\hline
\end{tabular}

(a) Radionuclide.

(b) Mixed Analyte Performance Evaluation Program.

(c) Evaluation Rating ( $\mathrm{A}=$ acceptable, $\mathrm{W}=$ Acceptable with warning, $\mathrm{N}=$ Not acceptable).

(d) Not applicable for statistically zero result per MAPEP. 
Table 7.3 - Mixed Analyte Performance Evaluation Program Review for WIPP Laboratories, 2010, Third Set (Series 23)

\begin{tabular}{|c|c|c|c|c|c|c|c|c|}
\hline \multirow[b]{3}{*}[\mathrm{RN}]{$^{\mathrm{a}}$} & \multicolumn{4}{|c|}{$\begin{array}{c}\text { MATRIX: Air Filter (Bq/Filter) } \\
\text { MAPEP-10-RdF23 }\end{array}$} & \multicolumn{4}{|c|}{$\begin{array}{l}\text { MATRIX: Water (Bq/L) } \\
\text { MAPEP-10-MaW23 }\end{array}$} \\
\hline & \multicolumn{4}{|c|}{ Reported MAPEP } & \multicolumn{4}{|c|}{ Reported MAPEP } \\
\hline & Value & Value & $E^{c}$ & $\begin{array}{c}\% \\
\text { Bias }\end{array}$ & Value & Value & $\mathbf{E}^{\mathrm{c}}$ & $\%$ Bias \\
\hline${ }^{241} \mathrm{Am}$ & 0.115 & 0.115 & $A$ & 0.0 & 0.00689 & $d$ & $A$ & $d$ \\
\hline${ }^{60} \mathrm{Co}$ & 3.08 & 2.92 & A & 5.5 & 28.5 & 28.3 & $A$ & 0.7 \\
\hline${ }^{137} \mathrm{Cs}$ & -0.11 & $d$ & $A$ & $d$ & 42.9 & 44.2 & A & -2.9 \\
\hline${ }^{238} \mathrm{Pu}$ & 0.054 & 0.0489 & $A$ & 10.4 & 1.97 & 1.81 & $A$ & 8.8 \\
\hline${ }^{239 / 240} \mathrm{Pu}$ & 0.0824 & 0.082 & $A$ & 0.5 & 1.37 & 1.35 & $A$ & 1.5 \\
\hline${ }^{90} \mathrm{Sr}$ & 1.06 & 1.01 & A & 5.0 & 8.30 & 8.3 & A & 0.0 \\
\hline${ }^{233 / 234} U$ & 0.129 & 0.122 & A & 3.9 & 2.14 & 2.01 & A & 6.5 \\
\hline \multirow[t]{3}{*}{${ }^{238} \mathrm{U}$} & 0.132 & 0.127 & $A$ & 3.9 & 2.21 & 2.07 & $A$ & 6.8 \\
\hline & \multicolumn{4}{|c|}{$\begin{array}{l}\text { MATRIX: Soil (Bq/kg) } \\
\text { MAPEP-10-MaS23 }\end{array}$} & \multicolumn{4}{|c|}{$\begin{array}{c}\text { MATRIX: Vegetation (Bq/Sample) } \\
\text { MAPEP-10-RdV23 }\end{array}$} \\
\hline & \multicolumn{4}{|c|}{ Reported MAPEP ${ }^{b}$} & \multicolumn{4}{|c|}{ Reported MAPEP } \\
\hline$[\mathrm{RN}]^{\mathrm{a}}$ & Value & Value & $E^{c}$ & $\begin{array}{c}\% \\
\text { Bias }\end{array}$ & Value & Value & $E^{c}$ & $\%$ Bias \\
\hline${ }^{241} \mathrm{Am}$ & 79.5 & 87 & $A$ & -8.6 & 0.284 & 0.27 & $A$ & 5.2 \\
\hline${ }^{60} \mathrm{Co}$ & 349 & 343 & $A$ & 1.7 & 0.0474 & $d$ & $A$ & $d$ \\
\hline${ }^{137} \mathrm{Cs}$ & 662 & 670 & $A$ & -1.2 & 5.97 & 5.88 & $A$ & 1.5 \\
\hline${ }^{238} \mathrm{Pu}$ & 68.6 & 64 & $A$ & 7.2 & 0.248 & 0.221 & $A$ & 12.2 \\
\hline${ }^{239 / 240} \mathrm{Pu}$ & 72.4 & 71 & $A$ & 2.0 & 0.00115 & 0.001 & $A$ & $d$ \\
\hline${ }^{90} \mathrm{Sr}$ & 1.47 & $d$ & $A$ & $d$ & 2.72 & 2.63 & $A$ & 3.4 \\
\hline${ }^{233 / 234} U$ & 282 & 278 & $A$ & 1.4 & 0.353 & 0.32 & $A$ & 10.3 \\
\hline${ }^{238} \mathrm{U}$ & 283 & 289 & $A$ & -2.1 & 0.353 & 0.33 & $A$ & 7.0 \\
\hline
\end{tabular}
(a) Radionuclide.
(b) Mixed Analyte Performance Evaluation Program.
(c) Evaluation Rating ( $\mathrm{A}=$ acceptable, $\mathrm{W}=$ Acceptable with warning, $\mathrm{N}=$ Not Acceptable).
(d) Not applicable for statistically zero result per MAPEP. 


\subsubsection{Representativeness}

Representativeness is the extent to which measurements actually represent the true environmental condition or population at the time a sample was collected. The primary objective of environmental monitoring is to protect the health and safety of the population surrounding the WIPP facility. According to the SOW, analytical representativeness is assured through the use of technically sound and accepted approaches for environmental investigations, including industry-standard procedures for sample collection and monitoring for potential sample cross-contamination through the analysis of field and laboratory method blank samples. These conditions were satisfied during the sample collection and analysis practices of the WIPP environmental monitoring program.

The environmental media samples (air, groundwater, surface water, soil, sediment, and biota) were collected from areas representative of potential pathways for intake of radionuclides. The samples were collected using generally accepted methodologies for environmental sampling, ensuring that they would be representative of the media sampled. Both sample collection blanks and laboratory method blanks were used to check for cross-contamination and to ensure sample integrity.

\subsection{Carlsbad Environmental Monitoring and Research Center}

CEMRC performed the analyses of VOC and hydrogen/methane samples collected in the WIPP underground during 2010.

\subsubsection{Completeness}

Completeness is defined in WP 12-VC.01, Confirmatory Volatile Organic Compound Monitoring Plan; and WP 12-VC.04, Quality Assurance Project Plan for Hydrogen and Methane Monitoring, as being "the percentage of the ratio of the number of valid sample results received versus the total number of samples collected."The quality assurance objective for completeness in the VOC monitoring program is 95 percent.

For 2010, 552 VOC samples (including field duplicates) were submitted to CEMRC for analysis; 551 of these produced valid data. For repository, disposal room, and ongoing VOC monitoring, the program completion percentage was 99.8 percent.

For 2010, 423 hydrogen and methane samples (including field duplicates) were submitted to CEMRC for analysis; 422 of these produced valid data. For hydrogen and methane monitoring, the program completion percentage was 99.7 percent. 


\subsubsection{Precision}

Precision is demonstrated in both the VOC monitoring and hydrogen and methane programs: by evaluating results from both laboratory duplicate analysis and field duplicate samples. The laboratory duplicate samples consist of an LCS and LCSD. The field duplicate is a duplicate sample that is collected parallel with the original sample. Both of these duplicate samples are evaluated using the relative percent difference (RPD), as defined in WP 12-VC.01 and WP 12-VC.04. The RPD is calculated using the following equation.

$$
R P D=\frac{(A-B)}{(|A+B|) / 2} \times 100
$$

Where:

$$
\begin{aligned}
& A=\text { Original Sample Result } \\
& B=\text { Duplicate Sample Result }
\end{aligned}
$$

During 2010, an LCS and an LCSD were generated and evaluated for all data packages discussed in Section 7.2.1. The result from the evaluation of the comparison resulted in 100 percent of the data within 25\% RPD.

Field duplicate samples are also collected and compared for precision. The acceptable range for the RPD between measured concentrations is \pm 35 percent. For each value reported over the MRL in 2010, each field duplicate met the acceptance criteria with the exception of four disposal room VOC samples and one ongoing disposal room VOC sample.

\subsubsection{Accuracy}

The VOC monitoring program evaluates both quantitative and qualitative accuracy and recovery of internal standards. Qualitative evaluation consists of the evaluation of standard ion abundance for the instrument tune; that is, a mass calibration check performed prior to analyses of calibration curves and samples.

The hydrogen and methane monitoring program evaluates quantitative accuracy. The quantitative evaluation includes performance verification for instrument calibrations and LCS recoveries. 


\subsubsection{Quantitative Accuracy}

\section{Instrument Calibrations}

Instrument calibrations are required to have a relative standard deviation percentage of less or equal to 30 percent for each analyte of the calibration. This is calculated by first calculating the relative response factor as indicated below:

Relative Response Factor $=\quad$ (Analyte Response)(Internal Standard Concentration) (Internal Standard Response)(Analyte Concentration)

Relative Standard Deviation $=\quad$ Standard Deviation of Relative Response Factor Average Relative Response Factor of Analyte $\times 100$

During 2010, 100 percent of instrument calibrations met the $\leq 30$ percent criteria.

\section{LCS Recoveries}

LCS recoveries are required to have a percent recovery of \pm 25 (75-125\%R) percent. LCS recoveries are calculated as follows:

\section{Percent Recovery $=\frac{\text { Concentration Result }}{\text { Known Concentration }} \times 100$ Concentration Result}

During 2010, 100 percent of the LCS recoveries met the \pm 25 percent criterion.

\section{Internal Standard Area}

For VOC analyses, internal standard areas are compared to a calibrated standard to evaluate accuracy. The acceptance criteria is \pm 40 percent.

During 2010, 100 percent of all standards met this criterion.

\section{Sensitivity}

To meet sensitivity requirements, the method detection limit for each of the nine target compounds must be evaluated before sampling begins. The initial and annual method detection limit evaluation is performed in accordance with 40 CFR Part 136, "Guidelines Establishing Test Procedures for the Analysis of Pollutants," and with EPA/530-SW-90021, as revised and retitled, Quality Assurance and Quality Control (Chapter 1 of EPA SW-846, Test Methods for Evaluating Solid Waste, Physical/Chemical Methods) (1996). For 2010, CEMRC completed method detection limit studies for VOC analyses in October and for hydrogen methane analysis in August. 


\subsubsection{Qualitative Accuracy}

For VOC analyses, the standard ion abundance criteria for bromofluorobenzene is used to evaluate the accuracy of the analytical system in the identification of target analytes as well as unknown contaminants (qualitative accuracy). This ensures that the instrumentation is correctly identifying individual compounds during the analysis of air samples.

During 2010, all ion abundance criteria were within tolerance.

\subsubsection{Comparability}

There is no Permit requirement for comparability in the VOC monitoring program and the hydrogen and methane monitoring program. However, comparability is maintained through the use of consistent, approved standard operating procedures for sample collection and analyses.

\subsubsection{Representativeness}

There is no Permit requirement for representativeness in the VOC monitoring program or the hydrogen and methane monitoring program.

\subsection{Hall Environmental Analysis Laboratory}

HEAL was awarded the groundwater analysis contract in February 2008 and performed the chemical analyses for the spring and fall sampling in 2010 (Rounds 30 and 31). HEAL followed SOPs based on standard analytical methods from EPA and from Standard Methods for the Examination of Water and Wastewater.

\subsubsection{Completeness}

The seven WQSP monitoring wells were sampled twice during 2010, March through May, and September through November, for the WIPP groundwater detection monitoring program. The completeness objective was met as analytical results were received for all the samples submitted (100 percent completeness).

\subsubsection{Precision}

The groundwater samples generally contained detectable concentrations of the major cations including calcium, magnesium, potassium, and sodium, as well as chloride, sulfate, TOC, density, TDS, total suspended solids (TSS), pH, conductivity, and alkalinity. Total organic carbon (TOC) and total organic halogen (TOX) were detected in many of the groundwater samples at concentrations between the method detection limit (MDL) and method reporting limit (MRL). HEAL subcontracted the TOX analyses to Columbia Analytical Services and subcontracted the trace metals analysis for antimony, arsenic, selenium, and thallium by inductively coupled plasma emission spectroscopy combined with inductively coupled plasma mass spectrometry (ICP-MS) to Anatek Laboratories in order to achieve the requisite detection limit requirements. 
Precision was based on the analysis results of the duplicate well samples, duplicate analyses of a single well sample for some general chemistry parameter methods, as well as the precision of the recoveries of LCS/LCSD and MS/MSD pairs.

The precision quality assurance objective for duplicate $\mathrm{VOC}$ and semivolatile organic compound (SVOC) analyses include RPDs of $\leq 20$ for VOCs in LCS/LCSD samples and MS/MSD samples and RPDs $\leq 20$ for SVOCs in LCS/LCSD samples and MS/MSD samples. Another precision quality assurance objective included agreement of daily calibration standard concentrations to within 20 percent difference (bias) from the initial calibration curve.

The precision quality assurance objective for duplicate metals analyses was RPDs $\leq 20$ for trace metals, cation metals, and mercury in LCS/LCSD and MS/MSD samples.

The precision quality assurance objective for the duplicate general chemistry indicator parameter analyses was a RPD $\leq 20$.

There was only one well with detection of a volatile organic compound; no detections of semivolatile organic compounds; and very few detections of trace metals in any of the groundwater samples, and thus the precision data for these target analytes was primarily based on the analysis results of the QC samples. The set of groundwater samples with detection of the VOC compound 2-butanone in the primary and duplicate groundwater samples also had detections for the compound at similar concentrations in both the field blank and trip blank and thus the groundwater samples likely did not contain the compound.

Table 7.4 shows the analysis results for which the precision objective of $<20$ RPD for duplicate groundwater samples was not met. The table also shows for MS/MSD samples in parentheses where the precision objective of $\leq 20$ RPD was not met. 
Waste Isolation Pilot Plant Annual Site Environmental Report for 2010 DOE/WIPP-11-2225

Table 7.4 - Individual Cases Where the Precision Objective Was Not Met in 2010 for Groundwater Samples and Associated QA/QC Sample Analyses

\begin{tabular}{|c|c|c|c|c|c|}
\hline Well & Round & Parameter & Primary Sample & Duplicate Sample & RPD \\
\hline WQSP-1 & 30 & TOX & $0.25 \mathrm{mg} / \mathrm{L}$ & $0.13 \mathrm{mg} / \mathrm{L}$ & 63 \\
\hline WQSP-1 & 30 & $\mathrm{Se}$ & $0.0398 \mathrm{mg} / \mathrm{L}$ & $0.0301 \mathrm{mg} / \mathrm{L}$ & 28 \\
\hline WQSP-1 & 30 & Hexachlorobenzene & 74.6 ug/L (MS) & 92.0 ug/L (MSD) & 20.9 \\
\hline WQSP-2 & 30 & TOX & $0.34 \mathrm{mg} / \mathrm{L}$ & $0.53 \mathrm{mg} / \mathrm{L}$ & 44 \\
\hline WQSP-2 & 30 & Pentachlorophenol & 63.8 ug/L (MS) & 45.2 ug/L (MSD) & 34.1 \\
\hline WQSP-3 & 30 & TOC & $0.28 \mathrm{ug} / \mathrm{L}$ & $1.61 \mathrm{ug} / \mathrm{L}$ & $140(a)$ \\
\hline WQSP-3 & 30 & TOX & $0.50 \mathrm{mg} / \mathrm{L}$ & $0.38 \mathrm{mg} / \mathrm{L}$ & 27 \\
\hline WQSP-3 & 30 & $\mathrm{Ba}$ & $0.063 \mathrm{mg} / \mathrm{L}$ & $0.051 \mathrm{mg} / \mathrm{L}$ & 21 \\
\hline WQSP-3 & 30 & $\mathrm{Fe}$ & $0.89 \mathrm{mg} / \mathrm{L}$ & $0.34 \mathrm{mg} / \mathrm{L}$ & 89 (a) \\
\hline WQSP-3 & 30 & $\mathrm{~V}$ & $0.12 \mathrm{mg} / \mathrm{L}$ & $0.067 \mathrm{mg} / \mathrm{L}$ & 57 \\
\hline WQSP-3 & 30 & SVOC MS/MSD & (b) & (b) & (b) \\
\hline WQSP-4 & 30 & TOC & $0.84 \mathrm{mg} / \mathrm{L}$ & $0.28 \mathrm{mg} / \mathrm{L}$ & $100(a)$ \\
\hline WQSP-4 & 30 & TOX & $0.20 \mathrm{mg} / \mathrm{L}$ & $0.25 \mathrm{mg} / \mathrm{L}$ & 22 \\
\hline WQSP-4 & 30 & TSS & $131 \mathrm{mg} / \mathrm{L}$ & $46 \mathrm{mg} / \mathrm{L}$ & 96 \\
\hline WQSP-4 & 30 & $\mathrm{Ba}$ & $0.028 \mathrm{mg} / \mathrm{L}$ & $0.036 \mathrm{mg} / \mathrm{L}$ & 25 \\
\hline WQSP-4 & 30 & $\mathrm{Fe}$ & $0.48 \mathrm{mg} / \mathrm{L}$ & $0.29 \mathrm{mg} / \mathrm{L}$ & 49 \\
\hline WQSP-4 & 30 & $\mathrm{Se}$ & $0.0062 \mathrm{mg} / \mathrm{L}$ & $0.0083 \mathrm{mg} / \mathrm{L}$ & 29 \\
\hline WQSP-4 & 30 & pentachlorophenol & $49.3 \mathrm{ug} / \mathrm{L}(\mathrm{MS})$ & 39.9 ug/L (MSD) & 23.5 \\
\hline WQSP-5 & 30 & TOC & $1.22 \mathrm{mg} / \mathrm{L}$ & $1.62 \mathrm{mg} / \mathrm{L}$ & $28(a)$ \\
\hline WQSP-5 & 30 & $\mathrm{Fe}$ & $0.51 \mathrm{mg} / \mathrm{L}$ & $0.32 \mathrm{mg} / \mathrm{L}$ & $46(a)$ \\
\hline WQSP-6 & 30 & TSS & $13 \mathrm{mg} / \mathrm{L}$ & $10 \mathrm{mg} / \mathrm{L}$ & 26 \\
\hline WQSP-6 & 30 & 2,4-dinitrophenol & $82.0 \mathrm{ug} / \mathrm{L}$ & 55.6 ug/L (MSD) & 38 \\
\hline WQSP-6 & 30 & pentachlorophenol & $79.9 \mathrm{ug} / \mathrm{L}$ & 40.5 ug/L (MSD) & 65 \\
\hline WQSP-6A & 30 & TOC & $0.40 \mathrm{mg} / \mathrm{L}$ & $0.29 \mathrm{mg} / \mathrm{L}$ & 32 (a) \\
\hline WQSP-6A & 30 & $\mathrm{Fe}$ & $0.045 \mathrm{mg} / \mathrm{L}$ & $0.035 \mathrm{mg} / \mathrm{L}$ & 25 (a) \\
\hline WQSP-6A & 30 & SVOC MS/MSD & (c) & (c) & (c) \\
\hline WQSP-1 & 31 & TOX & $150 \mathrm{ug} / \mathrm{L}$ & $200 \mathrm{ug} / \mathrm{L}$ & 29 \\
\hline WQSP-1 & 31 & TOX & 1030 ug/L (MS) & 531 ug/L (MSD) & 64 \\
\hline WQSP-1 & 31 & Se & $0.0026 \mathrm{mg} / \mathrm{L}$ & $0.0020 \mathrm{mg} / \mathrm{L}$ & 26 \\
\hline WQSP-1 & 31 & pentachlorophenol & 24.6 ug/L (MS) & 33.3 ug/L (MSD) & 30 \\
\hline WQSP-2 & 31 & TOX & $0.18 \mathrm{mg} / \mathrm{L}$ & $0.34 \mathrm{mg} / \mathrm{L}$ & 62 \\
\hline WQSP-3 & 31 & TOC & $0.40 \mathrm{mg} / \mathrm{L}$ & $0.30 \mathrm{mg} / \mathrm{L}$ & 29 (a) \\
\hline WQSP-3 & 31 & TOX & $0.51 \mathrm{mg} / \mathrm{L}$ & $0.87 \mathrm{mg} / \mathrm{L}$ & 52 \\
\hline WQSP-3 & 31 & TSS & $99 \mathrm{mg} / \mathrm{L}$ & 124 mg/L & 22 \\
\hline WQSP-3 & 31 & $\mathrm{Ba}$ & $0.022 \mathrm{mg} / \mathrm{L}$ & $0.027 \mathrm{mg} / \mathrm{L}$ & $20(a)$ \\
\hline WQSP-3 & 31 & $\mathrm{Fe}$ & $0.24 \mathrm{mg} / \mathrm{L}$ & $0.32 \mathrm{mg} / \mathrm{L}$ & $29(\mathrm{a})$ \\
\hline WQSP-3 & 31 & SVOC MS/MSD & (d) & (d) & (d) \\
\hline WQSP-4 & 31 & TOC & $0.36 \mathrm{ug} / \mathrm{L}$ & $0.48 \mathrm{ug} / \mathrm{L}$ & $29(a)$ \\
\hline WQSP-4 & 31 & TSS & $65 \mathrm{mg} / \mathrm{L}$ & 80 mg/L & 21 \\
\hline
\end{tabular}


Waste Isolation Pilot Plant Annual Site Environmental Report for 2010 DOE/WIPP-11-2225

Table 7.4 - Individual Cases Where the Precision Objective Was Not Met in 2010 for Groundwater Samples and Associated QA/QC Sample Analyses

\begin{tabular}{|c|c|c|c|c|c|}
\hline Well & Round & Parameter & Primary Sample & Duplicate Sample & RPD \\
\hline WQSP-4 & 31 & $\mathrm{Mg}$ & $1260 \mathrm{mg} / \mathrm{L}$ & $939 \mathrm{mg} / \mathrm{L}$ & 29 \\
\hline WQSP-4 & 31 & 2,4-dinitrophenol & $15.8 \mathrm{ug} / \mathrm{L}(\mathrm{MS})$ & $20.5 \mathrm{ug} / \mathrm{L}(\mathrm{MSD})$ & 25 \\
\hline WQSP-4 & 31 & 2-methylphenol & $51.8 \mathrm{ug} / \mathrm{L}(\mathrm{MS})$ & $64.9 \mathrm{ug} / \mathrm{L}(\mathrm{MSD})$ & 22 \\
\hline WQSP-4 & 31 & pentachlorophenol & $19.4 \mathrm{ug} / \mathrm{L}(\mathrm{MS})$ & $46.9 \mathrm{ug} / \mathrm{L}(\mathrm{MSD})$ & 24 \\
\hline WQSP-5 & 31 & TSS & $33 \mathrm{mg} / \mathrm{L}$ & $18 \mathrm{mg} / \mathrm{L}$ & 59 \\
\hline WQSP-5 & 31 & Fe & $0.37 \mathrm{mg} / \mathrm{L}$ & $0.48 \mathrm{mg} / \mathrm{L}$ & 26 \\
\hline WQSP-6 & 31 & TOC & $0.35 \mathrm{mg} / \mathrm{L}$ & $0.44 \mathrm{mg} / \mathrm{L}$ & 23 (a) \\
\hline WQSP-6 & 31 & TOX & $0.039 \mathrm{mg} / \mathrm{L}$ & $0.028 \mathrm{mg} / \mathrm{L}$ & 32 \\
\hline WQSP-6 & 31 & TSS & $11 \mathrm{mg} / \mathrm{L}$ & $17 \mathrm{mg} / \mathrm{L}$ & 43 \\
\hline WQSP-6 & 31 & Be & $0.0016 \mathrm{mg} / \mathrm{L}$ & $0.00059 \mathrm{mg} / \mathrm{L}$ & $92(a)$ \\
\hline WQSP-6 & 31 & Fe & $0.16 \mathrm{mg} / \mathrm{L}$ & $0.10 \mathrm{mg} / \mathrm{L}$ & $46(a)$ \\
\hline WQSP-6 & 31 & $V$ & $0.011 \mathrm{mg} / \mathrm{L}$ & $0.0038 \mathrm{mg} / \mathrm{L}$ & 97 (a) \\
\hline WQSP-6A & 31 & $2,4-$ dinitrophenol & $35.2 \mathrm{ug} / \mathrm{L}(\mathrm{MS})$ & $26.1 \mathrm{ug} / \mathrm{L}(\mathrm{MSD})$ & 29.8 \\
\hline WQSP-6A & 31 & pyridine & $40.3 \mathrm{ug} / \mathrm{L}(\mathrm{MS})$ & $49.3 \mathrm{ug} / \mathrm{L}(\mathrm{MSD})$ & 20.1 \\
\hline
\end{tabular}

(a) Concentrations are between the MDL and MRL and are J-flagged as estimated.

(b) All of the target SVOCs in the WQSP-3 MS/MSD except for 1,2-dichlorobenzene and 2,4-dinitrophenol yielded RPDs between 20 and 30 . The reason was not that one of the samples yielded particularly low recoveries, but rather that the MSD yielded unusually high recoveries.

(c) All of the target SVOCs in the WQSP-6A MS/MSD yielded RPDs ranging from 31.3 - 40.7 due to particularly high recoveries in the MS sample.

(d) The target SVOCs 1,2-dichlorobenzene, 1,4-dichlorobenzene, 2,4-dinitrophenol, 2-methylphenol, 3+4methylphenol, nitrobenzene, pentachlorophenol, and pyridine in the WQSP-3 MS/MSD samples yielded RPDS ranging from 20.3 - 36.1 due to variable recoveries of the spiked compounds. The compounds that met the $<20$ RPD quality assurance objective were 2,4-dinitrotoluene, hexachlorobenzene, and hexachloroethane.

Considering the hundreds of groundwater sample and QA/QC sample data points that were generated, the number of duplicate samples that did not meet the precision quality assurance objective was 3.3\%. There was also a consistent pattern of certain analytes appearing on the list in Table 7.4. TSS (total suspended solids) and TOX (total organic halogen) are the two analytes measured by analytical methods that are the most challenged by the high-TDS samples. The TSS measurements appear to be a function of how long the samples are allowed to settle before an aliquot of sample is taken for analysis. TOX analyses are affected by the high chloride concentrations in the DMP samples. The quality assurance objectives for precision have not always been met. In addition, the QC objective of retaining 90 percent of the measured TOX in the groundwater samples on the front granular activated carbon is generally not met. Since no halogenated organic compounds have been detected in any of the samples by GC/MS, it is unlikely that the groundwater samples contain organic halogen even though trace concentrations are measured and reported.

Another group of analytes appearing in Table 7.4 are trace metals with most of the concentrations below the MRL but above the MDL and are thus J-flagged as estimated. The precision would not be expected to be as good for analytes with concentrations less than the lowest calibration standard. The same applies to TOC with most concentrations less than the MRL. 


\section{Waste Isolation Pilot Plant Annual Site Environmental Report for 2010 DOE/WIPP-11-2225}

No SVOC compounds were detected in the groundwater samples, but several data packets contained one or more SVOC compounds that did not meet the precision quality assurance objective for recovery of the compounds spiked into MS and MSD samples. The variable recoveries between the two samples was generally due to one of the samples having unusually high recoveries rather than lower recoveries.

\subsubsection{Accuracy}

The accuracy of the analyses was checked by analyzing initial calibration verification standards (ICVs), continuing calibration verification standards (CCVs), method blanks, laboratory control samples and duplicate laboratory control samples, which are blank spikes (LCS/LCSD), matrix spikes, and matrix spike duplicates (MS/MSD) as specified in the standard methods and in the corresponding lab SOPs. The daily calibration standards were used to confirm that the response in the daily standard closely matched the corresponding response during the initial calibration. The method blanks were used to confirm that the accuracy of the groundwater sample analyses was not adversely affected by the presence of any of the target analytes as background contaminants that may have been introduced during sample preparation and analysis. The laboratory control sample (LCS) was analyzed to check that the analytical method was in control by measuring the percent recoveries of the target analytes spiked into clean water.

MS and MSD samples were prepared and analyzed to check the effect of the groundwater sample matrix on the accuracy of the analytical measurements as percent recovery. The MS and MSD samples were generated by spiking the target constituents and general chemistry indicator parameter analytes into separate portions of the primary groundwater samples. The samples were analyzed, and the recoveries of the volatile and semivolatile organic and metal constituents and general chemistry indicator parameters measured and reported. The quality assurance objectives for the recoveries of the target analytes from the high-brine MS/MSD samples were generally wider than for the LCS/LCSD samples, which used clean water as the sample matrix. The laboratories used WQSP well groundwater samples for all the MS/MSD samples, and thus the MS/MSD recoveries provided relevant information about the effect of the groundwater matrix on the accuracy of measuring the target analytes.

Table 7.5 summarizes the QC samples for which the accuracy QA objective, as measured by percent recovery, was not met during the Round 30 and 31 samples collected and analyzed in 2010. None of the target analytes were detected in method blank samples as contaminants, and thus accuracy was not adversely affected by contamination. The recoveries of analytes which contained native sample concentrations greater than four times the matrix spike concentration, such as the major cations, chloride, and sulfate, are not included in Table 7.4 since MS/MSD data are not required per EPA guidance for samples with high native concentrations of a given analyte.

\section{Organics}

The accuracy quality assurance objectives for the organic constituents included recoveries of $70-130$ percent recovery for VOCs from LCS/LCSD samples and MS/MSD samples and recoveries determined by the lab's historical control chart limits 
for SVOCs in LCS/LCSD and MS/MSD samples. The recovery objectives for the SVOCs were generally wider than for VOCs. Other quality assurance objectives include agreement of daily calibration standard concentrations to within 20 percent difference (bias) from the initial calibration curve and method blanks with any detected analytes at concentrations less than the MRL and preferably not detected at all.

Every calibration standard, groundwater sample, and quality control sample analyzed by GC/MS served as a surrogate spike sample in that the surrogate recovery compounds were spiked into the samples prior to analysis, and their recoveries were reported as a measure of accuracy of the analyses.

As shown in Table 7.5, most of the cases of organics not meeting the quality assurance objective for recovery was due to high recoveries for three particular compounds including isobutanol (isobutyl alcohol), 2-butanone (methylethyl ketone), and $1,1,2,2$,-tetrachloroethane. Table 7.5 is nearly identical to the same table for the 2009 ASER.

The reason for the high recoveries of isobutanol and 2-butanone is likely due to the higher purging efficiencies from brine solution than from the relatively clean calibration standards. The effect was not seen in WQSP-6A with lower salt concentration. The 1,1,2,2-tetrachloroethane recoveries are also higher than the quality assurance objective in a few MS/MSD samples, probably due to degradation and conversion of other chlorinated organic compounds to 1,1,2,2-tetrachloroethane such as the dichloroethylenes and trichloroethylene. These compounds yielded slightly lower MS/MSD recoveries than the other VOCs. 


\section{Waste Isolation Pilot Plant Annual Site Environmental Report for 2010 DOE/WIPP-11-2225}

Table 7.5 - Individual Cases where the Accuracy Quality Assurance Objective Analyses was not Met in 2010 for Groundwater QA Sample

\begin{tabular}{|c|c|c|c|c|c|c|}
\hline Well & Round & Parameter & Sample & $\% \operatorname{Rec}$ & Sample & \% Rec \\
\hline WQSP-1 & 30 & Isobutanol (70-130) & MS & 157 & MSD & 160 \\
\hline WQSP-1 & 30 & 2-butanone (70-130) & MS & 134 & MSD & 147 \\
\hline WQSP-1 & 30 & 1,1,2,2-tetrachloroethane (70-130) & MS & 140 & MSD & 144 \\
\hline WQSP-1 & 30 & TOX (82-121) & MS & 580 & MSD & 580 \\
\hline WQSP-2 & 30 & Isobutanol (70-130) & MS & 158 & MSD & 154 \\
\hline WQSP-2 & 30 & 2-butanone (70-130) & MS & 145 & MSD & 143 \\
\hline WQSP-2 & 30 & 1,1,2,2-tetrachloroethane (70-130) & MS & 134 & MSD & $127(\mathrm{a})$ \\
\hline WQSP-2 & 30 & TOX (82-121) & MS & 134 & MSD & 123 \\
\hline WQSP-3 & 30 & Mercury (75-125) & MS & 327 & MSD & 333 \\
\hline WQSP-3 & 30 & Isobutanol (70-130) & MS & 239 & MSD & 246 \\
\hline WQSP-3 & 30 & 2-butanone (70-130) & MS & 274 & MSD & 279 \\
\hline WQSP-3 & 30 & 1,1,2,2-tetrachloroethane (70-130) & MS & 202 & MSD & 207 \\
\hline WQSP-3 & 30 & TOX(82-121) & MS & 134 & MSD & 123 \\
\hline WQSP-4 & 30 & Isobutanol (70-130) & MS & 189 & MSD & 182 \\
\hline WQSP-4 & 30 & 2-butanone (70-130) & MS & 172 & MSD & 168 \\
\hline WQSP-4 & 30 & 1,1,2,2-tetrachloroethane (70-130) & MS & 157 & MSD & 154 \\
\hline WQSP-5 & 30 & Isobutanol (70-130) & MS & $125(\mathrm{a})$ & MSD & 141 \\
\hline WQSP-6 & 30 & Isobutanol (70-130) & MS & 138 & MSD & 119 (a) \\
\hline WQSP-1 & 31 & Isobutanol (70-130) & MS & 143 & MSD & 146 \\
\hline WQSP-1 & 31 & 2-Butanone (70-130) & MS & 240 & MSD & 237 \\
\hline WQSP-1 & 31 & TOX (82-121) & MS & $88(a)$ & MSD & 38 \\
\hline WQSP-2 & 31 & Isobutanol (70-130) & MS & 132 & MSD & 156 \\
\hline WQSP-2 & 31 & 2-Butanone (70-130) & MS & 162 & MSD & 191 \\
\hline WQSP-3 & 31 & Isobutanol (70-130) & MS & 234 & MSD & 234 \\
\hline WQSP-3 & 31 & 2-Butanone (70-130) & MS & 353 & MSD & 369 \\
\hline WQSP-3 & 31 & 1,1,2,2-tetrachloroethane (70-130) & MS & 152 & MSD & 161 \\
\hline WQSP-3 & 31 & Mercury (75-125) & MS & 63.8 & MSD & 59.4 \\
\hline WQSP-3 & 31 & TOX (82-121) & MS & 110 & MSD & 130 \\
\hline WQSP-4 & 31 & Isobutanol (70-130) & MS & 183 & MSD & 183 \\
\hline WQSP-4 & 31 & 2-Butanone (70-130) & MS & 196 & MSD & 190 \\
\hline WQSP-4 & 31 & 1,1,2,2-tetrachloroethane (70-130) & MS & 146 & MSD & 142 \\
\hline WQSP-5 & 31 & Isobutanol (70-130) & MS & 136 & MSD & 140 \\
\hline WQSP-5 & 31 & 2-butanone (70-130) & MS & 281 & MSD & 284 \\
\hline WQSP-6 & 31 & 2-butanone (70-130) & MS & 220 & MSD & 223 \\
\hline
\end{tabular}

(a) Concentrations are between the MDL and MRL and are J-flagged as estimated.

(b) All of the target SVOCs in the WQSP-3 MS/MSD except for 1,2-dichlorobenzene and 2,4-dinitrophenol yielded RPDs between 20 and 30 . The reason was not that one of the samples yielded particularly low recoveries, but rather that the MSD yielded unusually high recoveries.

(c) All of the target SVOCs in the WQSP-6A MS/MSD yielded RPDs ranging from $31.3-40.7$ due to particularly high recoveries in the MS sample.

(d) The target SVOCs 1,2-dichlorobenzene, 1,4-dichlorobenzene, 2,4-dinitrophenol, 2-methylphenol, 3+4-methylphenol, nitrobenzene, pentachlorophenol, and pyridine in the WQSP-3 MS/MSD samples yielded RPDs ranging from $20.3-36.1$ due to variable recoveries of the spiked compounds. The compounds that met the $<20$ RPD quality assurance objective were 2,4-dinitrotoluene, hexachlorobenzene, and hexachloroethane. 
With respect to SVOCs, some recoveries that were not in the lab's historical control chart range or not in the range suggest by EPA guidance range of 40 to 140 percent for base/neutral compounds and 30 to 130 percent for acidic compounds are not included in Table 7.5. All of the SVOC recoveries were higher than the low limit on the lab's historical control chart range, but were higher than the upper limit of the lab's historical control chart range. Some recoveries were higher than the lab's low control chart range limit but were lower than the upper range specified by the EPA guidance.

Since all the LCS/LCSD recoveries readily met the recovery objectives, it was possible to determine which compounds were adversely affected by the high-TDS groundwater matrix based on the MS/MSD recoveries. The compounds that appeared to be most affected included 2,4-dinitrophenol, 2,4-dinitrotoluene, hexachlorobenzene, 2-methylphenol, 3+4-methylphenol, and pentachlorophenol. However, none of these compounds were detected in the groundwater samples.

\section{Metals}

The accuracy quality assurance objectives for the metals included recoveries of 80 120 percent for metals and mercury in LCS/LCSD samples and $75-125$ percent recovery in MS/MSD samples with any detected analytes at concentrations less than the MRL and preferably not detected at all.

The only metal that did not meet the quality assurance recovery objective in all the spiked samples was mercury, and for each round the recoveries that were out of the range were for WQSP-3, the groundwater with the highest salt concentration. The recoveries were significantly higher than the objective in Round 30 and slightly lower than the objective in Round 31. The reason for this disparity is not known, but mercury was not detected in any of the groundwater samples.

\section{General Chemistry Indicator Parameters}

The accuracy quality assurance objectives for the general chemistry indicator parameters are generally tighter than for the constituent organics and metals with recoveries of 80 - 120 percent with any detected analytes at concentrations less than the MRL and preferably not detected at all.

Table 7.5 contains five total organic halogen (TOX) MS/MSD pairs where the recovery quality assurance objectives were not met. TOX, TSS (for which MS/MSD analyses are not performed) and nitrate analyses are the three general chemistry indicator parameter analytes whose analytical methods are the most challenged by the high-TDS samples.

TOX analyses are adversely affected by the high chloride concentrations in the DMP groundwater samples since the method relies on washing all the chloride off the front and backup collection columns prior to analysis. The lab's quality assurance objective for recovery of TOX from spiked MS and MSD samples is 82-121 percent recovery. The method QC objective of retaining 90 percent of the measured TOX in the groundwater samples on the front granular activated carbon column has not been met for high-brine groundwater samples; however, 10 of the 14 TOX MS/MSD analyses did meet the quality assurance objective for recovery. 
The recovery results for nitrate in all the MS/MSD pairs met the quality assurance objective for accuracy; however, high concentrations of chloride in the groundwater samples raise the method reporting limit. Nitrate has only been detected in the relatively shallow Dewey Lake WQSP-6A well, which has significantly lower brine concentration than the Culebra wells. Even though the method detection limits are higher in the Culebra samples (WQSP-1 - WQSP-6), nitrate has not been detected in these samples, and it is unlikely that it is present.

Overall, the quality of the accuracy QC data was excellent with nearly all the spiked LCS/LCSD and MS/MSD data meeting the quality assurance objectives.

\subsubsection{Comparability}

The Permit requires that groundwater analytical results be comparable by reporting data in consistent units and collecting and analyzing samples using consistent methodology. These comparability requirements were met through the use of consistent, approved standard operating procedures for sample collection and analyses. The normal reporting units for metals and general chemistry parameters were $\mathrm{mg} / \mathrm{L}$, and the normal reporting limits for organics were ug/L.

HEAL and its subcontract laboratories are certified by several states and by the National Environmental Laboratory Accreditation Program (NELAP) through Oregon for HEAL and Anatek and through Florida for Columbia Analytical Services. HEAL's state certifications include Oregon, Utah, Texas, New Mexico, and Arizona. As such, the labs participate in interlaboratory evaluation programs including on-site NELAC QA audits. The labs also regularly analyze performance evaluation samples provided by a NELAC-accredited Proficiency Standard Vendor such as Wibby Environmental. HEAL also analyzed MAPEP performance evaluation samples as part of the DOE performance evaluation program. The Wibby Water Supply performance evaluation samples included trace metals, mercury, pH, TOC, regulated VOCs, unregulated VOCs, and the Wibby Water Pollution performance evaluation samples included TDS, TSS, nitrate, TKN, alkalinity, trace metals, mercury, specific conductance, $\mathrm{pH}$, VOCs, SVOCs (acids and base-neutrals), and the MAPEP performance evaluation samples included SVOCs.

In 2010, HEAL analyzed three sets of Wibby Water Supply Proficiency Testing Studies and two sets of MAPEP PE samples that were analyzed for SVOCs in water. The Wibby samples covered nearly all of the WIPP target VOC, SVOC, metal, and general chemistry parameters, although not all parameters were analyzed in all three sets. The only WIPP target parameter not present in any of the PE samples was the VOC compound isobutyl alcohol. Of the dozens of individual parameter measurements made by HEAL in the five sets of PE samples, all the results were acceptable with the following three exceptions:

- $\quad$ The VOC 1,1,2,2-tetrachloroethane was Not Acceptable and high in one of the VOC PE samples when HEAL reported $21.1 \mathrm{ug} / \mathrm{L}$ compared to the actual concentration of $15.2 \mathrm{ug} / \mathrm{L}$. 
- $\quad$ The VOC 2-butanone was Not Acceptable and high in one of the VOC $\mathrm{PE}$ samples when HEAL reported $73.0 \mathrm{ug} / \mathrm{L}$ compared to the actual concentration of $44.4 \mathrm{ug} / \mathrm{L}$.

- $\quad$ HEAL reported the presence of hexachlorobenzene in a sample in which it was not present (false positive).

For the analytes that HEAL subcontracted to other analytical laboratories, Columbia Analytical Services obtained acceptable analysis results for TOX in various performance evaluation samples, and Anatek Laboratory obtained acceptable results for trace metals by ICP/MS in various performance evaluation samples.

\subsubsection{Representativeness}

The groundwater DMP is designed so that representative groundwater samples are collected from specific monitoring well locations. Prior to collecting the final samples from each well, serial samples were collected and analyzed in an on-site mobile laboratory to help determine whether the water being pumped from the monitoring wells was stable and representative of the natural groundwater at each well. The parameters analyzed in the mobile laboratory included temperature, $\mathrm{pH}$, specific gravity, alkalinity, specific conductance, chlorides, divalent cations, and total iron. The final samples for analysis of VOCs, SVOCs, metals and general chemistry parameters were collected only when it had been determined from serial sampling and analysis that the water being pumped was representative of the natural groundwater at each location. 
This page intentionally left blank 
Appendix A - References

10 CFR Part 834. "Radiation Protection of the Public and the Environment." Proposed Rule. Code of Federal Regulations. Office of the Federal Register, National Archives and Records Administration, Washington, D.C.

10 CFR Part 1021. "National Environmental Policy Act Implementing Procedures." Code of Federal Regulations. Office of the Federal Register, National Archives and Records Administration, Washington, D.C.

40 CFR Part 61. "National Emission Standards for Hazardous Air Pollutants." Code of Federal Regulations. Office of the Federal Register, National Archives and Records Administration, Washington, D.C.

40 CFR §61.92. "National Emission Standards for Hazardous Air Pollutants Subpart H." Code of Federal Regulations. Office of Federal Register, National Archives and Records Administration, Washington, D.C.

40 CFR §61.93. "Emission Monitoring and Test Procedure." Code of Federal Regulations. Office of the Federal Register, National Archives and Records Administration, Washington, D.C.

40 CFR Part 61, Subpart H. "National Emission Standards for Emissions of Radionuclides Other Than Radon from Department of Energy Facilities." Code of Federal Regulations. Office of the Federal Register, National Archives and Records Administration, Washington, D.C.

40 CFR §122.1(b). "Scope of the NPDES Permit Requirement." Code of Federal Regulations. Office of the Federal Register, National Archives and Records Administration, Washington, D.C.

40 CFR Part 136. "Guidelines Establishing Test Procedures for the Analysis of Pollutants." Code of Federal Regulations. Office of the Federal Register, National Archives and Records Administration, Washington, D.C.

40 CFR Part 141. "National Primary Drinking Water Regulations." Code of Federal Regulations. Office of the Federal Register, National Archives and Records Administration, Washington, D.C.

40 CFR §141.66. "Maximum Contaminant Levels for Radionuclides." Code of Federal Regulations. Office of the Federal Register, National Archives and Records Administration, Washington, D.C.

40 CFR Part 143. "National Secondary Drinking Water Regulations." Code of Federal Regulations. Office of the Federal Register, National Archives and Records Administration, Washington, D.C. 
Appendix A - References

40 CFR Parts 150-189. Federal Insecticide, Fungicide, and Rodenticide Act (FIFRA) Regulations. Code of Federal Regulations. Office of the Federal Register, National Archives and Records Administration, Washington, D.C.

40 CFR Part 191. "Environmental Radiation Protection Standards for Management and Disposal of Spent Nuclear Fuel, High-Level and Transuranic Radioactive Wastes." Code of Federal Regulations. Office of the Federal Register, National Archives and Records Administration, Washington, D.C.

40 CFR Part 191, Subpart A. "Environmental Standards for Management and Storage." Code of Federal Regulations. Office of the Federal Register, National Archives and Records Administration, Washington, D.C.

40 CFR Part 191, Subpart B. "Environmental Standards for Disposal." Code of Federal Regulations. Office of the Federal Register, National Archives and Records Administration, Washington, D.C.

40 CFR Part 191, Subpart C. "Environmental Standards for Ground-Water Protection." Code of Federal Regulations. Office of the Federal Register, National Archives and Records Administration, Washington, D.C.

40 CFR §191.03, Subpart A. "Protection of the Environment." Code of Federal Regulations. Office of the Federal Register, National Archives and Records Administration, Washington, D.C.

40 CFR §191.15. "Individual Protection Requirements." Code of Federal Regulations. Office of the Federal Register, National Archives and Records Administration, Washington, D.C.

40 CFR §191.16. "Alternative Provisions for Disposal." Code of Federal Regulations. Office of the Federal Register, National Archives and Records Administration, Washington, D.C.

40 CFR Part 194. "Criteria for the Certification and Re-Certification of the Waste Isolation Pilot Plant's Compliance With the 40 CFR Part 191 Disposal Regulations." Code of Federal Regulations. Office of the Federal Register, National Archives and Records Administration, Washington, D.C.

40 CFR §194.21. "Inspections." Code of Federal Regulations. Office of the Federal Register, National Archives and Records Administration, Washington, D.C.

40 CFR Part 262. "Standards Applicable to Generators of Hazardous Waste." Code of Federal Regulations. Office of the Federal Register, National Archives and Records Administration, Washington, D.C. 
Appendix A - References

40 CFR Part 264. "Standards for Owners and Operators of Hazardous Waste Treatment, Storage, and Disposal Facilities." Code of Federal Regulations. Office of the Federal Register, National Archives and Records Administration, Washington, D.C.

40 CFR Part 264, Subpart F. "Releases from Solid Waste Management Units." Code of Federal Regulations. Office of the Federal Register, National Archives and Records Administration, Washington, D.C.

40 CFR Part 264, Subpart X. "Miscellaneous Units." Code of Federal Regulations. Office of the Federal Register, National Archives and Records Administration, Washington, D.C.

40 CFR Part 270. "EPA Administered Permit Programs: the Hazardous Waste Permit Program." Code of Federal Regulations. Office of the Federal Register, National Archives and Records Administration, Washington, D.C.

40 CFR Part 280. "Technical Standards and Corrective Action Requirements for Owners and Operators of Underground Storage Tanks (UST)." Code of Federal Regulations. Office of the Federal Register, National Archives and Records Administration, Washington, D.C.

40 CFR Part 300. "National Oil and Hazardous Substances Pollution Contingency Plan." Code of Federal Regulations. Office of the Federal Register, National Archives and Records Administration, Washington, D.C.

40 CFR Part 302. "Designation, Reportable Quantities, and Notification." Code of Federal Regulations. Office of the Federal Register, National Archives and Records Administration, Washington, D.C.

40 CFR Part 313. "Toxics Release Inventory." Code of Federal Regulations. Office of the Federal Register, National Archives and Records Administration, Washington, D.C.

40 CFR Part 355. "Emergency Planning and Notification." Code of Federal Regulations. Office of the Federal Register, National Archives and Records Administration, Washington, D.C.

40 CFR Part 370. "Hazardous Chemical Reporting: Community Right-to-Know." Code of Federal Regulations. Office of Federal Register, National Archives and Records Administration. Washington, D.C.

40 CFR Part 372. "Toxic Chemical Release Reporting: Community Right to Know." Code of Federal Regulations. Office of the Federal Register, National Archives and Records Administration, Washington, D.C.

40 CFR Part 373. "Reporting Hazardous Substance Activity When Selling of Transferring Federal Real Property." Code of Federal Regulations. Office of the Federal Register, National Archives and Records Administration, Washington, D.C. 
Appendix A - References

40 CFR Part 761. "Polychlorinated Biphenyls (PCBs) Manufacturing, Processing, Distribution in Commerce, and Use Prohibitions." Code of Federal Regulations. Office of the Federal Register, National Archives and Records Administration, Washington, D.C.

40 CFR Parts 1500-1508. "Council on Environmental Quality." Code of Federal Regulations. Office of the Federal Register, National Archives and Records Administration, Washington, D.C.

50 CFR Part 17. "Endangered and Threatened Plants and Wildlife." Code of Federal Regulations. Office of the Federal Register, National Archives and Records Administration, Washington, D.C.

50 CFR Part 20. "Migratory Bird Hunting." Code of Federal Regulations. National Archives and Records Administration, Washington, D.C.

20.2.72 NMAC. "Construction Permits." Title 20 New Mexico Administrative Code Santa $\mathrm{Fe}, \mathrm{NM}$

20.4.1.300 NMAC "Adoption of 40 CFR Part 262." Title 20 New Mexico Administrative Code Santa Fe, NM.

20.4.1.500 NMAC. "Adoption of 40 CFR Part 264." Title 20, New Mexico Administrative Code. Santa Fe, NM.

20.4.900 NMAC. "Adoption of 40 CFR Part 270." Title 20, New Mexico Administrative Code Santa Fe, NM.

20.5 NMAC. "Petroleum Storage Tanks." Title 20, New Mexico Administrative Code. Santa Fe, NM.

20.6.2 NMAC. "Ground and Surface Water Protection." Title 20, New Mexico Administrative Code. Santa Fe, NM.

20.7.10 NMAC. "Drinking Water." Title 20 New Mexico Administrative Code. Santa Fe, NM.

7 U.S.C. §§136, et seq. Federal Insecticide, Fungicide, and Rodenticide Act [FIFRA] U.S. Government Printing Office, Washington, D.C.

15 U.S.C. §§2601, et seq. Toxic Substances Control Act. U.S. Government Printing Office, Washington, D.C.

16 U.S.C. §§470, et seq. National Historic Preservation Act. United States Code. U.S. Government Printing Office, Washington, D.C.

16 U.S.C. §§703, et seq. Migratory Bird Treaty Act. United States Code. U.S. Government Printing Office, Washington, D.C. 
Appendix A - References

16 U.S.C. §§1531, et seq. Endangered Species Act of 1973. United States Code. U.S. Government Printing Office, Washington, D.C.

33 U.S.C. §§1251, et seq. Federal Water Pollution Control Act of 1948 [Clean Water Act] Section 402. United States Code. U.S. Government Printing Office, Washington, D.C.

42 U.S.C. §§300f, et seq. Safe Drinking Water Act. United States Code. U.S. Government Printing Office, Washington, D.C.

42 U.S.C. §2011, et seq. Atomic Energy Act of 1954, as amended. United States Code. U.S. Government Printing Office, Washington, D.C.

42 U.S.C. §§4321, et seq. National Environmental Policy Act. United States Code. U.S. Government Printing Office, Washington, D.C.

42 U.S.C. §§6901, et seq. Resource Conservation and Recovery Act. United States Code. U.S. Government Printing Office, Washington, D.C.

42 U.S.C. §§6901-6992, et seq. Solid Waste Disposal Act. United States Code. U.S. Government Printing Office, Washington, D.C.

42 U.S.C. §§7401, et seq. Clean Air Act. United States Code. U.S. Government Printing Office, Washington, D.C.

42 U.S.C. §§9601, et seq. Comprehensive Environmental Response, Compensation, and Liability Act (including the Superfund Amendments and Reauthorization Act of 1986). United States Code. U.S. Government Printing Office, Washington, D.C.

42 U.S.C. §10101, et seq. Nuclear Waste Policy Act of 1982. United States Code. U.S. Government Printing Office, Washington, D.C.

42 U.S.C. \$11001. Superfund Amendments and Reauthorization Act of 1986 [SARA]

Title III. United States Code. U.S. Government Printing Office, Washington, D.C.

43 U.S.C. §§1701, et seq. Federal Land Policy and Management Act. United States Code. U.S. Government Printing Office, Washington, D.C.

ANSI/HPS N13.12-1999, Surface and Volume Radioactivity Standards for Clearance.

ANSI N13.30. 1996. Performance Criteria for Radiobioassay. Health Physics Society, Washington, D.C.

Beauheim, R. L. 1986. Analysis of Pumping Tests of the Culebra Dolomite Conducted at the H-3 Hydropad at the Waste Isolation Pilot Plant (WIPP) Site. SAND86 2311, Sandia National Laboratories, Albuquerque, NM. 
Appendix A - References

Beauheim, R. L. 1987. Interpretations of Single-Well Hydraulic Tests Conducted at and Near the Waste Isolation Pilot Plant (WIPP) Site, 1983-1987. SAND87-0039, Sandia National Laboratories, Albuquerque, NM.

Beauheim, R. L., T. F. Dale, and J. F. Pickens. 1991. Interpretations of Single-Well Hydraulic Tests of the Rustler Formation Conducted in the Vicinity of the Waste Isolation Pilot Plant Site, 1988-1989. SAND89-0869, Sandia National Laboratories, Albuquerque, NM.

Beauheim, R. L., and G. J. Ruskauff. 1998. Analysis of Hydraulic Tests of the Culebra and Magenta Dolomites and Dewey Lake Redbeds Conducted at the Waste Isolation Pilot Plant Site. SAND98-0049, Sandia National Laboratories, Albuquerque, NM.

Beauheim, R. L., and R. M. Roberts. 2002. "Hydrology and Hydraulic Properties of a Bedded Evaporite Formation." Journal of Hydrology, v. 259, pp. 66-88.

Beck, Harold L. and B. G. Bennet. 2002. Historical Overview of Atmospheric Nuclear Weapon Testing and Estimates of Fallout in the Continental United States. Health Phys 82:591-608.

Bowman, D. O., and R. M. Roberts. 2009. Analysis Report for AP-070: Analysis of Culebra and Magenta Hydraulic Tests Performed Between January 2005 and August 2008. ERMS 550906. Sandia National Laboratories. Carlsbad, NM.

CAP88-PC. 2007. CAP88-PC Version 3.0 User Guide. Office of Radiation and Indoor Air, U.S. Environmental Protection Agency, Washington, DC.

Daniel B. Stephens \& Associates, Inc. 2003. Water Budget Analysis of the Shallow Subsurface Water at the Waste Isolation Pilot Plant, Carlsbad, NM.

DOE Order 151.1C. 2005. Comprehensive Emergency Management System. U.S. Department of Energy, Washington, D.C.

DOE Order 231.1A. 2004. Environment, Safety, and Health Reporting. U.S. Department of Energy, Washington, D.C.

DOE Order 414.1D. 2011. Quality Assurance. U.S. Department of Energy, Washington, D.C.

DOE Order 435.1. 1999. Radioactive Waste Management. U.S. Department of Energy, Washington, D.C.

DOE Order 450.1A. 2008. Environmental Protection Program. U.S. Department of Energy, Washington D.C.

DOE Order 451.1B. 2010. National Environmental Policy Act Compliance Program. U.S. Department of Energy, Washington, D.C. 
Appendix A - References

DOE Order 5400.5. 1993. Radiation Protection of the Public and the Environment. U.S. Department of Energy, Washington, D.C.

DOE/CAO-96-2184. 1996. Title 40 CFR Part 191 Compliance Certification Application for the Waste Isolation Pilot Plant. U.S. Department of Energy, Carlsbad Field Office. Carlsbad, NM.

DOE/CBFO-94-1012. 2010. Quality Assurance Program Document. Waste Isolation Pilot Plant, Carlsbad, NM.

DOE/EH-0173T. 1991. Environmental Regulatory Guide for Radiological Effluent Monitoring and Environmental Surveillance. Department of Environment, Safety, and Health, U.S. Department of Energy, Washington, D.C.

DOE/EIS-0026-FS. 1990. Final Supplement Environmental Impact Statement for the Waste Isolation Pilot Plant [SEIS-I]. U.S. Department of Energy, Washington, D.C.

DOE/EIS-0026-S-2. 1997. Waste Isolation Pilot Plant Disposal Phase Final Supplemental Environmental Impact Statement (SEIS-II). Volumes 1 through 3. U.S. Department of Energy, Washington, D.C.

DOE-STD-1153-2002. 2003. A Graded Approach for Evaluating Radiation Doses to Aquatic and Terrestrial Biota. National Technical Information Service, Washington, D.C.

DOE/WIPP-92-037. 1992. Statistical Summary of the Radiological Baseline for the Waste Isolation Pilot Plant. Waste Isolation Pilot Plant, Carlsbad, NM.

DOE/WIPP-93-004. 2002. Waste Isolation Pilot Plant Land Management Plan. Waste Isolation Pilot Plant, Carlsbad, NM.

DOE/WIPP-97-2219. 1997. Exhaust Shaft Hydraulic Assessment Data Report. Waste Isolation Pilot Plant. Carlsbad, NM.

DOE/WIPP-98-2285. 1998. Waste Isolation Pilot Plant RCRA Background Groundwater Quality Baseline Report. Waste Isolation Pilot Plant, Carlsbad, NM.

DOE/WIPP-99-2194. 2008. Waste Isolation Pilot Plant Environmental Monitoring Plan. Waste Isolation Pilot Plant, Carlsbad, NM.

DOE/WIPP-02-3122. 2010. Transuranic Waste Acceptance Criteria for the Waste Isolation Pilot Plant. Waste Isolation Pilot Plant, Carlsbad, NM.

DOE/WIPP-04-3231. 2004 WIPP Compliance Recertification Application - Main Volume. Waste Isolation Pilot Plant, NM

DOEMIPP-05-3318. 2005. Waste Isolation Pilot Plant Environmental Management System Description. Waste Isolation Pilot Plant, Carlsbad, NM. 
Appendix A - References

DOE/WIPP-08-3372. 2009. Waste Isolation Pilot Plant Documented Safety Analysis. Waste Isolation Pilot Plant, Carlsbad, NM.

DOE/WIPP-08-3375. 2008. Basic Data Report for Piezometers PZ-13, PZ-14, and PZ 15 and SSW. Waste Isolation Pilot Plant. Carlsbad, NM.

DOE/WIPP-09-3424. 2009. Compliance Recertification Application. Waste Isolation Pilot Plant, Carlsbad, NM.

DOE/WIPP-09-3443. 2009. Semiannual VOC, Hydrogen, and Methane Data Summary Report. Waste Isolation Pilot Plant, Carlsbad, NM.

DOE/WIPP-10-2171. 2008. Waste Isolation Pilot Plant Biennial Environmental Compliance Report. Waste Isolation Pilot Plant, Carlsbad, NM.

DOE/WIPP-11-3326. 2010. Basic Data Report for Well Plugging and Abandonment, Reconfiguration, and New Well Drilling Activities for Fiscal Year 2010. Waste Isolation Pilot Plant, Carlsbad, NM.

Doherty, J. 2002. PEST: Model Independent Parameter Estimation. Watermark Numerical Computing, Brisbane, Australia.

DP-831. 2003. WIPP Discharge Permit. New Mexico Environment Department, Santa Fe, NM.

EPA/530-SW-90-021. 1996. Quality Assurance and Quality Control. U.S. Environmental Protection Agency, Washington, D.C.

EPA. 1994. Draft Contract Laboratory Program Volatile Organics Analysis of Ambient Air in Canisters.

EPA Compendium Method TO-15. 1999. Determination of Volatile Organic Compounds (VOCs) in Air Collected in Specially-Prepared Canisters and Analysis By Gas Chromatography/Mass Spectrometry (GC/MS). U.S. Environmental Protection Agency, Washington, D.C.

EPA Docket A-98-49, Item II-B3-108.

EPA SW-846. 1996. Test Methods for Evaluating Solid Waste, Physical/Chemical Methods. U.S. Environmental Protection Agency, Washington, D.C.

Executive Order 13101. 1998. Greening the Government Through Waste Prevention, Recycling, and Federal Acquisition. Office of the President, Washington, D.C.

Executive Order 13123. 1999. Greening the Government Through Efficient Energy Management. Office of the President, Washington, D.C. 
Appendix A - References

Executive Order 13134. 1999. Developing and Promoting Biobased Products and Bioenergy. Office of the President, Washington, D.C.

Executive Order 13148. 1998. Greening the Government Through Leadership in Environmental Management. Office of the President, Washington, D.C.

Executive Order 13149. 2000. Greening the Government Through Federal Fleet and Transportation Efficiency. Office of the President, Washington, D.C.

Executive Order 13423. 2007. Strengthening Federal Environmental, Energy, and Transportation Management. Office of the President, Washington, D.C.

Executive Order 13514, 2009. Federal Leadership in Environmental, Energy, and Economic Performance Office of the President Washington, D.C.

Harbaugh, A. W., E. R. Banta, M. C. Hill, and M. G. McDonald. 2000. MODFLOW 2000, The U.S. Geological Survey Modular Ground-Water Model - User Guide to Modularization Concepts and the Ground-Water Flow Process. U.S. Geological Survey Open-File Report 00-92.

Hillesheim, M. B., R.L. Beauheim, and R. G. Richardson. 2006. "Overview of the WIPP Groundwater Monitoring Programs with Inferences about Karst in the WIPP Vicinity," in L. Land, V. W. Lueth, W. Raatz, P. Boston, and D. L. Love, eds., Caves and Karst of Southeastern New Mexico. New Mexico Geological Society, 57th Annual Fall Field Conference Guidebook. 277-286.

International Atomic Energy Agency. 1992. Technical Report Series No. 332, Effects of Ionizing Radiation on Plants and Animals at Levels Implied by Current Radiation Protection Standards. Vienna, Austria.

ISO 14001. Environmental Management Systems - Specification with Guidance for Use. 2004. International Organizations for Standardization, Geneva, Switzerland.

IT Corporation. 2000. Waste Isolation Pilot Plant RCRA Background Groundwater Quality Baseline Update Report. Albuquerque, NM.

Kuhlman, K. L. 2010. "Development of Culebra T Fields for CRA 2009 PABC." Sandia National Laboratories, Carlsbad, NM.

Lowry, T. S., and R. L. Beauheim. 2004. Analysis Report, Task 2 of AP-110, Evaluation of Water-Level Rise in the Culebra Due to Recharge from Refining Process Water Discharged onto Potash Tailings Piles. ERMS 536239. Carlsbad, NM: Sandia WIPP Records Center.

Lowry, T. S., and R. L. Beauheim. 2005. Analysis Report, Task 3 of AP-110, Evaluation of Water-Level Rise in the Culebra Due to Leakage Through Poorly Plugged and 
Appendix A - References

Abandoned Potash Boreholes. ERMS 540187. Carlsbad, NM: Sandia WIPP Records Center.

MacLellan, J. A. 1999. "Hanford Decision Level for Alpha Spectrometry Bioassay Analyses Based on the Sample-Specific Total Propagated Uncertainty." Presented at the 46th Annual Conference on Bioassay, Analytical, and Environmental Radiochemistry, Seattle, WA, November 12-17, 2000.

Mercer, J. W. 1983. Geohydrology of the Proposed Waste Isolation Pilot Plant Site, Los Medaños Area, Southeastern New Mexico. Water Resources Investigations, Report 834016, U.S. Geological Survey.

Mercer, J. W. and B. R. Orr. 1977. Review and Analysis of Geologic Conditions Near the Site of a Potential Nuclear Waste Repository Eddy and Lea Counties, New Mexico. U.S. Geological Survey Open-File Rept., 77-123.

Minnema, D. M. and L. W. Brewer. 1983. Background Radiation Measurements at Waste Isolation Pilot Plant Site, Carlsbad, NM. SAND83-1296.

MP 1.28, Integrated Safety Management. Washington TRU Solutions LLC, Waste Isolation Pilot Plant, Carlsbad, NM.

NCRP. 1987. Report No. 94, Exposure of the Population in the United States and Canada from Natural Background Radiation. National Council on Radiation Protection and Measurements. Bethesda, MD.

NCRP. 1991. Report No. 109, Effects of Ionizing Radiation on Aquatic Organisms. National Council on Radiation Protection and Measurements. Bethesda, MD.

NCRP. 2009. Report No. 160, Ionizing Radiation Exposure of the Population of the United States. National Council on Radiation Protection and Measurements. Bethesda, MD.

NM4890139088-TSDF. 1999. Waste Isolation Pilot Plant Hazardous Waste Facility Permit. New Mexico Environment Department, Santa Fe, NM.

NMSA 1978. §74-4-1. New Mexico Hazardous Waste Act. New Mexico Statutes Annotated 1978. State of New Mexico, Santa Fe, NM.

NMSA 1978. §74-6-1. New Mexico Water Quality Act. New Mexico Statutes Annotated. State of New Mexico, Santa Fe, NM.

Popielak, R.S.; R. L. Beauheim, S. R. Black, W. E. Coons, C. T. Ellingson, and R. L. Olsen. 1993. Brine Reservoirs in the Castile Formation, Waste isolation Pilot Plant (WIPP) Project, Southeastern New Mexico. TME 3153. NM: U.S. Department of Energy WIPP Project Office, Carlsbad, NM. 
Appendix A - References

Powers, D. W. 2004. Analysis Report, Task 1B of AP-110, Identify Plugged and Abandoned Oil or Gas Wells Not Sealed Through the Culebra with Cement, and Units to Which the Culebra Might Be Connected. ERMS 538279. Sandia WIPP Records Center, Carlsbad, NM.

Public Law 96-164. National Security and Military Applications of Nuclear Energy Authorization Act of 1980.

Public Law 98-616, 98 Stat. 322. 1984. Hazardous and Solid Wastes Amendments Act of 1984.

Public Law 102-579. Waste Isolation Pilot Plant Land Withdrawal Act. October 1992, as amended October 1996 by Public Law 104-201.

Rocky Flats Annual Report of Site Surveillance and Maintenance Activities-CY2008, Doc. No. S05247, U.S. Department of Energy, April, 2009

Rudeen, D. K. 2003. User's Manual for DTRKMF Version 1.00. ERMS 523246. Sandia National Laboratories, Carlsbad, NM.

SP 9-9 2009. Preparation of Culebra Potentiometric Surface Contour Maps. Sandia National Laboratories.

Stormont, J. C., C. L. Howard, and J. J. K. Daemen. 1991. Changes in Rock Salt Permeability Due to Nearby Excavation. In: Roegiers, J. C. (Ed.), Rock Mechanics as a Multidisciplinary Science. Proceedings of the 32nd U.S. Symposium, the University of Oklahoma, Norman, OK. July 10-12, 1991. A. A. Balkema, Brookfield, VT, pp. 899-907.

UNSCEAR. 2000. Sources and Effects of Ionizing Radiation. 2000 Report, Vol. 1. United Nations Scientific Committee on the Effects of Atomic Radiation.

WP 02-1, WIPP Groundwater Monitoring Program Plan. Washington TRU Solutions LLC. Waste Isolation Pilot Plant, Carlsbad, NM.

WP 02-EM3004, WIPP Radiological Data Verification and Validation. Washington TRU Solutions LLC. Waste Isolation Pilot Plant, Carlsbad. NM

WP 12-VC.01, Confirmatory Volatile Organic Compound Monitoring Program. Washington TRU Solutions LLC. Waste Isolation Pilot Plant, Carlsbad, NM.

WP 12-VC.04, Quality Assurance Project Plan for Hydrogen and Methane Monitoring. Washington TRU Solutions LLC. Waste Isolation Pilot Plant, Carlsbad, NM.

WP 13-1, Washington TRU Solutions LLC Quality Assurance Program Description. Washington TRU Solutions LLC. Waste Isolation Pilot Plant, Carlsbad, NM 
This page intentionally left blank 


\section{Waste Isolation Pilot Plant Annual Site Environmental Report for 2010 DOE/WIPP-11-2225}

Appendix B - Active Environmental Permits

Table B.1 - Active Environmental Permits and Approvals for the Waste Isolation Pilot Plant as of December 31, 2010

\begin{tabular}{|c|c|c|c|c|c|c|}
\hline & Granting Agency & Type of Permit & $\begin{array}{l}\text { Permit } \\
\text { Number }\end{array}$ & $\begin{array}{l}\text { Granted/ } \\
\text { Submitted }\end{array}$ & Expiration & $\begin{array}{l}\text { Current } \\
\text { Permit } \\
\text { Status }\end{array}$ \\
\hline 1. & $\begin{array}{l}\text { Department of the Interior } \\
\text { Bureau of Land } \\
\text { Management }\end{array}$ & $\begin{array}{l}\text { Right-of-Way for the North } \\
\text { Access Road }\end{array}$ & NM55676 & $08 / 24 / 83$ & None & Active \\
\hline 2. & $\begin{array}{l}\text { Department of the Interior } \\
\text { Bureau of Land } \\
\text { Management }\end{array}$ & Right-of-Way for Railroad & NM55699 & $09 / 27 / 83$ & None & Active \\
\hline 3. & $\begin{array}{l}\text { Department of the Interior } \\
\text { Bureau of Land } \\
\text { Management }\end{array}$ & $\begin{array}{l}\text { Right-of-Way for Dosimetry } \\
\text { and Aerosol Sampling Sites }\end{array}$ & NM63136 & $07 / 31 / 86$ & $07 / 31 / 11$ & Active \\
\hline 4. & $\begin{array}{l}\text { Department of the Interior } \\
\text { Bureau of Land } \\
\text { Management }\end{array}$ & $\begin{array}{l}\text { Right-of-Way for Seven } \\
\text { Subsidence Monuments }\end{array}$ & NM65801 & $11 / 07 / 86$ & None & Active \\
\hline 5. & $\begin{array}{l}\text { Department of the Interior } \\
\text { Bureau of Land } \\
\text { Management }\end{array}$ & $\begin{array}{l}\text { Right-of-Way for Aerosol } \\
\text { Sampling Site }\end{array}$ & NM77921 & 08/18/89 & 08/18/19 & Active \\
\hline 6. & $\begin{array}{l}\text { Department of the Interior } \\
\text { Bureau of Land } \\
\text { Management }\end{array}$ & $\begin{array}{l}\text { Right-of-Way for two } \\
\text { Survey Monuments }\end{array}$ & NM82245 & $12 / 13 / 89$ & $12 / 13 / 19$ & Active \\
\hline 7. & $\begin{array}{l}\text { Department of the Interior } \\
\text { Bureau of Land } \\
\text { Management }\end{array}$ & $\begin{array}{l}\text { Right-of-Way for South } \\
\text { Access Road }\end{array}$ & NM123703 & $1 / 27 / 10$ & $12 / 31 / 39$ & Active \\
\hline 8. & $\begin{array}{l}\text { Department of the Interior } \\
\text { Bureau of Land } \\
\text { Management }\end{array}$ & $\begin{array}{l}\text { Right-of-Way for Duval } \\
\text { Telephone Line }\end{array}$ & NM60174 & $11 / 06 / 96$ & $03 / 08 / 15$ & Active \\
\hline 9. & $\begin{array}{l}\text { Department of the Interior } \\
\text { Bureau of Land } \\
\text { Management }\end{array}$ & $\begin{array}{l}\text { Right-of-Way for Wells } \\
\text { AEC-7 and AEC-8 }\end{array}$ & NM108365 & $8 / 30 / 02$ & $08 / 30 / 32$ & Active \\
\hline 10. & $\begin{array}{l}\text { Department of the Interior } \\
\text { Bureau of Land } \\
\text { Management }\end{array}$ & Right-of-Way for ERDA-6 & NM108365 & $8 / 30 / 02$ & $08 / 30 / 32$ & Active \\
\hline 11. & $\begin{array}{l}\text { Department of the Interior } \\
\text { Bureau of Land } \\
\text { Management }\end{array}$ & $\begin{array}{l}\text { Right-of-Way for Well C- } \\
2756 \text { (P18) }\end{array}$ & NM108365 & $8 / 30 / 02$ & $08 / 30 / 32$ & Active \\
\hline 12. & $\begin{array}{l}\text { Department of the Interior } \\
\text { Bureau of Land } \\
\text { Management }\end{array}$ & $\begin{array}{l}\text { Right-of-Way for Monitoring } \\
\text { Well C-2664 (Cabin Baby) }\end{array}$ & NM107944 & $04 / 23 / 02$ & $04 / 23 / 32$ & Active \\
\hline 13. & $\begin{array}{l}\text { Department of the Interior, } \\
\text { Bureau of Land } \\
\text { Management }\end{array}$ & $\begin{array}{l}\text { Right-of-Way for Seismic } \\
\text { Monitoring Station }\end{array}$ & NM85426 & 9/23/1991 & None & Active \\
\hline 14. & $\begin{array}{l}\text { Department of the Interior, } \\
\text { Bureau of Land } \\
\text { Management }\end{array}$ & $\begin{array}{l}\text { Right-of-Way for Wells C- } \\
2725(\mathrm{H}-4 \mathrm{~A}), \mathrm{C}-2775(\mathrm{H}- \\
\text { 4B), and C-2776 }(\mathrm{H}-4 \mathrm{C})\end{array}$ & $\begin{array}{c}\text { NM-6-5 } \\
\text { Cooperative } \\
\text { Agreement }\end{array}$ & $4 / 27 / 1978$ & None & Active \\
\hline
\end{tabular}




\section{Waste Isolation Pilot Plant Annual Site Environmental Report for 2010 DOE/WIPP-11-2225}

Appendix B - Active Environmental Permits

Table B.1 - Active Environmental Permits and Approvals for the Waste Isolation Pilot Plant as of December 31, 2010

\begin{tabular}{|c|c|c|c|c|c|c|}
\hline & Granting Agency & Type of Permit & $\begin{array}{l}\text { Permit } \\
\text { Number }\end{array}$ & $\begin{array}{l}\text { Granted/ } \\
\text { Submitted }\end{array}$ & Expiration & $\begin{array}{l}\text { Current } \\
\text { Permit } \\
\text { Status }\end{array}$ \\
\hline 15. & $\begin{array}{l}\text { Department of the Interior, } \\
\text { Bureau of Land } \\
\text { Management }\end{array}$ & $\begin{array}{l}\text { Right-of-Way for Monitoring } \\
\text { Wells C-2723 (WIPP-25), } \\
\text { C-2724 (WIPP-26), C-2722 } \\
\text { WIPP-27), C-2636 (WIPP- } \\
\text { 28), C-2743 (WIPP-29), } \\
\text { and C-2727 (WIPP-30) }\end{array}$ & $\begin{array}{l}\text { NM-6-5 } \\
\text { Cooperative } \\
\text { Agreement }\end{array}$ & 6/14/1978 & None & Active \\
\hline 16. & $\begin{array}{l}\text { Department of the Interior } \\
\text { Bureau of Land } \\
\text { Management }\end{array}$ & $\begin{array}{l}\text { Right-of-Way for Aerosol } \\
\text { Sampling Sites }\end{array}$ & NM77921 & $10 / 03 / 89$ & 08/18/19 & Active \\
\hline 17. & $\begin{array}{l}\text { New Mexico State Land } \\
\text { Office }\end{array}$ & $\begin{array}{l}\text { Right-of-Way Easement for } \\
\text { Accessing State Trust } \\
\text { Lands in Eddy and Lea } \\
\text { Counties }\end{array}$ & R25430 & $9 / 28 / 04$ & $9 / 28 / 14$ & Active \\
\hline 18. & $\begin{array}{l}\text { Department of Interior } \\
\text { Bureau of Land } \\
\text { Management }\end{array}$ & $\begin{array}{l}\text { Right-of-Way for Valor } \\
\text { Telecom }\end{array}$ & NM113339 & 8/9/05 & $12 / 31 / 34$ & Active \\
\hline 19. & $\begin{array}{l}\text { Department of Interior } \\
\text { Bureau of Land } \\
\text { Management }\end{array}$ & $\begin{array}{l}\text { Right-of-Way for South } \\
\text { Access Road Fence }\end{array}$ & NM094304 & 3/15/95 & $\stackrel{\ln }{\text { Perpetuity }}$ & Active \\
\hline 20. & $\begin{array}{l}\text { New Mexico Commissioner } \\
\text { of Public Lands }\end{array}$ & $\begin{array}{l}\text { Right-of-Way for High } \\
\text { Volume Air Sampler }\end{array}$ & RW-22789 & $10 / 03 / 85$ & $10 / 03 / 20$ & Active \\
\hline 21. & $\begin{array}{l}\text { New Mexico Environment } \\
\text { Department Groundwater } \\
\text { Bureau }\end{array}$ & Discharge Permit & DP-831 & 9/9/08 & 9/9/13 & Active \\
\hline 22. & $\begin{array}{l}\text { New Mexico Environment } \\
\text { Department Air Quality } \\
\text { Bureau }\end{array}$ & $\begin{array}{l}\text { Operating Permit for Two } \\
\text { Backup Diesel Generators }\end{array}$ & $310-M-2$ & $12 / 07 / 93$ & None & Active \\
\hline 23. & $\begin{array}{l}\text { New Mexico Environment } \\
\text { Department-UST Bureau }\end{array}$ & $\begin{array}{l}\text { Underground Storage } \\
\text { Tanks }\end{array}$ & $\begin{array}{l}\text { NMED2300 } \\
\text { (Number } \\
\text { changes } \\
\text { annually) }\end{array}$ & $7 / 1 / 2010$ & $6 / 30 / 11$ & Active \\
\hline 24. & $\begin{array}{l}\text { New Mexico State Engineer } \\
\text { Office }\end{array}$ & $\begin{array}{l}\text { Monitoring Well Exhaust } \\
\text { Shaft Exploratory Borehole }\end{array}$ & C-2801 & $02 / 23 / 01$ & None & Active \\
\hline 25. & $\begin{array}{l}\text { New Mexico State Engineer } \\
\text { Office }\end{array}$ & $\begin{array}{l}\text { Monitoring Well Exhaust } \\
\text { Shaft Exploratory Borehole }\end{array}$ & C-2802 & 02/23/01 & None & Active \\
\hline 26. & $\begin{array}{l}\text { New Mexico State Engineer } \\
\text { Office }\end{array}$ & $\begin{array}{l}\text { Monitoring Well Exhaust } \\
\text { Shaft Exploratory Borehole }\end{array}$ & C-2803 & 02/23/01 & None & Active \\
\hline 27. & $\begin{array}{l}\text { New Mexico State Engineer } \\
\text { Office }\end{array}$ & Monitoring Well & C-2811 & 03/02/02 & None & Active \\
\hline 28. & $\begin{array}{l}\text { New Mexico State Engineer } \\
\text { Office }\end{array}$ & $\begin{array}{l}\text { Appropriation: WQSP-1 } \\
\text { Well }\end{array}$ & C-2413 & $10 / 21 / 96$ & None & Active \\
\hline 29. & $\begin{array}{l}\text { New Mexico State Engineer } \\
\text { Office }\end{array}$ & $\begin{array}{l}\text { Appropriation: WQSP-2 } \\
\text { Well }\end{array}$ & C-2414 & $10 / 21 / 96$ & None & Active \\
\hline 30. & $\begin{array}{l}\text { New Mexico State Engineer } \\
\text { Office }\end{array}$ & $\begin{array}{l}\text { Appropriation: WQSP-3 } \\
\text { Well }\end{array}$ & C-2415 & $10 / 21 / 96$ & None & Active \\
\hline 31. & $\begin{array}{l}\text { New Mexico State Engineer } \\
\text { Office }\end{array}$ & $\begin{array}{l}\text { Appropriation: WQSP-4 } \\
\text { Well }\end{array}$ & C-2416 & $10 / 21 / 96$ & None & Active \\
\hline
\end{tabular}




\section{Waste Isolation Pilot Plant Annual Site Environmental Report for 2010 DOE/WIPP-11-2225}

Appendix B - Active Environmental Permits

Table B.1 - Active Environmental Permits and Approvals for the Waste Isolation Pilot Plant as of December 31, 2010

\begin{tabular}{|c|c|c|c|c|c|c|}
\hline & Granting Agency & Type of Permit & $\begin{array}{l}\text { Permit } \\
\text { Number }\end{array}$ & $\begin{array}{l}\text { Granted/ } \\
\text { Submitted }\end{array}$ & Expiration & $\begin{array}{c}\text { Current } \\
\text { Permit } \\
\text { Status }\end{array}$ \\
\hline 32. & $\begin{array}{l}\text { New Mexico State Engineer } \\
\text { Office }\end{array}$ & $\begin{array}{l}\text { Appropriation: WQSP-5 } \\
\text { Well }\end{array}$ & C-2417 & $10 / 21 / 96$ & None & Active \\
\hline 33. & $\begin{array}{l}\text { New Mexico State Engineer } \\
\text { Office }\end{array}$ & $\begin{array}{l}\text { Appropriation: WQSP-6 } \\
\text { Well }\end{array}$ & C-2418 & $10 / 21 / 96$ & None & Active \\
\hline 34. & $\begin{array}{l}\text { New Mexico State Engineer } \\
\text { Office }\end{array}$ & $\begin{array}{l}\text { Appropriation: WQSP-6a } \\
\text { Well }\end{array}$ & C-2419 & $10 / 21 / 96$ & None & Active \\
\hline 35. & $\begin{array}{l}\text { New Mexico State Engineer } \\
\text { Office }\end{array}$ & Monitoring Well AEC-7 & C-2742 & $11 / 06 / 00$ & None & Active \\
\hline 36. & $\begin{array}{l}\text { New Mexico State Engineer } \\
\text { Office }\end{array}$ & Monitoring Well AEC-8 & C-2744 & $11 / 06 / 00$ & None & $P \& A$ \\
\hline 37. & $\begin{array}{l}\text { New Mexico State Engineer } \\
\text { Office }\end{array}$ & Monitoring Well Cabin Baby & C-2664 & 07/30/99 & None & Active \\
\hline 38. & $\begin{array}{l}\text { New Mexico State Engineer } \\
\text { Office }\end{array}$ & Monitoring Well DOE-1 & C-2757 & $11 / 06 / 00$ & None & $P \& A$ \\
\hline 39. & $\begin{array}{l}\text { New Mexico State Engineer } \\
\text { Office }\end{array}$ & Monitoring Well DOE-2 & C-2682 & $04 / 17 / 00$ & None & Active \\
\hline 40. & $\begin{array}{l}\text { New Mexico State Engineer } \\
\text { Office }\end{array}$ & Monitoring Well ERDA-9 & C-2752 & $11 / 06 / 00$ & None & Active \\
\hline 41. & $\begin{array}{l}\text { New Mexico State Engineer } \\
\text { Office }\end{array}$ & Monitoring Well H-1 & C-2765 & $11 / 06 / 00$ & None & $P \& A$ \\
\hline 42. & $\begin{array}{l}\text { New Mexico State Engineer } \\
\text { Office }\end{array}$ & Monitoring Well H-2A & C-2762 & $11 / 06 / 00$ & None & $P \& A$ \\
\hline 43. & $\begin{array}{l}\text { New Mexico State Engineer } \\
\text { Office }\end{array}$ & Monitoring Well H-2B1 & C-2758 & $11 / 06 / 00$ & None & Active \\
\hline 44. & $\begin{array}{l}\text { New Mexico State Engineer } \\
\text { Office }\end{array}$ & Monitoring Well H-2B2 & C-2763 & $11 / 06 / 00$ & None & Active \\
\hline 45. & $\begin{array}{l}\text { New Mexico State Engineer } \\
\text { Office }\end{array}$ & Monitoring Well H-2C & C-2759 & $11 / 06 / 00$ & None & $P \& A$ \\
\hline 46. & $\begin{array}{l}\text { New Mexico State Engineer } \\
\text { Office }\end{array}$ & Monitoring Well H-3B1 & C-2764 & $11 / 06 / 00$ & None & Active \\
\hline 47. & $\begin{array}{l}\text { New Mexico State Engineer } \\
\text { Office }\end{array}$ & Monitoring Well H-3B2 & C-2760 & $11 / 06 / 00$ & None & Active \\
\hline 48. & $\begin{array}{l}\text { New Mexico State Engineer } \\
\text { Office }\end{array}$ & Monitoring Well H-3B3 & C-2761 & $11 / 06 / 00$ & None & $P \& A$ \\
\hline 49. & $\begin{array}{l}\text { New Mexico State Engineer } \\
\text { Office }\end{array}$ & Monitoring Well H-3D & C-3207 & $11 / 06 / 00$ & None & Active \\
\hline 50. & $\begin{array}{l}\text { New Mexico State Engineer } \\
\text { Office }\end{array}$ & Monitoring Well $\mathrm{H}-4 \mathrm{~A}$ & C-2725 & $11 / 06 / 00$ & None & $P \& A$ \\
\hline 51. & $\begin{array}{l}\text { New Mexico State Engineer } \\
\text { Office }\end{array}$ & Monitoring Well H-4B & C-2775 & $11 / 06 / 00$ & None & $P \& A$ \\
\hline 52. & $\begin{array}{l}\text { New Mexico State Engineer } \\
\text { Office }\end{array}$ & Monitoring Well $\mathrm{H}-4 \mathrm{C}$ & C-2776 & $11 / 06 / 00$ & None & Active \\
\hline 53. & $\begin{array}{l}\text { New Mexico State Engineer } \\
\text { Office }\end{array}$ & Monitoring Well H-5A & C-2746 & $11 / 06 / 00$ & None & $P \& A$ \\
\hline
\end{tabular}




\section{Waste Isolation Pilot Plant Annual Site Environmental Report for 2010 DOE/WIPP-11-2225}

Appendix B - Active Environmental Permits

Table B.1 - Active Environmental Permits and Approvals for the Waste Isolation Pilot Plant as of December 31, 2010

\begin{tabular}{|c|c|c|c|c|c|c|}
\hline & Granting Agency & Type of Permit & $\begin{array}{l}\text { Permit } \\
\text { Number }\end{array}$ & $\begin{array}{l}\text { Granted/ } \\
\text { Submitted }\end{array}$ & Expiration & $\begin{array}{l}\text { Current } \\
\text { Permit } \\
\text { Status }\end{array}$ \\
\hline 54. & $\begin{array}{l}\text { New Mexico State Engineer } \\
\text { Office }\end{array}$ & Monitoring Well H-5B & C-2745 & $11 / 06 / 00$ & None & Active \\
\hline 55. & $\begin{array}{l}\text { New Mexico State Engineer } \\
\text { Office }\end{array}$ & Monitoring Well H-5C & C-2747 & $11 / 06 / 00$ & None & Active \\
\hline 56. & $\begin{array}{l}\text { New Mexico State Engineer } \\
\text { Office }\end{array}$ & Monitoring Well H-6A & C-2751 & $11 / 06 / 00$ & None & $P \& A$ \\
\hline 57. & $\begin{array}{l}\text { New Mexico State Engineer } \\
\text { Office }\end{array}$ & Monitoring Well H-6B & C-2749 & $11 / 06 / 00$ & None & $P \& A$ \\
\hline 58. & $\begin{array}{l}\text { New Mexico State Engineer } \\
\text { Office }\end{array}$ & Monitoring Well H-6C & C-2750 & $11 / 06 / 00$ & None & Active \\
\hline 59. & $\begin{array}{l}\text { New Mexico State Engineer } \\
\text { Office }\end{array}$ & Monitoring Well H-7A & C-2694 & 04/17/00 & None & $P \& A$ \\
\hline 60. & $\begin{array}{l}\text { New Mexico State Engineer } \\
\text { Office }\end{array}$ & Monitoring Well H-7B1 & C-2770 & $11 / 06 / 00$ & None & Active \\
\hline 61. & $\begin{array}{l}\text { New Mexico State Engineer } \\
\text { Office }\end{array}$ & Monitoring Well H-7B2 & C-2771 & $11 / 06 / 00$ & None & Active \\
\hline 62. & $\begin{array}{l}\text { New Mexico State Engineer } \\
\text { Office }\end{array}$ & Monitoring Well H-8A & C-2780 & $11 / 06 / 00$ & None & Active \\
\hline 63. & $\begin{array}{l}\text { New Mexico State Engineer } \\
\text { Office }\end{array}$ & Monitoring Well H-9A & C-2785 & $11 / 06 / 00$ & None & $P \& A$ \\
\hline 64. & $\begin{array}{l}\text { New Mexico State Engineer } \\
\text { Office }\end{array}$ & Monitoring Well H-9B & C-2783 & $11 / 06 / 00$ & None & $P \& A$ \\
\hline 65. & $\begin{array}{l}\text { New Mexico State Engineer } \\
\text { Office }\end{array}$ & Monitoring Well H-9C & C-2784 & $11 / 06 / 00$ & None & Active \\
\hline 66. & $\begin{array}{l}\text { New Mexico State Engineer } \\
\text { Office }\end{array}$ & Monitoring Well H-10A & C-2779 & $11 / 06 / 00$ & None & Active \\
\hline 67. & $\begin{array}{l}\text { New Mexico State Engineer } \\
\text { Office }\end{array}$ & Monitoring Well $\mathrm{H}-10 \mathrm{~B}$ & C-2778 & $11 / 06 / 00$ & None & $P \& A$ \\
\hline 68. & $\begin{array}{l}\text { New Mexico State Engineer } \\
\text { Office }\end{array}$ & Monitoring Well $\mathrm{H}-10 \mathrm{C}$ & C-2695 & 04/17/00 & None & Active \\
\hline 69. & $\begin{array}{l}\text { New Mexico State Engineer } \\
\text { Office }\end{array}$ & Monitoring Well H-11B1 & C-2767 & $11 / 06 / 00$ & None & Active \\
\hline 70. & $\begin{array}{l}\text { New Mexico State Engineer } \\
\text { Office }\end{array}$ & Monitoring Well H-11B2 & C-2687 & 04/17/00 & None & Active \\
\hline 71. & $\begin{array}{l}\text { New Mexico State Engineer } \\
\text { Office }\end{array}$ & Monitoring Well H-11B3 & C-2768 & $11 / 06 / 00$ & None & $P \& A$ \\
\hline 72. & $\begin{array}{l}\text { New Mexico State Engineer } \\
\text { Office }\end{array}$ & Monitoring Well H-11B4 & C-2769 & $11 / 06 / 00$ & None & Active \\
\hline 73. & $\begin{array}{l}\text { New Mexico State Engineer } \\
\text { Office }\end{array}$ & Monitoring Well H-12 & C-2777 & $11 / 06 / 00$ & None & Active \\
\hline 74. & $\begin{array}{l}\text { New Mexico State Engineer } \\
\text { Office }\end{array}$ & Monitoring Well H-14 & C-2766 & $11 / 06 / 00$ & None & Active \\
\hline 75. & $\begin{array}{l}\text { New Mexico State Engineer } \\
\text { Office }\end{array}$ & Monitoring Well H-15 & C-2685 & 04/17/00 & None & Active \\
\hline
\end{tabular}




\section{Waste Isolation Pilot Plant Annual Site Environmental Report for 2010 DOE/WIPP-11-2225}

Appendix B - Active Environmental Permits

Table B.1 - Active Environmental Permits and Approvals for the Waste Isolation Pilot Plant as of December 31, 2010

\begin{tabular}{|c|c|c|c|c|c|c|}
\hline & Granting Agency & Type of Permit & $\begin{array}{l}\text { Permit } \\
\text { Number }\end{array}$ & $\begin{array}{l}\text { Granted/ } \\
\text { Submitted }\end{array}$ & Expiration & $\begin{array}{c}\text { Current } \\
\text { Permit } \\
\text { Status }\end{array}$ \\
\hline 76. & $\begin{array}{l}\text { New Mexico State Engineer } \\
\text { Office }\end{array}$ & Monitoring Well H-16 & C-2753 & $11 / 06 / 00$ & None & Active \\
\hline 77. & $\begin{array}{l}\text { New Mexico State Engineer } \\
\text { Office }\end{array}$ & Monitoring Well H-17 & C-2773 & $11 / 06 / 00$ & None & Active \\
\hline 78. & $\begin{array}{l}\text { New Mexico State Engineer } \\
\text { Office }\end{array}$ & Monitoring Well H-18 & C-2683 & $04 / 17 / 00$ & None & Active \\
\hline 79. & $\begin{array}{l}\text { New Mexico State Engineer } \\
\text { Office }\end{array}$ & Monitoring Well H-19B0 & C-2420 & 01/25/95 & None & Active \\
\hline 80. & $\begin{array}{l}\text { New Mexico State Engineer } \\
\text { Office }\end{array}$ & Monitoring Well H-19B1 & C-2420 & 01/25/95 & None & Active \\
\hline 81. & $\begin{array}{l}\text { New Mexico State Engineer } \\
\text { Office }\end{array}$ & Monitoring Well H-19B2 & C-2421 & 01/25/95 & None & Active \\
\hline 82. & $\begin{array}{l}\text { New Mexico State Engineer } \\
\text { Office }\end{array}$ & Monitoring Well H-19B3 & C-2422 & 01/25/95 & None & Active \\
\hline 83. & $\begin{array}{l}\text { New Mexico State Engineer } \\
\text { Office }\end{array}$ & Monitoring Well H-19B4 & C-2423 & 01/25/95 & None & Active \\
\hline 84. & $\begin{array}{l}\text { New Mexico State Engineer } \\
\text { Office }\end{array}$ & Monitoring Well H-19B5 & C-2424 & 01/25/95 & None & Active \\
\hline 85. & $\begin{array}{l}\text { New Mexico State Engineer } \\
\text { Office }\end{array}$ & Monitoring Well H-19B6 & C-2425 & 01/25/95 & None & Active \\
\hline 86. & $\begin{array}{l}\text { New Mexico State Engineer } \\
\text { Office }\end{array}$ & Monitoring Well H-19B7 & C-2426 & 01/25/95 & None & Active \\
\hline 87. & $\begin{array}{l}\text { New Mexico State Engineer } \\
\text { Office }\end{array}$ & Monitoring Well P-14 & C-2637 & 01/02/99 & None & $P \& A$ \\
\hline 88. & $\begin{array}{l}\text { New Mexico State Engineer } \\
\text { Office }\end{array}$ & Monitoring Well P-15 & C-2686 & $04 / 17 / 00$ & None & $P \& A$ \\
\hline 89. & $\begin{array}{l}\text { New Mexico State Engineer } \\
\text { Office }\end{array}$ & Monitoring Well P-17 & C-2774 & $11 / 06 / 00$ & None & $P \& A$ \\
\hline 90. & $\begin{array}{l}\text { New Mexico State Engineer } \\
\text { Office }\end{array}$ & Monitoring Well P-18 & C-2756 & $11 / 06 / 00$ & None & $P \& A$ \\
\hline 91. & $\begin{array}{l}\text { New Mexico State Engineer } \\
\text { Office }\end{array}$ & Monitoring Well WIPP-12 & C-2639 & 01/12/99 & None & $P \& A$ \\
\hline 92. & $\begin{array}{l}\text { New Mexico State Engineer } \\
\text { Office }\end{array}$ & Monitoring Well WIPP-13 & C-2748 & $11 / 06 / 00$ & None & Active \\
\hline 93. & $\begin{array}{l}\text { New Mexico State Engineer } \\
\text { Office }\end{array}$ & Monitoring Well WIPP-18 & C-2684 & $04 / 17 / 00$ & None & Active \\
\hline 94. & $\begin{array}{l}\text { New Mexico State Engineer } \\
\text { Office }\end{array}$ & Monitoring Well WIPP-19 & C-2755 & $11 / 06 / 00$ & None & Active \\
\hline 95. & $\begin{array}{l}\text { New Mexico State Engineer } \\
\text { Office }\end{array}$ & Monitoring Well WIPP-21 & C-2754 & $11 / 06 / 00$ & None & $P \& A$ \\
\hline 96. & $\begin{array}{l}\text { New Mexico State Engineer } \\
\text { Office }\end{array}$ & Monitoring Well WIPP-25 & C-2723 & $07 / 26 / 00$ & None & $P \& A$ \\
\hline 97. & $\begin{array}{l}\text { New Mexico State Engineer } \\
\text { Office }\end{array}$ & Monitoring Well WIPP-26 & C-2724 & $11 / 06 / 00$ & None & $P \& A$ \\
\hline
\end{tabular}




\section{Waste Isolation Pilot Plant Annual Site Environmental Report for 2010 DOE/WIPP-11-2225}

Appendix B - Active Environmental Permits

Table B.1 - Active Environmental Permits and Approvals for the Waste Isolation Pilot Plant as of December 31, 2010

\begin{tabular}{|c|c|c|c|c|c|c|}
\hline & Granting Agency & Type of Permit & $\begin{array}{l}\text { Permit } \\
\text { Number }\end{array}$ & $\begin{array}{l}\text { Granted/ } \\
\text { Submitted }\end{array}$ & Expiration & $\begin{array}{l}\text { Current } \\
\text { Permit } \\
\text { Status }\end{array}$ \\
\hline 98. & $\begin{array}{l}\text { New Mexico State Engineer } \\
\text { Office }\end{array}$ & Monitoring Well WIPP-27 & C-2722 & $11 / 06 / 00$ & None & $P \& A$ \\
\hline 99. & $\begin{array}{l}\text { New Mexico State Engineer } \\
\text { Office }\end{array}$ & Monitoring Well WIPP28 & C-2636 & $01 / 12 / 99$ & None & $P \& A$ \\
\hline 100. & $\begin{array}{l}\text { New Mexico State Engineer } \\
\text { Office }\end{array}$ & Monitoring Well WIPP-29 & C-2743 & $11 / 06 / 00$ & None & $P \& A$ \\
\hline 101. & $\begin{array}{l}\text { New Mexico State Engineer } \\
\text { Office }\end{array}$ & Monitoring Well WIPP-30 & C-2727 & $08 / 04 / 00$ & None & $P \& A$ \\
\hline 102. & $\begin{array}{l}\text { New Mexico State Engineer } \\
\text { Office }\end{array}$ & Monitoring Well H-6BR & C-3362 & $12 / 27 / 07$ & None & Active \\
\hline 103. & $\begin{array}{l}\text { New Mexico State Engineer } \\
\text { Office }\end{array}$ & Monitoring Well H-15R & C-3361 & $12 / 27 / 07$ & None & Active \\
\hline 104. & $\begin{array}{l}\text { New Mexico State Engineer } \\
\text { Office }\end{array}$ & Monitoring Well SNL-2 & C-2948 & 2/14/03 & None & Active \\
\hline 105. & $\begin{array}{l}\text { New Mexico State Engineer } \\
\text { Office }\end{array}$ & Monitoring Well SNL-9 & C-2950 & 2/14/03 & None & Active \\
\hline 106. & $\begin{array}{l}\text { New Mexico State Engineer } \\
\text { Office }\end{array}$ & Monitoring Well SNL-12 & C-2954 & $2 / 25 / 03$ & None & Active \\
\hline 107. & $\begin{array}{l}\text { New Mexico State Engineer } \\
\text { Office }\end{array}$ & Monitoring Well SNL-1 & C-2953 & $2 / 25 / 03$ & None & Active \\
\hline 108. & $\begin{array}{l}\text { New Mexico State Engineer } \\
\text { Office }\end{array}$ & Monitoring Well SNL-3 & C-2949 & $2 / 14 / 03$ & None & Active \\
\hline 109. & $\begin{array}{l}\text { New Mexico State Engineer } \\
\text { Office }\end{array}$ & Monitoring Well SNL-5 & C-3002 & 10/1/03 & None & Active \\
\hline 110. & $\begin{array}{l}\text { New Mexico State Engineer } \\
\text { Office }\end{array}$ & Monitoring Well IMC-461 & C-3015 & $11 / 25 / 03$ & None & Active \\
\hline 111. & $\begin{array}{l}\text { New Mexico State Engineer } \\
\text { Office }\end{array}$ & Monitoring Well SNL-10 & C-3221 & $7 / 26 / 05$ & None & Active \\
\hline 112. & $\begin{array}{l}\text { New Mexico State Engineer } \\
\text { Office }\end{array}$ & Monitoring Well SNL-16 & C-3220 & $7 / 26 / 05$ & None & Active \\
\hline 113. & $\begin{array}{l}\text { New Mexico State Engineer } \\
\text { Office }\end{array}$ & Monitoring Well SNL-17 & C-3222 & $7 / 26 / 05$ & None & Active \\
\hline 114. & $\begin{array}{l}\text { U.S. Environmental } \\
\text { Protection Agency } \\
\text { Region } 6\end{array}$ & $\begin{array}{l}\text { Conditions of Approval for } \\
\text { Disposal of PCB/TRU and } \\
\text { PCB/TRU Mixed Waste at } \\
\text { the US Department of } \\
\text { Energy (DOE) Waste } \\
\text { Isolation Pilot Plant (WIPP) } \\
\text { Carlsbad, New Mexico }\end{array}$ & N/A & $4 / 30 / 08$ & $4 / 30 / 13$ & Active \\
\hline 115. & $\begin{array}{l}\text { U.S. Fish and Wildlife } \\
\text { Service }\end{array}$ & $\begin{array}{l}\text { Migratory Bird Special } \\
\text { Purpose - Relocate }\end{array}$ & MB155189-0 & $6 / 1 / 10$ & $5 / 31 / 12$ & Active \\
\hline 116. & $\begin{array}{l}\text { New Mexico State Engineer } \\
\text { Office }\end{array}$ & Monitoring Well $\mathrm{H}-4 \mathrm{bR}$ & C-3404 & 1/13/09 & None & Active \\
\hline 117. & $\begin{array}{l}\text { New Mexico State Engineer } \\
\text { Office }\end{array}$ & Monitoring Well H-9bR & $\begin{array}{l}\text { C-2783- } \\
\text { POD2 }\end{array}$ & $7 / 14 / 10$ & None & Active \\
\hline
\end{tabular}


Appendix B - Active Environmental Permits

Table B.1 - Active Environmental Permits and Approvals for the Waste Isolation Pilot Plant as of December 31, 2010

\begin{tabular}{|c|l|l|c|c|c|c|}
\hline \multicolumn{1}{|c|}{ Granting Agency } & \multicolumn{1}{|c|}{ Type of Permit } & $\begin{array}{c}\text { Permit } \\
\text { Number }\end{array}$ & $\begin{array}{c}\text { Granted } \\
\text { Submitted }\end{array}$ & $\begin{array}{c}\text { Current } \\
\text { Expiration } \\
\text { Permit } \\
\text { Status }\end{array}$ \\
\hline 118. & $\begin{array}{l}\text { New Mexico State Engineer } \\
\text { Office }\end{array}$ & Monitoring Well C-2737 & C-2737 & $9 / 27 / 00$ & None & Active \\
\hline 119. & $\begin{array}{l}\text { New Mexico State Engineer } \\
\text { Office }\end{array}$ & Monitoring Well WIPP-11 & C-3112 & $12 / 27 / 07$ & None & Active \\
\hline 120. & $\begin{array}{l}\text { New Mexico State Engineer } \\
\text { Office }\end{array}$ & Monitoring Well SNL-6 & C-3151 & $2 / 10 / 05$ & None & Active \\
\hline
\end{tabular}

P\&A - Plugged and Abandoned 
This page intentionally left blank 
Waste Isolation Pilot Plant Annual Site Environmental Report for 2010 DOE/WIPP-11-2225

Appendix C - Location Codes

Table C.1 - Codes Used to Identify the Sites from which Samples were Collected

\begin{tabular}{|c|c|c|c|}
\hline Code & Location & Code & Location \\
\hline BHT & Bottom of the Hill Iank & PD2 & Pond $\underline{2}$ (Infiltration Control) \\
\hline BLK & BLanK & PEC & $\underline{\text { PECos river }}$ \\
\hline BRA & BRAntley lake & PKT & PoKer Irap \\
\hline CBD & $\underline{\text { Carls }} \underline{B} a \underline{D}$ & PP1 & Polishing Pond 1 A (DP-831) \\
\hline COW & COyote Well (deionized water blank) & PP2 & Polishing Pond $\underline{2}$ B (DP-831) \\
\hline COY & $\underline{\text { COYote (surface water duplicate) }}$ & RED & $\underline{\mathrm{RED}}$ tank \\
\hline EBA & Evaporation Basin $\underline{A}$ & SEC & SouthE्ast $\underline{\text { Control }}$ \\
\hline EB1 & Salt Storage Exxtension Basin I & SMR & SMith $\underline{\text { Ranch }}$ \\
\hline EB2 & Salt Storage Extension Basin II & SOO & Sample 으 Oppportunity* \\
\hline EPA & Evaporation Pond A (DP-831) & SP1 & Settling Pond $\underline{1}$ A (DP-831) \\
\hline EPB & Evaporation Pond $\underline{B}$ (DP-831) & SP2 & Settling Pond $\underline{2}$ A (DP-831) \\
\hline EPC & Evaporation Pond $\underline{\mathrm{C}}$ (DP-831) & SPE & Salt Pile Evaporation Pond \\
\hline FWT & Fresh Water Tank & SWL & SeWage Lagoons \\
\hline HIL & $\underline{\mathrm{HILI}}$ tank & TUT & $\underline{\text { TUT tank }}$ \\
\hline $\mathrm{H} 19$ & $\underline{\mathrm{H}-19}$ Evaporation Pond & UPR & 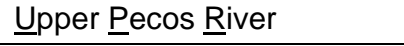 \\
\hline IDN & $\underline{\ln } \underline{\mathrm{Di}} \mathrm{a} \underline{\mathrm{N}}$ tank & WAB & 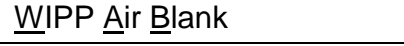 \\
\hline LST & Lo $\underline{\text { St }}$ Tank & WEE & WIPP East \\
\hline MLR & MiLlis Ranch & WFF & 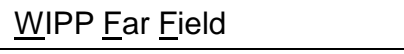 \\
\hline NOY & $\underline{\text { NOYa tank }}$ & WIP & $\underline{\text { WIPP } 16 \text { sections }}$ \\
\hline $\mathrm{PCN}$ & 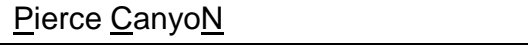 & WSS & $\underline{\text { WIPP South }}$ \\
\hline PD1 & Pond $\underline{1}$ (Infiltration Control) & & \\
\hline
\end{tabular}

* Sample taken where found 
This page intentionally left blank 
Appendix D - Radiochemical Equations

\section{Detection}

Detection

All radionuclides with the exception of the gamma spectroscopy targets $\left({ }^{137} \mathrm{Cs},{ }^{60} \mathrm{Co}\right.$, and ${ }^{40} \mathrm{~K}$ ) are considered "detected" if the radionuclide activity or concentration [RN] is greater than the minimum detectable concentration and greater than the total propagated uncertainty at the 2 sigma level. The gamma radionuclides are considered detected when the above criteria are met and the gamma spectroscopy software used to identify the peak generates an associated identification confidence of 90 percent or greater (ID Confidence $\geq 0.90$ ).

\section{Minimum Detectable Concentration (MDC)}

The MDC is the smallest amount (activity or mass) of a radionuclide in a sample that will be detected with a 5 percent probability of nondetection while accepting a 5 percent probability of erroneously deciding that a positive quantity of a radionuclide is present in an appropriate blank sample. This method assures that any claimed MDC has at least a 95 percent chance of being detected. It is possible to achieve a very low level of detection by analyzing a large sample size and counting for a very long time. The WIPP Laboratories uses the following equation for calculating the MDCs for each radionuclide in various sample matrices:

$$
M D C=\frac{4.66 \sqrt{S}}{K T}+\frac{3.00}{K T}
$$

Where:

$\mathrm{S}=$ Net method blank counts; when method blank counts $=0$, average of the last 30 blanks analyzed are substituted

$\mathrm{K}=\mathrm{A}$ correction factor that includes items such as unit conversions, sample volume/weight, decay correction, detector efficiency, chemical recovery, abundance correction, etc.

$\mathrm{T}=$ Counting time where the background and sample counting time are identical

For further evaluation of the MDC, refer to ANSI N13.30, Performance Criteria for Radiobioassay.

\section{Total Propagated Uncertainty (TPU)}

The TPU is an estimate of the uncertainty in the measurement due to all sources, including counting error, measurement error, chemical recovery error, detector efficiency, randomness of radioactive decay, and any other sources of uncertainty.

The TPU for each data point must be reported at the $2 \sigma$ level $(2 \sigma$ TPU). For further discussion of TPU, refer to ANSI N13.30. 
Appendix D - Radiochemical Equations

\section{Relative Error Ratio (RER)}

The RER is a method, similar to a t-test, with which to compare duplicate results (see Chapters 4 and 7; WP 02-EM3004, Radiological Data Verification and Validation).

$$
\operatorname{RER}=\frac{(\text { MeanActivity)ori }-(\text { MeanActivity }) d u p}{\sqrt{(2 \sigma T P U)^{2} \text { ori }+(2 \sigma T P U)^{2} \text { dup }}}
$$

Where:

$(\text { Mean Activity })^{\text {ori }} \quad=$ Mean Activity of the Original or Primary Sample

$(\text { Mean Activity })^{\text {dup }}=$ Mean Activity of the Duplicate Sample

$2 \sigma T P U=$ Total Propagated errors at the 2 sigma level

\section{Percent Bias (\% Bias)}

The percent bias is a measure of the accuracy of radiochemical separation methods and counting instruments; that is, a measure of how reliable the results of analyses are when compared to the actual values.

$$
\% \text { BIAS }=\left[\frac{A_{m}-A_{k}}{A_{k}} * 100 \%\right.
$$

Where:

$\%$ BIAS = Percent Bias

Am = Measured Sample Activity

Ak $\quad=$ Known Sample Activity 
Appendix E - Time Trend Plots for Detectable Constituents in Groundwater

The seven WQSP wells had been sampled 29 times prior to the two sampling rounds conducted in 2010. The first 10 sampling rounds conducted from 1995 through 2000 (prior to receiving mixed waste at the WIPP site) were used to establish the original baseline for groundwater chemistry at each sampling location. The baseline sample set is used to determine whether statistically significant changes have occurred at any well. The following time trend charts show the Round 30 and Round 31 results with respect to the established baseline.

The baseline was established incorporating data from three different laboratories. The wide ranges of target analyte concentrations measured during the baseline resulted from past difficulties in analyzing the high-brine groundwater from the WIPP site. The contract laboratories used variable dilution factors when analyzing the samples resulting in variable detection limits for some analytes.

The analytes include constituents that are defined as the target 20 volatile and 12 semivolatile organics, as well as 14 trace metals. Time trend plots are not included for these. The other analytes include the general chemistry indicator parameters. The general chemistry parameters include the common cation metals, calcium, magnesium, potassium, and sodium; the anions chloride and sulfate; density, $\mathrm{pH}$, specific conductance, TDS, total suspended solids, TOC, and total organic halogens. Time trend plots are provided below for the following general chemistry parameters: dissolved calcium, chloride, dissolved magnesium, $\mathrm{pH}$, dissolved potassium, sulfate and TDS. These plots show the concentrations in the primary sample and the duplicate sample for all sampling rounds.

The 2010 laboratory analytical results were verified and validated in accordance with WIPP procedures and U.S. Environmental Protection Agency technical guidance. Sampling Round 30 samples were taken March through May 2010 and Sampling Round 31 samples were taken September through November 2010. See Appendix F for the concentrations of all the target analytes in the WQSP groundwater wells.

Techniques were established to compare the current detection monitoring data to data generated during the baseline study. A 95th UTLV or a 95th percentile was determined from those data sets where analytical parameters were measured at concentrations above the reporting limits. A 95th percentile was established for those parameters that were not detected in greater than 15 percent of the samples (less than 15 percent detects for the analyte).

An external outlier test was performed on all the current WIPP facility groundwater monitoring data. In the external test, a newly obtained sample result for a selected groundwater target analyte, such as TDS, is simply compared with the established 10 rounds of baseline (background) data to determine whether the suspected outlier is greater, or less, than the 95th UTLV or 95th percentile.

The groundwater analysis results from year 2010 Round 30 were compared with the baseline water quality statistics to determine whether any measurable or statistically significant changes in water quality have, or are, occurring. The concentrations of the 
Appendix E - Time Trend Plots for Detectable Constituents in Groundwater

Permit-required target analytes in Round 30 were evaluated against the established 95th UTLV or 95th percentile baseline statistic calculated for each monitoring well. Review of the Round 30 chemical analysis data demonstrated that all Permit-required target constituent (volatile and semivolatile organics and trace metal) concentrations were lower than the 95th UTLV or 95th percentile concentrations. All the general chemistry indicator parameter concentrations were lower than the 95th UTLV or 95th percentile concentrations with the following exceptions for anions and TSS:

- $\quad$ WQSP-1 contained a chloride concentration just above the 95th UTLV in the duplicate groundwater samples but not in the primary groundwater sample. The chloride concentration was $40,800 \mathrm{mg} / \mathrm{L}$ compared to the 95th UTLV concentration of $40,472 \mathrm{mg} / \mathrm{L}$. The TSS concentration in the duplicate sample was $35 \mathrm{mg} / \mathrm{L}$, just above the 95th percentile concentration of $33.3 \mathrm{mg} / \mathrm{L}$.

- $\quad$ WQSP-3 contained sulfate concentrations just above the 95th UTLV in both the primary and duplicate sample at $8,070 \mathrm{mg} / \mathrm{L}$ and $8,080 \mathrm{mg} / \mathrm{L}$, respectively, compared to the 95th UTLV concentration of $8,015 \mathrm{mg} / \mathrm{L}$. The TSS concentration in the duplicate sample of $115 \mathrm{mg} / \mathrm{L}$ was just above the 95th percentile concentration of $107 \mathrm{mg} / \mathrm{L}$.

- $\quad$ WQSP-4 contained chloride concentrations of $65,500 \mathrm{mg} / \mathrm{L}$ and 69,000 $\mathrm{mg} / \mathrm{L}$ in the primary and duplicate groundwater samples, respectively, compared to the 95th UTLV concentration of $63,960 \mathrm{mg} / \mathrm{L}$.

Review of the Round 31 chemical analysis data demonstrated that all Permit-required target constituent (volatile and semivolatile organics and metal) concentrations were lower than the 95th UTLV or 95th percentile concentrations. The general chemistry indicator parameter analyses data showed that six (6) of the seven (7) wells contained nine (9) measurements where one or both of the primary and duplicate sample contained a measured concentration of a parameter higher than the 95th UTLV or 95th percentile. Four (4) of the wells involved the concentrations of an anion (95th UTLV) and five (5) of the wells involved a TSS concentration (95th percentile).

- $\quad$ WQSP-1 contained a chloride concentration just above the 95th UTLV in the duplicate groundwater sample but not in the primary groundwater sample. The chloride concentration was $40,800 \mathrm{mg} / \mathrm{L}$ compared to the 95th UTLV concentration of $40,472 \mathrm{mg} / \mathrm{L}$. The TSS concentration in the duplicate sample was $35 \mathrm{mg} / \mathrm{L}$, just above the 95th percentile concentration of $33.3 \mathrm{mg} / \mathrm{L}$.

- $\quad$ WQSP-2 contained a primary sample chloride concentration of 39,900 $\mathrm{mg} / \mathrm{L}$, just above the 95th UTLV concentration of $39,670 \mathrm{mg} / \mathrm{L}$. The duplicate sample concentration was lower than the 95th UTLV.

- $\quad$ WQSP-3 contained a sulfate concentration of $8,160 \mathrm{mg} / \mathrm{L}$ in the primary sample, just above the 95th UTLV concentration of $8,015 \mathrm{mg} / \mathrm{L}$. The 
Appendix E - Time Trend Plots for Detectable Constituents in Groundwater

duplicate sample concentration was lower than the 95th UTLV. The duplicate sample contained a TSS concentration of $124 \mathrm{mg} / \mathrm{L}$, which is higher than the 95th percentile concentration of $107 \mathrm{mg} / \mathrm{L}$.

- $\quad$ WQSP-4 contained sulfate concentrations of $8,080 \mathrm{mg} / \mathrm{L}$ and $7,970 \mathrm{mg} / \mathrm{L}$ in the primary and duplicate groundwater samples, respectively, compared to the 95th UTLV concentration of $7,927 \mathrm{mg} / \mathrm{L}$. The TSS concentration of $65 \mathrm{mg} / \mathrm{L}$ in the primary sample and $80 \mathrm{mg} / \mathrm{L}$ in the duplicate sample were both higher than the 95th percentile concentration of $57.0 \mathrm{mg} / \mathrm{L}$.

- $\quad$ WQSP-5 contained TSS concentrations of $33 \mathrm{mg} / \mathrm{L}$ in the primary sample and $18 \mathrm{mg} / \mathrm{L}$ in the duplicate sample, both of which were higher than the 95th percentile concentration of $<10 \mathrm{mg} / \mathrm{L}$.

- $\quad$ WQSP-6 contained a TSS concentration of $17 \mathrm{mg} / \mathrm{L}$ in the duplicate sample, which was higher than the 95th percentile concentration of 14.8 $\mathrm{mg} / \mathrm{L}$. (The primary sample concentration was lower than the 95th percentile.)

Evaluation of the chemical analysis data for the hazardous waste constituents and general chemistry indicator parameters indicates that is no evidence of any external contamination in any of the groundwater samples.

\section{WQSP-1 Calcium, Dissolved}

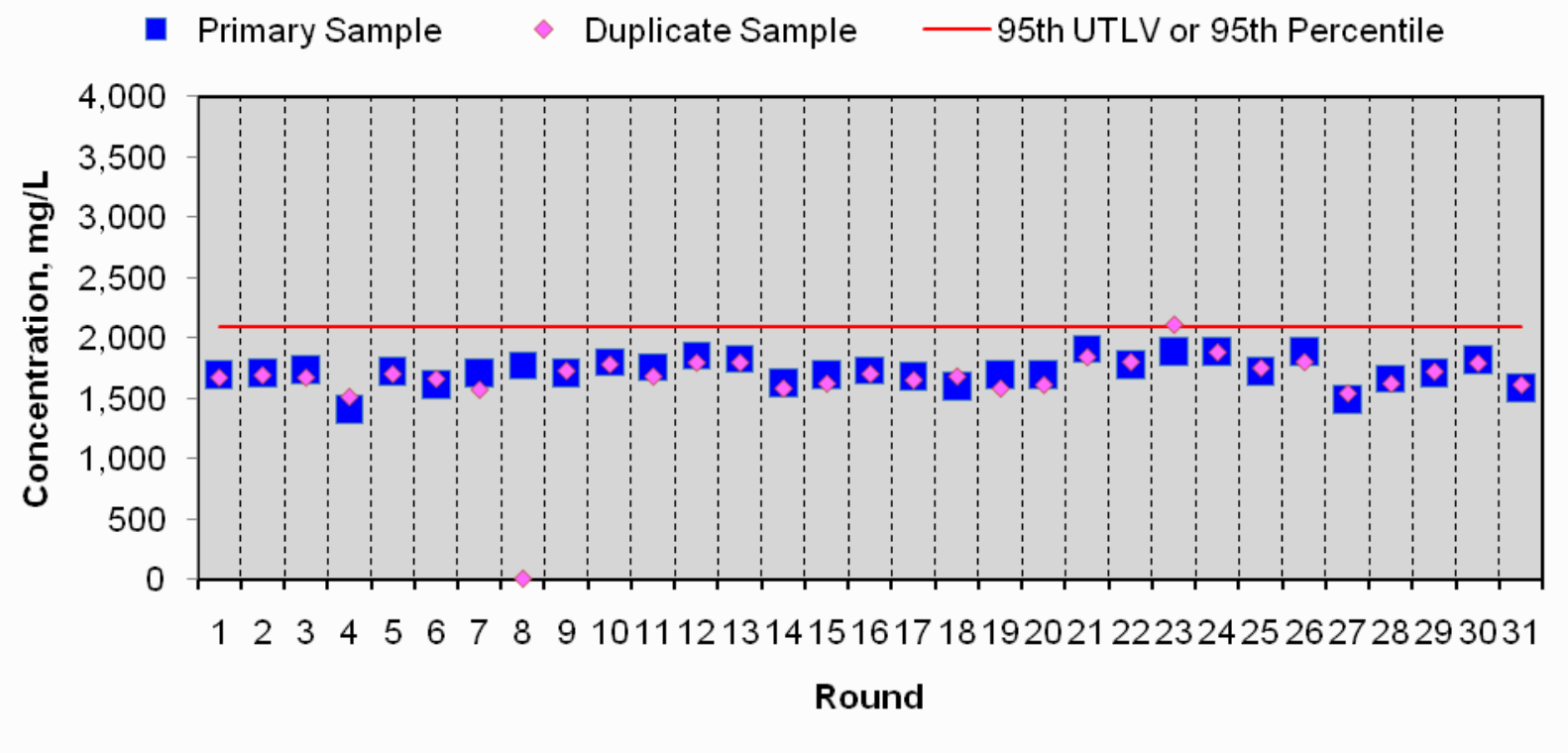


Waste Isolation Pilot Plant Annual Site Environmental Report for 2010 DOE/WIPP-11-2225

Appendix E - Time Trend Plots for Detectable Constituents in Groundwater

\section{WQSP-1 Chloride}

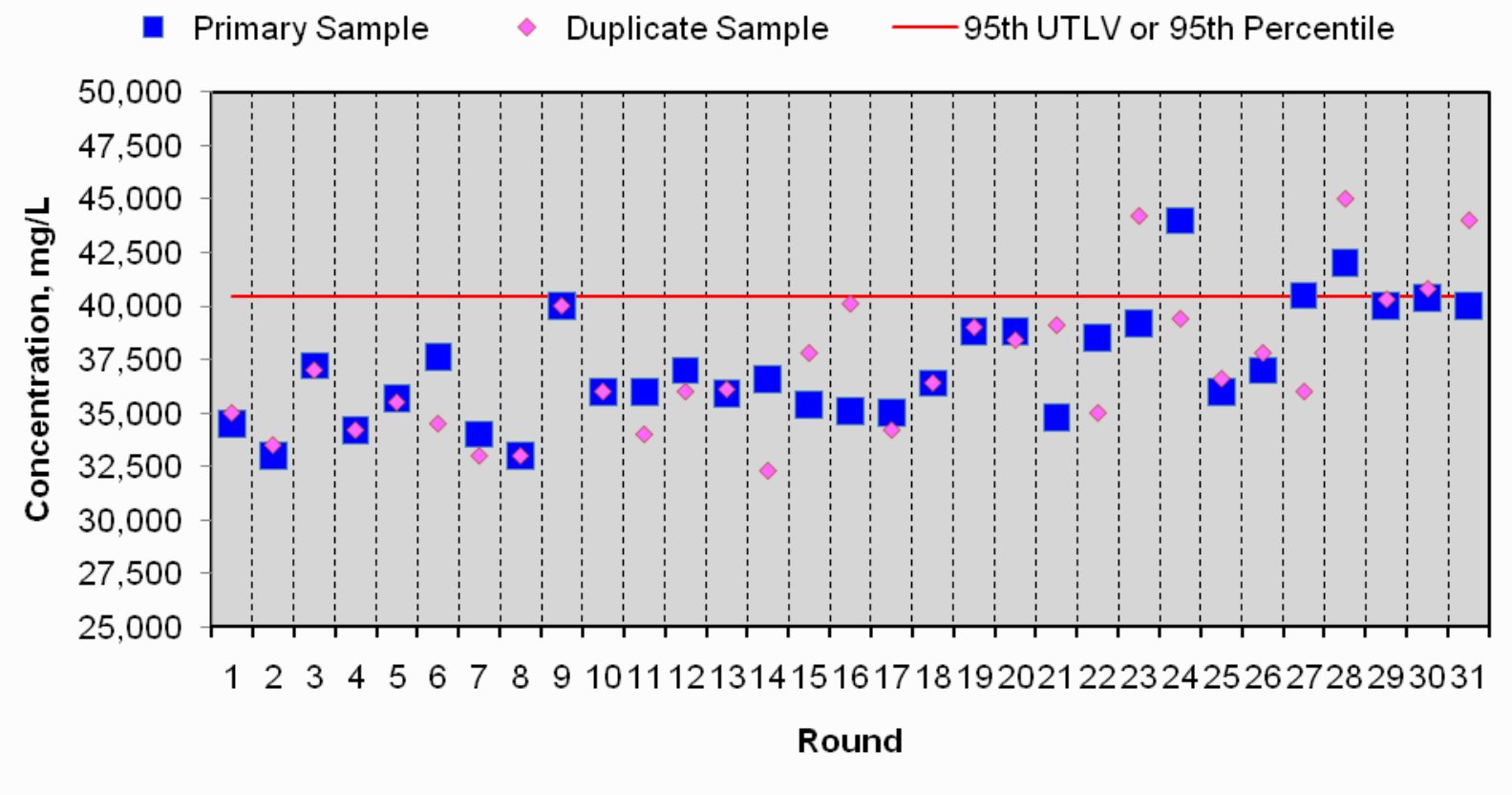

\section{WQSP-1 Magnesium, Dissolved}

Primary Sample $\quad$ Duplicate Sample — 95th UTLV or 95th Percentile

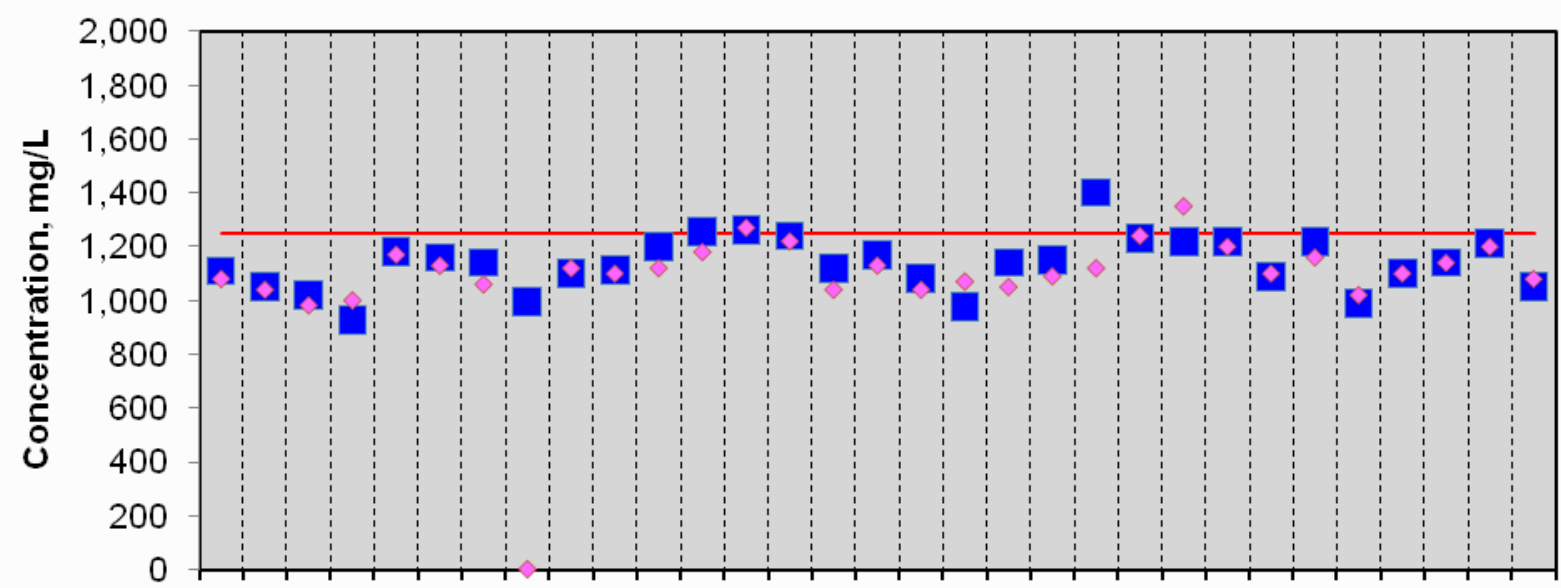

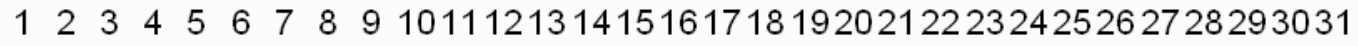

Round 
Waste Isolation Pilot Plant Annual Site Environmental Report for 2010 DOE/WIPP-11-2225

Appendix E - Time Trend Plots for Detectable Constituents in Groundwater

\section{WQSP-1 pH}

Primary Sample $\quad$ Duplicate Sample —Lower Limit —upper Limit

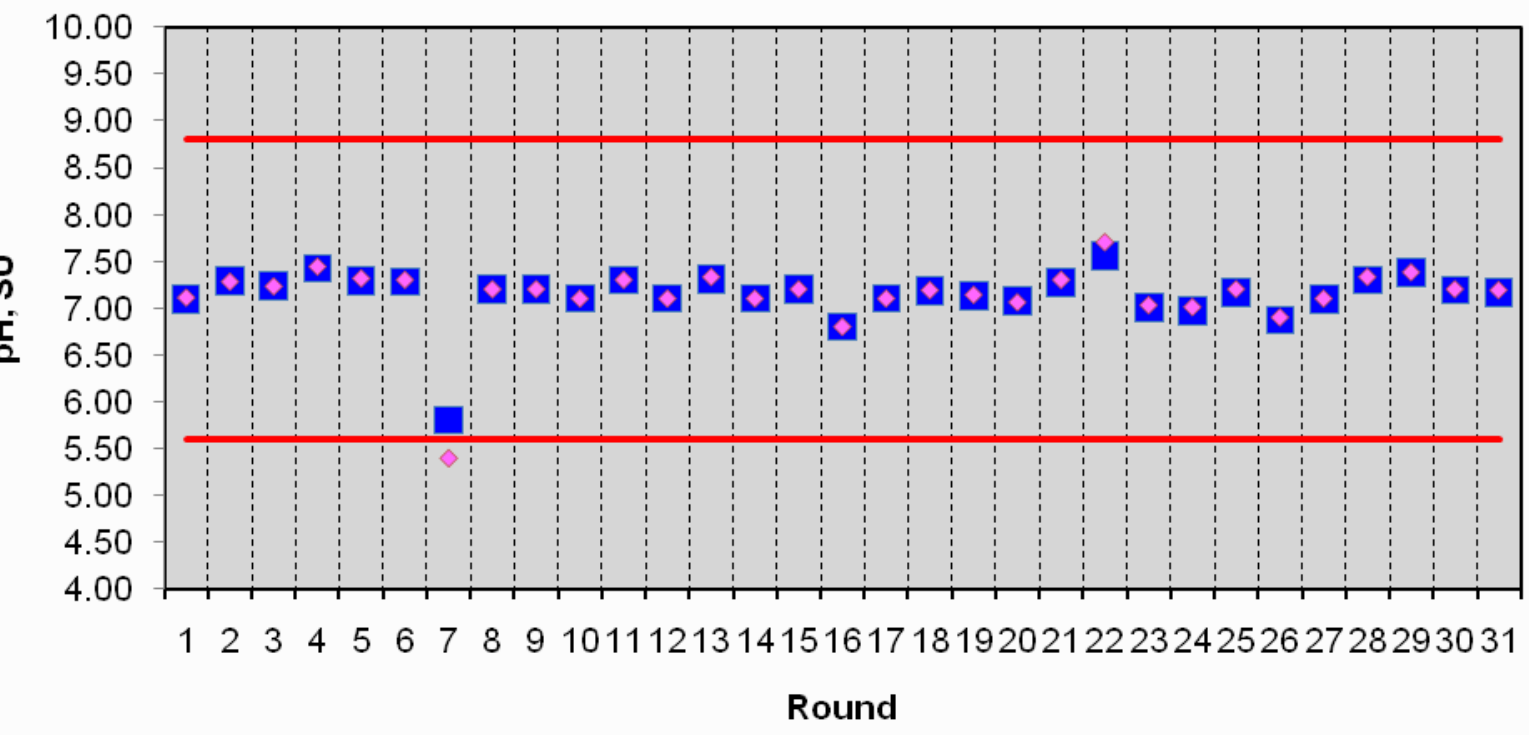

\section{WQSP-1 Potassium, Dissolved}

Primary Sample $\quad \diamond$ Duplicate Sample — 95th UTLV or 95th Percentile

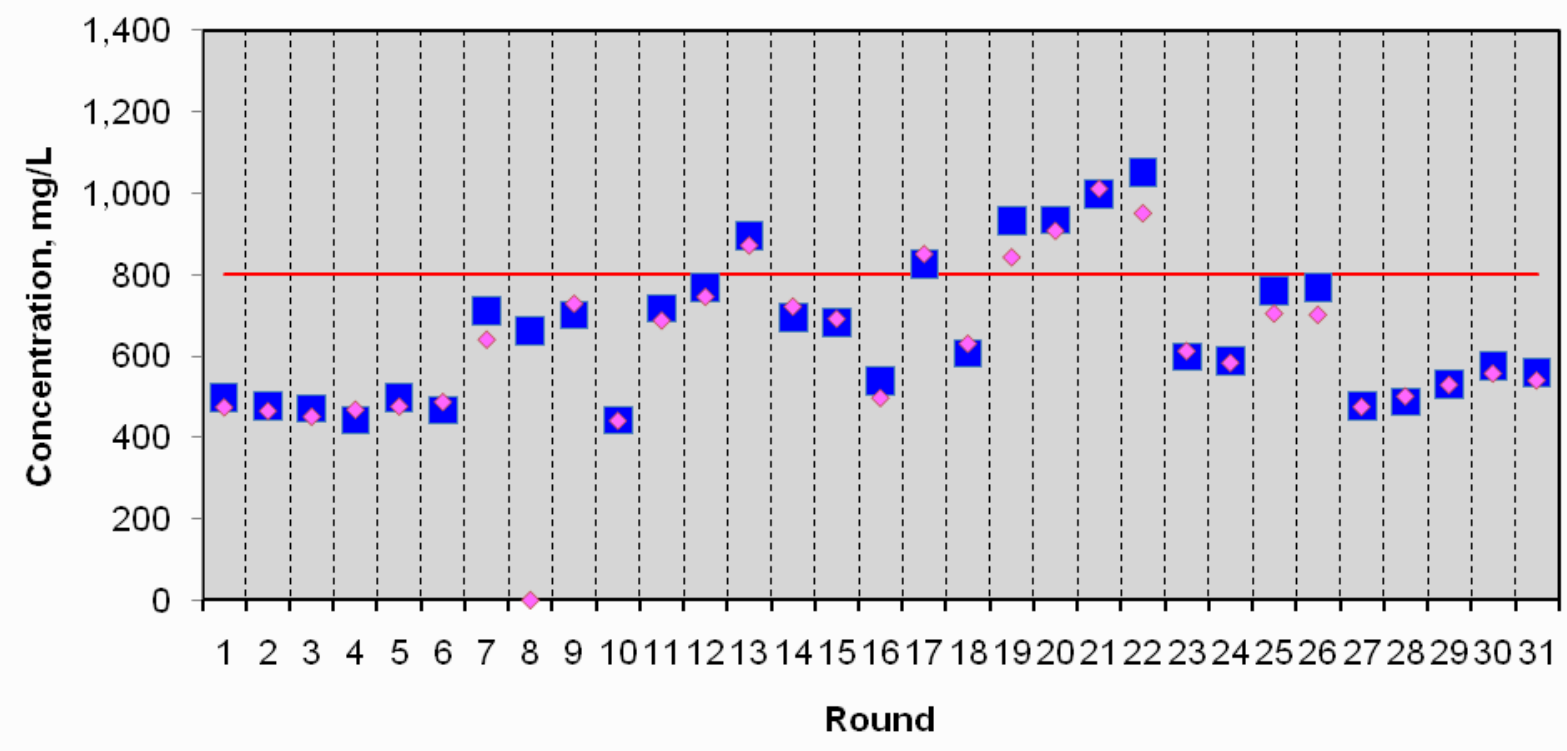


Waste Isolation Pilot Plant Annual Site Environmental Report for 2010 DOE/WIPP-11-2225

Appendix E - Time Trend Plots for Detectable Constituents in Groundwater

\section{WQSP-1 Sulfate}

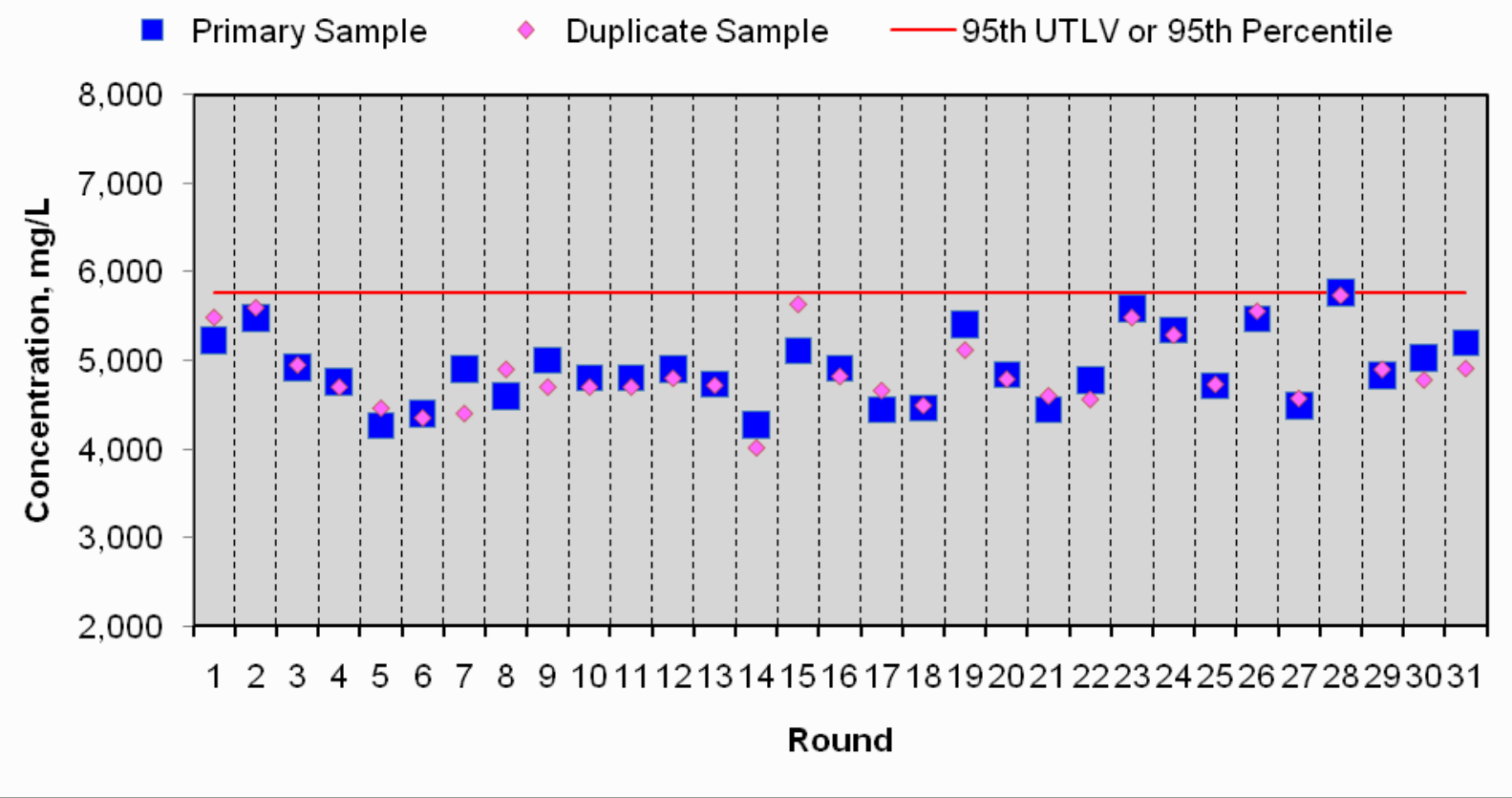

\section{WQSP-1 Total Dissolved Solids}

- Primary Sample $\quad$ Duplicate Sample — 95th UTLV or 95th Percentile

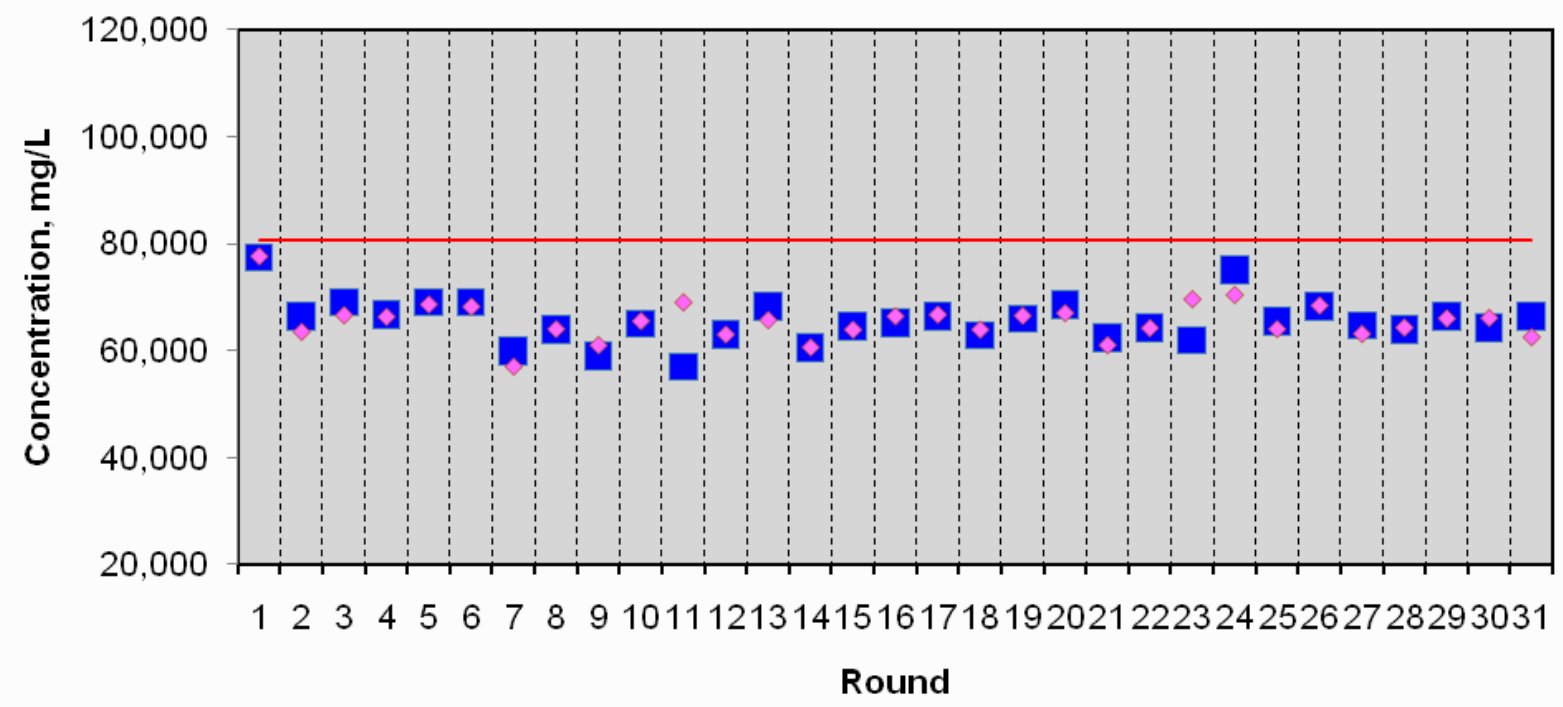


Waste Isolation Pilot Plant Annual Site Environmental Report for 2010 DOE/WIPP-11-2225

Appendix E - Time Trend Plots for Detectable Constituents in Groundwater

\section{WQSP-2 Calcium, Dissolved}

Primary Sample $\quad$ Duplicate Sample — $\quad$ 95th UTLV or 95th Percentile

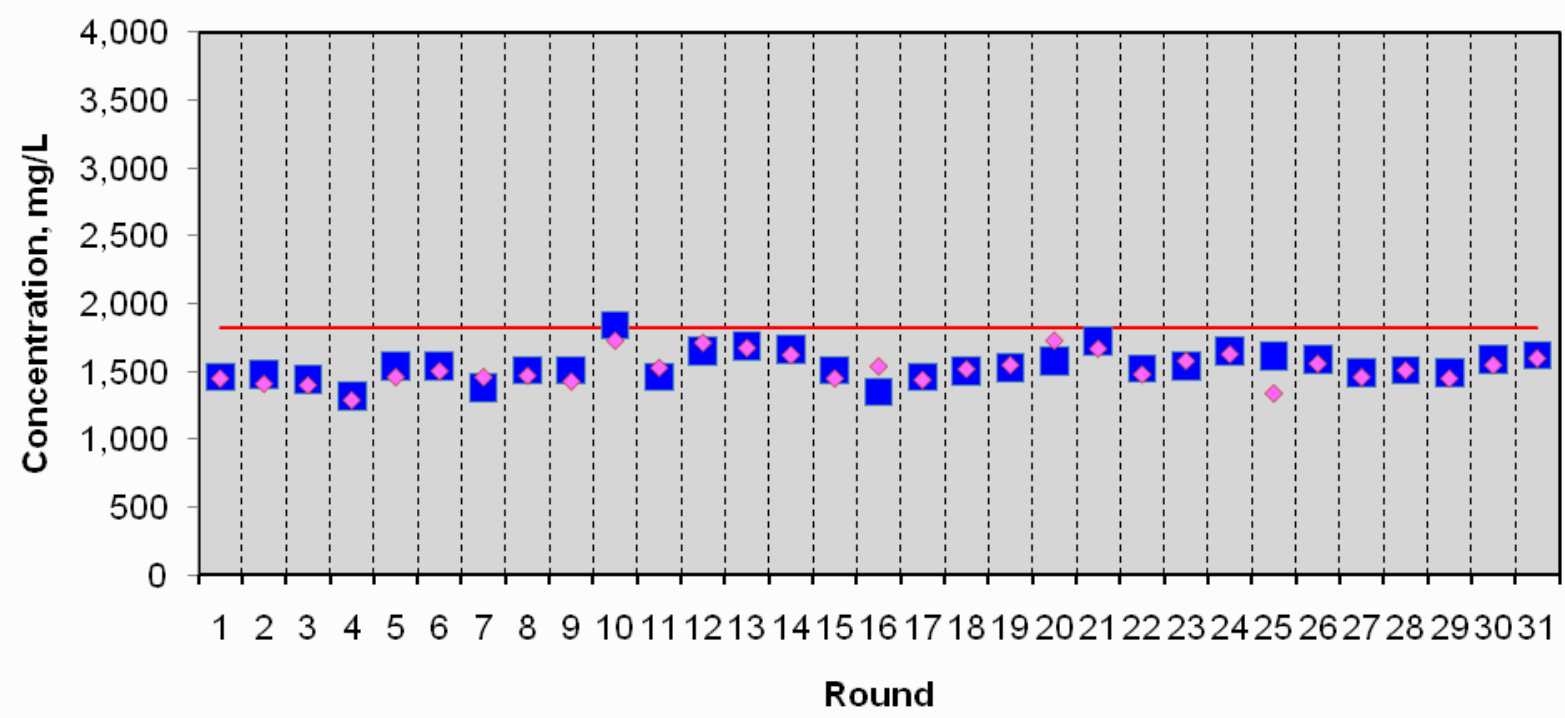

WQSP-2 Chloride

Primary Sample $\quad$ Duplicate Sample — 95th UTLV or 95th Percentile

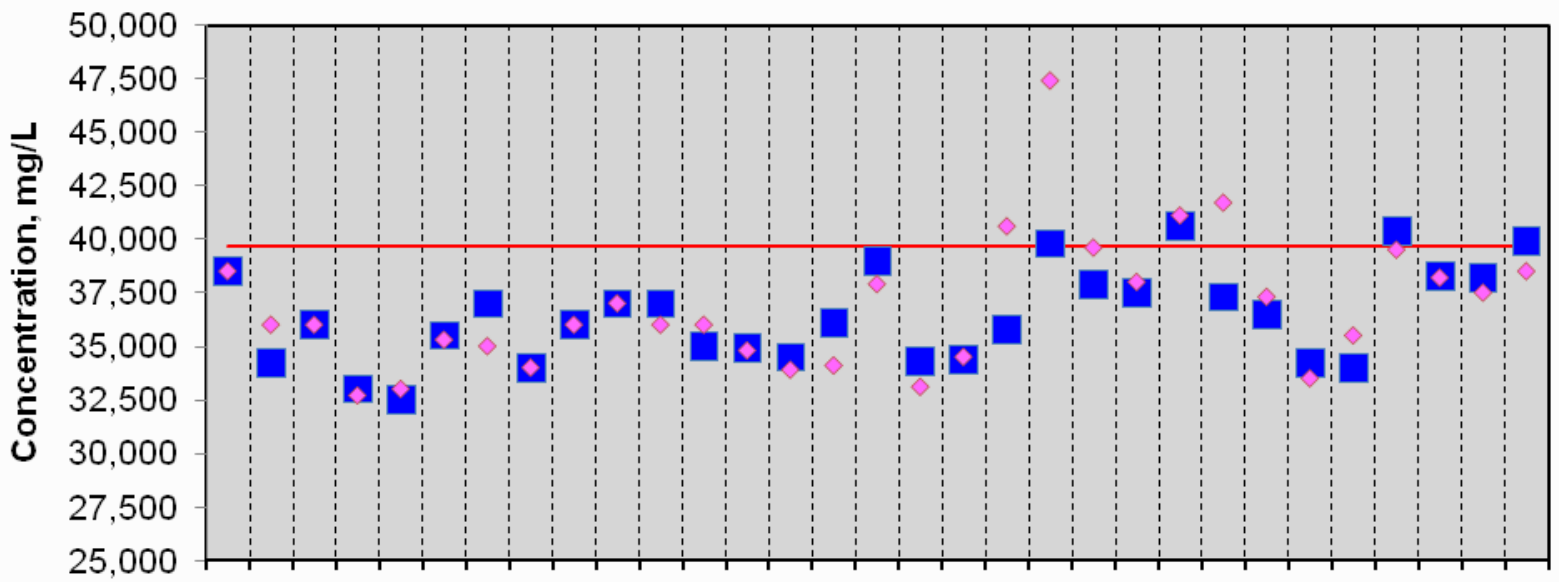

$1223 \begin{array}{llllllll}4 & 5 & 6 & 7 & 8 & 9 & 10111213141516171819202122232425262728293031\end{array}$

Round 
Waste Isolation Pilot Plant Annual Site Environmental Report for 2010 DOE/WIPP-11-2225

Appendix E - Time Trend Plots for Detectable Constituents in Groundwater

\section{WQSP-2 Magnesium, Dissolved}

Primary Sample $\quad$ Duplicate Sample — $\quad$ 95th UTLV or 95th Percentile

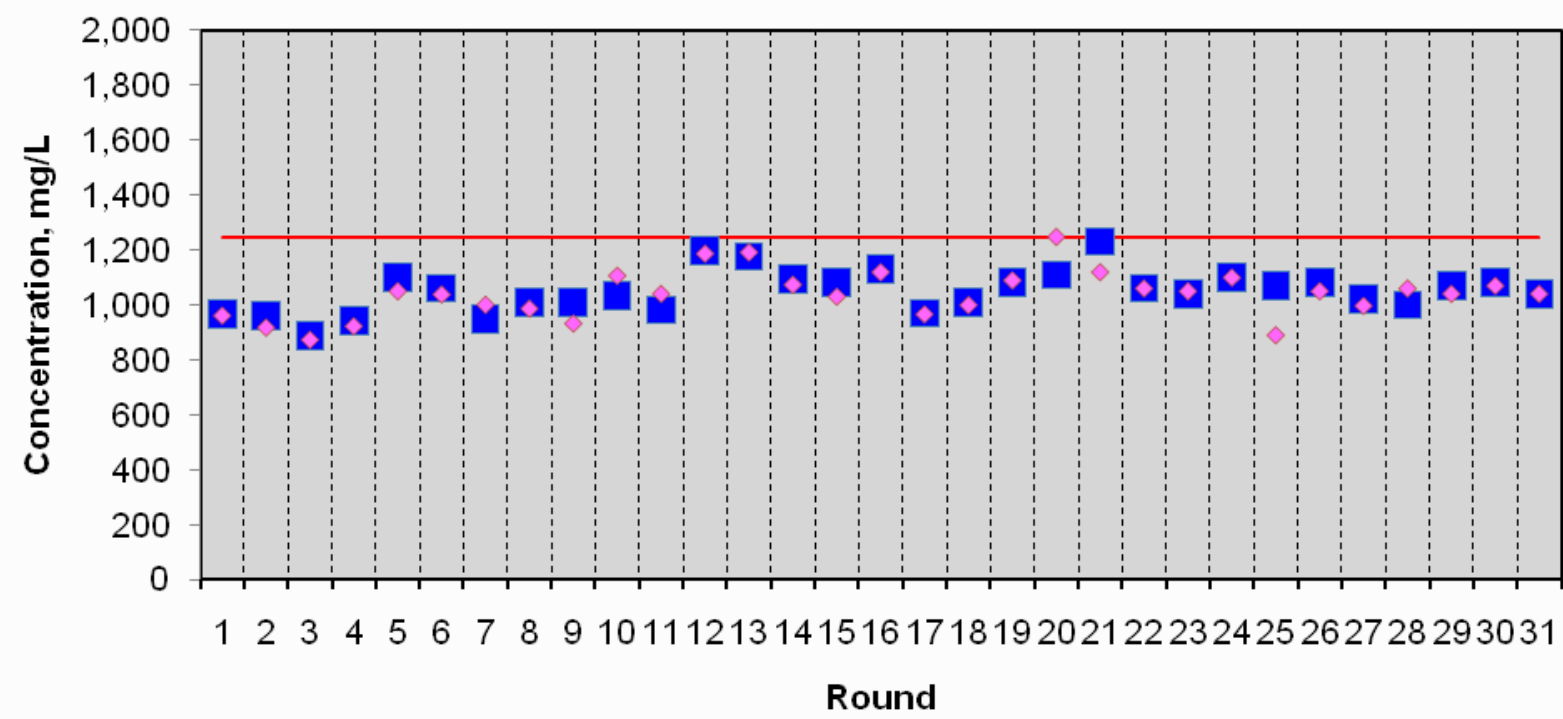

\section{WQSP-2 pH}

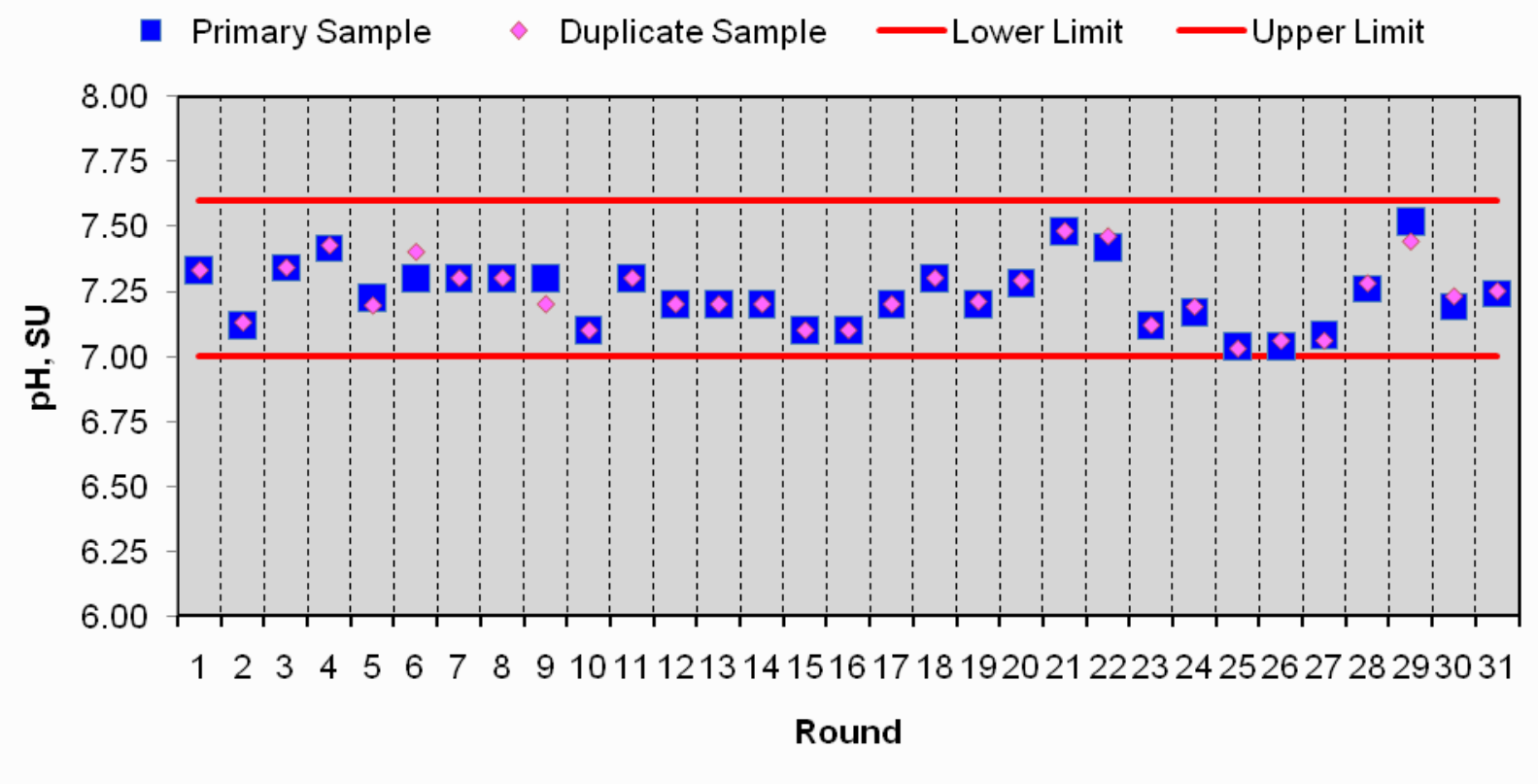


Waste Isolation Pilot Plant Annual Site Environmental Report for 2010 DOE/WIPP-11-2225

Appendix E - Time Trend Plots for Detectable Constituents in Groundwater

\section{WQSP-2 Potassium, Dissolved}

Primary Sample $\quad$ Duplicate Sample — $\quad$ 95th UTLV or 95th Percentile

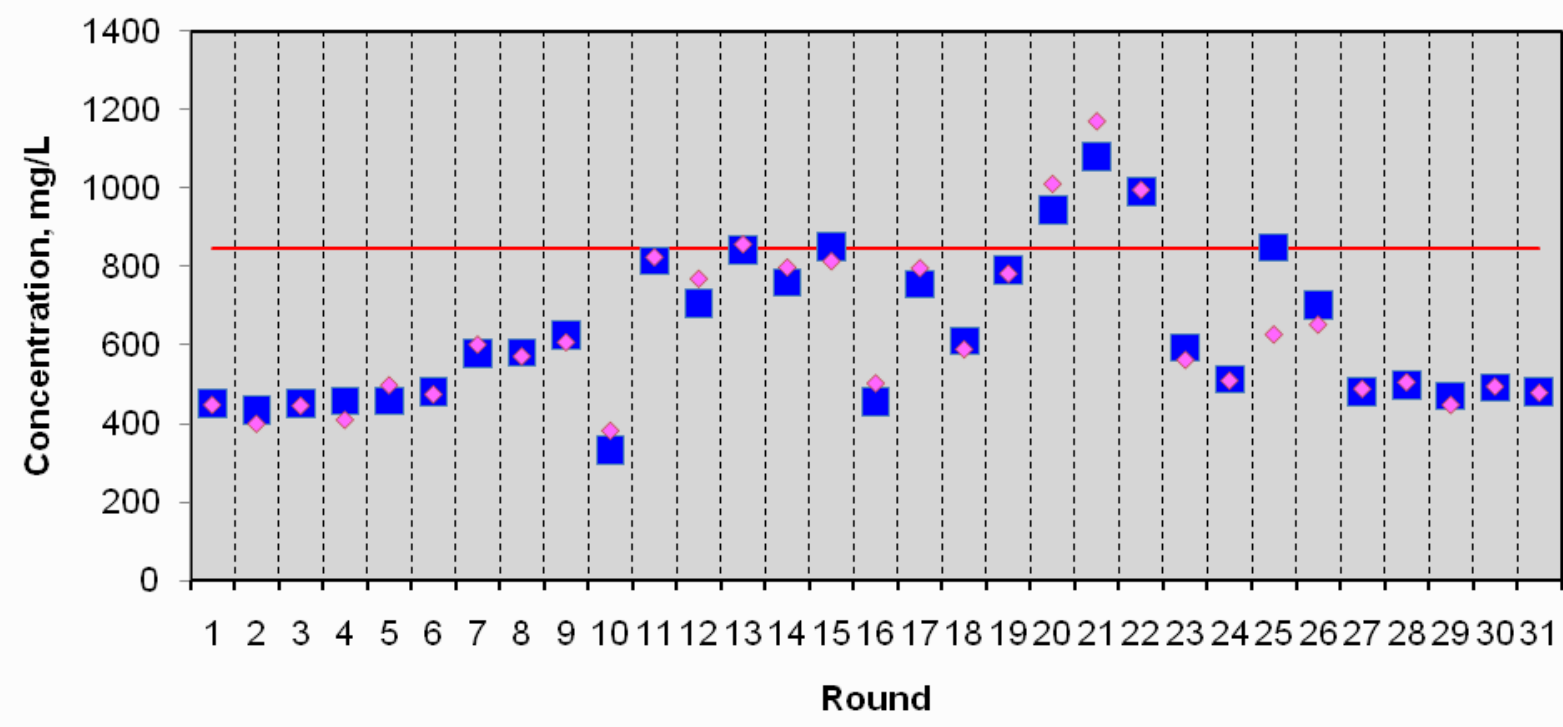

\section{WQSP-2 Sulfate}

Primary Sample $\quad$ Duplicate Sample — 95th UTLV or 95th Percentile

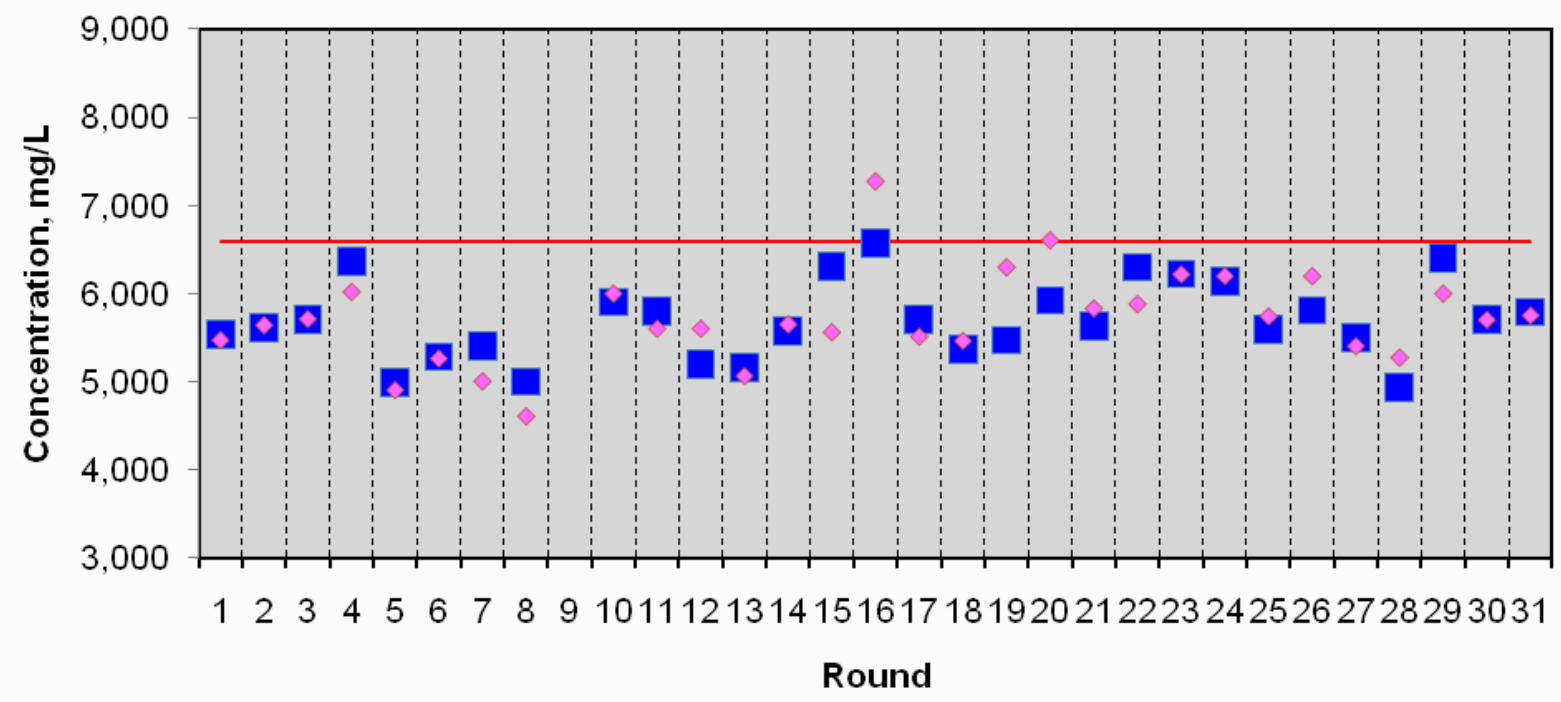


Waste Isolation Pilot Plant Annual Site Environmental Report for 2010 DOE/WIPP-11-2225

Appendix E - Time Trend Plots for Detectable Constituents in Groundwater

\section{WQSP-2 Total Dissolved Solids}

Primary Sample $\quad \forall$ Duplicate Sample — 95th UTLV or 95th Percentile

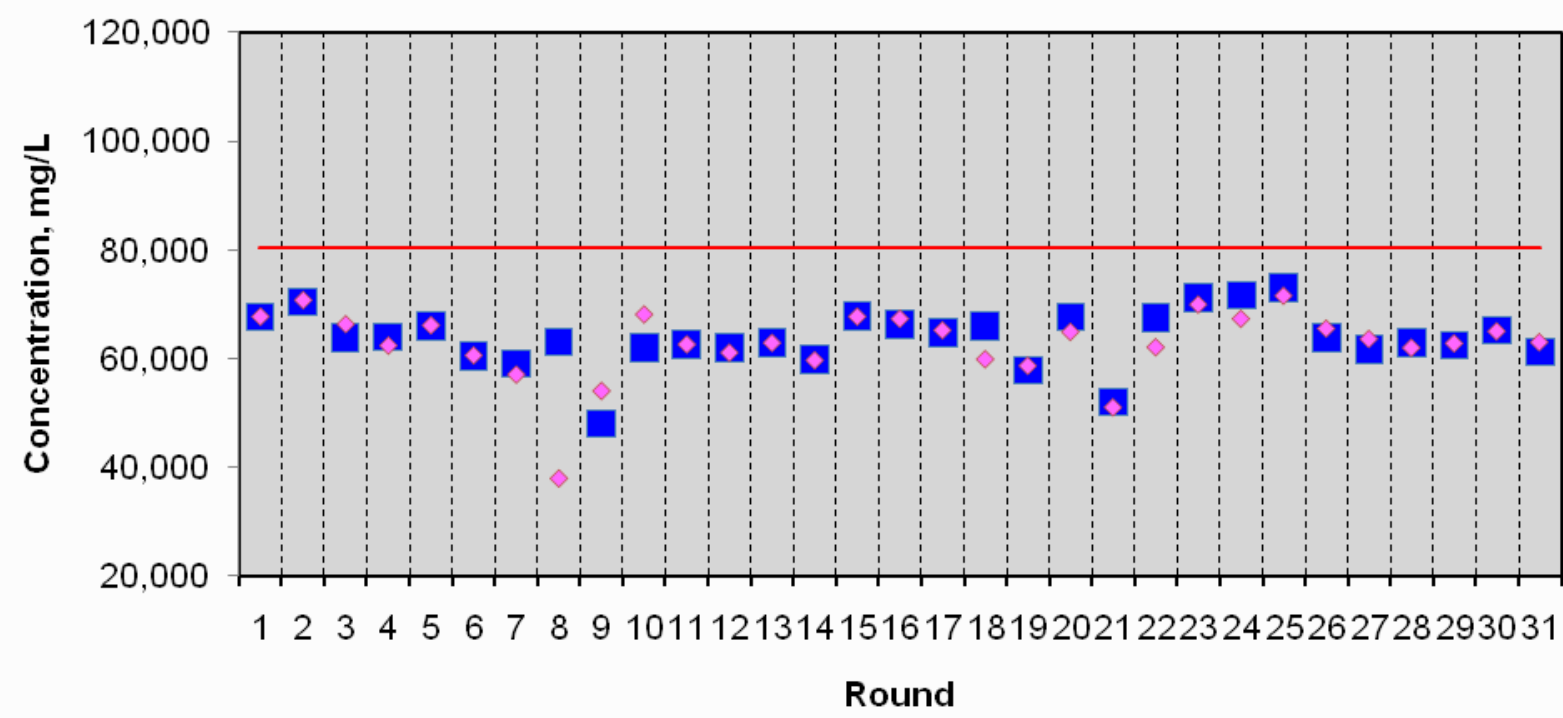

\section{WQSP-3 Calcium, Dissolved}

Primary Sample $\quad$ Duplicate Sample — 95th UTLV or 95th Percentile

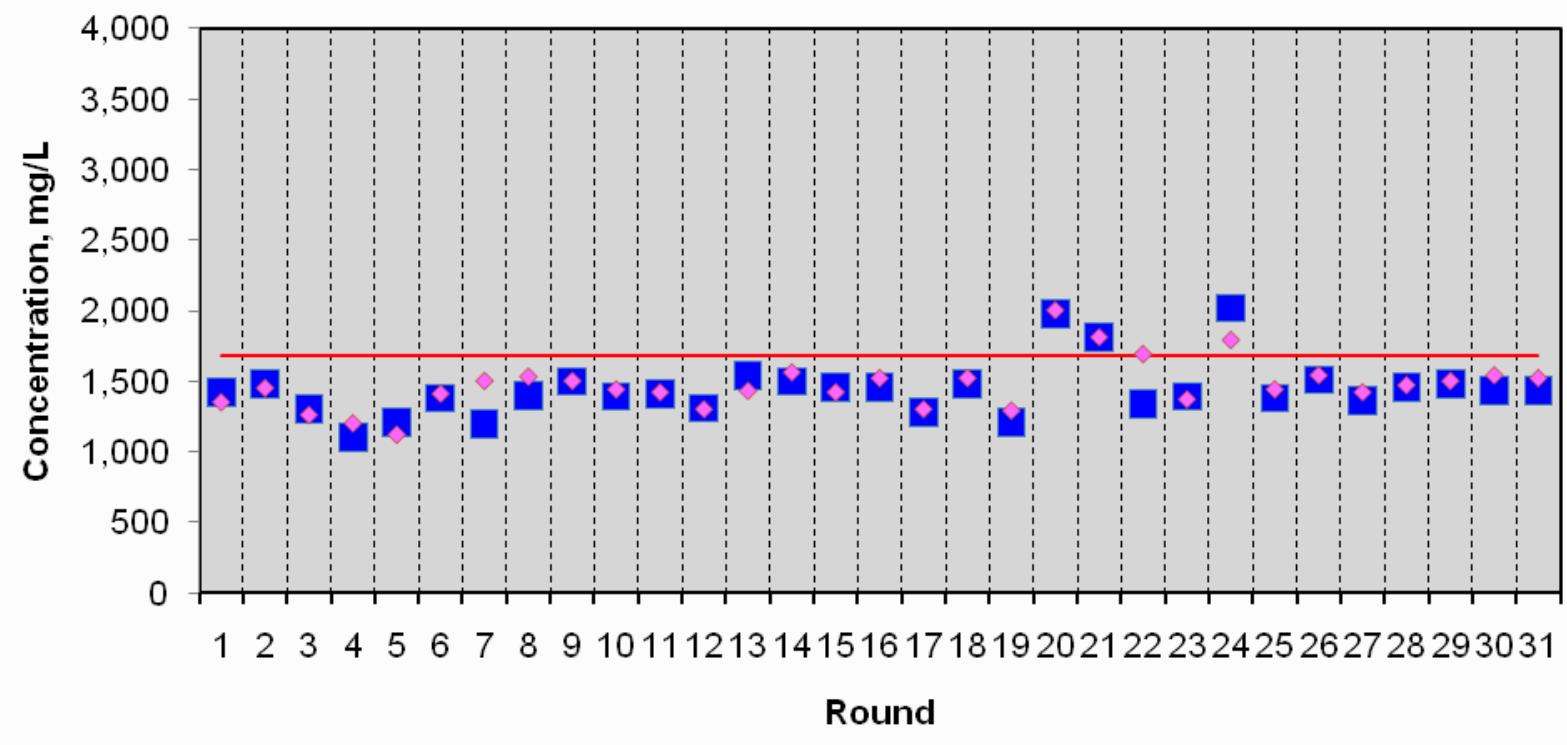


Waste Isolation Pilot Plant Annual Site Environmental Report for 2010 DOE/WIPP-11-2225

Appendix E - Time Trend Plots for Detectable Constituents in Groundwater

\section{WQSP-3 Chloride}

Primary Sample $\quad \forall$ Duplicate Sample — 95th UTLV or 95th Percentile

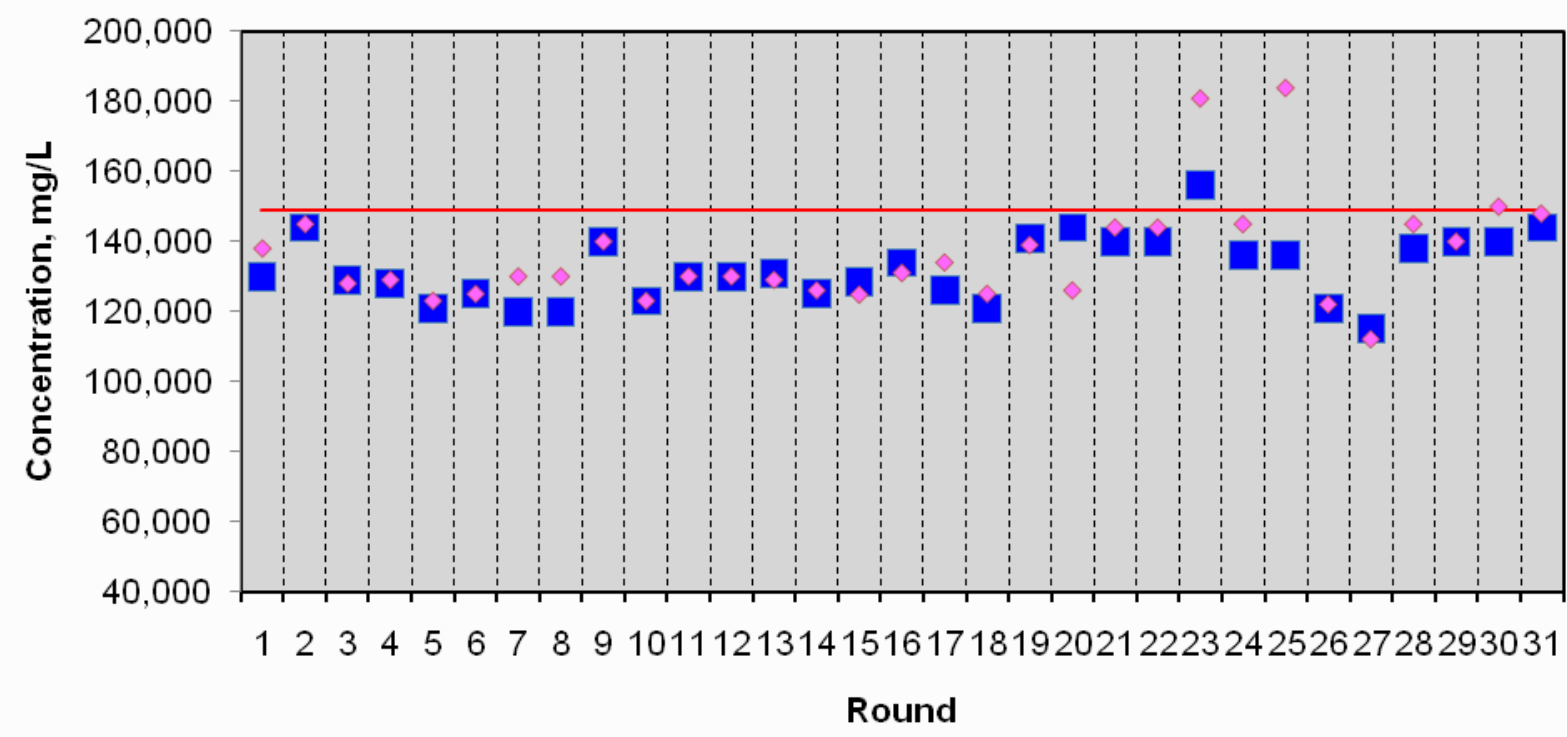

WQSP-3 Magnesium, Dissolved

Primary Sample $\quad$ Duplicate Sample — 95th UTLV or 95th Percentile

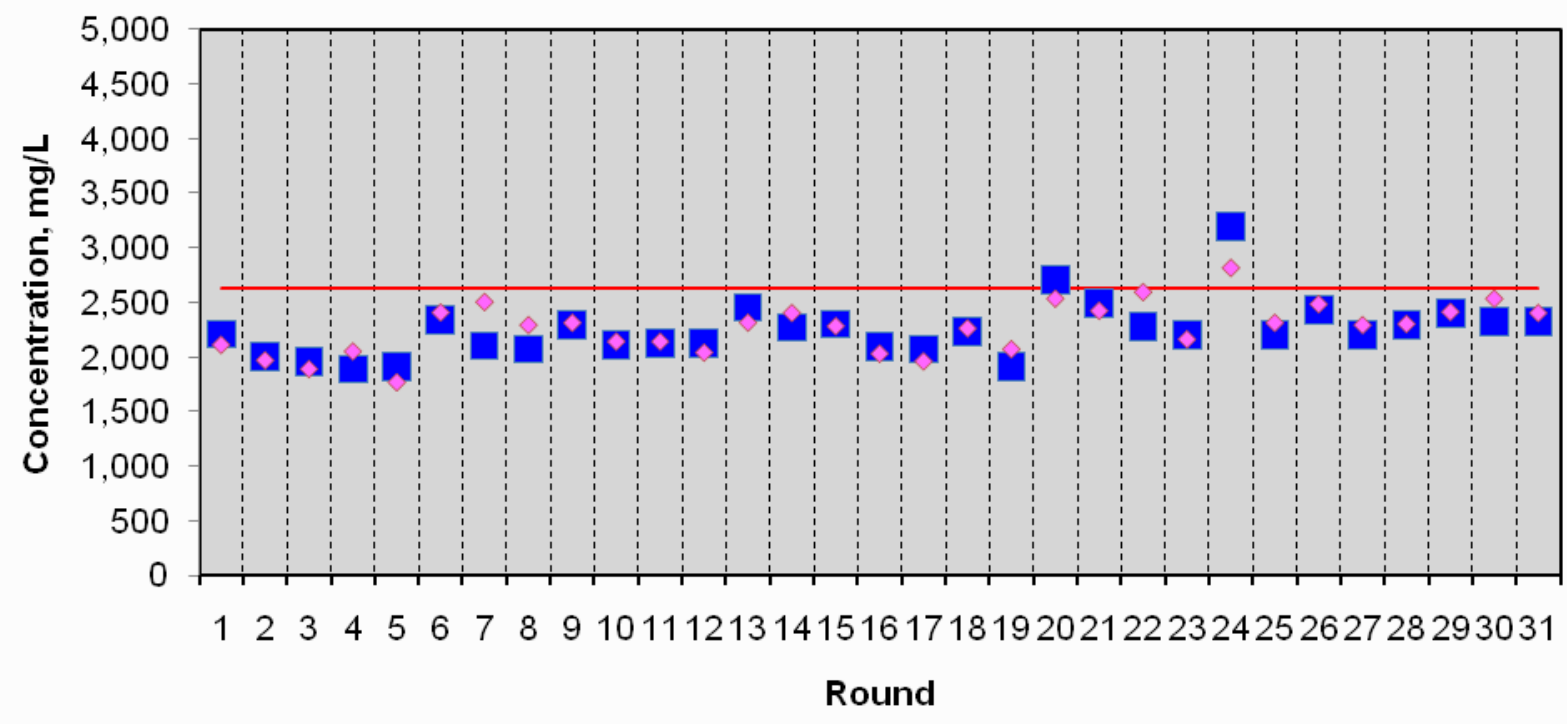


Waste Isolation Pilot Plant Annual Site Environmental Report for 2010 DOE/WIPP-11-2225

Appendix E - Time Trend Plots for Detectable Constituents in Groundwater

\section{WQSP-3 pH}

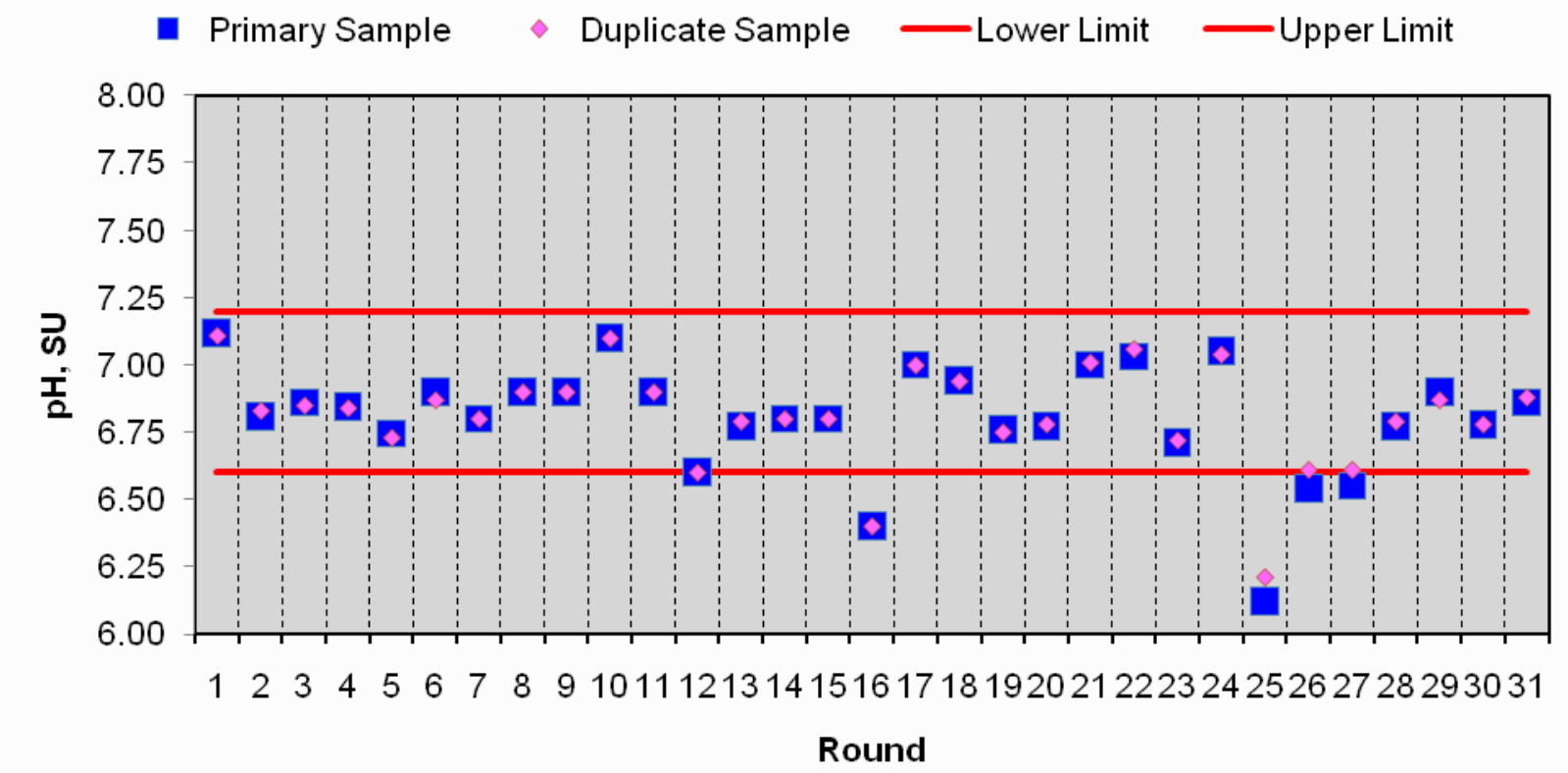

\section{WQSP-3 Potassium, Dissolved}

Primary Sample $\quad$ Duplicate Sample — 95th UTLV or 95th Percentile

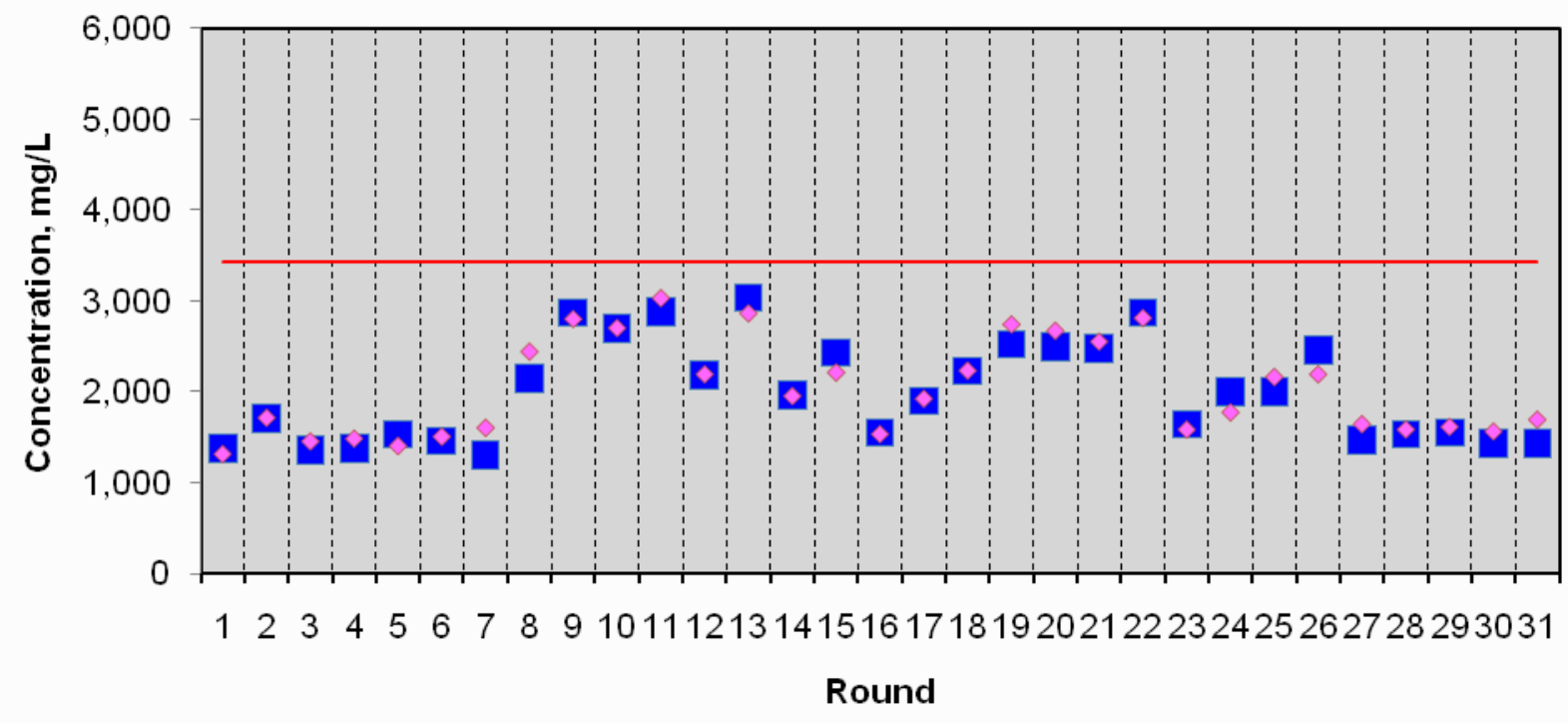


Waste Isolation Pilot Plant Annual Site Environmental Report for 2010 DOE/WIPP-11-2225

Appendix E - Time Trend Plots for Detectable Constituents in Groundwater

\section{WQSP-3 Sulfate}

Primary Sample $\quad$ Duplicate Sample — $\quad$ 95th UTLV or 95th Percentile

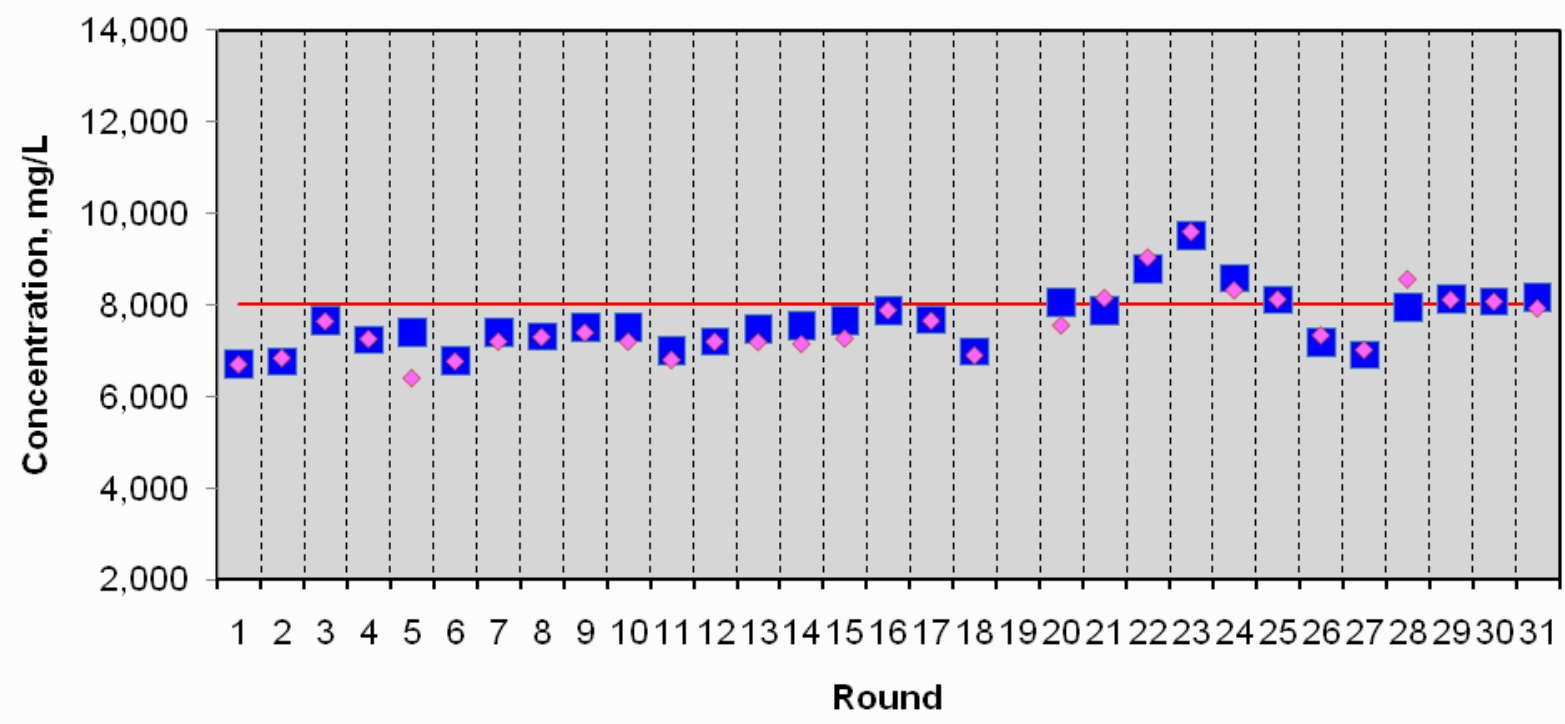

WQSP-3 Total Dissolved Solids

Primary Sample $\quad$ Duplicate Sample — 95th UTLV or 95th Percentile

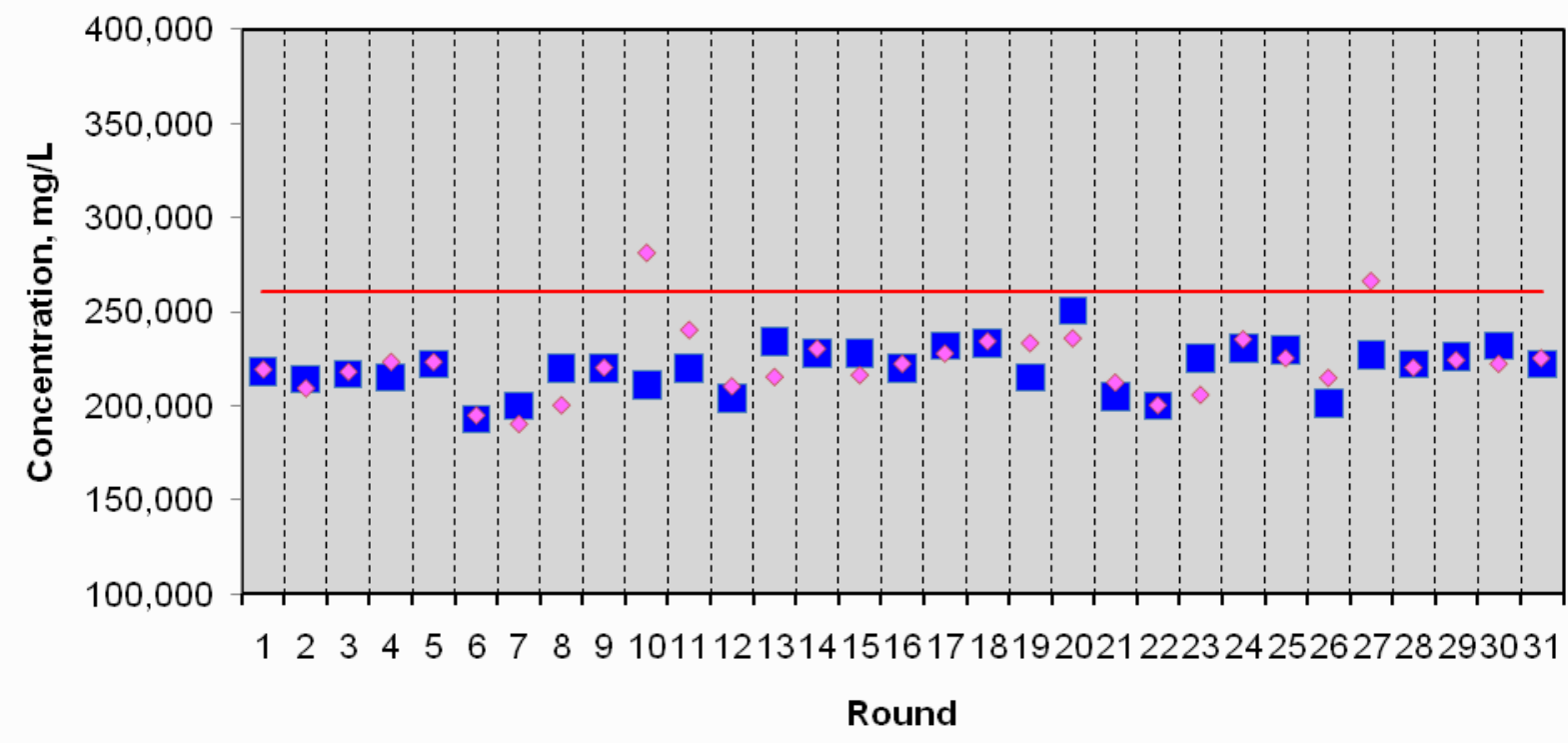


Waste Isolation Pilot Plant Annual Site Environmental Report for 2010 DOE/WIPP-11-2225

Appendix E - Time Trend Plots for Detectable Constituents in Groundwater

\section{WQSP-4 Calcium, Dissolved}

Primary Sample $\quad \Delta$ Duplicate Sample — 95th UTLV or 95th Percentile

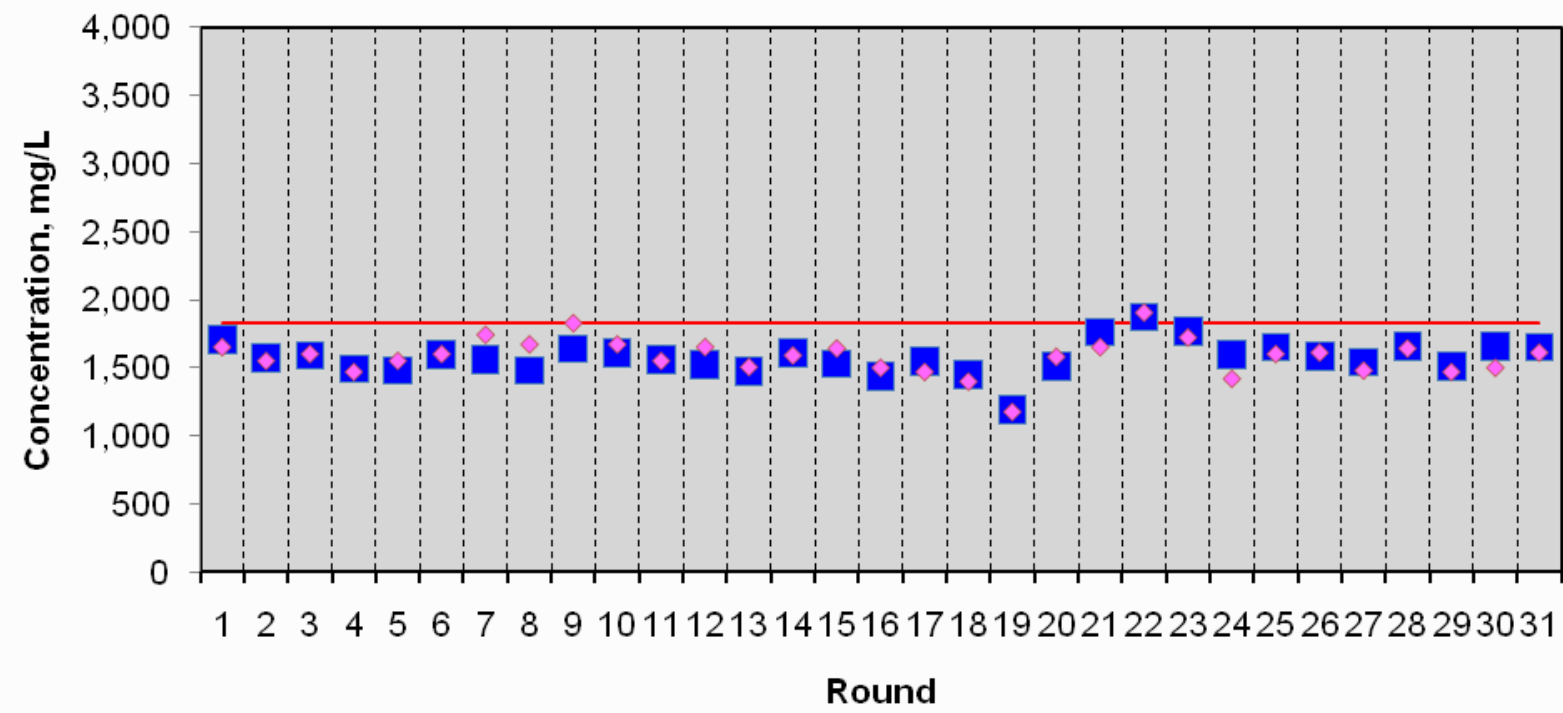

\section{WQSP-4 Chloride}

Primary Sample $\quad \Delta$ Duplicate Sample — 95th UTLV or 95th Percentile

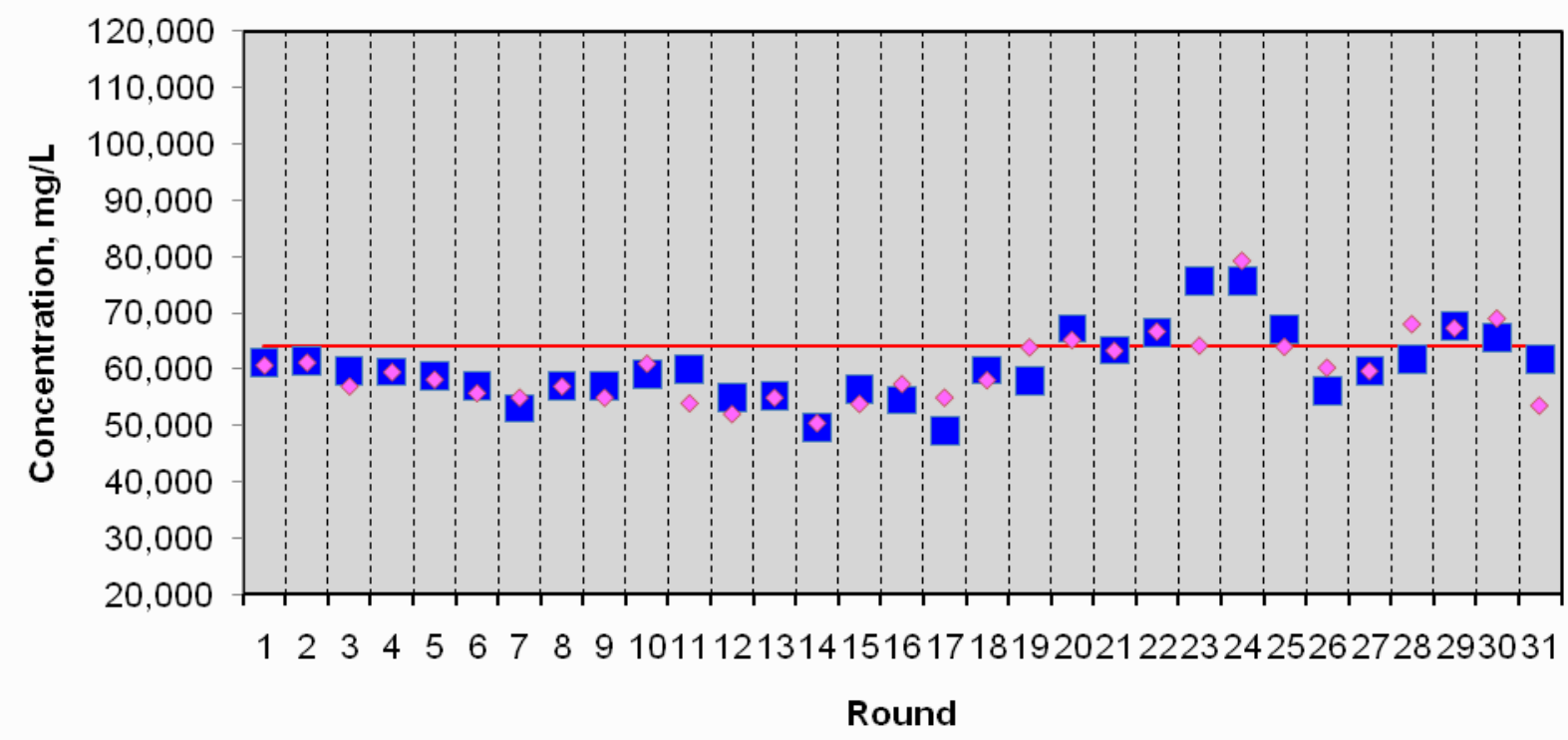


Waste Isolation Pilot Plant Annual Site Environmental Report for 2010 DOE/WIPP-11-2225

Appendix E - Time Trend Plots for Detectable Constituents in Groundwater

\section{WQSP-4 Magnesium, Dissolved}

Primary Sample $\quad$ Duplicate Sample — 95th UTLV or 95th Percentile

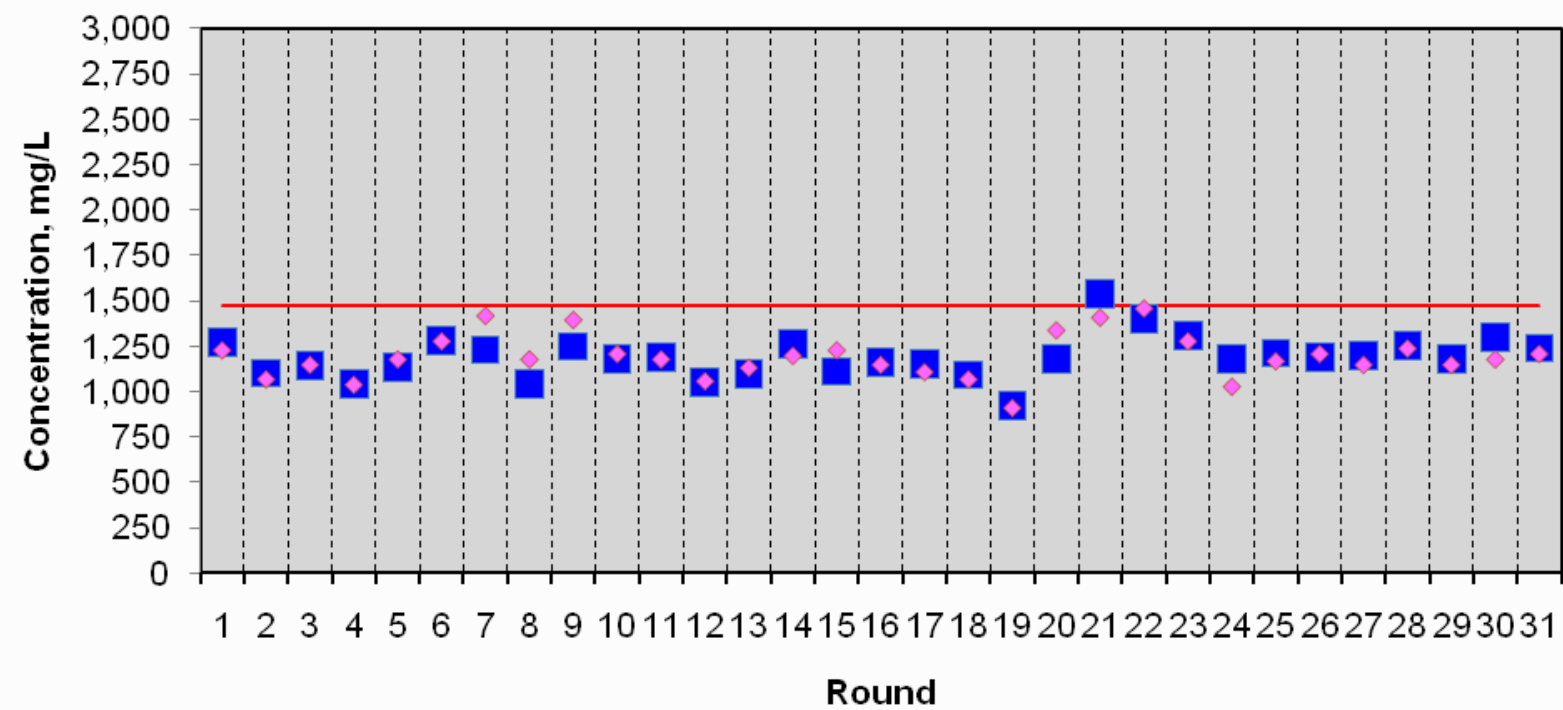

WQSP-4 $\mathrm{pH}$

Primary Sample $\quad$ Duplicate Sample $\quad$ Lower Limit -Upper Limit

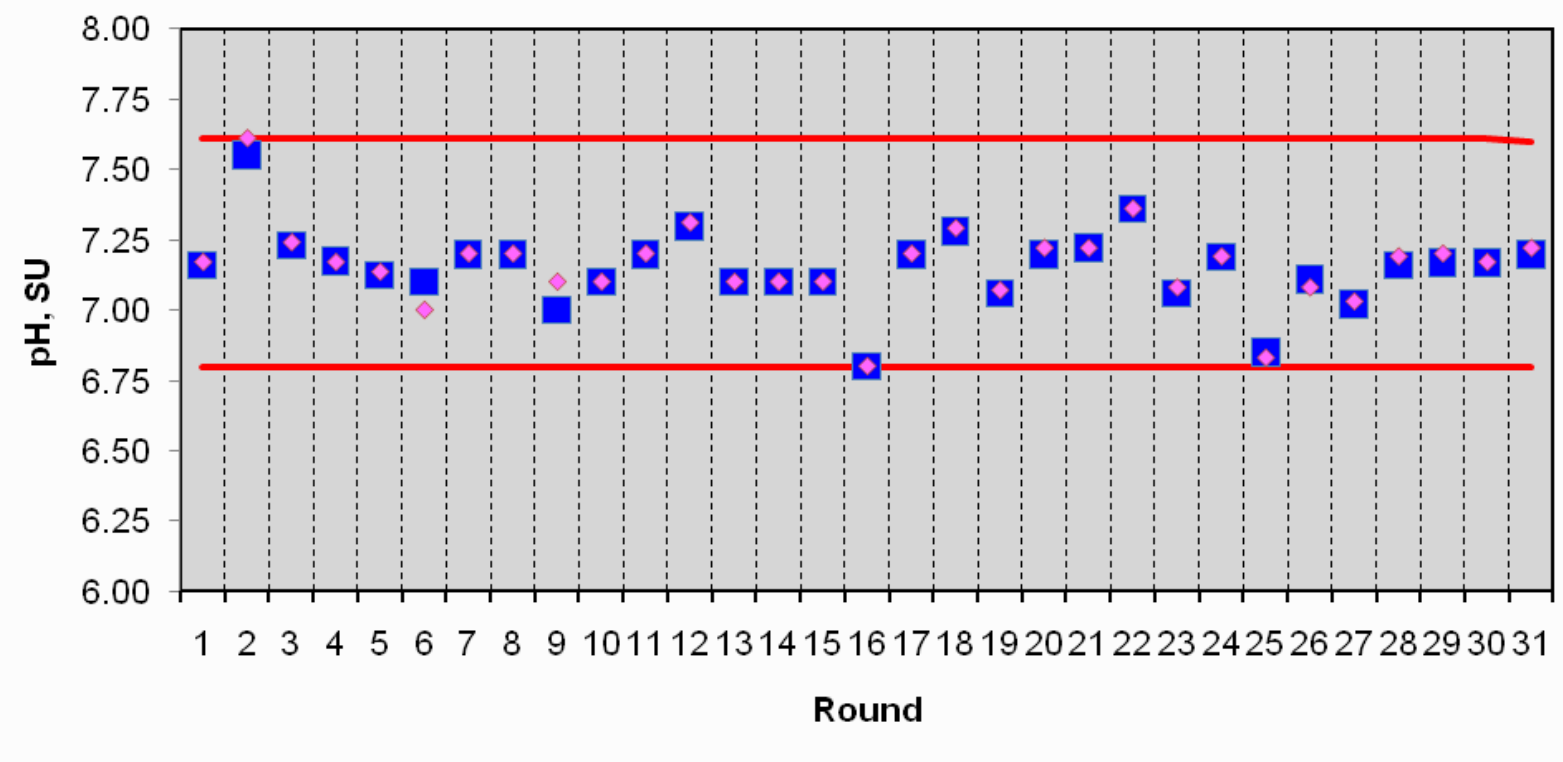


Waste Isolation Pilot Plant Annual Site Environmental Report for 2010 DOE/WIPP-11-2225

Appendix E - Time Trend Plots for Detectable Constituents in Groundwater

\section{WQSP-4 Potassium, Dissolved}

Primary Sample $\quad$ Duplicate Sample — 95th UTLV or 95th Percentile

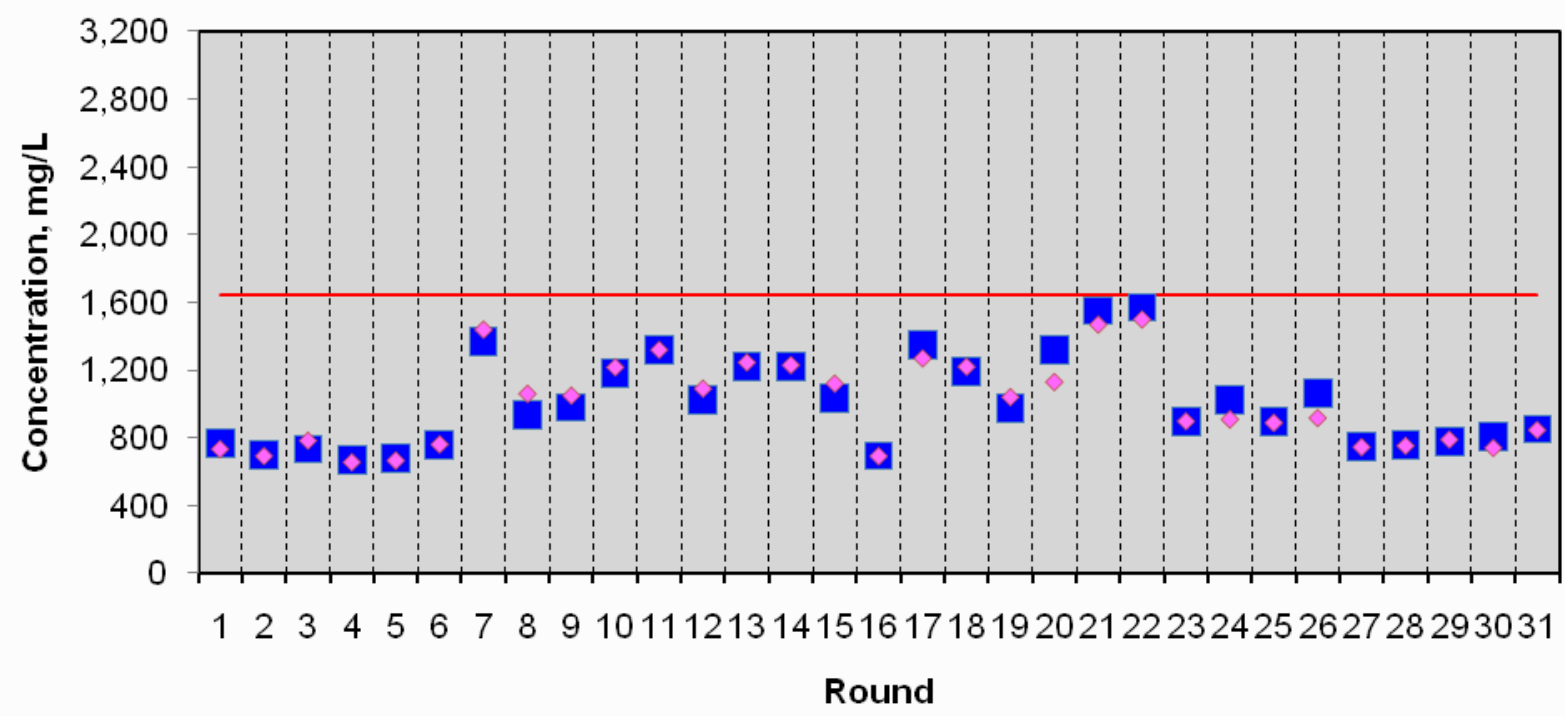

WQSP-4 Sulfate

Primary Sample $\quad$ Duplicate Sample — $\quad$ 95th UTLV or 95th Percentile

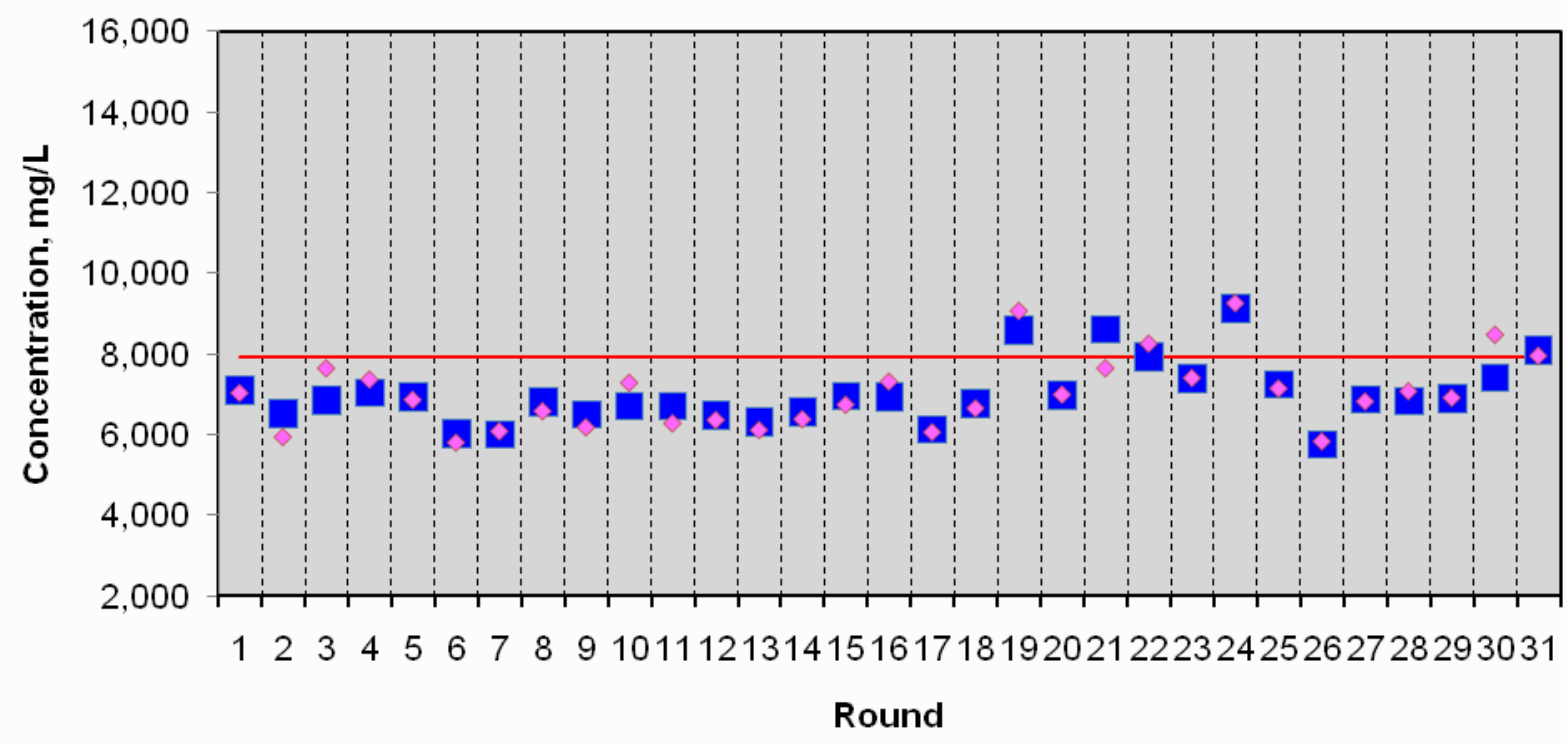


Waste Isolation Pilot Plant Annual Site Environmental Report for 2010 DOE/WIPP-11-2225

Appendix E - Time Trend Plots for Detectable Constituents in Groundwater

\section{WQSP-4 Total Dissolved Solids}

Primary Sample $\quad$ Duplicate Sample — $\quad$ 95th UTLV or 95th Percentile

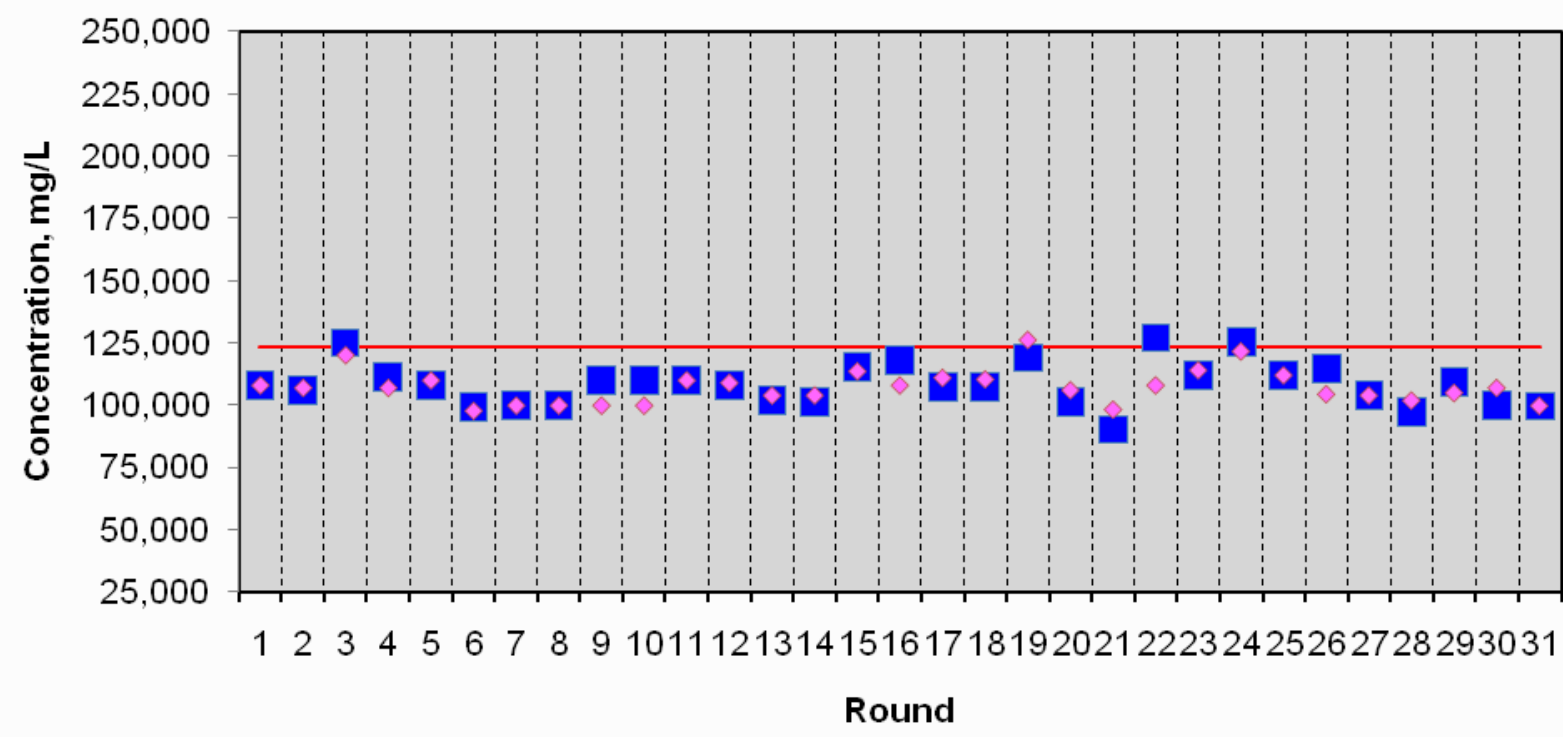

WQSP-5 Calcium, Dissolved

Primary Sample $\quad$ Duplicate Sample — 95th UTLV or 95th Percentile

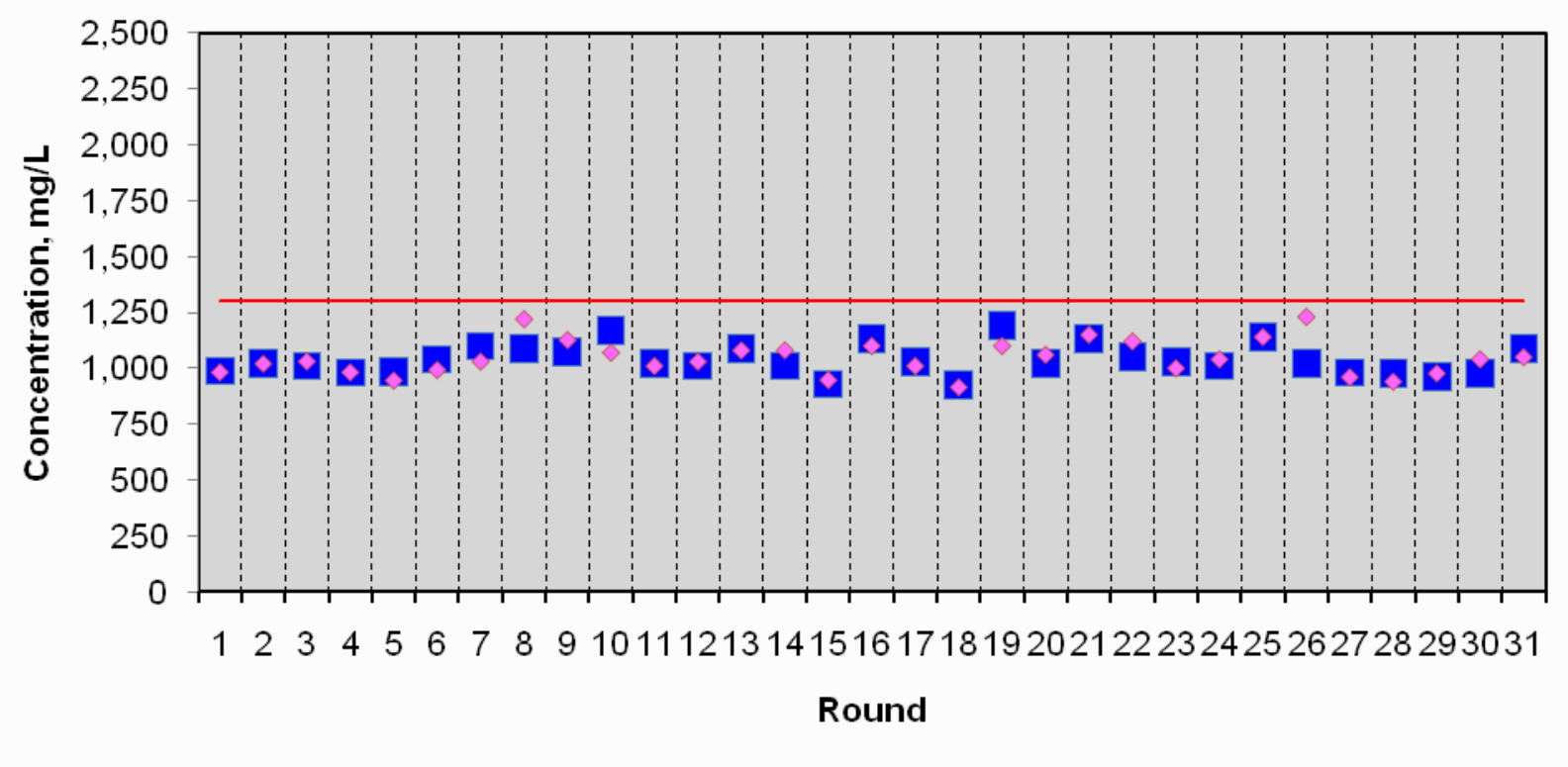


Waste Isolation Pilot Plant Annual Site Environmental Report for 2010 DOE/WIPP-11-2225

Appendix E - Time Trend Plots for Detectable Constituents in Groundwater

\section{WQSP-5 Chloride}

Primary Sample $\quad$ Duplicate Sample — $\quad$ 95th UTLV or 95th Percentile

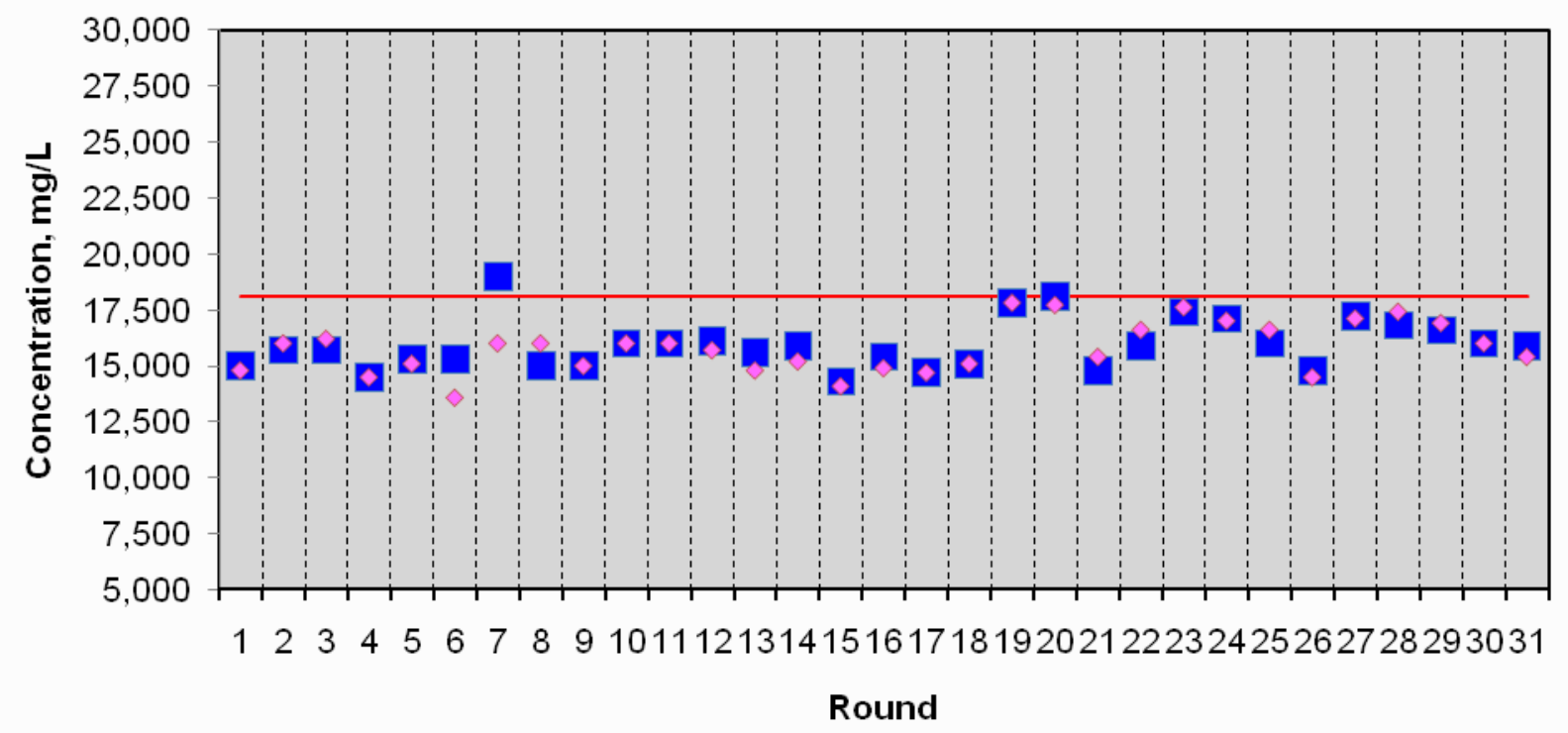

\section{WQSP-5 Magnesium, Dissolved}

Primary Sample $\quad$ Duplicate Sample — 95th UTLV or 95th Percentile

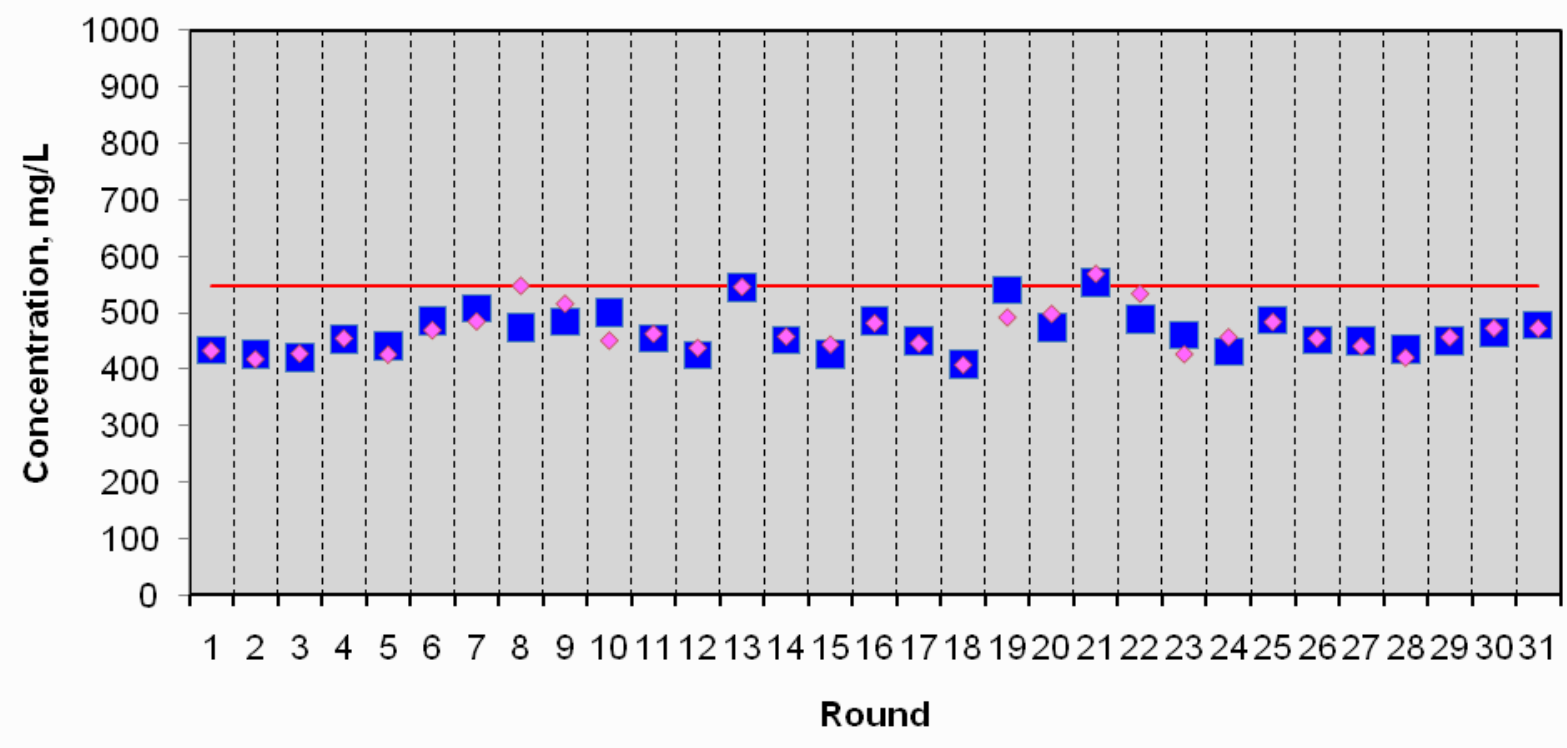


Waste Isolation Pilot Plant Annual Site Environmental Report for 2010 DOE/WIPP-11-2225

Appendix E - Time Trend Plots for Detectable Constituents in Groundwater

\section{WQSP-5 pH}

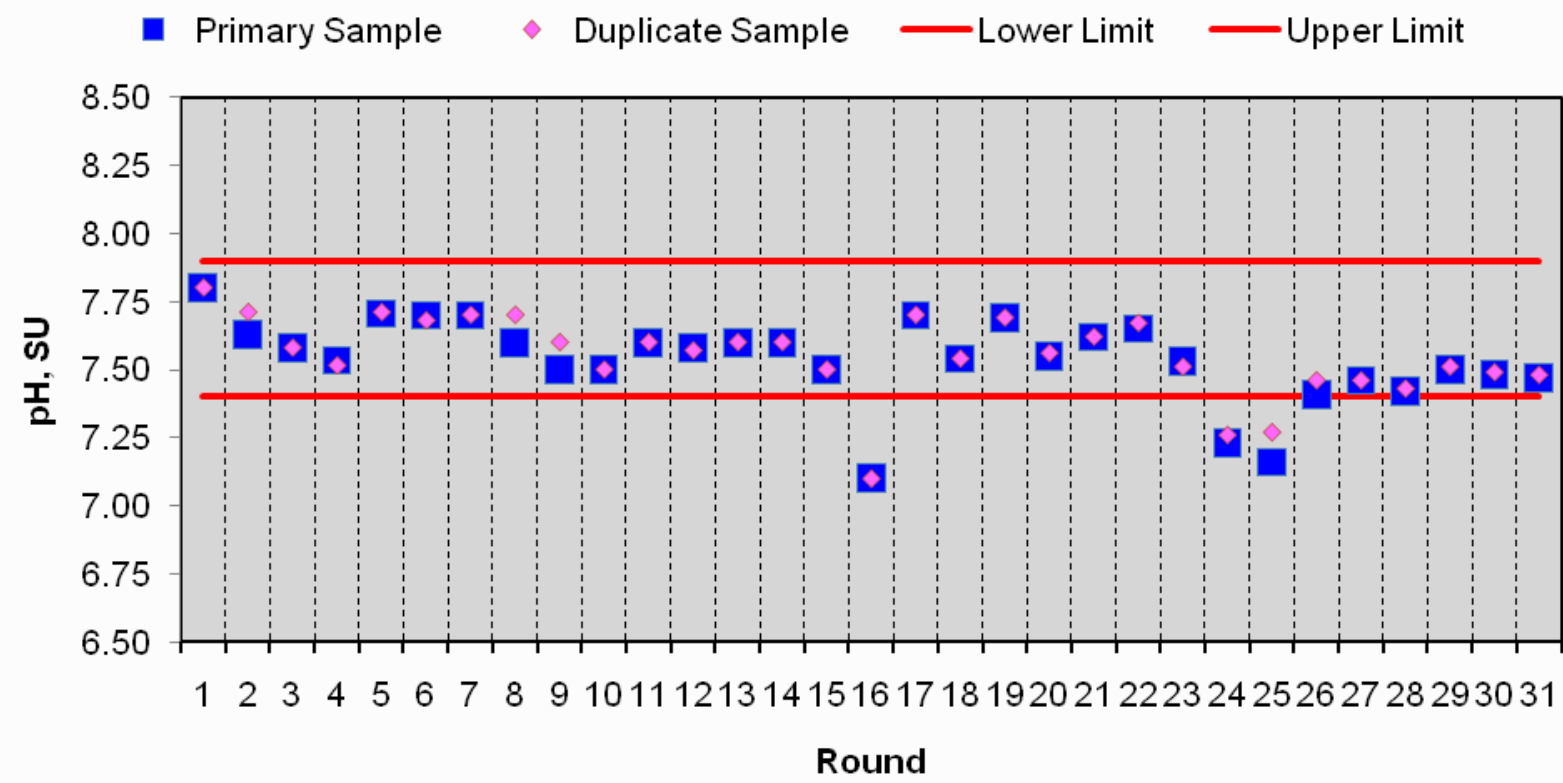

\section{WQSP-5 Potassium, Dissolved}

Primary Sample $\quad$ Duplicate Sample — $\quad$ 95th UTLV or 95th Percentile

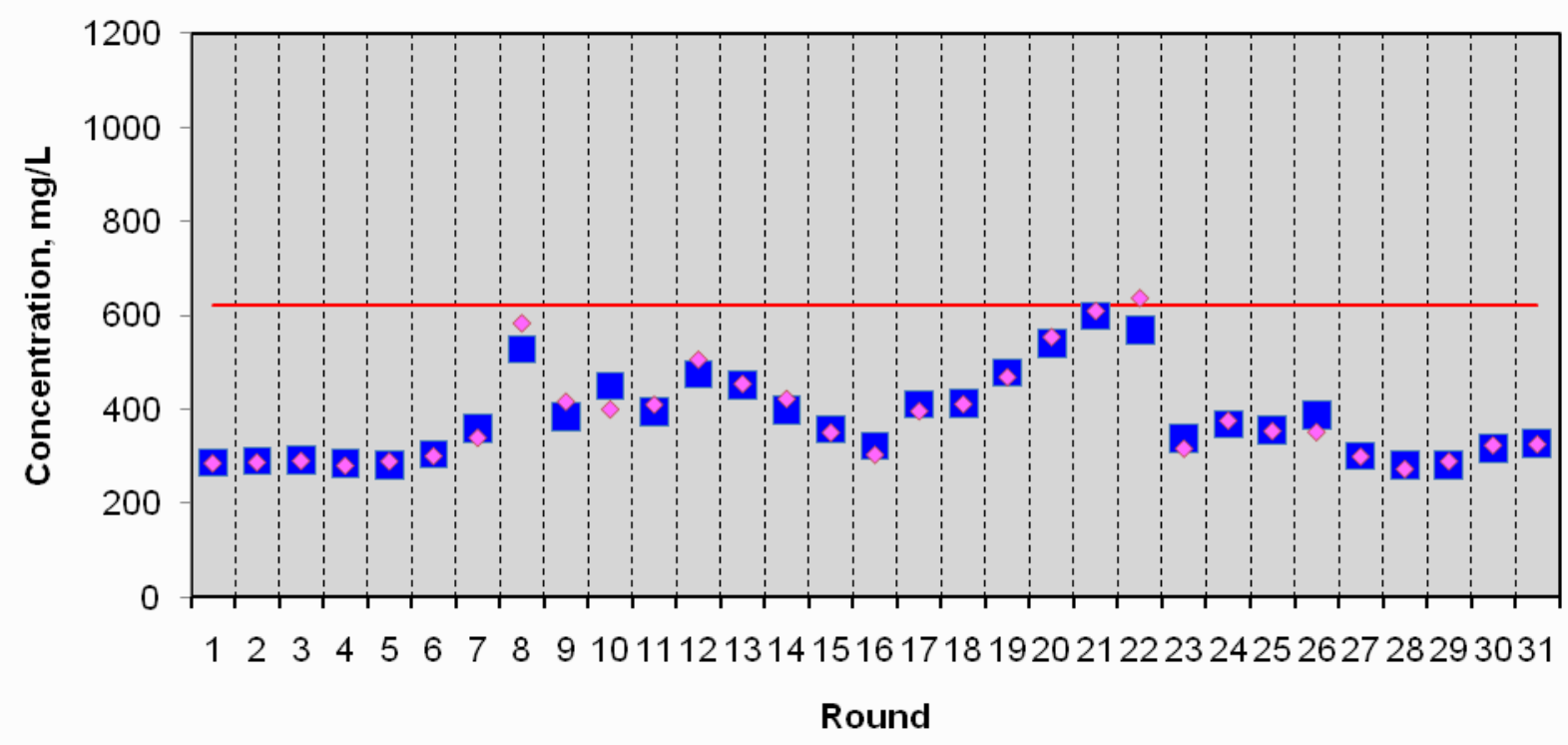


Waste Isolation Pilot Plant Annual Site Environmental Report for 2010 DOE/WIPP-11-2225

Appendix E - Time Trend Plots for Detectable Constituents in Groundwater

\section{WQSP-5 Sulfate}

Primary Sample $\quad$ Duplicate Sample — $\quad$ 95th UTLV or 95th Percentile

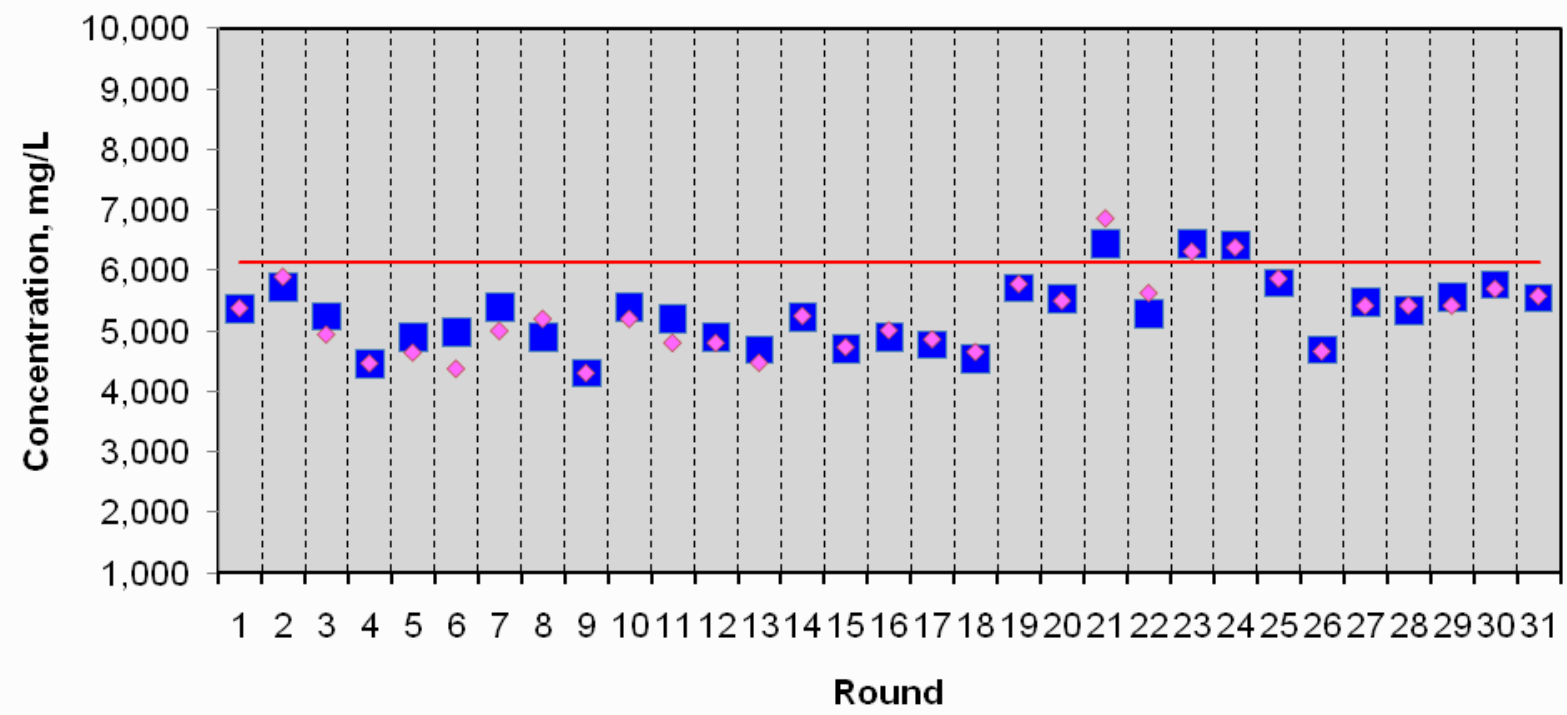

\section{WQSP-5 Total Dissolved Solids}

Primary Sample $\quad \forall$ Duplicate Sample — $\quad$ 95th UTLV or 95th Percentile

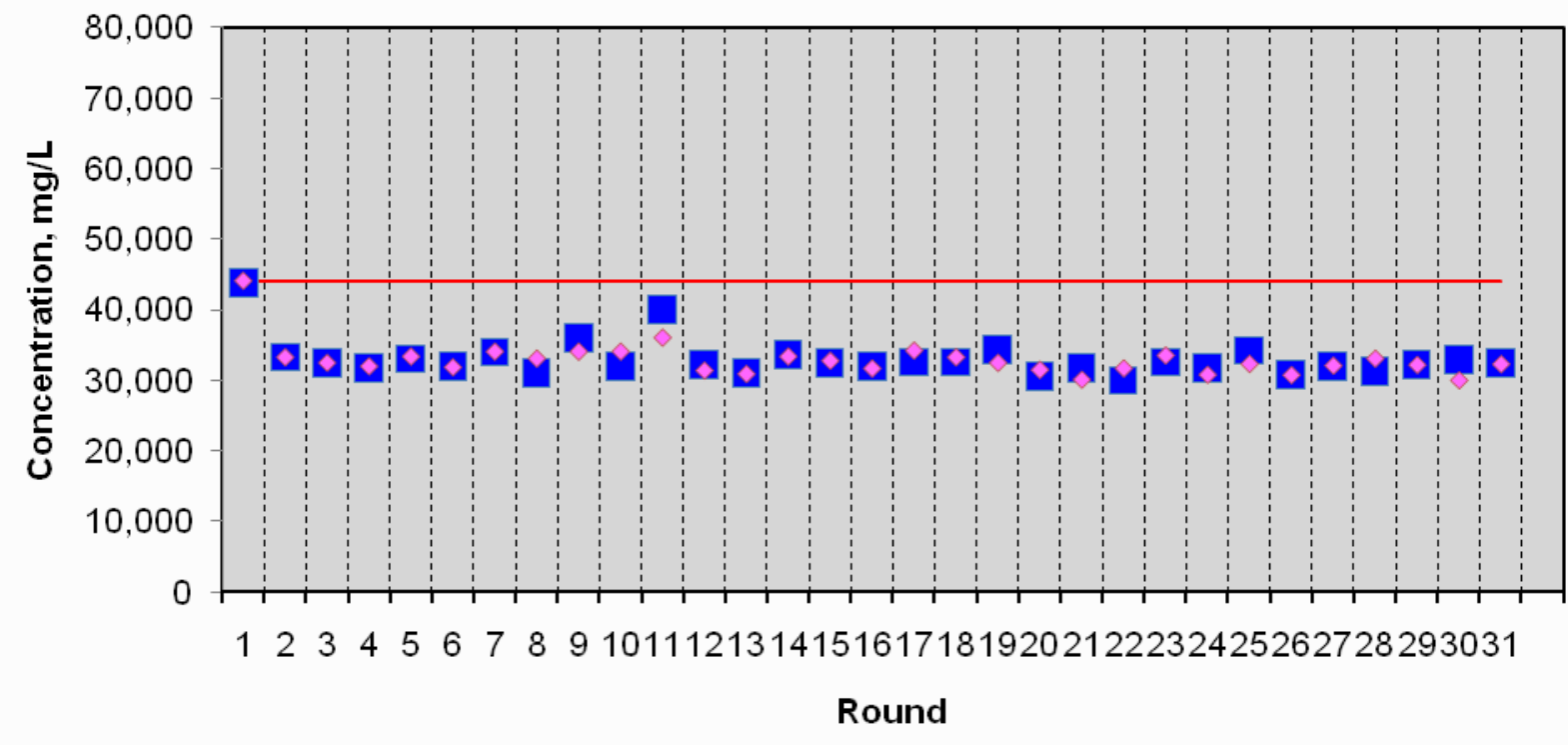


Waste Isolation Pilot Plant Annual Site Environmental Report for 2010 DOE/WIPP-11-2225

Appendix E - Time Trend Plots for Detectable Constituents in Groundwater

\section{WQSP-6 Calcium, Dissolved}

Primary Sample $\quad$ Duplicate Sample — $\quad$ 95th UTLV or 95th Percentile

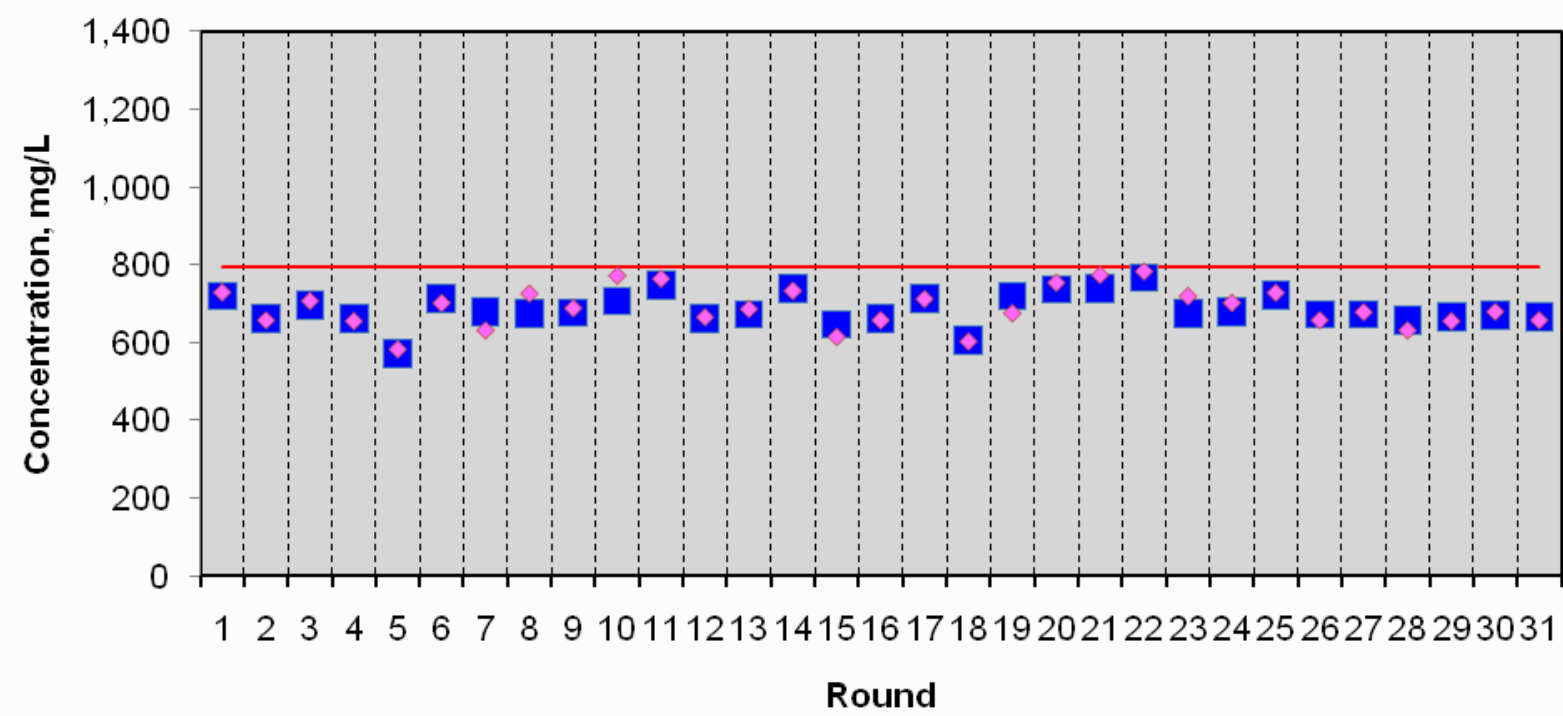

\section{WQSP-6 Chloride}

Primary Sample $\quad \Delta$ Duplicate Sample — 95th UTLV or 95th Percentile

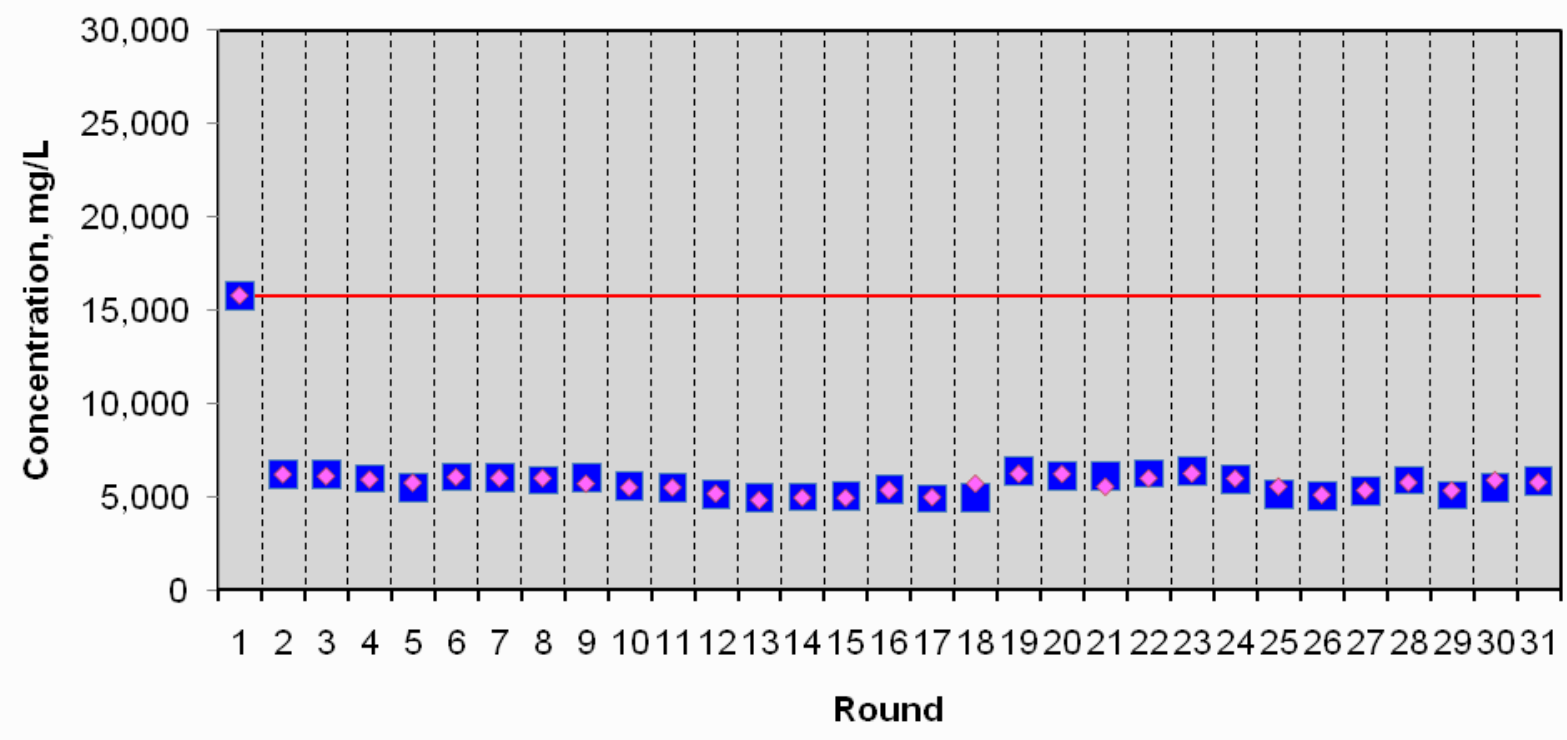


Waste Isolation Pilot Plant Annual Site Environmental Report for 2010 DOE/WIPP-11-2225

Appendix E - Time Trend Plots for Detectable Constituents in Groundwater

\section{WQSP-6 Magnesium, Dissolved}

Primary Sample $\quad$ Duplicate Sample — $\quad$ 95th UTLV or 95th Percentile

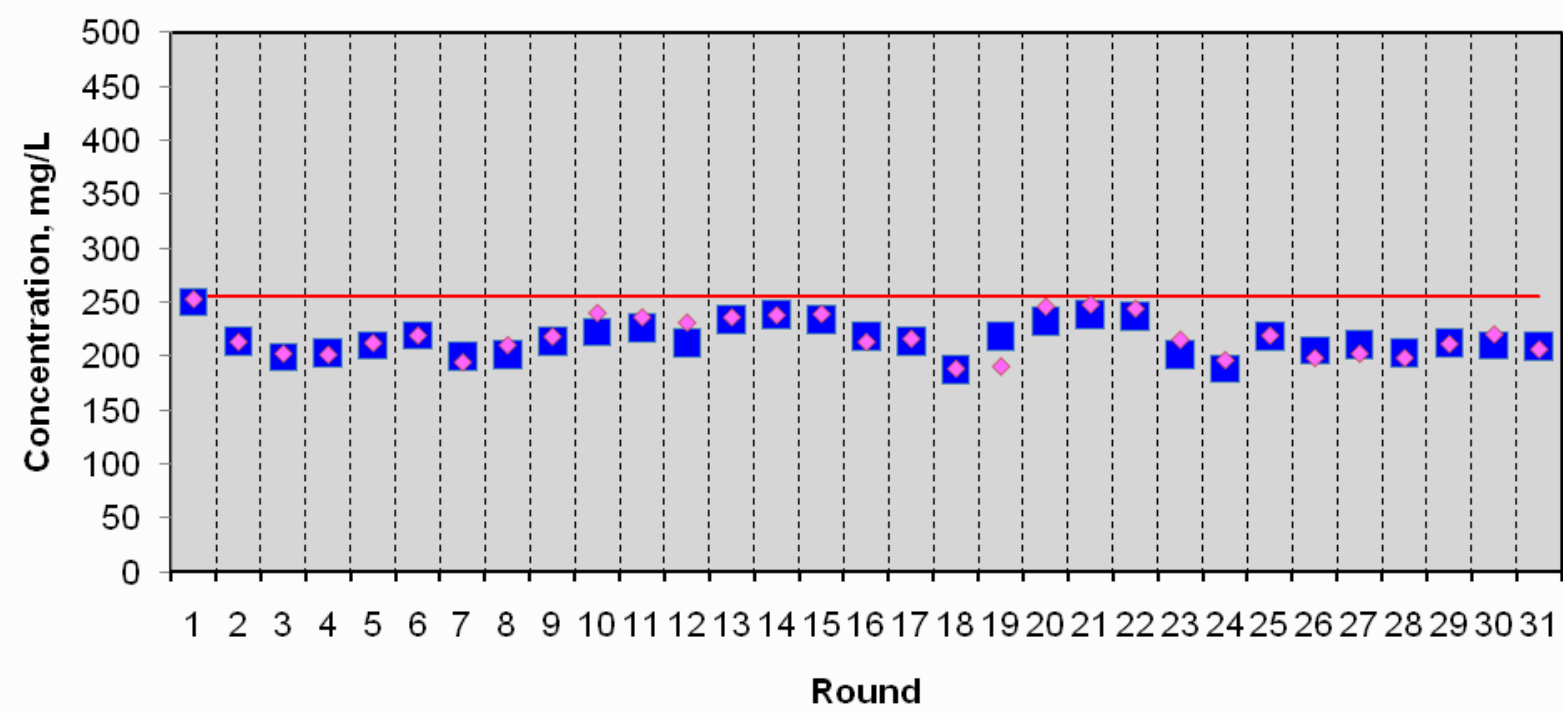

\section{WQSP-6 pH}

Primary Sample $\quad$ Duplicate Sample $\quad$ Lower Limit Upper Limit

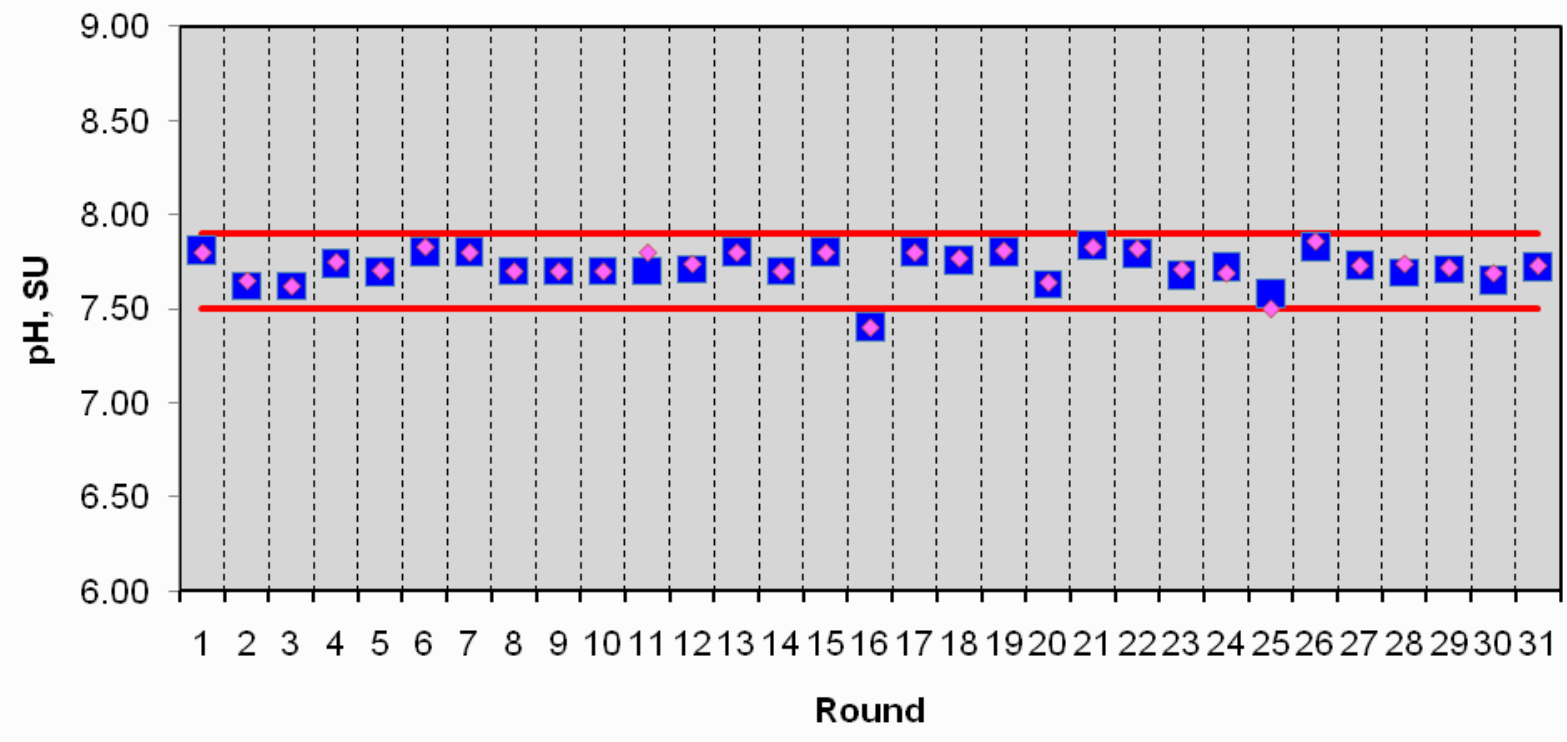


Waste Isolation Pilot Plant Annual Site Environmental Report for 2010 DOE/WIPP-11-2225

Appendix E - Time Trend Plots for Detectable Constituents in Groundwater

\section{WQSP-6 Sulfate}

Primary Sample $\quad$ Duplicate Sample — 95th UTLV or 95th Percentile

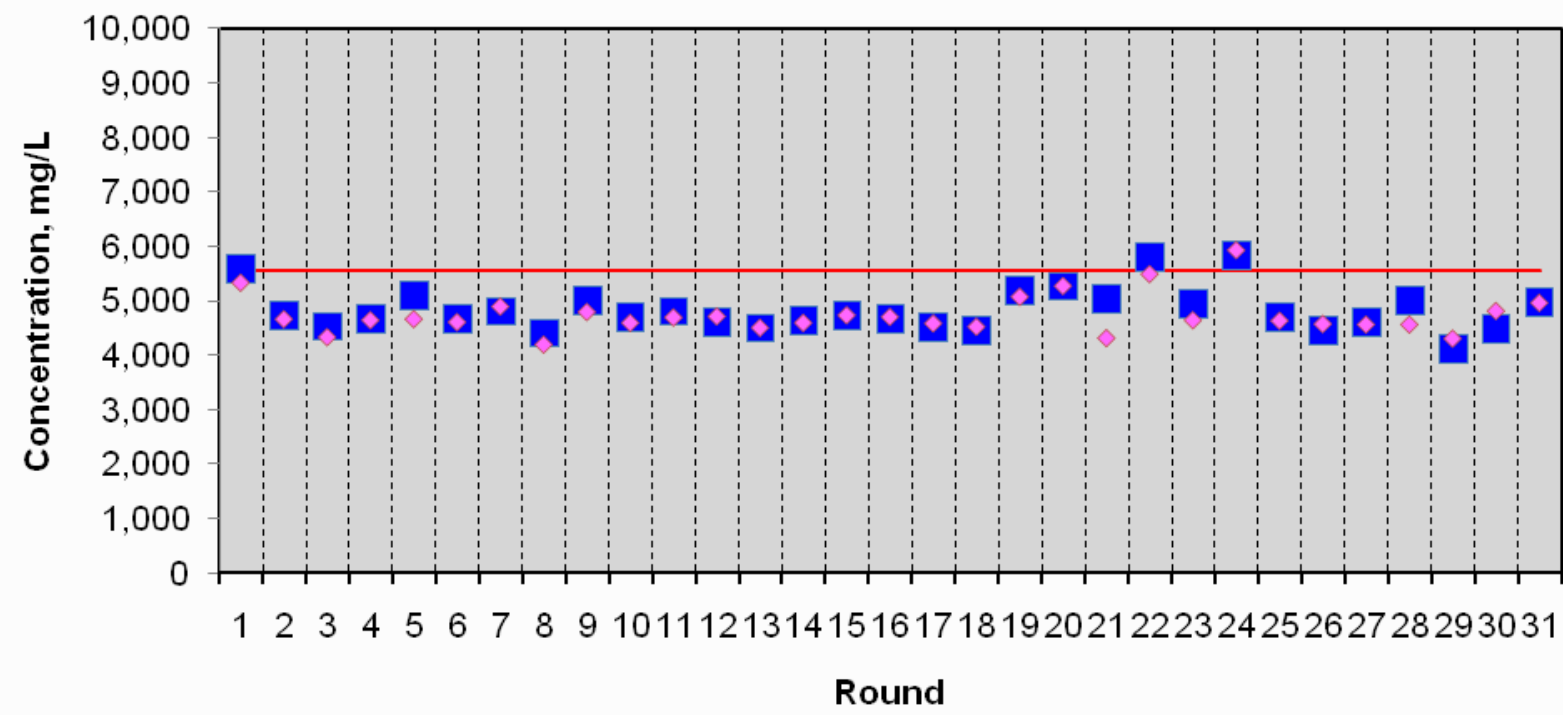

\section{WQSP-6 Total Dissolved Solids}

Primary Sample $\quad \Delta$ Duplicate Sample — 95th UTLV or 95th Percentile

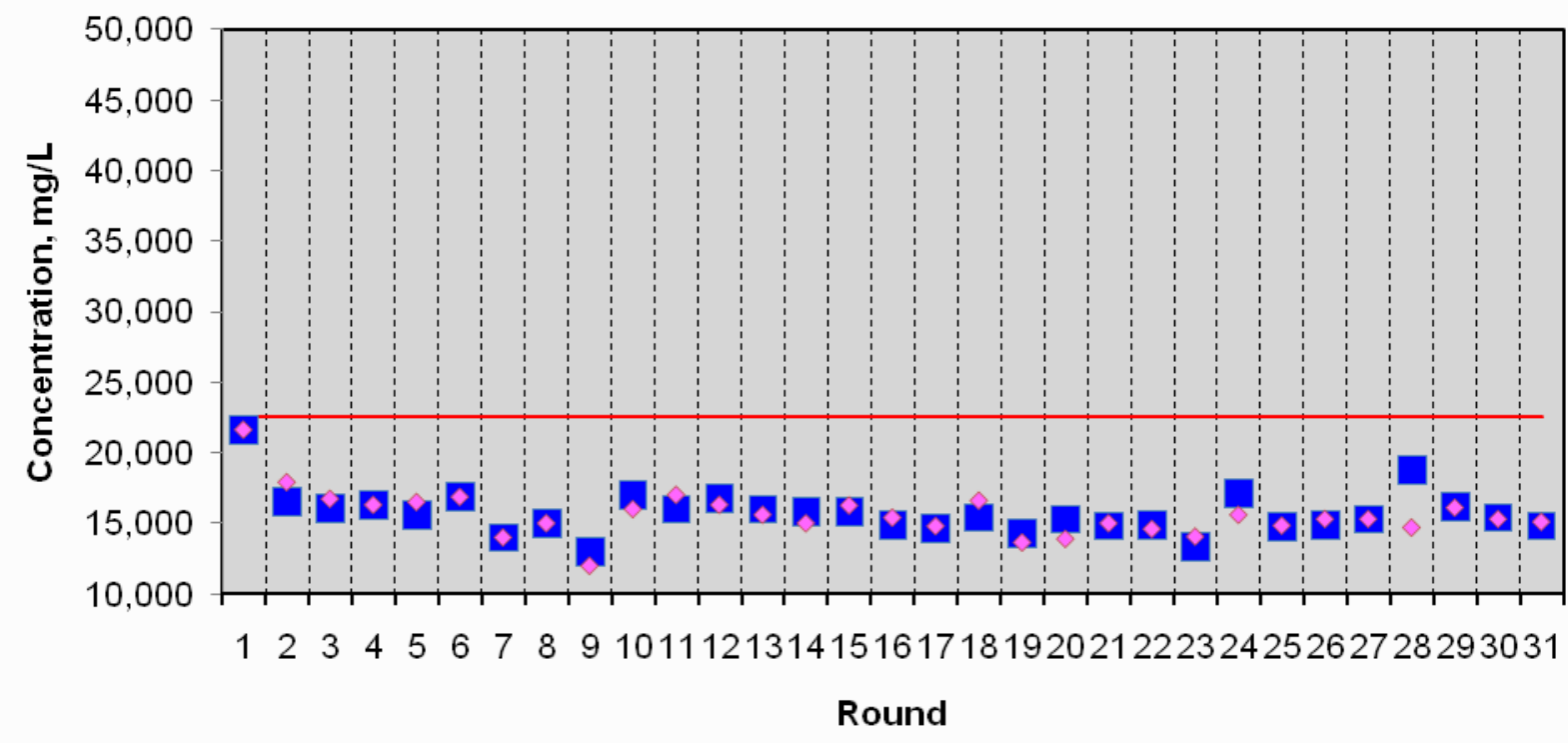


Waste Isolation Pilot Plant Annual Site Environmental Report for 2010 DOE/WIPP-11-2225

Appendix E - Time Trend Plots for Detectable Constituents in Groundwater

\section{WQSP-6A Calcium, Dissolved}

Primary Sample $\quad$ Duplicate Sample — $\quad$ 95th UTLV or 95th Percentile

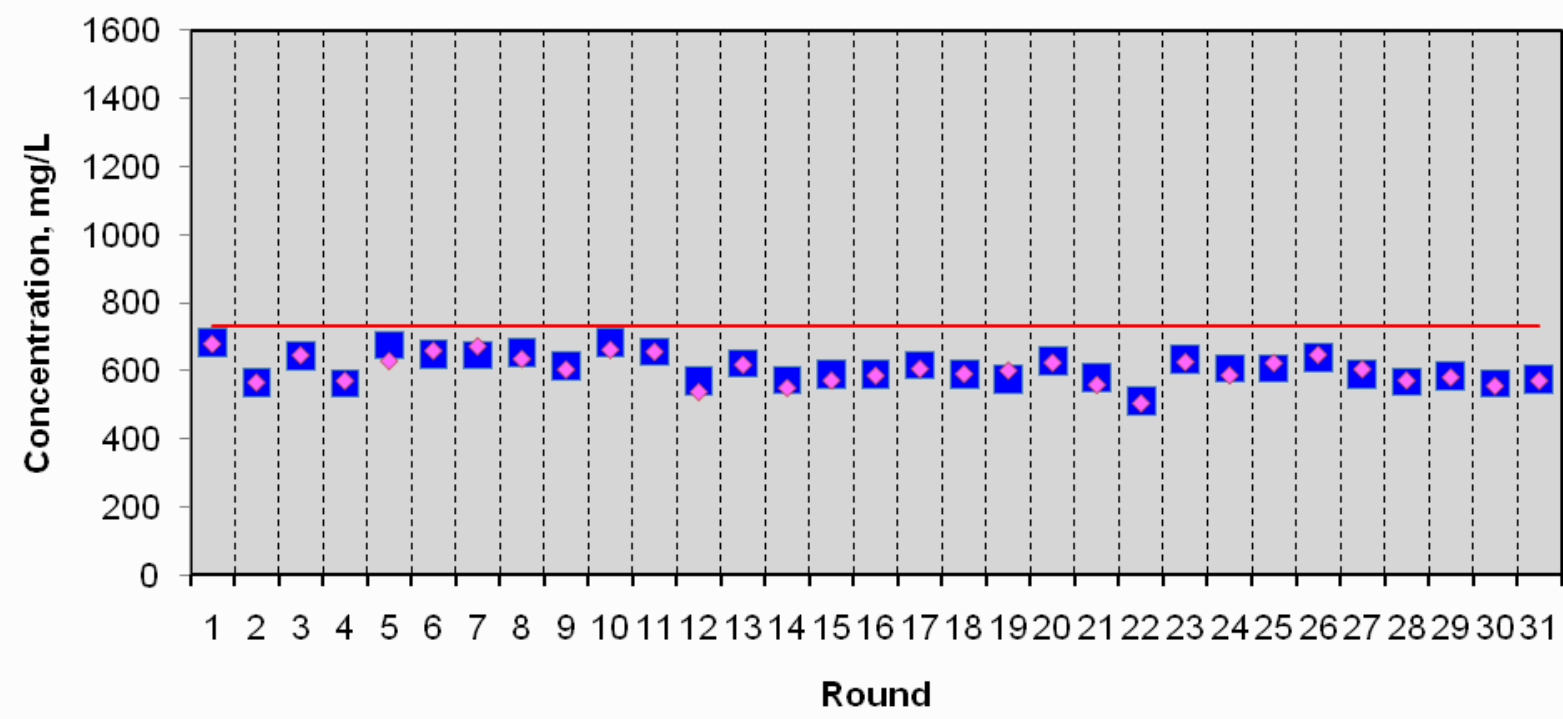

\section{WQSP-6A Chloride}

Primary Sample $\quad \Delta$ Duplicate Sample — 95th UTLV or 95th Percentile

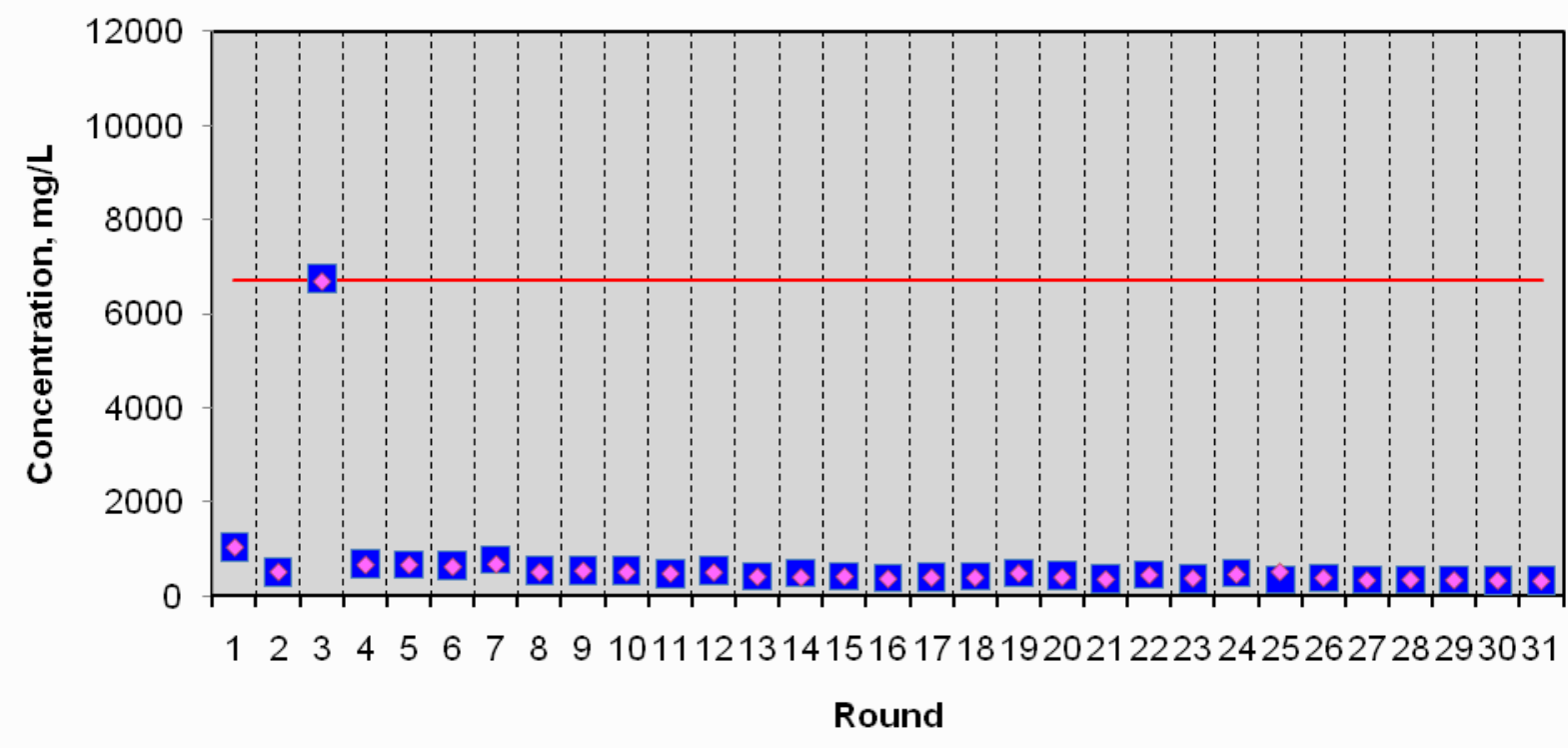


Waste Isolation Pilot Plant Annual Site Environmental Report for 2010 DOE/WIPP-11-2225

Appendix E - Time Trend Plots for Detectable Constituents in Groundwater

\section{WQSP-6A Magnesium, Dissolved}

Primary Sample $\quad$ Duplicate Sample — $\quad$ 95th UTLV or 95th Percentile

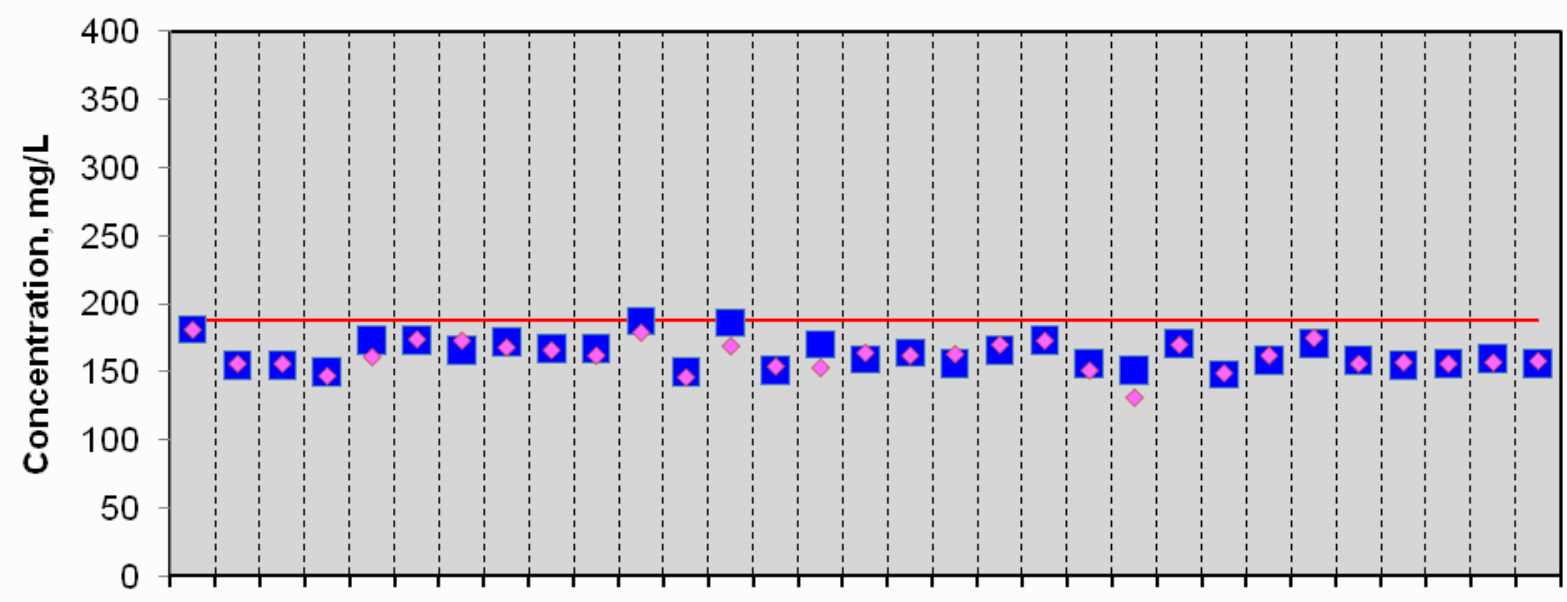

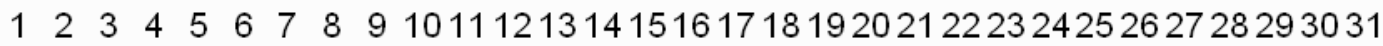

Round

\section{WQSP-6A pH}

Primary Sample $\quad$ Duplicate Sample - Lower Limit -Upper Limit

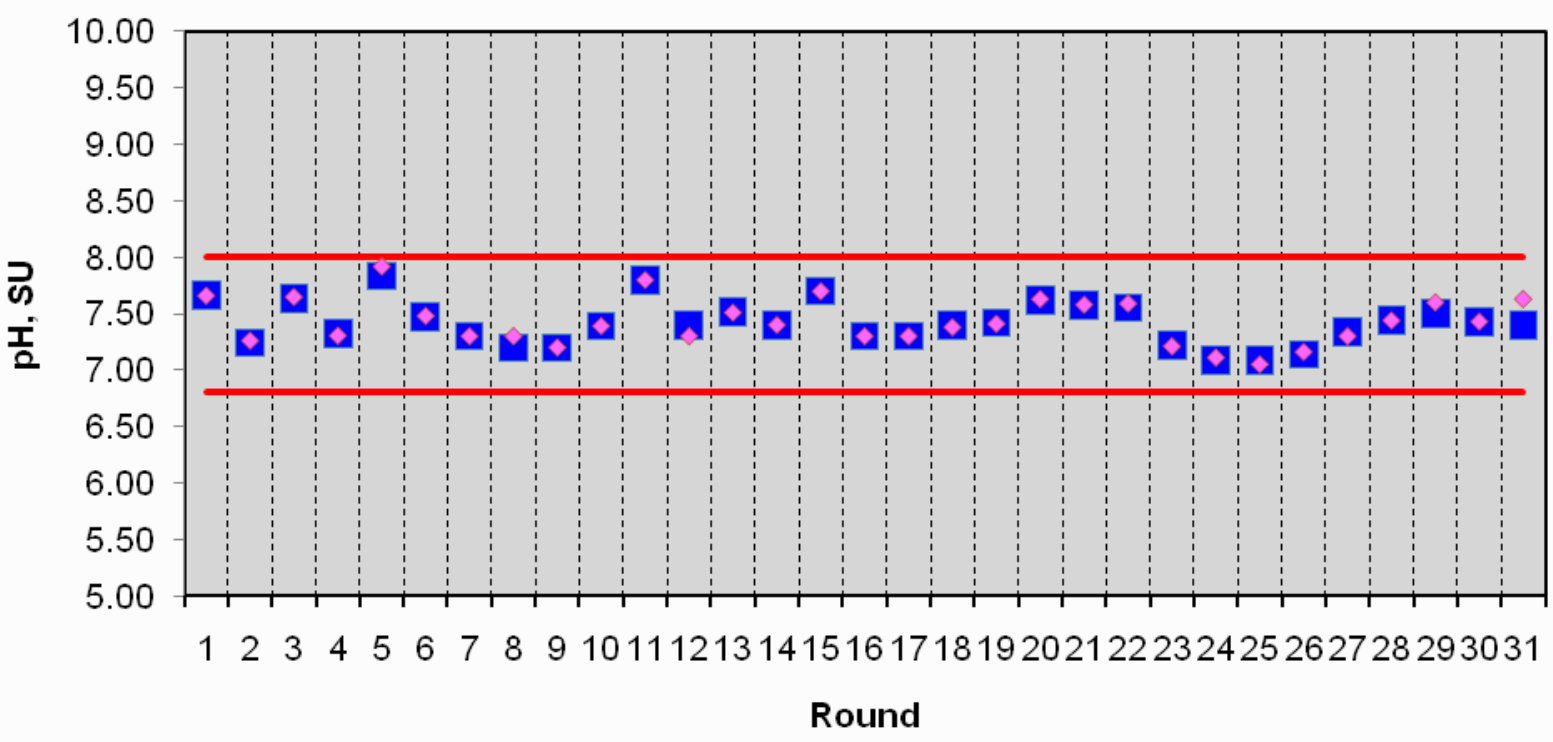


Waste Isolation Pilot Plant Annual Site Environmental Report for 2010 DOE/WIPP-11-2225

Appendix E - Time Trend Plots for Detectable Constituents in Groundwater

\section{WQSP-6A Potassium, Dissolved}

Primary Sample $\quad$ Duplicate Sample — 95th UTLV or 95th Percentile

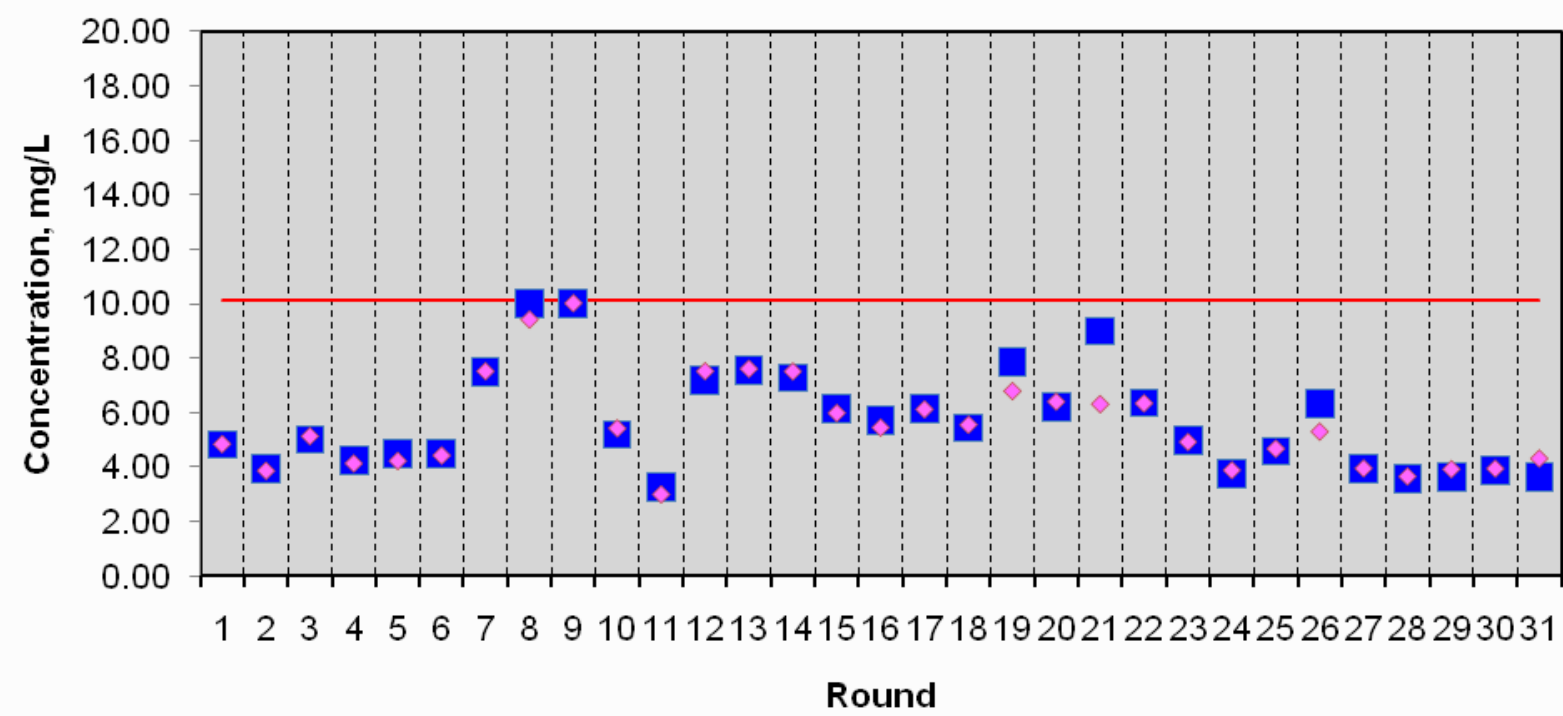

\section{WQSP-6A Sulfate}

Primary Sample $\quad \Delta$ Duplicate Sample — 95th UTLV or 95th Percentile

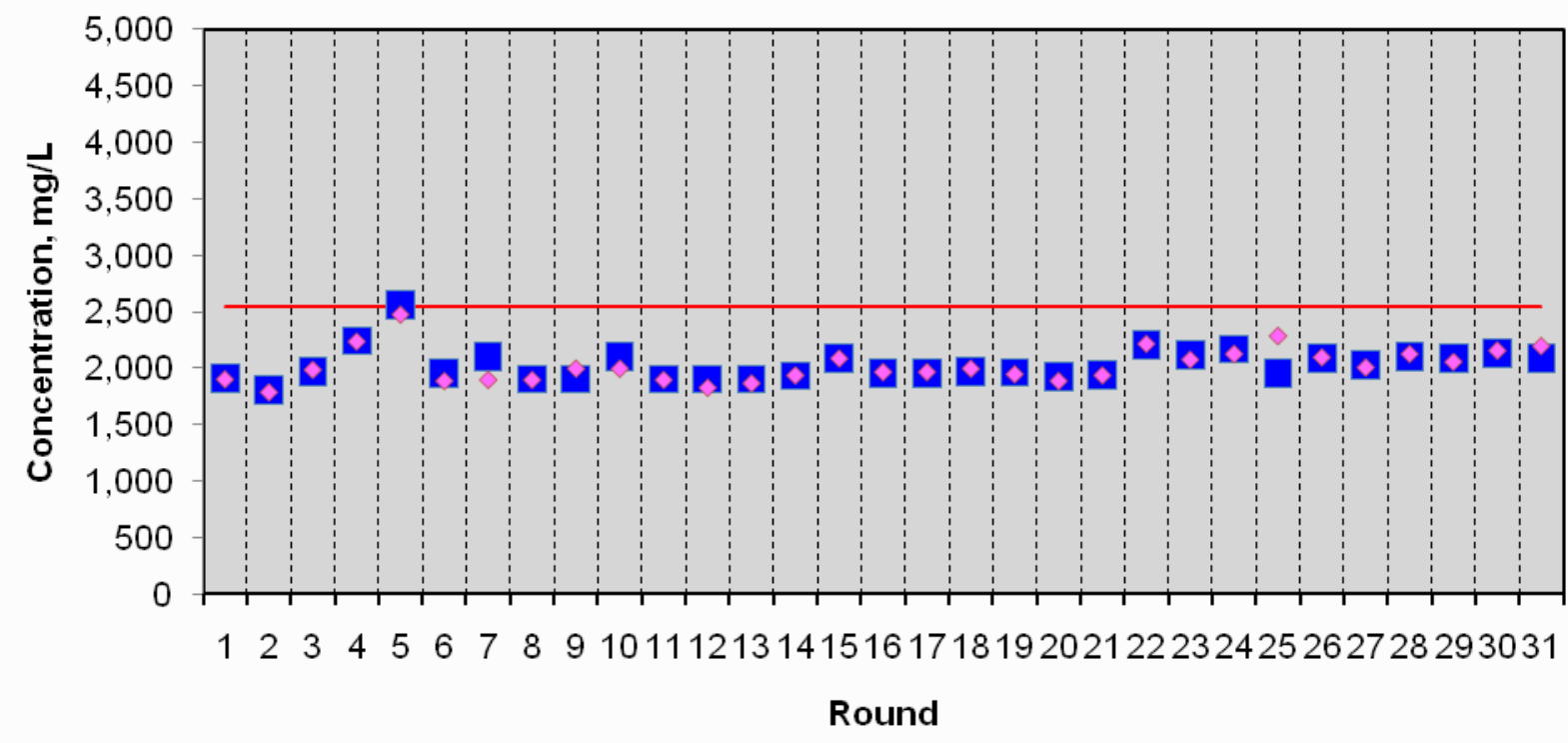


Waste Isolation Pilot Plant Annual Site Environmental Report for 2010 DOE/WIPP-11-2225

Appendix E - Time Trend Plots for Detectable Constituents in Groundwater

\section{WQSP-6A Total Dissolved Solids}

Primary Sample $\quad$ Duplicate Sample — 95th UTLV or 95th Percentile

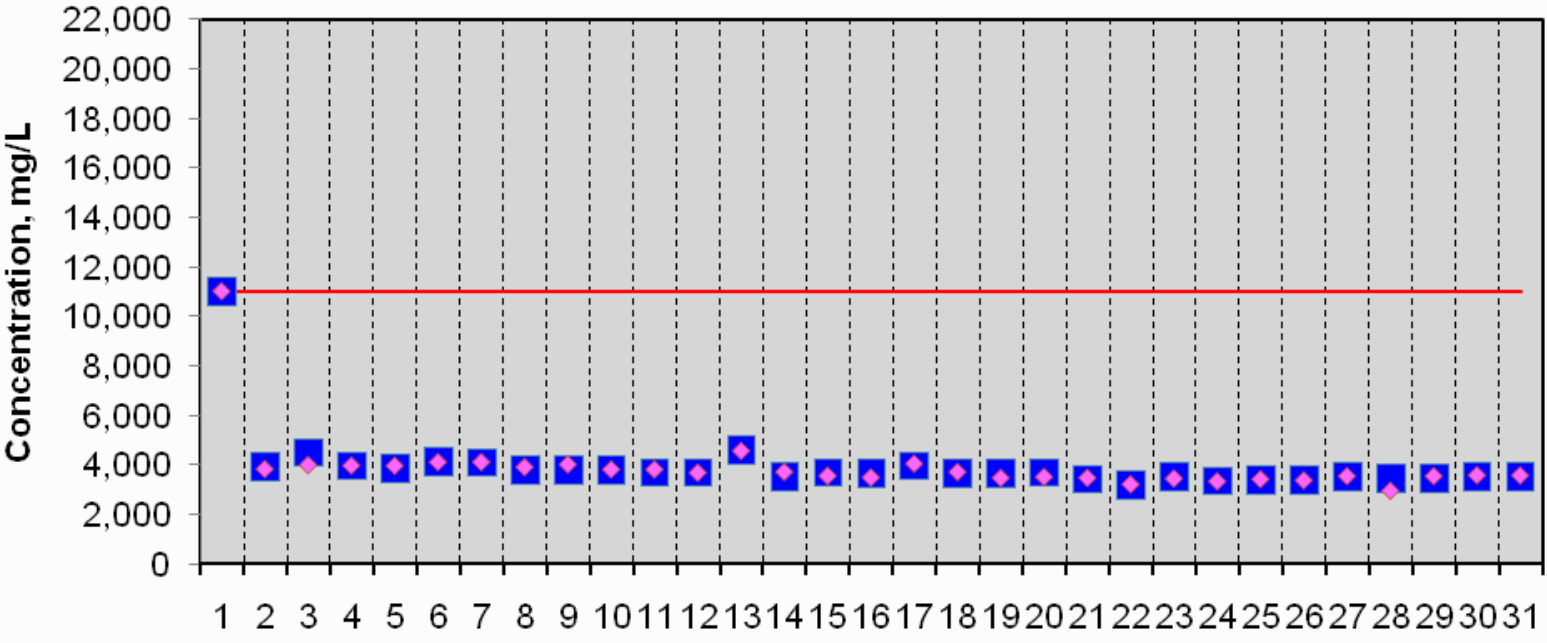

Round 
This page intentionally left blank 


\section{Waste Isolation Pilot Plant Annual Site Environmental Report for 2010 DOE/WIPP-11-2225}

\section{Appendix F - Groundwater Data Tables}

Table F.1 - Analytical Results for Groundwater Sampled from Well WQSP - 1

\begin{tabular}{|c|c|c|c|c|c|c|c|c|}
\hline \multirow[b]{2}{*}{ Parameter } & \multicolumn{2}{|c|}{ Round 30} & \multicolumn{2}{|c|}{ Round 31} & \multirow[b]{2}{*}{ Units } & \multicolumn{2}{|c|}{$\begin{array}{c}\text { Method } \\
\text { Reporting Limit }\end{array}$} & \multirow[b]{2}{*}{$\begin{array}{l}\text { 95th } \\
\text { UTLV }^{\mathrm{a}}\end{array}$} \\
\hline & Sample & Duplicate & Sample & Duplicate & & $\begin{array}{c}\text { Round } \\
30\end{array}$ & $\begin{array}{c}\text { Round } \\
31\end{array}$ & \\
\hline 1,1,1-Trichloroethane & $<1$ & $<1$ & $<1$ & $<1$ & $\mu \mathrm{g} / \mathrm{L}$ & 1 & 1 & $<\mathrm{RL}^{\mathrm{b}}$ \\
\hline 1,1,2,2-Tetrachloroethane & $<1$ & $<1$ & $<1$ & $<1$ & $\mu \mathrm{g} / \mathrm{L}$ & 1 & 1 & $<R L$ \\
\hline 1,1,2-Trichloroethane & $<1$ & $<1$ & $<1$ & $<1$ & $\mu \mathrm{g} / \mathrm{L}$ & 1 & 1 & $<\mathrm{RL}$ \\
\hline 1,1-Dichloroethane & $<1$ & $<1$ & $<1$ & $<1$ & $\mu \mathrm{g} / \mathrm{L}$ & 1 & 1 & $<\mathrm{RL}$ \\
\hline 1,1-Dichloroethylene & $<1$ & $<1$ & $<1$ & $<1$ & $\mu \mathrm{g} / \mathrm{L}$ & 1 & 1 & $<\mathrm{RL}$ \\
\hline 1,2-Dichloroethane & $<1$ & $<1$ & $<1$ & $<1$ & $\mu \mathrm{g} / \mathrm{L}$ & 1 & 1 & $<\mathrm{RL}$ \\
\hline Carbon tetrachloride & $<1$ & $<1$ & $<1$ & $<1$ & $\mu \mathrm{g} / \mathrm{L}$ & 1 & 1 & $<\mathrm{RL}$ \\
\hline Chlorobenzene & $<1$ & $<1$ & $<1$ & $<1$ & $\mu \mathrm{g} / \mathrm{L}$ & 1 & 1 & $<\mathrm{RL}$ \\
\hline Chloroform & $<1$ & $<1$ & $<1$ & $<1$ & $\mu \mathrm{g} / \mathrm{L}$ & 1 & 1 & $<\mathrm{RL}$ \\
\hline cis-1,2-Dichloroethylene & $<1$ & $<1$ & $<1$ & $<1$ & $\mu \mathrm{g} / \mathrm{L}$ & 1 & 1 & $<\mathrm{RL}$ \\
\hline trans-1,2-Dichloroethylene & $<1$ & $<1$ & $<1$ & $<1$ & $\mu \mathrm{g} / \mathrm{L}$ & 1 & 1 & $<R L$ \\
\hline 2-butanone & $<5$ & $<5$ & $<5$ & $<5$ & $\mu g / L$ & 5 & 5 & $<R L$ \\
\hline Isobutanol & $<5$ & $<5$ & $<5$ & $<5$ & $\mu \mathrm{g} / \mathrm{L}$ & 5 & 5 & $<R L$ \\
\hline Methylene chloride & $<5$ & $<5$ & $<5$ & $<5$ & $\mu \mathrm{g} / \mathrm{L}$ & 5 & 5 & $<\mathrm{RL}$ \\
\hline Tetrachloroethylene & $<1$ & $<1$ & $<1$ & $<1$ & $\mu \mathrm{g} / \mathrm{L}$ & 1 & 1 & $<R L$ \\
\hline Toluene & $<1$ & $<1$ & $<1$ & $<1$ & $\mu \mathrm{g} / \mathrm{L}$ & 1 & 1 & $<\mathrm{RL}$ \\
\hline Trichloroethylene & $<1$ & $<1$ & $<1$ & $<1$ & $\mu \mathrm{g} / \mathrm{L}$ & 1 & 1 & $<\mathrm{RL}$ \\
\hline Trichlorofluoromethane & $<1$ & $<1$ & $<1$ & $<1$ & $\mu \mathrm{g} / \mathrm{L}$ & 1 & 1 & $<R L$ \\
\hline Vinyl chloride & $<1$ & $<1$ & $<1$ & $<1$ & $\mu \mathrm{g} / \mathrm{L}$ & 1 & 1 & $<R L$ \\
\hline Xylene & $<1$ & $<1$ & $<1$ & $<1$ & $\mu \mathrm{g} / \mathrm{L}$ & 1 & 1 & $<\mathrm{RL}$ \\
\hline 1,2-Dichlorobenzene & $<5$ & $<5$ & $<5$ & $<5$ & $\mu \mathrm{g} / \mathrm{L}$ & 5 & 5 & $<R L$ \\
\hline 1,4-Dichlorobenzene & $<5$ & $<5$ & $<5$ & $<5$ & $\mu \mathrm{g} / \mathrm{L}$ & 5 & 5 & $<R L$ \\
\hline 2,4-Dinitrophenol & $<5$ & $<5$ & $<5$ & $<5$ & $\mu \mathrm{g} / \mathrm{L}$ & 5 & 5 & $<R L$ \\
\hline 2,4-Dinitrotoluene & $<5$ & $<5$ & $<5$ & $<5$ & $\mu \mathrm{g} / \mathrm{L}$ & 5 & 5 & $<R L$ \\
\hline 2-Methylphenol & $<5$ & $<5$ & $<5$ & $<5$ & $\mu \mathrm{g} / \mathrm{L}$ & 5 & 5 & $<R L$ \\
\hline 3-Methylphenol/4-Methylphenol & $<5$ & $<5$ & $<5$ & $<5$ & $\mu \mathrm{g} / \mathrm{L}$ & 5 & 5 & $<R L$ \\
\hline Hexachlorobenzene & $<5$ & $<5$ & $<5$ & $<5$ & $\mu \mathrm{g} / \mathrm{L}$ & 5 & 5 & $<R L$ \\
\hline Hexachloroethane & $<5$ & $<5$ & $<5$ & $<5$ & $\mu \mathrm{g} / \mathrm{L}$ & 5 & 5 & $<\mathrm{RL}$ \\
\hline Nitrobenzene & $<5$ & $<5$ & $<5$ & $<5$ & $\mu \mathrm{g} / \mathrm{L}$ & 5 & 5 & $<R L$ \\
\hline Pentachlorophenol & $<5$ & $<5$ & $<5$ & $<5$ & $\mu \mathrm{g} / \mathrm{L}$ & 5 & 5 & $<R L$ \\
\hline Pyridine & $<5$ & $<5$ & $<5$ & $<5$ & $\mu \mathrm{g} / \mathrm{L}$ & 5 & 5 & $<R L$ \\
\hline Alkalinity & 48.7 & 48.8 & 50.8 & 50.7 & $\mathrm{mg} / \mathrm{L}$ & 4.0 & 4.0 & 55.8 \\
\hline Chloride & 40,400 & 40,800 & 40,000 & 44,000 & $\mathrm{mg} / \mathrm{L}$ & 500 & 500 & 40,472 \\
\hline Specific Gravity & 1.043 & 1.045 & 1.042 & 1.039 & $\mathrm{~g} / \mathrm{ml}$ & $N / A^{d}$ & $N / A^{d}$ & 1.07 \\
\hline Nitrate (as N) & $<0.1$ & $<0.1$ & $<1.1$ & $<1.1$ & $\mathrm{mg} / \mathrm{L}$ & 1.0 & 5.0 & $<10.0$ \\
\hline $\mathrm{pH}$ & 7.19 & 7.20 & 7.17 & 7.19 & $S U^{c}$ & $N / A^{d}$ & $N / A^{d}$ & $5.6-8.8$ \\
\hline
\end{tabular}




\section{Waste Isolation Pilot Plant Annual Site Environmental Report for 2010 DOE/WIPP-11-2225}

\section{Appendix F - Groundwater Data Tables}

Table F.1 - Analytical Results for Groundwater Sampled from Well WQSP - 1

\begin{tabular}{|c|c|c|c|c|c|c|c|c|}
\hline \multirow[b]{2}{*}{ Parameter } & \multicolumn{2}{|c|}{ Round 30} & \multicolumn{2}{|c|}{ Round 31} & \multirow[b]{2}{*}{ Units } & \multicolumn{2}{|c|}{$\begin{array}{c}\text { Method } \\
\text { Reporting Limit }\end{array}$} & \multirow[b]{2}{*}{$\begin{array}{l}\text { 95th } \\
\text { UTLV }^{\mathrm{a}}\end{array}$} \\
\hline & Sample & Duplicate & Sample & Duplicate & & $\begin{array}{l}\text { Round } \\
30\end{array}$ & $\begin{array}{c}\text { Round } \\
31\end{array}$ & \\
\hline Specific conductance & 113,000 & 114,000 & 122,000 & 122,000 & $\mu \mathrm{mhos} / \mathrm{cm}$ & N/A & N/A & 175,000 \\
\hline Sulfate & 5,030 & 4,780 & 5,200 & 4,910 & $\mathrm{mg} / \mathrm{L}$ & 100 & 100 & 5,757 \\
\hline Total dissolved solids & 64,200 & 66,100 & 66,500 & 62,500 & $\mathrm{mg} / \mathrm{L}$ & 1,000 & 1,000 & 80,700 \\
\hline Total organic carbon & $0.66 \mathrm{~J}$ & $0.80 \mathrm{~J}$ & $0.83 \mathrm{~J}$ & $0.84 \mathrm{~J}$ & $\mathrm{mg} / \mathrm{L}$ & 1.0 & 1.0 & $<5.0$ \\
\hline Total organic halogen & 0.25 & 0.13 & 0.15 & 0.20 & $\mathrm{mg} / \mathrm{L}$ & 0.10 & 0.050 & 14.6 \\
\hline Total suspended solids & 31 & 35 & 32 & 34 & $\mathrm{mg} / \mathrm{L}$ & 10 & 10 & 33.3 \\
\hline Antimony & 0.0238 & 0.0224 & $<0.0020$ & $<0.0020$ & $\mathrm{mg} / \mathrm{L}$ & 0.0050 & 0.0020 & 0.33 \\
\hline Arsenic & $<0.0050$ & $<0.0050$ & $<0.0020$ & $<0.0023$ & $\mathrm{mg} / \mathrm{L}$ & 0.0050 & 0.0020 & $<0.1$ \\
\hline Barium & $0.032 \mathrm{~J}$ & $0.029 \mathrm{~J}$ & 0.036 & 0.032 & $\mathrm{mg} / \mathrm{L}$ & 0.050 & 0.10 & $<1.0$ \\
\hline Beryllium & $0.0021 \mathrm{~J}$ & $0.0023 \mathrm{~J}$ & $0.0054 \mathrm{~J}$ & $0.0056 \mathrm{~J}$ & $\mathrm{mg} / \mathrm{L}$ & 0.015 & 0.030 & $<0.02$ \\
\hline Cadmium & $<0.0030$ & $<0.0030$ & $<0.0030$ & $<0.0030$ & $\mathrm{mg} / \mathrm{L}$ & 0.015 & 0.020 & $<0.2$ \\
\hline Calcium & 1,870 & 1,800 & 1,710 & 1,810 & $\mathrm{mg} / \mathrm{L}$ & 13 & 50 & 2,087 \\
\hline Chromium & $<0.011$ & $<0.011$ & $<0.022$ & $<0.022$ & $\mathrm{mg} / \mathrm{L}$ & 0.030 & 0.060 & $<0.5$ \\
\hline Iron & $0.19 \mathrm{~J}$ & $<0.027$ & $0.24 \mathrm{~J}$ & $0.24 \mathrm{~J}$ & $\mathrm{mg} / \mathrm{L}$ & 0.25 & 0.25 & 0.91 \\
\hline Lead & $<0.018$ & $<0.018$ & $<0.036$ & $<0.036$ & $\mathrm{mg} / \mathrm{L}$ & 0.025 & 0.050 & 0.105 \\
\hline Magnesium & 1,220 & 1,180 & 1,130 & 1,200 & $\mathrm{mg} / \mathrm{L}$ & 13 & 50 & 1,247 \\
\hline Mercury & $<0.0020$ & $<0.0020$ & $<0.0010$ & $<0.0010$ & $\mathrm{mg} / \mathrm{L}$ & 0.0020 & 0.0010 & $<0.002$ \\
\hline Nickel & $<0.0025$ & $<0.0025$ & $<0.0050$ & $<0.0050$ & $\mathrm{mg} / \mathrm{L}$ & 0.050 & 0.10 & 0.490 \\
\hline Potassium & 530 & 505 & 478 & 514 & $\mathrm{mg} / \mathrm{L}$ & 25 & 100 & 799 \\
\hline Selenium & 0.0398 & 0.0301 & $<0.0020$ & $<0.0020$ & $\mathrm{mg} / \mathrm{L}$ & 0.0050 & 0.0020 & 0.150 \\
\hline Silver & $<0.0030$ & $<0.0030$ & $<0.0060$ & $<0.0060$ & $\mathrm{mg} / \mathrm{L}$ & 0.025 & 0.050 & $<0.5$ \\
\hline Sodium & 20,500 & 19,600 & 21,000 & 19,900 & $\mathrm{mg} / \mathrm{L}$ & 250 & 250 & 22,090 \\
\hline Thallium & $<0.0050$ & $<0.0050$ & $<0.0020$ & $<0.0020$ & $\mathrm{mg} / \mathrm{L}$ & 0.0050 & 0.0020 & 0.98 \\
\hline Vanadium & $0.023 \mathrm{~J}$ & $0.024 \mathrm{~J}$ & $0.033 \mathrm{~J}$ & $0.031 \mathrm{~J}$ & $\mathrm{mg} / \mathrm{L}$ & 0.25 & 0.50 & $<0.1$ \\
\hline
\end{tabular}

(a) $95^{\text {th }}$ Upper tolerance limit value, equivalent to $95 \%$ confidence limit. $95^{\text {th }}$ percentile for nitrate, TOC, TOX, TSS, and trace metals.

(b) Reporting limit. Value corresponds to method reporting limit (MRL).

(c) Standard unit.

(d) Not applicable.

(e) J Analyte detected at an estimated concentration between the MDL and the MRL (PQL). Less than $(<)$ concentrations correspond to MDL. 


\section{Waste Isolation Pilot Plant Annual Site Environmental Report for 2010 DOE/WIPP-11-2225}

\section{Appendix F - Groundwater Data Tables}

Table F.2 - Analytical Results for Groundwater Sampled from Well WQSP - 2

\begin{tabular}{|c|c|c|c|c|c|c|c|c|}
\hline \multirow[b]{2}{*}{ Parameter } & \multicolumn{2}{|c|}{ Round 30} & \multicolumn{2}{|c|}{ Round 31} & \multirow[b]{2}{*}{ Units } & \multicolumn{2}{|c|}{$\begin{array}{c}\text { Method } \\
\text { Reporting Limit }\end{array}$} & \multirow[b]{2}{*}{$\begin{array}{l}\text { 95th } \\
\text { UTLV }^{\mathrm{a}}\end{array}$} \\
\hline & Sample & Duplicate & Sample & Duplicate & & $\begin{array}{c}\text { Round } \\
30\end{array}$ & $\begin{array}{c}\text { Round } \\
\quad 31\end{array}$ & \\
\hline 1,1,1-Trichloroethane & $<1$ & $<1$ & $<1$ & $<1$ & $\mu \mathrm{g} / \mathrm{L}$ & 1 & 1 & $<\mathrm{RL}^{\mathrm{b}}$ \\
\hline 1,1,2,2-Tetrachloroethane & $<1$ & $<1$ & $<1$ & $<1$ & $\mu \mathrm{g} / \mathrm{L}$ & 1 & 1 & $<\mathrm{RL}$ \\
\hline 1,1,2-Trichloroethane & $<1$ & $<1$ & $<1$ & $<1$ & $\mu \mathrm{g} / \mathrm{L}$ & 1 & 1 & $<\mathrm{RL}$ \\
\hline 1,1-Dichloroethane & $<1$ & $<1$ & $<1$ & $<1$ & $\mu \mathrm{g} / \mathrm{L}$ & 1 & 1 & $<\mathrm{RL}$ \\
\hline 1,1-Dichloroethylene & $<1$ & $<1$ & $<1$ & $<1$ & $\mu \mathrm{g} / \mathrm{L}$ & 1 & 1 & $<\mathrm{RL}$ \\
\hline 1,2-Dichloroethane & $<1$ & $<1$ & $<1$ & $<1$ & $\mu \mathrm{g} / \mathrm{L}$ & 1 & 1 & $<R L$ \\
\hline Carbon tetrachloride & $<1$ & $<1$ & $<1$ & $<1$ & $\mu \mathrm{g} / \mathrm{L}$ & 1 & 1 & $<R L$ \\
\hline Chlorobenzene & $<1$ & $<1$ & $<1$ & $<1$ & $\mu \mathrm{g} / \mathrm{L}$ & 1 & 1 & $<\mathrm{RL}$ \\
\hline Chloroform & $<1$ & $<1$ & $<1$ & $<1$ & $\mu \mathrm{g} / \mathrm{L}$ & 1 & 1 & $<\mathrm{RL}$ \\
\hline cis-1,2-Dichloroethylene & $<1$ & $<1$ & $<1$ & $<1$ & $\mu \mathrm{g} / \mathrm{L}$ & 1 & 1 & $<\mathrm{RL}$ \\
\hline trans-1,2-Dichloroethylene & $<1$ & $<1$ & $<1$ & $<1$ & $\mu \mathrm{g} / \mathrm{L}$ & 1 & 1 & $<R L$ \\
\hline 2-butanone & $<5$ & $<5$ & $<5$ & $<5$ & $\mu \mathrm{g} / \mathrm{L}$ & 5 & 5 & $<\mathrm{RL}$ \\
\hline Isobutanol & $<5$ & $<5$ & $<5$ & $<5$ & $\mu \mathrm{g} / \mathrm{L}$ & 5 & 5 & $<R L$ \\
\hline Methylene chloride & $<5$ & $<5$ & $<5$ & $<5$ & $\mu \mathrm{g} / \mathrm{L}$ & 5 & 5 & $<\mathrm{RL}$ \\
\hline Tetrachloroethylene & $<1$ & $<1$ & $<1$ & $<1$ & $\mu \mathrm{g} / \mathrm{L}$ & 1 & 1 & $<\mathrm{RL}$ \\
\hline Toluene & $<1$ & $<1$ & $<1$ & $<1$ & $\mu \mathrm{g} / \mathrm{L}$ & 1 & 1 & $<\mathrm{RL}$ \\
\hline Trichloroethylene & $<1$ & $<1$ & $<1$ & $<1$ & $\mu \mathrm{g} / \mathrm{L}$ & 1 & 1 & $<\mathrm{RL}$ \\
\hline Trichlorofluoromethane & $<1$ & $<1$ & $<1$ & $<1$ & $\mu \mathrm{g} / \mathrm{L}$ & 1 & 1 & $<\mathrm{RL}$ \\
\hline Vinyl chloride & $<1$ & $<1$ & $<1$ & $<1$ & $\mu \mathrm{g} / \mathrm{L}$ & 1 & 1 & $<\mathrm{RL}$ \\
\hline Xylene & $<1$ & $<1$ & $<1$ & $<1$ & $\mu \mathrm{g} / \mathrm{L}$ & 1 & 1 & $<R L$ \\
\hline 1,2-Dichlorobenzene & $<5$ & $<5$ & $<5$ & $<5$ & $\mu \mathrm{g} / \mathrm{L}$ & 5 & 5 & $<\mathrm{RL}$ \\
\hline 1,4-Dichlorobenzene & $<5$ & $<5$ & $<5$ & $<5$ & $\mu \mathrm{g} / \mathrm{L}$ & 5 & 5 & $<\mathrm{RL}$ \\
\hline 2,4-Dinitrophenol & $<5$ & $<5$ & $<5$ & $<5$ & $\mu \mathrm{g} / \mathrm{L}$ & 5 & 5 & $<R L$ \\
\hline 2,4-Dinitrotoluene & $<5$ & $<5$ & $<5$ & $<5$ & $\mu \mathrm{g} / \mathrm{L}$ & 5 & 5 & $<\mathrm{RL}$ \\
\hline 2-Methylphenol & $<5$ & $<5$ & $<5$ & $<5$ & $\mu \mathrm{g} / \mathrm{L}$ & 5 & 5 & $<\mathrm{RL}$ \\
\hline 3-Methylphenol/4-Methylphenol & $<5$ & $<5$ & $<5$ & $<5$ & $\mu \mathrm{g} / \mathrm{L}$ & 5 & 5 & $<\mathrm{RL}$ \\
\hline Hexachlorobenzene & $<5$ & $<5$ & $<5$ & $<5$ & $\mu \mathrm{g} / \mathrm{L}$ & 5 & 5 & $<\mathrm{RL}$ \\
\hline Hexachloroethane & $<5$ & $<5$ & $<5$ & $<5$ & $\mu \mathrm{g} / \mathrm{L}$ & 5 & 5 & $<\mathrm{RL}$ \\
\hline Nitrobenzene & $<5$ & $<5$ & $<5$ & $<5$ & $\mu \mathrm{g} / \mathrm{L}$ & 5 & 5 & $<\mathrm{RL}$ \\
\hline Pentachlorophenol & $<5$ & $<5$ & $<5$ & $<5$ & $\mu \mathrm{g} / \mathrm{L}$ & 5 & 5 & $<\mathrm{RL}$ \\
\hline Pyridine & $<5$ & $<5$ & $<5$ & $<5$ & $\mu \mathrm{g} / \mathrm{L}$ & 5 & 5 & $<\mathrm{RL}$ \\
\hline Alkalinity & 45.3 & 45.8 & 47.2 & 47.3 & $\mathrm{mg} / \mathrm{L}$ & 20 & 20 & 70.3 \\
\hline Chloride & 38,200 & 37,500 & 39,900 & 38,500 & $\mathrm{mg} / \mathrm{L}$ & 500 & 500 & 39,670 \\
\hline Specific Gravity & 1.044 & 1.042 & 1.040 & 1.040 & $\mathrm{~g} / \mathrm{ml}$ & $N / A^{c}$ & $N / A^{c}$ & 1.06 \\
\hline Nitrate (as N) & $<2.1$ & $<2.1$ & $<1.1$ & $<1.1$ & $\mathrm{mg} / \mathrm{L}$ & 20 & 5.0 & $<10.0$ \\
\hline $\mathrm{pH}$ & 7.26 & 7.28 & 7.24 & 7.25 & $S U^{d}$ & 0.1 & 0.1 & $7.0-7.6$ \\
\hline
\end{tabular}




\section{Waste Isolation Pilot Plant Annual Site Environmental Report for 2010 DOE/WIPP-11-2225}

\section{Appendix F - Groundwater Data Tables}

Table F.2 - Analytical Results for Groundwater Sampled from Well WQSP - 2

\begin{tabular}{|c|c|c|c|c|c|c|c|c|}
\hline \multirow[b]{2}{*}{ Parameter } & \multicolumn{2}{|c|}{ Round 30} & \multicolumn{2}{|c|}{ Round 31} & \multirow[b]{2}{*}{ Units } & \multicolumn{2}{|c|}{$\begin{array}{c}\text { Method } \\
\text { Reporting Limit }\end{array}$} & \multirow[b]{2}{*}{$\begin{array}{l}\text { 95th } \\
\text { UTLV }^{\mathrm{a}}\end{array}$} \\
\hline & Sample & Duplicate & Sample & Duplicate & & $\begin{array}{l}\text { Round } \\
\qquad 30\end{array}$ & $\begin{array}{l}\text { Round } \\
31\end{array}$ & \\
\hline Specific conductance & 112,000 & 112,000 & 120,000 & 116,000 & $\mu \mathrm{mhos} / \mathrm{cm}$ & 0.5 & 0.5 & 124,000 \\
\hline Sulfate & 5,710 & 5,700 & 5,790 & 5,750 & $\mathrm{mg} / \mathrm{L}$ & 100 & 100 & 6,590 \\
\hline Total dissolved solids & 65,200 & 64,900 & 61,200 & 62,900 & $\mathrm{mg} / \mathrm{L}$ & 1,000 & 1,000 & 80,500 \\
\hline Total organic carbon & $0.34 \mathrm{~J}$ & $0.53 \mathrm{~J}$ & $0.41 \mathrm{~J}$ & $0.39 \mathrm{~J}$ & $\mathrm{mg} / \mathrm{L}$ & 1.0 & 1.0 & 7.97 \\
\hline Total organic halogen & 0.078 & 0.16 & 0.18 & 0.34 & $\mathrm{mg} / \mathrm{L}$ & 0.04 & 0.05 & 63.8 \\
\hline Total suspended solids & 37 & 38 & 28 & 25 & $\mathrm{mg} / \mathrm{L}$ & 10 & 10 & 43.0 \\
\hline Antimony & $<0.010$ & $<0.010$ & $<0.0050$ & $<0.0050$ & $\mathrm{mg} / \mathrm{L}$ & 0.010 & 0.0050 & $<0.5$ \\
\hline Arsenic & $<0.010$ & $<0.010$ & $<0.0050$ & $<0.0050$ & $\mathrm{mg} / \mathrm{L}$ & 0.010 & 0.0050 & 0.062 \\
\hline Barium & $0.028 \mathrm{~J}$ & $0.027 \mathrm{~J}$ & $<0.029 \mathrm{~J}$ & $0.029 \mathrm{~J}$ & $\mathrm{mg} / \mathrm{L}$ & 0.10 & 0.050 & $<1.0$ \\
\hline Beryllium & $0.0054 \mathrm{~J}$ & $0.0059 \mathrm{~J}$ & 0.0021 & 0.0023 & $\mathrm{mg} / \mathrm{L}$ & 0.030 & 0.015 & $<1.0$ \\
\hline Cadmium & $<0.0030$ & $<0.0030$ & $<0.0015$ & $<0.0015$ & $\mathrm{mg} / \mathrm{L}$ & 0.020 & 0.010 & $<0.5$ \\
\hline Calcium & 1,500 & 1,590 & 1,680 & 1,620 & $\mathrm{mg} / \mathrm{L}$ & 25 & 10 & 1,827 \\
\hline Chromium & $<0.022$ & $<0.022$ & $<0.011$ & $<0.011$ & $\mathrm{mg} / \mathrm{L}$ & 0.060 & 0.030 & $<0.5$ \\
\hline Iron & $<0.053$ & $0.15 \mathrm{~J}$ & $0.24 \mathrm{~J}$ & $0.27 \mathrm{~J}$ & $\mathrm{mg} / \mathrm{L}$ & 0.50 & 0.25 & 0.910 \\
\hline Lead & $<0.036$ & $<0.036$ & $<0.018$ & $<0.018$ & $\mathrm{mg} / \mathrm{L}$ & 0.050 & 0.025 & 0.163 \\
\hline Magnesium & 1,050 & 1,120 & 1,130 & 1,090 & $\mathrm{mg} / \mathrm{L}$ & 25 & 10 & 1,244 \\
\hline Mercury & $<0.0010$ & $<0.0010$ & $<0.0010$ & $<0.0010$ & $\mathrm{mg} / \mathrm{L}$ & 0.0010 & 0.0010 & $<0.002$ \\
\hline Nickel & $<0.0050$ & $<0.0050$ & $<0.0025$ & $<0.0025$ & $\mathrm{mg} / \mathrm{L}$ & 0.10 & 0.050 & 0.370 \\
\hline Potassium & 498 & 559 & 545 & 518 & $\mathrm{mg} / \mathrm{L}$ & 10 & 20 & 845 \\
\hline Selenium & $<0.010$ & $<0.010$ & $<0.0050$ & $<0.0050$ & $\mathrm{mg} / \mathrm{L}$ & 0.010 & 0.0050 & 0.150 \\
\hline Silver & $<0.0060$ & $<0.0060$ & $<0.0030$ & $<0.0030$ & $\mathrm{mg} / \mathrm{L}$ & 0.050 & 0.025 & $<0.5$ \\
\hline Sodium & 21,700 & 21,400 & 16,200 & 19,200 & $\mathrm{mg} / \mathrm{L}$ & 250 & 250 & 21,900 \\
\hline Thallium & $<0.010$ & $<0.010$ & $<0.0050$ & $<0.0050$ & $\mathrm{mg} / \mathrm{L}$ & 0.010 & 0.0050 & 0.980 \\
\hline Vanadium & $0.036 \mathrm{~J}$ & $0.037 \mathrm{~J}$ & $0.022 \mathrm{~J}$ & $0.023 \mathrm{~J}$ & $\mathrm{mg} / \mathrm{L}$ & 0.50 & 0.25 & $<0.1$ \\
\hline $\begin{array}{l}\text { (a) } 95^{\text {th }} \text { Upper tolerance } \\
\text { and trace metals. } \\
\text { (b) Reporting limit. Value } \\
\text { (c) Not applicable. } \\
\text { (d) Standard unit. } \\
\text { (e) J Analyte detected a } \\
\text { concentrations corre }\end{array}$ & $\begin{array}{l}\text { e, equival } \\
\text { onds to } m\end{array}$ & $\begin{array}{l}\text { ent to } 95 \% \\
\text { ethod repor }\end{array}$ & $\begin{array}{l}\text { confidence } \\
\text { ting limit ( }\end{array}$ & $\begin{array}{l}\text { limit; } 95^{\text {th }} p \\
\text { MRL). }\end{array}$ & ercentile for & nitrate, $\mathrm{T}$ & C, TOX, & TSS, \\
\hline
\end{tabular}




\section{Waste Isolation Pilot Plant Annual Site Environmental Report for 2010 DOE/WIPP-11-2225}

Appendix F - Groundwater Data Tables

Table F.3 - Analytical Results for Groundwater Sampled from Well WQSP - 3

\begin{tabular}{|c|c|c|c|c|c|c|c|c|}
\hline \multirow[b]{2}{*}{ Parameter } & \multicolumn{2}{|c|}{ Round 30} & \multicolumn{2}{|c|}{ Round 31} & \multirow[b]{2}{*}{ Units } & \multicolumn{2}{|c|}{$\begin{array}{c}\text { Method } \\
\text { Reporting Limit }\end{array}$} & \multirow[b]{2}{*}{$\begin{array}{l}\text { 95th } \\
\text { UTLV }^{\mathrm{a}}\end{array}$} \\
\hline & Sample & Duplicate & Sample & Duplicate & & $\begin{array}{c}\text { Round } \\
30\end{array}$ & $\begin{array}{c}\text { Round } \\
31\end{array}$ & \\
\hline 1,1,1-Trichloroethane & $<1$ & $<1$ & $<1$ & $<1$ & $\mu \mathrm{g} / \mathrm{L}$ & 1 & 1 & $<\mathrm{RL}^{\mathrm{b}}$ \\
\hline 1,1,2,2-Tetrachloroethane & $<1$ & $<1$ & $<1$ & $<1$ & $\mu g / L$ & 1 & 1 & $<\mathrm{RL}$ \\
\hline 1,1,2-Trichloroethane & $<1$ & $<1$ & $<1$ & $<1$ & $\mu g / L$ & 1 & 1 & $<\mathrm{RL}$ \\
\hline 1,1-Dichloroethane & $<1$ & $<1$ & $<1$ & $<1$ & $\mu g / L$ & 1 & 1 & $<R L$ \\
\hline 1,1-Dichloroethylene & $<1$ & $<1$ & $<1$ & $<1$ & $\mu g / L$ & 1 & 1 & $<R L$ \\
\hline 1,2-Dichloroethane & $<1$ & $<1$ & $<1$ & $<1$ & $\mu \mathrm{g} / \mathrm{L}$ & 1 & 1 & $<\mathrm{RL}$ \\
\hline Carbon tetrachloride & $<1$ & $<1$ & $<1$ & $<1$ & $\mu g / L$ & 1 & 1 & $<\mathrm{RL}$ \\
\hline Chlorobenzene & $<1$ & $<1$ & $<1$ & $<1$ & $\mu g / L$ & 1 & 1 & $<R L$ \\
\hline Chloroform & $<1$ & $<1$ & $<1$ & $<1$ & $\mu g / L$ & 1 & 1 & $<R L$ \\
\hline cis-1,2-Dichloroethylene & $<1$ & $<1$ & $<1$ & $<1$ & $\mu g / L$ & 1 & 1 & $<R L$ \\
\hline trans-1,2-Dichloroethylene & $<1$ & $<1$ & $<1$ & $<1$ & $\mu \mathrm{g} / \mathrm{L}$ & 1 & 1 & $<\mathrm{RL}$ \\
\hline 2-butanone & $<5$ & $<5$ & $<5$ & $<5$ & $\mu g / L$ & 5 & 5 & $<R L$ \\
\hline Isobutanol & $<5$ & $<5$ & $<5$ & $<5$ & $\mu g / L$ & 5 & 5 & $<R L$ \\
\hline Methylene chloride & $<5$ & $<5$ & $<5$ & $<5$ & $\mu g / L$ & 5 & 5 & $<\mathrm{RL}$ \\
\hline Tetrachloroethylene & $<1$ & $<1$ & $<1$ & $<1$ & $\mu g / L$ & 1 & 1 & $<\mathrm{RL}$ \\
\hline Toluene & $<1$ & $<1$ & $<1$ & $<1$ & $\mu g / L$ & 1 & 1 & $<\mathrm{RL}$ \\
\hline Trichloroethylene & $<1$ & $<1$ & $<1$ & $<1$ & $\mu \mathrm{g} / \mathrm{L}$ & 1 & 1 & $<\mathrm{RL}$ \\
\hline Trichlorofluoromethane & $<1$ & $<1$ & $<1$ & $<1$ & $\mu \mathrm{g} / \mathrm{L}$ & 1 & 1 & $<\mathrm{RL}$ \\
\hline Vinyl chloride & $<1$ & $<1$ & $<1$ & $<1$ & $\mu \mathrm{g} / \mathrm{L}$ & 1 & 1 & $<\mathrm{RL}$ \\
\hline Xylene & $<1$ & $<1$ & $<1$ & $<1$ & $\mu g / L$ & 1 & 1 & $<\mathrm{RL}$ \\
\hline 1,2-Dichlorobenzene & $<5$ & $<5$ & $<5$ & $<5$ & $\mu g / L$ & 5 & 5 & $<\mathrm{RL}$ \\
\hline 1,4-Dichlorobenzene & $<5$ & $<5$ & $<5$ & $<5$ & $\mu g / L$ & 5 & 5 & $<\mathrm{RL}$ \\
\hline 2,4-Dinitrophenol & $<5$ & $<5$ & $<5$ & $<5$ & $\mu \mathrm{g} / \mathrm{L}$ & 5 & 5 & $<\mathrm{RL}$ \\
\hline 2,4-Dinitrotoluene & $<5$ & $<5$ & $<5$ & $<5$ & $\mu g / L$ & 5 & 5 & $<\mathrm{RL}$ \\
\hline 2-Methylphenol & $<5$ & $<5$ & $<5$ & $<5$ & $\mu g / L$ & 5 & 5 & $<\mathrm{RL}$ \\
\hline 3-Methylphenol/4-Methylphenol & $<5$ & $<5$ & $<5$ & $<5$ & $\mu g / L$ & 5 & 5 & $<\mathrm{RL}$ \\
\hline Hexachlorobenzene & $<5$ & $<5$ & $<5$ & $<5$ & $\mu \mathrm{g} / \mathrm{L}$ & 5 & 5 & $<\mathrm{RL}$ \\
\hline Hexachloroethane & $<5$ & $<5$ & $<5$ & $<5$ & $\mu \mathrm{g} / \mathrm{L}$ & 5 & 5 & $<\mathrm{RL}$ \\
\hline Nitrobenzene & $<5$ & $<5$ & $<5$ & $<5$ & $\mu \mathrm{g} / \mathrm{L}$ & 5 & 5 & $<\mathrm{RL}$ \\
\hline Pentachlorophenol & $<5$ & $<5$ & $<5$ & $<5$ & $\mu \mathrm{g} / \mathrm{L}$ & 5 & 5 & $<\mathrm{RL}$ \\
\hline Pyridine & $<5$ & $<5$ & $<5$ & $<5$ & $\mu \mathrm{g} / \mathrm{L}$ & 5 & 5 & $<\mathrm{RL}$ \\
\hline Alkalinity & 30.7 & 29.9 & 35.4 & 35.6 & $\mathrm{mg} / \mathrm{L}$ & 20 & 20 & 54.4 \\
\hline Chloride & 140,000 & 150,000 & 144,000 & 148,000 & $\mathrm{mg} / \mathrm{L}$ & 1,000 & 2,000 & 149,100 \\
\hline Specific Gravity & 1.140 & 1.143 & 1.141 & 1.138 & $\mathrm{~g} / \mathrm{ml}$ & $N / A^{c}$ & $N / A^{c}$ & 1.17 \\
\hline Nitrate (as N) & $<2.1$ & $<2.1$ & $<1.1$ & $<1.1$ & $\mathrm{mg} / \mathrm{L}$ & 20 & 5.0 & $<12.0$ \\
\hline $\mathrm{pH}$ & 6.77 & 6.79 & 6.86 & 6.88 & $S U^{d}$ & 0.1 & 0.1 & $6.6-7.2$ \\
\hline
\end{tabular}




\section{Waste Isolation Pilot Plant Annual Site Environmental Report for 2010 DOE/WIPP-11-2225}

\section{Appendix F - Groundwater Data Tables}

Table F.3 - Analytical Results for Groundwater Sampled from Well WQSP - 3

\begin{tabular}{|c|c|c|c|c|c|c|c|c|}
\hline \multirow[b]{2}{*}{ Parameter } & \multicolumn{2}{|c|}{ Round 30} & \multicolumn{2}{|c|}{ Round 31} & \multirow[b]{2}{*}{ Units } & \multicolumn{2}{|c|}{$\begin{array}{c}\text { Method } \\
\text { Reporting Limit }\end{array}$} & \multirow[b]{2}{*}{$\begin{array}{l}\text { 95th } \\
\text { UTLV }^{\mathrm{a}}\end{array}$} \\
\hline & Sample & Duplicate & Sample & Duplicate & & $\begin{array}{c}\text { Round } \\
30\end{array}$ & $\begin{array}{c}\text { Round } \\
31\end{array}$ & \\
\hline Specific conductance & 328,000 & 329,000 & 340,000 & 343,000 & $\mu \mathrm{mhos} / \mathrm{c}$ & 0.5 & $0.5^{c}$ & 517,000 \\
\hline Sulfate & 8,070 & 8,080 & 8,160 & 7,930 & $\mathrm{mg} / \mathrm{L}$ & 100 & 100 & 8,015 \\
\hline Total dissolved solids & 222,000 & 232,00 & 222,000 & 225,000 & $\mathrm{mg} / \mathrm{L}$ & 2,000 & 1,000 & 261,000 \\
\hline Total organic carbon & $0.28 \mathrm{~J}$ & 1.61 & $0.40 \mathrm{~J}^{\mathrm{e}}$ & $0.30 \mathrm{~J}^{\mathrm{e}}$ & $\mathrm{mg} / \mathrm{L}$ & 1.0 & 1.0 & $<5.0$ \\
\hline Total organic halogen & 0.50 & 0.38 & 0.51 & 0.87 & $\mathrm{mg} / \mathrm{L}$ & 0.04 & 0.40 & 55.0 \\
\hline Total suspended solids & 96 & 115 & 99 & 124 & $\mathrm{mg} / \mathrm{L}$ & 10 & 10 & 107.0 \\
\hline Antimony & $<0.010$ & $<0.010$ & $<0.0050$ & $<0.0050$ & $\mathrm{mg} / \mathrm{L}$ & 0.010 & 0.0050 & $<1.0$ \\
\hline Arsenic & $<0.010$ & $<0.010$ & $<0.0050$ & $<0.0050$ & $\mathrm{mg} / \mathrm{L}$ & 0.010 & 0.0050 & $<1.0$ \\
\hline Barium & $0.063 \mathrm{~J}^{\mathrm{e}}$ & $0.045 \mathrm{~J}^{\mathrm{e}}$ & $0.022 \mathrm{~J}^{\mathrm{e}}$ & $0.027 \mathrm{~J}^{\mathrm{e}}$ & $\mathrm{mg} / \mathrm{L}$ & 0.50 & 0.25 & $<1.0$ \\
\hline Beryllium & $0.020 \mathrm{~J}^{\mathrm{e}}$ & $<0.010$ & $0.021 \mathrm{~J}^{\mathrm{e}}$ & $0.021 \mathrm{~J}^{\mathrm{e}}$ & $\mathrm{mg} / \mathrm{L}$ & 0.15 & 0.075 & $<0.1$ \\
\hline Cadmium & $<0.015$ & $<0.015$ & $<0.075$ & $<0.075$ & $\mathrm{mg} / \mathrm{L}$ & 0.10 & 0.050 & $<0.5$ \\
\hline Calcium & 1,520 & 1,480 & 1,490 & 1,310 & $\mathrm{mg} / \mathrm{L}$ & 50 & 50 & 1,680 \\
\hline Chromium & $<0.11$ & $<0.11$ & $<0.055$ & $<0.055$ & $\mathrm{mg} / \mathrm{L}$ & 0.30 & 0.15 & $<2.0$ \\
\hline Iron & $0.89 \mathrm{~J}^{\mathrm{e}}$ & $0.34 \mathrm{~J}^{\mathrm{e}}$ & $0.24 \mathrm{~J}$ & $0.32 \mathrm{~J}$ & $\mathrm{mg} / \mathrm{L}$ & 2.5 & 1.25 & $<4.0$ \\
\hline Lead & $<0.18$ & $<0.18$ & $<0.090$ & $<0.090$ & $\mathrm{mg} / \mathrm{L}$ & 0.25 & 0.12 & 0.80 \\
\hline Magnesium & 2,490 & 2,430 & 2,250 & 2,010 & $\mathrm{mg} / \mathrm{L}$ & 50 & 12 & 2,625 \\
\hline Mercury & $<0.0010$ & $<0.0010$ & $<0.0010$ & $<0.0010$ & $\mathrm{mg} / \mathrm{L}$ & 0.0010 & 0.0010 & $<0.002$ \\
\hline Nickel & $<0.025$ & $<0.025$ & $<0.012$ & $<0.012$ & $\mathrm{mg} / \mathrm{L}$ & 0.50 & 0.25 & $<5.0$ \\
\hline Potassium & 1,570 & 1,560 & 1,600 & 1,390 & $\mathrm{mg} / \mathrm{L}$ & 100 & 25 & 3,438 \\
\hline Selenium & $<0.010$ & $<0.010$ & $<0.0050$ & $<0.0050$ & $\mathrm{mg} / \mathrm{L}$ & 0.010 & 0.0050 & $<2.0$ \\
\hline Silver & $<0.030$ & $<0.030$ & $<0.015$ & $<0.015$ & $\mathrm{mg} / \mathrm{L}$ & 0.25 & 0.12 & 0.310 \\
\hline Sodium & 81,700 & 76,800 & 75,700 & 73,800 & $\mathrm{mg} / \mathrm{L}$ & 500 & 1,250 & 140,400 \\
\hline Thallium & $<0.010$ & $<0.010$ & $<0.0050$ & $<0.0050$ & $\mathrm{mg} / \mathrm{L}$ & 0.010 & 0.0050 & 5.80 \\
\hline Vanadium & $0.12 \mathrm{~J}^{\mathrm{e}}$ & $0.067 \mathrm{~J}^{\mathrm{e}}$ & $0.11 \mathrm{~J}^{\mathrm{e}}$ & $0.0 .096 \mathrm{~J}^{\mathrm{e}}$ & $\mathrm{mg} / \mathrm{L}$ & 2.5 & 1.2 & $<5.0$ \\
\hline $\begin{array}{l}\text { (a) } 95^{\text {th }} \text { Upper tolerance } \\
\text { and trace metals. } \\
\text { (b) Reporting limit. Value } \\
\text { (c) Not applicable. } \\
\text { (d) Standard unit. } \\
\text { (e) J Analyte detected a } \\
\text { concentrations corre }\end{array}$ & le, equiva & $\begin{array}{l}\text { ent to } 95 \% \text { c } \\
\text { ethod report }\end{array}$ & $\begin{array}{l}\text { confidence } \\
\text { ing limit ( }\end{array}$ & $\begin{array}{l}\text { limit; } 95^{\text {th }} p \epsilon \\
\text { MRL). }\end{array}$ & rcentile for & nitrate, $\mathrm{T}$ & DC, TOX & TSS, \\
\hline
\end{tabular}




\section{Waste Isolation Pilot Plant Annual Site Environmental Report for 2010 DOE/WIPP-11-2225}

\section{Appendix F - Groundwater Data Tables}

Table F.4 - Analytical Results for Groundwater Sampled from Well WQSP - 4

\begin{tabular}{|c|c|c|c|c|c|c|c|c|}
\hline \multirow[b]{2}{*}{ Parameter } & \multicolumn{2}{|c|}{ Round 30} & \multicolumn{2}{|c|}{ Round 31} & \multirow[b]{2}{*}{ Units } & \multicolumn{2}{|c|}{$\begin{array}{c}\text { Method } \\
\text { Reporting Limit }\end{array}$} & \multirow[b]{2}{*}{$\begin{array}{l}\text { 95th } \\
\text { UTLV }^{\mathrm{a}}\end{array}$} \\
\hline & Sample & Duplicate & Sample & Duplicate & & $\begin{array}{l}\text { Round } \\
30\end{array}$ & $\begin{array}{c}\text { Round } \\
31\end{array}$ & \\
\hline 1,1,1-Trichloroethane & $<1$ & $<1$ & $<1$ & $<1$ & $\mu \mathrm{g} / \mathrm{L}$ & 1 & 1 & $<\mathrm{RL}^{\mathrm{b}}$ \\
\hline 1,1,2,2-Tetrachloroethane & $<1$ & $<1$ & $<1$ & $<1$ & $\mu \mathrm{g} / \mathrm{L}$ & 1 & 1 & $<\mathrm{RL}$ \\
\hline 1,1,2-Trichloroethane & $<1$ & $<1$ & $<1$ & $<1$ & $\mu \mathrm{g} / \mathrm{L}$ & 1 & 1 & $<R L$ \\
\hline 1,1-Dichloroethane & $<1$ & $<1$ & $<1$ & $<1$ & $\mu g / L$ & 1 & 1 & $<\mathrm{RL}$ \\
\hline 1,1-Dichloroethylene & $<1$ & $<1$ & $<1$ & $<1$ & $\mu \mathrm{g} / \mathrm{L}$ & 1 & 1 & $<\mathrm{RL}$ \\
\hline 1,2-Dichloroethane & $<1$ & $<1$ & $<1$ & $<1$ & $\mu \mathrm{g} / \mathrm{L}$ & 1 & 1 & $<\mathrm{RL}$ \\
\hline Carbon tetrachloride & $<1$ & $<1$ & $<1$ & $<1$ & $\mu \mathrm{g} / \mathrm{L}$ & 1 & 1 & $<\mathrm{RL}$ \\
\hline Chlorobenzene & $<1$ & $<1$ & $<1$ & $<1$ & $\mu \mathrm{g} / \mathrm{L}$ & 1 & 1 & $<\mathrm{RL}$ \\
\hline Chloroform & $<1$ & $<1$ & $<1$ & $<1$ & $\mu \mathrm{g} / \mathrm{L}$ & 1 & 1 & $<R L$ \\
\hline cis-1,2-Dichloroethylene & $<1$ & $<1$ & $<1$ & $<1$ & $\mu \mathrm{g} / \mathrm{L}$ & 1 & 1 & $<R L$ \\
\hline trans-1,2-Dichloroethylene & $<1$ & $<1$ & $<1$ & $<1$ & $\mu \mathrm{g} / \mathrm{L}$ & 1 & 1 & $<R L$ \\
\hline 2-butanone & $<5$ & $<5$ & $<5$ & $<5$ & $\mu g / L$ & 5 & 5 & $<\mathrm{RL}$ \\
\hline Isobutanol & $<5$ & $<5$ & $<5$ & $<5$ & $\mu g / L$ & 5 & 5 & $<R L$ \\
\hline Methylene chloride & $<5$ & $<5$ & $<5$ & $<5$ & $\mu \mathrm{g} / \mathrm{L}$ & 5 & 5 & $<\mathrm{RL}$ \\
\hline Tetrachloroethylene & $<1$ & $<1$ & $<1$ & $<1$ & $\mu \mathrm{g} / \mathrm{L}$ & 1 & 1 & $<R L$ \\
\hline Toluene & $<1$ & $<1$ & $<1$ & $<1$ & $\mu \mathrm{g} / \mathrm{L}$ & 1 & 1 & $<\mathrm{RL}$ \\
\hline Trichloroethylene & $<1$ & $<1$ & $<1$ & $<1$ & $\mu \mathrm{g} / \mathrm{L}$ & 1 & 1 & $<R L$ \\
\hline Trichlorofluoromethane & $<1$ & $<1$ & $<1$ & $<1$ & $\mu \mathrm{g} / \mathrm{L}$ & 1 & 1 & $<R L$ \\
\hline Vinyl chloride & $<1$ & $<1$ & $<1$ & $<1$ & $\mu \mathrm{g} / \mathrm{L}$ & 1 & 1 & $<R L$ \\
\hline Xylene & $<1$ & $<1$ & $<1$ & $<1$ & $\mu \mathrm{g} / \mathrm{L}$ & 1 & 1 & $<R L$ \\
\hline 1,2-Dichlorobenzene & $<5$ & $<5$ & $<5$ & $<5$ & $\mu \mathrm{g} / \mathrm{L}$ & 5 & 5 & $<\mathrm{RL}$ \\
\hline 1,4-Dichlorobenzene & $<5$ & $<5$ & $<5$ & $<5$ & $\mu \mathrm{g} / \mathrm{L}$ & 5 & 5 & $<R L$ \\
\hline 2,4-Dinitrophenol & $<5$ & $<5$ & $<5$ & $<5$ & $\mu \mathrm{g} / \mathrm{L}$ & 5 & 5 & $<\mathrm{RL}$ \\
\hline 2,4-Dinitrotoluene & $<5$ & $<5$ & $<5$ & $<5$ & $\mu g / L$ & 5 & 5 & $<\mathrm{RL}$ \\
\hline 2-Methylphenol & $<5$ & $<5$ & $<5$ & $<5$ & $\mu \mathrm{g} / \mathrm{L}$ & 5 & 5 & $<\mathrm{RL}$ \\
\hline 3-Methylphenol/4-Methylphenol & $<5$ & $<5$ & $<5$ & $<5$ & $\mu \mathrm{g} / \mathrm{L}$ & 5 & 5 & $<\mathrm{RL}$ \\
\hline Hexachlorobenzene & $<5$ & $<5$ & $<5$ & $<5$ & $\mu \mathrm{g} / \mathrm{L}$ & 5 & 5 & $<\mathrm{RL}$ \\
\hline Hexachloroethane & $<5$ & $<5$ & $<5$ & $<5$ & $\mu \mathrm{g} / \mathrm{L}$ & 5 & 5 & $<R L$ \\
\hline Nitrobenzene & $<5$ & $<5$ & $<5$ & $<5$ & $\mu \mathrm{g} / \mathrm{L}$ & 5 & 5 & $<\mathrm{RL}$ \\
\hline Pentachlorophenol & $<5$ & $<5$ & $<5$ & $<5$ & $\mu \mathrm{g} / \mathrm{L}$ & 5 & 5 & $<\mathrm{RL}$ \\
\hline Pyridine & $<5$ & $<5$ & $<5$ & $<5$ & $\mu \mathrm{g} / \mathrm{L}$ & 5 & 5 & $<R L$ \\
\hline Alkalinity & 37.0 & 38.0 & 39.0 & 38.9 & $\mathrm{mg} / \mathrm{L}$ & 20 & 20 & 47.1 \\
\hline Chloride & 65,500 & 69,000 & 61,700 & 53,600 & $\mathrm{mg} / \mathrm{L}$ & 500 & 1,000 & 63,960 \\
\hline Specific Gravity & 1.074 & 1.074 & 1.067 & 1.068 & $\mathrm{~g} / \mathrm{ml}$ & $N / A^{c}$ & $N / A^{c}$ & 1.09 \\
\hline Nitrate (as N) & $<1.1$ & $<1.1$ & $<2.1$ & $<2.1$ & $\mathrm{mg} / \mathrm{L}$ & 5.0 & 10 & $<10.0$ \\
\hline $\mathrm{pH}$ & 7.17 & 7.17 & 7.22 & 7.21 & $S U^{d}$ & $N / A^{c}$ & $N / A^{c}$ & $6.8-7.6$ \\
\hline
\end{tabular}




\section{Waste Isolation Pilot Plant Annual Site Environmental Report for 2010 DOE/WIPP-11-2225}

\section{Appendix F - Groundwater Data Tables}

Table F.4 - Analytical Results for Groundwater Sampled from Well WQSP - 4

\begin{tabular}{|c|c|c|c|c|c|c|c|c|}
\hline \multirow[b]{2}{*}{ Parameter } & \multicolumn{2}{|c|}{ Round 30} & \multicolumn{2}{|c|}{ Round 31} & \multirow[b]{2}{*}{ Units } & \multicolumn{2}{|c|}{$\begin{array}{c}\text { Method } \\
\text { Reporting Limit }\end{array}$} & \multirow[b]{2}{*}{$\begin{array}{l}\text { 95th } \\
\text { UTLV }^{\mathrm{a}}\end{array}$} \\
\hline & Sample & Duplicate & Sample & Duplicate & & $\begin{array}{c}\text { Round } \\
30\end{array}$ & $\begin{array}{l}\text { Round } \\
31\end{array}$ & \\
\hline Specific conductance & 181,000 & 183,000 & 184,000 & 184,000 & $\mu \mathrm{mhos} / \mathrm{cm}$ & 0.5 & 0.5 & 319,800 \\
\hline Sulfate & 7,410 & 8,490 & 8,080 & 7,970 & $\mathrm{mg} / \mathrm{L}$ & 100 & 100 & 7,927 \\
\hline Total dissolved solids & 100,00 & 107,000 & 99,400 & 99,900 & $\mathrm{mg} / \mathrm{L}$ & 1,000 & 1,000 & 123,500 \\
\hline Total organic carbon & $0.84 \mathrm{~J}$ & $0.28 \mathrm{~J}$ & $0.36 \mathrm{~J}^{\mathrm{e}}$ & $0.48 \mathrm{~J}^{\mathrm{e}}$ & $\mathrm{mg} / \mathrm{L}$ & 1.0 & 1.0 & $<5.0$ \\
\hline Total organic halogen & 0.20 & 0.25 & 0.40 & 0.45 & $\mathrm{mg} / \mathrm{L}$ & 0.050 & 0.010 & 17.0 \\
\hline Total suspended solids & 131 & 46 & 65 & 80 & $\mathrm{mg} / \mathrm{L}$ & 10 & 10 & 57.0 \\
\hline Antimony & $<0.0050$ & $<0.0050$ & $<0.010$ & $<0.010$ & $\mathrm{mg} / \mathrm{L}$ & 0.0050 & 0.010 & $<10.0$ \\
\hline Arsenic & 0.0067 & 0.0055 & $<0.010$ & $<0.010$ & $\mathrm{mg} / \mathrm{L}$ & 0.0050 & 0.010 & $<0.5$ \\
\hline Barium & $0.028 \mathrm{~J}^{\mathrm{e}}$ & $0.036 \mathrm{~J}^{\mathrm{e}}$ & $0.033 \mathrm{~J}^{\mathrm{e}}$ & $0.028 \mathrm{~J}^{\mathrm{e}}$ & $\mathrm{mg} / \mathrm{L}$ & 0.50 & 0.10 & 1.0 \\
\hline Beryllium & $<0.010$ & $<0.010$ & $<0.0020$ & $<0.0020$ & $\mathrm{mg} / \mathrm{L}$ & 0.15 & 0.030 & 0.250 \\
\hline Cadmium & $<0.015$ & $<0.015$ & $<0.0030$ & $<0.0030$ & $\mathrm{mg} / \mathrm{L}$ & 0.10 & 0.020 & $<0.5$ \\
\hline Calcium & 1,670 & 1,630 & 1,570 & 1,370 & $\mathrm{mg} / \mathrm{L}$ & 25 & 10 & 1,834 \\
\hline Chromium & $<0.11$ & $<0.11$ & $<0.022$ & $<0.022$ & $\mathrm{mg} / \mathrm{L}$ & 0.30 & 0.060 & $<2.0$ \\
\hline Iron & $0.48 \mathrm{~J}$ & $0.29 \mathrm{~J}$ & $0.27 \mathrm{~J}$ & $0.24 \mathrm{~J}$ & $\mathrm{mg} / \mathrm{L}$ & 2.5 & 0.50 & 2.245 \\
\hline Lead & $<0.18$ & $<0.18$ & $<0.036$ & $<0.036$ & $\mathrm{mg} / \mathrm{L}$ & 0.25 & 0.050 & 0.525 \\
\hline Magnesium & 1,330 & 1,300 & 1,260 & 939 & $\mathrm{mg} / \mathrm{L}$ & 25 & 10 & 1,472 \\
\hline Mercury & $<0.0010$ & $<0.0010$ & $<0.0010$ & $<0.0010$ & $\mathrm{mg} / \mathrm{L}$ & 0.0010 & 0.001 & $<0.002$ \\
\hline Nickel & $<0.025$ & $<0.025$ & $<0.0050$ & $<0.0050$ & $\mathrm{mg} / \mathrm{L}$ & 0.50 & 0.10 & $<5.0$ \\
\hline Potassium & 793 & 782 & 826 & 713 & $\mathrm{mg} / \mathrm{L}$ & 50 & 10 & 1,648 \\
\hline Selenium & 0.0062 & 0.0083 & $<0.010$ & $<0.010$ & $\mathrm{mg} / \mathrm{L}$ & 0.0050 & 0.010 & 2.009 \\
\hline Silver & $<0.030$ & $<0.030$ & $<0.0060$ & $<0.0060$ & $\mathrm{mg} / \mathrm{L}$ & 0.25 & 0.050 & 0.519 \\
\hline Sodium & 39,500 & 38,400 & 34,900 & 30,000 & $\mathrm{mg} / \mathrm{L}$ & 250 & 500 & 38,790 \\
\hline Thallium & $<0.0050$ & $<0.0050$ & $<0.010$ & $<0.010$ & $\mathrm{mg} / \mathrm{L}$ & 0.0050 & 0.010 & 1.0 \\
\hline Vanadium & $0.066 \mathrm{~J}^{\mathrm{e}}$ & $0.066 \mathrm{~J}^{\mathrm{e}}$ & $0.040 \mathrm{~J}^{\mathrm{e}}$ & $0.042 \mathrm{~J}^{\mathrm{e}}$ & mg/L & 2.5 & 0.50 & $<5.0$ \\
\hline $\begin{array}{l}\text { (a) } 95^{\text {th }} \text { Upper tolerance } \\
\text { and trace metals. } \\
\text { (b) Reporting limit. Value } \\
\text { (c) Not applicable. } \\
\text { (d) Standard unit. } \\
\text { (e) J Analyte detected at } \\
\text { concentrations corres }\end{array}$ & ends to $m$ & $\begin{array}{l}\text { lent to } 95 \% \\
\text { lethod report }\end{array}$ & $\begin{array}{l}\text { confidence } \\
\text { ting limit ( }\end{array}$ & $\begin{array}{l}\text { limit; } 95^{\text {th }} p \\
\text { ARL). }\end{array}$ & ercentile for & nitrate, $T$ & DC, TOX, & TSS, \\
\hline
\end{tabular}




\section{Waste Isolation Pilot Plant Annual Site Environmental Report for 2010 DOE/WIPP-11-2225}

Appendix F - Groundwater Data Tables

Table F.5 - Analytical Results for Groundwater Sampled from Well WQSP - 5

\begin{tabular}{|c|c|c|c|c|c|c|c|c|}
\hline \multirow[b]{2}{*}{ Parameter } & \multicolumn{2}{|c|}{ Round 30} & \multicolumn{2}{|c|}{ Round 31} & \multirow[b]{2}{*}{ Units } & \multicolumn{2}{|c|}{$\begin{array}{c}\text { Method } \\
\text { Reporting Limit }\end{array}$} & \multirow[b]{2}{*}{$\begin{array}{l}\text { 95th } \\
\text { UTLV }^{\mathrm{a}}\end{array}$} \\
\hline & Sample & Duplicate & Sample & Duplicate & & $\begin{array}{l}\text { Round } \\
\quad 30\end{array}$ & $\begin{array}{l}\text { Round } \\
\quad 31\end{array}$ & \\
\hline 1,1,1-Trichloroethane & $<1$ & $<1$ & $<1$ & $<1$ & $\mu \mathrm{g} / \mathrm{L}$ & 1 & 1 & $<\mathrm{RL}^{\mathrm{b}}$ \\
\hline 1,1,2,2-Tetrachloroethane & $<1$ & $<1$ & $<1$ & $<1$ & $\mu g / L$ & 1 & 1 & $<R L$ \\
\hline 1,1,2-Trichloroethane & $<1$ & $<1$ & $<1$ & $<1$ & $\mu \mathrm{g} / \mathrm{L}$ & 1 & 1 & $<R L$ \\
\hline 1,1-Dichloroethane & $<1$ & $<1$ & $<1$ & $<1$ & $\mu \mathrm{g} / \mathrm{L}$ & 1 & 1 & $<\mathrm{RL}$ \\
\hline 1,1-Dichloroethylene & $<1$ & $<1$ & $<1$ & $<1$ & $\mu \mathrm{g} / \mathrm{L}$ & 1 & 1 & $<R L$ \\
\hline 1,2-Dichloroethane & $<1$ & $<1$ & $<1$ & $<1$ & $\mu \mathrm{g} / \mathrm{L}$ & 1 & 1 & $<R L$ \\
\hline Carbon tetrachloride & $<1$ & $<1$ & $<1$ & $<1$ & $\mu \mathrm{g} / \mathrm{L}$ & 1 & 1 & $<R L$ \\
\hline Chlorobenzene & $<1$ & $<1$ & $<1$ & $<1$ & $\mu \mathrm{g} / \mathrm{L}$ & 1 & 1 & $<R L$ \\
\hline Chloroform & $<1$ & $<1$ & $<1$ & $<1$ & $\mu \mathrm{g} / \mathrm{L}$ & 1 & 1 & $<R L$ \\
\hline cis-1,2-Dichloroethylene & $<1$ & $<1$ & $<1$ & $<1$ & $\mu \mathrm{g} / \mathrm{L}$ & 1 & 1 & $<\mathrm{RL}$ \\
\hline trans-1,2-Dichloroethylene & $<1$ & $<1$ & $<1$ & $<1$ & $\mu \mathrm{g} / \mathrm{L}$ & 1 & 1 & $<R L$ \\
\hline 2-butanone & $<5$ & $<5$ & $<5$ & $<5$ & $\mu \mathrm{g} / \mathrm{L}$ & 5 & 5 & $<R L$ \\
\hline Isobutanol & $<5$ & $<5$ & $<5$ & $<5$ & $\mu g / L$ & 5 & 5 & $<R L$ \\
\hline Methylene chloride & $<5$ & $<5$ & $<5$ & $<5$ & $\mu \mathrm{g} / \mathrm{L}$ & 5 & 5 & $<R L$ \\
\hline Tetrachloroethylene & $<1$ & $<1$ & $<1$ & $<1$ & $\mu \mathrm{g} / \mathrm{L}$ & 1 & 1 & $<R L$ \\
\hline Toluene & $<1$ & $<1$ & $<1$ & $<1$ & $\mu \mathrm{g} / \mathrm{L}$ & 1 & 1 & $<R L$ \\
\hline Trichloroethylene & $<1$ & $<1$ & $<1$ & $<1$ & $\mu g / L$ & 1 & 1 & $<R L$ \\
\hline Trichlorofluoromethane & $<1$ & $<1$ & $<1$ & $<1$ & $\mu \mathrm{g} / \mathrm{L}$ & 1 & 1 & $<R L$ \\
\hline Vinyl chloride & $<1$ & $<1$ & $<1$ & $<1$ & $\mu \mathrm{g} / \mathrm{L}$ & 1 & 1 & $<\mathrm{RL}$ \\
\hline Xylene & $<1$ & $<1$ & $<1$ & $<1$ & $\mu \mathrm{g} / \mathrm{L}$ & 1 & 1 & $<R L$ \\
\hline 1,2-Dichlorobenzene & $<5$ & $<5$ & $<5$ & $<5$ & $\mu \mathrm{g} / \mathrm{L}$ & 5 & 5 & $<R L$ \\
\hline 1,4-Dichlorobenzene & $<5$ & $<5$ & $<5$ & $<5$ & $\mu \mathrm{g} / \mathrm{L}$ & 5 & 5 & $<\mathrm{RL}$ \\
\hline 2,4-Dinitrophenol & $<20$ & $<20$ & $<5$ & $<5$ & $\mu \mathrm{g} / \mathrm{L}$ & 20 & 5 & $<R L$ \\
\hline 2,4-Dinitrotoluene & $<5$ & $<5$ & $<5$ & $<5$ & $\mu \mathrm{g} / \mathrm{L}$ & 5 & 5 & $<R L$ \\
\hline 2-Methylphenol & $<5$ & $<5$ & $<5$ & $<5$ & $\mu \mathrm{g} / \mathrm{L}$ & 5 & 5 & $<\mathrm{RL}$ \\
\hline 3-Methylphenol/4-Methylphenol & $<5$ & $<5$ & $<5$ & $<5$ & $\mu \mathrm{g} / \mathrm{L}$ & 5 & 5 & $<\mathrm{RL}$ \\
\hline Hexachlorobenzene & $<5$ & $<5$ & $<5$ & $<5$ & $\mu \mathrm{g} / \mathrm{L}$ & 5 & 5 & $<R L$ \\
\hline Hexachloroethane & $<5$ & $<5$ & $<5$ & $<5$ & $\mu \mathrm{g} / \mathrm{L}$ & 5 & 5 & $<\mathrm{RL}$ \\
\hline Nitrobenzene & $<5$ & $<5$ & $<5$ & $<5$ & $\mu g / L$ & 5 & 5 & $<R L$ \\
\hline Pentachlorophenol & $<5$ & $<5$ & $<5$ & $<5$ & $\mu g / L$ & 5 & 5 & $<\mathrm{RL}$ \\
\hline Pyridine & $<5$ & $<5$ & $<5$ & $<5$ & $\mu g / L$ & 5 & 5 & $<\mathrm{RL}$ \\
\hline Alkalinity & 45.1 & 45.0 & 45.7 & 46.0 & $\mathrm{mg} / \mathrm{L}$ & 20 & 20 & 56 \\
\hline Chloride & 16,000 & 16,000 & 15,900 & 15,400 & $\mathrm{mg} / \mathrm{L}$ & 200 & 200 & 18,100 \\
\hline Specific Gravity & 1.017 & 1.016 & 1.023 & 1.022 & $\mathrm{~g} / \mathrm{ml}$ & $N / A^{c}$ & $N / A^{c}$ & 1.04 \\
\hline Nitrate (as N) & $<1.1$ & $<1.1$ & $<1.1$ & $<1.1$ & $\mathrm{mg} / \mathrm{L}$ & 5.0 & 5.0 & $<10$ \\
\hline $\mathrm{pH}$ & 7.48 & 7.49 & 7.47 & 7.48 & $S U^{d}$ & 0.1 & $N / A^{c}$ & $7.4-7.9$ \\
\hline
\end{tabular}




\section{Waste Isolation Pilot Plant Annual Site Environmental Report for 2010 DOE/WIPP-11-2225}

\section{Appendix F - Groundwater Data Tables}

Table F.5 - Analytical Results for Groundwater Sampled from Well WQSP - 5

\begin{tabular}{|c|c|c|c|c|c|c|c|c|}
\hline \multirow[b]{2}{*}{ Parameter } & \multicolumn{2}{|c|}{ Round 30} & \multicolumn{2}{|c|}{ Round 31} & \multirow[b]{2}{*}{ Units } & \multicolumn{2}{|c|}{$\begin{array}{c}\text { Method } \\
\text { Reporting Limit }\end{array}$} & \multirow[b]{2}{*}{$\begin{array}{l}\text { 95th } \\
\text { UTLV }^{\mathrm{a}}\end{array}$} \\
\hline & Sample & Duplicate & Sample & Duplicate & & $\begin{array}{l}\text { Round } \\
30\end{array}$ & $\begin{array}{c}\text { Round } \\
31\end{array}$ & \\
\hline Specific conductance & 49,100 & 49,800 & 49,000 & 50,000 & $\mu \mathrm{mhos} / \mathrm{cm}$ & 0.1 & 0.1 & 67,700 \\
\hline Sulfate & 5,760 & 5,700 & 5,540 & 5,580 & $\mathrm{mg} / \mathrm{L}$ & 100 & 100 & 6,129 \\
\hline Total dissolved solids & 32,900 & 29,900 & 32,500 & 32,200 & $\mathrm{mg} / \mathrm{L}$ & 1,000 & 2,000 & 43,950 \\
\hline Total organic carbon & 1.22 & 1.62 & $0.94 \mathrm{~J}^{\mathrm{e}}$ & $0.89 \mathrm{~J}^{\mathrm{e}}$ & $\mathrm{mg} / \mathrm{L}$ & 1.0 & 1.0 & $<5.0$ \\
\hline Total organic halogen & 0.038 & 0.035 & 0.080 & 0.088 & $\mathrm{mg} / \mathrm{L}$ & 0.010 & 0.010 & 8.37 \\
\hline Total suspended solids & 11 & 11 & 33 & 18 & $\mathrm{mg} / \mathrm{L}$ & 10 & 10 & $<10.0$ \\
\hline Antimony & $<0.010$ & $<0.010$ & $<0.0020$ & $<0.0020$ & $\mathrm{mg} / \mathrm{L}$ & 0.010 & 0.0020 & 0.073 \\
\hline Arsenic & $<0.010$ & $<0.010$ & 0.0029 & 0.0026 & $\mathrm{mg} / \mathrm{L}$ & 0.010 & 0.0020 & $<0.5$ \\
\hline Barium & $<0.010$ & $0.012 \mathrm{~J}$ & $0.019 \mathrm{~J}^{\mathrm{e}}$ & $0.023 \mathrm{~J}^{\mathrm{e}}$ & $\mathrm{mg} / \mathrm{L}$ & 0.25 & 0.10 & $<1.0$ \\
\hline Beryllium & $<0.0050$ & $<0.0050$ & 0.0022 & 0.0024 & $\mathrm{mg} / \mathrm{L}$ & 0.075 & 0.030 & $<0.02$ \\
\hline Cadmium & $<0.0075$ & $<0.0075$ & $<0.0030$ & $<0.0030$ & $\mathrm{mg} / \mathrm{L}$ & 0.050 & $<0.020$ & $<0.05$ \\
\hline Calcium & 1,050 & 1,060 & 973 & 976 & $\mathrm{mg} / \mathrm{L}$ & 13 & 5.0 & 1,303 \\
\hline Chromium & $<0.055$ & $<0.055$ & $<0.022$ & $<0.022$ & $\mathrm{mg} / \mathrm{L}$ & 0.15 & 0.060 & $<0.5$ \\
\hline Iron & $0.51 \mathrm{~J}$ & $0.32 \mathrm{~J}$ & $0.37 \mathrm{~J}$ & $0.48 \mathrm{~J}$ & $\mathrm{mg} / \mathrm{L}$ & 1.25 & 0.50 & 0.795 \\
\hline Lead & $<0.090$ & $<0.090$ & $<0.036$ & $<0.036$ & $\mathrm{mg} / \mathrm{L}$ & 0.13 & 0.050 & $<0.05$ \\
\hline Magnesium & 492 & 492 & 461 & 461 & $\mathrm{mg} / \mathrm{L}$ & 12 & 5.0 & 547 \\
\hline Mercury & $<0.00020$ & $<0.00020$ & $<0.00020$ & $<0.00020$ & $\mathrm{mg} / \mathrm{L}$ & 0.00020 & 0.00020 & $<0.002$ \\
\hline Nickel & $<0.0125$ & $<0.0125$ & $<0.0050$ & $<0.0050$ & $\mathrm{mg} / \mathrm{L}$ & 0.25 & 0.10 & $<0.1$ \\
\hline Potassium & 313 & 319 & 305 & 305 & $\mathrm{mg} / \mathrm{L}$ & 25 & 10 & 622 \\
\hline Selenium & $<0.010$ & $<0.010$ & $<0.0020$ & $<0.0020$ & $\mathrm{mg} / \mathrm{L}$ & 0.010 & 0.0020 & $<0.1$ \\
\hline Silver & $<0.015$ & $<0.015$ & $<0.0060$ & $<0.0060$ & $\mathrm{mg} / \mathrm{L}$ & 0.13 & 0.050 & $<0.5$ \\
\hline Sodium & 10,200 & 10,100 & 9,550 & 9,610 & $\mathrm{mg} / \mathrm{L}$ & 125 & 100 & 11,190 \\
\hline Thallium & $<0.010$ & $<0.010$ & $<0.0020$ & $<0.0020$ & $\mathrm{mg} / \mathrm{L}$ & 0.010 & 0.0020 & 0.209 \\
\hline Vanadium & $<0.0275$ & $<0.0275$ & $0.028 \mathrm{~J}$ & $0.032 \mathrm{~J}$ & $\mathrm{mg} / \mathrm{L}$ & 1.25 & 0.50 & 2.70 \\
\hline $\begin{array}{l}\text { (a) } 95^{\text {th }} \text { Upper tolerance } \\
\text { trace metals. } \\
\text { (b) Reporting limit. Value } \\
\text { (c) Not applicable. } \\
\text { (d) Standard unit. } \\
\text { (e) J Analyte detected a } \\
\text { concentrations corre }\end{array}$ & $\begin{array}{l}\text { ue, equival } \\
\text { ponds to m }\end{array}$ & ent to $95 \%$ & $\begin{array}{l}\text { confidence } \\
\text { ing limit (M }\end{array}$ & $\begin{array}{l}\text { limit; } 95^{\text {th }} \text { pe } \\
R L) \text {. }\end{array}$ & rcentile for $n$ & hitrate, TO & C, TOX, 1 & SS, and \\
\hline
\end{tabular}




\section{Waste Isolation Pilot Plant Annual Site Environmental Report for 2010 DOE/WIPP-11-2225}

\section{Appendix F - Groundwater Data Tables}

Table F.6 - Analytical Results for Groundwater Sampled from Well WQSP - 6

\begin{tabular}{|c|c|c|c|c|c|c|c|c|}
\hline \multirow[b]{2}{*}{ Parameter } & \multicolumn{2}{|c|}{ Round 30} & \multicolumn{2}{|c|}{ Round 31} & \multirow[b]{2}{*}{ Units } & \multicolumn{2}{|c|}{$\begin{array}{c}\text { Method } \\
\text { Reporting Limit }\end{array}$} & \multirow[b]{2}{*}{$\begin{array}{l}\text { 95th } \\
\text { UTLV }^{\mathrm{a}}\end{array}$} \\
\hline & Sample & Duplicate & Sample & Duplicate & & $\begin{array}{c}\text { Round } \\
30\end{array}$ & $\begin{array}{c}\text { Round } \\
31\end{array}$ & \\
\hline 1,1,1-Trichloroethane & $<1$ & $<1$ & $<1$ & $<1$ & $\mu \mathrm{g} / \mathrm{L}$ & 1 & 1 & $<\mathrm{RL}^{\mathrm{b}}$ \\
\hline 1,1,2,2-Tetrachloroethane & $<1$ & $<1$ & $<1$ & $<1$ & $\mu \mathrm{g} / \mathrm{L}$ & 1 & 1 & $<R L$ \\
\hline 1,1,2-Trichloroethane & $<1$ & $<1$ & $<1$ & $<1$ & $\mu \mathrm{g} / \mathrm{L}$ & 1 & 1 & $<\mathrm{RL}$ \\
\hline 1,1-Dichloroethane & $<1$ & $<1$ & $<1$ & $<1$ & $\mu \mathrm{g} / \mathrm{L}$ & 1 & 1 & $<R L$ \\
\hline 1,1-Dichloroethylene & $<1$ & $<1$ & $<1$ & $<1$ & $\mu \mathrm{g} / \mathrm{L}$ & 1 & 1 & $<R L$ \\
\hline 1,2-Dichloroethane & $<1$ & $<1$ & $<1$ & $<1$ & $\mu \mathrm{g} / \mathrm{L}$ & 1 & 1 & $<\mathrm{RL}$ \\
\hline Carbon tetrachloride & $<1$ & $<1$ & $<1$ & $<1$ & $\mu \mathrm{g} / \mathrm{L}$ & 1 & 1 & $<R L$ \\
\hline Chlorobenzene & $<1$ & $<1$ & $<1$ & $<1$ & $\mu \mathrm{g} / \mathrm{L}$ & 1 & 1 & $<R L$ \\
\hline Chloroform & $<1$ & $<1$ & $<1$ & $<1$ & $\mu \mathrm{g} / \mathrm{L}$ & 1 & 1 & $<R L$ \\
\hline cis-1,2-Dichloroethylene & $<1$ & $<1$ & $<1$ & $<1$ & $\mu \mathrm{g} / \mathrm{L}$ & 1 & 1 & $<\mathrm{RL}$ \\
\hline trans-1,2-Dichloroethylene & $<1$ & $<1$ & $<1$ & $<1$ & $\mu g / L$ & 1 & 1 & $<\mathrm{RL}$ \\
\hline 2-butanone & $<5$ & $<5$ & $<5$ & $<5$ & $\mu \mathrm{g} / \mathrm{L}$ & 5 & 5 & $<R L$ \\
\hline Isobutanol & $<5$ & $<5$ & $<5$ & $<5$ & $\mu \mathrm{g} / \mathrm{L}$ & 5 & 5 & $<\mathrm{RL}$ \\
\hline Methylene chloride & $<5$ & $<5$ & $<5$ & $<5$ & $\mu \mathrm{g} / \mathrm{L}$ & 5 & 5 & $<\mathrm{RL}$ \\
\hline Tetrachloroethylene & $<1$ & $<1$ & $<1$ & $<1$ & $\mu \mathrm{g} / \mathrm{L}$ & 1 & 1 & $<R L$ \\
\hline Toluene & $<1$ & $<1$ & $<1$ & $<1$ & $\mu \mathrm{g} / \mathrm{L}$ & 1 & 1 & $<\mathrm{RL}$ \\
\hline Trichloroethylene & $<1$ & $<1$ & $<1$ & $<1$ & $\mu \mathrm{g} / \mathrm{L}$ & 1 & 1 & $<\mathrm{RL}$ \\
\hline Trichlorofluoromethane & $<1$ & $<1$ & $<1$ & $<1$ & $\mu \mathrm{g} / \mathrm{L}$ & 1 & 1 & $<\mathrm{RL}$ \\
\hline Vinyl chloride & $<1$ & $<1$ & $<1$ & $<1$ & $\mu \mathrm{g} / \mathrm{L}$ & 1 & 1 & $<\mathrm{RL}$ \\
\hline Xylene & $<1$ & $<1$ & $<1$ & $<1$ & $\mu \mathrm{g} / \mathrm{L}$ & 1 & 1 & $<\mathrm{RL}$ \\
\hline 1,2-Dichlorobenzene & $<5$ & $<5$ & $<5$ & $<5$ & $\mu g / L$ & 5 & 5 & $<R L$ \\
\hline 1,4-Dichlorobenzene & $<5$ & $<5$ & $<5$ & $<5$ & $\mu \mathrm{g} / \mathrm{L}$ & 5 & 5 & $<R L$ \\
\hline 2,4-Dinitrophenol & $<5$ & $<5$ & $<5$ & $<5$ & $\mu \mathrm{g} / \mathrm{L}$ & 5 & 5 & $<\mathrm{RL}$ \\
\hline 2,4-Dinitrotoluene & $<5$ & $<5$ & $<5$ & $<5$ & $\mu \mathrm{g} / \mathrm{L}$ & 5 & 5 & $<\mathrm{RL}$ \\
\hline 2-Methylphenol & $<5$ & $<5$ & $<5$ & $<5$ & $\mu \mathrm{g} / \mathrm{L}$ & 5 & 5 & $<\mathrm{RL}$ \\
\hline 3-Methylphenol4-Methylphenol & $<5$ & $<5$ & $<5$ & $<5$ & $\mu \mathrm{g} / \mathrm{L}$ & 5 & 5 & $<\mathrm{RL}$ \\
\hline Hexachlorobenzene & $<5$ & $<5$ & $<5$ & $<5$ & $\mu \mathrm{g} / \mathrm{L}$ & 5 & 5 & $<\mathrm{RL}$ \\
\hline Hexachloroethane & $<5$ & $<5$ & $<5$ & $<5$ & $\mu \mathrm{g} / \mathrm{L}$ & 5 & 5 & $<\mathrm{RL}$ \\
\hline Nitrobenzene & $<5$ & $<5$ & $<5$ & $<5$ & $\mu \mathrm{g} / \mathrm{L}$ & 5 & 5 & $<R L$ \\
\hline Pentachlorophenol & $<5$ & $<5$ & $<5$ & $<5$ & $\mu \mathrm{g} / \mathrm{L}$ & 5 & 5 & $<\mathrm{RL}$ \\
\hline Pyridine & $<5$ & $<5$ & $<5$ & $<5$ & $\mu g / L$ & 5 & 5 & $<R L$ \\
\hline Alkalinity & 44.4 & 38.7 & 46.5 & 47.3 & $\mathrm{mg} / \mathrm{L}$ & 20 & 20 & 55.8 \\
\hline Chloride & 5,510 & 5,890 & 5,850 & 5,770 & $\mathrm{mg} / \mathrm{L}$ & 50 & 50 & 15,800 \\
\hline Specific Gravity & 1.013 & 1.011 & 1.009 & 1.007 & $\mathrm{~g} / \mathrm{ml}$ & 0.0 & $N / A^{c}$ & 1.02 \\
\hline Nitrate (as N) & $<0.21$ & $<0.21$ & $<0.21$ & $<0.21$ & $\mathrm{mg} / \mathrm{L}$ & 1.1 & 1.1 & 7.450 \\
\hline $\mathrm{pH}$ & 7.65 & 7.69 & 7.72 & 7.73 & $S U^{d}$ & $N / A^{c}$ & $N / A^{c}$ & $7.5-7.9$ \\
\hline
\end{tabular}




\section{Waste Isolation Pilot Plant Annual Site Environmental Report for 2010 DOE/WIPP-11-2225}

\section{Appendix F - Groundwater Data Tables}

Table F.6 - Analytical Results for Groundwater Sampled from Well WQSP - 6

\begin{tabular}{|c|c|c|c|c|c|c|c|c|}
\hline \multirow[b]{2}{*}{ Parameter } & \multicolumn{2}{|c|}{ Round 30} & \multicolumn{2}{|c|}{ Round 31} & \multirow[b]{2}{*}{ Units } & \multicolumn{2}{|c|}{$\begin{array}{c}\text { Method } \\
\text { Reporting Limit }\end{array}$} & \multirow[b]{2}{*}{$\begin{array}{l}\text { 95th } \\
\text { UTLV }^{\text {a }}\end{array}$} \\
\hline & Sample & Duplicate & Sample & Duplicate & & $\begin{array}{l}\text { Round } \\
30\end{array}$ & $\begin{array}{c}\text { Round } \\
31\end{array}$ & \\
\hline Specific conductance & 24,000 & 19,900 & 25,400 & 25,200 & $\mu \mathrm{mhos} / \mathrm{cm}$ & 0.1 & $N / A^{c}$ & 27,660 \\
\hline Sulfate & 4,480 & 4,820 & 4,980 & 4,970 & $\mathrm{mg} / \mathrm{L}$ & 100 & 100 & 5,557 \\
\hline Total dissolved solids & 15,400 & 15,300 & 14,800 & 15,100 & $\mathrm{mg} / \mathrm{L}$ & 200 & 100 & 22,500 \\
\hline Total organic carbon & 1.02 & 1.12 & $0.35 \mathrm{~J}^{\mathrm{e}}$ & $0.44 \mathrm{~J}^{\mathrm{e}}$ & $\mathrm{mg} / \mathrm{L}$ & 1.0 & 1.0 & 10.14 \\
\hline Total organic halogen & 0.016 & 0.019 & 0.039 & 0.028 & $\mathrm{mg} / \mathrm{L}$ & 0.010 & 0.010 & 1.54 \\
\hline Total suspended solids & 13 & 10 & 11 & 17 & $\mathrm{mg} / \mathrm{L}$ & 10 & 10 & 14.8 \\
\hline Antimony & $<0.0050$ & $<0.0050$ & $<0.0025$ & $<0.0025$ & $\mathrm{mg} / \mathrm{L}$ & 0.0050 & 0.0025 & 0.140 \\
\hline Arsenic & $<0.0050$ & $<0.0050$ & 0.0032 & 0.0033 & $\mathrm{mg} / \mathrm{L}$ & 0.0050 & 0.0025 & $<0.5$ \\
\hline Barium & 0.0103 & 0.0105 & $0.098 \mathrm{~J}$ & $0.010 \mathrm{~J}$ & $\mathrm{mg} / \mathrm{L}$ & 0.010 & 0.050 & $<1.0$ \\
\hline Beryllium & $<0.002$ & $<0.0002$ & $0.0016 \mathrm{~J}$ & $0.00059 \mathrm{~J}$ & $\mathrm{mg} / \mathrm{L}$ & 0.0030 & 0.015 & $<0.02$ \\
\hline Cadmium & $<0.0003$ & $<0.0003$ & $<0.0015$ & $<0.0015$ & $\mathrm{mg} / \mathrm{L}$ & 0.0020 & 0.010 & $<0.05$ \\
\hline Calcium & 671 & 673 & 680 & 657 & $\mathrm{mg} / \mathrm{L}$ & 5.0 & 5.0 & 796 \\
\hline Chromium & $<0.0022$ & $<0.0022$ & $<0.011$ & $<0.011$ & $\mathrm{mg} / \mathrm{L}$ & 0.0060 & 0.030 & $<0.5$ \\
\hline Iron & $0.098 \mathrm{~J}$ & $0.092 \mathrm{~J}$ & $0.16 \mathrm{~J}$ & $0.10 \mathrm{~J}$ & $\mathrm{mg} / \mathrm{L}$ & 0.050 & 0.25 & 3.105 \\
\hline Lead & $<0.018$ & $<0.018$ & $<0.018$ & $<0.018$ & $\mathrm{mg} / \mathrm{L}$ & 0.025 & 0.025 & 0.150 \\
\hline Magnesium & 215 & 211 & 212 & 207 & $\mathrm{mg} / \mathrm{L}$ & 5.0 & 2.5 & 255 \\
\hline Mercury & $<0.0002$ & $<0.0002$ & $<0.00020$ & $<0.00020$ & $\mathrm{mg} / \mathrm{L}$ & 0.00020 & 0.00020 & $<0.002$ \\
\hline Nickel & $<0.0025$ & $<0.0025$ & $<0.0025$ & $<0.0025$ & $\mathrm{mg} / \mathrm{L}$ & 0.050 & 0.050 & $<0.5$ \\
\hline Potassium & 155 & 154 & 151 & 146 & $\mathrm{mg} / \mathrm{L}$ & 5.0 & 5.0 & 270 \\
\hline Selenium & $<0.0050$ & $<0.0050$ & $<0.0025$ & $<0.0025$ & $\mathrm{mg} / \mathrm{L}$ & 0.0050 & 0.0025 & 0.100 \\
\hline Silver & $<0.0006$ & $<0.0006$ & $<0.0030$ & $<0.0030$ & $\mathrm{mg} / \mathrm{L}$ & 0.0050 & 0.025 & $<0.5$ \\
\hline Sodium & 4,420 & 4,450 & 4,270 & 4,200 & $\mathrm{mg} / \mathrm{L}$ & 50 & 25 & 6,290 \\
\hline Thallium & $<0.0050$ & $<0.0050$ & $<0.0025$ & $<0.0025$ & $\mathrm{mg} / \mathrm{L}$ & 0.0050 & 0.0025 & 0.560 \\
\hline Vanadium & $0.0056 \mathrm{~J}$ & $0.0057 \mathrm{~J}$ & $0.011 \mathrm{~J}^{\mathrm{e}}$ & $0.0038 \mathrm{~J}^{\mathrm{e}}$ & $\mathrm{mg} / \mathrm{L}$ & 0.050 & 0.25 & 0.070 \\
\hline
\end{tabular}

(a) $95^{\text {th }}$ Upper tolerance limit value, equivalent to $95 \%$ confidence limit; $95^{\text {th }}$ percentile for nitrate, TOC, TOX, TSS, and trace metals.

(b) Reporting limit. Value corresponds to method reporting limit (MRL).

(c) Not applicable.

(d) Standard unit.

(e) J Analyte detected at an estimated concentration between the MDL and the MRL (PQL). Less than (<) concentrations correspond to MDL. 


\section{Waste Isolation Pilot Plant Annual Site Environmental Report for 2010 DOE/WIPP-11-2225}

Appendix F - Groundwater Data Tables

Table F.7 Analytical Results for Groundwater Sampled from Well WQSP 6A

\begin{tabular}{|c|c|c|c|c|c|c|c|c|}
\hline \multirow[b]{2}{*}{ Parameter } & \multicolumn{2}{|c|}{ Round 30} & \multicolumn{2}{|c|}{ Round 31} & \multirow[b]{2}{*}{ Units } & \multicolumn{2}{|c|}{$\begin{array}{c}\text { Method } \\
\text { Reporting Limit }\end{array}$} & \multirow[b]{2}{*}{$\begin{array}{l}\text { 95th } \\
\text { UTLV }^{\mathrm{a}}\end{array}$} \\
\hline & Sample & Duplicate & Sample & Duplicate & & $\begin{array}{c}\text { Round } \\
30\end{array}$ & $\begin{array}{c}\text { Round } \\
\quad 31\end{array}$ & \\
\hline 1,1,1-Trichloroethane & $<1$ & $<1$ & $<1$ & $<1$ & $\mu g / L$ & 1 & 1 & $<\mathrm{RL}^{\mathrm{b}}$ \\
\hline 1,1,2,2-Tetrachloroethane & $<1$ & $<1$ & $<1$ & $<1$ & $\mu g / L$ & 1 & 1 & $<\mathrm{RL}$ \\
\hline 1,1,2-Trichloroethane & $<1$ & $<1$ & $<1$ & $<1$ & $\mu g / L$ & 1 & 1 & $<\mathrm{RL}$ \\
\hline 1,1-Dichloroethane & $<1$ & $<1$ & $<1$ & $<1$ & $\mu g / L$ & 1 & 1 & $<\mathrm{RL}$ \\
\hline 1,1-Dichloroethylene & $<1$ & $<1$ & $<1$ & $<1$ & $\mu g / L$ & 1 & 1 & $<\mathrm{RL}$ \\
\hline 1,2-Dichloroethane & $<1$ & $<1$ & $<1$ & $<1$ & $\mu \mathrm{g} / \mathrm{L}$ & 1 & 1 & $<\mathrm{RL}$ \\
\hline Carbon tetrachloride & $<1$ & $<1$ & $<1$ & $<1$ & $\mu \mathrm{g} / \mathrm{L}$ & 1 & 1 & $<\mathrm{RL}$ \\
\hline Chlorobenzene & $<1$ & $<1$ & $<1$ & $<1$ & $\mu g / L$ & 1 & 1 & $<\mathrm{RL}$ \\
\hline Chloroform & $<1$ & $<1$ & $<1$ & $<1$ & $\mu \mathrm{g} / \mathrm{L}$ & 1 & 1 & $<\mathrm{RL}$ \\
\hline cis-1,2-Dichloroethylene & $<1$ & $<1$ & $<1$ & $<1$ & $\mu g / L$ & 1 & 1 & $<\mathrm{RL}$ \\
\hline trans-1,2-Dichloroethylene & $<1$ & $<1$ & $<1$ & $<1$ & $\mu g / L$ & 1 & 1 & $<\mathrm{RL}$ \\
\hline 2-butanone & $<5$ & $<5$ & $<5$ & $<5$ & $\mu \mathrm{g} / \mathrm{L}$ & 5 & 5 & $<\mathrm{RL}$ \\
\hline Isobutanol & $<5$ & $<5$ & $<5$ & $<5$ & $\mathrm{mg} / \mathrm{L}$ & 5 & 5 & $<\mathrm{RL}$ \\
\hline Methylene chloride & $<5$ & $<5$ & $<5$ & $<5$ & $\mu g / L$ & 5 & 5 & $<\mathrm{RL}$ \\
\hline Tetrachloroethylene & $<1$ & $<1$ & $<1$ & $<1$ & $\mu g / L$ & 1 & 1 & $<R L$ \\
\hline Toluene & $<1$ & $<1$ & $<1$ & $<1$ & $\mu g / L$ & 1 & 1 & $<R L$ \\
\hline Trichloroethylene & $<1$ & $<1$ & $<1$ & $<1$ & $\mu g / L$ & 1 & 1 & $<\mathrm{RL}$ \\
\hline Trichlorofluoromethane & $<1$ & $<1$ & $<1$ & $<1$ & $\mu \mathrm{g} / \mathrm{L}$ & 1 & 1 & $<\mathrm{RL}$ \\
\hline Vinyl chloride & $<1$ & $<1$ & $<1$ & $<1$ & $\mu \mathrm{g} / \mathrm{L}$ & 1 & 1 & $<\mathrm{RL}$ \\
\hline Xylene & $<1$ & $<1$ & $<1$ & $<1$ & $\mu \mathrm{g} / \mathrm{L}$ & 1 & 1 & $<\mathrm{RL}$ \\
\hline 1,2-Dichlorobenzene & $<5$ & $<5$ & $<5$ & $<5$ & $\mu \mathrm{g} / \mathrm{L}$ & 5 & 5 & $<\mathrm{RL}$ \\
\hline 1,4-Dichlorobenzene & $<5$ & $<5$ & $<5$ & $<5$ & $\mu \mathrm{g} / \mathrm{L}$ & 5 & 5 & $<\mathrm{RL}$ \\
\hline 2,4-Dinitrophenol & $<5$ & $<6$ & $<5$ & $<5$ & $\mu \mathrm{g} / \mathrm{L}$ & 5 & 5 & $<\mathrm{RL}$ \\
\hline 2,4-Dinitrotoluene & $<5$ & $<5$ & $<5$ & $<5$ & $\mu \mathrm{g} / \mathrm{L}$ & 5 & 5 & $<\mathrm{RL}$ \\
\hline 2-Methylphenol & $<5$ & $<5$ & $<5$ & $<5$ & $\mu \mathrm{g} / \mathrm{L}$ & 5 & 5 & $<\mathrm{RL}$ \\
\hline 3-Methylphenol/4-Methylphenol & $<5$ & $<5$ & $<5$ & $<5$ & $\mu \mathrm{g} / \mathrm{L}$ & 5 & 5 & $<\mathrm{RL}$ \\
\hline Hexachlorobenzene & $<5$ & $<5$ & $<5$ & $<5$ & $\mu \mathrm{g} / \mathrm{L}$ & 5 & 5 & $<\mathrm{RL}$ \\
\hline Hexachloroethane & $<5$ & $<5$ & $<5$ & $<5$ & $\mu \mathrm{g} / \mathrm{L}$ & 5 & 5 & $<\mathrm{RL}$ \\
\hline Nitrobenzene & $<5$ & $<5$ & $<5$ & $<5$ & $\mu \mathrm{g} / \mathrm{L}$ & 5 & 5 & $<\mathrm{RL}$ \\
\hline Pentachlorophenol & $<5$ & $<5$ & $<5$ & $<5$ & $\mu \mathrm{g} / \mathrm{L}$ & 5 & 5 & $<\mathrm{RL}$ \\
\hline Pyridine & $<5$ & $<5$ & $<5$ & $<5$ & $\mu \mathrm{g} / \mathrm{L}$ & 5 & 5 & $<\mathrm{RL}$ \\
\hline Alkalinity & 102 & 103 & 106 & 105 & $\mathrm{mg} / \mathrm{L}$ & 20 & 20 & 113 \\
\hline Chloride & 329 & 331 & 321 & 320 & $\mathrm{mg} / \mathrm{L}$ & 5.0 & 5.0 & 6,723 \\
\hline Specific Gravity & 1.000 & 0.995 & 1.004 & 1.005 & $\mathrm{~g} / \mathrm{ml}$ & 0 & 0 & 1.01 \\
\hline Nitrate (as N) & 6.37 & 6.72 & 6.34 & 6.34 & $\mathrm{mg} / \mathrm{L}$ & 5.0 & 5.0 & 12.2 \\
\hline $\mathrm{pH}$ & 7.43 & 7.43 & 7.40 & 7.63 & SU & 0.1 & 0.1 & $6.8-8.0$ \\
\hline
\end{tabular}




\section{Waste Isolation Pilot Plant Annual Site Environmental Report for 2010 DOE/WIPP-11-2225}

\section{Appendix F - Groundwater Data Tables}

Table F.7 Analytical Results for Groundwater Sampled from Well WQSP 6A

\begin{tabular}{|c|c|c|c|c|c|c|c|c|}
\hline \multirow[b]{2}{*}{ Parameter } & \multicolumn{2}{|c|}{ Round 30} & \multicolumn{2}{|c|}{ Round 31} & \multirow[b]{2}{*}{ Units } & \multicolumn{2}{|c|}{$\begin{array}{c}\text { Method } \\
\text { Reporting Limit }\end{array}$} & \multirow[b]{2}{*}{$\begin{array}{l}\text { 95th } \\
\text { UTLV }^{\mathrm{a}}\end{array}$} \\
\hline & Sample & Duplicate & Sample & Duplicate & & $\begin{array}{l}\text { Round } \\
30\end{array}$ & $\begin{array}{l}\text { Round } \\
31\end{array}$ & \\
\hline Specific conductance & 3,550 & 3,570 & 3,580 & 3,580 & $\mu \mathrm{mhos} / \mathrm{cm}$ & 0.01 & 0.01 & 5,192 \\
\hline Sulfate & 2,130 & 2,160 & 2,090 & 2,200 & $\mathrm{mg} / \mathrm{L}$ & 25 & 25 & 2,543 \\
\hline Total dissolved solids & 3,520 & 3,570 & 3,500 & 3,560 & $\mathrm{mg} / \mathrm{L}$ & 40 & 40 & 11,000 \\
\hline Total organic carbon & $0.40 \mathrm{~J}$ & $0.29 \mathrm{~J}$ & $0.15 \mathrm{~J}$ & $0.13 \mathrm{~J}$ & $\mathrm{mg} / \mathrm{L}$ & 1.0 & 1.0 & 15.45 \\
\hline Total organic halogen & $<0.01$ & $<0.01$ & $<0.01$ & $(f)$ & $\mathrm{mg} / \mathrm{L}$ & 0.01 & 0.01 & 0.19 \\
\hline Total suspended solids & $<10$ & $2 \mathrm{~J}$ & $2 \mathrm{~J}$ & $2 \mathrm{~J}$ & $\mathrm{mg} / \mathrm{L}$ & 10 & 10 & 91.0 \\
\hline Antimony & $<0.0010$ & $<0.0010$ & $<0.010$ & $<0.010$ & $\mathrm{mg} / \mathrm{L}$ & 0.0010 & 0.010 & 0.480 \\
\hline Arsenic & $<0.0010$ & $<0.0010$ & $<0.0010$ & $<0.0010$ & $\mathrm{mg} / \mathrm{L}$ & 0.0010 & 0.0010 & $<0.5$ \\
\hline Barium & $<0.0040$ & $<0.0040$ & $0.0086 \mathrm{~J}$ & $0.0089 \mathrm{~J}$ & $\mathrm{mg} / \mathrm{L}$ & 0.010 & 0.010 & $<0.1$ \\
\hline Beryllium & $<0.0002$ & $<0.0002$ & $<0.0020$ & $<0.0020$ & $\mathrm{mg} / \mathrm{L}$ & 0.0030 & 0.0030 & $<0.01$ \\
\hline Cadmium & $<0.0003$ & $<0.0003$ & $<0.0030$ & $<0.0030$ & $\mathrm{mg} / \mathrm{L}$ & 0.0020 & 0.0020 & $<0.05$ \\
\hline Calcium & 638 & 629 & 558 & 567 & $\mathrm{mg} / \mathrm{L}$ & 5.0 & 5.0 & 733 \\
\hline Chromium & $<0.0022$ & $<0.0022$ & $<0.00022$ & $<0.00022$ & $\mathrm{mg} / \mathrm{L}$ & 0.0060 & 0.0060 & $<0.5$ \\
\hline Iron & $<0.045$ & $<0.035$ & $0.031 \mathrm{~J}$ & $0.027 \mathrm{~J}$ & $\mathrm{mg} / \mathrm{L}$ & 0.050 & 0.050 & 0.505 \\
\hline Lead & $<0.0036$ & $<0.0036$ & $<0.0036$ & $<0.0036$ & $\mathrm{mg} / \mathrm{L}$ & 0.0050 & 0.0050 & $<0.05$ \\
\hline Magnesium & 169 & 170 & 155 & 159 & $\mathrm{mg} / \mathrm{L}$ & 5.0 & 2.5 & 188 \\
\hline Mercury & $<0.0002$ & $<0.00020$ & $<0.00020$ & $<0.00020$ & $\mathrm{mg} / \mathrm{L}$ & 0.00020 & 0.00020 & $<0.002$ \\
\hline Nickel & $0.0044 \mathrm{~J}$ & $0.0045 \mathrm{~J}$ & $0.0049 \mathrm{~J}$ & $0.0056 \mathrm{~J}$ & $\mathrm{mg} / \mathrm{L}$ & 0.010 & 0.010 & 0.284 \\
\hline Potassium & 4.24 & 4.22 & 3.68 & 3.97 & $\mathrm{mg} / \mathrm{L}$ & 1.0 & 1.0 & 10.1 \\
\hline Selenium & 0.023 & 0.024 & 0.023 & 0.023 & $\mathrm{mg} / \mathrm{L}$ & 0.0010 & 0.010 & 0.220 \\
\hline Silver & $<0.0006$ & $<0.0006$ & $<0.00060$ & $<0.00060$ & $\mathrm{mg} / \mathrm{L}$ & 0.0050 & 0.00060 & $<0.5$ \\
\hline Sodium & 226 & 225 & 209 & 213 & $\mathrm{mg} / \mathrm{L}$ & 5.0 & 5.0 & 369 \\
\hline Thallium & $<0.0010$ & $<0.0010$ & $<0.0010$ & $<0.0010$ & $\mathrm{mg} / \mathrm{L}$ & 0.0010 & 0.0010 & $<0.058$ \\
\hline Vanadium & 0.057 & 0.056 & 0.050 & 0.052 & $\mathrm{mg} / \mathrm{L}$ & 0.050 & 0.050 & $<0.5$ \\
\hline $\begin{array}{l}\text { (a) } 95^{\text {th }} \text { Upper tolerance } \\
\text { and trace metals. } \\
\text { (b) Reporting limit. Value } \\
\text { (c) Not applicable. } \\
\text { (d) Standard unit. } \\
\text { (e) J Analyte detected a } \\
\text { concentrations corre }\end{array}$ & je, equival & $\begin{array}{l}\text { lent to } 95 \% \\
\text { lethod repor }\end{array}$ & $\begin{array}{l}\text { confidence } \\
\text { ting limit ( }\end{array}$ & $\begin{array}{l}\text { limit; } 95^{\text {th }} p e \\
\text { ARL). }\end{array}$ & ercentile for & nitrate, $\mathrm{TC}$ & OC, TOX, & TSS, \\
\hline
\end{tabular}


Appendix F - Groundwater Data Tables

Table F.8 - WIPP Well Inventory for 2010

\begin{tabular}{|c|c|c|c|c|c|c|c|}
\hline \multicolumn{4}{|c|}{ Sorted by Active Wells at Year-End } & \multicolumn{4}{|c|}{$\begin{array}{l}\text { Sorted by Formation for Wells Measured at Least } \\
\text { Once in } 2010\end{array}$} \\
\hline Count & $\begin{array}{l}\text { Well } \\
\text { Number }\end{array}$ & Zone & Notes & Count & $\begin{array}{l}\text { Well } \\
\text { Number }\end{array}$ & Zone & $\begin{array}{l}\text { Reason Not } \\
\text { Assessed for } \\
\text { Long-Term Water } \\
\text { Level Trend in } \\
\text { Culebra }\end{array}$ \\
\hline 1 & AEC-7 & CUL & & 1 & CB-1(PIP) & $\mathrm{B} / \mathrm{C}$ & \\
\hline 2 & C-2505 & SR/D & & 2 & DOE-2 & $\mathrm{B} / \mathrm{C}$ & \\
\hline 3 & C-2506 & SR/D & & 3 & AEC-7 & CUL & \\
\hline 4 & C-2507 & SR/D & & 4 & ERDA-9 & CUL & \\
\hline 5 & C-2737 & MAG/CUL & & 5 & $\mathrm{H}-02 \mathrm{~b} 2$ & CUL & \\
\hline 6 & C-2811 & SR/D & & 6 & $\mathrm{H}-03 \mathrm{~b} 2$ & CUL & \\
\hline 7 & CB-1(PIP) & $\mathrm{B} / \mathrm{C}$ & & 7 & $\mathrm{H}-04 \mathrm{bR}$ & CUL & \\
\hline 8 & DOE-2 & $\mathrm{B} / \mathrm{C}$ & & 8 & $\mathrm{H}-05 \mathrm{~b}$ & CUL & \\
\hline 9 & ERDA-9 & CUL & & 9 & $\mathrm{H}-06 \mathrm{bR}$ & CUL & \\
\hline 10 & $\mathrm{H}-02 \mathrm{~b} 1$ & MAG & & 10 & H-07b1 & CUL & \\
\hline 11 & $\mathrm{H}-02 \mathrm{~b} 2$ & CUL & & 11 & $\mathrm{H}-10 \mathrm{c}$ & CUL & \\
\hline 12 & $\mathrm{H}-03 \mathrm{~b} 1$ & MAG & & 12 & $\mathrm{H}-11 \mathrm{~b} 4$ & CUL & \\
\hline 13 & $\mathrm{H}-03 \mathrm{~b} 2$ & CUL & & 13 & $\mathrm{H}-12$ & CUL & \\
\hline 14 & $\mathrm{H}-03 \mathrm{D}$ & $\mathrm{SR} / \mathrm{D}$ & $\begin{array}{l}\text { dry; not measured in } \\
2010\end{array}$ & 14 & $\mathrm{H}-17$ & CUL & \\
\hline 15 & $\mathrm{H}-04 \mathrm{bR}$ & CUL & & 15 & $\mathrm{H}-19 \mathrm{b0}$ & CUL & \\
\hline 16 & $\mathrm{H}-04 \mathrm{C}$ & MAG & & 16 & $\mathrm{H}-19 \mathrm{~b} 2$ & CUL & Redundant to $\mathrm{H} 19 \mathrm{b0}$ \\
\hline 17 & $\mathrm{H}-05 \mathrm{~b}$ & CUL & & 17 & $\mathrm{H}-19 \mathrm{~b} 3$ & CUL & Redundant to $\mathrm{H} 19 \mathrm{b0}$ \\
\hline 18 & $\mathrm{H}-06 \mathrm{bR}$ & CUL & & 18 & $\mathrm{H}-19 \mathrm{~b} 4$ & CUL & Redundant to $\mathrm{H} 19 \mathrm{~b} 0$ \\
\hline 19 & $\mathrm{H}-06 \mathrm{c}$ & MAG & & 19 & $\mathrm{H}-19 \mathrm{~b} 5$ & CUL & Redundant to $\mathrm{H} 19 \mathrm{~b} 0$ \\
\hline 20 & $\mathrm{H}-07 \mathrm{~b} 1$ & CUL & & 20 & $\mathrm{H}-19 \mathrm{~b} 6$ & CUL & Redundant to $\mathrm{H} 19 \mathrm{b0}$ \\
\hline 21 & $\mathrm{H}-08 \mathrm{a}$ & MAG & & 21 & $\mathrm{H}-19 \mathrm{~b} 7$ & CUL & Redundant to $\mathrm{H} 19 \mathrm{~b} 0$ \\
\hline 22 & $\mathrm{H}-09 \mathrm{c}$ & MAG & $\begin{array}{l}\text { Reconfigured to } \\
\text { Magenta only in } \\
2010\end{array}$ & 22 & $\mathrm{I}-461$ & CUL & \\
\hline 23 & $\mathrm{H}-09 \mathrm{bR}$ & CUL & New in 2010 & 23 & SNL-01 & CUL & \\
\hline 24 & $\mathrm{H}-10 \mathrm{a}$ & MAG & & 24 & SNL-02 & CUL & \\
\hline 25 & $\mathrm{H}-10 \mathrm{c}$ & CUL & & 25 & SNL-03 & CUL & \\
\hline 26 & $\mathrm{H}-11 \mathrm{~b} 2$ & MAG & & 26 & SNL-05 & CUL & \\
\hline 27 & $\mathrm{H}-11 \mathrm{~b} 4$ & CUL & & 27 & SNL-6 & CUL & $\begin{array}{l}\text { Depressed from } \\
\text { projected equilibrium }\end{array}$ \\
\hline 28 & $\mathrm{H}-12$ & CUL & & 28 & SNL-08 & CUL & \\
\hline 29 & $\mathrm{H}-14$ & MAG & & 29 & SNL-09 & CUL & \\
\hline 30 & $\mathrm{H}-15 \mathrm{R}$ & CUL & & 30 & $\mathrm{H}-15 \mathrm{R}$ & CUL & \\
\hline 31 & $\mathrm{H}-15$ & MAG & & 31 & SNL-10 & CUL & \\
\hline 32 & $\mathrm{H}-16$ & CUL & & 32 & $\mathrm{H}-16$ & CUL & \\
\hline
\end{tabular}


Appendix F - Groundwater Data Tables

Table F.8 - WIPP Well Inventory for 2010

\begin{tabular}{|c|c|c|c|c|c|c|c|}
\hline \multicolumn{4}{|c|}{ Sorted by Active Wells at Year-End } & \multicolumn{4}{|c|}{$\begin{array}{l}\text { Sorted by Formation for Wells Measured at Least } \\
\text { Once in } 2010\end{array}$} \\
\hline Count & $\begin{array}{l}\text { Well } \\
\text { Number }\end{array}$ & Zone & Notes & Count & $\begin{array}{l}\text { Well } \\
\text { Number }\end{array}$ & Zone & $\begin{array}{l}\text { Reason Not } \\
\text { Assessed for } \\
\text { Long-Term Water } \\
\text { Level Trend in } \\
\text { Culebra }\end{array}$ \\
\hline 33 & $\mathrm{H}-17$ & CUL & & 33 & SNL-12 & CUL & \\
\hline 34 & $\mathrm{H}-18$ & MAG & & 34 & SNL-13 & CUL & $\begin{array}{l}\text { Rise from oil field } \\
\text { activities }\end{array}$ \\
\hline 35 & $\mathrm{H}-19 \mathrm{b0}$ & CUL & & 35 & SNL-14 & CUL & \\
\hline 36 & $\mathrm{H}-19 \mathrm{~b} 2$ & CUL & & 36 & SNL-15 & CUL & $\begin{array}{l}\text { Depressed from } \\
\text { projected equilibrium }\end{array}$ \\
\hline 37 & $\mathrm{H}-19 \mathrm{~b} 3$ & CUL & & 37 & SNL-16 & CUL & \\
\hline 38 & $\mathrm{H}-19 \mathrm{~b} 4$ & CUL & & 38 & SNL-17 & CUL & \\
\hline 39 & $\mathrm{H}-19 \mathrm{~b} 5$ & CUL & & 39 & SNL-18 & CUL & \\
\hline 40 & $\mathrm{H}-19 \mathrm{~b} 6$ & CUL & & 40 & SNL-19 & CUL & \\
\hline 41 & $\mathrm{H}-19 \mathrm{~b} 7$ & CUL & & 41 & WIPP-11 & CUL & \\
\hline 42 & I-461 & CUL & & 42 & WIPP-13 & CUL & \\
\hline 43 & SNL-01 & CUL & & 43 & WIPP-19 & CUL & \\
\hline 44 & SNL-02 & CUL & & 44 & WQSP-1 & CUL & \\
\hline 45 & SNL-03 & CUL & & 45 & WQSP-2 & CUL & \\
\hline 46 & SNL-05 & CUL & & 46 & WQSP-3 & CUL & \\
\hline 47 & SNL-06 & CUL & & 47 & WQSP-4 & CUL & \\
\hline 48 & SNL-08 & CUL & & 48 & WQSP-5 & CUL & \\
\hline 49 & SNL-09 & CUL & & 49 & WQSP-6 & CUL & \\
\hline 50 & SNL-10 & CUL & & 50 & WQSP-6A & $\mathrm{DL}$ & \\
\hline 51 & SNL-12 & CUL & & 51 & $\mathrm{H}-02 \mathrm{~b} 1$ & MAG & \\
\hline 52 & SNL-13 & CUL & & 52 & $\mathrm{H}-03 \mathrm{~b} 1$ & MAG & \\
\hline 53 & SNL-14 & CUL & & 53 & $\mathrm{H}-04 \mathrm{c}$ & MAG & \\
\hline 54 & SNL-15 & CUL & & 54 & $\mathrm{H}-06 \mathrm{c}$ & MAG & \\
\hline 55 & SNL-16 & CUL & & 55 & $\mathrm{H}-08 \mathrm{a}$ & MAG & \\
\hline 56 & SNL-17 & CUL & & 56 & $\mathrm{H}-10 \mathrm{a}$ & MAG & \\
\hline 57 & SNL-18 & CUL & & 57 & $\mathrm{H}-11 \mathrm{~b} 2$ & MAG & \\
\hline 58 & SNL-19 & CUL & & 58 & $\mathrm{H}-14$ & MAG & \\
\hline 59 & PZ-01 & SR/D & & 59 & $\mathrm{H}-18$ & MAG & \\
\hline 60 & PZ-02 & SR/D & & 60 & WIPP-18 & MAG & \\
\hline 61 & PZ-03 & SR/D & & 61 & $\mathrm{H}-15$ & MAG & \\
\hline 62 & PZ-04 & SR/D & & 62 & $\mathrm{H}-09 \mathrm{c}$ & MAG / CUL & \\
\hline 63 & PZ-05 & SR/D & & 63 & C-2737 & MAG / CUL & \\
\hline 64 & PZ-06 & SR/D & & 64 & $\mathrm{C}-2505$ & SR/D & \\
\hline 65 & PZ-07 & $\mathrm{SR} / \mathrm{D}$ & & 65 & C-2506 & SR/D & \\
\hline
\end{tabular}




\section{Waste Isolation Pilot Plant Annual Site Environmental Report for 2010 DOE/WIPP-11-2225}

Appendix F - Groundwater Data Tables

Table F.8 - WIPP Well Inventory for 2010

\begin{tabular}{|c|c|c|c|c|c|c|c|}
\hline \multicolumn{4}{|c|}{ Sorted by Active Wells at Year-End } & \multicolumn{4}{|c|}{$\begin{array}{l}\text { Sorted by Formation for Wells Measured at Least } \\
\text { Once in } 2010\end{array}$} \\
\hline Count & $\begin{array}{l}\text { Well } \\
\text { Number }\end{array}$ & Zone & Notes & Count & $\begin{array}{l}\text { Well } \\
\text { Number }\end{array}$ & Zone & $\begin{array}{l}\text { Reason Not } \\
\text { Assessed for } \\
\text { Long-Term Water } \\
\text { Level Trend in } \\
\text { Culebra }\end{array}$ \\
\hline 66 & PZ-08 & SR/D & & 66 & C-2507 & $\mathrm{SR} / \mathrm{D}$ & \\
\hline 67 & PZ-09 & SR/D & & 67 & C-2811 & SR/D & \\
\hline 68 & PZ-10 & SR/D & & 68 & PZ-01 & SR/D & \\
\hline 69 & PZ-11 & SR/D & & 69 & PZ-02 & SR/D & \\
\hline 70 & PZ-12 & SR/D & & 70 & PZ-03 & SR/D & \\
\hline 71 & PZ-13 & $\mathrm{SR} / \mathrm{D}$ & & 71 & PZ-04 & $\mathrm{SR} / \mathrm{D}$ & \\
\hline 72 & PZ-14 & SR/D & & 72 & PZ-05 & SR/D & \\
\hline 73 & PZ-15 & SR/D & & 73 & PZ-06 & SR/D & \\
\hline 74 & WIPP-11 & CUL & & 74 & PZ-07 & SR/D & \\
\hline 75 & WIPP-13 & CUL & & 75 & PZ-08 & SR/D & \\
\hline 76 & WIPP-18 & MAG & & 76 & PZ-09 & SR/D & \\
\hline 77 & WIPP-19 & CUL & & 77 & PZ-10 & SR/D & \\
\hline 78 & WQSP-1 & CUL & & 78 & PZ-11 & SR/D & \\
\hline 79 & WQSP-2 & CUL & & 79 & PZ-12 & SR/D & \\
\hline 80 & WQSP-3 & CUL & & 80 & PZ-13 & SR/D & \\
\hline 81 & WQSP-4 & CUL & & 81 & PZ-14 & SR/D & \\
\hline 82 & WQSP-5 & CUL & & 82 & PZ-15 & SR/D & \\
\hline 83 & WQSP-6 & CUL & & 83 & $H-03 D$ & $\mathrm{SR} / \mathrm{D}$ & $\begin{array}{l}\text { Dry; not measured in } \\
2010\end{array}$ \\
\hline 84 & WQSP-6A & DL & & & & & \\
\hline
\end{tabular}

Table F.9 - Water Levels

\begin{tabular}{|c|c|c|c|c|c|c|c|}
\hline Well Number & Zone & Date & $\begin{array}{c}\text { Adjusted } \\
\text { Depth Top } \\
\text { of Casing } \\
\text { (ft) }\end{array}$ & $\begin{array}{c}\text { Adjusted } \\
\text { Depth } \\
\text { (meters) }\end{array}$ & $\begin{array}{c}\text { Water Level } \\
\text { Elevation } \\
\text { (ft amsl) }\end{array}$ & $\begin{array}{c}\text { Elevation in } \\
\text { Meters } \\
\text { (amsl) }\end{array}$ & $\begin{array}{c}\text { Adjusted } \\
\text { Freshwater } \\
\text { Head (ft amsl) }\end{array}$ \\
\hline AEC-7 & CUL & $01 / 12 / 10$ & 612.95 & 186.83 & 3044.11 & 927.84 & 3064.87 \\
\hline AEC-7 & CUL & $02 / 09 / 10$ & 612.74 & 186.76 & 3044.32 & 927.91 & 3065.10 \\
\hline AEC-7 & CUL & $03 / 23 / 10$ & 612.73 & 186.76 & 3044.33 & 927.91 & 3065.11 \\
\hline AEC-7 & CUL & $04 / 19 / 10$ & 612.78 & 186.78 & 3044.28 & 927.90 & 3065.05 \\
\hline AEC-7 & CUL & $05 / 18 / 10$ & 612.78 & 186.78 & 3044.28 & 927.90 & 3065.05 \\
\hline AEC-7 & CUL & $06 / 08 / 10$ & 612.80 & 186.78 & 3044.26 & 927.89 & 3065.03 \\
\hline AEC-7 & CUL & $07 / 14 / 10$ & 612.73 & 186.76 & 3044.33 & 927.91 & 3065.11 \\
\hline AEC-7 & CUL & $08 / 10 / 10$ & 612.72 & 186.76 & 3044.34 & 927.91 & 3065.12 \\
\hline AEC-7 & CUL & $09 / 13 / 10$ & 612.76 & 186.77 & 3044.30 & 927.90 & 3065.08 \\
\hline
\end{tabular}




\section{Waste Isolation Pilot Plant Annual Site Environmental Report for 2010 DOE/WIPP-11-2225}

Appendix F - Groundwater Data Tables

Table F.9 - Water Levels

\begin{tabular}{|c|c|c|c|c|c|c|c|}
\hline Well Number & Zone & Date & $\begin{array}{l}\text { Adjusted } \\
\text { Depth Top } \\
\text { of Casing } \\
\text { (ft) }\end{array}$ & $\begin{array}{c}\text { Adjusted } \\
\text { Depth } \\
\text { (meters) }\end{array}$ & $\begin{array}{l}\text { Water Level } \\
\text { Elevation } \\
\text { (ft amsl) }\end{array}$ & $\begin{array}{l}\text { Elevation in } \\
\text { Meters } \\
\text { (amsl) }\end{array}$ & $\begin{array}{c}\text { Adjusted } \\
\text { Freshwater } \\
\text { Head (ft amsl) }\end{array}$ \\
\hline AEC-7 & CUL & $10 / 21 / 10$ & 612.86 & 186.80 & 3044.20 & 927.87 & 3064.97 \\
\hline AEC-7 & CUL & $11 / 09 / 10$ & 612.80 & 186.78 & 3044.26 & 927.89 & 3065.03 \\
\hline AEC-7 & CUL & $12 / 01 / 10$ & 612.70 & 186.75 & 3044.36 & 927.92 & 3065.14 \\
\hline C-2737 (PIP) & CUL & $01 / 13 / 10$ & 386.42 & 117.78 & 3014.34 & 918.77 & 3022.57 \\
\hline C-2737 (PIP) & CUL & $02 / 10 / 10$ & 386.47 & 117.80 & 3014.29 & 918.76 & 3022.51 \\
\hline C-2737 (PIP) & CUL & $03 / 24 / 10$ & 386.54 & 117.82 & 3014.22 & 918.73 & 3022.44 \\
\hline C-2737 (PIP) & CUL & $04 / 21 / 10$ & 386.60 & 117.84 & 3014.16 & 918.72 & 3022.38 \\
\hline C-2737 (PIP) & CUL & 05/18/10 & 386.82 & 117.90 & 3013.94 & 918.65 & 3022.15 \\
\hline C-2737 (PIP) & CUL & 06/09/10 & 386.78 & 117.89 & 3013.98 & 918.66 & 3022.20 \\
\hline C-2737 (PIP) & CUL & 07/14/10 & 386.54 & 117.82 & 3014.22 & 918.73 & 3022.44 \\
\hline C-2737 (PIP) & CUL & 08/11/10 & 386.61 & 117.84 & 3014.15 & 918.71 & 3022.37 \\
\hline C-2737 (PIP) & CUL & 09/14/10 & 386.67 & 117.86 & 3014.09 & 918.69 & 3022.31 \\
\hline C-2737 (PIP) & CUL & $10 / 22 / 10$ & 386.84 & 117.91 & 3013.92 & 918.64 & 3022.13 \\
\hline C-2737 (PIP) & CUL & $11 / 10 / 10$ & 386.88 & 117.92 & 3013.88 & 918.63 & 3022.09 \\
\hline C-2737 (PIP) & CUL & $12 / 06 / 10$ & 387.15 & 118.00 & 3013.61 & 918.55 & 3021.82 \\
\hline ERDA-9 & CUL & $01 / 13 / 10$ & 398.87 & 121.58 & 3011.30 & 917.84 & 3033.58 \\
\hline ERDA-9 & CUL & 02/10/10 & 398.85 & 121.57 & 3011.32 & 917.85 & 3033.60 \\
\hline ERDA-9 & CUL & $03 / 24 / 10$ & 398.72 & 121.53 & 3011.45 & 917.89 & 3033.74 \\
\hline ERDA-9 & CUL & $04 / 21 / 10$ & 398.65 & 121.51 & 3011.52 & 917.91 & 3033.82 \\
\hline ERDA-9 & CUL & 05/19/10 & 398.66 & 121.51 & 3011.51 & 917.91 & 3033.81 \\
\hline ERDA-9 & CUL & 06/08/10 & 398.45 & 121.45 & 3011.72 & 917.97 & 3034.03 \\
\hline ERDA-9 & CUL & $07 / 14 / 10$ & 398.26 & 121.39 & 3011.91 & 918.03 & 3034.23 \\
\hline ERDA-9 & CUL & $08 / 11 / 10$ & 398.20 & 121.37 & 3011.97 & 918.05 & 3034.30 \\
\hline ERDA-9 & CUL & $09 / 14 / 10$ & 398.27 & 121.39 & 3011.90 & 918.03 & 3034.22 \\
\hline ERDA-9 & CUL & $10 / 20 / 10$ & 398.31 & 121.40 & 3011.86 & 918.01 & 3034.18 \\
\hline ERDA-9 & CUL & $11 / 10 / 10$ & 398.31 & 121.40 & 3011.86 & 918.01 & 3034.18 \\
\hline ERDA-9 & CUL & $12 / 06 / 10$ & 398.54 & 121.47 & 3011.63 & 917.94 & 3033.93 \\
\hline $\mathrm{H}-02 \mathrm{~b} 2$ & CUL & $01 / 13 / 10$ & 335.65 & 102.31 & 3042.71 & 927.42 & 3046.01 \\
\hline $\mathrm{H}-02 \mathrm{~b} 2$ & CUL & 02/10/10 & 335.69 & 102.32 & 3042.67 & 927.41 & 3045.97 \\
\hline $\mathrm{H}-02 \mathrm{~b} 2$ & CUL & $03 / 25 / 10$ & 335.83 & 102.36 & 3042.53 & 927.36 & 3045.83 \\
\hline $\mathrm{H}-02 \mathrm{~b} 2$ & CUL & $04 / 21 / 10$ & 335.63 & 102.30 & 3042.73 & 927.42 & 3046.03 \\
\hline $\mathrm{H}-02 \mathrm{~b} 2$ & CUL & 05/18/10 & 335.85 & 102.37 & 3042.51 & 927.36 & 3045.81 \\
\hline $\mathrm{H}-02 \mathrm{~b} 2$ & CUL & 06/07/10 & 335.94 & 102.39 & 3042.42 & 927.33 & 3045.72 \\
\hline $\mathrm{H}-02 \mathrm{~b} 2$ & CUL & $07 / 14 / 10$ & 335.78 & 102.35 & 3042.58 & 927.38 & 3045.88 \\
\hline $\mathrm{H}-02 \mathrm{~b} 2$ & CUL & 08/10/10 & 335.81 & 102.35 & 3042.55 & 927.37 & 3045.85 \\
\hline $\mathrm{H}-02 \mathrm{~b} 2$ & CUL & 09/13/10 & 335.76 & 102.34 & 3042.60 & 927.38 & 3045.90 \\
\hline $\mathrm{H}-02 \mathrm{~b} 2$ & CUL & $10 / 22 / 10$ & 335.53 & 102.27 & 3042.83 & 927.45 & 3046.13 \\
\hline
\end{tabular}




\section{Waste Isolation Pilot Plant Annual Site Environmental Report for 2010 DOE/WIPP-11-2225}

Appendix F - Groundwater Data Tables

Table F.9 - Water Levels

\begin{tabular}{|c|c|c|c|c|c|c|c|}
\hline Well Number & Zone & Date & $\begin{array}{l}\text { Adjusted } \\
\text { Depth Top } \\
\text { of Casing } \\
\text { (ft) }\end{array}$ & $\begin{array}{l}\text { Adjusted } \\
\text { Depth } \\
\text { (meters) }\end{array}$ & $\begin{array}{l}\text { Water Level } \\
\text { Elevation } \\
\text { (ft amsl) }\end{array}$ & $\begin{array}{l}\text { Elevation in } \\
\text { Meters } \\
\text { (amsl) }\end{array}$ & $\begin{array}{c}\text { Adjusted } \\
\text { Freshwater } \\
\text { Head (ft amsl) }\end{array}$ \\
\hline $\mathrm{H}-02 \mathrm{~b} 2$ & CUL & $11 / 10 / 10$ & 335.45 & 102.25 & 3042.91 & 927.48 & 3046.21 \\
\hline $\mathrm{H}-02 \mathrm{~b} 2$ & CUL & $12 / 03 / 10$ & 335.51 & 102.26 & 3042.85 & 927.46 & 3046.15 \\
\hline $\mathrm{H}-03 \mathrm{~b} 2$ & CUL & $01 / 13 / 10$ & 387.76 & 118.19 & 3002.15 & 915.06 & 3014.75 \\
\hline $\mathrm{H}-03 \mathrm{~b} 2$ & CUL & 02/10/10 & 387.61 & 118.14 & 3002.30 & 915.10 & 3014.90 \\
\hline $\mathrm{H}-03 \mathrm{~b} 2$ & CUL & 03/24/10 & 387.91 & 118.23 & 3002.00 & 915.01 & 3014.59 \\
\hline $\mathrm{H}-03 \mathrm{~b} 2$ & CUL & $04 / 21 / 10$ & 388.00 & 118.26 & 3001.91 & 914.98 & 3014.50 \\
\hline $\mathrm{H}-03 \mathrm{~b} 2$ & CUL & 05/19/10 & 387.79 & 118.20 & 3002.12 & 915.05 & 3014.72 \\
\hline $\mathrm{H}-03 \mathrm{~b} 2$ & CUL & 06/08/10 & 387.79 & 118.20 & 3002.12 & 915.05 & 3014.72 \\
\hline $\mathrm{H}-03 \mathrm{~b} 2$ & CUL & 07/13/10 & 387.54 & 118.12 & 3002.37 & 915.12 & 3014.98 \\
\hline $\mathrm{H}-03 \mathrm{~b} 2$ & CUL & 08/11/10 & 387.65 & 118.16 & 3002.26 & 915.09 & 3014.86 \\
\hline $\mathrm{H}-03 \mathrm{~b} 2$ & CUL & 09/14/10 & 387.78 & 118.20 & 3002.13 & 915.05 & 3014.73 \\
\hline $\mathrm{H}-03 \mathrm{~b} 2$ & CUL & $10 / 20 / 10$ & 388.59 & 118.44 & 3001.32 & 914.80 & 3013.88 \\
\hline $\mathrm{H}-03 \mathrm{~b} 2$ & CUL & $11 / 11 / 10$ & 388.13 & 118.30 & 3001.78 & 914.94 & 3014.36 \\
\hline $\mathrm{H}-03 \mathrm{~b} 2$ & CUL & $12 / 03 / 10$ & 388.08 & 118.29 & 3001.83 & 914.96 & 3014.41 \\
\hline $\mathrm{H}-04 \mathrm{bR}$ & CUL & $01 / 13 / 10$ & 330.14 & 100.63 & 3004.50 & 915.77 & 3007.70 \\
\hline $\mathrm{H}-04 \mathrm{bR}$ & CUL & 02/08/10 & 329.79 & 100.52 & 3004.85 & 915.88 & 3008.06 \\
\hline $\mathrm{H}-04 \mathrm{bR}$ & CUL & 03/23/10 & 329.74 & 100.50 & 3004.90 & 915.89 & 3008.11 \\
\hline $\mathrm{H}-04 \mathrm{bR}$ & CUL & $04 / 20 / 10$ & 329.93 & 100.56 & 3004.71 & 915.84 & 3007.91 \\
\hline $\mathrm{H}-04 \mathrm{bR}$ & CUL & 05/18/10 & 330.07 & 100.61 & 3004.57 & 915.79 & 3007.77 \\
\hline $\mathrm{H}-04 \mathrm{bR}$ & CUL & 06/08/10 & 330.18 & 100.64 & 3004.46 & 915.76 & 3007.66 \\
\hline $\mathrm{H}-04 \mathrm{bR}$ & CUL & $07 / 12 / 10$ & 330.24 & 100.66 & 3004.40 & 915.74 & 3007.60 \\
\hline $\mathrm{H}-04 \mathrm{bR}$ & CUL & 08/09/10 & 330.33 & 100.68 & 3004.31 & 915.71 & 3007.51 \\
\hline $\mathrm{H}-04 \mathrm{bR}$ & CUL & 09/10/10 & 330.33 & 100.68 & 3004.31 & 915.71 & 3007.51 \\
\hline $\mathrm{H}-04 \mathrm{bR}$ & CUL & $10 / 21 / 10$ & 330.42 & 100.71 & 3004.22 & 915.69 & 3007.41 \\
\hline $\mathrm{H}-04 \mathrm{bR}$ & CUL & $11 / 11 / 10$ & 330.44 & 100.72 & 3004.20 & 915.68 & 3007.39 \\
\hline $\mathrm{H}-04 \mathrm{bR}$ & CUL & $12 / 01 / 10$ & 330.54 & 100.75 & 3004.10 & 915.65 & 3007.29 \\
\hline $\mathrm{H}-05 \mathrm{~b}$ & CUL & $01 / 12 / 10$ & 467.31 & 142.44 & 3039.47 & 926.43 & 3082.00 \\
\hline $\mathrm{H}-05 \mathrm{~b}$ & CUL & 02/09/10 & 467.09 & 142.37 & 3039.69 & 926.50 & 3082.24 \\
\hline $\mathrm{H}-05 \mathrm{~b}$ & CUL & 03/23/10 & 467.12 & 142.38 & 3039.66 & 926.49 & 3082.20 \\
\hline $\mathrm{H}-05 \mathrm{~b}$ & CUL & 04/19/10 & 467.23 & 142.41 & 3039.55 & 926.45 & 3082.08 \\
\hline $\mathrm{H}-05 \mathrm{~b}$ & CUL & 05/18/10 & 467.35 & 142.45 & 3039.43 & 926.42 & 3081.95 \\
\hline $\mathrm{H}-05 \mathrm{~b}$ & CUL & 06/08/10 & 467.30 & 142.43 & 3039.48 & 926.43 & 3082.01 \\
\hline $\mathrm{H}-05 \mathrm{~b}$ & CUL & 07/13/10 & 467.25 & 142.42 & 3039.53 & 926.45 & 3082.06 \\
\hline $\mathrm{H}-05 \mathrm{~b}$ & CUL & 08/09/10 & 467.39 & 142.46 & 3039.39 & 926.41 & 3081.91 \\
\hline $\mathrm{H}-05 \mathrm{~b}$ & CUL & 09/10/10 & 467.41 & 142.47 & 3039.37 & 926.40 & 3081.89 \\
\hline $\mathrm{H}-05 \mathrm{~b}$ & CUL & $10 / 21 / 10$ & 467.52 & 142.50 & 3039.26 & 926.37 & 3081.76 \\
\hline $\mathrm{H}-05 \mathrm{~b}$ & CUL & $11 / 09 / 10$ & 467.43 & 142.47 & 3039.35 & 926.39 & 3081.86 \\
\hline
\end{tabular}




\section{Waste Isolation Pilot Plant Annual Site Environmental Report for 2010 DOE/WIPP-11-2225}

Appendix F - Groundwater Data Tables

Table F.9 - Water Levels

\begin{tabular}{|c|c|c|c|c|c|c|c|}
\hline Well Number & Zone & Date & $\begin{array}{l}\text { Adjusted } \\
\text { Depth Top } \\
\text { of Casing } \\
\text { (ft) }\end{array}$ & $\begin{array}{l}\text { Adjusted } \\
\text { Depth } \\
\text { (meters) }\end{array}$ & $\begin{array}{l}\text { Water Level } \\
\text { Elevation } \\
\text { (ft amsl) }\end{array}$ & $\begin{array}{l}\text { Elevation in } \\
\text { Meters } \\
\text { (amsl) }\end{array}$ & $\begin{array}{c}\text { Adjusted } \\
\text { Freshwater } \\
\text { Head (ft amsl) }\end{array}$ \\
\hline $\mathrm{H}-05 \mathrm{~b}$ & CUL & $12 / 01 / 10$ & 467.52 & 142.50 & 3039.26 & 926.37 & 3081.76 \\
\hline $\mathrm{H}-06 \mathrm{bR}$ & CUL & $01 / 12 / 10$ & 289.92 & 88.37 & 3059.30 & 932.47 & 3071.41 \\
\hline $\mathrm{H}-06 \mathrm{bR}$ & CUL & 02/08/10 & 289.57 & 88.26 & 3059.65 & 932.58 & 3071.78 \\
\hline $\mathrm{H}-06 \mathrm{bR}$ & CUL & $03 / 22 / 10$ & 289.60 & 88.27 & 3059.62 & 932.57 & 3071.75 \\
\hline $\mathrm{H}-06 \mathrm{bR}$ & CUL & 04/19/10 & 289.82 & 88.34 & 3059.40 & 932.51 & 3071.52 \\
\hline $\mathrm{H}-06 \mathrm{bR}$ & CUL & 05/18/10 & 290.00 & 88.39 & 3059.22 & 932.45 & 3071.33 \\
\hline $\mathrm{H}-06 \mathrm{bR}$ & CUL & 06/09/10 & 290.15 & 88.44 & 3059.07 & 932.40 & 3071.18 \\
\hline $\mathrm{H}-06 \mathrm{bR}$ & CUL & 07/13/10 & 289.83 & 88.34 & 3059.39 & 932.50 & 3071.51 \\
\hline $\mathrm{H}-06 \mathrm{bR}$ & CUL & 08/10/10 & 289.22 & 88.15 & 3060.00 & 932.69 & 3072.14 \\
\hline $\mathrm{H}-06 \mathrm{bR}$ & CUL & 09/10/10 & 288.78 & 88.02 & 3060.44 & 932.82 & 3072.60 \\
\hline $\mathrm{H}-06 \mathrm{bR}$ & CUL & $10 / 20 / 10$ & 288.75 & 88.01 & 3060.47 & 932.83 & 3072.63 \\
\hline $\mathrm{H}-06 \mathrm{bR}$ & CUL & $11 / 09 / 10$ & 288.43 & 87.91 & 3060.79 & 932.93 & 3072.96 \\
\hline $\mathrm{H}-06 \mathrm{bR}$ & CUL & $12 / 03 / 10$ & 288.74 & 88.01 & 3060.48 & 932.83 & 3072.64 \\
\hline H-07b1 & CUL & $01 / 11 / 10$ & 166.16 & 50.65 & 2997.56 & 913.66 & 2998.18 \\
\hline H-07b1 & CUL & 02/08/10 & 165.79 & 50.53 & 2997.93 & 913.77 & 2998.55 \\
\hline $\mathrm{H}-07 \mathrm{~b} 1$ & CUL & $03 / 22 / 10$ & 165.81 & 50.54 & 2997.91 & 913.76 & 2998.53 \\
\hline H-07b1 & CUL & 04/19/10 & 165.79 & 50.53 & 2997.93 & 913.77 & 2998.55 \\
\hline $\mathrm{H}-07 \mathrm{~b} 1$ & CUL & 05/17/10 & 165.85 & 50.55 & 2997.87 & 913.75 & 2998.49 \\
\hline H-07b1 & CUL & 06/07/10 & 165.78 & 50.53 & 2997.94 & 913.77 & 2998.56 \\
\hline H-07b1 & CUL & $07 / 12 / 10$ & 165.82 & 50.54 & 2997.90 & 913.76 & 2998.52 \\
\hline H-07b1 & CUL & 08/09/10 & 165.83 & 50.54 & 2997.89 & 913.76 & 2998.51 \\
\hline $\mathrm{H}-07 \mathrm{~b} 1$ & CUL & 09/10/10 & 165.70 & 50.51 & 2998.02 & 913.80 & 2998.65 \\
\hline $\mathrm{H}-07 \mathrm{~b} 1$ & CUL & $10 / 20 / 10$ & 167.50 & 51.05 & 2996.22 & 913.25 & 2996.83 \\
\hline $\mathrm{H}-07 \mathrm{~b} 1$ & CUL & $11 / 10 / 10$ & 165.93 & 50.58 & 2997.79 & 913.73 & 2998.41 \\
\hline $\mathrm{H}-07 \mathrm{~b} 1$ & CUL & $12 / 02 / 10$ & 166.00 & 50.60 & 2997.72 & 913.71 & 2998.34 \\
\hline H-09c (PIP) & CUL & $01 / 11 / 10$ & 410.12 & 125.00 & 2996.93 & 913.46 & 2998.45 \\
\hline $\mathrm{H}-09 \mathrm{c}(\mathrm{PIP})$ & CUL & 02/08/10 & 409.98 & 124.96 & 2997.07 & 913.51 & 2998.59 \\
\hline $\mathrm{H}-09 \mathrm{c}(\mathrm{PIP})$ & CUL & 03/22/10 & 410.03 & 124.98 & 2997.02 & 913.49 & 2998.54 \\
\hline $\mathrm{H}-09 \mathrm{c}(\mathrm{PIP})$ & CUL & 04/19/10 & 410.33 & 125.07 & 2996.72 & 913.40 & 2998.24 \\
\hline $\mathrm{H}-09 \mathrm{c}(\mathrm{PIP})$ & CUL & 05/17/10 & 411.14 & 125.32 & 2995.91 & 913.15 & 2997.42 \\
\hline $\mathrm{H}-09 \mathrm{c}(\mathrm{PIP})$ & CUL & 06/08/10 & 410.65 & 125.17 & 2996.40 & 913.30 & 2997.92 \\
\hline $\mathrm{H}-09 \mathrm{c}(\mathrm{PIP})$ & CUL & $07 / 12 / 10$ & 410.67 & 125.17 & 2996.38 & 913.30 & 2997.90 \\
\hline $\mathrm{H}-09 \mathrm{c}(\mathrm{PIP})$ & CUL & 08/10/10 & 410.52 & 125.13 & 2996.53 & 913.34 & 2998.05 \\
\hline $\mathrm{H}-09 \mathrm{c}(\mathrm{PIP})$ & CUL & 09/13/10 & 411.16 & 125.32 & 2995.89 & 913.15 & 2997.40 \\
\hline $\mathrm{H}-10 \mathrm{c}$ & CUL & $01 / 12 / 10$ & 719.97 & 219.45 & 2968.43 & 904.78 & 3027.77 \\
\hline $\mathrm{H}-10 \mathrm{c}$ & CUL & 02/09/10 & 719.66 & 219.35 & 2968.74 & 904.87 & 3028.11 \\
\hline $\mathrm{H}-10 \mathrm{c}$ & CUL & 03/23/10 & 719.50 & 219.30 & 2968.90 & 904.92 & 3028.29 \\
\hline
\end{tabular}




\section{Waste Isolation Pilot Plant Annual Site Environmental Report for 2010 DOE/WIPP-11-2225}

Appendix F - Groundwater Data Tables

Table F.9 - Water Levels

\begin{tabular}{|c|c|c|c|c|c|c|c|}
\hline Well Number & Zone & Date & $\begin{array}{l}\text { Adjusted } \\
\text { Depth Top } \\
\text { of Casing } \\
\text { (ft) }\end{array}$ & $\begin{array}{l}\text { Adjusted } \\
\text { Depth } \\
\text { (meters) }\end{array}$ & $\begin{array}{l}\text { Water Level } \\
\text { Elevation } \\
\text { (ft amsl) }\end{array}$ & $\begin{array}{l}\text { Elevation in } \\
\text { Meters } \\
\text { (amsl) }\end{array}$ & $\begin{array}{c}\text { Adjusted } \\
\text { Freshwater } \\
\text { Head (ft amsl) }\end{array}$ \\
\hline $\mathrm{H}-10 \mathrm{c}$ & CUL & 04/19/10 & 719.63 & 219.34 & 2968.77 & 904.88 & 3028.14 \\
\hline $\mathrm{H}-10 \mathrm{c}$ & CUL & 05/17/10 & 719.74 & 219.38 & 2968.66 & 904.85 & 3028.02 \\
\hline $\mathrm{H}-10 \mathrm{c}$ & CUL & 06/08/10 & 719.61 & 219.34 & 2968.79 & 904.89 & 3028.17 \\
\hline $\mathrm{H}-10 \mathrm{c}$ & CUL & 07/13/10 & 719.55 & 219.32 & 2968.85 & 904.91 & 3028.23 \\
\hline $\mathrm{H}-10 \mathrm{c}$ & CUL & 08/11/10 & 719.64 & 219.35 & 2968.76 & 904.88 & 3028.13 \\
\hline $\mathrm{H}-10 \mathrm{c}$ & CUL & 09/13/10 & 719.83 & 219.40 & 2968.57 & 904.82 & 3027.93 \\
\hline $\mathrm{H}-10 \mathrm{c}$ & CUL & $10 / 21 / 10$ & 719.77 & 219.39 & 2968.63 & 904.84 & 3027.99 \\
\hline $\mathrm{H}-10 \mathrm{c}$ & CUL & $11 / 10 / 10$ & 719.70 & 219.36 & 2968.70 & 904.86 & 3028.07 \\
\hline $\mathrm{H}-10 \mathrm{c}$ & CUL & $12 / 02 / 10$ & 719.87 & 219.42 & 2968.53 & 904.81 & 3027.88 \\
\hline $\mathrm{H}-11 \mathrm{~b} 4$ & CUL & $01 / 12 / 10$ & 423.17 & 128.98 & 2987.62 & 910.63 & 3006.40 \\
\hline $\mathrm{H}-11 \mathrm{~b} 4$ & CUL & 02/09/10 & 422.73 & 128.85 & 2988.06 & 910.76 & 3006.87 \\
\hline $\mathrm{H}-11 \mathrm{~b} 4$ & CUL & 03/23/10 & 422.55 & 128.79 & 2988.24 & 910.82 & 3007.06 \\
\hline $\mathrm{H}-11 \mathrm{~b} 4$ & CUL & 04/20/10 & 422.78 & 128.86 & 2988.01 & 910.75 & 3006.81 \\
\hline $\mathrm{H}-11 \mathrm{~b} 4$ & CUL & 05/17/10 & 423.05 & 128.95 & 2987.74 & 910.66 & 3006.53 \\
\hline $\mathrm{H}-11 \mathrm{~b} 4$ & CUL & 06/07/10 & 423.07 & 128.95 & 2987.72 & 910.66 & 3006.51 \\
\hline $\mathrm{H}-11 \mathrm{~b} 4$ & CUL & 07/13/10 & 422.89 & 128.90 & 2987.90 & 910.71 & 3006.70 \\
\hline $\mathrm{H}-11 \mathrm{~b} 4$ & CUL & 08/09/10 & 423.21 & 128.99 & 2987.58 & 910.61 & 3006.36 \\
\hline $\mathrm{H}-11 \mathrm{~b} 4$ & CUL & 09/13/10 & 423.18 & 128.99 & 2987.61 & 910.62 & 3006.39 \\
\hline $\mathrm{H}-11 \mathrm{~b} 4$ & CUL & $10 / 21 / 10$ & 423.30 & 129.02 & 2987.49 & 910.59 & 3006.26 \\
\hline $\mathrm{H}-11 \mathrm{~b} 4$ & CUL & $11 / 10 / 10$ & 423.27 & 129.01 & 2987.52 & 910.60 & 3006.30 \\
\hline $\mathrm{H}-11 \mathrm{~b} 4$ & CUL & $12 / 01 / 10$ & 423.33 & 129.03 & 2987.46 & 910.58 & 3006.23 \\
\hline $\mathrm{H}-12$ & CUL & $01 / 12 / 10$ & 456.79 & 139.23 & 2970.54 & 905.42 & 3007.56 \\
\hline $\mathrm{H}-12$ & CUL & 02/09/10 & 456.39 & 139.11 & 2970.94 & 905.54 & 3008.00 \\
\hline $\mathrm{H}-12$ & CUL & 03/23/10 & 455.85 & 138.94 & 2971.48 & 905.71 & 3008.59 \\
\hline $\mathrm{H}-12$ & CUL & 04/19/10 & 455.84 & 138.94 & 2971.49 & 905.71 & 3008.60 \\
\hline $\mathrm{H}-12$ & CUL & 05/17/10 & 456.02 & 138.99 & 2971.31 & 905.66 & 3008.40 \\
\hline $\mathrm{H}-12$ & CUL & 06/07/10 & 455.98 & 138.98 & 2971.35 & 905.67 & 3008.45 \\
\hline $\mathrm{H}-12$ & CUL & 07/13/10 & 456.07 & 139.01 & 2971.26 & 905.64 & 3008.35 \\
\hline $\mathrm{H}-12$ & CUL & 08/11/10 & 456.23 & 139.06 & 2971.10 & 905.59 & 3008.17 \\
\hline $\mathrm{H}-12$ & CUL & 09/13/10 & 456.35 & 139.10 & 2970.98 & 905.55 & 3008.04 \\
\hline $\mathrm{H}-12$ & CUL & $10 / 21 / 10$ & 456.44 & 139.12 & 2970.89 & 905.53 & 3007.94 \\
\hline $\mathrm{H}-12$ & CUL & $11 / 10 / 10$ & 456.49 & 139.14 & 2970.84 & 905.51 & 3007.89 \\
\hline $\mathrm{H}-12$ & CUL & $12 / 02 / 10$ & 456.57 & 139.16 & 2970.76 & 905.49 & 3007.80 \\
\hline $\mathrm{H}-15 \mathrm{R}$ & CUL & $01 / 13 / 10$ & 507.30 & 154.63 & 2974.72 & 906.69 & 3018.57 \\
\hline $\mathrm{H}-15 \mathrm{R}$ & CUL & 02/10/10 & 507.04 & 154.55 & 2974.98 & 906.77 & 3018.86 \\
\hline $\mathrm{H}-15 \mathrm{R}$ & CUL & 03/24/10 & 506.84 & 154.48 & 2975.18 & 906.83 & 3019.09 \\
\hline $\mathrm{H}-15 \mathrm{R}$ & CUL & $04 / 21 / 10$ & 506.89 & 154.50 & 2975.13 & 906.82 & 3019.03 \\
\hline
\end{tabular}




\section{Waste Isolation Pilot Plant Annual Site Environmental Report for 2010 DOE/WIPP-11-2225}

Appendix F - Groundwater Data Tables

Table F.9 - Water Levels

\begin{tabular}{|c|c|c|c|c|c|c|c|}
\hline Well Number & Zone & Date & $\begin{array}{c}\text { Adjusted } \\
\text { Depth Top } \\
\text { of Casing } \\
\text { (ft) }\end{array}$ & $\begin{array}{l}\text { Adjusted } \\
\text { Depth } \\
\text { (meters) }\end{array}$ & $\begin{array}{l}\text { Water Level } \\
\text { Elevation } \\
\text { (ft amsl) }\end{array}$ & $\begin{array}{l}\text { Elevation in } \\
\text { Meters } \\
\text { (amsl) }\end{array}$ & $\begin{array}{c}\text { Adjusted } \\
\text { Freshwater } \\
\text { Head (ft amsl) }\end{array}$ \\
\hline $\mathrm{H}-15 \mathrm{R}$ & CUL & 05/19/10 & 507.07 & 154.55 & 2974.95 & 906.76 & 3018.83 \\
\hline$H-15 R$ & CUL & 06/08/10 & 507.11 & 154.57 & 2974.91 & 906.75 & 3018.78 \\
\hline$H-15 R$ & CUL & $07 / 14 / 10$ & 507.04 & 154.55 & 2974.98 & 906.77 & 3018.86 \\
\hline $\mathrm{H}-15 \mathrm{R}$ & CUL & 08/11/10 & 507.11 & 154.57 & 2974.91 & 906.75 & 3018.78 \\
\hline $\mathrm{H}-15 \mathrm{R}$ & CUL & 09/14/10 & 507.25 & 154.61 & 2974.77 & 906.71 & 3018.63 \\
\hline$H-15 R$ & CUL & $10 / 20 / 10$ & 507.25 & 154.61 & 2974.77 & 906.71 & 3018.63 \\
\hline $\mathrm{H}-15 \mathrm{R}$ & CUL & $11 / 11 / 10$ & 507.27 & 154.62 & 2974.75 & 906.70 & 3018.60 \\
\hline$H-15 R$ & CUL & $12 / 03 / 10$ & 507.34 & 154.64 & 2974.68 & 906.68 & 3018.53 \\
\hline $\mathrm{H}-16$ & CUL & $01 / 13 / 10$ & 376.72 & 114.82 & 3033.34 & 924.56 & 3046.51 \\
\hline $\mathrm{H}-16$ & CUL & 02/10/10 & 376.16 & 114.65 & 3033.90 & 924.73 & 3047.09 \\
\hline $\mathrm{H}-16$ & CUL & $03 / 25 / 10$ & 375.63 & 114.49 & 3034.43 & 924.89 & 3047.64 \\
\hline $\mathrm{H}-16$ & CUL & $04 / 21 / 10$ & 374.61 & 114.18 & 3035.45 & 925.21 & 3048.70 \\
\hline $\mathrm{H}-16$ & CUL & 05/19/10 & 374.34 & 114.10 & 3035.72 & 925.29 & 3048.98 \\
\hline $\mathrm{H}-16$ & CUL & 06/10/10 & 374.02 & 114.00 & 3036.04 & 925.38 & 3049.32 \\
\hline $\mathrm{H}-16$ & CUL & 07/14/10 & 373.85 & 113.95 & 3036.21 & 925.44 & 3049.49 \\
\hline $\mathrm{H}-16$ & CUL & 08/11/10 & 373.77 & 113.93 & 3036.29 & 925.46 & 3049.58 \\
\hline $\mathrm{H}-16$ & CUL & 09/14/10 & 373.75 & 113.92 & 3036.31 & 925.47 & 3049.60 \\
\hline $\mathrm{H}-16$ & CUL & $10 / 22 / 10$ & 373.52 & 113.85 & 3036.54 & 925.54 & 3049.84 \\
\hline $\mathrm{H}-16$ & CUL & $11 / 11 / 10$ & 373.61 & 113.88 & 3036.45 & 925.51 & 3049.74 \\
\hline $\mathrm{H}-16$ & CUL & $12 / 06 / 10$ & 374.47 & 114.14 & 3035.59 & 925.25 & 3048.85 \\
\hline $\mathrm{H}-17$ & CUL & $01 / 12 / 10$ & 418.03 & 127.42 & 2967.21 & 904.41 & 3008.04 \\
\hline $\mathrm{H}-17$ & CUL & $02 / 08 / 10$ & 417.48 & 127.25 & 2967.76 & 904.57 & 3008.66 \\
\hline $\mathrm{H}-17$ & CUL & $03 / 23 / 10$ & 417.50 & 127.25 & 2967.74 & 904.57 & 3008.64 \\
\hline $\mathrm{H}-17$ & CUL & 04/20/10 & 417.60 & 127.28 & 2967.64 & 904.54 & 3008.52 \\
\hline $\mathrm{H}-17$ & CUL & 05/17/10 & 417.72 & 127.32 & 2967.52 & 904.50 & 3008.39 \\
\hline $\mathrm{H}-17$ & CUL & 06/07/10 & 417.70 & 127.31 & 2967.54 & 904.51 & 3008.41 \\
\hline $\mathrm{H}-17$ & CUL & $07 / 13 / 10$ & 417.65 & 127.30 & 2967.59 & 904.52 & 3008.47 \\
\hline $\mathrm{H}-17$ & CUL & 08/09/10 & 417.75 & 127.33 & 2967.49 & 904.49 & 3008.35 \\
\hline $\mathrm{H}-17$ & CUL & 09/13/10 & 417.94 & 127.39 & 2967.30 & 904.43 & 3008.14 \\
\hline $\mathrm{H}-17$ & CUL & $10 / 21 / 10$ & 417.97 & 127.40 & 2967.27 & 904.42 & 3008.10 \\
\hline $\mathrm{H}-17$ & CUL & $11 / 10 / 10$ & 418.00 & 127.41 & 2967.24 & 904.41 & 3008.07 \\
\hline $\mathrm{H}-17$ & CUL & $12 / 01 / 10$ & 418.20 & 127.47 & 2967.04 & 904.35 & 3007.84 \\
\hline $\mathrm{H}-19 \mathrm{b0}$ & CUL & 01/13/10 & 425.36 & 129.65 & 2992.97 & 912.26 & 3014.98 \\
\hline $\mathrm{H}-19 \mathrm{~b} 0$ & CUL & 02/10/10 & 425.21 & 129.60 & 2993.12 & 912.30 & 3015.14 \\
\hline $\mathrm{H}-19 \mathrm{b0}$ & CUL & $03 / 24 / 10$ & 425.32 & 129.64 & 2993.01 & 912.27 & 3015.03 \\
\hline $\mathrm{H}-19 \mathrm{~b} 0$ & CUL & $04 / 20 / 10$ & 425.80 & 129.78 & 2992.53 & 912.12 & 3014.51 \\
\hline $\mathrm{H}-19 \mathrm{b0}$ & CUL & 05/19/10 & 425.41 & 129.66 & 2992.92 & 912.24 & 3014.93 \\
\hline
\end{tabular}




\section{Waste Isolation Pilot Plant Annual Site Environmental Report for 2010 DOE/WIPP-11-2225}

Appendix F - Groundwater Data Tables

Table F.9 - Water Levels

\begin{tabular}{|c|c|c|c|c|c|c|c|}
\hline Well Number & Zone & Date & $\begin{array}{l}\text { Adjusted } \\
\text { Depth Top } \\
\text { of Casing } \\
\text { (ft) }\end{array}$ & $\begin{array}{l}\text { Adjusted } \\
\text { Depth } \\
\text { (meters) }\end{array}$ & $\begin{array}{l}\text { Water Level } \\
\text { Elevation } \\
\text { (ft amsl) }\end{array}$ & $\begin{array}{l}\text { Elevation in } \\
\text { Meters } \\
\text { (amsl) }\end{array}$ & $\begin{array}{c}\text { Adjusted } \\
\text { Freshwater } \\
\text { Head (ft amsl) }\end{array}$ \\
\hline $\mathrm{H}-19 \mathrm{b0}$ & CUL & 06/09/10 & 425.40 & 129.66 & 2992.93 & 912.25 & 3014.94 \\
\hline $\mathrm{H}-19 \mathrm{b0}$ & CUL & 07/13/10 & 425.28 & 129.63 & 2993.05 & 912.28 & 3015.07 \\
\hline $\mathrm{H}-19 \mathrm{b0}$ & CUL & 08/11/10 & 425.32 & 129.64 & 2993.01 & 912.27 & 3015.03 \\
\hline $\mathrm{H}-19 \mathrm{b0}$ & CUL & 09/14/10 & 425.48 & 129.69 & 2992.85 & 912.22 & 3014.86 \\
\hline $\mathrm{H}-19 \mathrm{b0}$ & CUL & $10 / 21 / 10$ & 425.19 & 129.60 & 2993.14 & 912.31 & 3015.17 \\
\hline $\mathrm{H}-19 \mathrm{b0}$ & CUL & $11 / 11 / 10$ & 425.75 & 129.77 & 2992.58 & 912.14 & 3014.57 \\
\hline $\mathrm{H}-19 \mathrm{b0}$ & CUL & $12 / 01 / 10$ & 425.72 & 129.76 & 2992.61 & 912.15 & 3014.60 \\
\hline $\mathrm{H}-19 \mathrm{~b} 2$ & CUL & 03/24/10 & 426.66 & 130.05 & 2992.27 & 912.04 & 3014.01 \\
\hline $\mathrm{H}-19 \mathrm{~b} 2$ & CUL & 06/09/10 & 426.77 & 130.08 & 2992.16 & 912.01 & 3013.89 \\
\hline $\mathrm{H}-19 \mathrm{~b} 2$ & CUL & 09/14/10 & 426.84 & 130.10 & 2992.09 & 911.99 & 3013.82 \\
\hline $\mathrm{H}-19 \mathrm{~b} 2$ & CUL & $12 / 01 / 10$ & 427.07 & 130.17 & 2991.86 & 911.92 & 3013.57 \\
\hline $\mathrm{H}-19 \mathrm{b3}$ & CUL & 03/24/10 & 426.89 & 130.12 & 2992.13 & 912.00 & 3013.10 \\
\hline H-19b3 & CUL & 06/18/10 & 427.04 & 130.16 & 2991.98 & 911.96 & 3012.95 \\
\hline $\mathrm{H}-19 \mathrm{b3}$ & CUL & 09/14/10 & 427.05 & 130.16 & 2991.97 & 911.95 & 3012.93 \\
\hline H-19b3 & CUL & $12 / 01 / 10$ & 427.31 & 130.24 & 2991.71 & 911.87 & 3012.66 \\
\hline $\mathrm{H}-19 \mathrm{~b} 4$ & CUL & 03/24/10 & 426.15 & 129.89 & 2992.83 & 912.21 & 3012.54 \\
\hline $\mathrm{H}-19 \mathrm{~b} 4$ & CUL & 06/09/10 & 426.24 & 129.92 & 2992.74 & 912.19 & 3012.44 \\
\hline $\mathrm{H}-19 \mathrm{~b} 4$ & CUL & 09/14/10 & 426.30 & 129.94 & 2992.68 & 912.17 & 3012.38 \\
\hline $\mathrm{H}-19 \mathrm{~b} 4$ & CUL & $12 / 01 / 10$ & 426.53 & 130.01 & 2992.45 & 912.10 & 3012.13 \\
\hline H-19b5 & CUL & 03/24/10 & 426.14 & 129.89 & 2992.44 & 912.10 & 3013.43 \\
\hline H-19b5 & CUL & 06/09/10 & 426.21 & 129.91 & 2992.37 & 912.07 & 3013.36 \\
\hline $\mathrm{H}-19 \mathrm{~b} 5$ & CUL & 09/14/10 & 426.30 & 129.94 & 2992.28 & 912.05 & 3013.26 \\
\hline H-19b5 & CUL & $12 / 01 / 10$ & 426.57 & 130.02 & 2992.01 & 911.96 & 3012.98 \\
\hline H-19b6 & CUL & 03/24/10 & 426.80 & 130.09 & 2992.22 & 912.03 & 3013.20 \\
\hline H-19b6 & CUL & 06/09/10 & 426.91 & 130.12 & 2992.11 & 912.00 & 3013.08 \\
\hline $\mathrm{H}-19 \mathrm{~b} 6$ & CUL & 09/14/10 & 426.98 & 130.14 & 2992.04 & 911.97 & 3013.01 \\
\hline $\mathrm{H}-19 \mathrm{~b} 6$ & CUL & $12 / 01 / 10$ & 427.20 & 130.21 & 2991.82 & 911.91 & 3012.77 \\
\hline $\mathrm{H}-19 \mathrm{~b} 7$ & CUL & 03/24/10 & 426.83 & 130.10 & 2992.11 & 912.00 & 3014.39 \\
\hline $\mathrm{H}-19 \mathrm{~b} 7$ & CUL & 06/09/10 & 426.91 & 130.12 & 2992.03 & 911.97 & 3014.31 \\
\hline $\mathrm{H}-19 \mathrm{~b} 7$ & CUL & 09/14/10 & 426.98 & 130.14 & 2991.96 & 911.95 & 3014.23 \\
\hline $\mathrm{H}-19 \mathrm{~b} 7$ & CUL & $12 / 01 / 10$ & 427.24 & 130.22 & 2991.70 & 911.87 & 3013.96 \\
\hline I-461 & CUL & $01 / 11 / 10$ & 239.09 & 72.87 & 3044.52 & 927.97 & 3045.48 \\
\hline I-461 & CUL & 02/08/10 & 238.72 & 72.76 & 3044.89 & 928.08 & 3045.85 \\
\hline I-461 & CUL & $03 / 22 / 10$ & 238.76 & 72.77 & 3044.85 & 928.07 & 3045.81 \\
\hline I-461 & CUL & $04 / 20 / 10$ & 239.15 & 72.89 & 3044.46 & 927.95 & 3045.42 \\
\hline I-461 & CUL & 05/18/10 & 239.48 & 72.99 & 3044.13 & 927.85 & 3045.09 \\
\hline I-461 & CUL & 06/09/10 & 239.83 & 73.10 & 3043.78 & 927.74 & 3044.74 \\
\hline
\end{tabular}




\section{Waste Isolation Pilot Plant Annual Site Environmental Report for 2010 DOE/WIPP-11-2225}

Appendix F - Groundwater Data Tables

Table F.9 - Water Levels

\begin{tabular}{|c|c|c|c|c|c|c|c|}
\hline Well Number & Zone & Date & $\begin{array}{c}\text { Adjusted } \\
\text { Depth Top } \\
\text { of Casing } \\
\text { (ft) }\end{array}$ & $\begin{array}{l}\text { Adjusted } \\
\text { Depth } \\
\text { (meters) }\end{array}$ & $\begin{array}{l}\text { Water Level } \\
\text { Elevation } \\
\text { (ft amsl) }\end{array}$ & $\begin{array}{l}\text { Elevation in } \\
\text { Meters } \\
\text { (amsl) }\end{array}$ & $\begin{array}{c}\text { Adjusted } \\
\text { Freshwater } \\
\text { Head (ft amsl) }\end{array}$ \\
\hline $\mathrm{I}-461$ & CUL & $07 / 12 / 10$ & 239.38 & 72.96 & 3044.23 & 927.88 & 3045.19 \\
\hline I-461 & CUL & 08/09/10 & 238.10 & 72.57 & 3045.51 & 928.27 & 3046.48 \\
\hline I-461 & CUL & 09/10/10 & 237.87 & 72.50 & 3045.74 & 928.34 & 3046.71 \\
\hline I-461 & CUL & $10 / 20 / 10$ & 238.25 & 72.62 & 3045.36 & 928.23 & 3046.33 \\
\hline $\mathrm{I}-461$ & CUL & $11 / 09 / 10$ & 238.18 & 72.60 & 3045.43 & 928.25 & 3046.40 \\
\hline $\mathrm{I}-461$ & CUL & $12 / 02 / 10$ & 238.58 & 72.72 & 3045.03 & 928.13 & 3046.00 \\
\hline SNL-01 & CUL & $01 / 11 / 10$ & 434.63 & 132.48 & 3078.21 & 938.24 & 3083.56 \\
\hline SNL-01 & CUL & $02 / 09 / 10$ & 434.53 & 132.44 & 3078.31 & 938.27 & 3083.66 \\
\hline SNL-01 & CUL & $03 / 22 / 10$ & 434.02 & 132.29 & 3078.82 & 938.42 & 3084.18 \\
\hline SNL-01 & CUL & 04/20/10 & 433.99 & 132.28 & 3078.85 & 938.43 & 3084.22 \\
\hline SNL-01 & CUL & 05/18/10 & 434.06 & 132.30 & 3078.78 & 938.41 & 3084.14 \\
\hline SNL-01 & CUL & 06/09/10 & 434.04 & 132.30 & 3078.80 & 938.42 & 3084.16 \\
\hline SNL-01 & CUL & $07 / 12 / 10$ & 433.95 & 132.27 & 3078.89 & 938.45 & 3084.26 \\
\hline SNL-01 & CUL & $08 / 10 / 10$ & 433.26 & 132.06 & 3079.58 & 938.66 & 3084.97 \\
\hline SNL-01 & CUL & 09/10/10 & 433.39 & 132.10 & 3079.45 & 938.62 & 3084.83 \\
\hline SNL-01 & CUL & $10 / 20 / 10$ & 431.95 & 131.66 & 3080.89 & 939.06 & 3086.32 \\
\hline SNL-01 & CUL & $11 / 09 / 10$ & 431.51 & 131.52 & 3081.33 & 939.19 & 3086.77 \\
\hline SNL-01 & CUL & $12 / 01 / 10$ & 431.80 & 131.61 & 3081.04 & 939.10 & 3086.47 \\
\hline SNL-02 & CUL & $01 / 11 / 10$ & 252.66 & 77.01 & 3070.40 & 935.86 & 3072.14 \\
\hline SNL-02 & CUL & $02 / 08 / 10$ & 252.25 & 76.89 & 3070.81 & 935.98 & 3072.56 \\
\hline SNL-02 & CUL & $03 / 22 / 10$ & 252.43 & 76.94 & 3070.63 & 935.93 & 3072.38 \\
\hline SNL-02 & CUL & 04/20/10 & 252.76 & 77.04 & 3070.30 & 935.83 & 3072.04 \\
\hline SNL-02 & CUL & 05/18/10 & 253.06 & 77.13 & 3070.00 & 935.74 & 3071.74 \\
\hline SNL-02 & CUL & 06/10/10 & 253.29 & 77.20 & 3069.77 & 935.67 & 3071.51 \\
\hline SNL-02 & CUL & $07 / 12 / 10$ & 252.61 & 77.00 & 3070.45 & 935.87 & 3072.20 \\
\hline SNL-02 & CUL & 08/10/10 & 251.14 & 76.55 & 3071.92 & 936.32 & 3073.68 \\
\hline SNL-02 & CUL & 09/10/10 & 250.78 & 76.44 & 3072.28 & 936.43 & 3074.04 \\
\hline SNL-02 & CUL & $10 / 20 / 10$ & 251.19 & 76.56 & 3071.87 & 936.31 & 3073.63 \\
\hline SNL-02 & CUL & $11 / 09 / 10$ & 251.22 & 76.57 & 3071.84 & 936.30 & 3073.60 \\
\hline SNL-02 & CUL & $12 / 01 / 10$ & 251.61 & 76.69 & 3071.45 & 936.18 & 3073.20 \\
\hline SNL-03 & CUL & $01 / 12 / 10$ & 419.02 & 127.72 & 3071.33 & 936.14 & 3082.45 \\
\hline SNL-03 & CUL & $02 / 09 / 10$ & 418.82 & 127.66 & 3071.53 & 936.20 & 3082.66 \\
\hline SNL-03 & CUL & $03 / 22 / 10$ & 418.59 & 127.59 & 3071.76 & 936.27 & 3082.89 \\
\hline SNL-03 & CUL & 04/20/10 & 418.61 & 127.59 & 3071.74 & 936.27 & 3082.87 \\
\hline SNL-03 & CUL & $05 / 19 / 10$ & 418.70 & 127.62 & 3071.65 & 936.24 & 3082.78 \\
\hline SNL-03 & CUL & 06/09/10 & 418.78 & 127.64 & 3071.57 & 936.21 & 3082.70 \\
\hline SNL-03 & CUL & $07 / 13 / 10$ & 418.61 & 127.59 & 3071.74 & 936.27 & 3082.87 \\
\hline
\end{tabular}




\section{Waste Isolation Pilot Plant Annual Site Environmental Report for 2010 DOE/WIPP-11-2225}

Appendix F - Groundwater Data Tables

Table F.9 - Water Levels

\begin{tabular}{|c|c|c|c|c|c|c|c|}
\hline Well Number & Zone & Date & $\begin{array}{l}\text { Adjusted } \\
\text { Depth Top } \\
\text { of Casing } \\
\text { (ft) }\end{array}$ & $\begin{array}{l}\text { Adjusted } \\
\text { Depth } \\
\text { (meters) }\end{array}$ & $\begin{array}{l}\text { Water Level } \\
\text { Elevation } \\
\text { (ft amsl) }\end{array}$ & $\begin{array}{l}\text { Elevation in } \\
\text { Meters } \\
\text { (amsl) }\end{array}$ & $\begin{array}{c}\text { Adjusted } \\
\text { Freshwater } \\
\text { Head (ft amsl) }\end{array}$ \\
\hline SNL-03 & CUL & 08/10/10 & 418.49 & 127.56 & 3071.86 & 936.30 & 3083.00 \\
\hline SNL-03 & CUL & 09/10/10 & 417.82 & 127.35 & 3072.53 & 936.51 & 3083.69 \\
\hline SNL-03 & CUL & $10 / 20 / 10$ & 417.31 & 127.20 & 3073.04 & 936.66 & 3084.22 \\
\hline SNL-03 & CUL & $11 / 10 / 10$ & 416.87 & 127.06 & 3073.48 & 936.80 & 3084.67 \\
\hline SNL-03 & CUL & $12 / 02 / 10$ & 416.84 & 127.05 & 3073.51 & 936.81 & 3084.70 \\
\hline SNL-05 & CUL & $01 / 11 / 10$ & 307.74 & 93.80 & 3072.24 & 936.42 & 3075.31 \\
\hline SNL-05 & CUL & 02/08/10 & 307.47 & 93.72 & 3072.51 & 936.50 & 3075.58 \\
\hline SNL-05 & CUL & $03 / 22 / 10$ & 307.35 & 93.68 & 3072.63 & 936.54 & 3075.70 \\
\hline SNL-05 & CUL & $04 / 20 / 10$ & 307.45 & 93.71 & 3072.53 & 936.51 & 3075.60 \\
\hline SNL-05 & CUL & 05/18/10 & 307.60 & 93.76 & 3072.38 & 936.46 & 3075.45 \\
\hline SNL-05 & CUL & 06/10/10 & 307.60 & 93.76 & 3072.38 & 936.46 & 3075.45 \\
\hline SNL-05 & CUL & $07 / 12 / 10$ & 307.56 & 93.74 & 3072.42 & 936.47 & 3075.49 \\
\hline SNL-05 & CUL & 08/10/10 & 306.89 & 93.54 & 3073.09 & 936.68 & 3076.17 \\
\hline SNL-05 & CUL & 09/10/10 & 306.29 & 93.36 & 3073.69 & 936.86 & 3076.77 \\
\hline SNL-05 & CUL & $10 / 20 / 10$ & 306.00 & 93.27 & 3073.98 & 936.95 & 3077.07 \\
\hline SNL-05 & CUL & $11 / 09 / 10$ & 305.62 & 93.15 & 3074.36 & 937.06 & 3077.45 \\
\hline SNL-05 & CUL & $12 / 01 / 10$ & 305.84 & 93.22 & 3074.14 & 937.00 & 3077.23 \\
\hline SNL-06 & CUL & $01 / 12 / 10$ & 765.74 & 233.40 & 2880.37 & 877.94 & 3013.18 \\
\hline SNL-06 & CUL & 02/09/10 & 760.48 & 231.79 & 2885.63 & 879.54 & 3019.66 \\
\hline SNL-06 & CUL & 03/23/10 & 752.76 & 229.44 & 2893.35 & 881.89 & 3029.17 \\
\hline SNL-06 & CUL & 04/19/10 & 747.94 & 227.97 & 2898.17 & 883.36 & 3035.11 \\
\hline SNL-06 & CUL & 05/18/10 & 743.03 & 226.48 & 2903.08 & 884.86 & 3041.16 \\
\hline SNL-06 & CUL & 06/08/10 & 739.23 & 225.32 & 2906.88 & 886.02 & 3045.84 \\
\hline SNL-06 & CUL & $07 / 14 / 10$ & 733.05 & 223.43 & 2913.06 & 887.90 & 3053.46 \\
\hline SNL-06 & CUL & 08/10/10 & 728.47 & 222.04 & 2917.64 & 889.30 & 3059.10 \\
\hline SNL-06 & CUL & 09/13/10 & 722.73 & 220.29 & 2923.38 & 891.05 & 3066.17 \\
\hline SNL-06 & CUL & $10 / 21 / 10$ & 716.42 & 218.36 & 2929.69 & 892.97 & 3073.95 \\
\hline SNL-06 & CUL & $11 / 09 / 10$ & 713.21 & 217.39 & 2932.90 & 893.95 & 3077.90 \\
\hline SNL-06 & CUL & $12 / 01 / 10$ & 709.74 & 216.33 & 2936.37 & 895.01 & 3082.18 \\
\hline SNL-08 & CUL & $01 / 12 / 10$ & 544.69 & 166.02 & 3011.04 & 917.76 & 3050.57 \\
\hline SNL-08 & CUL & 02/09/10 & 542.80 & 165.45 & 3012.93 & 918.34 & 3052.63 \\
\hline SNL-08 & CUL & $03 / 23 / 10$ & 542.44 & 165.34 & 3013.29 & 918.45 & 3053.03 \\
\hline SNL-08 & CUL & 04/19/10 & 542.83 & 165.45 & 3012.90 & 918.33 & 3052.60 \\
\hline SNL-08 & CUL & 05/18/10 & 543.02 & 165.51 & 3012.71 & 918.27 & 3052.39 \\
\hline SNL-08 & CUL & 06/08/10 & 543.06 & 165.52 & 3012.67 & 918.26 & 3052.35 \\
\hline SNL-08 & CUL & 07/13/10 & 543.14 & 165.55 & 3012.59 & 918.24 & 3052.26 \\
\hline SNL-08 & CUL & 08/09/10 & 543.28 & 165.59 & 3012.45 & 918.19 & 3052.11 \\
\hline
\end{tabular}




\section{Waste Isolation Pilot Plant Annual Site Environmental Report for 2010 DOE/WIPP-11-2225}

Appendix F - Groundwater Data Tables

Table F.9 - Water Levels

\begin{tabular}{|c|c|c|c|c|c|c|c|}
\hline Well Number & Zone & Date & $\begin{array}{l}\text { Adjusted } \\
\text { Depth Top } \\
\text { of Casing } \\
\text { (ft) }\end{array}$ & $\begin{array}{l}\text { Adjusted } \\
\text { Depth } \\
\text { (meters) }\end{array}$ & $\begin{array}{l}\text { Water Level } \\
\text { Elevation } \\
\text { (ft amsl) }\end{array}$ & $\begin{array}{l}\text { Elevation in } \\
\text { Meters } \\
\text { (amsl) }\end{array}$ & $\begin{array}{c}\text { Adjusted } \\
\text { Freshwater } \\
\text { Head (ft amsl) }\end{array}$ \\
\hline SNL-08 & CUL & 09/13/10 & 543.51 & 165.66 & 3012.22 & 918.12 & 3051.86 \\
\hline SNL-08 & CUL & $10 / 21 / 10$ & 543.47 & 165.65 & 3012.26 & 918.14 & 3051.90 \\
\hline SNL-08 & CUL & $11 / 10 / 10$ & 543.44 & 165.64 & 3012.29 & 918.15 & 3051.93 \\
\hline SNL-08 & CUL & $12 / 01 / 10$ & 543.67 & 165.71 & 3012.06 & 918.08 & 3051.68 \\
\hline SNL-09 & CUL & $01 / 11 / 10$ & 311.00 & 94.79 & 3049.96 & 929.63 & 3054.57 \\
\hline SNL-09 & CUL & 02/08/10 & 310.53 & 94.65 & 3050.43 & 929.77 & 3055.05 \\
\hline SNL-09 & CUL & $03 / 22 / 10$ & 310.56 & 94.66 & 3050.40 & 929.76 & 3055.02 \\
\hline SNL-09 & CUL & 04/19/10 & 310.82 & 94.74 & 3050.14 & 929.68 & 3054.75 \\
\hline SNL-09 & CUL & 05/18/10 & 310.96 & 94.78 & 3050.00 & 929.64 & 3054.61 \\
\hline SNL-09 & CUL & 06/09/10 & 311.21 & 94.86 & 3049.75 & 929.56 & 3054.36 \\
\hline SNL-09 & CUL & $07 / 12 / 10$ & 311.09 & 94.82 & 3049.87 & 929.60 & 3054.48 \\
\hline SNL-09 & CUL & 08/09/10 & 310.35 & 94.59 & 3050.61 & 929.83 & 3055.23 \\
\hline SNL-09 & CUL & 09/10/10 & 309.84 & 94.44 & 3051.12 & 929.98 & 3055.75 \\
\hline SNL-09 & CUL & $10 / 20 / 10$ & 310.10 & 94.52 & 3050.86 & 929.90 & 3055.49 \\
\hline SNL-09 & CUL & $11 / 09 / 10$ & 309.92 & 94.46 & 3051.04 & 929.96 & 3055.67 \\
\hline SNL-09 & CUL & $12 / 02 / 10$ & 310.33 & 94.59 & 3050.63 & 929.83 & 3055.25 \\
\hline SNL-10 & CUL & $01 / 12 / 10$ & 325.90 & 99.33 & 3051.69 & 930.16 & 3054.28 \\
\hline SNL-10 & CUL & 02/09/10 & 325.72 & 99.28 & 3051.87 & 930.21 & 3054.46 \\
\hline SNL-10 & CUL & 03/23/10 & 325.45 & 99.20 & 3052.14 & 930.29 & 3054.73 \\
\hline SNL-10 & CUL & 04/20/10 & 325.62 & 99.25 & 3051.97 & 930.24 & 3054.56 \\
\hline SNL-10 & CUL & 05/18/10 & 325.82 & 99.31 & 3051.77 & 930.18 & 3054.36 \\
\hline SNL-10 & CUL & 06/07/10 & 325.97 & 99.36 & 3051.62 & 930.13 & 3054.21 \\
\hline SNL-10 & CUL & $07 / 12 / 10$ & 325.95 & 99.35 & 3051.64 & 930.14 & 3054.23 \\
\hline SNL-10 & CUL & 08/09/10 & 325.78 & 99.30 & 3051.81 & 930.19 & 3054.40 \\
\hline SNL-10 & CUL & 09/10/10 & 325.35 & 99.17 & 3052.24 & 930.32 & 3054.83 \\
\hline SNL-10 & CUL & $10 / 20 / 10$ & 325.34 & 99.16 & 3052.25 & 930.33 & 3054.84 \\
\hline SNL-10 & CUL & $11 / 10 / 10$ & 325.24 & 99.13 & 3052.35 & 930.36 & 3054.94 \\
\hline SNL-10 & CUL & $12 / 03 / 10$ & 325.44 & 99.19 & 3052.15 & 930.30 & 3054.74 \\
\hline SNL-12 & CUL & $01 / 11 / 10$ & 337.64 & 102.91 & 3001.82 & 914.95 & 3002.75 \\
\hline SNL-12 & CUL & 02/08/10 & 336.78 & 102.65 & 3002.68 & 915.22 & 3003.62 \\
\hline SNL-12 & CUL & $03 / 22 / 10$ & 337.28 & 102.80 & 3002.18 & 915.06 & 3003.11 \\
\hline SNL-12 & CUL & $04 / 19 / 10$ & 337.40 & 102.84 & 3002.06 & 915.03 & 3002.99 \\
\hline SNL-12 & CUL & 05/17/10 & 337.73 & 102.94 & 3001.73 & 914.93 & 3002.66 \\
\hline SNL-12 & CUL & 06/08/10 & 337.66 & 102.92 & 3001.80 & 914.95 & 3002.73 \\
\hline SNL-12 & CUL & $07 / 12 / 10$ & 337.71 & 102.93 & 3001.75 & 914.93 & 3002.68 \\
\hline SNL-12 & CUL & 08/10/10 & 337.82 & 102.97 & 3001.64 & 914.90 & 3002.57 \\
\hline SNL-12 & CUL & 09/13/10 & 337.99 & 103.02 & 3001.47 & 914.85 & 3002.40 \\
\hline
\end{tabular}




\section{Waste Isolation Pilot Plant Annual Site Environmental Report for 2010 DOE/WIPP-11-2225}

Appendix F - Groundwater Data Tables

Table F.9 - Water Levels

\begin{tabular}{|c|c|c|c|c|c|c|c|}
\hline Well Number & Zone & Date & $\begin{array}{c}\text { Adjusted } \\
\text { Depth Top } \\
\text { of Casing } \\
\text { (ft) }\end{array}$ & $\begin{array}{l}\text { Adjusted } \\
\text { Depth } \\
\text { (meters) }\end{array}$ & $\begin{array}{l}\text { Water Level } \\
\text { Elevation } \\
\text { (ft amsl) }\end{array}$ & $\begin{array}{l}\text { Elevation in } \\
\text { Meters } \\
\text { (amsl) }\end{array}$ & $\begin{array}{c}\text { Adjusted } \\
\text { Freshwater } \\
\text { Head (ft amsl) }\end{array}$ \\
\hline SNL-12 & CUL & $10 / 20 / 10$ & 338.05 & 103.04 & 3001.41 & 914.83 & 3002.34 \\
\hline SNL-12 & CUL & $11 / 10 / 10$ & 338.00 & 103.02 & 3001.46 & 914.85 & 3002.39 \\
\hline SNL-12 & CUL & $12 / 02 / 10$ & 338.14 & 103.07 & 3001.32 & 914.80 & 3002.25 \\
\hline SNL-13 & CUL & $01 / 12 / 10$ & 285.43 & 87.00 & 3008.79 & 917.08 & 3011.68 \\
\hline SNL-13 & CUL & 02/09/10 & 285.26 & 86.95 & 3008.96 & 917.13 & 3011.86 \\
\hline SNL-13 & CUL & $03 / 23 / 10$ & 282.95 & 86.24 & 3011.27 & 917.84 & 3014.22 \\
\hline SNL-13 & CUL & 04/19/10 & 281.62 & 85.84 & 3012.60 & 918.24 & 3015.59 \\
\hline SNL-13 & CUL & 05/18/10 & 280.80 & 85.59 & 3013.42 & 918.49 & 3016.43 \\
\hline SNL-13 & CUL & 06/07/10 & 280.50 & 85.50 & 3013.72 & 918.58 & 3016.74 \\
\hline SNL-13 & CUL & $07 / 12 / 10$ & 279.99 & 85.34 & 3014.23 & 918.74 & 3017.26 \\
\hline SNL-13 & CUL & 08/09/10 & 279.90 & 85.31 & 3014.32 & 918.76 & 3017.35 \\
\hline SNL-13 & CUL & 09/10/10 & 279.71 & 85.26 & 3014.51 & 918.82 & 3017.55 \\
\hline SNL-13 & CUL & $10 / 20 / 10$ & 279.84 & 85.30 & 3014.38 & 918.78 & 3017.41 \\
\hline SNL-13 & CUL & $11 / 10 / 10$ & 279.82 & 85.29 & 3014.40 & 918.79 & 3017.43 \\
\hline SNL-13 & CUL & $12 / 02 / 10$ & 280.00 & 85.34 & 3014.22 & 918.73 & 3017.25 \\
\hline SNL-14 & CUL & $01 / 12 / 10$ & 376.80 & 114.85 & 2991.61 & 911.84 & 3005.07 \\
\hline SNL-14 & CUL & 02/08/10 & 376.07 & 114.63 & 2992.34 & 912.07 & 3005.84 \\
\hline SNL-14 & CUL & 03/23/10 & 376.22 & 114.67 & 2992.19 & 912.02 & 3005.68 \\
\hline SNL-14 & CUL & $04 / 20 / 10$ & 376.38 & 114.72 & 2992.03 & 911.97 & 3005.51 \\
\hline SNL-14 & CUL & 05/17/10 & 376.75 & 114.83 & 2991.66 & 911.86 & 3005.13 \\
\hline SNL-14 & CUL & 06/07/10 & 376.74 & 114.83 & 2991.67 & 911.86 & 3005.14 \\
\hline SNL-14 & CUL & $07 / 13 / 10$ & 376.77 & 114.84 & 2991.64 & 911.85 & 3005.11 \\
\hline SNL-14 & CUL & 08/09/10 & 376.85 & 114.86 & 2991.56 & 911.83 & 3005.02 \\
\hline SNL-14 & CUL & $09 / 13 / 10$ & 376.97 & 114.90 & 2991.44 & 911.79 & 3004.90 \\
\hline SNL-14 & CUL & $10 / 20 / 10$ & 377.03 & 114.92 & 2991.38 & 911.77 & 3004.83 \\
\hline SNL-14 & CUL & $11 / 10 / 10$ & 377.03 & 114.92 & 2991.38 & 911.77 & 3004.83 \\
\hline SNL-14 & CUL & $12 / 01 / 10$ & 377.10 & 114.94 & 2991.31 & 911.75 & 3004.76 \\
\hline SNL-15 & CUL & $01 / 12 / 10$ & 599.12 & 182.61 & 2880.81 & 878.07 & 2953.64 \\
\hline SNL-15 & CUL & 02/09/10 & 597.37 & 182.08 & 2882.56 & 878.60 & 2955.79 \\
\hline SNL-15 & CUL & 03/23/10 & 594.74 & 181.28 & 2885.19 & 879.41 & 2959.01 \\
\hline SNL-15 & CUL & 04/19/10 & 593.20 & 180.81 & 2886.73 & 879.88 & 2960.90 \\
\hline SNL-15 & CUL & $05 / 17 / 10$ & 591.55 & 180.30 & 2888.38 & 880.38 & 2962.92 \\
\hline SNL-15 & CUL & 06/08/10 & 590.17 & 179.88 & 2889.76 & 880.80 & 2964.61 \\
\hline SNL-15 & CUL & $07 / 14 / 10$ & 588.14 & 179.27 & 2891.79 & 881.42 & 2967.10 \\
\hline SNL-15 & CUL & 08/10/10 & 586.56 & 178.78 & 2893.37 & 881.90 & 2969.03 \\
\hline SNL-15 & CUL & 09/13/10 & 584.70 & 178.22 & 2895.23 & 882.47 & 2971.31 \\
\hline SNL-15 & CUL & $10 / 21 / 10$ & 582.69 & 177.60 & 2897.24 & 883.08 & 2973.77 \\
\hline
\end{tabular}




\section{Waste Isolation Pilot Plant Annual Site Environmental Report for 2010 DOE/WIPP-11-2225}

Appendix F - Groundwater Data Tables

Table F.9 - Water Levels

\begin{tabular}{|c|c|c|c|c|c|c|c|}
\hline Well Number & Zone & Date & $\begin{array}{l}\text { Adjusted } \\
\text { Depth Top } \\
\text { of Casing } \\
\text { (ft) }\end{array}$ & $\begin{array}{l}\text { Adjusted } \\
\text { Depth } \\
\text { (meters) }\end{array}$ & $\begin{array}{l}\text { Water Level } \\
\text { Elevation } \\
\text { (ft amsl) }\end{array}$ & $\begin{array}{l}\text { Elevation in } \\
\text { Meters } \\
\text { (amsl) }\end{array}$ & $\begin{array}{c}\text { Adjusted } \\
\text { Freshwater } \\
\text { Head (ft amsl) }\end{array}$ \\
\hline SNL-15 & CUL & $11 / 10 / 10$ & 581.60 & 177.27 & 2898.33 & 883.41 & 2975.11 \\
\hline SNL-15 & CUL & $12 / 01 / 10$ & 581.23 & 177.16 & 2898.70 & 883.52 & 2975.56 \\
\hline SNL-16 & CUL & $01 / 11 / 10$ & 124.09 & 37.82 & 3008.91 & 917.12 & 3010.14 \\
\hline SNL-16 & CUL & 02/08/10 & 123.75 & 37.72 & 3009.25 & 917.22 & 3010.49 \\
\hline SNL-16 & CUL & $03 / 22 / 10$ & 123.70 & 37.70 & 3009.30 & 917.23 & 3010.54 \\
\hline SNL-16 & CUL & 04/19/10 & 123.96 & 37.78 & 3009.04 & 917.16 & 3010.28 \\
\hline SNL-16 & CUL & 05/17/10 & 123.24 & 37.56 & 3009.76 & 917.37 & 3011.01 \\
\hline SNL-16 & CUL & 06/07/10 & 124.36 & 37.90 & 3008.64 & 917.03 & 3009.87 \\
\hline SNL-16 & CUL & $07 / 12 / 10$ & 124.09 & 37.82 & 3008.91 & 917.12 & 3010.14 \\
\hline SNL-16 & CUL & 08/09/10 & 123.50 & 37.64 & 3009.50 & 917.30 & 3010.74 \\
\hline SNL-16 & CUL & 09/10/10 & 123.53 & 37.65 & 3009.47 & 917.29 & 3010.71 \\
\hline SNL-16 & CUL & $10 / 20 / 10$ & 123.74 & 37.72 & 3009.26 & 917.22 & 3010.50 \\
\hline SNL-16 & CUL & $11 / 10 / 10$ & 123.77 & 37.73 & 3009.23 & 917.21 & 3010.47 \\
\hline SNL-16 & CUL & $12 / 02 / 10$ & 123.92 & 37.77 & 3009.08 & 917.17 & 3010.32 \\
\hline SNL-17 & CUL & $01 / 11 / 10$ & 232.46 & 70.85 & 3005.60 & 916.11 & 3006.19 \\
\hline SNL-17 & CUL & 02/09/10 & 232.29 & 70.80 & 3005.77 & 916.16 & 3006.36 \\
\hline SNL-17 & CUL & $03 / 22 / 10$ & 232.25 & 70.79 & 3005.81 & 916.17 & 3006.40 \\
\hline SNL-17 & CUL & 04/19/10 & 232.34 & 70.82 & 3005.72 & 916.14 & 3006.31 \\
\hline SNL-17 & CUL & 05/17/10 & 232.48 & 70.86 & 3005.58 & 916.10 & 3006.17 \\
\hline SNL-17 & CUL & 06/07/10 & 232.40 & 70.84 & 3005.66 & 916.13 & 3006.25 \\
\hline SNL-17 & CUL & $07 / 12 / 10$ & 232.52 & 70.87 & 3005.54 & 916.09 & 3006.13 \\
\hline SNL-17 & CUL & 08/10/10 & 232.59 & 70.89 & 3005.47 & 916.07 & 3006.05 \\
\hline SNL-17 & CUL & 09/13/10 & 232.52 & 70.87 & 3005.54 & 916.09 & 3006.13 \\
\hline SNL-17 & CUL & $10 / 20 / 10$ & 232.82 & 70.96 & 3005.24 & 916.00 & 3005.82 \\
\hline SNL-17 & CUL & $11 / 10 / 10$ & 232.69 & 70.92 & 3005.37 & 916.04 & 3005.95 \\
\hline SNL-17 & CUL & $12 / 02 / 10$ & 232.81 & 70.96 & 3005.25 & 916.00 & 3005.83 \\
\hline SNL-18 & CUL & $01 / 11 / 10$ & 301.56 & 91.92 & 3073.88 & 936.92 & 3075.13 \\
\hline SNL-18 & CUL & 02/09/10 & 301.52 & 91.90 & 3073.92 & 936.93 & 3075.17 \\
\hline SNL-18 & CUL & $03 / 22 / 10$ & 301.14 & 91.79 & 3074.30 & 937.05 & 3075.55 \\
\hline SNL-18 & CUL & 04/20/10 & 301.25 & 91.82 & 3074.19 & 937.01 & 3075.44 \\
\hline SNL-18 & CUL & 05/18/10 & 301.30 & 91.84 & 3074.14 & 937.00 & 3075.39 \\
\hline SNL-18 & CUL & 06/10/10 & 301.39 & 91.86 & 3074.05 & 936.97 & 3075.30 \\
\hline SNL-18 & CUL & $07 / 12 / 10$ & 301.27 & 91.83 & 3074.17 & 937.01 & 3075.42 \\
\hline SNL-18 & CUL & 08/10/10 & 300.63 & 91.63 & 3074.81 & 937.20 & 3076.06 \\
\hline SNL-18 & CUL & 09/10/10 & 299.94 & 91.42 & 3075.50 & 937.41 & 3076.76 \\
\hline SNL-18 & CUL & $10 / 20 / 10$ & 299.70 & 91.35 & 3075.74 & 937.49 & 3077.00 \\
\hline SNL-18 & CUL & $11 / 09 / 10$ & 299.54 & 91.30 & 3075.90 & 937.53 & 3077.16 \\
\hline
\end{tabular}




\section{Waste Isolation Pilot Plant Annual Site Environmental Report for 2010 DOE/WIPP-11-2225}

Appendix F - Groundwater Data Tables

Table F.9 - Water Levels

\begin{tabular}{|c|c|c|c|c|c|c|c|}
\hline Well Number & Zone & Date & $\begin{array}{l}\text { Adjusted } \\
\text { Depth Top } \\
\text { of Casing } \\
\text { (ft) }\end{array}$ & $\begin{array}{l}\text { Adjusted } \\
\text { Depth } \\
\text { (meters) }\end{array}$ & $\begin{array}{l}\text { Water Level } \\
\text { Elevation } \\
\text { (ft amsl) }\end{array}$ & $\begin{array}{l}\text { Elevation in } \\
\text { Meters } \\
\text { (amsl) }\end{array}$ & $\begin{array}{c}\text { Adjusted } \\
\text { Freshwater } \\
\text { Head (ft amsl) }\end{array}$ \\
\hline SNL-18 & CUL & $12 / 01 / 10$ & 299.64 & 91.33 & 3075.80 & 937.50 & 3077.06 \\
\hline SNL-19 & CUL & $01 / 11 / 10$ & 151.32 & 46.12 & 3071.33 & 936.14 & 3072.76 \\
\hline SNL-19 & CUL & 02/08/10 & 151.10 & 46.06 & 3071.55 & 936.21 & 3072.98 \\
\hline SNL-19 & CUL & $03 / 22 / 10$ & 151.33 & 46.13 & 3071.32 & 936.14 & 3072.75 \\
\hline SNL-19 & CUL & 04/20/10 & 151.60 & 46.21 & 3071.05 & 936.06 & 3072.47 \\
\hline SNL-19 & CUL & 05/18/10 & 151.78 & 46.26 & 3070.87 & 936.00 & 3072.29 \\
\hline SNL-19 & CUL & 06/10/10 & 152.04 & 46.34 & 3070.61 & 935.92 & 3072.03 \\
\hline SNL-19 & CUL & $07 / 12 / 10$ & 150.94 & 46.01 & 3071.71 & 936.26 & 3073.14 \\
\hline SNL-19 & CUL & 08/10/10 & 149.44 & 45.55 & 3073.21 & 936.71 & 3074.65 \\
\hline SNL-19 & CUL & 09/10/10 & 149.29 & 45.50 & 3073.36 & 936.76 & 3074.80 \\
\hline SNL-19 & CUL & $10 / 20 / 10$ & 149.69 & 45.63 & 3072.96 & 936.64 & 3074.40 \\
\hline SNL-19 & CUL & $11 / 09 / 10$ & 149.76 & 45.65 & 3072.89 & 936.62 & 3074.33 \\
\hline SNL-19 & CUL & $12 / 01 / 10$ & 150.09 & 45.75 & 3072.56 & 936.52 & 3073.99 \\
\hline WIPP-11 & CUL & $01 / 12 / 10$ & 363.68 & 110.85 & 3064.10 & 933.94 & 3082.38 \\
\hline WIPP-11 & CUL & 02/10/10 & 363.53 & 110.80 & 3064.25 & 933.98 & 3082.54 \\
\hline WIPP-11 & CUL & $03 / 22 / 10$ & 363.32 & 110.74 & 3064.46 & 934.05 & 3082.76 \\
\hline WIPP-11 & CUL & 04/20/10 & 363.35 & 110.75 & 3064.43 & 934.04 & 3082.72 \\
\hline WIPP-11 & CUL & 05/19/10 & 363.50 & 110.79 & 3064.28 & 933.99 & 3082.57 \\
\hline WIPP-11 & CUL & 06/08/10 & 363.63 & 110.83 & 3064.15 & 933.95 & 3082.43 \\
\hline WIPP-11 & CUL & 07/13/10 & 363.44 & 110.78 & 3064.34 & 934.01 & 3082.63 \\
\hline WIPP-11 & CUL & 08/10/10 & 363.34 & 110.75 & 3064.44 & 934.04 & 3082.73 \\
\hline WIPP-11 & CUL & 09/09/10 & 362.54 & 110.50 & 3065.24 & 934.29 & 3083.56 \\
\hline WIPP-11 & CUL & $10 / 20 / 10$ & 362.15 & 110.38 & 3065.63 & 934.40 & 3083.97 \\
\hline WIPP-11 & CUL & $11 / 10 / 10$ & 361.74 & 110.26 & 3066.04 & 934.53 & 3084.39 \\
\hline WIPP-11 & CUL & $12 / 02 / 10$ & 361.75 & 110.26 & 3066.03 & 934.53 & 3084.38 \\
\hline WIPP-13 & CUL & $01 / 12 / 10$ & 344.94 & 105.14 & 3060.73 & 932.91 & 3077.40 \\
\hline WIPP-13 & CUL & 02/10/10 & 344.79 & 105.09 & 3060.88 & 932.96 & 3077.56 \\
\hline WIPP-13 & CUL & $03 / 24 / 10$ & 344.53 & 105.01 & 3061.14 & 933.04 & 3077.83 \\
\hline WIPP-13 & CUL & 04/20/10 & 344.48 & 105.00 & 3061.19 & 933.05 & 3077.88 \\
\hline WIPP-13 & CUL & 05/19/10 & 344.57 & 105.02 & 3061.10 & 933.02 & 3077.79 \\
\hline WIPP-13 & CUL & 06/09/10 & 344.67 & 105.06 & 3061.00 & 932.99 & 3077.68 \\
\hline WIPP-13 & CUL & $07 / 14 / 10$ & 344.52 & 105.01 & 3061.15 & 933.04 & 3077.84 \\
\hline WIPP-13 & CUL & 08/10/10 & 344.20 & 104.91 & 3061.47 & 933.14 & 3078.17 \\
\hline WIPP-13 & CUL & 09/10/10 & 343.49 & 104.70 & 3062.18 & 933.35 & 3078.91 \\
\hline WIPP-13 & CUL & $10 / 21 / 10$ & 342.89 & 104.51 & 3062.78 & 933.54 & 3079.54 \\
\hline WIPP-13 & CUL & $11 / 10 / 10$ & 342.49 & 104.39 & 3063.18 & 933.66 & 3079.96 \\
\hline WIPP-13 & CUL & $12 / 02 / 10$ & 342.47 & 104.38 & 3063.20 & 933.66 & 3079.98 \\
\hline
\end{tabular}




\section{Waste Isolation Pilot Plant Annual Site Environmental Report for 2010 DOE/WIPP-11-2225}

Appendix F - Groundwater Data Tables

Table F.9 - Water Levels

\begin{tabular}{|c|c|c|c|c|c|c|c|}
\hline Well Number & Zone & Date & $\begin{array}{l}\text { Adjusted } \\
\text { Depth Top } \\
\text { of Casing } \\
\text { (ft) }\end{array}$ & $\begin{array}{l}\text { Adjusted } \\
\text { Depth } \\
\text { (meters) }\end{array}$ & $\begin{array}{l}\text { Water Level } \\
\text { Elevation } \\
\text { (ft amsl) }\end{array}$ & $\begin{array}{l}\text { Elevation in } \\
\text { Meters } \\
\text { (amsl) }\end{array}$ & $\begin{array}{c}\text { Adjusted } \\
\text { Freshwater } \\
\text { Head (ft amsl) }\end{array}$ \\
\hline WIPP-19 & CUL & $01 / 13 / 10$ & 390.18 & 118.93 & 3044.93 & 928.09 & 3064.31 \\
\hline WIPP-19 & CUL & 02/10/10 & 390.25 & 118.95 & 3044.86 & 928.07 & 3064.23 \\
\hline WIPP-19 & CUL & $03 / 24 / 10$ & 390.16 & 118.92 & 3044.95 & 928.10 & 3064.33 \\
\hline WIPP-19 & CUL & $04 / 21 / 10$ & 390.06 & 118.89 & 3045.05 & 928.13 & 3064.43 \\
\hline WIPP-19 & CUL & 05/19/10 & 390.25 & 118.95 & 3044.86 & 928.07 & 3064.23 \\
\hline WIPP-19 & CUL & 06/09/10 & 390.34 & 118.98 & 3044.77 & 928.05 & 3064.14 \\
\hline WIPP-19 & CUL & 07/13/10 & 390.12 & 118.91 & 3044.99 & 928.11 & 3064.37 \\
\hline WIPP-19 & CUL & 08/09/10 & 390.22 & 118.94 & 3044.89 & 928.08 & 3064.26 \\
\hline WIPP-19 & CUL & 09/09/10 & 389.96 & 118.86 & 3045.15 & 928.16 & 3064.54 \\
\hline WIPP-19 & CUL & $10 / 21 / 10$ & 389.64 & 118.76 & 3045.47 & 928.26 & 3064.87 \\
\hline WIPP-19 & CUL & $11 / 09 / 10$ & 388.88 & 118.53 & 3046.23 & 928.49 & 3065.67 \\
\hline WIPP-19 & CUL & $12 / 02 / 10$ & 389.52 & 118.73 & 3045.59 & 928.30 & 3065.00 \\
\hline WQSP-1 & CUL & $01 / 13 / 10$ & 359.85 & 109.68 & 3059.40 & 932.51 & 3075.67 \\
\hline WQSP-1 & CUL & 02/10/10 & 359.77 & 109.66 & 3059.48 & 932.53 & 3075.76 \\
\hline WQSP-1 & CUL & 03/24/10 & 359.61 & 109.61 & 3059.64 & 932.58 & 3075.93 \\
\hline WQSP-1 & CUL & 04/19/10 & 359.73 & 109.65 & 3059.52 & 932.54 & 3075.80 \\
\hline WQSP-1 & CUL & 05/19/10 & 359.72 & 109.64 & 3059.53 & 932.54 & 3075.81 \\
\hline WQSP-1 & CUL & 06/07/10 & 359.92 & 109.70 & 3059.33 & 932.48 & 3075.60 \\
\hline WQSP-1 & CUL & $07 / 14 / 10$ & 359.77 & 109.66 & 3059.48 & 932.53 & 3075.76 \\
\hline WQSP-1 & CUL & 08/11/10 & 359.46 & 109.56 & 3059.79 & 932.62 & 3076.08 \\
\hline WQSP-1 & CUL & 09/10/10 & 358.92 & 109.40 & 3060.33 & 932.79 & 3076.65 \\
\hline WQSP-1 & CUL & $10 / 21 / 10$ & 358.36 & 109.23 & 3060.89 & 932.96 & 3077.23 \\
\hline WQSP-1 & CUL & $11 / 09 / 10$ & 357.99 & 109.12 & 3061.26 & 933.07 & 3077.62 \\
\hline WQSP-1 & CUL & $12 / 03 / 10$ & 358.14 & 109.16 & 3061.11 & 933.03 & 3077.46 \\
\hline WQSP-2 & CUL & $01 / 13 / 10$ & 399.50 & 121.77 & 3064.37 & 934.02 & 3083.52 \\
\hline WQSP-2 & CUL & 02/10/10 & 399.49 & 121.76 & 3064.38 & 934.02 & 3083.53 \\
\hline WQSP-2 & CUL & 03/24/10 & 399.29 & 121.70 & 3064.58 & 934.08 & 3083.74 \\
\hline WQSP-2 & CUL & 04/21/10 & 399.22 & 121.68 & 3064.65 & 934.11 & 3083.81 \\
\hline WQSP-2 & CUL & 05/19/10 & 399.60 & 121.80 & 3064.27 & 933.99 & 3083.42 \\
\hline WQSP-2 & CUL & 06/09/10 & 399.66 & 121.82 & 3064.21 & 933.97 & 3083.35 \\
\hline WQSP-2 & CUL & 07/13/10 & 399.50 & 121.77 & 3064.37 & 934.02 & 3083.52 \\
\hline WQSP-2 & CUL & 08/09/10 & 399.36 & 121.72 & 3064.51 & 934.06 & 3083.67 \\
\hline WQSP-2 & CUL & 09/09/10 & 398.63 & 121.50 & 3065.24 & 934.29 & 3084.43 \\
\hline WQSP-2 & CUL & $10 / 21 / 10$ & 398.15 & 121.36 & 3065.72 & 934.43 & 3084.93 \\
\hline WQSP-2 & CUL & $11 / 09 / 10$ & 397.77 & 121.24 & 3066.10 & 934.55 & 3085.33 \\
\hline WQSP-2 & CUL & $12 / 02 / 10$ & 397.94 & 121.29 & 3065.93 & 934.50 & 3085.15 \\
\hline WQSP-3 & CUL & 01/13/10 & 463.97 & 141.42 & 3016.17 & 919.33 & 3073.18 \\
\hline
\end{tabular}




\section{Waste Isolation Pilot Plant Annual Site Environmental Report for 2010 DOE/WIPP-11-2225}

Appendix F - Groundwater Data Tables

Table F.9 - Water Levels

\begin{tabular}{|c|c|c|c|c|c|c|c|}
\hline Well Number & Zone & Date & $\begin{array}{c}\text { Adjusted } \\
\text { Depth Top } \\
\text { of Casing } \\
\text { (ft) }\end{array}$ & $\begin{array}{c}\text { Adjusted } \\
\text { Depth } \\
\text { (meters) }\end{array}$ & $\begin{array}{l}\text { Water Level } \\
\text { Elevation } \\
\text { (ft amsl) }\end{array}$ & $\begin{array}{l}\text { Elevation in } \\
\text { Meters } \\
\text { (amsl) }\end{array}$ & $\begin{array}{c}\text { Adjusted } \\
\text { Freshwater } \\
\text { Head (ft amsl) }\end{array}$ \\
\hline WQSP-3 & CUL & 02/10/10 & 463.77 & 141.36 & 3016.37 & 919.39 & 3073.40 \\
\hline WQSP-3 & CUL & 03/24/10 & 463.52 & 141.28 & 3016.62 & 919.47 & 3073.69 \\
\hline WQSP-3 & CUL & 04/21/10 & 463.46 & 141.26 & 3016.68 & 919.48 & 3073.76 \\
\hline WQSP-3 & CUL & 05/19/10 & 464.92 & 141.71 & 3015.22 & 919.04 & 3072.09 \\
\hline WQSP-3 & CUL & $06 / 09 / 10$ & 464.34 & 141.53 & 3015.80 & 919.22 & 3072.75 \\
\hline WQSP-3 & CUL & 07/13/10 & 463.91 & 141.40 & 3016.23 & 919.35 & 3073.24 \\
\hline WQSP-3 & CUL & 08/09/10 & 463.63 & 141.31 & 3016.51 & 919.43 & 3073.56 \\
\hline WQSP-3 & CUL & $09 / 09 / 10$ & 463.30 & 141.21 & 3016.84 & 919.53 & 3073.94 \\
\hline WQSP-3 & CUL & $10 / 21 / 10$ & 462.80 & 141.06 & 3017.34 & 919.69 & 3074.51 \\
\hline WQSP-3 & CUL & $11 / 09 / 10$ & 464.62 & 141.62 & 3015.52 & 919.13 & 3072.43 \\
\hline WQSP-3 & CUL & $12 / 02 / 10$ & 463.47 & 141.27 & 3016.67 & 919.48 & 3073.75 \\
\hline WQSP-4 & CUL & 01/13/10 & 442.63 & 134.91 & 2990.46 & 911.49 & 3015.49 \\
\hline WQSP-4 & CUL & 02/10/10 & 442.42 & 134.85 & 2990.67 & 911.56 & 3015.72 \\
\hline WQSP-4 & CUL & $03 / 24 / 10$ & 442.60 & 134.90 & 2990.49 & 911.50 & 3015.52 \\
\hline WQSP-4 & CUL & 04/20/10 & 443.00 & 135.03 & 2990.09 & 911.38 & 3015.09 \\
\hline WQSP-4 & CUL & 05/19/10 & 442.64 & 134.92 & 2990.45 & 911.49 & 3015.48 \\
\hline WQSP-4 & CUL & 06/09/10 & 442.72 & 134.94 & 2990.37 & 911.46 & 3015.39 \\
\hline WQSP-4 & CUL & $07 / 12 / 10$ & 442.56 & 134.89 & 2990.53 & 911.51 & 3015.57 \\
\hline WQSP-4 & CUL & 08/11/10 & 442.62 & 134.91 & 2990.47 & 911.50 & 3015.50 \\
\hline WQSP-4 & CUL & 09/14/10 & 442.76 & 134.95 & 2990.33 & 911.45 & 3015.35 \\
\hline WQSP-4 & CUL & $10 / 21 / 10$ & 443.23 & 135.10 & 2989.86 & 911.31 & 3014.85 \\
\hline WQSP-4 & CUL & $11 / 11 / 10$ & 442.98 & 135.02 & 2990.11 & 911.39 & 3015.12 \\
\hline WQSP-4 & CUL & $12 / 03 / 10$ & 442.94 & 135.01 & 2990.15 & 911.40 & 3015.16 \\
\hline WQSP-5 & CUL & 01/13/10 & 378.05 & 115.23 & 3006.33 & 916.33 & 3013.35 \\
\hline WQSP-5 & CUL & 02/10/10 & 377.96 & 115.20 & 3006.42 & 916.36 & 3013.44 \\
\hline WQSP-5 & CUL & 03/24/10 & 378.75 & 115.44 & 3005.63 & 916.12 & 3012.63 \\
\hline WQSP-5 & CUL & $04 / 20 / 10$ & 378.34 & 115.32 & 3006.04 & 916.24 & 3013.05 \\
\hline WQSP-5 & CUL & 05/19/10 & 378.18 & 115.27 & 3006.20 & 916.29 & 3013.21 \\
\hline WQSP-5 & CUL & 06/08/10 & 378.12 & 115.25 & 3006.26 & 916.31 & 3013.27 \\
\hline WQSP-5 & CUL & $07 / 12 / 10$ & 378.01 & 115.22 & 3006.37 & 916.34 & 3013.39 \\
\hline WQSP-5 & CUL & $08 / 11 / 10$ & 378.07 & 115.24 & 3006.31 & 916.32 & 3013.33 \\
\hline WQSP-5 & CUL & $09 / 14 / 10$ & 378.17 & 115.27 & 3006.21 & 916.29 & 3013.22 \\
\hline WQSP-5 & CUL & $10 / 22 / 10$ & 379.05 & 115.53 & 3005.33 & 916.02 & 3012.32 \\
\hline WQSP-5 & CUL & $11 / 11 / 10$ & 378.55 & 115.38 & 3005.83 & 916.18 & 3012.83 \\
\hline WQSP-5 & CUL & $12 / 03 / 10$ & 378.46 & 115.35 & 3005.92 & 916.20 & 3012.93 \\
\hline WQSP-6 & CUL & $01 / 13 / 10$ & 343.25 & 104.62 & 3021.47 & 920.94 & 3025.02 \\
\hline WQSP-6 & CUL & $02 / 10 / 10$ & 343.12 & 104.58 & 3021.60 & 920.98 & 3025.16 \\
\hline
\end{tabular}




\section{Waste Isolation Pilot Plant Annual Site Environmental Report for 2010 DOE/WIPP-11-2225}

Appendix F - Groundwater Data Tables

Table F.9 - Water Levels

\begin{tabular}{|c|c|c|c|c|c|c|c|}
\hline Well Number & Zone & Date & $\begin{array}{c}\text { Adjusted } \\
\text { Depth Top } \\
\text { of Casing } \\
\text { (ft) }\end{array}$ & $\begin{array}{l}\text { Adjusted } \\
\text { Depth } \\
\text { (meters) }\end{array}$ & $\begin{array}{l}\text { Water Level } \\
\text { Elevation } \\
\text { (ft amsl) }\end{array}$ & $\begin{array}{l}\text { Elevation in } \\
\text { Meters } \\
\text { (amsl) }\end{array}$ & $\begin{array}{c}\text { Adjusted } \\
\text { Freshwater } \\
\text { Head (ft amsl) }\end{array}$ \\
\hline WQSP-6 & CUL & $03 / 24 / 10$ & 344.19 & 104.91 & 3020.53 & 920.66 & 3024.07 \\
\hline WQSP-6 & CUL & 04/20/10 & 343.43 & 104.68 & 3021.29 & 920.89 & 3024.84 \\
\hline WQSP-6 & CUL & 05/19/10 & 343.20 & 104.61 & 3021.52 & 920.96 & 3025.07 \\
\hline WQSP-6 & CUL & 06/08/10 & 343.30 & 104.64 & 3021.42 & 920.93 & 3024.97 \\
\hline WQSP-6 & CUL & $07 / 12 / 10$ & 343.19 & 104.60 & 3021.53 & 920.96 & 3025.09 \\
\hline WQSP-6 & CUL & 08/11/10 & 343.18 & 104.60 & 3021.54 & 920.97 & 3025.10 \\
\hline WQSP-6 & CUL & 09/10/10 & 343.23 & 104.62 & 3021.49 & 920.95 & 3025.04 \\
\hline WQSP-6 & CUL & $10 / 22 / 10$ & 344.01 & 104.85 & 3020.71 & 920.71 & 3024.25 \\
\hline WQSP-6 & CUL & $11 / 11 / 10$ & 343.67 & 104.75 & 3021.05 & 920.82 & 3024.60 \\
\hline WQSP-6 & CUL & $12 / 03 / 10$ & 343.58 & 104.72 & 3021.14 & 920.84 & 3024.69 \\
\hline $\begin{array}{c}\text { C-2737 } \\
\text { (ANNULUS) }\end{array}$ & MAG & $01 / 13 / 10$ & 257.50 & 78.49 & 3143.26 & 958.07 & NA \\
\hline $\begin{array}{c}\mathrm{C}-2737 \\
\text { (ANNULUS) }\end{array}$ & MAG & 02/10/10 & 257.76 & 78.57 & 3143.00 & 957.99 & NA \\
\hline $\begin{array}{c}\text { C-2737 } \\
\text { (ANNULUS) }\end{array}$ & MAG & 03/24/10 & 257.09 & 78.36 & 3143.67 & 958.19 & NA \\
\hline $\begin{array}{c}\mathrm{C}-2737 \\
\text { (ANNULUS) }\end{array}$ & MAG & $04 / 21 / 10$ & 257.08 & 78.36 & 3143.68 & 958.19 & NA \\
\hline $\begin{array}{c}\text { C-2737 } \\
\text { (ANNULUS) }\end{array}$ & MAG & 05/18/10 & 257.22 & 78.40 & 3143.54 & 958.15 & NA \\
\hline $\begin{array}{c}\text { C-2737 } \\
\text { (ANNULUS) }\end{array}$ & MAG & 06/09/10 & 257.20 & 78.39 & 3143.56 & 958.16 & NA \\
\hline $\begin{array}{c}\text { C-2737 } \\
\text { (ANNULUS) }\end{array}$ & MAG & $07 / 14 / 10$ & 257.08 & 78.36 & 3143.68 & 958.19 & NA \\
\hline $\begin{array}{c}\text { C-2737 } \\
\text { (ANNULUS) }\end{array}$ & MAG & $08 / 11 / 10$ & 257.09 & 78.36 & 3143.67 & 958.19 & NA \\
\hline $\begin{array}{c}\text { C-2737 } \\
\text { (ANNULUS) }\end{array}$ & MAG & 09/14/10 & 257.05 & 78.35 & 3143.71 & 958.20 & NA \\
\hline $\begin{array}{c}\text { C-2737 } \\
\text { (ANNULUS) }\end{array}$ & MAG & $10 / 22 / 10$ & 256.86 & 78.29 & 3143.90 & 958.26 & NA \\
\hline $\begin{array}{c}\text { C-2737 } \\
\text { (ANNULUS) }\end{array}$ & MAG & $11 / 10 / 10$ & 256.77 & 78.26 & 3143.99 & 958.29 & NA \\
\hline $\begin{array}{c}\text { C-2737 } \\
\text { (ANNULUS) }\end{array}$ & MAG & $12 / 06 / 10$ & 256.98 & 78.33 & 3143.78 & 958.22 & NA \\
\hline $\mathrm{H}-02 \mathrm{~b} 1$ & MAG & 01/13/10 & 234.84 & 71.58 & 3143.65 & 958.18 & NA \\
\hline $\mathrm{H}-02 \mathrm{~b} 1$ & MAG & 02/10/10 & 234.72 & 71.54 & 3143.77 & 958.22 & NA \\
\hline $\mathrm{H}-02 \mathrm{~b} 1$ & MAG & $03 / 25 / 10$ & 234.61 & 71.51 & 3143.88 & 958.25 & NA \\
\hline $\mathrm{H}-03 \mathrm{~b} 1$ & MAG & $01 / 13 / 10$ & 245.61 & 74.86 & 3145.11 & 958.63 & NA \\
\hline $\mathrm{H}-03 \mathrm{~b} 1$ & MAG & 02/10/10 & 245.23 & 74.75 & 3145.49 & 958.75 & NA \\
\hline $\mathrm{H}-03 \mathrm{~b} 1$ & MAG & $03 / 24 / 10$ & 244.91 & 74.65 & 3145.81 & 958.84 & NA \\
\hline H-03b1 & MAG & $04 / 21 / 10$ & 244.85 & 74.63 & 3145.87 & 958.86 & NA \\
\hline
\end{tabular}




\section{Waste Isolation Pilot Plant Annual Site Environmental Report for 2010 DOE/WIPP-11-2225}

Appendix F - Groundwater Data Tables

Table F.9 - Water Levels

\begin{tabular}{|c|c|c|c|c|c|c|c|}
\hline Well Number & Zone & Date & $\begin{array}{c}\text { Adjusted } \\
\text { Depth Top } \\
\text { of Casing } \\
\text { (ft) }\end{array}$ & $\begin{array}{l}\text { Adjusted } \\
\text { Depth } \\
\text { (meters) }\end{array}$ & $\begin{array}{l}\text { Water Level } \\
\text { Elevation } \\
\text { (ft amsl) }\end{array}$ & $\begin{array}{l}\text { Elevation in } \\
\text { Meters } \\
\text { (amsl) }\end{array}$ & $\begin{array}{c}\text { Adjusted } \\
\text { Freshwater } \\
\text { Head (ft amsl) }\end{array}$ \\
\hline H-03b1 & MAG & 05/19/10 & 244.80 & 74.62 & 3145.92 & 958.88 & NA \\
\hline H-03b1 & MAG & 06/08/10 & 244.82 & 74.62 & 3145.90 & 958.87 & NA \\
\hline $\mathrm{H}-03 \mathrm{~b} 1$ & MAG & $07 / 13 / 10$ & 244.65 & 74.57 & 3146.07 & 958.92 & NA \\
\hline $\mathrm{H}-03 \mathrm{~b} 1$ & MAG & $08 / 11 / 10$ & 244.64 & 74.57 & 3146.08 & 958.93 & NA \\
\hline $\mathrm{H}-03 \mathrm{~b} 1$ & MAG & $09 / 14 / 10$ & 244.70 & 74.58 & 3146.02 & 958.91 & NA \\
\hline $\mathrm{H}-03 \mathrm{~b} 1$ & MAG & $10 / 20 / 10$ & 244.60 & 74.55 & 3146.12 & 958.94 & NA \\
\hline $\mathrm{H}-03 \mathrm{~b} 1$ & MAG & $11 / 11 / 10$ & 244.49 & 74.52 & 3146.23 & 958.97 & NA \\
\hline $\mathrm{H}-03 \mathrm{~b} 1$ & MAG & $12 / 03 / 10$ & 244.56 & 74.54 & 3146.16 & 958.95 & NA \\
\hline $\mathrm{H}-04 \mathrm{c}$ & MAG & $01 / 13 / 10$ & 186.60 & 56.88 & 3147.68 & 959.41 & NA \\
\hline $\mathrm{H}-04 \mathrm{c}$ & MAG & $02 / 08 / 10$ & 186.34 & 56.80 & 3147.94 & 959.49 & NA \\
\hline $\mathrm{H}-04 \mathrm{C}$ & MAG & $03 / 23 / 10$ & 186.35 & 56.80 & 3147.93 & 959.49 & NA \\
\hline $\mathrm{H}-06 \mathrm{c}$ & MAG & 07/13/10 & 278.26 & 84.81 & 3070.43 & 935.87 & NA \\
\hline $\mathrm{H}-06 \mathrm{c}$ & MAG & 08/10/10 & 278.22 & 84.80 & 3070.47 & 935.88 & NA \\
\hline $\mathrm{H}-06 \mathrm{c}$ & MAG & 09/10/10 & 278.19 & 84.79 & 3070.50 & 935.89 & NA \\
\hline $\mathrm{H}-06 \mathrm{c}$ & MAG & $10 / 20 / 10$ & 278.22 & 84.80 & 3070.47 & 935.88 & NA \\
\hline $\mathrm{H}-06 \mathrm{c}$ & MAG & $11 / 09 / 10$ & 277.96 & 84.72 & 3070.73 & 935.96 & NA \\
\hline $\mathrm{H}-06 \mathrm{c}$ & MAG & $12 / 03 / 10$ & 278.13 & 84.77 & 3070.56 & 935.91 & NA \\
\hline $\mathrm{H}-08 \mathrm{a}$ & MAG & $07 / 12 / 10$ & 431.34 & 131.47 & 3001.94 & 914.99 & NA \\
\hline $\mathrm{H}-08 \mathrm{a}$ & MAG & $08 / 11 / 10$ & 424.66 & 129.44 & 3008.62 & 917.03 & NA \\
\hline $\mathrm{H}-08 \mathrm{a}$ & MAG & 09/13/10 & 419.92 & 127.99 & 3013.36 & 918.47 & NA \\
\hline $\mathrm{H}-08 \mathrm{a}$ & MAG & $10 / 20 / 10$ & 416.38 & 126.91 & 3016.90 & 919.55 & NA \\
\hline $\mathrm{H}-08 \mathrm{a}$ & MAG & $11 / 10 / 10$ & 414.94 & 126.47 & 3018.34 & 919.99 & NA \\
\hline $\mathrm{H}-08 \mathrm{a}$ & MAG & $12 / 02 / 10$ & 413.68 & 126.09 & 3019.60 & 920.37 & NA \\
\hline $\begin{array}{c}\mathrm{H}-09 \mathrm{c} \\
\text { (ANNULUS) }\end{array}$ & MAG & $01 / 11 / 10$ & 268.69 & 81.90 & 3138.36 & 956.57 & NA \\
\hline $\begin{array}{c}\mathrm{H}-09 \mathrm{c} \\
\text { (ANNULUS) }\end{array}$ & MAG & 02/08/10 & 268.28 & 81.77 & 3138.77 & 956.70 & NA \\
\hline $\begin{array}{c}\mathrm{H}-09 \mathrm{c} \\
\text { (ANNULUS) }\end{array}$ & MAG & $03 / 22 / 10$ & 268.40 & 81.81 & 3138.65 & 956.66 & NA \\
\hline $\begin{array}{c}\mathrm{H}-09 \mathrm{c} \\
\text { (ANNULUS) }\end{array}$ & MAG & 04/19/10 & 268.40 & 81.81 & 3138.65 & 956.66 & NA \\
\hline $\begin{array}{c}\mathrm{H}-09 \mathrm{c} \\
\text { (ANNULUS) }\end{array}$ & MAG & 05/17/10 & 268.43 & 81.82 & 3138.62 & 956.65 & NA \\
\hline $\begin{array}{c}\mathrm{H}-09 \mathrm{c} \\
\text { (ANNULUS) }\end{array}$ & MAG & 06/08/10 & 268.28 & 81.77 & 3138.77 & 956.70 & NA \\
\hline $\begin{array}{c}\mathrm{H}-09 \mathrm{c} \\
\text { (ANNULUS) }\end{array}$ & MAG & $07 / 12 / 10$ & 268.06 & 81.70 & 3138.99 & 956.76 & NA \\
\hline $\begin{array}{c}\mathrm{H}-09 \mathrm{c} \\
\text { (ANNULUS) }\end{array}$ & MAG & 08/10/10 & 268.13 & 81.73 & 3138.92 & 956.74 & NA \\
\hline
\end{tabular}




\section{Waste Isolation Pilot Plant Annual Site Environmental Report for 2010 DOE/WIPP-11-2225}

Appendix F - Groundwater Data Tables

Table F.9 - Water Levels

\begin{tabular}{|c|c|c|c|c|c|c|c|}
\hline Well Number & Zone & Date & $\begin{array}{c}\text { Adjusted } \\
\text { Depth Top } \\
\text { of Casing } \\
\text { (ft) }\end{array}$ & $\begin{array}{l}\text { Adjusted } \\
\text { Depth } \\
\text { (meters) }\end{array}$ & $\begin{array}{l}\text { Water Level } \\
\text { Elevation } \\
\text { (ft amsl) }\end{array}$ & $\begin{array}{l}\text { Elevation in } \\
\text { Meters } \\
\text { (amsl) }\end{array}$ & $\begin{array}{c}\text { Adjusted } \\
\text { Freshwater } \\
\text { Head (ft amsl) }\end{array}$ \\
\hline $\begin{array}{c}\mathrm{H}-09 \mathrm{c} \\
\text { (ANNULUS) }\end{array}$ & MAG & 09/13/10 & 268.26 & 81.77 & 3138.79 & 956.70 & NA \\
\hline $\mathrm{H}-10 \mathrm{a}$ & MAG & $01 / 12 / 10$ & 467.01 & 142.34 & 3221.44 & 981.89 & NA \\
\hline $\mathrm{H}-10 \mathrm{a}$ & MAG & 02/09/10 & 466.88 & 142.31 & 3221.57 & 981.93 & NA \\
\hline $\mathrm{H}-10 \mathrm{a}$ & MAG & 03/23/10 & 932.20 & 284.13 & 2756.25 & 840.11 & NA \\
\hline $\mathrm{H}-10 \mathrm{a}$ & MAG & 04/19/10 & 638.35 & 194.57 & 3050.10 & 929.67 & NA \\
\hline $\mathrm{H}-10 \mathrm{a}$ & MAG & 05/17/10 & 593.74 & 180.97 & 3094.71 & 943.27 & NA \\
\hline $\mathrm{H}-10 \mathrm{a}$ & MAG & 06/08/10 & 584.30 & 178.09 & 3104.15 & 946.14 & NA \\
\hline $\mathrm{H}-10 \mathrm{a}$ & MAG & $07 / 13 / 10$ & 579.16 & 176.53 & 3109.29 & 947.71 & NA \\
\hline $\mathrm{H}-10 \mathrm{a}$ & MAG & 08/11/10 & 577.71 & 176.09 & 3110.74 & 948.15 & NA \\
\hline $\mathrm{H}-10 \mathrm{a}$ & MAG & 09/13/10 & 576.93 & 175.85 & 3111.52 & 948.39 & NA \\
\hline $\mathrm{H}-10 \mathrm{a}$ & MAG & $10 / 21 / 10$ & 576.52 & 175.72 & 3111.93 & 948.52 & NA \\
\hline $\mathrm{H}-10 \mathrm{a}$ & MAG & $11 / 10 / 10$ & 576.38 & 175.68 & 3112.07 & 948.56 & NA \\
\hline $\mathrm{H}-10 \mathrm{a}$ & MAG & $12 / 02 / 10$ & 576.25 & 175.64 & 3112.20 & 948.60 & NA \\
\hline $\mathrm{H}-11 \mathrm{~b} 2$ & MAG & 01/12/10 & 273.34 & 83.31 & 3138.52 & 956.62 & NA \\
\hline $\mathrm{H}-11 \mathrm{~b} 2$ & MAG & 02/09/10 & 273.01 & 83.21 & 3138.85 & 956.72 & NA \\
\hline $\mathrm{H}-11 \mathrm{~b} 2$ & MAG & 03/23/10 & 273.04 & 83.22 & 3138.82 & 956.71 & NA \\
\hline $\mathrm{H}-11 \mathrm{~b} 2$ & MAG & 04/20/10 & 273.03 & 83.22 & 3138.83 & 956.72 & NA \\
\hline $\mathrm{H}-11 \mathrm{~b} 2$ & MAG & 05/17/10 & 273.04 & 83.22 & 3138.82 & 956.71 & NA \\
\hline $\mathrm{H}-11 \mathrm{~b} 2$ & MAG & 06/07/10 & 272.98 & 83.20 & 3138.88 & 956.73 & NA \\
\hline $\mathrm{H}-11 \mathrm{~b} 2$ & MAG & $07 / 13 / 10$ & 272.82 & 83.16 & 3139.04 & 956.78 & NA \\
\hline $\mathrm{H}-11 \mathrm{~b} 2$ & MAG & 08/09/10 & 272.88 & 83.17 & 3138.98 & 956.76 & NA \\
\hline $\mathrm{H}-11 \mathrm{~b} 2$ & MAG & 09/13/10 & 272.89 & 83.18 & 3138.97 & 956.76 & NA \\
\hline $\mathrm{H}-11 \mathrm{~b} 2$ & MAG & $10 / 21 / 10$ & 272.88 & 83.17 & 3138.98 & 956.76 & NA \\
\hline $\mathrm{H}-11 \mathrm{~b} 2$ & MAG & $11 / 10 / 10$ & 272.82 & 83.16 & 3139.04 & 956.78 & NA \\
\hline $\mathrm{H}-11 \mathrm{~b} 2$ & MAG & $12 / 01 / 10$ & 272.82 & 83.16 & 3139.04 & 956.78 & NA \\
\hline $\mathrm{H}-14$ & MAG & $01 / 12 / 10$ & 235.32 & 71.73 & 3111.76 & 948.46 & NA \\
\hline $\mathrm{H}-14$ & MAG & 02/10/10 & 231.33 & 70.51 & 3115.75 & 949.68 & NA \\
\hline $\mathrm{H}-14$ & MAG & 03/23/10 & 226.73 & 69.11 & 3120.35 & 951.08 & NA \\
\hline $\mathrm{H}-14$ & MAG & 04/20/10 & 224.20 & 68.34 & 3122.88 & 951.85 & NA \\
\hline $\mathrm{H}-14$ & MAG & 05/18/10 & 222.10 & 67.70 & 3124.98 & 952.49 & NA \\
\hline $\mathrm{H}-14$ & MAG & 06/07/10 & 220.75 & 67.28 & 3126.33 & 952.91 & NA \\
\hline $\mathrm{H}-14$ & MAG & $07 / 12 / 10$ & 218.83 & 66.70 & 3128.25 & 953.49 & NA \\
\hline $\mathrm{H}-14$ & MAG & 08/09/10 & 217.52 & 66.30 & 3129.56 & 953.89 & NA \\
\hline $\mathrm{H}-14$ & MAG & 09/10/10 & 216.20 & 65.90 & 3130.88 & 954.29 & NA \\
\hline $\mathrm{H}-14$ & MAG & $10 / 21 / 10$ & 214.85 & 65.49 & 3132.23 & 954.70 & NA \\
\hline $\mathrm{H}-14$ & MAG & $11 / 11 / 10$ & 214.28 & 65.31 & 3132.80 & 954.88 & NA \\
\hline
\end{tabular}




\section{Waste Isolation Pilot Plant Annual Site Environmental Report for 2010 DOE/WIPP-11-2225}

Appendix F - Groundwater Data Tables

Table F.9 - Water Levels

\begin{tabular}{|c|c|c|c|c|c|c|c|}
\hline Well Number & Zone & Date & $\begin{array}{l}\text { Adjusted } \\
\text { Depth Top } \\
\text { of Casing } \\
\text { (ft) }\end{array}$ & $\begin{array}{l}\text { Adjusted } \\
\text { Depth } \\
\text { (meters) }\end{array}$ & $\begin{array}{l}\text { Water Level } \\
\text { Elevation } \\
\text { (ft amsl) }\end{array}$ & $\begin{array}{l}\text { Elevation in } \\
\text { Meters } \\
\text { (amsl) }\end{array}$ & $\begin{array}{c}\text { Adjusted } \\
\text { Freshwater } \\
\text { Head (ft amsl) }\end{array}$ \\
\hline $\mathrm{H}-14$ & MAG & $12 / 03 / 10$ & 213.71 & 65.14 & 3133.37 & 955.05 & NA \\
\hline $\mathrm{H}-15$ & MAG & $01 / 13 / 10$ & 351.56 & 107.16 & 3131.94 & 954.62 & NA \\
\hline $\mathrm{H}-15$ & MAG & 02/10/10 & 351.06 & 107.00 & 3132.44 & 954.77 & NA \\
\hline $\mathrm{H}-15$ & MAG & $03 / 24 / 10$ & 350.55 & 106.85 & 3132.95 & 954.92 & NA \\
\hline $\mathrm{H}-15$ & MAG & $04 / 21 / 10$ & 350.29 & 106.77 & 3133.21 & 955.00 & NA \\
\hline $\mathrm{H}-15$ & MAG & 05/19/10 & 350.18 & 106.73 & 3133.32 & 955.04 & NA \\
\hline $\mathrm{H}-15$ & MAG & 06/08/10 & 350.03 & 106.69 & 3133.47 & 955.08 & NA \\
\hline $\mathrm{H}-15$ & MAG & $07 / 14 / 10$ & 349.57 & 106.55 & 3133.93 & 955.22 & NA \\
\hline $\mathrm{H}-15$ & MAG & 08/11/10 & 349.37 & 106.49 & 3134.13 & 955.28 & NA \\
\hline $\mathrm{H}-15$ & MAG & 09/14/10 & 349.09 & 106.40 & 3134.41 & 955.37 & NA \\
\hline $\mathrm{H}-15$ & MAG & $10 / 20 / 10$ & 348.35 & 106.18 & 3135.15 & 955.59 & NA \\
\hline $\mathrm{H}-15$ & MAG & $11 / 11 / 10$ & 348.05 & 106.09 & 3135.45 & 955.69 & NA \\
\hline $\mathrm{H}-15$ & MAG & $12 / 03 / 10$ & 347.75 & 105.99 & 3135.75 & 955.78 & NA \\
\hline $\mathrm{H}-18$ & MAG & $01 / 13 / 10$ & 263.96 & 80.46 & 3150.25 & 960.20 & NA \\
\hline $\mathrm{H}-18$ & MAG & $02 / 10 / 10$ & 263.50 & 80.31 & 3150.71 & 960.34 & NA \\
\hline $\mathrm{H}-18$ & MAG & 03/23/10 & 262.86 & 80.12 & 3151.35 & 960.53 & NA \\
\hline $\mathrm{H}-18$ & MAG & 04/19/10 & 262.78 & 80.10 & 3151.43 & 960.56 & NA \\
\hline $\mathrm{H}-18$ & MAG & 05/19/10 & 262.50 & 80.01 & 3151.71 & 960.64 & NA \\
\hline $\mathrm{H}-18$ & MAG & 06/09/10 & 262.37 & 79.97 & 3151.84 & 960.68 & NA \\
\hline $\mathrm{H}-18$ & MAG & 07/13/10 & 261.94 & 79.84 & 3152.27 & 960.81 & NA \\
\hline $\mathrm{H}-18$ & MAG & 08/10/10 & 261.82 & 79.80 & 3152.39 & 960.85 & NA \\
\hline $\mathrm{H}-18$ & MAG & 09/09/10 & 261.60 & 79.74 & 3152.61 & 960.92 & NA \\
\hline $\mathrm{H}-18$ & MAG & $10 / 20 / 10$ & 261.47 & 79.70 & 3152.74 & 960.96 & NA \\
\hline $\mathrm{H}-18$ & MAG & $11 / 09 / 10$ & 261.15 & 79.60 & 3153.06 & 961.05 & NA \\
\hline $\mathrm{H}-18$ & MAG & $12 / 03 / 10$ & 261.22 & 79.62 & 3152.99 & 961.03 & NA \\
\hline WIPP-18 & MAG & $04 / 21 / 10$ & 319.11 & 97.26 & 3138.46 & 956.60 & NA \\
\hline WIPP-18 & MAG & 05/19/10 & 309.57 & 94.36 & 3148.00 & 959.51 & NA \\
\hline WIPP-18 & MAG & 06/09/10 & 309.17 & 94.24 & 3148.40 & 959.63 & NA \\
\hline WIPP-18 & MAG & $07 / 13 / 10$ & 308.84 & 94.13 & 3148.73 & 959.73 & NA \\
\hline WIPP-18 & MAG & 08/09/10 & 308.75 & 94.11 & 3148.82 & 959.76 & NA \\
\hline WIPP-18 & MAG & 09/09/10 & 308.59 & 94.06 & 3148.98 & 959.81 & NA \\
\hline WIPP-18 & MAG & $10 / 20 / 10$ & 308.50 & 94.03 & 3149.07 & 959.84 & NA \\
\hline WIPP-18 & MAG & $11 / 09 / 10$ & 308.40 & 94.00 & 3149.17 & 959.87 & NA \\
\hline WIPP-18 & MAG & $12 / 02 / 10$ & 308.32 & 93.98 & 3149.25 & 959.89 & NA \\
\hline WQSP-6a & $\mathrm{DL}$ & $01 / 13 / 10$ & 167.06 & 50.92 & 3196.99 & 974.44 & NA \\
\hline WQSP-6a & DL & $02 / 10 / 10$ & 167.20 & 50.96 & 3196.85 & 974.40 & NA \\
\hline WQSP-6a & DL & 03/24/10 & 167.03 & 50.91 & 3197.02 & 974.45 & NA \\
\hline
\end{tabular}




\section{Waste Isolation Pilot Plant Annual Site Environmental Report for 2010 DOE/WIPP-11-2225}

Appendix F - Groundwater Data Tables

Table F.9 - Water Levels

\begin{tabular}{|c|c|c|c|c|c|c|c|}
\hline Well Number & Zone & Date & $\begin{array}{c}\text { Adjusted } \\
\text { Depth Top } \\
\text { of Casing } \\
\text { (ft) }\end{array}$ & $\begin{array}{l}\text { Adjusted } \\
\text { Depth } \\
\text { (meters) }\end{array}$ & $\begin{array}{l}\text { Water Level } \\
\text { Elevation } \\
\text { (ft amsl) }\end{array}$ & $\begin{array}{l}\text { Elevation in } \\
\text { Meters } \\
\text { (amsl) }\end{array}$ & $\begin{array}{c}\text { Adjusted } \\
\text { Freshwater } \\
\text { Head (ft amsl) }\end{array}$ \\
\hline WQSP-6a & DL & 04/20/10 & 167.11 & 50.94 & 3196.94 & 974.43 & NA \\
\hline WQSP-6a & DL & 05/19/10 & 167.15 & 50.95 & 3196.90 & 974.42 & NA \\
\hline WQSP-6a & $\mathrm{DL}$ & 06/08/10 & 167.25 & 50.98 & 3196.80 & 974.38 & NA \\
\hline WQSP-6a & DL & $07 / 12 / 10$ & 167.14 & 50.94 & 3196.91 & 974.42 & NA \\
\hline WQSP-6a & DL & 08/11/10 & 167.30 & 50.99 & 3196.75 & 974.37 & NA \\
\hline WQSP-6a & DL & 09/10/10 & 167.24 & 50.97 & 3196.81 & 974.39 & NA \\
\hline WQSP-6a & DL & $10 / 22 / 10$ & 167.17 & 50.95 & 3196.88 & 974.41 & NA \\
\hline WQSP-6a & DL & $11 / 11 / 10$ & 167.19 & 50.96 & 3196.86 & 974.40 & NA \\
\hline WQSP-6a & DL & $12 / 03 / 10$ & 167.33 & 51.00 & 3196.72 & 974.36 & NA \\
\hline CB-1 & $\mathrm{B} / \mathrm{C}$ & 01/12/10 & 319.37 & 97.34 & 3009.75 & 917.37 & NA \\
\hline CB-1 & $\mathrm{B} / \mathrm{C}$ & 02/08/10 & 318.78 & 97.16 & 3010.34 & 917.55 & NA \\
\hline CB-1 & $\mathrm{B} / \mathrm{C}$ & 03/23/10 & 318.32 & 97.02 & 3010.80 & 917.69 & NA \\
\hline CB-1 & $\mathrm{B} / \mathrm{C}$ & 04/20/10 & 318.15 & 96.97 & 3010.97 & 917.74 & NA \\
\hline CB-1 & $\mathrm{B} / \mathrm{C}$ & 05/17/10 & 318.03 & 96.94 & 3011.09 & 917.78 & NA \\
\hline CB-1 & $\mathrm{B} / \mathrm{C}$ & 06/07/10 & 317.79 & 96.86 & 3011.33 & 917.85 & NA \\
\hline CB-1 & $B / C$ & 07/13/10 & 317.28 & 96.71 & 3011.84 & 918.01 & NA \\
\hline CB-1 & $\mathrm{B} / \mathrm{C}$ & 08/09/10 & 317.02 & 96.63 & 3012.10 & 918.09 & NA \\
\hline CB-1 & $\mathrm{B} / \mathrm{C}$ & 09/13/10 & 316.82 & 96.57 & 3012.30 & 918.15 & NA \\
\hline CB-1 & $\mathrm{B} / \mathrm{C}$ & $10 / 21 / 10$ & 316.32 & 96.41 & 3012.80 & 918.30 & NA \\
\hline CB-1 & $\mathrm{B} / \mathrm{C}$ & $11 / 10 / 10$ & 316.01 & 96.32 & 3013.11 & 918.40 & NA \\
\hline CB-1 & $\mathrm{B} / \mathrm{C}$ & $12 / 01 / 10$ & 315.98 & 96.31 & 3013.14 & 918.41 & NA \\
\hline DOE-2 & $\mathrm{B} / \mathrm{C}$ & $01 / 12 / 10$ & 352.78 & 107.53 & 3066.40 & 934.64 & NA \\
\hline DOE-2 & $\mathrm{B} / \mathrm{C}$ & $02 / 10 / 10$ & 352.47 & 107.43 & 3066.71 & 934.73 & NA \\
\hline DOE-2 & $\mathrm{B} / \mathrm{C}$ & $03 / 24 / 10$ & 352.47 & 107.43 & 3066.71 & 934.73 & NA \\
\hline DOE-2 & $\mathrm{B} / \mathrm{C}$ & 04/20/10 & 352.51 & 107.45 & 3066.67 & 934.72 & NA \\
\hline DOE-2 & $\mathrm{B} / \mathrm{C}$ & 05/19/10 & 352.45 & 107.43 & 3066.73 & 934.74 & NA \\
\hline DOE-2 & $\mathrm{B} / \mathrm{C}$ & 06/09/10 & 352.43 & 107.42 & 3066.75 & 934.75 & NA \\
\hline DOE-2 & $\mathrm{B} / \mathrm{C}$ & 07/13/10 & 352.40 & 107.41 & 3066.78 & 934.75 & NA \\
\hline DOE-2 & $\mathrm{B} / \mathrm{C}$ & 08/10/10 & 352.40 & 107.41 & 3066.78 & 934.75 & NA \\
\hline DOE-2 & $\mathrm{B} / \mathrm{C}$ & 09/09/10 & 352.45 & 107.43 & 3066.73 & 934.74 & NA \\
\hline DOE-2 & $\mathrm{B} / \mathrm{C}$ & $10 / 21 / 10$ & 352.45 & 107.43 & 3066.73 & 934.74 & NA \\
\hline DOE-2 & $\mathrm{B} / \mathrm{C}$ & $11 / 10 / 10$ & 352.42 & 107.42 & 3066.76 & 934.75 & NA \\
\hline DOE-2 & $\mathrm{B} / \mathrm{C}$ & $12 / 02 / 10$ & 352.48 & 107.44 & 3066.70 & 934.73 & NA \\
\hline C-2505 & SR/D & 03/25/10 & 45.57 & 13.89 & 3367.36 & 1026.37 & NA \\
\hline C-2505 & SR/D & 06/10/10 & 45.57 & 13.89 & 3367.36 & 1026.37 & NA \\
\hline C-2505 & $S R / D$ & 09/14/10 & 45.80 & 13.96 & 3367.13 & 1026.30 & NA \\
\hline C-2505 & SR/D & $12 / 06 / 10$ & 45.63 & 13.91 & 3367.30 & 1026.35 & NA \\
\hline
\end{tabular}




\section{Waste Isolation Pilot Plant Annual Site Environmental Report for 2010 DOE/WIPP-11-2225}

Appendix F - Groundwater Data Tables

Table F.9 - Water Levels

\begin{tabular}{|c|c|c|c|c|c|c|c|}
\hline Well Number & Zone & Date & $\begin{array}{l}\text { Adjusted } \\
\text { Depth Top } \\
\text { of Casing } \\
\text { (ft) }\end{array}$ & $\begin{array}{l}\text { Adjusted } \\
\text { Depth } \\
\text { (meters) }\end{array}$ & $\begin{array}{l}\text { Water Level } \\
\text { Elevation } \\
\text { (ft amsl) }\end{array}$ & $\begin{array}{l}\text { Elevation in } \\
\text { Meters } \\
\text { (amsl) }\end{array}$ & $\begin{array}{c}\text { Adjusted } \\
\text { Freshwater } \\
\text { Head (ft amsl) }\end{array}$ \\
\hline C-2506 & SR/D & $03 / 25 / 10$ & 44.92 & 13.69 & 3367.92 & 1026.54 & NA \\
\hline C-2506 & SR/D & 06/10/10 & 44.94 & 13.70 & 3367.90 & 1026.54 & NA \\
\hline C-2506 & SR/D & 09/14/10 & 45.19 & 13.77 & 3367.65 & 1026.46 & NA \\
\hline C-2506 & SR/D & $12 / 06 / 10$ & 45.03 & 13.73 & 3367.81 & 1026.51 & NA \\
\hline C-2507 & SR/D & $03 / 25 / 10$ & 45.35 & 13.82 & 3364.56 & 1025.52 & NA \\
\hline C-2507 & SR/D & 06/10/10 & 45.33 & 13.82 & 3364.58 & 1025.52 & NA \\
\hline C-2507 & SR/D & 09/14/10 & 45.53 & 13.88 & 3364.38 & 1025.46 & NA \\
\hline C-2507 & SR/D & $12 / 06 / 10$ & 45.43 & 13.85 & 3364.48 & 1025.49 & NA \\
\hline C-2811 & SR/D & 03/24/10 & 52.80 & 16.09 & 3346.04 & 1019.87 & NA \\
\hline C-2811 & SR/D & 06/08/10 & 52.99 & 16.15 & 3345.85 & 1019.81 & NA \\
\hline C-2811 & SR/D & 09/14/10 & 53.14 & 16.20 & 3345.70 & 1019.77 & NA \\
\hline C-2811 & SR/D & $12 / 06 / 10$ & 52.82 & 16.10 & 3346.02 & 1019.87 & NA \\
\hline PZ-01 & SR/D & $03 / 25 / 10$ & 42.17 & 12.85 & 3371.11 & 1027.51 & NA \\
\hline PZ-01 & SR/D & 06/10/10 & 42.09 & 12.83 & 3371.19 & 1027.54 & NA \\
\hline PZ-01 & SR/D & $12 / 06 / 10$ & 41.96 & 12.79 & 3371.32 & 1027.58 & NA \\
\hline PZ-02 & SR/D & 03/25/10 & 42.70 & 13.01 & 3370.66 & 1027.38 & NA \\
\hline PZ-02 & SR/D & 06/10/10 & 42.61 & 12.99 & 3370.75 & 1027.40 & NA \\
\hline PZ-02 & SR/D & 09/14/10 & 42.97 & 13.10 & 3370.39 & 1027.29 & NA \\
\hline PZ-02 & SR/D & $12 / 06 / 10$ & 42.91 & 13.08 & 3370.45 & 1027.31 & NA \\
\hline PZ-03 & SR/D & 03/25/10 & 43.98 & 13.41 & 3372.14 & 1027.83 & NA \\
\hline PZ-03 & SR/D & 06/10/10 & 43.87 & 13.37 & 3372.25 & 1027.86 & NA \\
\hline PZ-03 & SR/D & 09/14/10 & 43.19 & 13.16 & 3372.93 & 1028.07 & NA \\
\hline PZ-03 & SR/D & $12 / 06 / 10$ & 44.23 & 13.48 & 3371.89 & 1027.75 & NA \\
\hline PZ-04 & SR/D & $03 / 25 / 10$ & 46.41 & 14.15 & 3365.60 & 1025.84 & NA \\
\hline PZ-04 & SR/D & 06/10/10 & 46.31 & 14.12 & 3365.70 & 1025.87 & NA \\
\hline PZ-04 & SR/D & 09/14/10 & 46.49 & 14.17 & 3365.52 & 1025.81 & NA \\
\hline PZ-04 & SR/D & $12 / 06 / 10$ & 46.24 & 14.09 & 3365.77 & 1025.89 & NA \\
\hline PZ-05 & SR/D & 03/25/10 & 42.65 & 13.00 & 3372.59 & 1027.97 & NA \\
\hline PZ-05 & SR/D & 06/10/10 & 42.54 & 12.97 & 3372.70 & 1028.00 & NA \\
\hline PZ-05 & SR/D & 09/14/10 & 42.90 & 13.08 & 3372.34 & 1027.89 & NA \\
\hline PZ-05 & SR/D & $12 / 06 / 10$ & 42.82 & 13.05 & 3372.42 & 1027.91 & NA \\
\hline PZ-06 & SR/D & $03 / 25 / 10$ & 43.52 & 13.26 & 3369.81 & 1027.12 & NA \\
\hline PZ-06 & SR/D & 06/10/10 & 43.40 & 13.23 & 3369.93 & 1027.15 & NA \\
\hline PZ-06 & SR/D & 09/14/10 & 43.36 & 13.22 & 3369.97 & 1027.17 & NA \\
\hline PZ-06 & SR/D & $12 / 06 / 10$ & 43.10 & 13.14 & 3370.23 & 1027.25 & NA \\
\hline PZ-07 & SR/D & 03/25/10 & 37.14 & 11.32 & 3376.70 & 1029.22 & NA \\
\hline PZ-07 & SR/D & 06/10/10 & 36.91 & 11.25 & 3376.93 & 1029.29 & NA \\
\hline
\end{tabular}




\section{Waste Isolation Pilot Plant Annual Site Environmental Report for 2010 DOE/WIPP-11-2225}

Appendix F - Groundwater Data Tables

Table F.9 - Water Levels

\begin{tabular}{|c|c|c|c|c|c|c|c|}
\hline Well Number & Zone & Date & $\begin{array}{c}\text { Adjusted } \\
\text { Depth Top } \\
\text { of Casing } \\
\text { (ft) }\end{array}$ & $\begin{array}{l}\text { Adjusted } \\
\text { Depth } \\
\text { (meters) }\end{array}$ & $\begin{array}{l}\text { Water Level } \\
\text { Elevation } \\
\text { (ft amsl) }\end{array}$ & $\begin{array}{l}\text { Elevation in } \\
\text { Meters } \\
\text { (amsl) }\end{array}$ & $\begin{array}{c}\text { Adjusted } \\
\text { Freshwater } \\
\text { Head (ft amsl) }\end{array}$ \\
\hline PZ-07 & SR/D & 09/09/10 & 37.02 & 11.28 & 3376.82 & 1029.25 & NA \\
\hline $\mathrm{PZ}-07$ & SR/D & $12 / 03 / 10$ & 36.90 & 11.25 & 3376.94 & 1029.29 & NA \\
\hline $\mathrm{PZ}-08$ & SR/D & $03 / 24 / 10$ & 62.26 & 18.98 & 3355.93 & 1022.89 & NA \\
\hline PZ-08 & SR/D & 06/10/10 & 62.12 & 18.93 & 3356.07 & 1022.93 & NA \\
\hline PZ-08 & SR/D & 09/09/10 & 62.30 & 18.99 & 3355.89 & 1022.88 & NA \\
\hline $\mathrm{PZ}-08$ & SR/D & $12 / 03 / 10$ & 62.61 & 19.08 & 3355.58 & 1022.78 & NA \\
\hline PZ-09 & SR/D & 03/25/10 & 57.19 & 17.43 & 3363.90 & 1025.32 & NA \\
\hline PZ-09 & SR/D & $06 / 10 / 10$ & 57.01 & 17.38 & 3364.08 & 1025.37 & NA \\
\hline PZ-09 & SR/D & 09/09/10 & 57.13 & 17.41 & 3363.96 & 1025.33 & NA \\
\hline PZ-09 & SR/D & $12 / 03 / 10$ & 57.45 & 17.51 & 3363.64 & 1025.24 & NA \\
\hline PZ-10 & SR/D & 03/25/10 & 37.73 & 11.50 & 3368.00 & 1026.57 & NA \\
\hline PZ-10 & SR/D & 06/10/10 & 37.91 & 11.55 & 3367.82 & 1026.51 & NA \\
\hline $\mathrm{PZ}-10$ & SR/D & 09/09/10 & 37.74 & 11.50 & 3367.99 & 1026.56 & NA \\
\hline $\mathrm{PZ}-10$ & SR/D & $12 / 06 / 10$ & 37.89 & 11.55 & 3367.84 & 1026.52 & NA \\
\hline $\mathrm{PZ}-11$ & $\mathrm{SR} / \mathrm{D}$ & 03/25/10 & 44.74 & 13.64 & 3374.04 & 1028.41 & NA \\
\hline PZ-11 & $\mathrm{SR} / \mathrm{D}$ & 06/10/10 & 44.49 & 13.56 & 3374.29 & 1028.48 & NA \\
\hline PZ-11 & SR/D & 09/09/10 & 44.47 & 13.55 & 3374.31 & 1028.49 & NA \\
\hline PZ-11 & SR/D & $12 / 03 / 10$ & 44.35 & 13.52 & 3374.43 & 1028.53 & NA \\
\hline PZ-12 & SR/D & 03/25/10 & 51.80 & 15.79 & 3357.12 & 1023.25 & NA \\
\hline PZ-12 & SR/D & 06/10/10 & 51.78 & 15.78 & 3357.14 & 1023.26 & NA \\
\hline PZ-12 & SR/D & 09/09/10 & 51.63 & 15.74 & 3357.29 & 1023.30 & NA \\
\hline $\mathrm{PZ}-12$ & SR/D & $12 / 06 / 10$ & 51.76 & 15.78 & 3357.16 & 1023.26 & NA \\
\hline $\mathrm{PZ}-13$ & SR/D & $03 / 24 / 10$ & 65.37 & 19.92 & 3356.87 & 1023.17 & NA \\
\hline $\mathrm{PZ}-13$ & SR/D & 06/08/10 & 65.51 & 19.97 & 3356.73 & 1023.13 & NA \\
\hline PZ-13 & SR/D & 09/09/10 & 65.60 & 19.99 & 3356.64 & 1023.10 & NA \\
\hline PZ-13 & SR/D & $12 / 03 / 10$ & 65.89 & 20.08 & 3356.35 & 1023.02 & NA \\
\hline PZ-14 & SR/D & 03/24/10 & 67.04 & 20.43 & 3353.54 & 1022.16 & NA \\
\hline PZ-14 & SR/D & 06/08/10 & 67.14 & 20.46 & 3353.44 & 1022.13 & NA \\
\hline PZ-14 & SR/D & 09/09/10 & 67.16 & 20.47 & 3353.42 & 1022.12 & NA \\
\hline $\mathrm{PZ}-14$ & SR/D & $12 / 03 / 10$ & 67.38 & 20.54 & 3353.20 & 1022.06 & NA \\
\hline PZ-15 & SR/D & 03/24/10 & 47.11 & 14.36 & 3383.75 & 1031.37 & NA \\
\hline PZ-15 & SR/D & 06/08/10 & 47.26 & 14.40 & 3383.60 & 1031.32 & NA \\
\hline PZ-15 & $\mathrm{SR} / \mathrm{D}$ & 09/09/10 & 47.18 & 14.38 & 3383.68 & 1031.35 & NA \\
\hline PZ-15 & SR/D & $12 / 03 / 10$ & 47.35 & 14.43 & 3383.51 & 1031.29 & NA \\
\hline
\end{tabular}


Waste Isolation Pilot Plant Annual Site Environmental Report for 2010

DOE/WIPP-11-2225

Appendix G - Air Sampling Data: Concentrations of Radionuclides in Air Filter Composites

Table G.1 - 2010 Radionuclide Concentrations (Bq/sample) in Quarterly Composite Air Filters Collected from Locations Surrounding the WIPP Site

See Appendix C for sampling location codes

\begin{tabular}{|c|c|c|c|c|c|c|c|c|c|c|c|c|c|}
\hline \multirow[b]{2}{*}{ Location } & \multirow[b]{2}{*}{ Quarter } & \multicolumn{4}{|c|}{${ }^{233 / 234} U$} & \multicolumn{4}{|c|}{${ }^{235} U$} & \multicolumn{4}{|c|}{${ }^{238} \mathrm{U}$} \\
\hline & & {$[R N]^{(a)}$} & $2 \sigma \mathrm{TPU}^{(\mathrm{b})}$ & $\mathrm{MDC}^{(\mathrm{c})}$ & $Q^{(d)}$ & [RN] & $2 \sigma$ TPU & MDC & $\mathbf{Q}$ & [RN] & $2 \sigma$ TPU & MDC & Q \\
\hline \multirow[t]{4}{*}{ CBD } & 1 & 4.59E-03 & 2.95E-03 & $1.04 \mathrm{E}-03$ & $U$ & 6.81E-04 & 1.07E-03 & $6.15 \mathrm{E}-04$ & $U$ & 4.56E-03 & 2.86E-03 & $9.10 \mathrm{E}-04$ & $U$ \\
\hline & 2 & 7.39E-03 & 2.37E-03 & 1.09E-03 & + & $-3.39 E-05$ & 1.49E-04 & 5.36E-04 & U & 9.27E-03 & $2.74 \mathrm{E}-03$ & 9.78E-04 & + \\
\hline & 3 & 8.60E-04 & 2.14E-03 & $6.24 \mathrm{E}-03$ & U & $-5.01 E-04$ & 2.71E-04 & 8.30E-04 & $U$ & $1.75 \mathrm{E}-03$ & 2.25E-03 & 7.01E-03 & U \\
\hline & 4 (Avg) & 6.39E-03 & $2.65 E-03$ & 4.94E-03 & $\mathrm{U} /+$ & 5.82E-04 & 6.68E-04 & 9.87E-04 & $U$ & 3.73E-03 & 2.40E-03 & 6.51E-03 & $U$ \\
\hline \multirow{3}{*}{ MLR } & 2 (Avg) & 8.46E-03 & $2.75 \mathrm{E}-03$ & 1.12E-03 & + & 3.09E-04 & 5.49E-04 & 5.74E-04 & $U$ & 9.65E-03 & $2.98 \mathrm{E}-03$ & $1.01 \mathrm{E}-03$ & + \\
\hline & 3 & 8.74E-04 & 2.06E-03 & $6.20 \mathrm{E}-03$ & $U$ & $-6.24 \mathrm{E}-05$ & 5.23E-04 & 7.87E-04 & U & 1.76E-03 & 2.15E-03 & 6.97E-03 & $U$ \\
\hline & 4 & 8.11E-03 & 2.91E-03 & 4.93E-03 & + & 4.35E-05 & 3.47E-04 & 9.86E-04 & $U$ & 3.68E-03 & 2.38E-03 & 6.51E-03 & $U$ \\
\hline \multirow[t]{3}{*}{ SEC } & 1 & -1.08E-03 & 2.02E-03 & $1.05 E-03$ & $U$ & $-1.80 \mathrm{E}-04$ & $6.53 \mathrm{E}-04$ & 6.23E-04 & $U$ & $-5.43 E-04$ & $1.96 \mathrm{E}-03$ & 9.17E-04 & $U$ \\
\hline & 2 & 7.09E-03 & 2.43E-03 & 1.13E-03 & + & $-4.38 \mathrm{E}-05$ & 1.78E-04 & 5.86E-04 & $U$ & 7.07E-03 & 2.42E-03 & $1.02 \mathrm{E}-03$ & + \\
\hline & 3 (Avg) & 2.61E-03 & 2.35E-03 & $6.21 \mathrm{E}-03$ & U & 8.76E-05 & 6.66E-04 & 7.93E-04 & U & 5.00E-04 & 1.96E-03 & 6.98E-03 & U \\
\hline \multirow[t]{4}{*}{ SMR } & 1 & $-1.63 E-04$ & 2.25E-03 & 1.09E-03 & $U$ & $-6.46 \mathrm{E}-04$ & 3.52E-04 & 6.77E-04 & $U$ & $-1.40 \mathrm{E}-03$ & 1.93E-03 & $9.60 \mathrm{E}-04$ & $U$ \\
\hline & 2 & 7.88E-03 & 2.45E-03 & $1.08 \mathrm{E}-03$ & + & 5.74E-04 & 6.80E-04 & 5.16E-04 & U & 6.23E-03 & 2.12E-03 & 9.62E-04 & + \\
\hline & 3 & 1.86E-03 & 2.34E-03 & $6.24 \mathrm{E}-03$ & $U$ & $1.22 \mathrm{E}-04$ & 7.28E-04 & 8.36E-04 & U & 1.53E-03 & 2.22E-03 & 7.01E-03 & $U$ \\
\hline & 4 & 7.34E-03 & 3.10E-03 & 5.01E-03 & + & 4.22E-04 & 6.92E-04 & 1.07E-03 & U & 4.40E-03 & 2.74E-03 & 6.58E-03 & U \\
\hline \multirow[t]{4}{*}{ WEE } & 1 & $-9.62 E-04$ & 1.70E-03 & 9.09E-04 & $U$ & 1.99E-05 & 6.34E-04 & 4.53E-04 & U & 4.98E-05 & $1.74 \mathrm{E}-03$ & 7.79E-04 & U \\
\hline & 2 & 7.87E-03 & 2.86E-03 & 1.17E-03 & + & 9.27E-04 & 9.69E-04 & 6.34E-04 & U & 6.71E-03 & 2.57E-03 & $1.06 \mathrm{E}-03$ & + \\
\hline & 3 & $-1.28 \mathrm{E}-04$ & 1.93E-03 & 6.20E-03 & $U$ & $-2.98 E-04$ & 4.22E-04 & 7.85E-04 & U & $-1.93 E-03$ & 1.62E-03 & 6.97E-03 & $\mathrm{U}$ \\
\hline & 4 & 4.65E-03 & 2.66E-03 & 5.03E-03 & $U$ & 2.53E-04 & 6.10E-04 & 1.10E-03 & U & 3.92E-03 & 2.73E-03 & 6.60E-03 & U \\
\hline
\end{tabular}


Waste Isolation Pilot Plant Annual Site Environmental Report for 2010

DOE/WIPP-11-2225

Appendix G - Air Sampling Data: Concentrations of Radionuclides in Air Filter Composites

Table G.1 - 2010 Radionuclide Concentrations (Bq/sample) in Quarterly Composite Air Filters Collected from Locations Surrounding the WIPP Site

See Appendix C for sampling location codes

\begin{tabular}{|c|c|c|c|c|c|c|c|c|c|c|c|c|c|}
\hline \multirow[b]{2}{*}{ Location } & \multirow[b]{2}{*}{ Quarter } & \multicolumn{4}{|c|}{${ }^{233 / 234} U$} & \multicolumn{4}{|c|}{${ }^{235} \mathrm{U}$} & \multicolumn{4}{|c|}{${ }^{238} \mathrm{U}$} \\
\hline & & {$[R N]^{(a)}$} & $2 \sigma \mathrm{TPU}^{(\mathrm{b})}$ & $\mathrm{MDC}^{(\mathrm{c})}$ & $Q^{(d)}$ & [RN] & $2 \sigma$ TPU & MDC & $\mathbf{Q}$ & [RN] & $2 \sigma$ TPU & MDC & $\mathbf{Q}$ \\
\hline \multirow[t]{4}{*}{ WFF } & 1 & -1.87E-03 & 1.61E-03 & 9.16E-04 & U & -1.06E-04 & 5.57E-04 & 4.61E-04 & $U$ & -1.33E-03 & 1.56E-03 & 7.86E-04 & $U$ \\
\hline & 2 & 5.03E-03 & 2.29E-03 & 1.06E-03 & + & 2.40E-04 & 6.41E-04 & 4.94E-04 & U & 5.54E-03 & 2.42E-03 & 9.44E-04 & + \\
\hline & 3 & 7.80E-04 & 1.96E-03 & 6.17E-03 & U & -1.96E-05 & 6.33E-04 & 7.44E-04 & U & $-4.07 \mathrm{E}-04$ & 1.73E-03 & 6.94E-03 & U \\
\hline & 4 & 4.68E-03 & 2.38E-03 & 4.95E-03 & U & $6.48 \mathrm{E}-04$ & 7.67E-04 & 1.00E-03 & $U$ & 3.11E-03 & 2.32E-03 & $6.52 \mathrm{E}-03$ & $U$ \\
\hline \multirow[t]{4}{*}{ WSS } & 1 (Avg) & $-1.33 E-03$ & $1.72 \mathrm{E}-03$ & 4.29E-03 & $U$ & $-3.73 E-04$ & 4.58E-04 & $-1.60 \mathrm{E}-03$ & U & $-2.53 E-04$ & $1.76 \mathrm{E}-03$ & 5.29E-03 & $U$ \\
\hline & 2 & 6.73E-03 & 2.40E-03 & 1.10E-03 & + & 3.32E-04 & 5.01E-04 & 5.49E-04 & $U$ & 6.84E-03 & 2.43E-03 & 9.89E-04 & + \\
\hline & 3 & 5.56E-04 & 1.94E-03 & 6.18E-03 & U & $-2.94 \mathrm{E}-04$ & 3.86E-04 & 7.54E-04 & U & $-1.66 \mathrm{E}-03$ & 1.57E-03 & 6.94E-03 & U \\
\hline & 4 & 4.06E-03 & 2.14E-03 & 4.91E-03 & U & 3.29E-04 & 5.13E-04 & 9.51E-04 & U & $1.25 \mathrm{E}-03$ & 1.93E-03 & 6.48E-03 & $U$ \\
\hline \multicolumn{2}{|r|}{ Mean } & 3.51E-03 & 2.33E-03 & 3.44E-03 & & 1.14E-04 & 5.66E-04 & 6.59E-04 & & $2.77 \mathrm{E}-03$ & 2.22E-03 & 4.00E-03 & \\
\hline \multicolumn{2}{|r|}{ Minimum $^{(\mathrm{e})}$} & -1.87E-03 & $1.61 \mathrm{E}-03$ & 9.16E-04 & & $-6.46 \mathrm{E}-04$ & 3.52E-04 & 6.77E-04 & & $-1.93 E-03$ & 1.62E-03 & 6.97E-03 & \\
\hline \multicolumn{2}{|c|}{ Maximum $^{(\mathrm{e})}$} & 8.46E-03 & $2.75 \mathrm{E}-03$ & 1.12E-03 & & $9.27 \mathrm{E}-04$ & 9.69E-04 & 6.34E-04 & & $9.65 \mathrm{E}-03$ & 2.98E-03 & 1.01E-03 & \\
\hline WAB & $1^{(f)}$ & 3.52E-04 & 3.64E-04 & 7.80E-04 & U & 5.75E-05 & 2.23E-04 & 2.93E-04 & $U$ & 2.01E-04 & 2.83E-04 & 6.50E-04 & $U$ \\
\hline \multirow[t]{3}{*}{$(\text { Blank) })^{(f)}$} & 2 & 4.74E-03 & $1.71 \mathrm{E}-03$ & $1.05 \mathrm{E}-03$ & + & $-5.47 \mathrm{E}-05$ & 1.77E-04 & 4.80E-04 & U & 5.32E-03 & $1.83 \mathrm{E}-03$ & 9.33E-04 & + \\
\hline & 3 & $6.24 \mathrm{E}-03$ & $2.16 \mathrm{E}-03$ & 6.17E-03 & + & 4.21E-04 & 6.33E-04 & 7.47E-04 & $U$ & 5.94E-03 & 2.09E-03 & 6.94E-03 & $U$ \\
\hline & 4 & 5.02E-03 & 1.77E-03 & 4.93E-03 & + & 7.19E-05 & $3.74 \mathrm{E}-04$ & $9.76 \mathrm{E}-04$ & $U$ & 6.86E-03 & 2.14E-03 & 6.50E-03 & + \\
\hline
\end{tabular}

(a) Radionuclide activity of the primary sample. Only radionuclides with activities greater than $2 \sigma$ TPU and MDC are considered detections.

(b) 2 times the Total Propagated Uncertainty.

(c) Minimum Detectable Concentration.

(d) Qualifier. Indicates whether radionuclide was detected. Plus (+) equals detected. $U$ equals undetected.

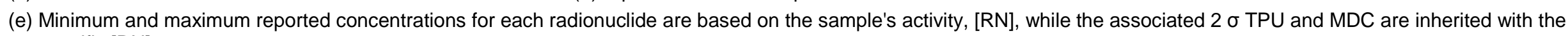
specific [RN].

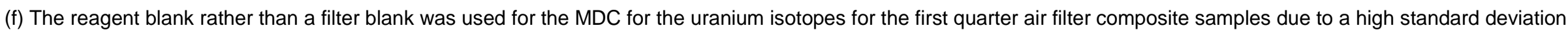
associated with only two filter blanks.

U/+ Isotope detected in one of the duplicates but not the other. 
Waste Isolation Pilot Plant Annual Site Environmental Report for 2010

DOE/WIPP-11-2225

Appendix G - Air Sampling Data: Concentrations of Radionuclides in Air Filter Composites

Table G.1 - 2010 Radionuclide Concentrations (Bq/sample) in Quarterly Composite Air Filters Collected from Locations Surrounding the WIPP Site

See Appendix C for sampling location codes

\begin{tabular}{|c|c|c|c|c|c|c|c|c|c|c|c|c|c|}
\hline \multirow[b]{2}{*}{ Location } & \multirow[b]{2}{*}{ Quarter } & \multicolumn{4}{|c|}{${ }^{241} \mathrm{Am}$} & \multicolumn{4}{|c|}{${ }^{238} \mathrm{Pu}$} & \multicolumn{4}{|c|}{${ }^{239 / 240} \mathrm{Pu}$} \\
\hline & & {$[\mathrm{RN}]^{(\mathrm{a})}$} & $2 \sigma \mathrm{TPU}^{(\mathrm{b})}$ & $\mathrm{MDC}^{(\mathrm{c})}$ & $Q^{(d)}$ & [RN] & $2 \sigma$ TPU & MDC & $\mathbf{Q}$ & [RN] & $2 \sigma \mathrm{TPU}$ & MDC & Q \\
\hline \multirow[t]{4}{*}{ CBD } & 1 & $-2.81 E-04$ & 6.00E-04 & $6.25 E-02$ & $U$ & 2.54E-04 & 5.63E-04 & 1.24E-01 & $U$ & $-1.41 E-04$ & 2.60E-04 & 6.23E-02 & $U$ \\
\hline & 2 & 4.36E-04 & 6.56E-04 & 5.78E-04 & $U$ & $1.04 \mathrm{E}-04$ & 4.66E-04 & 3.93E-04 & $U$ & -8.98E-05 & 2.14E-04 & 4.53E-04 & $U$ \\
\hline & 3 & 4.47E-06 & 5.59E-04 & 8.88E-04 & $U$ & $-1.82 \mathrm{E}-04$ & 2.40E-04 & 5.84E-04 & $U$ & -1.00E-04 & $1.98 \mathrm{E}-04$ & 4.21E-04 & $U$ \\
\hline & 4 (Avg) & $1.05 E-05$ & 5.99E-04 & 9.18E-04 & $U$ & 8.10E-05 & 7.59E-04 & 8.49E-04 & $U$ & $-1.28 \mathrm{E}-04$ & 5.00E-04 & 7.25E-04 & U \\
\hline \multirow{3}{*}{ MLR } & 2 (Avg) & 2.37E-04 & 6.35E-04 & 5.92E-04 & $U$ & -7.33E-05 & 3.77E-04 & 4.60E-04 & $U$ & 6.97E-05 & 4.16E-04 & 5.20E-04 & $U$ \\
\hline & 3 & $-3.21 E-04$ & 5.78E-04 & 9.61E-04 & $U$ & 8.70E-05 & 4.52E-04 & 5.53E-04 & $U$ & 1.03E-04 & 3.55E-04 & 3.89E-04 & U \\
\hline & 4 & -2.97E-04 & 3.69E-04 & 1.03E-03 & $U$ & -1.87E-04 & 4.43E-04 & 7.20E-04 & U & 1.43E-04 & 4.26E-04 & 5.96E-04 & $U$ \\
\hline \multirow[t]{3}{*}{ SEC } & 1 & $-1.66 \mathrm{E}-04$ & 5.54E-04 & $6.25 \mathrm{E}-02$ & U & 5.05E-04 & 7.25E-04 & 1.24E-01 & U & -9.57E-05 & 2.09E-04 & 6.23E-02 & U \\
\hline & 2 & 8.15E-04 & 9.07E-04 & 6.97E-04 & $U$ & $6.52 \mathrm{E}-05$ & 5.85E-04 & 6.51E-04 & $U$ & 1.05E-04 & 5.52E-04 & 7.10E-04 & U \\
\hline & 3 (Avg) & 2.16E-05 & 6.47E-04 & 9.65E-04 & $U$ & 1.37E-06 & 4.02E-04 & 5.61E-04 & $U$ & $-5.74 \mathrm{E}-05$ & 2.39E-04 & 3.97E-04 & $U$ \\
\hline \multirow[t]{4}{*}{ SMR } & 1 & $-1.48 \mathrm{E}-04$ & $6.41 \mathrm{E}-04$ & 6.26E-02 & U & $-2.78 \mathrm{E}-04$ & 3.90E-04 & 1.24E-01 & $U$ & $-1.74 \mathrm{E}-04$ & 3.07E-04 & 6.23E-02 & U \\
\hline & 2 & $1.28 \mathrm{E}-04$ & $5.86 \mathrm{E}-04$ & 6.26E-04 & U & $0.00 \mathrm{E}+00$ & 4.35E-04 & 4.59E-04 & U & 3.13E-04 & 4.34E-04 & 5.19E-04 & U \\
\hline & 3 & 1.03E-04 & 7.71E-04 & 1.01E-03 & $U$ & 3.04E-04 & 5.88E-04 & $5.74 \mathrm{E}-04$ & $U$ & -1.17E-04 & 2.12E-04 & 4.10E-04 & U \\
\hline & 4 & $2.72 \mathrm{E}-04$ & 8.84E-04 & 1.05E-03 & $U$ & -1.34E-05 & 4.43E-04 & $6.75 \mathrm{E}-04$ & $U$ & $-6.43 E-05$ & 3.23E-04 & 5.51E-04 & U \\
\hline \multirow[t]{4}{*}{ WEE } & 1 & $-1.30 \mathrm{E}-04$ & 2.96E-04 & 6.23E-02 & U & 1.04E-04 & 5.03E-04 & 1.24E-01 & U & $1.44 \mathrm{E}-06$ & 3.89E-04 & 6.23E-02 & U \\
\hline & 2 & 2.73E-04 & 6.68E-04 & 6.19E-04 & U & 5.35E-04 & 6.73E-04 & 4.08E-04 & $U$ & 3.68E-05 & 3.56E-04 & 4.68E-04 & U \\
\hline & 3 & 2.11E-04 & $6.85 E-04$ & 9.33E-04 & $U$ & 1.52E-04 & 4.74E-04 & 5.82E-04 & $U$ & $-1.15 E-04$ & 2.14E-04 & 4.18E-04 & U \\
\hline & 4 & 4.62E-04 & 8.44E-04 & 9.77E-04 & $U$ & $-3.80 \mathrm{E}-04$ & $3.40 \mathrm{E}-04$ & $6.28 \mathrm{E}-04$ & $U$ & $6.29 \mathrm{E}-05$ & 3.40E-04 & 5.04E-04 & U \\
\hline \multirow[t]{2}{*}{ WFF } & 1 & 5.53E-04 & 6.97E-04 & 6.23E-02 & $\mathrm{U}$ & 2.39E-04 & 7.38E-04 & 1.24E-01 & $U$ & 7.06E-05 & 4.25E-04 & $6.24 \mathrm{E}-02$ & U \\
\hline & 2 & $-3.39 E-05$ & 4.26E-04 & 5.70E-04 & $U$ & -8.46E-06 & 3.56E-04 & $3.75 \mathrm{E}-04$ & $U$ & $1.26 \mathrm{E}-04$ & 4.27E-04 & 4.35E-04 & $U$ \\
\hline
\end{tabular}


Waste Isolation Pilot Plant Annual Site Environmental Report for 2010

DOE/WIPP-11-2225

Appendix G - Air Sampling Data: Concentrations of Radionuclides in Air Filter Composites

Table G.1 - 2010 Radionuclide Concentrations (Bq/sample) in Quarterly Composite Air Filters Collected from Locations Surrounding the WIPP Site

See Appendix C for sampling location codes

\begin{tabular}{|c|c|c|c|c|c|c|c|c|c|c|c|c|c|}
\hline \multirow[b]{2}{*}{ Location } & \multirow[b]{2}{*}{ Quarter } & \multicolumn{4}{|c|}{${ }^{241} \mathrm{Am}$} & \multicolumn{4}{|c|}{${ }^{238} \mathrm{Pu}$} & \multicolumn{4}{|c|}{${ }^{239 / 240} \mathrm{Pu}$} \\
\hline & & {$[R N]^{(a)}$} & $2 \sigma \mathrm{TPU}^{(\mathrm{b})}$ & $\mathrm{MDC}^{(\mathrm{c})}$ & $Q^{(d)}$ & [RN] & $2 \sigma$ TPU & MDC & $\mathbf{Q}$ & [RN] & $2 \sigma \mathrm{TPU}$ & MDC & $\mathbf{Q}$ \\
\hline & 3 & 8.43E-05 & 7.08E-04 & 9.76E-04 & $U$ & $-3.48 \mathrm{E}-04$ & 3.63E-04 & 5.64E-04 & $U$ & $-5.40 E-05$ & 1.31E-04 & 4.00E-04 & U \\
\hline & 4 & $-4.17 \mathrm{E}-04$ & 5.02E-04 & 1.08E-03 & U & 1.14E-04 & 5.00E-04 & 6.69E-04 & U & 8.48E-05 & 3.87E-04 & $5.45 E-04$ & U \\
\hline \multirow[t]{4}{*}{ WSS } & 1 (Avg) & $-2.66 \mathrm{E}-04$ & 4.03E-04 & $6.23 \mathrm{E}-02$ & $U$ & $2.25 \mathrm{E}-04$ & 5.54E-04 & $1.24 \mathrm{E}-01$ & U & $-1.24 \mathrm{E}-04$ & 2.27E-04 & $6.22 \mathrm{E}-02$ & U \\
\hline & 2 & $-5.66 E-05$ & 4.30E-04 & 5.59E-04 & U & $-1.32 E-04$ & 2.63E-04 & 4.03E-04 & U & $1.36 \mathrm{E}-05$ & 3.67E-04 & 4.63E-04 & U \\
\hline & 3 & 1.98E-04 & 6.63E-04 & 9.21E-04 & U & 4.51E-06 & 3.83E-04 & 5.49E-04 & U & 1.69E-04 & 3.11E-04 & 3.86E-04 & U \\
\hline & 4 & $3.42 \mathrm{E}-04$ & 8.75E-04 & $1.06 \mathrm{E}-03$ & $U$ & 8.49E-05 & 5.12E-04 & 6.68E-04 & U & -9.84E-05 & 3.41E-04 & 5.44E-04 & U \\
\hline \multicolumn{2}{|r|}{ Mean } & 4.87E-05 & $6.11 \mathrm{E}-04$ & $1.62 \mathrm{E}-02$ & & 3.55E-05 & 4.76E-04 & 3.15E-02 & & $-2.93 E-06$ & 3.34E-04 & 1.59E-02 & \\
\hline \multicolumn{2}{|c|}{ Minimum $^{(\mathrm{e})}$} & $-5.04 \mathrm{E}-04$ & 4.37E-04 & $6.25 \mathrm{E}-02$ & & $-3.80 E-04$ & 3.40E-04 & $6.28 \mathrm{E}-04$ & & $-1.74 \mathrm{E}-04$ & 3.07E-04 & $6.23 E-02$ & \\
\hline \multicolumn{2}{|c|}{ Maximum $^{(\mathrm{e})}$} & 8.15E-04 & 9.07E-04 & 6.97E-04 & & 5.35E-04 & $6.73 \mathrm{E}-04$ & 4.08E-04 & & 3.13E-04 & 4.34E-04 & 5.19E-04 & \\
\hline WAB & 1 & $1.41 \mathrm{E}-04$ & 2.91E-04 & $6.21 \mathrm{E}-02$ & U & $-1.35 E-05$ & 1.96E-04 & $1.24 \mathrm{E}-01$ & U & 8.94E-06 & 1.80E-04 & $6.21 E-02$ & U \\
\hline \multirow[t]{3}{*}{ (Blank) } & 2 & 8.21E-04 & 8.27E-04 & 5.70E-04 & $U$ & 3.65E-04 & 5.36E-04 & 4.29E-04 & $U$ & 2.91E-04 & 4.03E-04 & 4.89E-04 & U \\
\hline & 3 & 3.73E-04 & 6.33E-04 & 9.23E-04 & U & 5.54E-05 & 3.79E-04 & $5.45 E-04$ & U & 1.38E-05 & 2.77E-04 & 3.81E-04 & U \\
\hline & 4 & 1.33E-04 & 7.12E-04 & 9.91E-04 & U & $1.24 \mathrm{E}-04$ & 5.65E-04 & 6.77E-04 & U & -1.07E-04 & 2.29E-04 & 5.53E-04 & $U$ \\
\hline
\end{tabular}

(a) Radionuclide activity of the primary sample. Only radionuclides with activities greater than $2 \sigma$ TPU and MDC are considered detections.

(b) 2 times the Total Propagated Uncertainty.

(c) Minimum Detectable Concentration.

(d) Qualifier. Indicates whether radionuclide was detected. Plus (+) equals detected. $U$ equals undetected.

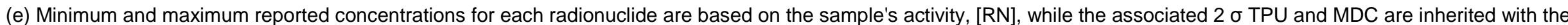
specific [RN]. 
Waste Isolation Pilot Plant Annual Site Environmental Report for 2010

DOE/WIPP-11-2225

Appendix G - Air Sampling Data: Concentrations of Radionuclides in Air Filter Composites

Table G.1 - 2010 Radionuclide Concentrations (Bq/sample) in Quarterly Composite Air Filters Collected from Locations Surrounding the WIPP Site

See Appendix $\mathrm{C}$ for sampling location codes

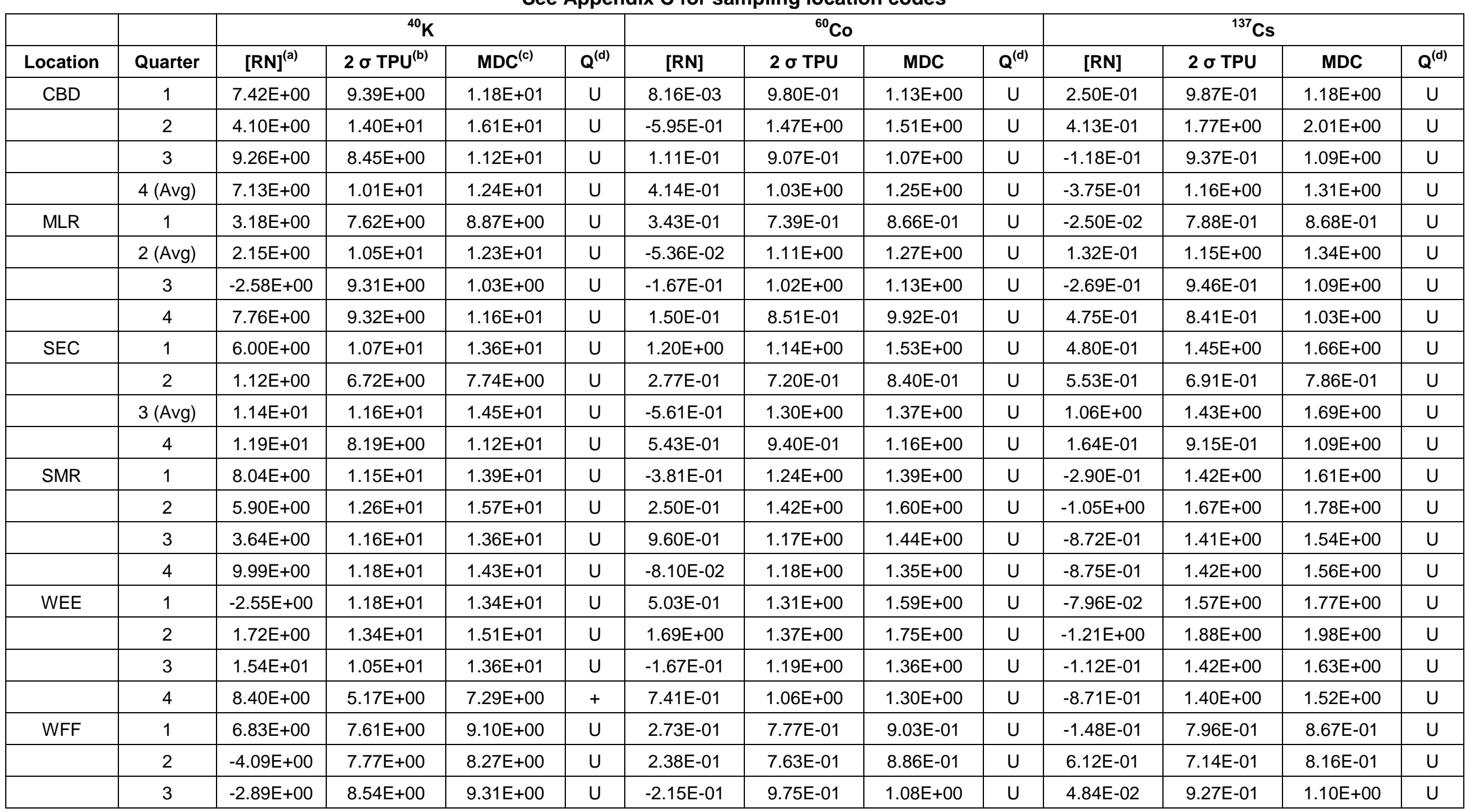


Waste Isolation Pilot Plant Annual Site Environmental Report for 2010

DOE/WIPP-11-2225

Appendix G - Air Sampling Data: Concentrations of Radionuclides in Air Filter Composites

Table G.1 - 2010 Radionuclide Concentrations (Bq/sample) in Quarterly Composite Air Filters Collected from Locations Surrounding the WIPP Site

See Appendix C for sampling location codes

\begin{tabular}{|c|c|c|c|c|c|c|c|c|c|c|c|c|c|}
\hline \multirow[b]{2}{*}{ Location } & \multirow[b]{2}{*}{ Quarter } & \multicolumn{4}{|c|}{${ }^{40} \mathrm{~K}$} & \multicolumn{4}{|c|}{${ }^{60} \mathrm{Co}$} & \multicolumn{4}{|c|}{${ }^{137} \mathrm{Cs}$} \\
\hline & & {$[R N]^{(a)}$} & $2 \sigma \mathrm{TPU}^{(\mathrm{b})}$ & $\mathrm{MDC}^{(\mathrm{c})}$ & $Q^{(d)}$ & [RN] & $2 \sigma \mathrm{TPU}$ & MDC & $\mathbf{Q}^{(\mathrm{d})}$ & [RN] & $2 \sigma$ TPU & MDC & $Q^{(d)}$ \\
\hline & 4 & $4.27 \mathrm{E}+00$ & $8.47 \mathrm{E}+00$ & $1.03 \mathrm{E}+01$ & $U$ & 5.20E-01 & 9.46E-01 & $1.15 \mathrm{E}+00$ & U & 6.80E-01 & 8.43E-01 & $1.03 \mathrm{E}+00$ & $U$ \\
\hline \multirow{2}{*}{ WSS } & 2 & 1.47E+01 & $1.11 \mathrm{E}+01$ & $1.54 \mathrm{E}+01$ & $U$ & $-1.30 \mathrm{E}-01$ & $1.53 \mathrm{E}+00$ & $1.67 \mathrm{E}+00$ & U & $1.64 \mathrm{E}+00$ & $1.54 \mathrm{E}+00$ & $1.84 \mathrm{E}+00$ & $U$ \\
\hline & 3 & $2.70 \mathrm{E}+00$ & $1.25 \mathrm{E}+01$ & $1.50 \mathrm{E}+01$ & U & $1.20 \mathrm{E}-01$ & $1.40 \mathrm{E}+00$ & $1.57 \mathrm{E}+00$ & U & 9.04E-01 & $1.51 \mathrm{E}+00$ & $1.76 \mathrm{E}+00$ & U \\
\hline & Mean & $5.42 \mathrm{E}+00$ & $9.95 \mathrm{E}+00$ & $1.18 \mathrm{E}+01$ & & 2.17E-01 & $1.09 E+00$ & $1.26 \mathrm{E}+00$ & & 3.19E-02 & $1.20 \mathrm{E}+00$ & $1.37 \mathrm{E}+00$ & \\
\hline \multicolumn{2}{|c|}{ Minimum $^{(\mathrm{e})}$} & $-4.09 E+00$ & 7.77E+00 & 8.27E+00 & & $-5.95 E-01$ & 1.47E+00 & $1.51 \mathrm{E}+00$ & & $-1.21 \mathrm{E}+00$ & $1.88 \mathrm{E}+00$ & $1.98 \mathrm{E}+00$ & \\
\hline \multicolumn{2}{|c|}{$\operatorname{Maximum}^{(\mathrm{e})}$} & $1.54 \mathrm{E}+01$ & $1.05 E+01$ & 1.36E+01 & & $1.69 \mathrm{E}+00$ & 1.37E+00 & $1.75 \mathrm{E}+00$ & & $1.64 \mathrm{E}+00$ & $1.54 \mathrm{E}+00$ & $1.84 \mathrm{E}+00$ & \\
\hline WAB & 1 & $-1.24 \mathrm{E}+00$ & $7.51 \mathrm{E}+00$ & 8.36E+00 & U & $-2.46 \mathrm{E}-01$ & 7.72E-01 & 8.44E-01 & $U$ & -2.04E-01 & 7.63E-01 & 8.26E-01 & U \\
\hline \multirow[t]{2}{*}{ (Blank) } & 2 & $3.08 \mathrm{E}+00$ & $8.84 \mathrm{E}+00$ & $1.06 \mathrm{E}+01$ & $U$ & 5.31E-02 & 9.50E-01 & $1.11 \mathrm{E}+00$ & U & -3.96E-01 & $9.56 \mathrm{E}-01$ & $1.07 \mathrm{E}+00$ & U \\
\hline & 3 & $3.88 \mathrm{E}+00$ & $1.20 \mathrm{E}+01$ & $1.46 \mathrm{E}+01$ & $U$ & -8.64E-01 & $1.45 \mathrm{E}+00$ & $1.42 \mathrm{E}+00$ & $U$ & $-9.72 \mathrm{E}-01$ & $1.64 \mathrm{E}+00$ & $1.77 \mathrm{E}+00$ & U \\
\hline
\end{tabular}

(a) Radionuclide activity of the primary sample. Only radionuclides with activities greater than $2 \sigma$ TPU and MDC are considered detections.

(b) 2 times the Total Propagated Uncertainty.

(c) Minimum Detectable Concentration.

(d) Qualifier. Indicates whether radionuclide was detected. Plus (+) equals detected. $U$ equals undetected.

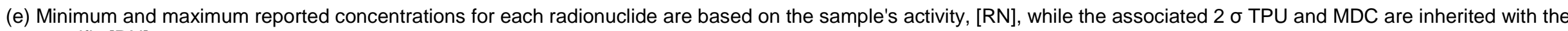
specific [RN]. 
Waste Isolation Pilot Plant Annual Site Environmental Report for 2010

DOE/WIPP-11-2225

Appendix G - Air Sampling Data: Concentrations of Radionuclides in Air Filter Composites

Table G.1 - 2010 Radionuclide Concentrations (Bq/sample) in Quarterly Composite Air Filters Collected from Locations Surrounding the WIPP Site

See Appendix C for sampling location codes

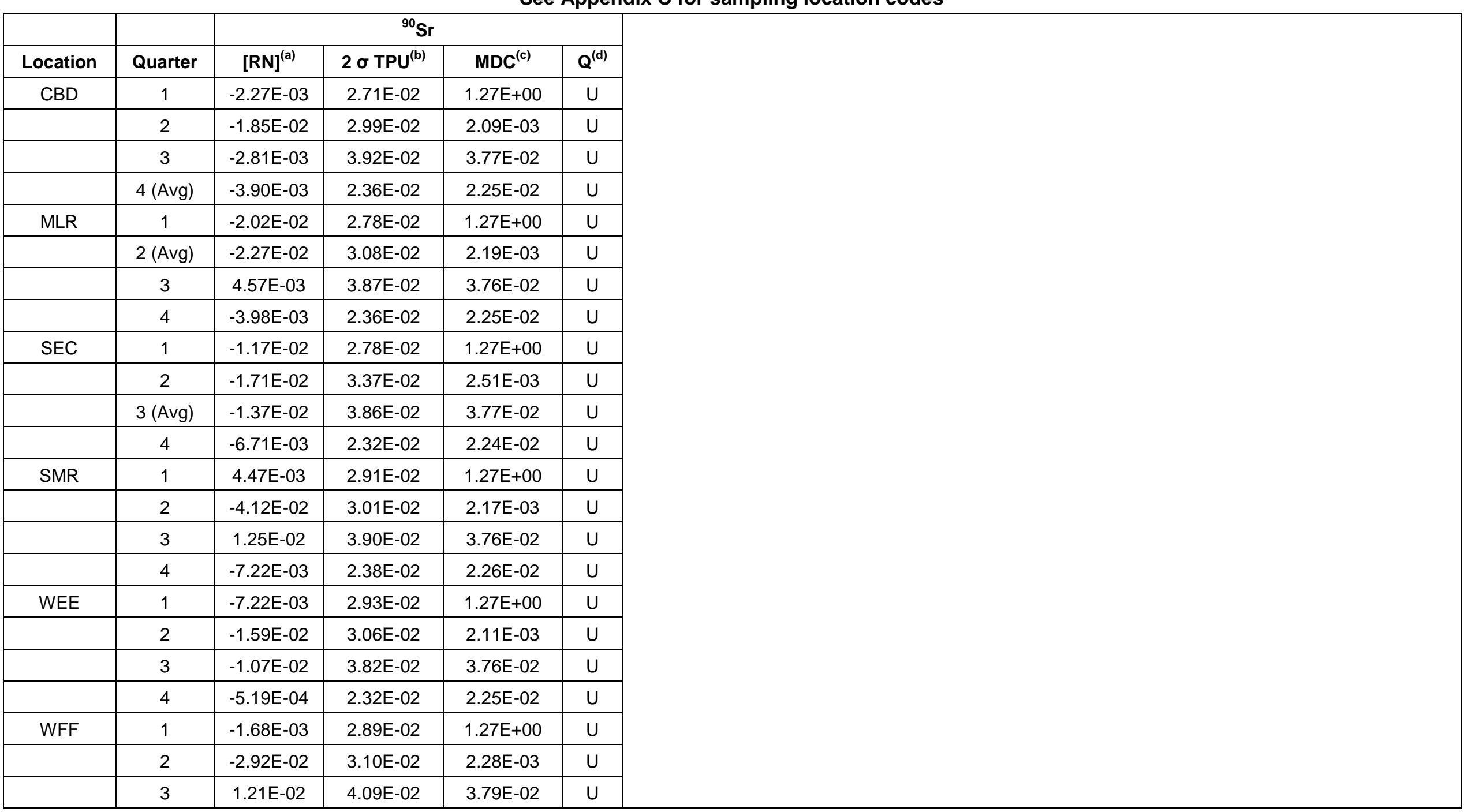


Waste Isolation Pilot Plant Annual Site Environmental Report for 2010

DOE/WIPP-11-2225

Appendix G - Air Sampling Data: Concentrations of Radionuclides in Air Filter Composites

Table G.1 - 2010 Radionuclide Concentrations (Bq/sample) in Quarterly Composite Air Filters Collected from Locations Surrounding the WIPP Site

See Appendix C for sampling location codes

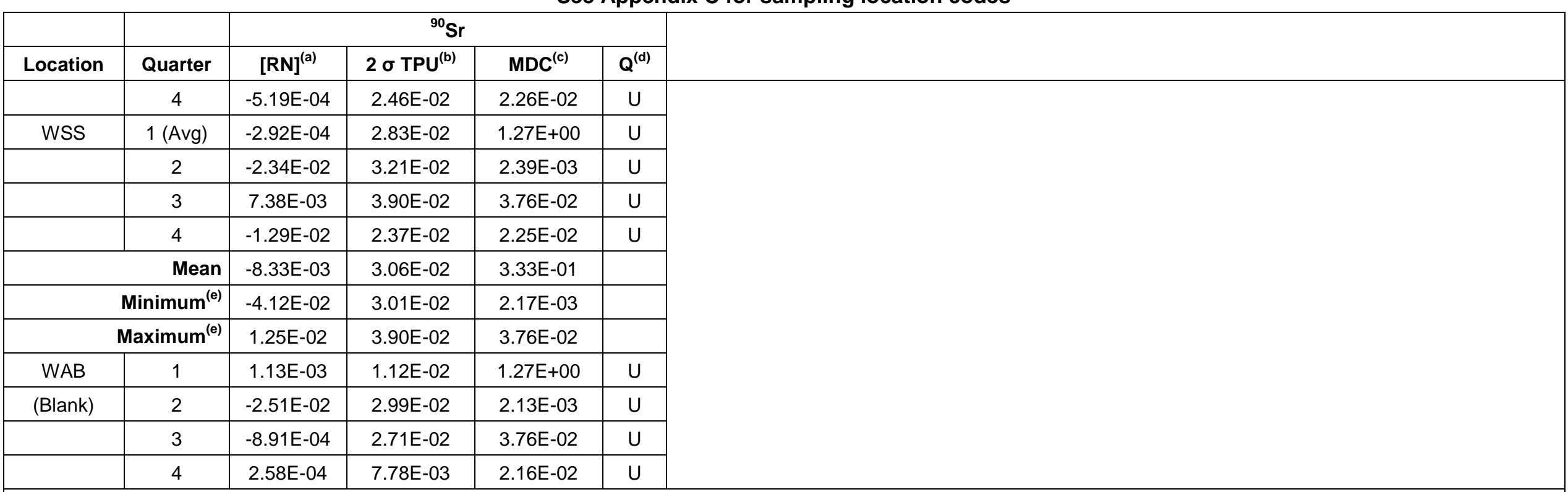

(a) Radionuclide activity of the primary sample. Only radionuclides with activities greater than $2 \sigma$ TPU and MDC are considered detections

(b) 2 times the Total Propagated Uncertainty.

(c) Minimum Detectable Concentration.

(d) Qualifier. Indicates whether radionuclide was detected. Plus (+) equals detected. $U$ equals undetected.

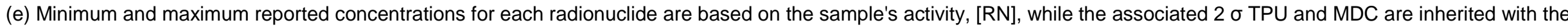
specific [RN]. 
Waste Isolation Pilot Plant Annual Site Environmental Report for 2010

DOE/WIPP-11-2225

Appendix G - Air Sampling Data: Concentrations of Radionuclides in Air Filter Composites

Table G.2 - 2010 Radionuclide Concentrations (Bq/m3) in Quarterly Composite Air Filters Collected from Locations Surrounding the WIPP Site

See Appendix $\mathrm{C}$ for sampling location codes

\begin{tabular}{|c|c|c|c|c|c|c|c|c|c|c|c|c|}
\hline \multirow[b]{2}{*}{ Location } & \multirow[b]{2}{*}{ Quarter } & \multirow[b]{2}{*}{ Vol, $\mathrm{m}^{3}$} & \multicolumn{2}{|c|}{${ }^{233 / 234} \mathrm{U}$} & \multicolumn{2}{|c|}{${ }^{235} U$} & \multicolumn{2}{|c|}{${ }^{238} \mathrm{U}$} & \multicolumn{2}{|c|}{${ }^{241} \mathrm{Am}$} & \multicolumn{2}{|c|}{${ }^{238} \mathrm{Pu}$} \\
\hline & & & Bq/sample & $\mathrm{Bq} / \mathrm{m}^{3}$ & Bq/sample & $\mathrm{Bq} / \mathrm{m}^{3}$ & Bq/sample & $\mathrm{Bq} / \mathrm{m}^{3}$ & Bq/sample & $\mathrm{Bq} / \mathrm{m}^{3}$ & Bq/sample & $\mathrm{Bq} / \mathrm{m}^{3}$ \\
\hline \multirow[t]{3}{*}{ CBD } & 1 & 7374.867 & 4.59E-03 & $6.22 \mathrm{E}-07$ & 6.81E-04 & 9.23E-08 & 4.56E-03 & $6.18 \mathrm{E}-07$ & $-2.81 \mathrm{E}-04$ & $-3.81 E-08$ & 2.54E-04 & $3.45 E-08$ \\
\hline & 3 & 7554.648 & 8.60E-04 & 1.14E-07 & $-5.01 E-04$ & $-6.63 E-08$ & 1.75E-03 & 2.32E-07 & 4.47E-06 & 5.92E-10 & $-1.82 \mathrm{E}-04$ & $-2.41 E-08$ \\
\hline & 4 (Avg) & 7356.492 & 6.39E-03 & 8.68E-07 & $5.82 \mathrm{E}-04$ & 7.91E-08 & 3.73E-03 & 5.07E-07 & $1.05 \mathrm{E}-05$ & $1.42 \mathrm{E}-09$ & 8.10E-05 & 1.10E-08 \\
\hline \multirow{3}{*}{ MLR } & $2(\mathrm{Avg})$ & 7297.768 & 8.46E-03 & 1.16E-06 & 3.09E-04 & 4.23E-08 & 9.65E-03 & $1.32 \mathrm{E}-06$ & 2.37E-04 & 3.24E-08 & $-7.33 E-05$ & $-1.00 \mathrm{E}-08$ \\
\hline & 3 & 7467.788 & 8.74E-04 & 1.17E-07 & $-6.24 \mathrm{E}-05$ & $-8.35 E-09$ & $1.76 \mathrm{E}-03$ & $2.36 \mathrm{E}-07$ & $-3.21 E-04$ & $-4.30 \mathrm{E}-08$ & 8.70E-05 & 1.17E-08 \\
\hline & 4 & 7437.313 & 8.11E-03 & 1.09E-06 & 4.35E-05 & 5.85E-09 & 3.68E-03 & 4.95E-07 & $-2.97 \mathrm{E}-04$ & $-4.00 \mathrm{E}-08$ & $-1.87 \mathrm{E}-04$ & $-2.51 E-08$ \\
\hline \multirow[t]{3}{*}{ SEC } & 1 & 7433.113 & $-1.08 E-03$ & $-1.45 E-07$ & $-1.80 \mathrm{E}-04$ & $-2.42 \mathrm{E}-08$ & $-5.43 E-04$ & $-7.30 \mathrm{E}-08$ & $-1.66 \mathrm{E}-04$ & $-2.23 E-08$ & 5.05E-04 & $6.80 \mathrm{E}-08$ \\
\hline & 2 & 7396.245 & 7.09E-03 & $9.58 \mathrm{E}-07$ & $-4.38 \mathrm{E}-05$ & $-5.93 E-09$ & 7.07E-03 & 9.56E-07 & 8.15E-04 & 1.10E-07 & 6.52E-05 & 8.82E-09 \\
\hline & 3 (Avg) & 7500.109 & $2.61 \mathrm{E}-03$ & $3.48 \mathrm{E}-07$ & 8.76E-05 & 1.17E-08 & 5.00E-04 & 6.67E-08 & 2.16E-05 & 2.88E-09 & 1.37E-06 & $1.82 \mathrm{E}-10$ \\
\hline \multirow[t]{4}{*}{ SMR } & 1 & 7392.841 & $-1.63 E-04$ & $-2.20 \mathrm{E}-08$ & $-6.46 \mathrm{E}-04$ & -8.73E-08 & $-1.40 \mathrm{E}-03$ & $-1.89 \mathrm{E}-07$ & $-1.48 \mathrm{E}-04$ & $-2.00 \mathrm{E}-08$ & $-2.78 \mathrm{E}-04$ & $-3.76 \mathrm{E}-08$ \\
\hline & 2 & 7235.184 & 7.88E-03 & 1.09E-06 & $5.74 \mathrm{E}-04$ & 7.93E-08 & 6.23E-03 & 8.61E-07 & $1.28 \mathrm{E}-04$ & 1.76E-08 & $0.00 \mathrm{E}+00$ & $0.00 \mathrm{E}+00$ \\
\hline & 3 & 7369.855 & 1.86E-03 & 2.52E-07 & $1.22 \mathrm{E}-04$ & 1.65E-08 & 1.53E-03 & 2.07E-07 & 1.03E-04 & $1.40 \mathrm{E}-08$ & 3.04E-04 & $4.12 \mathrm{E}-08$ \\
\hline & 4 & 7337.119 & 7.34E-03 & 1.00E-06 & 4.22E-04 & 5.76E-08 & 4.40E-03 & 5.99E-07 & $2.72 \mathrm{E}-04$ & 3.71E-08 & $-1.34 \mathrm{E}-05$ & $-1.83 E-09$ \\
\hline \multirow[t]{4}{*}{ WEE } & 1 & 7452.658 & $-9.62 E-04$ & $-1.29 E-07$ & 1.99E-05 & 2.66E-09 & 4.98E-05 & 6.68E-09 & $-1.30 \mathrm{E}-04$ & $-1.75 E-08$ & $1.04 \mathrm{E}-04$ & $1.40 \mathrm{E}-08$ \\
\hline & 2 & 7381.084 & 7.87E-03 & 1.07E-06 & 9.27E-04 & $1.26 \mathrm{E}-07$ & 6.71E-03 & 9.09E-07 & 2.73E-04 & 3.70E-08 & 5.35E-04 & 7.25E-08 \\
\hline & 3 & 7515.610 & $-1.28 \mathrm{E}-04$ & $-1.70 \mathrm{E}-08$ & $-2.98 \mathrm{E}-04$ & -3.96E-08 & -1.93E-03 & $-2.57 \mathrm{E}-07$ & 2.11E-04 & 2.81E-08 & $1.52 \mathrm{E}-04$ & 2.03E-08 \\
\hline & 4 & 7398.778 & 4.65E-03 & 6.29E-07 & 2.53E-04 & 3.41E-08 & 3.92E-03 & 5.30E-07 & 4.62E-04 & 6.24E-08 & $-3.80 E-04$ & $-5.13 E-08$ \\
\hline \multirow[t]{3}{*}{ WFF } & 1 & 7180.753 & -1.87E-03 & $-2.61 \mathrm{E}-07$ & -1.06E-04 & -1.48E-08 & $-1.33 \mathrm{E}-03$ & $-1.85 E-07$ & 5.53E-04 & 7.70E-08 & 2.39E-04 & 3.33E-08 \\
\hline & 2 & 7282.215 & 5.03E-03 & 6.91E-07 & $2.40 \mathrm{E}-04$ & 3.29E-08 & 5.54E-03 & 7.61E-07 & $-3.39 E-05$ & $-4.66 \mathrm{E}-09$ & $-8.46 \mathrm{E}-06$ & $-1.16 \mathrm{E}-09$ \\
\hline & 3 & 7450.820 & 7.80E-04 & $1.05 \mathrm{E}-07$ & -1.96E-05 & $-2.64 \mathrm{E}-09$ & $-4.07 \mathrm{E}-04$ & -5.47E-08 & 8.43E-05 & 1.13E-08 & $-3.48 \mathrm{E}-04$ & $-4.67 E-08$ \\
\hline
\end{tabular}


Waste Isolation Pilot Plant Annual Site Environmental Report for 2010

DOE/WIPP-11-2225

Appendix G - Air Sampling Data: Concentrations of Radionuclides in Air Filter Composites

Table G.2 - 2010 Radionuclide Concentrations (Bq/m3) in Quarterly Composite Air Filters Collected from Locations Surrounding the WIPP Site

See Appendix C for sampling location codes

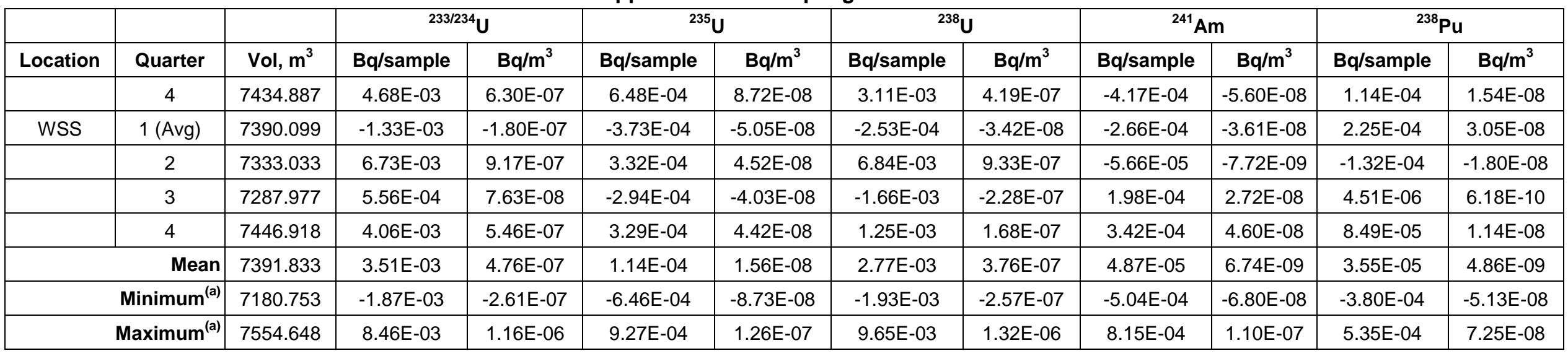

Table G.2 - 2010 Radionuclide Concentrations (Bq/m3) in Quarterly Composite Air Filters Collected from Locations Surrounding the WIPP Site

See Appendix C for sampling location codes

\begin{tabular}{|c|c|c|c|c|c|c|c|c|c|c|c|c|}
\hline \multirow[b]{2}{*}{ Location } & \multirow[b]{2}{*}{ Quarter } & \multirow[b]{2}{*}{ Vol, $\mathrm{m}^{3}$} & \multicolumn{2}{|c|}{${ }^{239 / 240} \mathrm{Pu}$} & \multicolumn{2}{|c|}{${ }^{90} \mathrm{Sr}$} & \multicolumn{2}{|c|}{${ }^{40} \mathrm{~K}$} & \multicolumn{2}{|c|}{${ }^{60} \mathrm{Co}$} & \multicolumn{2}{|c|}{${ }^{137} \mathrm{Cs}$} \\
\hline & & & Bq/sample & $\mathrm{Bq} / \mathrm{m}^{3}$ & Bq/sample & $\mathrm{Bq} / \mathrm{m}^{3}$ & Bq/sample & $\mathrm{Bq} / \mathrm{m}^{3}$ & Bq/sample & $\mathrm{Bq} / \mathrm{m}^{3}$ & Bq/sample & $\mathrm{Bq} / \mathrm{m}^{3}$ \\
\hline \multirow[t]{3}{*}{ CBD } & 1 & 7374.867 & $-1.41 \mathrm{E}-04$ & $-1.92 \mathrm{E}-08$ & $-2.27 \mathrm{E}-03$ & $-3.08 E-07$ & $7.42 \mathrm{E}+00$ & 1.01E-03 & 8.16E-03 & 1.11E-06 & 2.50E-01 & 3.39E-05 \\
\hline & 3 & 7554.648 & $-1.00 \mathrm{E}-04$ & -1.33E-08 & $-2.81 E-03$ & $-3.72 \mathrm{E}-07$ & $9.26 \mathrm{E}+00$ & 1.23E-03 & 1.11E-01 & 1.47E-05 & $-1.18 E-01$ & $-1.56 E-05$ \\
\hline & $4(\mathrm{Avg})$ & 7356.492 & $-1.28 E-04$ & $-1.74 \mathrm{E}-08$ & $-3.90 E-03$ & $-5.30 E-07$ & $7.13 E+00$ & 9.69E-04 & 4.14E-01 & 5.63E-05 & $-3.75 E-01$ & $-5.10 \mathrm{E}-05$ \\
\hline \multirow[t]{4}{*}{ MLR } & 1 & 7409.992 & $-5.39 \mathrm{E}-05$ & -7.28E-09 & $-2.02 \mathrm{E}-02$ & $-2.72 \mathrm{E}-06$ & $3.18 \mathrm{E}+00$ & 4.29E-04 & 3.43E-01 & 4.63E-05 & $-2.50 \mathrm{E}-02$ & $-3.38 \mathrm{E}-06$ \\
\hline & 2 (Avg) & 7297.768 & 6.97E-05 & 9.55E-09 & $-2.27 \mathrm{E}-02$ & $-3.12 E-06$ & $2.15 \mathrm{E}+00$ & 2.95E-04 & $-5.36 E-02$ & $-7.35 E-06$ & 1.32E-01 & $1.80 \mathrm{E}-05$ \\
\hline & 3 & 7467.788 & 1.03E-04 & 1.38E-08 & 4.57E-03 & $6.12 \mathrm{E}-07$ & $-2.58 E+00$ & $-3.46 \mathrm{E}-04$ & $-1.67 \mathrm{E}-01$ & $-2.24 \mathrm{E}-05$ & $-2.69 \mathrm{E}-01$ & $-3.60 \mathrm{E}-05$ \\
\hline & 4 & 7437.313 & 1.43E-04 & 1.93E-08 & $-3.98 E-03$ & $-5.35 E-07$ & $7.76 \mathrm{E}+00$ & 1.04E-03 & $1.50 \mathrm{E}-01$ & 2.02E-05 & 4.75E-01 & 6.38E-05 \\
\hline SEC & 1 & 7433.113 & $-9.57 E-05$ & $-1.29 E-08$ & $-1.17 \mathrm{E}-02$ & $-1.57 E-06$ & $6.00 \mathrm{E}+00$ & 8.07E-04 & $1.20 \mathrm{E}+00$ & 1.61E-04 & 4.80E-01 & $6.46 \mathrm{E}-05$ \\
\hline
\end{tabular}


Waste Isolation Pilot Plant Annual Site Environmental Report for 2010

DOE/WIPP-11-2225

Appendix G - Air Sampling Data: Concentrations of Radionuclides in Air Filter Composites

Table G.2 - 2010 Radionuclide Concentrations (Bq/m3) in Quarterly Composite Air Filters Collected from Locations Surrounding the WIPP Site

See Appendix C for sampling location codes

\begin{tabular}{|c|c|c|c|c|c|c|c|c|c|c|c|c|}
\hline \multirow[b]{2}{*}{ Location } & \multirow[b]{2}{*}{ Quarter } & \multirow[b]{2}{*}{ Vol, $\mathrm{m}^{3}$} & \multicolumn{2}{|c|}{${ }^{239 / 240} \mathrm{Pu}$} & \multicolumn{2}{|c|}{${ }^{90} \mathrm{Sr}$} & \multicolumn{2}{|c|}{${ }^{40} \mathrm{~K}$} & \multicolumn{2}{|c|}{${ }^{60} \mathrm{Co}$} & \multicolumn{2}{|c|}{${ }^{137} \mathrm{Cs}$} \\
\hline & & & Bq/sample & $\mathrm{Bq} / \mathrm{m}^{3}$ & Bq/sample & $\mathrm{Bq} / \mathrm{m}^{3}$ & Bq/sample & $\mathrm{Bq} / \mathrm{m}^{3}$ & Bq/sample & $\mathrm{Bq} / \mathrm{m}^{3}$ & Bq/sample & $\mathrm{Bq} / \mathrm{m}^{3}$ \\
\hline & 2 & 7396.245 & 1.05E-04 & $1.42 \mathrm{E}-08$ & $-1.71 \mathrm{E}-02$ & $-2.31 E-06$ & $1.12 \mathrm{E}+00$ & 1.51E-04 & 2.77E-01 & 3.75E-05 & 5.53E-01 & 7.48E-05 \\
\hline & 3 (Avg) & 7500.109 & $-5.74 \mathrm{E}-05$ & -7.66E-09 & $-1.37 \mathrm{E}-02$ & $-1.83 E-06$ & $1.14 \mathrm{E}+01$ & 1.53E-03 & $-5.61 \mathrm{E}-01$ & -7.47E-05 & $1.06 \mathrm{E}+00$ & 1.41E-04 \\
\hline & 4 & 7484.414 & 3.25E-05 & 4.34E-09 & $-6.71 E-03$ & -8.97E-07 & $1.19 \mathrm{E}+01$ & 1.59E-03 & 5.43E-01 & 7.26E-05 & 1.64E-01 & 2.19E-05 \\
\hline \multirow[t]{3}{*}{ SMR } & 1 & 7392.841 & $-1.74 \mathrm{E}-04$ & $-2.36 \mathrm{E}-08$ & 4.47E-03 & 6.04E-07 & $8.04 \mathrm{E}+00$ & 1.09E-03 & -3.81E-01 & $-5.15 E-05$ & $-2.90 \mathrm{E}-01$ & $-3.92 E-05$ \\
\hline & 3 & 7369.855 & -1.17E-04 & $-1.58 \mathrm{E}-08$ & $1.25 \mathrm{E}-02$ & 1.69E-06 & $3.64 \mathrm{E}+00$ & 4.94E-04 & 9.60E-01 & 1.30E-04 & $-8.72 \mathrm{E}-01$ & $-1.18 \mathrm{E}-04$ \\
\hline & 4 & 7337.119 & $-6.43 E-05$ & -8.76E-09 & $-7.22 \mathrm{E}-03$ & $-9.84 \mathrm{E}-07$ & $9.99 \mathrm{E}+00$ & 1.36E-03 & $-8.10 \mathrm{E}-02$ & $-1.10 \mathrm{E}-05$ & $-8.75 E-01$ & $-1.19 E-04$ \\
\hline \multirow[t]{4}{*}{ WEE } & 1 & 7452.658 & $1.44 \mathrm{E}-06$ & $1.93 E-10$ & $-7.22 \mathrm{E}-03$ & $-9.69 \mathrm{E}-07$ & $-2.55 E+00$ & $-3.43 E-04$ & 5.03E-01 & 6.75E-05 & -7.96E-02 & -1.07E-05 \\
\hline & 2 & 7381.084 & $3.68 \mathrm{E}-05$ & 4.99E-09 & $-1.59 \mathrm{E}-02$ & $-2.15 E-06$ & $1.72 \mathrm{E}+00$ & 2.33E-04 & $1.69 \mathrm{E}+00$ & 2.29E-04 & $-1.21 E+00$ & $-1.64 \mathrm{E}-04$ \\
\hline & 3 & 7515.610 & $-1.15 E-04$ & $-1.54 \mathrm{E}-08$ & -1.07E-02 & $-1.42 \mathrm{E}-06$ & $1.54 \mathrm{E}+01$ & $2.05 E-03$ & -1.67E-01 & $-2.22 \mathrm{E}-05$ & $-1.12 \mathrm{E}-01$ & $-1.49 E-05$ \\
\hline & 4 & 7398.778 & 6.29E-05 & 8.51E-09 & -5.19E-04 & -7.02E-08 & $8.40 \mathrm{E}+00$ & 1.14E-03 & 7.41E-01 & 1.00E-04 & -8.71E-01 & $-1.18 \mathrm{E}-04$ \\
\hline \multirow{3}{*}{ WFF } & 2 & 7282.215 & $1.26 \mathrm{E}-04$ & 1.73E-08 & $-2.92 \mathrm{E}-02$ & $-4.01 \mathrm{E}-06$ & $-4.09 E+00$ & $-5.61 E-04$ & 2.38E-01 & $3.26 \mathrm{E}-05$ & $6.12 \mathrm{E}-01$ & 8.41E-05 \\
\hline & 3 & 7450.820 & $-5.40 \mathrm{E}-05$ & -7.25E-09 & $1.21 \mathrm{E}-02$ & 1.63E-06 & $-2.89 E+00$ & -3.88E-04 & $-2.15 E-01$ & $-2.89 \mathrm{E}-05$ & 4.84E-02 & $6.50 \mathrm{E}-06$ \\
\hline & 4 & 7434.887 & 8.48E-05 & 1.14E-08 & $-5.19 E-04$ & -6.99E-08 & $4.27 \mathrm{E}+00$ & $5.75 \mathrm{E}-04$ & 5.20E-01 & 6.99E-05 & 6.80E-01 & 9.14E-05 \\
\hline \multirow[t]{4}{*}{ WSS } & 1 (Avg) & 7390.099 & $-1.24 \mathrm{E}-04$ & $-1.68 \mathrm{E}-08$ & $-2.92 \mathrm{E}-04$ & -3.96E-08 & $2.48 \mathrm{E}+00$ & 3.36E-04 & 4.31E-01 & 5.83E-05 & -3.43E-01 & $-4.64 \mathrm{E}-05$ \\
\hline & 2 & 7333.033 & 1.36E-05 & 1.85E-09 & $-2.34 \mathrm{E}-02$ & $-3.19 \mathrm{E}-06$ & $1.47 \mathrm{E}+01$ & 2.01E-03 & -1.30E-01 & -1.77E-05 & $1.64 \mathrm{E}+00$ & 2.24E-04 \\
\hline & 3 & 7287.977 & 1.69E-04 & 2.31E-08 & 7.38E-03 & 1.01E-06 & $2.70 \mathrm{E}+00$ & 3.70E-04 & $1.20 \mathrm{E}-01$ & 1.65E-05 & 9.04E-01 & $1.24 \mathrm{E}-04$ \\
\hline & 4 & 7446.918 & $-9.84 \mathrm{E}-05$ & $-1.32 \mathrm{E}-08$ & $-1.29 E-02$ & -1.73E-06 & $8.33 \mathrm{E}+00$ & 1.12E-03 & $-3.42 \mathrm{E}-01$ & $-4.60 \mathrm{E}-05$ & 1.24E-01 & $1.66 \mathrm{E}-05$ \\
\hline & Mean & 7391.833 & -2.93E-06 & $-3.20 E-10$ & -8.33E-03 & -1.13E-06 & $5.42 \mathrm{E}+00$ & 7.34E-04 & 2.17E-01 & 2.94E-05 & 3.19E-02 & 4.32E-06 \\
\hline & Minimum $^{(a)}$ & 7180.753 & $-1.74 \mathrm{E}-04$ & $-2.36 \mathrm{E}-08$ & $-4.12 \mathrm{E}-02$ & $-5.74 \mathrm{E}-06$ & $-4.09 E+00$ & -5.69E-04 & -5.95E-01 & $-8.29 \mathrm{E}-05$ & $-1.21 E+00$ & $-1.69 \mathrm{E}-04$ \\
\hline & Maximum $^{(a)}$ & 7554.648 & 3.13E-04 & 4.32E-08 & $1.25 \mathrm{E}-02$ & $1.65 \mathrm{E}-06$ & $1.54 \mathrm{E}+01$ & 2.04E-03 & $1.69 \mathrm{E}+00$ & $2.24 \mathrm{E}-04$ & $1.64 \mathrm{E}+00$ & 2.17E-04 \\
\hline
\end{tabular}


Waste Isolation Pilot Plant Annual Site Environmental Report for 2010 DOE/WIPP-11-2225

This page intentionally left blank 
Appendix $\mathrm{H}$ - Comparison of Detected Radionuclides to the Radiological Baseline

The figures in this appendix show the highest detected radionuclides from 2010 environmental monitoring sample analysis results compared to the 99 percent confidence interval radiological baseline values established for these isotopes (DOE/WIPP-92-037). Figures address air filter composite, groundwater, surface water, sediment, soil, and vegetation results. Note: all results with the exception of vegetation were compared to the baseline upper 99 percentile probability value. The baseline did not include probability distributions for vegetation; therefore, vegetation sample results are compared to the baseline mean values. A detailed discussion of environmental monitoring radionuclide sample results is presented in Chapter 4.
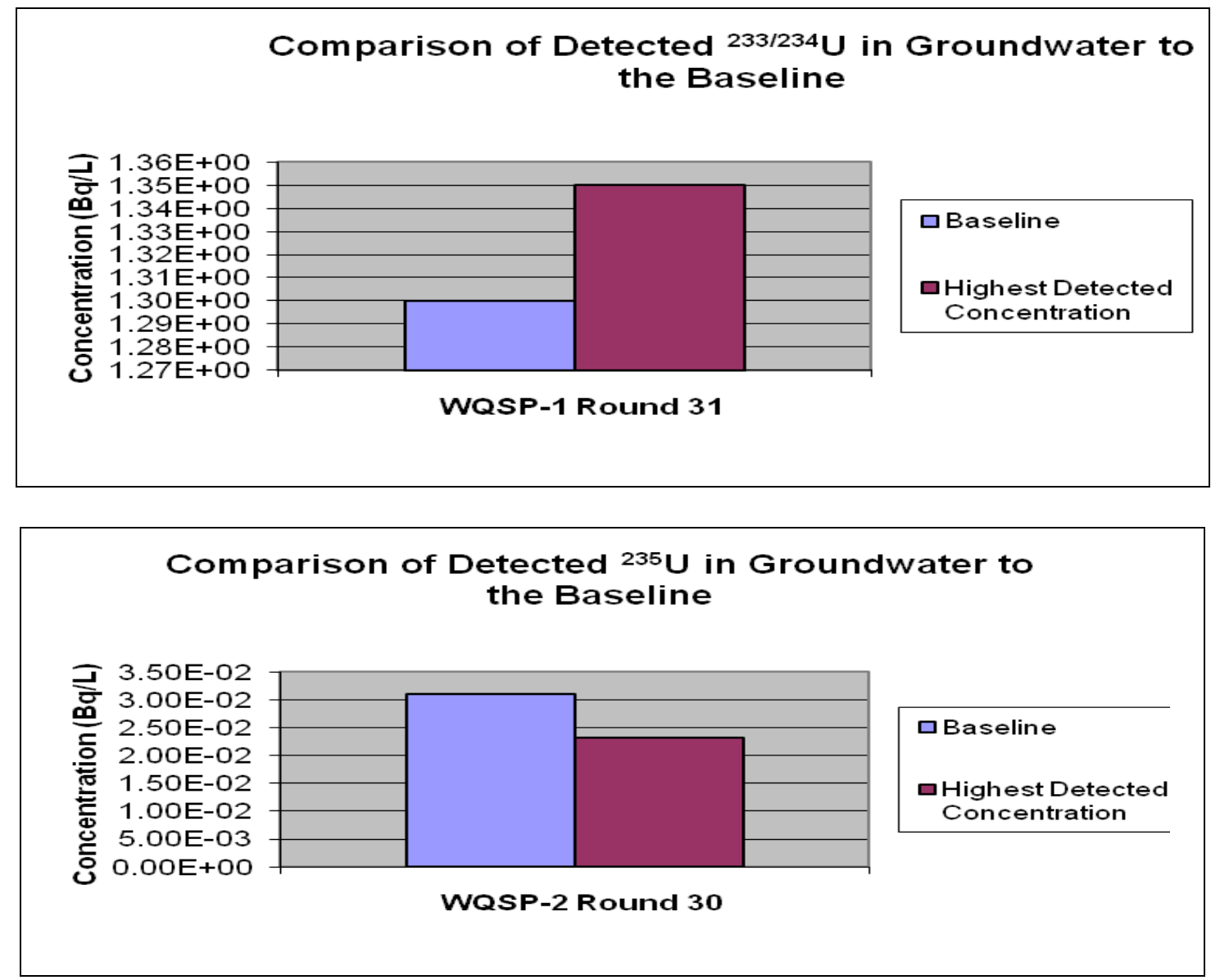
Appendix $\mathrm{H}$ - Comparison of Detected Radionuclides to the Radiological Baseline
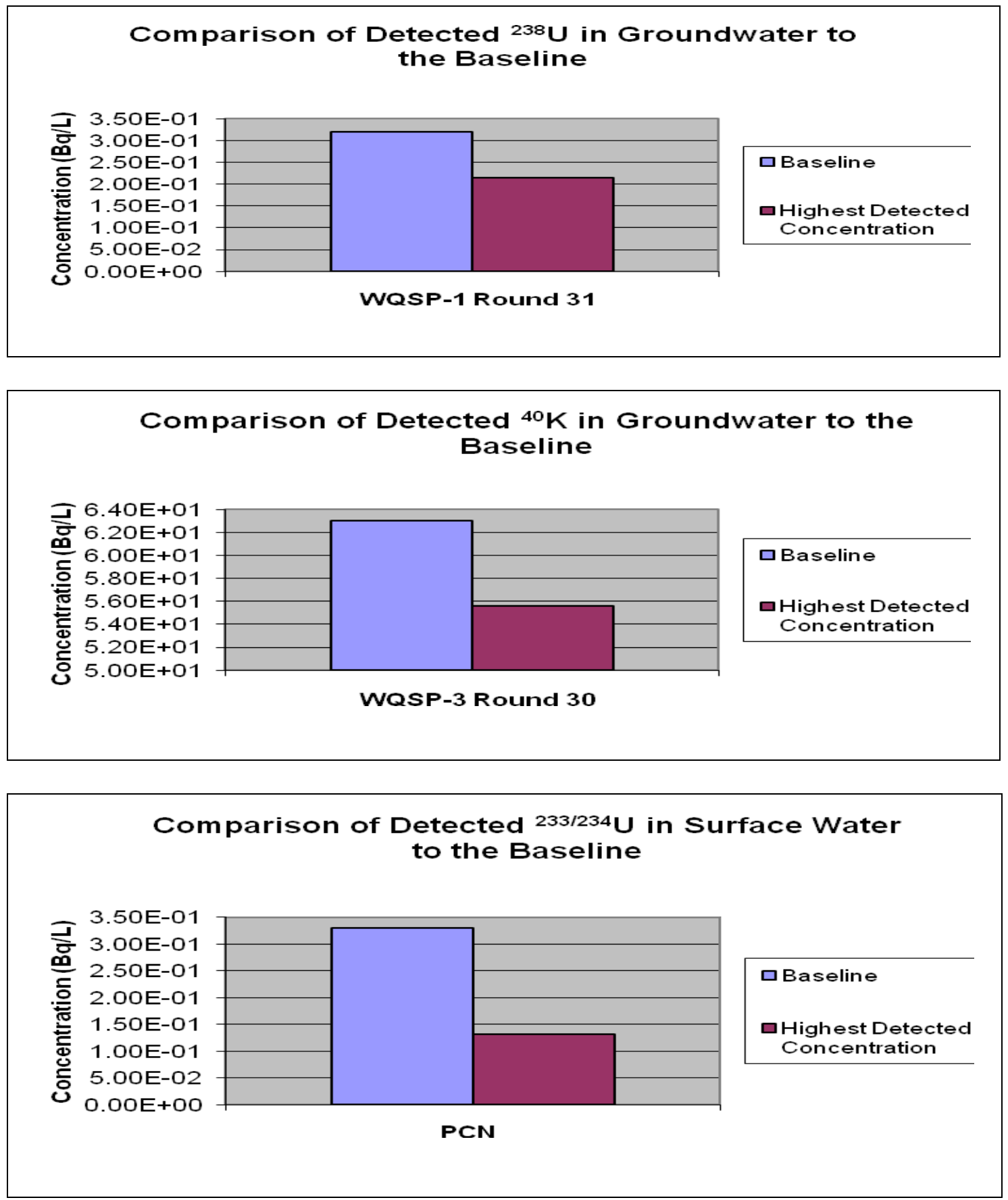
Appendix $\mathrm{H}$ - Comparison of Detected Radionuclides to the Radiological Baseline
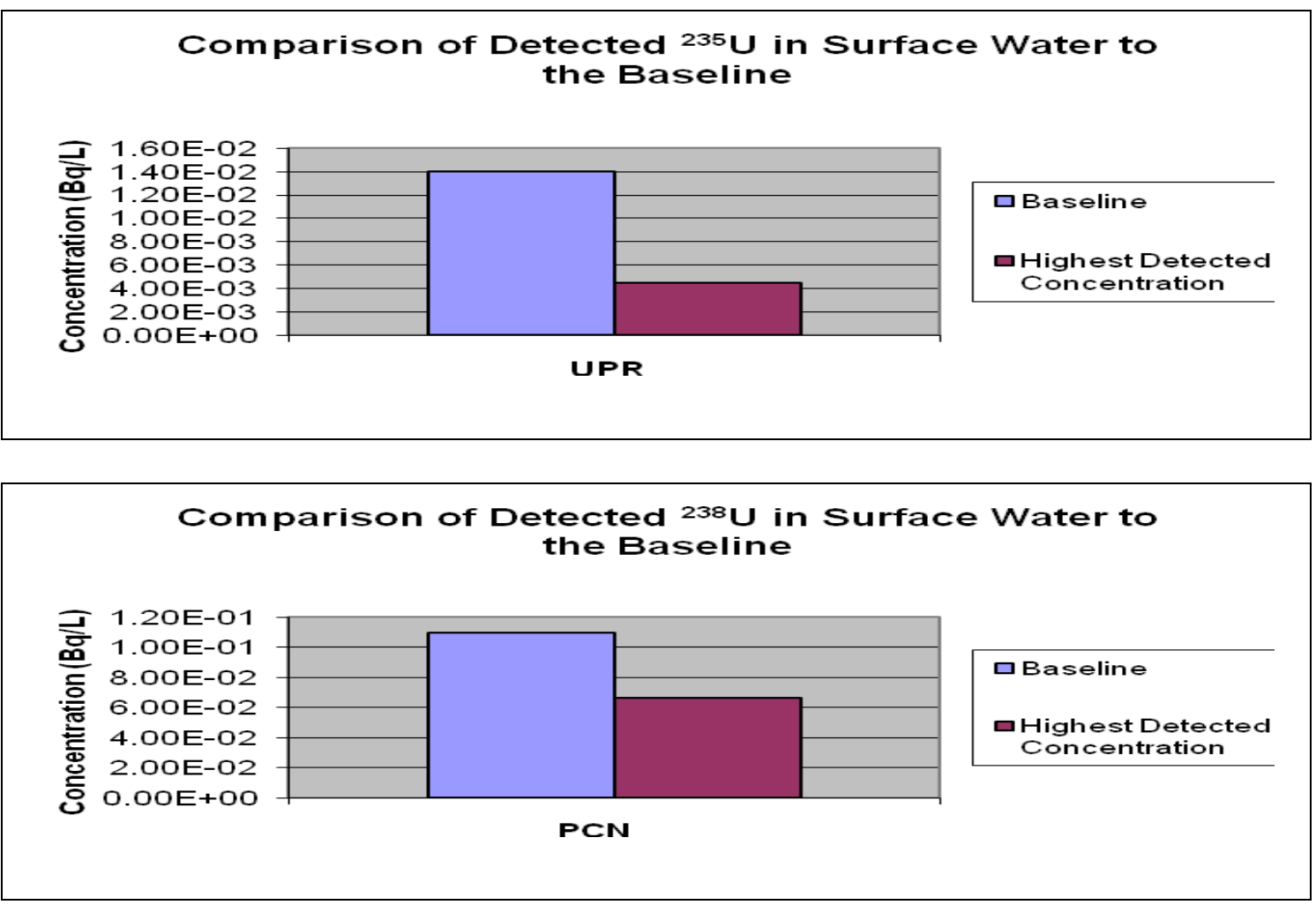

\section{Comparison of Detected ${ }^{40} \mathrm{~K}$ in Surface Water to the Baseline}
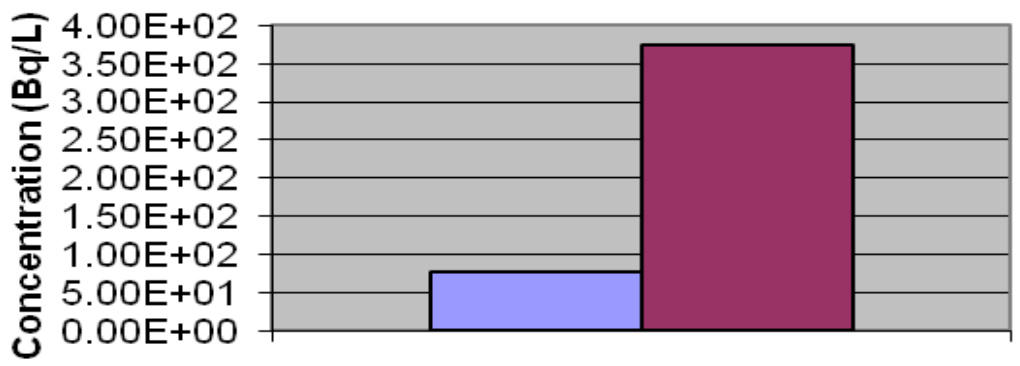

$\square$ Baseline

口Highest Detected Concentration

SWL 
Appendix $\mathrm{H}$ - Comparison of Detected Radionuclides to the Radiological Baseline
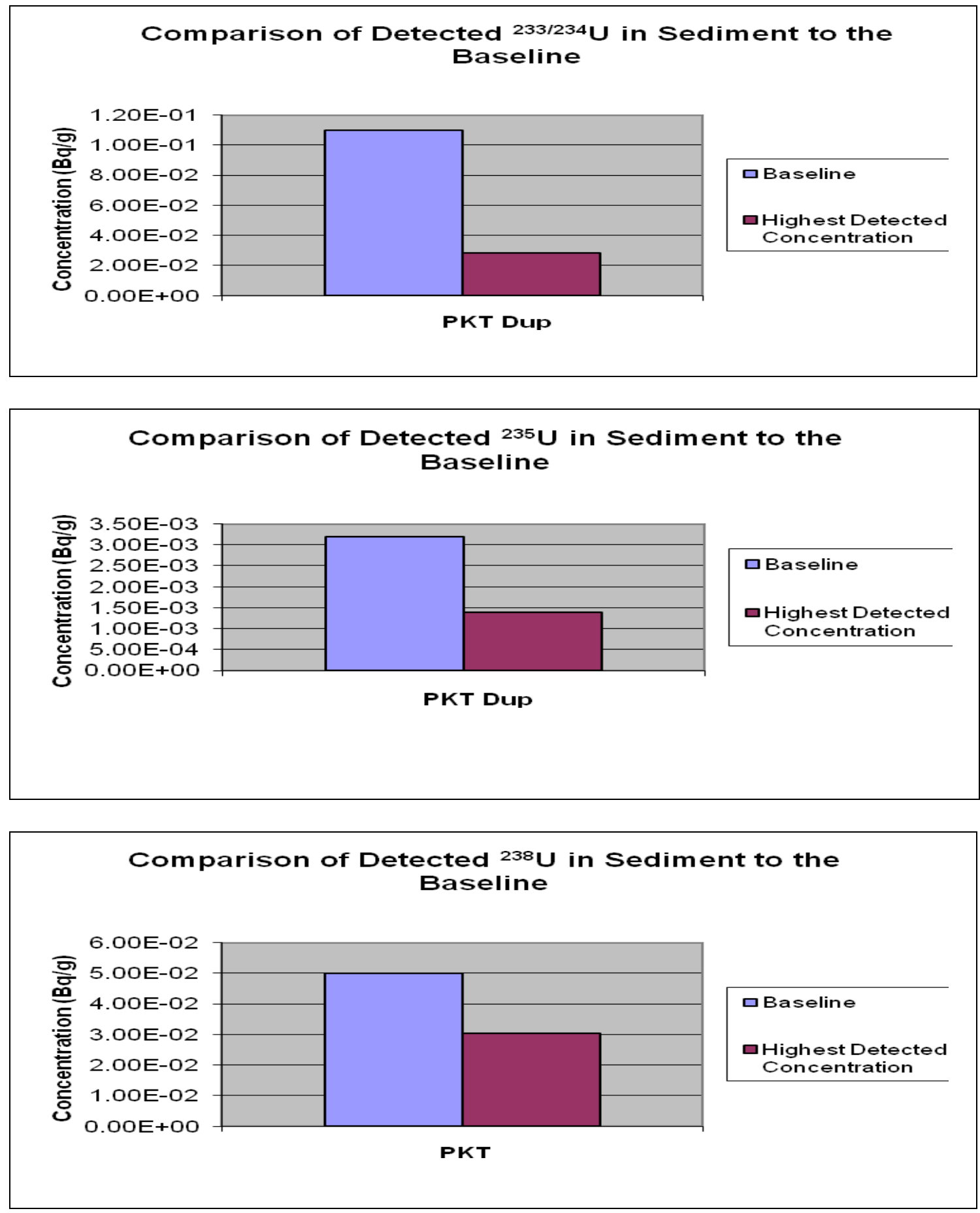
Appendix $\mathrm{H}$ - Comparison of Detected Radionuclides to the Radiological Baseline

\section{Comparison of Detected ${ }^{137} \mathrm{Cs}$ in Sediment to the Baseline}

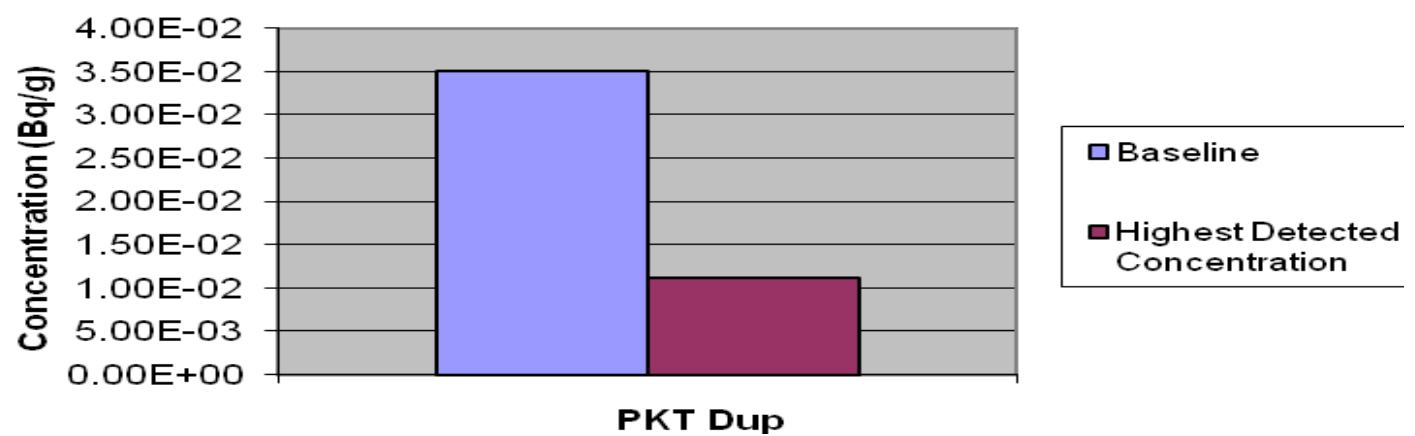

Comparison of Detected ${ }^{40} \mathrm{~K}$ in Sediment to the Baseline
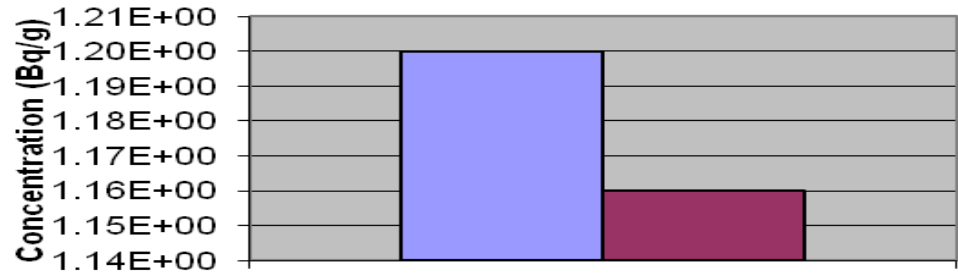

ㅁ Baseline

口Highest Detected Concentration

HIL

\section{Comparison of Detected $239 / 240 \mathrm{Pu}$ in Sediment to the}

Baseline
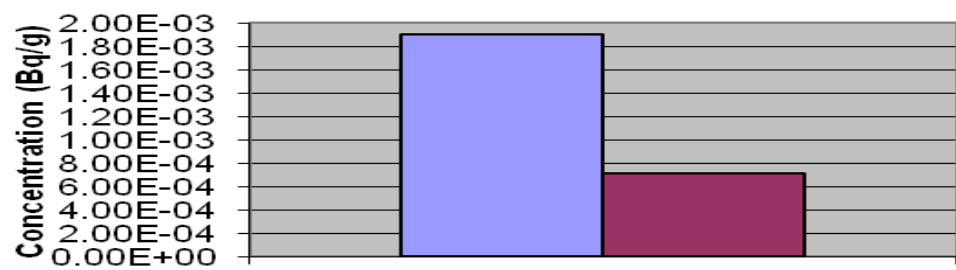

ㅁ Baseline

- Highest Detected Concentration

PKT 
Appendix $\mathrm{H}$ - Comparison of Detected Radionuclides to the Radiological Baseline
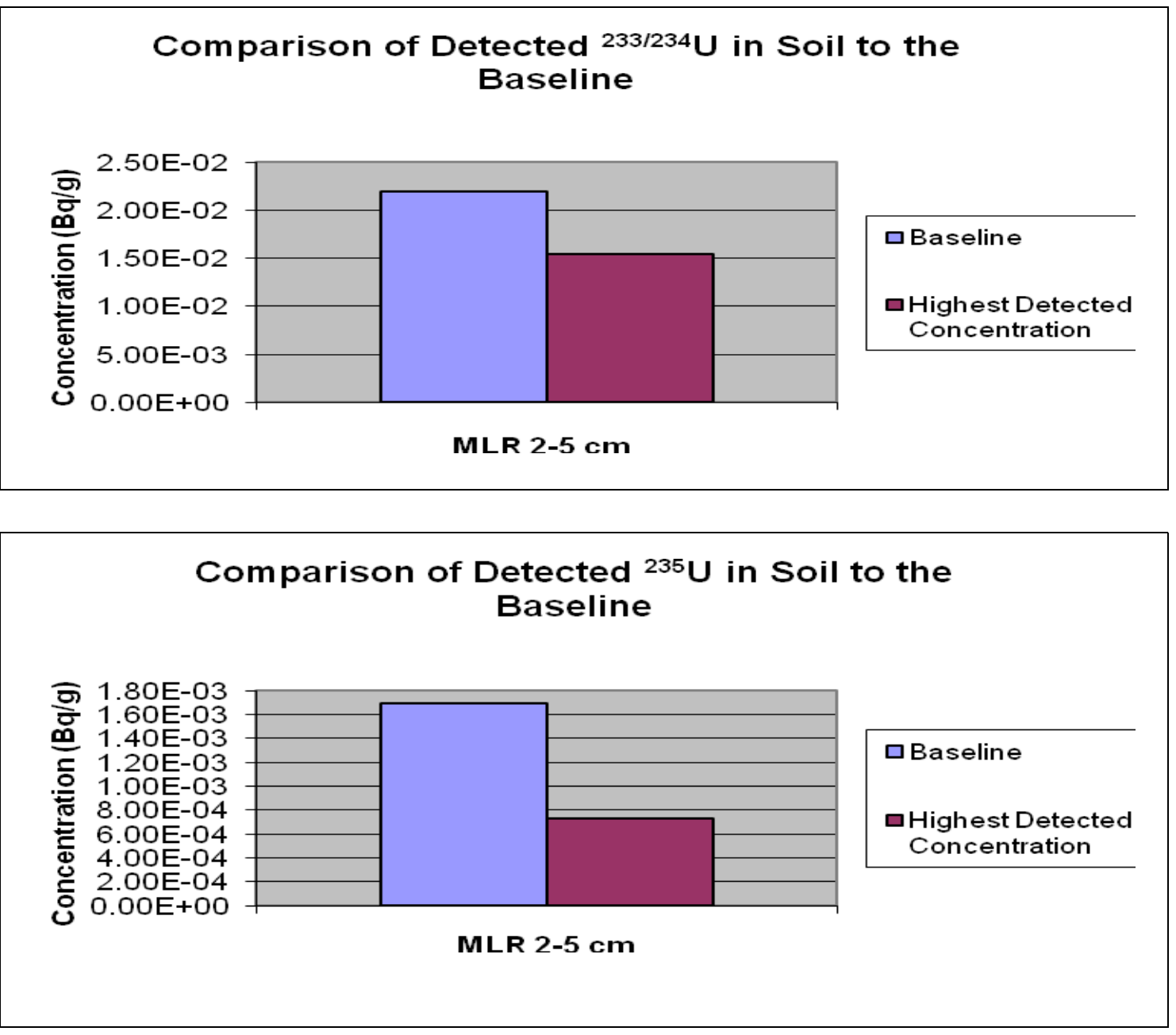

\section{Comparison of Detected ${ }^{238} \mathrm{U}$ in Soil to the Baseline}
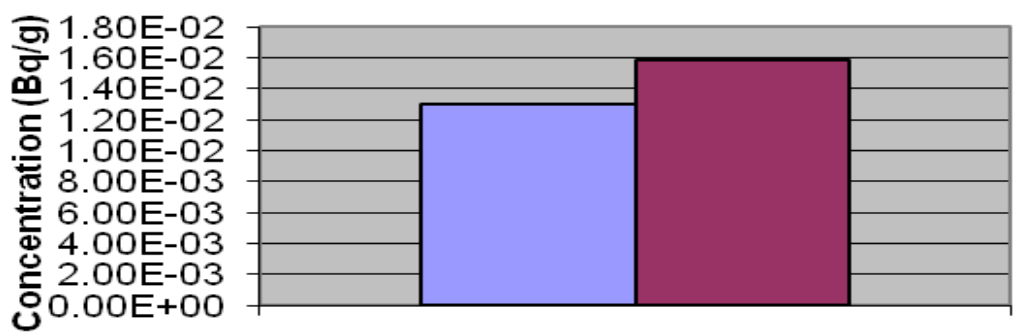

$\square$ Baseline

- Highest Detected Concentration

MLR 5-10 cm 
Appendix $\mathrm{H}$ - Comparison of Detected Radionuclides to the Radiological Baseline

\section{Comparison of Detected ${ }^{137} \mathrm{Cs}$ in Soil to the Baseline}

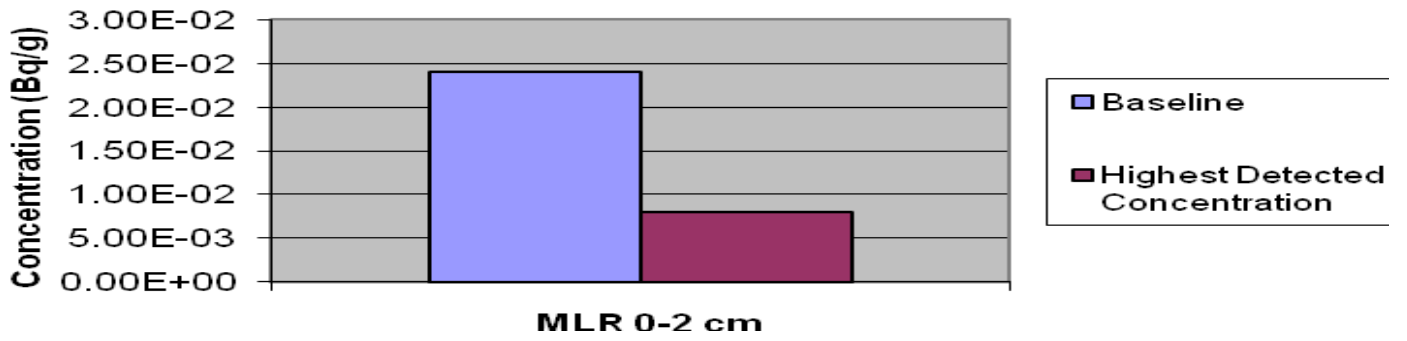

Comparison of Detected ${ }^{40} \mathrm{~K}$ in Soil to the Baseline
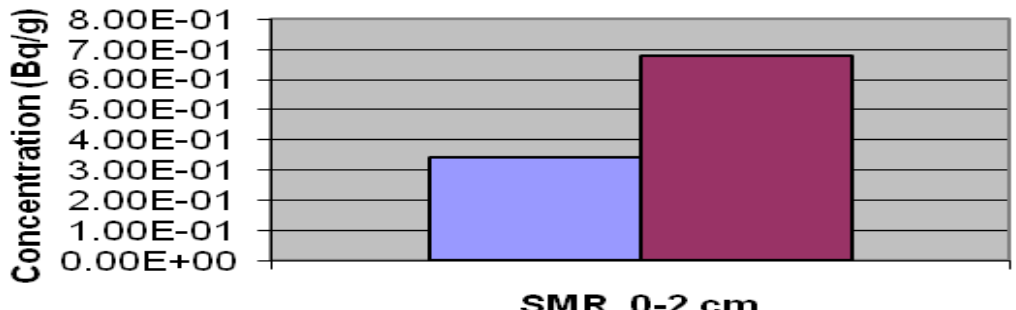

口 Baseline

$\square$ Highest Detected Concentration

SMR 0-2 cm

\section{Comparison of Detected $239 / 240 \mathrm{Pu}$ in Soil to the} Baseline
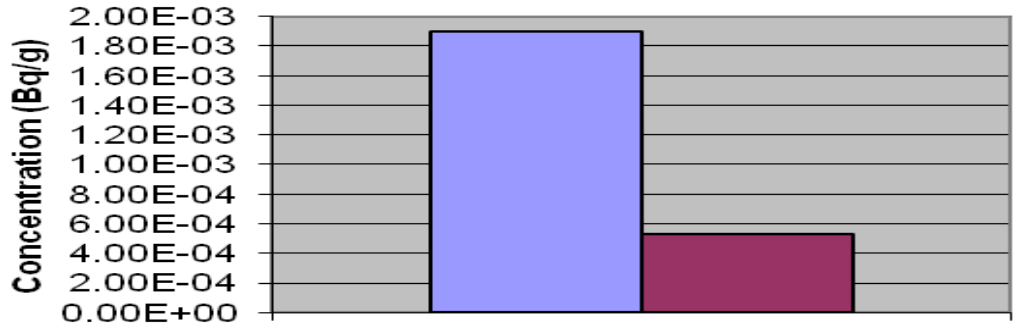

ㅁ Baseline

- Highest Detected Concentration

MLR 0-2 cm 
Appendix $\mathrm{H}$ - Comparison of Detected Radionuclides to the Radiological Baseline

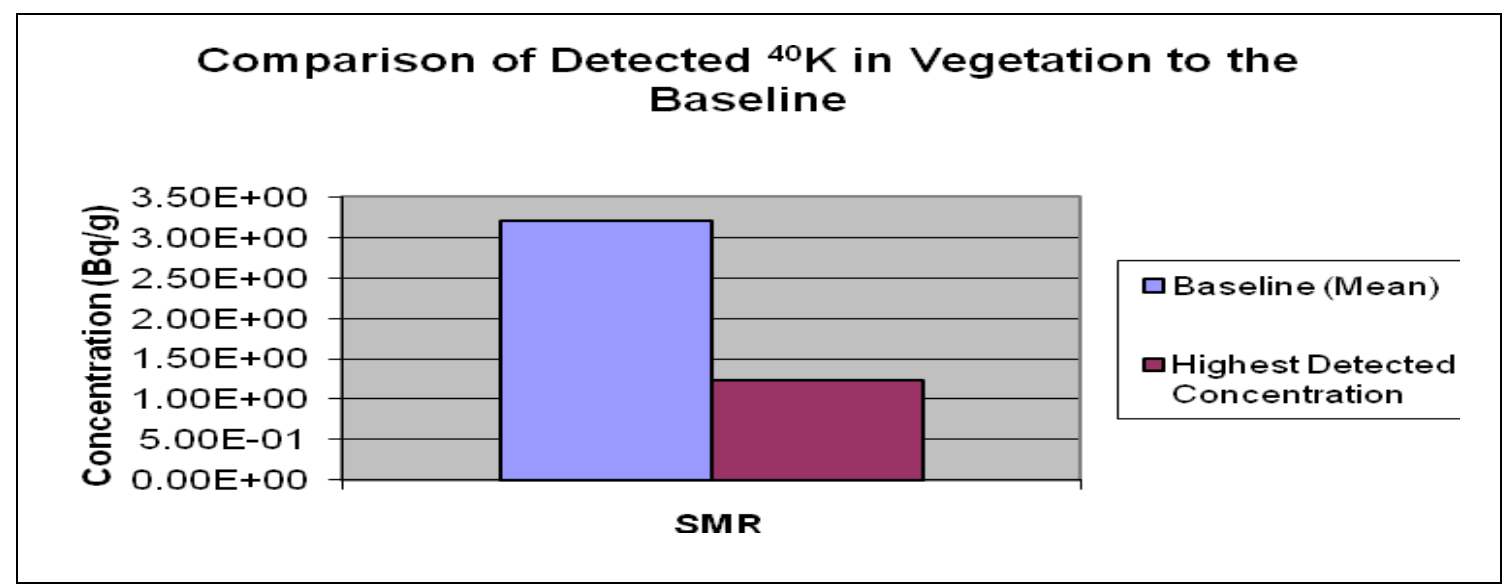

